\title{
SISTEMA DE OTIMIZAÇÃO HIDRÁULICA E ECONÔMICA DE REDE DE IRRIGAÇÃO LOCALIZADA USANDO ALGORITMOS GENÉTICOS
}

Tese apresentada à Escola de Engenharia de São Carlos da Universidade de São Paulo como parte dos requisitos para obtenção do título de Doutor em Engenharia.

Área de Concentração: Hidráulica e Saneamento Orientador: Prof. Dr. Edson Cezar Wendland 


\section{AUTORIZO A REPRODUÇÃO E DIVULGAÇÃO TOTAL OU PARCIAL DESTE TRABALHO, POR QUALQUER MEIO CONVENCIONAL OU ELETRÔNICO, PARA FINS DE ESTUDO E PESQUISA, DESDE QUE CITADA A FONTE.}

Ficha catalográfica preparada pela Seção de Tratamento da Informação do Serviço de Biblioteca - EESC/USP

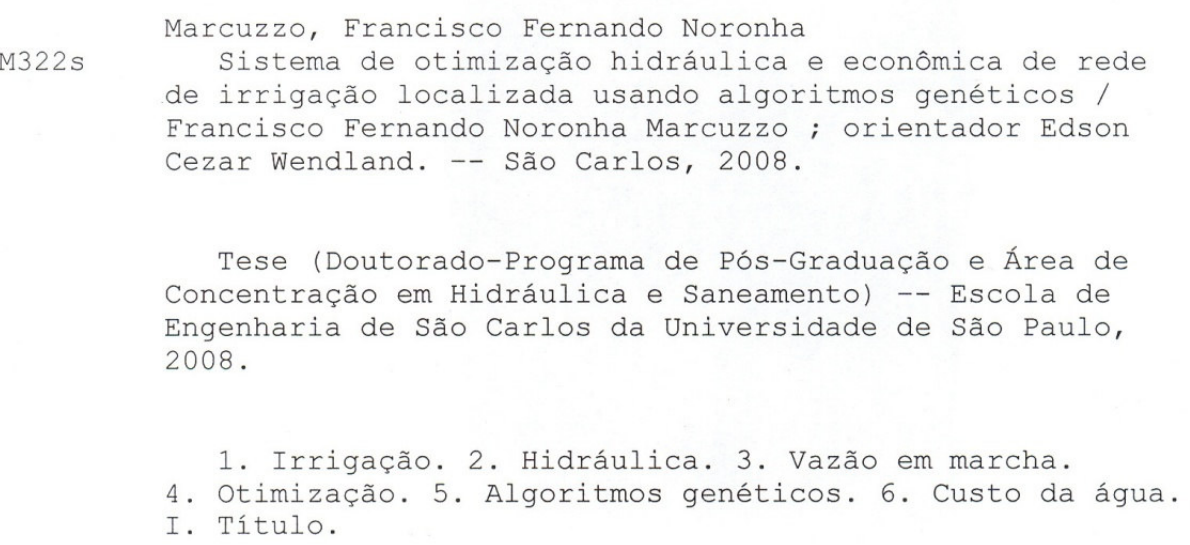


FOLHA DE JULGAMENTO

Candidato: Engenheiro FRANCISCO FERNANDO NORONHA MARCUZZO

Tese defendida e julgada em 10/10/2008 perante a Comissão Julgadora:

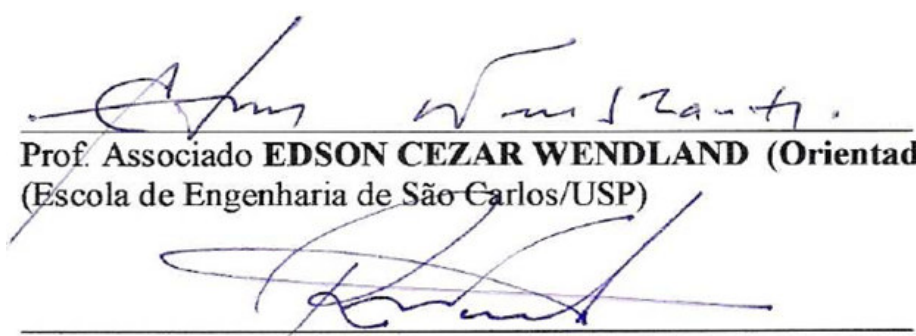

Prof. Associado RODRIGO DE MELO PORTO

(Escola de Engenharia de São Carlos/USP)
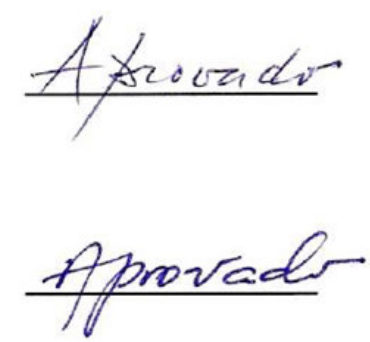

Anwovereso

Prof'. Dr'. MARIANGELA AMENDOLA

(Universidade Estadual de Campinas/UNICAMP)

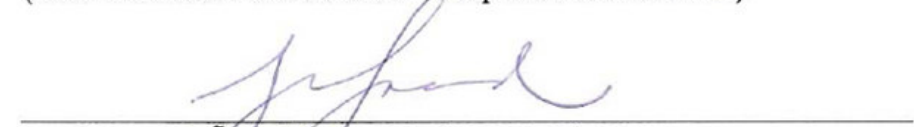

Prof. Dr. JOÃØ CARLOS CURY SAAD

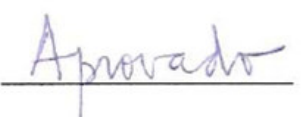

(Universidade Estadual Paulista "Júlio de Mesquita Filho"/UNESP/Campus de Botucatu)

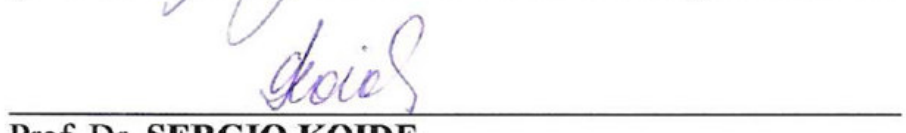

Prof. Dr. SERGIO KOIDE

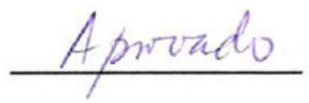

(Universidade de Brasília/UnB)

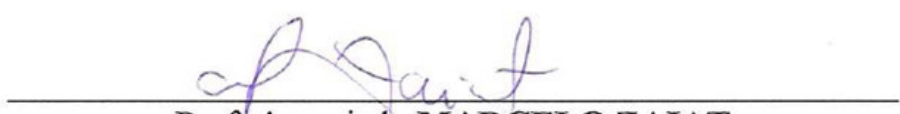

Prof Associado MARCELO ZAIAT

Coordenador do Programa de Pós-Graduação em

Engenharia (Hidráulica e Saneamento)

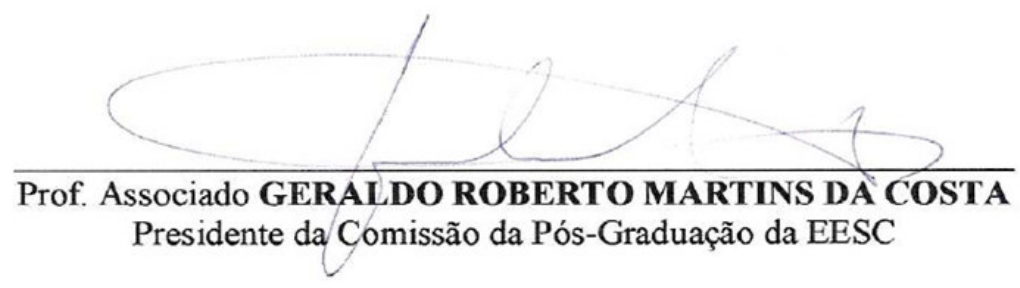




\section{Ofereço}

A todos que trabalham e

pesquisam em prol da

agricultura irrigada.

Dedico aos meus avós

Luzia Carolina de Noronha e Francisco Deodato de Noronha (in memorian)

Zenaide Magri e Basilio Rinaldo Marcuzzo (in memorian) 


\section{AGRADECIMENTOS}

A Deus Onisciente, Onipresente e Onipotente.

Aos amigos de Penápolis/SP Alexandre Teixeira, Rogerio Polonio, Rubenaldo Souza, Osmair Ferreira, Renato Polonio, Fabrizio, Giovani Sampaio, Pedro Trajano e Luiz Henrique Bonani. Aos amigos da UNESP de Botucatu/SP Luiz Bianchi (PitBull), Marcio (Moléstia), Fabio (Elvis), Rafael (Tião), Mortão, Noberto (Takumido), Jim e Bronha. Aos amigos do Laboratório de Hidráulica Computacional e do Departamento de Hidráulica e Saneamento Luiz Henrique Maldonado, Anderson Batista, Quaresma, Cristiano Almeida, Lijalen, Cristian, Isabela, Luis Gomes, Ivan Marin, Vinicius Camargo, André Oliveira, Mariano Franca, Fernanda Peruchi, Patrick, Taiana Homobono, Caio, Carlos Barreto, Eudes, Saulo Aires, Roberto Bergamo, Pavi, Sá, Rose, Flávia, Fernanda e André. Ao amigo Luiz Sérgio Vasconcelos do Nascimento pelas dicas e correções no código. Aos amigos da República Albergue (e agregados) Giovani Zito Gomes, Nilson Mozas, João (Djair), Sérgio (Mun-há), Fabio Zancheta, Marcelo Baiano, Marco Estabilizado, Rafael, Caruso, Leonardo, Seu Jorge, Zozó, Macarrão, Abrão, Éros, Cira, Andréa (Déia) e Karênina. Ao professor Edson Cezar Wendland pela orientação, amizade e conselhos. Ao Departamento de Hidráulica e Saneamento, a Escola de Engenharia de São Carlos e a Universidade de São Paulo pela oportunidade de desenvolvimento da tese de doutorado. A CAPES e ao CNPq (processo 141159/2006-5) pela bolsa de doutorado. Ao DAAD pelo intercâmbio acadêmico BrasilAlemanha-Chile o qual resultou no meu estágio durante o doutorado na Pontificia Universidad Catolica de Valparaiso e ao professor Eduardo Salgado pela amizade e orientação no período que estive no Chile. A todos que de uma forma direta ou indireta contribuirão para a conclusão desta tese de doutorado, e que por lapso de memória não foi citado acima, os meus sinceros agradecimentos e minha infindável gratidão. 
Se eu enxerguei mais longe foi por estar de pé sobre ombros de gigantes.

(Isaac Newton - 1642-1727)

Mede o que é mensurável e torna mensurável o que não o é.

(Galileo Galilei - 1564-1642) 


\section{RESUMO}

\section{MARCUZZO, F. F. N. Sistema de otimização hidráulica e econômica de rede de irrigação}

localizada usando algoritmos genéticos. 2008. 361 p. Tese (Doutorado). Escola de Engenharia de São Carlos, Universidade de São Paulo, São Carlos, 2008.

Sistemas de irrigação localizada são conhecidos pela economia no consumo de água. No entanto, por ser um sistema de rede fixa, os custos de instalação e de operação tendem a ser elevados e sua utilização inibida. O presente trabalho teve como objetivo principal otimizar redes de distribuição de água para irrigação localizada, frente a diferentes configurações de declividade do terreno ( $0 \%$ a $5 \%$ ) e tarifação de energia elétrica $\left(0,0884 \mathrm{R} \$ . \mathrm{kW}^{-1}\right.$ a 0,2652 $\left.\mathrm{R} \$ . \mathrm{kW}^{-1}\right)$ e água $\left(0,01 \mathrm{R} \$ .\left(\mathrm{m}^{3}\right)^{-1}\right.$ a $\left.0,10 \mathrm{R} \$ .\left(\mathrm{m}^{3}\right)^{-1}\right)$. As variáveis de decisão para otimização, com auxilio de algoritmos genéticos, foram os diâmetros de cada trecho da rede, pré-definidos por: dois para linhas laterais, quatro para linhas de derivação, quatro para linhas secundárias e um para linha principal. Foi desenvolvido um código em MatLab, considerando todas as perdas de energia distribuídas e localizadas entre o inicio da rede e o conjunto motobomba para uma rede de irrigação localizada padrão. A vazão em marcha ao longo das linhas laterais foi representada pela vazão de serviço de cada emissor. No final executou-se uma análise de sensibilidade. Os resultados mostram que o custo da rede varia entre 1816,42 a 2312,13 $\mathrm{R} \$ . \mathrm{ha}^{-1}$.ano ${ }^{-1}$. Observa-se que o aumento da declividade do terreno e da tarifa de energia elétrica diminui o custo proporcional com equipamentos e aumenta o custo total anualizado da rede de irrigação e o custo proporcional com energia elétrica.

Palavras-Chave: Irrigação, hidráulica, vazão em marcha, otimização, algoritmos genéticos, custo da água. 


\section{ABSTRACT}

\section{MARCUZZO, F. F. N. Hydraulic and economic optimization of low pressure irrigation}

network using genetic algorithm. 2008. 361 p. Thesis (Doctoral). São Carlos School of Engineering, University of São Paulo, São Carlos, 2008.

Low-pressure irrigation systems are known for the economical advantage in water consumption. However, the installation and operation costs tend to be high and its use inhibited. The present work has the objective to optimize distribution water networks in lowpressure irrigation systems with respect to different configurations of land declivity (between $0 \%$ and $5 \%$ ), electric energy cost (between $0.0884 \mathrm{R} \$ . \mathrm{kW}^{-1}$ and $0.2652 \mathrm{R} \$ . \mathrm{kW}^{-1}$ ) and water cost (between $0.01 \mathrm{R} \$ .\left(\mathrm{m}^{3}\right)^{-1}$ and $\left.0.10 \mathrm{R} \$ .\left(\mathrm{m}^{3}\right)^{-1}\right)$. The decision variable for optimization, with genetic algorithms, was the diameter of each stretch of the network, predefined as: two options for drip lines, four for derivation lines, four for secondary lines and one for main line. An optimization code was developed in MatLab, considering all the distributed and punctual energy losses between the network beginning and the pumping device for a low-pressure irrigation standard network. The outflow rate throughout the drip lines was represented by the service outflow of each emitter. Finally a sensitivity analysis was executed. The results show that the network cost varies between 1816.42 and $2312.13 \mathrm{R} \$ \cdot \mathrm{ha}^{-1} \cdot \mathrm{year}^{-1}$. The increase of the slope land and the tariff of electric energy diminishes the proportional cost with equipment and increases the total cost of irrigation network and the proportional cost with electric energy.

Keywords: Irrigation, hydraulic, outflow rate, optimization, genetic algorithm, water cost. 


\section{LISTA DE ABREVIATURAS E SIGLAS}

\begin{tabular}{|c|c|}
\hline $\mathrm{ABNT}$ & Associação Brasileira de Normas Técnicas \\
\hline $\mathrm{AG}$ & Algoritm Genetic \\
\hline ANA & Agência Nacional de Águas \\
\hline BNDS & Banco Nacional de Desenvolvimento Social \\
\hline CPFL & Compania Paulista de Força e Luz \\
\hline EESC & Escola de Engenharia de São Carlos \\
\hline EMBRAPA & Empresa Brasileira de Pesquisa Agropecuária \\
\hline ESALQ & Escola Superior de Agrícultura Luiz de Queiroz \\
\hline FAO & Organização das Nações Unidas para Agricultura e Alimentação \\
\hline FCA & Faculdade de Ciências Agronômicas \\
\hline GA & Algoritmos Genéticos \\
\hline ha & Hectares \\
\hline IAC & Instituto Agronômico de Campinas \\
\hline LHC & Laboratório de Hidráulica Computacional \\
\hline PL & Programação Linear \\
\hline PNL & Programação Não Linear \\
\hline PO & Pesquisa Operacional \\
\hline SBEA & Associação Brasileira de Engenharia Agrícola \\
\hline SHS & Departamento de Hidráulica e Saneamento \\
\hline UNESP & Universidade Estadual de São Paulo \\
\hline USP & Universidade de São Paulo \\
\hline
\end{tabular}




\section{LISTA DE FIGURAS}

Figura 1. Fluxograma básico do funcionamento de um algoritmo genético...........................86

Figura 2. Arranjo da área modelo para implantação da rede hidráulica de irrigação.............116

Figura 3. Leiaute da rede hidráulica do sistema de irrigação localizada, para uma área

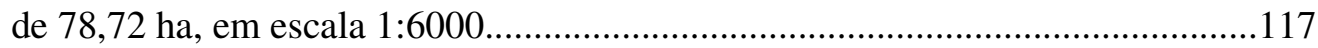

Figura 4. Detalhamento do quadrante 1 da Figura 3, em escala 1:2000.............................118

Figura 5. Detalhamento do quadrante 2 da Figura 3, em escala 1:2000.............................119

Figura 6. Detalhamento do quadrante 3 da Figura 3, em escala 1:2000..............................120

Figura 7. Primeira parte do fluxograma de dimensionamento da rede de irrigação...............128

Figura 8. Segunda parte do fluxograma de dimensionamento da rede de irrigação...............129

Figura 9. Representação esquemática do funcionamento do programa de otimização por algoritmo genético .154 


\section{LISTA DE GRÁFICOS}

Gráfico 1. Análise de regressão para determinação da lei de potencial cálculo do diâmetro molhado pelo microaspersor segundo a sua pressão de serviço

Gráfico 2. Função potencial de vazão do emissor

Gráfico 3. Análise de regressão para os coeficientes de perda de carga localizada (K) em uma contração brusca de diâmetros $\left(\mathrm{A}_{\mathrm{n}+1} / \mathrm{A}_{\mathrm{n}}\right)$, em relação à velocidade no trecho de menor diâmetro.

Gráfico 4. Curva e equação potencial de resposta a produtividade da planta segundo o volume de água aplicado.

Gráfico 5. Eficiência da função de aptidão para as declividades de 0, 2,5 e 5\%, com tarifa de água de $0,01 \mathrm{R} \$ .\left(\mathrm{m}^{3}\right)^{-1}$ e energia elétrica de $0,1768 \mathrm{R} \$ . \mathrm{kW}^{-1}$

Gráfico 6. Vazão em marcha e velocidade calculadas no dimensionamento da

linha lateral, sob dois diâmetros internos diferentes da tubulação.

Gráfico 7. Número de Reynolds nos emissores e as regiões que representam o escoamento rugoso, transicional e laminar.

Gráfico 8. Perda de carga localizada na contração da tubulação e a variação da perda de carga localizada ao longo dos emissores, perda de carga unitária entre os emissores, fator de atrito e a energia cinética, na linha lateral com vazão em marcha. Dados obtidos no dimensionamento da rede.

Gráfico 9. Variação das linhas de energia, piezométrica obtidos no dimensionamento da rede e a vazão nos emissores calculada posteriormente com a carga piezométrica em cada emissor. .185

Gráfico 10. Variação da velocidade calculada no dimensionamento da linha de derivação, segundo a vazão em marcha na tubulação e os diferentes 
diâmetros de cada trecho da tubulação (DLD1 = 204,2 mm, DLD2 = 144,0 mm, DLD3 = 120,0 mm e DLD4 = 97,6 mm), para a declividade de $0 \%$

Gráfico 11. Variação da velocidade calculada no dimensionamento da linha de derivação, segundo a vazão em marcha na tubulação e os diferentes diâmetros de cada trecho da tubulação (DLD1 = 204,2 mm, DLD2 = 144,0 mm, DLD3 = 120,0 mm e DLD4 = 97,6 mm), para a declividade de $2,5 \%$

Gráfico 12. Variação da velocidade calculada no dimensionamento da linha de derivação, segundo a vazão em marcha na tubulação e os diferentes diâmetros de cada trecho da tubulação (DLD1 = 204,2 mm, DLD2 = 144,0 mm, DLD3 = 120,0 mm e DLD4 = 97,6 mm), para a declividade de $5 \%$ 188

Gráfico 13. Variação do número de Reynolds ao longo da linha de derivação, sob vazão em marcha, para a declividade de $0 \%$

Gráfico 14. Variação do número de Reynolds ao longo da linha de derivação, sob vazão em marcha, para a declividade de $2,5 \%$

Gráfico 15. Variação do número de Reynolds ao longo da linha de derivação, sob vazão em marcha, para a declividade de $5 \%$

Gráfico 16. Perda de carga localizada na primeira, a segunda e a terceira contração da tubulação e o comportamento da perda de carga localizada com as linhas laterais, perda de carga unitária entre as linhas laterais, fator de atrito e a energia cinética, na linha de derivação com vazão em marcha. Dados obtidos no dimensionamento da rede para $0 \%$ de declividade 191 
Gráfico 17. Perda de carga localizada na primeira, a segunda e a terceira contração da tubulação e o comportamento da perda de carga localizada com as linhas laterais, perda de carga unitária entre as linhas laterais, fator de atrito e a energia cinética, na linha de derivação com vazão em marcha. Dados obtidos no dimensionamento da rede para 2,5\% de declividade.

Gráfico 18. Perda de carga localizada na primeira, a segunda e a terceira contração da tubulação e o comportamento da perda de carga localizada com as linhas laterais, perda de carga unitária entre as linhas laterais, fator de atrito e a energia cinética, na linha de derivação com vazão em marcha. Dados obtidos no dimensionamento da rede para $5 \%$ de declividade.

Gráfico 19. Variação das linhas de energia, piezométrica, de carga de pressão e da cota do terreno da linha de derivação, sob vazão em marcha, para $0 \%$ de declividade

Gráfico 20. Variação das linhas de energia, piezométrica, de carga de pressão e da cota do terreno da linha de derivação, sob vazão em marcha, para 2,5\% de declividade

Gráfico 21. Variação das linhas de energia, piezométrica, de carga de pressão e da cota do terreno da linha de derivação, sob vazão em marcha, para 5\% de declividade.

Gráfico 22. Plano de carga efetiva (energia) na unidade operacional para declividade de $0 \%$ 197

Gráfico 23. Plano de carga efetiva (energia) na unidade operacional para declividade de $2,5 \%$ 198

Gráfico 24. Plano de carga efetiva (energia) na unidade operacional para declividade de $5 \%$ 
Gráfico 25. Plano de carga hidráulica (pressão) na unidade operacional para declividade de $0 \%$. .202

Gráfico 26. Plano de carga hidráulica (pressão) na unidade operacional para declividade de $2,5 \%$

Gráfico 27. Plano de carga hidráulica (pressão) na unidade operacional para declividade de $5 \%$ .204

Gráfico 28. Distribuição da vazão na unidade operacional para declividade de 0\%...........206

Gráfico 29. Distribuição da vazão na unidade operacional para declividade de 2,5\% ........207

Gráfico 30. Distribuição da vazão na unidade operacional para declividade de 5\%...........208

Gráfico 31. Distribuição de produção na unidade operacional para declividade de $0 \%$......213

Gráfico 32. Distribuição de produção na unidade operacional para declividade de $2,5 \%$...214

Gráfico 33. Distribuição de produção na unidade operacional para declividade de 5\% ......215

Gráfico 34. Variação na convergência da função de aptidão para uma variação na tarifação da água entre 0,01 e $0,10 \mathrm{R} \$ .\left(\mathrm{m}^{3}\right)^{-1}$. 217

Gráfico 35. Diagrama de Moody 242

Gráfico 36. Equação da viscosidade cinemática da água segundo a temperatura. 354 


\section{LISTA DE QUADROS}

Quadro 1. Detalhamento dos diferentes trechos da rede hidráulica de irrigação.

Quadro 2. Detalhamento das opções de microaspersores pesquisados.

Quadro 3. Características físicas das opções de tubo de polietileno linear de baixa

densidade

Quadro 4. Características físicas das opções de tubo de PVC.

Quadro 5. Equipamentos e acessórios da rede hidráulica de irrigação localizada. 127

Quadro 6. Equações de perda de pressão por atrito em função de N (número de derivações na tubulação) e os respectivos valores de "m" (expoente de vazão ou velocidade da equação de perda de pressão) e "x" (relação entre a primeira derivação e a tomada de água em função das demais saídas eqüidistantes).

Quadro 7. Critérios para classificação em função de $U E$ e $U E_{b}$, de acordo com Bralts (1986)

Quadro 8. Critérios para classificação de $U s$, de acordo com Wilcox e Swailes (1947)

Quadro 9. Principais parâmetros de entrada e operadores genéticos que foram utilizados no funcionamento do algoritmo genético.

Quadro 10. Resumo dos principais parâmetros de entrada do código da função de aptidão 161

Quadro 11. Viscosidade cinemática da água segundo a sua temperatura. .354

Quadro 12. Margem percentual de segurança recomendável para motores elétricos. .355

Quadro 13. Perda de carga localizada dos gotejadores expressa como porcentagem da perda contínua ao longo da linha lateral. 355 
Quadro 14. Rugosidade absoluta de tubulação.....................................................................356

Quadro 15. Valores do coeficiente K para reduções bruscas...............................................356 


\section{LISTA DE SÍMBOLOS}

$\overline{\mathrm{q}} \quad$ média das vazões observadas

A área total irrigável disponível (função de aptidão) ou restrição de desigualdade (função de restrição)

a coeficiente "a" da função de produção da planta por lamina de água aplicada (função de aptidão)

ADLD1 área do tubo com Di1

ADLD2 área do tubo com Di2

ADLD3 área do tubo com Di3

ADLD4 área do tubo com Di4

$\mathrm{ADLi}_{\mathrm{n}} \quad$ área da tubulação da linha i no trecho $\mathrm{n}$

$\mathrm{ADLi}_{\mathrm{n}+1}$ área da tubulação da linha i no trecho $\mathrm{n}+1$

ADLL1 área do tubo com Di1

ADLL2 área do tubo com Di2

Aeq restrição de igualdade dos comprimentos totais

AGSU altura geométrica de sucção

Ama área molhada pelo emissor

AUI área útil irrigada

AUO área total de cada unidade operacional disponível

b coeficiente "b" da função de produção da planta por lamina de água aplicada (função de aptidão) ou restrição de desigualdade (função de restrição)

beq comprimento total das linhas

c coeficiente "c" da função de produção da planta por lamina de água aplicada.

CA custo da água para irrigação 
CAE custo da ampliação excêntrica

CANELFL custo do anel do fim de linha

CATG custo total com água

CB comprimento da Bobina da tubulação da linha lateral

CC capacidade de campo do solo

CC90 custo da curva de 90 graus de PVC

CCPVC custo da cola de PVC

CCSLL custo do conector de saída para linha lateral

CCTDLP custo da conexão "T" PVC na derivação

CCTDLS custo da conexão "T" PVC

CCTFLP custo da conexão "T" PVC do final de linha

CCULS custo da curva de 90 graus PVC

CEemax condutividade elétrica máxima do solo

CEemin condutividade elétrica mínima do solo

CEQ custo total com os equipamentos de irrigação

CF custo fixo anual

CFA custo do filtro de areia

CFD custo do filtro de disco

CFT custo do filtro de tela

$\mathrm{CH} \quad$ custo do hidrômetro

CIV custo do injetor Venturi

CLDD1 custo do tubo de PVC Di1

CLDD2 custo do tubo de PVC Di2

CLDD3 custo do tubo de PVC Di3

CLDD4 custo do tubo de PVC Di4 


\begin{tabular}{|c|c|}
\hline CLLD1 & custo do tubo de polietileno Di1 \\
\hline CLLD2 & custo do tubo de polietileno Di2 \\
\hline CLPDI & custo do tubo de PVC Di \\
\hline CLSD1 & custo do tubo de PVC Di1 \\
\hline CLSD2 & custo do tubo de PVC Di2 \\
\hline CLSD3 & custo do tubo de PVC Di3 \\
\hline CLSD4 & custo do tubo de PVC Di4 \\
\hline $\mathrm{CM}$ & custo do manômetro \\
\hline CMB & custo do motobomba \\
\hline $\mathrm{CPC}$ & custo do painel de controle \\
\hline CRDLD1 & custo do redutor de diâmetro Di1 para Di2 \\
\hline CRDLD2 & custo do redutor de diâmetro Di2 para Di3 \\
\hline CRDLD3 & custo do redutor de diâmetro Di3 para Di4 \\
\hline CRDLL & custo do redutor de diâmetro Di1 para Di2 \\
\hline CRDLS1 & custo do redutor de diâmetro Di1 para Di2 \\
\hline CRDLS2 & custo do redutor de diâmetro Di2 para Di3 \\
\hline CRDLS3 & custo do redutor de diâmetro Di3 para Di4 \\
\hline CRE & custo da redução excêntrica \\
\hline CRG & custo do registro \\
\hline CRLP & custo do registro da linha principal \\
\hline CRLS & custo do registro da linha secundária \\
\hline CTE & custo do microaspersor, dado em reais por unidade \\
\hline CTE & custo total com energia elétrica \\
\hline CTFL & custo do tampão de fim de linha \\
\hline CTS & custo do tubo de sucção de PVC Di \\
\hline
\end{tabular}


CUC coeficiente de uniformidade de Christiansen

CVE coeficiente de variação da vazão do emissor

CVF coeficiente de variação de fabricação do emissor

CVPC custo da válvula de pe com crivo

CVRPLS custo da válvula reguladora de pressão

DA densidade aparente do solo

Dcr diâmetro comercial do rotor

Dem diâmetro externo médio da tubulação

DhfLL12 diferença entre as perdas de carga distribuídas por emissor

DhfLL12M diferença entre as perdas de carga distribuídas por metro

DHV variação de pressão permitida na unidade operacional (linhas laterais + linhas de derivação)

DHVLD variação de pressão permitida na linha de derivação

DHVLL variação de pressão permitida na linha lateral

DI diâmetro interno da tubulação

Din diâmetro da tubulação na linha i no trecho n

DLD1 diâmetro da linha de derivação 1

DLD2 diâmetro da linha de derivação 2

DLD3 diâmetro da linha de derivação 3

DLD4 diâmetro da linha de derivação 4

DLin diâmetro da tubulação da linha i no trecho n

DLL1 diâmetro da linha lateral 1

DLL2 diâmetro da linha lateral 2

DLP diâmetro da linha principal 1

DLS1 diâmetro da linha secundária 1 
DLS2 diâmetro da linha secundária 2

DLS3 diâmetro da linha secundária 3

DLS4 diâmetro da linha secundária 4

DLSU diâmetro da linha de sucção

DN diâmetro nominal da tubulação

DPHELL desvio padrão da pressão dos emissores na linha lateral

DPHELLM desvio padrão da pressão por metro na linha lateral

DPQELL desvio padrão da vazão dos emissores na linha lateral

DPQELLM desvio padrão da vazão fictícia por metro na linha lateral

DTAS disponibilidade total de água no solo

DTNSR desconto na tarifa de energia elétrica

Du variação da umidade do solo

DZLD desvio geométrico no conjunto de linhas de derivação

DZLDD aclive e declividade total distribuída por ponto de emissão em toda a linha de derivação

DZLi aclive ou declive na linha $\mathrm{i}$

DZLin aclive ou declive na linha i no trecho $\mathrm{n}$

DZLinU aclive ou declive entre as saídas de água da linha i no trecho $\mathrm{n}$

DZLL desvio geométrico no conjunto de linhas laterais

DZLL1 aclive ou declive total no primeiro trecho da tubulação

DZLL1D aclive ou declividade distribuído por ponto de emissão no primeiro trecho da linha

DZLL1DM aclive ou declividade distribuído por metro no primeiro trecho da linha

DZLL1U aclive ou declive unitário entre os pontos de emissão

DZLL1UM aclive ou declive unitário por metro

DZLL2 aclive ou declive total no primeiro trecho da tubulação 
DZLL2D aclive ou declividade distribuído por ponto de emissão no primeiro trecho da linha

DZLL2DM aclive ou declividade distribuído por metro no primeiro trecho da linha

DZLL2U aclive ou declive unitário entre os pontos de emissão

DZLL2UM aclive ou declive unitário por metro

DZLLD aclive e declividade total distribuída por ponto de emissão em toda a linha lateral

DZLLin aclive ou declive distribuído por saída de água da linha i no trecho $\mathrm{n}$

DZLP desvio geométrico no conjunto da linha principal

DZLS desvio geométrico no conjunto de linhas secundárias

e espessura de parede da tubulação

E1D espaçamento da primeira linha de derivação até a tomada de água na linha principal

E1E espaçamento do primeiro emissor da linha lateral ate a linha de derivação

E1L espaçamento da primeira linha lateral ate a tomada de água na linha secundária

E1P espaçamento da tomada de água até a primeira linha secundária

E2D espaçamento da segunda linha de derivação até a tomada de água na linha principal

E2P espaçamento da tomada de água até a segunda linha secundária

E3D espaçamento da terceira linha de derivação até a tomada de água na linha principal

E3P espaçamento da tomada de água até a terceira linha secundária

E4D espaçamento da quarta linha de derivação até a tomada de água na linha principal

ECINETLin energia cinética da tubulação da linha i no trecho $n$

ECINETLL1M energia cinética por metro no primeiro trecho da linha lateral

ECINETLL1T energia cinética por emissor no primeiro trecho da linha lateral

ECINETLL2M energia cinética por metro no segundo trecho da linha lateral

ECINETLL2T energia cinética por emissor no segundo trecho da linha lateral 

EED espaçamento entre as linhas de derivação
EEE espaçamento entre emissores da linha lateral
EEL espaçamento entre as linhas laterais
EES espaçamento entre as linhas secundárias

EEUO espaçamento entre as unidades operacionais

EEUO espaçamento entre unidades operacionais

ELD rugosidade absoluta da tubulação da linha de derivação

ELL rugosidade absoluta da tubulação da linha lateral

ELP rugosidade absoluta da tubulação da linha principal

ELS rugosidade absoluta da tubulação da linha secundária

ELSU rugosidade absoluta da tubulação da linha de sucção

ERELL energia total requerida na entrada da linha lateral com dois diâmetros, considerando o desvio geométrico do terreno no calculo final

ETCA evapotranspiração da cultura no ano

ETg evapotranspiração media da cultura irrigada em um dia

ETo média diária da evapotranspiração anual

ETpc evapotranspiração da cultura em um dia

f custo total com a rede de irrigação ou fator de atrito da tubulação

F fator de disponibilidade de água no solo

fa função de aptidão

FAPNB fator de acréscimo a potencia necessária no conjunto motobomba elétrico

fin coeficiente de atrito para cálculo de perda de carga da tubulação na linha i no trecho $n$

FLD coeficiente de redução Scaloppi para Darcy-Weisbach, Manning e Swammee-Jain fLi fator de ajuste de diminuição da perda de pressão por atrito para tubulação i 
FLL coeficiente de redução Scaloppi para Darcy-Weisbach, Manning e SwammeeJain.

FPPL produtividade por planta de laranja

FRC fator de recuperação de capital

FRC fator de recuperação de capital

fSJT1 coeficiente de atrito de Swamee distribuído por emissor para o primeiro trecho da linha lateral

fSJT1M coeficiente de atrito de Swamee distribuído por metro para o primeiro trecho da linha lateral

fSJT2 coeficiente de atrito de Swamee distribuído por emissor para o primeiro trecho da linha lateral

fSJT2M coeficiente de atrito de Swamee distribuído por metro para o primeiro trecho da linha lateral

g aceleração da gravidade em metros por segundo

h pressão nominal (pressão de serviço). Pressão requerida na entrada do emissor

ha hectares

he pressão media requerida pelo microaspersor para aspergir a vazão unitária requerida

hfcc perda de carga no cabeçal de controle e dada pelo fabricante

hfin perda de carga na linha i no trecho $n$

hfLL1 perda de carga distribuída por emissor no primeiro trecho da linha lateral

hfLL1M perda de carga distribuída por metro no primeiro trecho da linha lateral

hfLL1MT perda ou ganho de carga total distribuída por metro no primeiro trecho da linha lateral considerando a declividade 
hfLL1T perda ou ganho de carga total distribuída por emissor no primeiro trecho da linha lateral considerando a declividade

hfLL2 perda de carga total distribuída no segundo trecho da linha lateral

hfLL2M perda de carga total distribuída por metro no segundo trecho da linha lateral

hfLL2MT perda ou ganho de carga total distribuída por metro no segundo trecho da linha lateral considerando a declividade

hfLL2T perda ou ganho de carga total distribuída por emissor no segundo trecho da linha lateral considerando a declividade

hLL12 pressão em cada emissor da linha lateral, considerando os dois trechos hLL12M pressão por metro na linha lateral, considerando os dois trechos hLL12MAX máxima pressão observada por emissor em toda linha lateral hLL12MEDIA pressão media observada por emissor em toda linha lateral hLL12MIN mínima pressão observada por emissor em toda linha lateral hLL12MMAX máxima pressão observada por metro em toda linha lateral hLL12MMEDIA pressão media observada por metro em toda linha lateral hLL12MMIN mínima pressão observada por metro em toda linha lateral hmin pressão mínima requerida pelo microaspersor para aspergir a vazão unitária requerida

$\mathrm{i}=0,06 \quad$ taxa anual de juros

IRN irrigação real necessária

IRNAIL irrigação real necessária ajustada para o turno de rega escolhido

ITN irrigação total necessária

J taxa anual de juros

Jin perda de carga unitária na linha i no trecho $\mathrm{n}$ 
jLLT1 perda de carga localizada distribuída por emissor para o primeiro trecho da linha lateral

jLLT1M perda de carga localizada distribuída por metro para o primeiro trecho da linha lateral

jLLT2 perda de carga localizada para o segundo trecho da linha lateral

jLLT2M perda de carga localizada distribuída por metro para o segundo trecho da linha lateral

k coeficiente para calculo da vazão unitária do emissor

KA2A1 coeficiente K para reduções bruscas de diâmetro de tubulação

$\mathrm{KA}_{n+1} \mathrm{~A}_{\mathrm{n}} \mathrm{Li}$ coeficiente para reduções bruscas de diâmetro de tubulação da linha i no trecho n

KC coeficiente de cultura para calculo da evapotranspiração da cultura a ser instalada

KE coeficiente de perda de carga localizada do emissor

KL fator de ajuste devido à aplicação localizada da água

KLL coeficiente de perda de carga localizada para os emissores acoplados na linha i no trecho $n$

KLS coeficiente de perda de carga localizada da linha secundária

KLSU coeficiente de perda de carga localizada para a válvula de pe com crivo

KPCF coeficiente de perda de carga de filtro de tela

KPCR coeficiente de perda de carga de registro de gaveta

KPCTD coeficiente de perda de carga de "T" passagem livre

KPCTSL coeficiente de perda de carga de "T" saída lateral

KPCV coeficiente de perda de carga de válvula reguladora de pressão

LB menores números aceitos nas variáveis de decisão

LET1 comprimento equivalente de "T" com passagem livre para o diâmetro DLS1

LET2 comprimento equivalente de "T" com passagem livre para o diâmetro DLS2 
LET3 comprimento equivalente de "T" com passagem livre para o diâmetro DLS3

LET4 comprimento equivalente de "T" com passagem livre para o diâmetro DLS4

LLA comprimento da linha adutora. Distância da saída da bomba ate o inicio da área a ser irrigada

LLD comprimento total da linha de derivação

LLD1 comprimento do primeiro trecho da linha de derivação com Di1

LLD2 comprimento do segundo trecho da linha de derivação com Di2

LLD3 comprimento do terceiro trecho da linha de derivação com Di3

LLD4 comprimento do quarto trecho da linha de derivação com Di4

LLin comprimento da linha i no trecho $n$

LLL comprimento total da linha lateral

LLL1 comprimento do primeiro trecho da linha lateral com Di1

LLL2 comprimento do segundo trecho da linha lateral com Di2

LLP comprimento total da linha principal

LLS comprimento total da linha secundária

LLSU comprimento total da linha de sucção

Lx lado de maior comprimento na área a ser irrigada

Ly lado de menor comprimento na área a ser irrigada

m expoente da vazão ou velocidade da equação de perda de carga de DarcyWeisbach, Manning e Swammee-Jain.

mca metros de coluna da água

$\mathrm{N}$ número de derivações na tubulação

n vida útil do equipamento

nbomba rendimento da bomba

NELL1 número de emissores no primeiro trecho da linha lateral 
NELL2 número de emissores no segundo trecho da linha lateral

NLLD1 número de linhas laterais no primeiro trecho da linha de derivação

NLLD2 número de linhas laterais no segundo trecho da linha de derivação

NLLD3 número de linhas laterais no terceiro trecho da linha de derivação

NLLD4 número de linhas laterais no quarto trecho da linha de derivação

NLLDn número de linhas laterais acopladas no trecho $\mathrm{n}$ da linha de derivação

nmotor rendimento do motor

NP número de emissores por planta

NPA número de emissores por planta ajustado para um número inteiro

NRLP número de registros na linha principal.

nrotores número de rotores

NSE número de saídas no emissor

NTD número total de linhas de derivação acopladas em cada linha secundária

NTDin número total de derivações na tubulação i

NTE número total de emissores na linha lateral

NTL número total de linhas laterais acopladas na linha de derivação

NTS número total de linhas secundárias acopladas na linha principal

NTUO número de subunidades do sistema

numel retorna o número de dados de um conjunto qualquer de números qualquer

NUOIS número de unidades operacionais irrigadas simultaneamente

nvars número de variáveis de decisão

PB peso da Bobina da tubulação da linha lateral

PCLA2A1 perda de carga localizada para a contração da tubulação

PCLA $_{n+1} A_{n} L i$ perda de carga localizada para a contração da tubulação de diâmetro $n+1$ para o diâmetro $n$ 
PCLELL1 perda de carga localizada com os emissores distribuída por emissor no primeiro trecho da tubulação

PCLELL1M perda de carga localizada com os emissores distribuída por metro no primeiro trecho da tubulação

PCLELL2 perda de carga localizada com os emissores no segundo trecho da tubulação

PCLELL2M perda de carga localizada com os emissores distribuída por metro no segundo trecho da tubulação

PCLELLT1 somatória da perda de carga localizada com os emissores no primeiro trecho da tubulação

PCLin perda de carga localizada com os emissores da tubulação na linha i no trecho n

PCTLL perda de carga total na linha lateral com dois diâmetros, sem considerar o desvio geométrico do terreno

PCTLLT perda de carga total na linha lateral com dois diâmetros, considerando o desvio geométrico do terreno

PEP precipitação efetiva

PM ponto de murcha permanente

Pma perímetro molhado pelo emissor

PRELL pressão requerida na entrada da linha lateral com dois diâmetros, considerando o desvio geométrico do terreno no calculo final

PRELLT pressão requerida na entrada da linha lateral com dois diâmetros, considerando o desvio geométrico do terreno trecho a trecho

PRFLD pressão requerida no final da linha de derivação

PS pressão de serviço ideal do emissor

PSmax pressão de serviço máxima do emissor

PSmin pressão de serviço mínima do emissor 


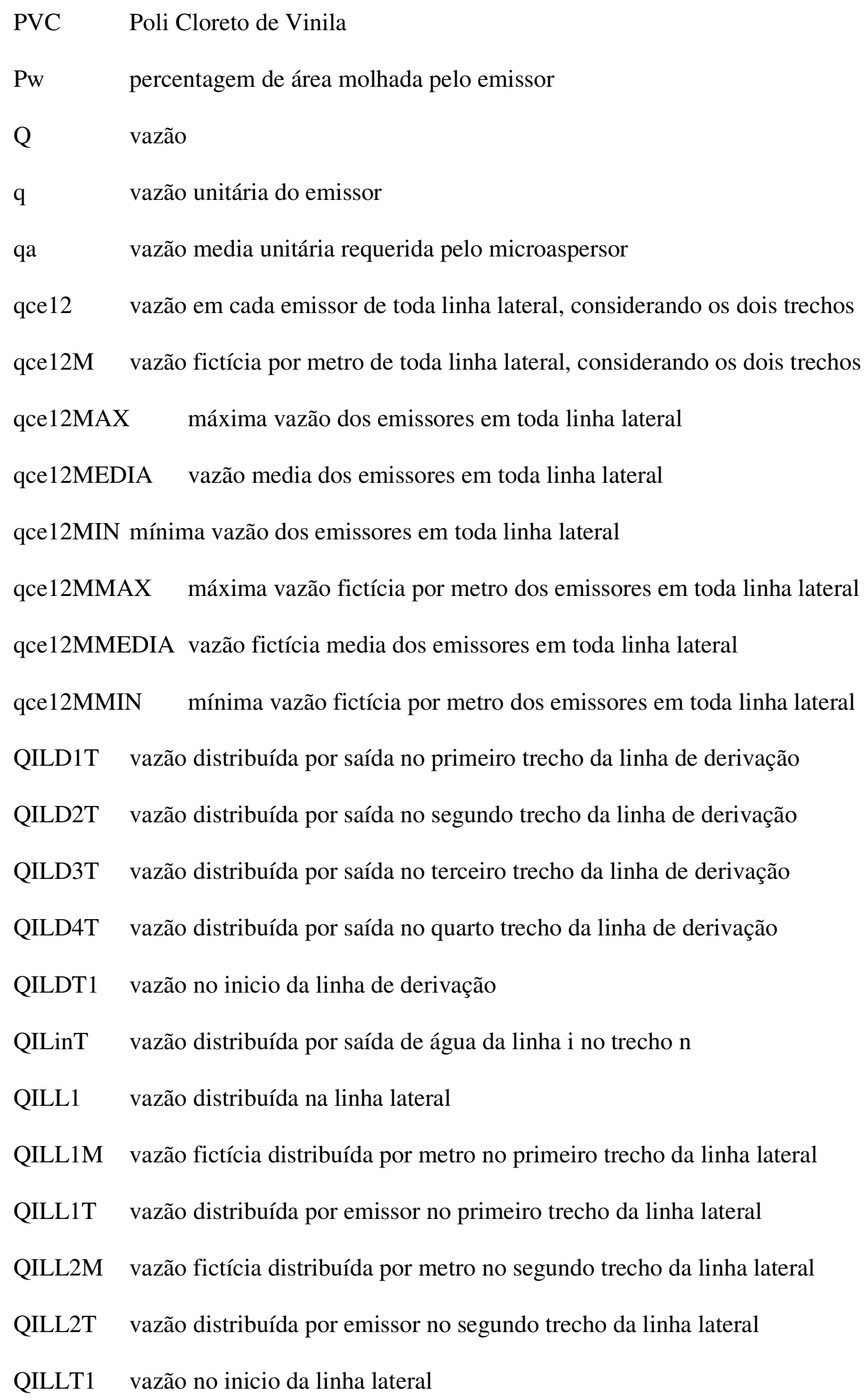


QILLT2 vazão no inicio do segundo trecho da linha lateral

Qin vazão na tubulação da linha i no trecho $n$

Qmáx $\quad$ vazão máxima na tubulação

qmin vazão mínima unitária para o microaspersor

qn média das $25 \%$ menores vazões observadas

RA2A1 relação entre a área da segunda com a primeira tubulação

$\mathrm{RA}_{\mathrm{n}+1} \mathrm{~A}_{\mathrm{n}} \mathrm{Li}$ relação entre a área da segunda e da primeira tubulação

Rein número de Reynolds na linha i no trecho $\mathrm{n}$

RELin número de Reynolds da linha i no trecho $\mathrm{n}$

RELL1 número de Reynolds distribuído por emissor para o primeiro trecho da linha lateral

RELL1M número de Reynolds distribuído por metro para o primeiro trecho da linha lateral

RELL2 número de Reynolds distribuído para o primeiro trecho da linha lateral

RELL2M número de Reynolds distribuído por metro para o segundo trecho da linha lateral

RELLT1 número de Reynolds para o primeiro trecho da linha lateral

RELLT2 número de Reynolds para o segundo trecho da linha lateral

RL razão de lixiviação

round arredonda para o número inteiro mais próximo

See espaçamento entre emissores para se ter um volume de solo molhado continuo

Sf espaçamento entre linhas

Sp espaçamento entre plantas

Sq desvio padrão da vazão do emissor

TaCUOIS tempo de irrigação por conjunto de unidades operacionais irrigadas simultaneamente

TDTEE tempo máximo para o desconto na tarifa de energia elétrica 
TFMBD tempo máximo de funcionamento da motobomba por dia

tic começa a contagem do tempo do MatLab

toc finaliza a contagem de tempo quando o programa parar

TR turno de rega calculado

TRE turno de rega escolhido, dado em dias. Tempo para que os mesmo conjuntos de unidades operacionais voltem a ser irrigados. Escolhe-se o TRE conforme o leiaute da rede, o TFMBD, NUOIS e o TaCUOIS

TRI turno de rega inteiro

TSR tarifa de energia elétrica para o setor rural

UB maiores números aceitos nas variáveis de decisão

UE uniformidade de emissão

UECLL uniformidade de emissão calculada na linha lateral, apos o dimensionamento

UEST uniformidade estatística de emissão

Us uniformidade estatística

V vida útil dos equipamentos ou viscosidade cinemática da água

VAHRELL variância da pressão dos emissores na linha lateral

VAHRELLM variância da pressão por metro na linha lateral

VAP volume de água aplicado

VAQRELL variância da vazão dos emissores na linha lateral

VAQRELLM variância da vazão fictícia por metro na linha lateral

VILL1 velocidade distribuída na linha lateral

VILL1M velocidade fictícia distribuída por metro no primeiro trecho da linha lateral

VILL1T velocidade distribuída por emissor no primeiro trecho da linha lateral

VILL2M velocidade fictícia distribuída por metro no segundo trecho da linha lateral

VILL2T velocidade distribuída no segundo trecho da linha lateral 


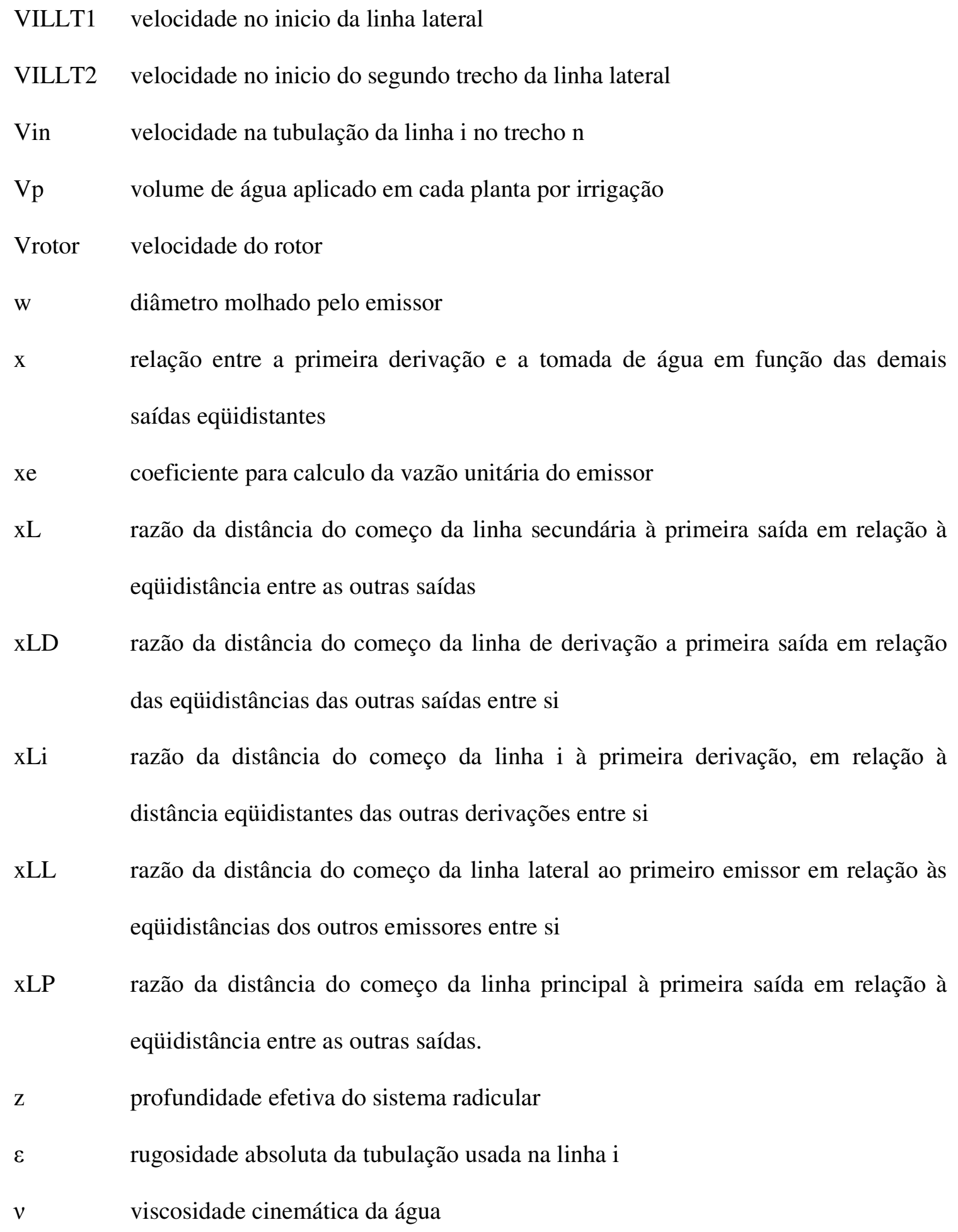




\section{LISTA DE TABELAS}

Tabela 1. Eficiência dos diferentes sistemas de irrigação................................................57

Tabela 2. Mínimo e máximo valores de $\mathrm{CEe}\left(\mathrm{ds} . \mathrm{m}^{-1}\right)$ para várias culturas........................135

Tabela 3. Tarifas de água e energia elétrica utilizadas na análise de sensibilidade..........162

Tabela 4. Diferenças na convergência dos valores da função de aptidão entre conjuntos de gerações para as declividades de $0,2,5$ e 5\%, com tarifa de água de $0,01 \mathrm{R} \$ .\left(\mathrm{m}^{3}\right)^{-1}$ e energia elétrica de $0,1768 \mathrm{R} \$ . \mathrm{kW}^{-1}$ 166

Tabela 5. Variáveis otimizadas segundo a variação da declividade e da tarifa de água na otimização da rede por algoritmos genéticos

Tabela 6. Variáveis otimizadas segundo a variação da declividade e da tarifa de energia elétrica na otimização da rede por algoritmos genéticos

Tabela 7. Custos obtidos segundo a variação da declividade e da tarifa de água na otimização da rede por algoritmos genéticos.

Tabela 8. Resultados percentuais dos custos obtidos segundo a variação da declividade e da tarifa de água na otimização da rede por algoritmos genéticos

Tabela 9. Custos obtidos segundo a variação da declividade e da tarifa de energia elétrica na otimização da rede por algoritmos genéticos

Tabela 10. Resultados percentuais dos custos obtidos segundo a variação da declividade e da tarifa de energia elétrica na otimização da rede por algoritmos genéticos 176

Tabela 11. Diâmetro, vazão, velocidade, energia cinética, fator de atrito e perda de carga unitária para a linha de sucção, linha principal e para as quatro tubulações que compõem a linha secundária 
Tabela 12. Energia requerida na entrada das linhas lateral, de derivação, secundária, principal e na motobomba, segundo a variação da declividade do terreno e da tarifa de energia elétrica.

Tabela 13. Potência requerida na motobomba, segundo a variação da declividade do terreno e da tarifa de energia elétrica.

Tabela 14. Carga efetiva (energia) máxima, mínima, média, amplitude absoluta e percentual observada nos emissores da unidade operacional segundo a variação da declividade do terreno e da tarifa de energia elétrica. 200

Tabela 15. Pressão máxima, mínima, média, amplitude absoluta e percentual observada nos emissores da unidade operacional segundo a variação da declividade do terreno e da tarifa de energia elétrica. .201

Tabela 16. Vazão nos emissores máxima, mínima, média, amplitude absoluta e percentual observada na unidade operacional segundo a variação da declividade do terreno e da tarifa de energia elétrica. 205

Tabela 17. Análise da uniformidade de emissão calculada por Keller e Karmelli $(1974)^{1}$ e Bralts $(1986)^{2}$, uniformidade estatística calculado por Wilcox e Swailes (1947) ${ }^{3}$ e diferença total de vazão entre o primeiro e o último emissor $\left(\mathrm{DPU}^{4}\right)$ na unidade operacional.

Tabela 18. Produtividade máxima, mínima, média, amplitude absoluta e percentual observada na unidade operacional segundo a variação da declividade do terreno e da tarifa de energia elétrica.

Tabela 19. Partição da evolução na convergência dos valores da função de aptidão (em R $\$ \cdot h a^{-1} \cdot$ ano $^{-1}$ e em \%) entre conjuntos de gerações para uma variação na tarifação da água entre 0,01 e $0,10 \mathrm{R} \$ .\left(\mathrm{m}^{3}\right)^{-1}$ 218 
Tabela 20. Variáveis otimizadas na variação da tarifação da água entre 0,01 e

$0,10 \mathrm{R} \$ .\left(\mathrm{m}^{3}\right)^{-1}$

Tabela 21. Variação no custo total do sistema de irrigação, equipamentos, energia

elétrica e água com variação na tarifação da água entre 0,01 e 0,10

$\mathrm{R} \$ .\left(\mathrm{m}^{3}\right)^{-1}$

Tabela 22. Variação percentual no custo total do sistema de irrigação, equipamentos, energia elétrica e água com a ampla variação na tarifação da água.

Tabela 23. Coeficientes de atrito f para construção do diagrama de Moody segundo o número de Reynolds e a rugosidade relativa da tubulação ( $\varepsilon$ /D)

Tabela 24. Coeficientes de atrito f para construção das retas de fronteira dos diferentes tipos de escoamento do diagrama de Moody segundo o número de Reynolds

Tabela 25. Coeficiente de redução F (para cálculo da perda de carga) em função de $\mathrm{N}$ (número de saídas na tubulação), m (expoente da equação de perda de carga) e de x (distância do primeiro emissor à entrada da linha lateral). .243

Tabela 26. Propriedades físicas usuais dos solos 355

Tabela 27. Cotação de emissores, em real (R\$) e em dólar (US\$), no mês de janeiro de 2007.

Tabela 28. Cotação de tubos de polietileno e PVC, em real (R\$) e em dólar (US\$), no mês de janeiro de 2007 . 358

Tabela 29. Cotação de estacas de microaspersor, adaptador de fim e início de linha e união pra tubo gotejador, em real (R\$) e em dólar (US\$), no mês de janeiro de 2007. 358 
Tabela 30. Cotação de redução soldável, tê de redução, adaptador de final de linha de PVC, curva $90^{\circ}$ e adesivo plástico para tubos de $\mathrm{PVC}$, em real $(\mathrm{R} \$)$ e em dólar (US\$), no mês de janeiro de 2007

Tabela 31. Cotação de filtro de areia completo, filtro metálico de tela e válvulas de retrolavagem, hidráulica de plástico, de alívio, piloto e relês e solenóides, em real (R\$) e em dólar (US\$), no mês de janeiro de 2007

Tabela 32. Cotação de painel de controle do sistema, em real (R\$) e em dólar (US\$), no mês de janeiro de 2007 360

Tabela 33. Cotação de hidrômetro e registro de esfera em PVC soldável, em real (R\$) e em dólar (US\$), no mês de janeiro de 2007

Tabela 34. Cotação de injetor de fertilizantes tipo Venturi, em real (R\$) e em dólar (US\$), no mês de janeiro de 2007

Tabela 35. Cotação do conjunto moto-bomba segundo a potência da bomba em cv (cavalo vapor) 


\section{SUMÁRIO}

AGRADECIMENTOS

EPÍGRAFE

RESUMO

ABSTRACT

LISTA DE ABREVIATURAS E SIGLAS

LISTA DE FIGURAS

LISTA DE QUADROS

LISTA DE SÍMBOLOS

LISTA DE TABELAS

SUMÁRIO

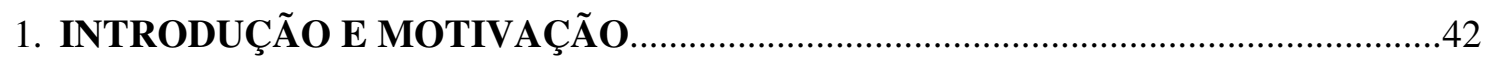

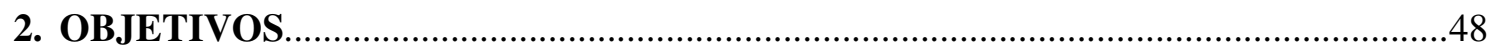

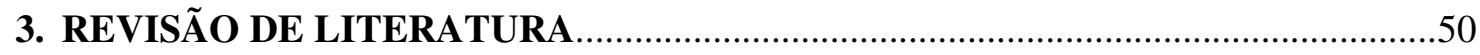

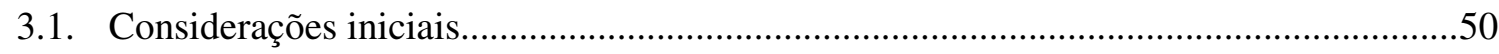

3.2. Métodos de Irrigação e sua importância......................................................................52

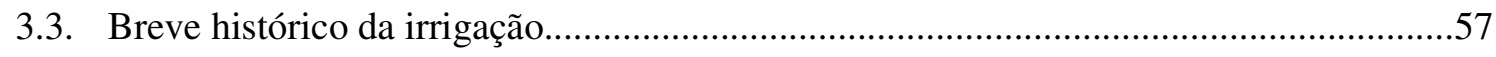

3.4. Breve avaliação da irrigação no Brasil.....................................................................60

3.5. Enquadramento da irrigação nos recursos hídricos.................................................63

3.6. Planejamento geral de um sistema de irrigação..........................................................68

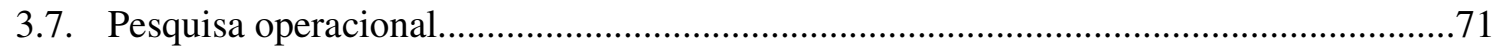

3.8. Otimização matemática em sistemas de irrigação......................................................74

3.9. Redes de distribuição, condutos mistos ou em série e sua otimização..........................79

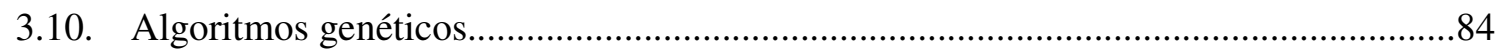




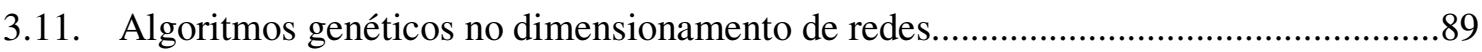

3.12. Parâmetros e operadores de algoritmos genéticos......................................................91

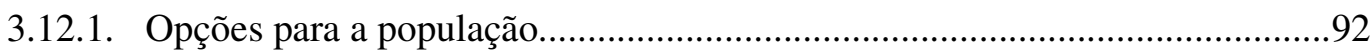

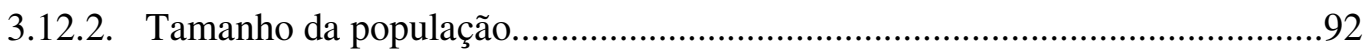

3.12.3. Função de criação..........................................................................................93

3.12.4. População inicial.......................................................................................93

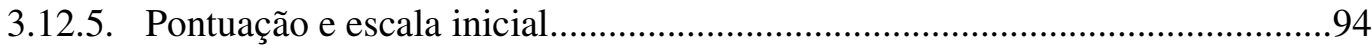

3.12.6. Escalonamento para a função de aptidão........................................................94

3.12.7. Operadores genéticos de seleção.............................................................96

3.12.8. Parâmetros de reprodução........................................................................97

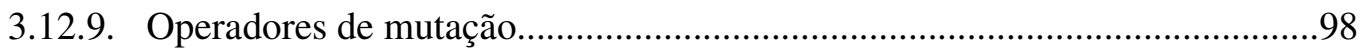

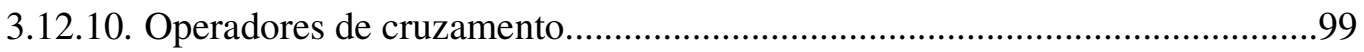

3.12.11. Opções de migração.....................................................................................101

3.12.12. Ajustes do algoritmo por penalidades.........................................................102

3.12.13. Critérios de parada do algoritmo...............................................................103

3.13. Custos fixos e variáveis em projetos de redes de irrigação........................................104

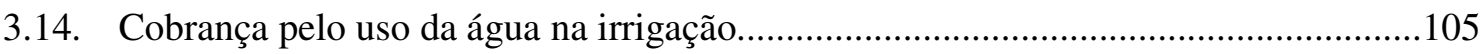

3.15. Simulações para análise de sensibilidade...............................................................106

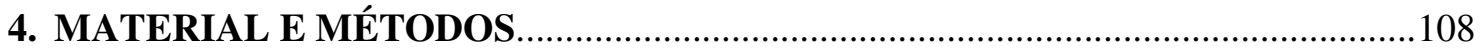

4.1. Considerações sobre o material e métodos.............................................................108

4.2. Problema a ser otimizado - Função de Aptidão...........................................................111

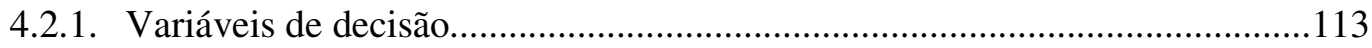

4.2.2. Restrições hidráulicas........................................................................... 114

4.3. Descrição da área e dos principais equipamentos utilizados....................................116

4.3.1. Área de implantação do sistema de irrigação.................................................116 
4.3.2. Leiaute da distribuição da rede hidráulica de irrigação em campo..................116

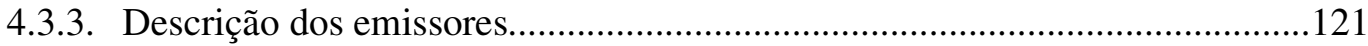

4.3.4. Descrição das tubulações de polietileno para linha lateral..............................123

4.3.5. Descrição das tubulações de PVC.............................................................125

4.3.6. Demais equipamentos e acessórios da rede hidráulica de irrigação................126

4.4. Fluxograma do dimensionamento da rede de irrigação localizada...............................128

4.5. Pré-dimensionamento e dimensionamento do sistema de irrigação localizada.............130

4.5.1. Cálculos preliminares ao dimensionamento da rede de distribuição de água do sistema de irrigação localizada

4.5.2. Equações de base para o dimensionamento da rede de distribuição

de água do sistema de irrigação localizada..............................................137

4.6. Uniformidade de emissão e uniformidade estatística.............................................150

4.7. Resumo dos principais parâmetros e operadores genéticos......................................152

4.8. Representação resumida do código de otimização por algoritmos genéticos..............153

4.9. Volume de água a ser aplicado e análise de produtividade......................................155

4.10. Ferramenta computacional utilizada na otimização.............................................156

4.11. Implementação e funcionamento da ferramenta computacional................................158

4.15. Dados iniciais de entrada do código da função de aptidão.......................................160

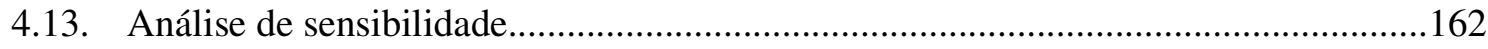

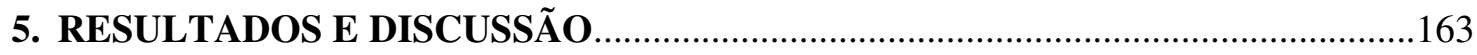

5.1. Espaço de busca e eficiência do sistema de otimização por algoritmos genéticos........164

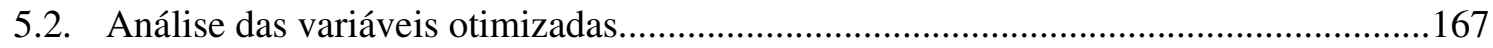

5.3. Análise econômica das redes de irrigação obtidas com a otimização...........................172

5.3.1. Análise econômica variando a declividade e a tarifa de água.......................172

5.3.2. Análise econômica variando a declividade e a tarifa de energia elétrica......174 
5.4. Análise hidráulica.

5.4.1. Análise hidráulica geral da rede de irrigação................................................177

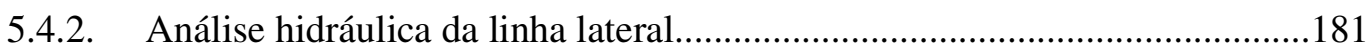

5.4.3. Análise hidráulica da linha de derivação..................................................186

5.4.4. Análise hidráulica da unidade operacional..................................................196

5.5. Uniformidade de emissão, uniformidade estatística e diferença de vazão entre o primeiro e último emissor na unidade operacional.........................................209

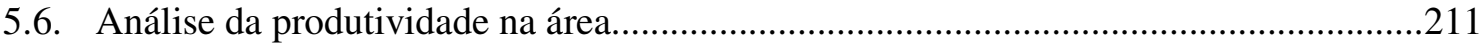

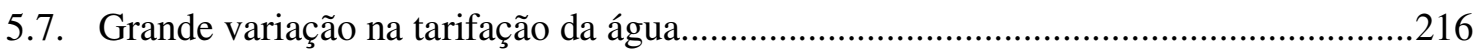

5.7.1. Variação na convegência da função de aptidão...........................................216

5.7.2. Análise das variáveis otimizadas e dos custos das redes de irrigação..........218

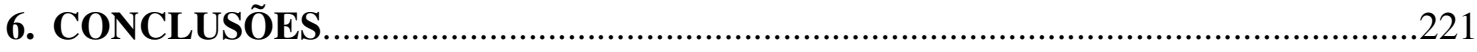

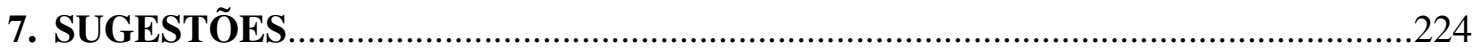

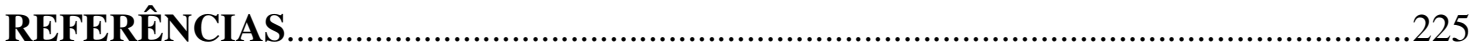

APENDICE A

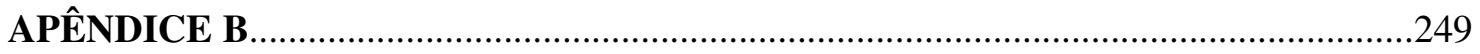

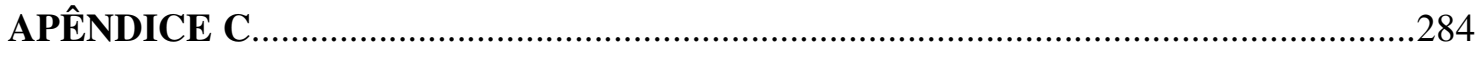

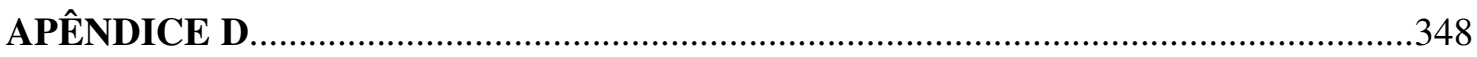

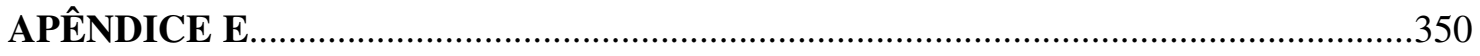

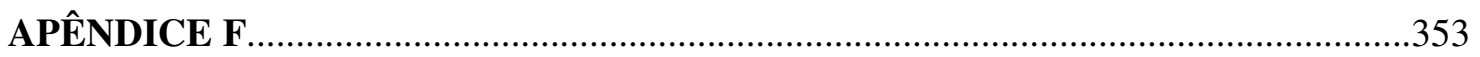

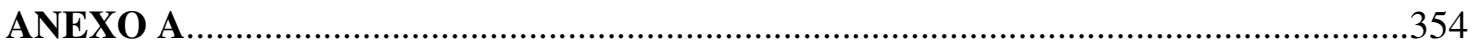

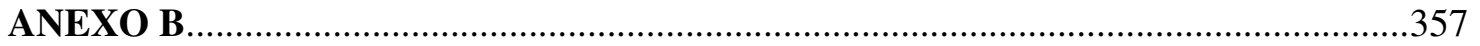




\section{INTRODUÇÃO E MOTIVAÇÃO}

A água doce, de origem fluvial e subterrânea, possui vital importância na produção agrícola, seja de forma direta na produção de alimentos de origem vegetal ou indireta na produção animal. Em conseqüência da crescente demanda por alimentos, devido ao vigoroso crescimento da população mundial e o aumento da renda em países populosos como China e Índia, a água, e toda tecnologia que a envolve, tornaram-se um foco de atenção especial não só no Brasil, mas em todo o planeta. A água também é considerada um recurso natural de valor econômico pela Agência Nacional de Águas do Brasil e passível de cobrança pelo seu uso. Portanto, o desenvolvimento de tecnologias e conceitos de uso e manejo de água envolvendo a política nacional e estadual de cobrança de recursos hídricos para o setor agrícola são importantes no meio acadêmico, em que há pesquisa de engenharia de água e solo.

Como os sistemas de irrigação são os principais consumidores de água no Brasil e no mundo, faz-se necessário que as pesquisas voltadas a projetos de concepção, uso e manejo de sistemas sejam contextualizadas e atualizadas para que os estudos tenham caráter não só cientifico, mas também prático e técnico, garantindo o retorno do avanço do conhecimento, então atingido, para a sociedade. Portanto, o paradoxo da crescente demanda de água no setor agrícola, que é o seu maior consumidor, a necessidade de economizá-la e a demanda por novas técnicas que envolvam o uso da água no meio rural, fomenta para que novos métodos de análise e tecnologias sejam alvos de pesquisa em diversas áreas do conhecimento.

A demanda de água para irrigação tende a se tornar cada vez maior em países em desenvolvimento, já que a demanda por alimentos e água para consumo humano direto crescem de forma contundente. Seja nas regiões com suficiente disponibilidade de água ou em regiões áridas e semi-áridas, a irrigação poderá sofrer limitações de ordem energética ou do 
próprio consumo de água, pela competição com outros setores. Possíveis casos de escassez de água direta para irrigação, ou da competição por energia para o bombeamento, impulsionam um maior discernimento da gestão eficiente e conjunta de recursos hídricos, bem como a pesquisa por ferramentas de análise visando à otimização desses recursos.

Muitos parâmetros iniciais de dimensionamento de sistemas de irrigação, como os que serão estudados neste trabalho (custos operacionais com energia elétrica e água), estão submetidos a outros setores da sociedade que influenciam o âmbito produtivo agrícola e das tecnologias da irrigação.

O fornecimento artificial de água às plantas é uma das práticas tecnológicas mais seguras para garantir a produção agrícola. Tais sistemas visam o fornecimento de água às culturas de interesse econômico, em quantidade adequada e no momento correto, tomando como base as condições de solo, disponibilidade de água, adversidades climáticas e do material genético a ser cultivado, fatores que variam conforme a região de implantação do campo produtivo.

Citam-se alguns benefícios da irrigação, como: aumento da produtividade, melhoria da qualidade dos produtos, exploração agrícola em regiões de clima inóspito (semi-árido ou árido), oferta de produtos em períodos de entressafra e a minimização dos riscos de abastecimento de alimentos para a população. As principais desvantagens da irrigação são o elevado consumo de água e alto custo de implementação e operação de sistemas pressurizados, sendo essas duas desvantagens, portanto, os focos centrais de estudo do presente trabalho.

No que se refere ao consumo de água, nota-se que no Brasil, a irrigação localizada representa um fator tecnológico imprescindível para se elevar a produtividade e garantir retorno econômico ao empreendimento agropecuário; devido ao déficit pluviométrico em 
algumas regiões e, principalmente, à distribuição irregular das precipitações ao longo do ano em outras, como no caso do Estado de São Paulo.

Por outro lado, no que se refere ao custo de implementação, os sistemas de irrigação localizada normalmente requerem elevado investimento podendo ser maior ou menor conforme o dimensionamento inicial e critérios de projeto estabelecidos pelo engenheiro projetista. Dependendo das combinações dos diversos parâmetros de projeto como por exemplo, vazão e diâmetro de tubulação, o sistema pode ser mais econômico na implantação ou na operação. A busca da melhor solução de tais combinações requer a utilização de técnicas e instrumentos capazes de auxiliar profissionais na análise de dimensionamento, planejamento e tomada de decisões no manejo do sistema. Neste sentido, a ferramenta de otimização matemática mostra-se promissora e, portanto é a selecionada neste trabalho.

$\mathrm{Na}$ agricultura irrigada, o planejamento adequado das instalações dos sistemas de irrigação e a administração cuidadosa dos recursos hídricos são essenciais para o empresário agrícola. O bom funcionamento do sistema de irrigação está diretamente subordinado à qualidade e longevidade dos componentes e, principalmente, aos cálculos de perda de carga durante o dimensionamento hidráulico da rede. Nesse processo de dimensionamento, em que há diferentes possibilidades de diâmetros frente a diferentes perdas de carga admissíveis na tubulação, o procedimento manual em busca da melhor solução torna-se trabalhoso e demorado. Nesse contexto, a utilização de ferramentas matemáticas de otimização, como os algoritmos genéticos, tornam-se úteis para auxiliar a tomada de decisão. A otimização matemática das instalações de sistemas de irrigação e do manejo do sistema, visando diminuir ou adequar os custos de produção de alimentos, sem desperdício de água e energia de bombeamento, vem ao encontro dos anseios da sociedade mundial e da agricultura irrigada moderna. 
Como são várias as possibilidades de combinações hidráulica e econômica na "tomada de decisão" por parte do projetista de sistema de irrigação, dados não simulados e/ou não otimizados podem levar à dúvida quando usados para análise comparativa em um dimensionamento de sistema de irrigação. Para tanto é pertinente avaliar, por exemplo, qual é a melhor vazão do sistema, segundo as necessidades hídricas da cultura instalada, segundo a tarifação de energia elétrica hora-sazonal e os fatores econômicos envolvidos no projeto. Somente após uma profunda análise de resultados combinatórios simulados, será factível apresentar uma melhor opção dentre as diversas variáveis envolvidas na "tomada de decisão".

No Brasil, a introdução da cobrança pelo uso da água é um instrumento de gestão dos recursos hídricos. Logicamente, num país onde a carga tributária chegou a atingir níveis intoleráveis, qualquer menção de novos encargos deve provocar reação contrária. Principalmente se se atenta para o fato de que a correta idéia do fundamento da cobrança ainda não chegou ao conhecimento da maioria da população. Nesse contexto, outro aspecto importante a ser considerado neste estudo, é o impacto da cobrança de água no custo final do sistema, que já está em fase de implementação por comitês de bacia hidrográfica no Estado de São Paulo. O cerne da questão, que será respondida neste trabalho, será qual o impacto dessa cobrança no custo operacional e total da rede para o empresário agrícola irrigante. Essa cobrança de água resultará em significante custo, a ponto de o irrigante investir em uma maior eficiência do sistema para economizar água? Ou continuará sendo a energia gasta pelo sistema de bombeamento, para vencer diferenças de altitudes e perdas de carga na rede de distribuição, o principal fator norteador para o investimento em eficiência do sistema de irrigação? Trabalhando-se com dados de entrada comerciais, como os dados de tarifação de energia elétrica, custo por metro cúbico de água e de equipamentos, busca-se analisar o efeito percentual real que a cobrança de água terá no custo total de um sistema de irrigação localizada. 
Desenvolver a utilização de ferramentas matemáticas e computacionais, visando à otimização dos fatores que envolvem a hidráulica e os custos de um sistema de irrigação, garantindo dados para análise do recurso natural água, é papel de grande relevância para pesquisadores da área de recursos hídricos em geral.

Além disso a otimização de sistemas de irrigação localizada, em que se consegue economia no uso da água e de energia elétrica, tende a ser cada vez mais importante quanto à preservação dos recursos naturais envolvidos direta e indiretamente. Por exemplo, sistemas de irrigação que consomem muita água, requerem diretamente mais energia elétrica para o bombeamento, fomentando a médio e longo prazo a criação de novas hidrelétricas para suprimento da demanda por energia. Tal fato provoca a criação de represamento da água, que por sua vez inunda regiões, afetando os recursos naturais e reduzindo ou eliminado áreas agricultáveis férteis, promovendo um ciclo em cadeia prejudicial para o homem.

Com os cenários acima apresentados, e visando sempre a um melhor desenvolvimento da pesquisa operacional na irrigação e uma análise de resultados da contribuição proposta, é que se tem como implicação, uma preocupação crescente quanto ao uso do recurso natural água e seu norteamento econômico para o produtor rural que lança mão da irrigação.

Neste trabalho, desenvolve-se um modelo de dimensionamento de rede de irrigação localizada para otimização por algoritmo genético, visando a uma análise comparativa de diferentes critérios iniciais de implantação e operação. Critérios iniciais de projeto para sistemas de irrigação com baixo consumo da água são analisados visando à otimização dos custos fixos de instalação do sistema tendo como restrições os recursos hídricos e energéticos. A combinação de diferentes restrições, como a quantidade de água outorgada e tempo disponível para o bombeamento, não são só de fundamental importância para o dimensionamento da rede de distribuição de água, mas afetam os custos de implementação e operação futura do sistema de irrigação. 
Dentre os fatores que envolvem os custos variáveis de operação do sistema, o peso parcial do custo de energia elétrica e de água, no custo total de operação, serão analisados, tendo em vista que a cobrança pelo uso da água, tanto de origem fluvial como subterrânea, já esta sendo implementada por governos estaduais e federal. Os fatores de análise dos custos fixos de implantação serão os diferentes diâmetros, para o mesmo trecho, das tubulações utilizadas na rede de distribuição de água no sistema, sendo esse fator submetido aos critérios iniciais de disponibilidade de água e tempo de irrigação, conforme o custo operacional. Em suma, no presente estudo de otimização de rede, simulou-se por meio de algoritmos genéticos, diferentes cenários de declividade do terreno, custos de energia elétrica e de água para irrigação, e o efeito desses critérios de projeto na hidráulica da rede de distribuição de água.

Os dados de entrada de custos foram a partir de uma base de dados comerciais, e tomou-se por base, além dos custos fixos e variáveis, as características hidráulicas e normas de projeto de distribuição de água em rede para sistemas de irrigação localizada. 


\section{OBJETIVOS}

O objetivo geral deste trabalho é desenvolver um modelo computacional para simulação e otimização de projetos de rede de distribuição de água em sistemas de irrigação localizada. O código desenvolvido apresenta o cálculo de toda perda de carga localizada no sistema, além do pré-dimensionamento necessário em todo projeto de irrigação. Para a otimização, é adotada a técnica dos algoritmos genéticos visando à minimização de custos anuais fixos e operacionais obedecendo às restrições hidráulicas da rede.

Os objetivos específicos deste trabalho são:

a) Análise do espaço de busca da solução e da eficiência do modelo de otimização por algoritmos genéticos. É feita uma avaliação do espaço de busca total e do espaço de busca percorrido pelo algoritmo genético na otimização e a verificação da eficiência do processo pela convergência da função de aptidão frente ao número de gerações.

b) Análise de sensibilidade das variáveis otimizadas. Executa-se uma análise das variáveis otimizadas utilizando-se de uma variação na declividade do terreno, tarifa de água e energia elétrica.

c) Análise de sensibilidade econômica do código desenvolvido. Estudo do efeito de diferentes dados de entrada nos custos do dimensionamento otimizado da rede. São analisados os resultados no custo total da rede aumentando a declividade do terreno e com o acréscimo e decréscimo percentual nas tarifas de água e energia elétrica.

d) Análise de sensibilidade hidráulica do código desenvolvido. Executa-se um estudo hidráulico da rede de distribuição de água obtida em cada simulação otimizada, considerando a variação de declividade e as tarifas de energia elétrica e água sem alterações, a fim de validar o dimensionamento da rede e o funcionamento do código. Para isto faz- se uma 
simulação numérica com as variáveis otimizadas, visando uma análise da distribuição de energia, pressão e vazão na rede como um todo e enfatizando uma análise mais detalhada nas linhas laterais e de derivação do sistema, onde ocorre a distribuição de vazão em marcha.

e) Análise da produção e de sua distribuição na área. Analisa-se a produção e sua distribuição na área segundo as vazões obtidas para as diferentes declividades do terreno estudadas e as tarifas de energia elétrica e água sem variações.

f) Análise da uniformidade de vazão por métodos consagrados pela literatura especializada. Objetivando-se analisar a qualidade dos resultados finais obtidos, executa-se uma avaliação da uniformidade de emissão, uniformidade estatística e diferença total entre o primeiro e o último emissor na unidade operacional.

g) Análise do efeito da ampla variação na tarifação da água. Estuda-se a ampla variação na tarifação da água nos custos de equipamentos, com energia elétrica e com a água do sistema de irrigação localizada. Análisa-se, concomitantemente, as variáveis otimizadas e a convergência da função de aptidão frente as diferentes tarifas de água com grande amplitude. 


\section{REVISÃO DE LITERATURA}

\subsection{Considerações iniciais}

O planeta Terra deveria ser chamado planeta Água, já que mais de dois terços (71\%) da superfície terrestre estão cobertos por água. Uma pessoa adulta precisa de 4 litros de água por dia para beber, mas para produzir seu alimento diário são necessários de 2 a 5 mil litros (ALLEN; PEREIRA; RAES, 1998; AGÊNCIA NACIONAL DE ÁGUAS, 2007b; DOORENBOS e PRUITT, 1977). O ser humano é composto de água (entre 70 e 75\%), a maior parte do peso do corpo dos seres vivos é composta de água e trocamos constantemente os nossos líquidos com o restante da natureza. Destaca-se, nesse ponto, a água encontrada nos alimentos de origem vegetal e animal, o que nos faz consumir água de forma indireta. Os vegetais contém uma porcentagem elevada de água: alface (95\%), tomate (94\%), melancia (92\%), couve-flor (92\%), melão (90\%), abacaxi (87\%), goiaba $(86 \%)$ e banana $(74 \%)$ (MIRANDA, 2004).

A água é um componente essencial da paisagem e do meio ambiente, e por isto, é vista como um recurso de valor agregado estimável com múltiplos usos e um bem natural essencial à vida humana na Terra. Destaca-se a importância dos recursos hídricos na geração de energia elétrica, abastecimento doméstico, industrial, navegação, recreação, agricultura, piscicultura, pesca e para assimilação, condução de esgotos e na irrigação na produção de alimentos. Os seres humanos já passaram por diversas crises, como decorrentes de epidemias, da falta de alimentos e petróleo, sendo que as próximas crises esperadas serão de energia e de disponibilidade de água de boa qualidade (PRUSKI E SILVA, 1997). 
Veloso et al. (2001), trabalhando com irrigação no estado do Piauí, constataram que para se produzir $10 \mathrm{~kg}$ de banana são necessários 2.625 litros de água. Com isto, verifica-se a necessidade de pesquisa e aprimoramento de tecnologias que visem à utilização mais eficiente da água.

Mesmo tendo a noção da importância da água, gastamos mais água do que temos disponível para captação em algumas regiões, poluímos bem mais do que consumimos, desperdiçamos um volume incalculável da água que tratamos para consumo humano direto, ou usamos para produzir nossas fontes de alimento. Tecnologias que vêm ao encontro da melhoria da eficiência de todos os processos produtivos, que se utilizam da água, estão em destaque. A irrigação, como principal consumidora de água doce, no Brasil e no mundo (AGÊNCIA NACIONAL DE ÁGUAS, 2007b), merece especial atenção quanto à tecnologia que a engloba, em especial técnicas que vêm ao encontro do aperfeiçoamento de sua utilização.

Destaca-se neste ponto a metodologia matemática denominada pesquisa operacional, que demonstra ser uma excelente ferramenta para a otimização de diferentes tipos de sistema de irrigação, melhorando essa tecnologia de aplicação artificial de água às plantas, como se encontra em Saad et al. (1994), Singh e Mahar (2003) e Reca (2006). Assim sendo, diminui o desperdício de água e os recursos econômicos envolvidos nos sistemas produtivos de alimentos que se utilizam da irrigação.

No que segue, tenta-se, de forma contextual, esclarecer e concatenar o leitor aos objetos de estudo deste trabalho, lançando mão de dados históricos, atuais, e de importância desse tipo de pesquisa no desenvolvimento de novas ferramentas tecnológicas para irrigação localizada. 
$\operatorname{Arantes}^{1}$ (1971, p.9 apud Fachin 2001, p.125) ressalta a pesquisa bibliográfica como o "ato de ler, selecionar, fichar, organizar e arquivar tópicos de interesse para a pesquisa em pauta". Todos os tipos de estudos devem ser apoiados e respaldados por uma pesquisa bibliográfica ampla e cuidadosa, mesmo que se baseie em uma pesquisa de laboratório ou de campo (FACHIN, 2001).

Para tanto, aborda-se nesta revisão de literatura, a irrigação e sua importância, um breve histórico da irrigação, uma breve avaliação da irrigação no Brasil e seu enquadramento nos recursos hídricos, o planejamento de um sistema de irrigação, conceitos de pesquisa operacional e algoritmos genéticos e sua aplicação na irrigação localizada.

De forma.a concatenar a Revisão da Literatura com a tese de doutorado, ao final dos principais tópicos é apresentado um resumo, relacionando o assunto revisado e sua aplicação ao estudo desenvolvido.

\subsection{Métodos de Irrigação e sua importância}

A irrigação consiste na aplicação artificial de água ao solo para compensar as deficiências pluviais, visando proporcionar um teor de umidade suficiente para a germinação da semente, crescimento, manutenção, produção e reprodução das plantas.

A irrigação, de um modo geral, é classificada em dois grandes grupos básicos, a de superfície e a pressurizada.

A irrigação de superfície classifica-se basicamente em dois tipos:

\footnotetext{
1 ARANTES, T.F. Pesquisa bibliográfica nas ciências biomédicas. São Paulo: Faculdade de Odontologia - USP. Revista n.XIII, 1971.
} 
a) irrigação por sulcos - consiste na condução da água até as plantas por sulcos (condutos ou canais) feitos no próprio solo, sem a utilização de qualquer outro tipo de energia além da gravidade;

b) irrigação por inundação - normalmente utilizada na irrigação de arroz, consiste na completa inundação da área a ser irrigada por uma lâmina de água de altura variável, dimensionada a partir de fatores edafoclimáticos.

A irrigação pressurizada pode ser classificada basicamente em:

a) irrigação por aspersão - consiste na aplicação de um grande volume de água, com pouca frequiência, através de aspersores que pulverizam a água no ar, de modo a tentar reproduzir o efeito da chuva. Tais sistemas utilizam grande quantidade de energia devido ao grande volume de água aplicada;

b) irrigação localizada - consiste na aplicação de pequenos volumes de água, normalmente o volume que a planta utilizará por poucos dias, e uma freqüência de aplicação maior. Esses sistemas, normalmente, utilizam pequenas quantidades de energia para o bombeamento. No entanto, a irrigação localizada apresenta um elevado custo de implantação e é utilizada majoritariamente na fruticultura e em outras culturas perenes. É também usada por produtores tecnificados de hortículas e flores, em especial pela reduzida necessidade de água.

Kuwabara e Matsura (1996, p. 276), em um trabalho sobre o comportamento hidráulico de linhas laterais de tubogotejadores, citam que entre os sistemas de irrigação, o que possibilita o melhor controle da lâmina é a irrigação localizada, por operar com baixas vazões e turnos de rega com maior freqüência.

A irrigação localizada pode ser classificada em dois tipos básicos:

a) gotejamento - a água é conduzida sob pressão por uma rede de tubulações, até ser aplicada ao solo através de gotejadores, diretamente próxima e sobre a zona radicular da 
planta, em alta frequência de aplicação e baixa intensidade de vazão. A eficiência é da ordem de 90\% (BERNARDO; SOARES; MANTOVANI, 2005), variando conforme o material utilizado e os parâmetros de projeto estabelecidos. Pode ser instalado sobre a superfície ou enterrado, dependendo essa decisão de uma análise criteriosa da cultura a ser irrigada e dos fatores edafoclimáticos da localidade.

Mantovani, Bernardo e Palaretti (2006, p. 207) escrevendo sobre gotejamento, citam que "as vazões são usualmente pequenas, variando de 2 a 10 L.h ${ }^{-1}$ ".

Kuwabara e Matsura (1996, p. 277) explicam que dentre os sistemas de irrigação localizada tem-se a irrigação por gotejamento, onde a água é fornecida através de tubos perfurados, ou por gotejadores conectados aos tubos de polietileno ou por tubogotejadores nas quais os emissores são fundidos dentro da tubulação.

Linsley e Franzini (1978, p.457-492) citam que na irrigação por gotejamento, a água, junto com os nutrientes, é aplicada ininterruptamente na base de cada planta, através de pequenos tubos plásticos, eliminando virtualmente qualquer evaporação a partir do solo, a infiltração profunda e o escoamento de superfície. Ou seja, a irrigação por gotejamento proporciona um elevado rendimento quanto ao uso da água e, devido a sua alta frequência, reduzem-se os problemas de salinidade do solo.

b) microaspersão - possui uma eficiência maior que a aspersão convencional, mas geralmente um pouco menor que o sistema de gotejamento (BERNARDO; SOARES; MANTOVANI, 2005). É muito utilizada para a irrigação de culturas perenes. Também é considerada irrigação localizada, porém a vazão dos emissores (chamados microaspersores) é maior que a dos gotejadores, possibilitando a aplicação de um maior volume de água no mesmo espaço de tempo, contudo diminuindo a sua eficiência de aplicação.

Mantovani, Bernardo e Palaretti (2006, p. 207), discorrendo sobre microaspersão, citam vazões variando de 22 a 250 L.h ${ }^{-1}$. 
Santiago, Montenegro e Montenegro (2004, p. 633), em uma pesquisa de campo sobre parâmetros hidráulicos de microaspersão, discorrem sobre o bom funcionamento do sistema, com coeficientes de uniformidade elevados, eficiência de aplicação boa e pouca variação na vazão e pressão do sistema, indicando uma excelente qualidade de sistema de irrigação em funcionamento no campo.

Carruthers, Rosegrant e Seckler (1997), em um trabalho sobre irrigação e segurança alimentar no século 21 , informam que a produção proveniente da irrigação é um assunto de grande interesse econômico mundial, onde o sucesso e a falha têm efeitos profundos no bemestar do todos aqueles empregados e pelos consumidores de alimentos. Os mesmos autores ainda escrevem que devido à grande escala de produção, o abastecimento e os preços de alimento no mundo estarão influenciados pelo desempenho dos produtores que se utilizam da irrigação.

Segundo a ABIMAQ (2002), "estudos científicos demonstram que o estresse causado pela falta de água reduz sensivelmente a produção vegetal, inviabilizando-a, por exemplo, em regiões de clima árido ou semi-árido, onde a falta de água é constante e limita a atividade agrícola". Contudo, como consequiência de uma irrigação realizada no momento adequado, aplicando-se a quantia certa de água, ocorrem índices de produtividade acima das médias das culturas, quando cultivadas sob condição de precipitação atmosférica somente (cultivos de sequeiro).

Mantovani, Bernardo e Palaretti (2006, p. 17), no livro sobre irrigação, citam que

É importante ter em mente o significado real da agricultura irrigada, que possibilita maior produção (mais de um plantio por ano) e produtividade (otimização no uso de áreas), bem como a geração de empregos permanentes, com os menores níveis de investimento, em comparação com 
outros setores da economia. Isso promove o aumento da renda e a diminuição do êxodo rural, melhorando sensivelmente as condições de vida dos produtores e suas famílias.

França (2001), em um trabalho sobre a importância da irrigação para a população do nordeste brasileiro, cita as seguintes vantagens: criação de emprego direto, salários pagos no perímetro superiores àqueles pagos pela indústria e comércio da região, diminuição no fluxo migratório rural-urbano e inter-regional, melhoria nas condições de saúde, educação, habitação e de lazer dos irrigantes.

O futuro da irrigação envolve produtividade e rentabilidade ao produtor, com eficiência no uso da água, da energia e de insumos e respeito ao meio ambiente. A busca desses conceitos vem sendo importante, mas limitada, pois tem sido focada do ponto de vista da engenharia, negligenciando-se o manejo e operação (MANTOVANI; BERNARDO; PALARETTI, 2006).

A escolha do sistema de irrigação a ser utilizado deve ser baseada na viabilidade técnica, econômica e social, visando a atender os interesses de produção. De uma maneira geral, os sistemas de irrigação por superfície são os de menor custo, os de aspersão de custo médio e a localizada de maior custo. Fora o custo, outra observação importante que o projetista e o usuário devem fazer é a eficiência do sistema quanto à utilização da água (Tabela 1).

Via de regra, alta eficiência do sistema implica alto custo de implantação, o que, na maioria dos casos, inibe a adoção desses sistemas de irrigação por parte da maioria dos produtores. Estender ao irrigante e aprimorar tecnologias que diminuam o custo dos sistemas de irrigação mais eficientes é um dos grandes desafios da atualidade para quem trabalha com irrigação no meio acadêmico. 
Tabela 1. Eficiência dos diferentes sistemas de irrigação

\begin{tabular}{|c|c|c|c|}
\hline \multicolumn{2}{|c|}{ Sistema de Irrigação } & $\begin{array}{c}\text { Eficiência } \\
\text { média máxima }\end{array}$ & $\begin{array}{l}\text { Eficiência média } \\
\text { mínima }\end{array}$ \\
\hline Macro grupo & " Nome do sistema & "------------------ & "7o --------------------- \\
\hline \multirow{3}{*}{ Superficial } & Sulcos & 70 & 40 \\
\hline & Corrugação & 70 & 40 \\
\hline & Inundação & 70 & 50 \\
\hline \multirow{7}{*}{ Aspersão } & Convencional portátil & 75 & 60 \\
\hline & Convencional semiportátil & 75 & 60 \\
\hline & Convencional permanente & 80 & 70 \\
\hline & Autopropelido & 70 & 60 \\
\hline & Ramal volante & 85 & 65 \\
\hline & Pivô central & 90 & 75 \\
\hline & Deslocamento linear & 90 & 75 \\
\hline \multirow{2}{*}{ Localizada } & Gotejamento & 90 & 85 \\
\hline & Microaspersão & 90 & 80 \\
\hline
\end{tabular}

Fonte: Adaptado de Marouelli, Silva e Silva (1998).

Com o exposto, verifica-se que a tecnologia da irrigação funciona como uma excelente ferramenta para a produção de alimentos. A irrigação, por suprir as necessidades hídricas das plantas em qualquer momento que se faça necessário, mesmo na falta ou má distribuição de chuva, diminui contundentemente a possibilidade de perda da produção. Com isto, verifica-se que, a tecnologia da irrigação localizada torna-se um fator de produção importante para a seguridade na disponibilidade de alimentos, gera empregos de melhor qualidade em comparação aos outros setores da agricultura, atende a questão ambiental e conflitos do uso múltiplo da água por economizá-la e gera uma maior capitalização do empresário agrícola, que obtém maior produtividade na área.

\subsection{Breve histórico da irrigação}

Não se pode afirmar com precisão quando foi a primeira vez que o ser humano utilizou a água de forma artificial para suprir as necessidades hídricas das plantas, mas isso 
seguramente distinguiu um importante passo à frente no curso da civilização humana. Quando se fala de história da irrigação confunde-se, na maioria das vezes, com a história da agricultura e da prosperidade econômica e modernidade de inúmeros povos antigos e modernos, em diferentes partes do planeta. As grandes civilizações da antiguidade originaram-se em regiões áridas próximas de cursos de água, onde a lavoura e o pasto para animais só existiam graças ao fornecimento artificial de água para as plantas (INFORMATIVO VERDE, 2004).

Tucci et al. (1993, p. 27), discorrendo sobre a história da utilização da água, citam que Mesmo não conhecendo a origem da água e o funcionamento dos fenômenos naturais, as civilizações antigas puderam explorar os recursos hídricos através de projetos de irrigação como os do Egito e Mesopotâmia, aquedutos para abastecimento de água romanos e irrigação e controle de inundação pelos chineses.

Vários estudos comprovam que a 4500 a.C. essa prática era utilizada pelos assírios, caldeus e babilônicos no continente asiático. Da mesma forma, as grandes aglomerações que se fixaram nas margens dos rios Huang Ho e Iang-Tse-Kiang na China (ano 2.000 a.C.), do Nilo, no Egito, do Tigre e do Eufrates, na Mesopotâmia e do Ganges, na Índia (ano 1000 a.C.), nasceram e cresceram graças à utilização abundante de seus recursos hídricos. No Egito Antigo, às margens do Rio Nilo, tem-se o registro do que foi a primeira obra de "engenharia" relacionada à irrigação. Foi quando o Faraó Ramsés III ordenou a construção de diques, represas e canais que melhoravam o aproveitamento das águas do Rio Nilo. Só mais tarde, há cerca de mil e quinhentos anos, é que a humanidade deslocou-se para regiões úmidas, onde a irrigação perdeu sua necessidade vital, transformando-se unicamente em prática subsidiária e 
pouco usada. Aí cresceram as grandes concentrações humanas, que foram forçadas, para sua subsistência, a explorar quase todo o solo arável (GIACOIA NETO, 2003).

\section{Linsley e Franzini (1978) citam em seu trabalho que}

[...] a primeira irrigação no continente americano é anterior à vinda dos europeus. Ainda estão em uso algumas das valas construídas pelos índios Hohokam no Vale do Rio Salt, no Arizona, antes de 1400. Os colonizadores espanhóis, sob a direção de Don Juan de Onate, construíram sistemas de irrigação no Novo México, em 1598. A utilização econômica dos estados do oeste dos EUA data de 1847, quando os pioneiros Mórmons construíram sua primeira barragem para irrigação, no pequeno rio City, em Salt Lake City, Utah. A partir dessa obra, que irrigou cerca de 2 ha de terra, a irrigação nos Estados Unidos estendeu-se a mais de $182.000 \mathrm{~km}^{2}$ até 1965.

O Informativo Verde (2004, p. 7), citando sobre a história da irrigação, diz que [...] no século XIX a irrigação ainda era feita sem aparelhamentos específicos e utilizava-se somente o método de inundação (especialmente na cultura do arroz) e através de sulcos. Com o início da produção de tubulações específicas e estudos de aplicação de água, é que realmente começamos a verificar uma grande evolução nos sistemas de irrigação e métodos. Um fato de extrema importância para o mundo da irrigação foi a invenção do primeiro aspersor de impacto. $\mathrm{Na}$ época, a invenção foi comparada à lâmpada de Thomas Edison e ao telefone de Alexander Grahm Bell. Orton Englehart foi um cultivador de citrus residente no sul da Califórnia. Ele inventou o primeiro aspersor de impacto em 1933 e revolucionou a história da produção de alimentos, iniciando uma nova era na irrigação mundial. 
Giacoia Neto (2003) cita que o Brasil, dotado de grandes áreas agricultáveis localizadas em regiões úmidas, não baseou sua agricultura na irrigação, embora haja registro que em 1589, os Jesuítas já praticavam a irrigação na antiga Fazenda Santa Cruz, no Estado do Rio de Janeiro.

\subsection{Breve avaliação da irrigação no Brasil}

Segundo a Agência Nacional das Águas (2007a), a área irrigada do Brasil atinge 3,7 milhões de hectares, o que equivale a quase $9 \%$ da área plantada com grãos. O baixo índice na irrigação não está relacionado com o estágio de desenvolvimento dos estados do Brasil, mas com o custo-benefício e as oportunidades na agricultura não-irrigada. O estado de São Paulo, por exemplo, dispõe de 4,5 milhões de hectares irrigáveis, mas só utiliza 470 mil, ou seja, 9,5\% da capacidade real. Nos dias atuais, dispõe-se da tecnologia mais avançada em irrigação no Brasil, contudo limitada à disponibilidade de investimento por parte dos agricultores, que em sua maioria lançam mão de empréstimos bancários para execução de projetos. Porém, a adoção de tais tecnologias passa por verdadeiros desafios, desde as formas de inundação por gravidade em áreas sistematizadas, pequenas ou enormes, de aspersão convencional ou por gotejamento, incluindo a químigação, até os sofisticados pivôs centrais que, unitariamente, podem cobrir mais de 150 hectares.

Nos dados divulgados pela Agência Nacional das Águas (2005), de toda a área cultivada no Brasil, apenas 5\% são irrigadas, sendo que esta pequena área irrigada é responsável por $16 \%$ da produção total e $35 \%$ do valor da produção agrícola total do Brasil. Verifica-se com o exposto acima que a agricultura irrigada é capaz de agregar maior valor à produção agrícola, quando comparada com o cultivo sem a utilização da irrigação, além de 
que é mais requisitada, como garantia de produção, por culturas mais nobres, que por si só já possuem maior valor agregado.

A decisão de adotar uma técnica de irrigação, dentre todas possíveis, tem exigido, dos agricultores brasileiros, grande cuidado na escolha da tecnologia e da cultura. O custo elevado justifica-se quando se trata de culturas de atividades cuja resposta se viabilize não só em termos de quantidade e de qualidade de produção, mas também pelo valor do produto colhido. Apesar de tudo, os cafeicultores do Centro-Oeste, principalmente no estado de Goiás, estão colhendo bons resultados com seus investimentos na irrigação em função do avanço da produtividade e da qualidade, não obstante enfrentando uma fase de preços baixos do produto. Produzir sementes também tem motivado os agricultores a lançarem mão da irrigação. A irrigação tem se enquadrado como garantia para um investimento elevado, pois o custo para produção de semente é extremamente alto, devido ao grande número de tratos culturais e alta tecnologia empregada. Assim, o agricultor tem segurança de que não vai perder sua produção por falta de água.

No Brasil, projetos de sistemas de irrigação por pivô central, por exemplo, envolvem grande aporte de investimentos, o que praticamente excluem os pequenos produtores, os quais recorrem ao sistema convencional de aspersão onde inclusive podem utilizar a corrente elétrica monofásica. Mesmo com os preços dos equipamentos muito elevados, um bom projeto com pivô central pode ter seu retorno em 4 anos. Todavia, a irrigação com pivô central para produção de grãos requer uma criteriosa análise de mercado de quem se dispõe a investir cerca de US\$1.300,00 em um único hectare em equipamentos e instalações, além dos gastos elevados com a operação e a manutenção. Em operação, o pivô central gasta cerca de 20 horas para fazer um giro completo sobre o seu eixo. No entanto, a tarifa especial sobre a energia gasta, subsidiada pelo governo, cobre apenas 8,5 horas de todo o tempo de uso do 
equipamento de irrigação. Um pivô de envergadura média, no Brasil, cobre em torno de 60 hectares e gasta perto de $80 \mathrm{kWh}$ por hectare irrigado (FOLEGATTI; PESSOA; PAZ, 1998).

O custo da energia elétrica corresponde a aproximadamente $22 \%$ do custo variável para implantar uma lavoura de milho irrigada no Brasil, desconsiderando os custos indiretos com amortização, manutenção e assistência técnica. Por isso, os produtores de grãos não estão motivados a usar esses equipamentos caros. A opção tem sido produzir o que o mercado remunera melhor, como sementes, feijão na entre safra, frutas e olerícolas. Opções como o cultivo de frutas e olerícolas tendem a requerer sistemas como a irrigação localizada (FOLEGATTI; PESSOA; PAZ, 1998).

A irrigação no Brasil está entrando numa fase em que a prioridade é a eficiência no uso da água, ou seja, a avaliação da quantidade de água que é efetivamente utilizada para o desenvolvimento das culturas em relação ao total de água aplicada. Quanto menor é a perda de água, seja por evaporação, escoamento superficial ou percolação em direção ao subsolo, maior é a eficiência da irrigação.

Já existem métodos de irrigação que trabalham com eficiência de aplicação de até 95\% (como o método estudado neste trabalho), praticamente eliminando as perdas envolvidas. Por isso, a irrigação no Brasil está demandando necessariamente equipamentos que possam distribuir a água com mais eficiência, evitando desperdícios, e, estudos mais precisos sobre fatores fisiológicos, pedológicos e climáticos, que determinam a quantidade correta de água a ser utilizada (SANTO, 2001).

Observa-se, portanto, que a irrigação é uma tecnologia importante na produção de alimentos no Brasil. Mesmo, no Brasil, sendo utilizada numa área pequena em comparação à área total cultivada, a irrigação é responsável pelo triplo da produção de uma mesma área sem irrigação e mais de um terço do valor de toda a produção nacional. Verifica-se com isto a importância do papel da irrigação na produção de alimentos e na economia do Brasil. 
3.5. Enquadramento da irrigação nos recursos hídricos

Apesar de ser, de longe, o setor que mais consome água (AGÊNCIA NACIONAL DE ÁGUAS, 2007b), a agricultura de irrigação tende a crescer algo em torno de $15 \%$ a $20 \%$ nos próximos 30 anos, atendendo à demanda crescente por mais alimentos, de uma população projetada em 8 bilhões de pessoas, além de responder à demanda econômica por produtos agrícolas de maior valor agregado (ALLEN; PEREIRA; RAES, 1998; AGÊNCIA NACIONAL DE ÁGUAS, 2007b; DOORENBOS e PRUITT, 1977).

Aproximadamente $70 \%$ dos recursos hídricos disponíveis atualmente são destinados à irrigação, contra apenas $20 \%$ para a indústria e menos de $10 \%$ para abastecimento da população (higiene e consumo direto). Nos países desenvolvidos, o percentual de uso da água para irrigação é ainda maior, chegando próximo dos $80 \%$. No entanto, mesmo lá, apenas $1 \%$ das áreas irrigadas adota o método de gotejamento, um dos mais eficientes na relação alimento por litro de água utilizada, uma vez que reduz a possibilidade de evaporação (ROBERT, 2001).

Em seu artigo sobre crise e negócio com água, Malvezzi (2004) mostra um novo panorama do conceito de exportar água dizendo

Hoje, o entendimento é que, exportar grãos, significa, em última instância, exportar água. Produzir grãos em território alheio é poupar água no próprio território. Técnicas pesadas como pivôs centrais e irrigação por sulco consomem ainda mais água que a microaspersão. A humanidade terá que rever seu consumo de água para irrigação. Não existem recursos hídricos para que esse modelo de produção continue ao infinito. 
Se a agricultura conseguir aumentar a sua produtividade por litro de água usado na produção de alimentos, a atenção sobre o seu uso no setor agrícola será reduzida e, a água, além de ser liberada para outros setores, poderia ser tratada com enfoque maior para uso humano direto, industrial e dessedentação de animais.

A simples melhora de $1 \%$ na eficiência do uso da água de irrigação, nos países em desenvolvimento de clima árido, significaria uma economia de 200 mil litros de água, por agricultor, por hectare por ano. Esse volume seria suficiente para matar a sede de 150 pessoas no período (ÁGUA E AGRICULTURA, 2006).

As áreas irrigadas, nos países em desenvolvimento, devem crescer dos atuais 202 para 242 milhões de hectares nos próximos anos. Na África, a potencialidade é de 40 milhões de hectares irrigáveis, dos quais apenas 12 estão irrigados. Em países do Primeiro Mundo, o total irrigado fica em torno dos 50 milhões de hectares, mas o potencial de ampliação é menor, porque a agricultura já é intensificada. A escolha da tecnologia mais adequada e, sobretudo, a promoção de métodos de irrigação que evitam o desperdício é fundamental para atender à demanda por alimentos, com o mínimo de impactos ambientais, como a degradação dos solos, dos aquíiferos ou os processos de salinização (ÁGUA E AGRICULTURA, 2006).

Há perímetros irrigados em que a baixa qualidade das águas de superfície, ou a falta da mesma, leva os agricultores a lançarem mão da captação de águas subterrâneas. Contudo, o uso descontrolado da água subterrânea na irrigação, que em geral é de excelente qualidade, está levando ao rebaixamento dos aqüíferos, em alguns casos, no impressionante ritmo de 1 a 3 metros por ano. Tentando evitar problemas futuros, a FAO (Food Agriculture Organization) indica em relatório divulgado em Kyoto em 1997, a adoção de tecnologias mais eficientes do que a tradicional inundação de campos ou o uso generalizado de aspersores e pivô central (os dois métodos de irrigação mais utilizados no Brasil) (WORLD WATER DEVELOPMENT REPORT, 2006). 
O exposto até então vem ao encontro aos anseios deste trabalho, que é o de contribuir com a melhoria tecnológica de um sistema de irrigação altamente eficiente na aplicação de água.

O documento da FAO, divulgado em Kyoto, em 1997, apresenta as seguintes afirmativas: "Não há uma única solução para manter a segurança alimentar quando a água é escassa"; "Todas as fontes de água - chuva, canais de irrigação, águas subterrâneas e águas servidas - são importantes. Todas podem ser desenvolvidas em condições adequadas. A melhor combinação de uso do solo, tipo de cultivo e fonte de água deve responder às características de cada ecossistema” (WORLD WATER DEVELOPMENT REPORT, 2006). Ferramentas, como a otimização matemática, que auxiliam a melhoria sistematizada deste quadro, ano a ano ganham maior importância e visibilidade.

Ultimamente tem-se gerado um excepcional destaque à racionalização do uso da água, propondo a utilização e o desenvolvimento sustentável devido às condições de escassez em seu uso múltiplo. Assim, o direito de uso da água deixou de ser livre e passou a ser passível de cobrança. Tanto na concessão, como na cobrança do uso da água, tem-se como instrumento a Legislação de Outorgas de Direito de Uso das Águas e seus domínios. Os pedidos de outorga são em sua maioria para irrigação, abastecimento público, lançamentos de efluentes de esgotamento sanitário, uso industrial e obras hidráulicas (AGÊNCIA NACIONAL DE ÁGUAS, 1997). Destaca-se, neste ponto, o cuidado especial para com a outorga de água na irrigação, devido ao grande volume de água consumida no funcionamento do sistema.

Com crescente demanda de tecnologia empregada na agricultura, na ânsia por maior produtividade, muitas áreas utilizam a irrigação por meio de grandes aspersores para o suprimento das necessidades hídrica das plantas. Na maioria das regiões agrícolas, que empregam estes sistemas que consomem grandes volumes de água, observa-se uma alta demanda dos mananciais de água doce devido ao grande número de equipamentos instalados 
e suas dimensões (BRAGA e OLIVEIRA, 2005). Com isso, a irrigação localizada torna-se uma alternativa para a economia de água nestas regiões.

Os recursos hídricos, mesmo sendo renováveis, podem se esgotar na prática, devido à alta taxa de exploração a que são submetidos pelo homem moderno, principalmente na irrigação. O Brasil é privilegiado em relação aos seus mananciais, respondendo por cerca de 11,6\% de toda a de água doce renovável disponível do mundo (WORLD WATER DEVELOPMENT REPORT, 2006). Entretanto, a maior parte dessa disponibilidade está concentrada na Bacia Amazônica, que se localiza muito longe do centro-sul do Brasil, o que nos obriga a ações responsáveis e acertadas, em relação ao uso dos recursos hídricos.

A despeito da inquietação atual com os recursos hídricos, em grande evidência, no Brasil, a primeira legislação pertinente data de 1934 e foi intitulada de "Código das Águas". A Constituição Federal de 1988, (Art. 20 e 25), atribui ao poder federal e aos Estados a responsabilidade de legislar sobre a utilização dos recursos hídricos no Brasil. Mais recentemente, criou-se a legislação conhecida por “Nova Lei das Águas” (Lei n 9.433, de 08 de janeiro de 1997), que traz inovações como o reconhecimento da água como um recurso limitado e com valor monetário, passível de cobrança pelo seu uso (AGÊNCIA NACIONAL DE ÁGUAS, 1997). Tais regulamentações implicam no desenvolvimento de novas tecnologias, que busquem uma melhor eficiência no uso da água tanto no meio agrícola como urbano, visando uma maior democratização e disponibilidade para futuras outorgas.

No Estado de São Paulo, o Departamento de Águas e Energia Elétrica é o órgão responsável pela expedição da outorga de uso e/ou interferência nos recursos hídricos, segundo o Decreto no 41.258 de 31 de outubro de 1996. A Legislação de Outorgas de Direito de Uso das Águas e seus domínios é um importante instrumento para gerenciar os recursos hídricos disponíveis entre os diversos usuários, entre eles a irrigação, que disputam os 
mananciais de água para as suas necessidades de consumo (DEPARTAMENTO DE ÁGUA E ENERGIA ELÉTRICA, 1996).

A fixação de um valor na cobrança pelo uso da água é um dos fatores limitantes de projetos agrícolas quanto à capacidade de pagamento, a qual depende do retorno econômico do empreendimento. No caso da Bacia do Paraíba do Sul, no Estado de São Paulo, a limitação da cobrança pela capacidade de pagamento surgiu de forma explícita. A cobrança naquela bacia, aprovada em 2002 e iniciada em 2003, abrange todos os setores usuários, inclusive o agrícola. A representação do setor agropecuário exigiu que a cobrança não provocasse acréscimos superiores a $0,5 \%$ nos seus custos de produção, alegando que não poderiam arcar com aumentos superiores, face à baixa rentabilidade da produção agrícola. Por esta razão o setor agropecuário pagou 40 vezes menos que o estipulado para o saneamento e a indústria. No primeiro ano de cobrança, o setor agrícola contribuiu com apenas R 10 mil (valor pago por 35 usuários, de um total de 700 usuários cadastrados), de uma arrecadação total de $\mathrm{R} \$ 8$ milhões (KELMAN e RAMOS, 2005).

Em seu trabalho sobre o uso do sensoriamento remoto na demanda de água pra irrigação, Braga e Oliveira (2005), relatam que

Após a implementação de vários projetos de irrigação sem a prévia quantificação do volume de água possível de ser utilizada, em algumas bacias como a do Guairá (São Paulo) e Rio Verde Grande (Minas Gerais), está gerando uma escassez de água à jusante para a manutenção de todo o sistema de irrigação. Tal situação levou em alguns momentos à total falta de água para o consumo humano, de animais e da fauna silvestre, causando com isso atritos entre os envolvidos e sérios impactos ambientais nas citadas regiões. 
A competição acirrada pela água, entre vários setores da sociedade, atreladas aos movimentos ecológicos que buscam a conscientização da população para preservação do meio ambiente, as áreas irrigadas deverão ser conduzidas com a premeditação adequada de seu uso sobre o potencial hídrico da região. Assim, busca-se uma maior eficiência e resultados, reduzindo os impactos ambientais no que ser refere à disponibilidade e qualidade de água para suas múltiplas finalidades (SILVA E PRUSKI, 1997), entre elas a irrigação.

3.6. Planejamento geral de um sistema de irrigação

Segundo Linsley e Franzini (1978) "não há dois projetos de irrigação idênticos e por isso não é possível estabelecer um roteiro rígido de normas para os projetos de irrigação". A relação seguinte resume, de maneira geral, as fases indispensáveis na elaboração da maioria dos projetos:

I. Classificação das terras;

II. Estimativa das necessidades de água para irrigação;

III. Identificação da disponibilidade de água;

IV. Análise da qualidade química da água disponível;

V. Projeto de um reservatório de acumulação para assegurar a quantidade de água necessária (caso seja necessário);

VI. Projeto de barragem e vertedor para o reservatório de acumulação ou das instalações para a captação da água (caso seja necessário);

VII. Projeto das redes de distribuição; 
VIII. Análise econômica do projeto para determinar se o custo calculado pode ser compensado pelos benefícios prováveis, e análise financeira para estabelecer um plano de amortização;

IX. Determinação dos direitos de propriedade da água (outorga);

X. Definição do tipo de organização que deverá operar o sistema; em alguns casos, este é o primeiro passo, pois a organização do sistema poderá também definir o projeto.

O presente trabalho tem o seu foco de estudo na otimização matemática do item VII (projeto das redes de distribuição), que está diretamente subordinado às diversas possibilidades das variáveis do item $\mathrm{X}$ (organização do sistema, por exemplo, tempo de bombeamento disponível por dia).

Rogers $^{2}$ et al. (1998, apud KELMAN e RAMOS, 2005), em um trabalho que tratava a água como um bem de valor social e econômico, fez uma avaliação mais completa do custo total de sistemas de irrigação, e propôs considerar os seguintes pontos:

a) Custo do capital $\rightarrow$ representa o valor dos investimentos em infra-estrutura hídrica, necessários para levar a água até a área irrigada (construções de canais, barragens, instalações de bombas, etc.);

b) Custo de operação e manutenção $\rightarrow$ representa os recursos despendidos para operação e manutenção da infra-estrutura (energia elétrica, pessoal, reparação de equipamentos, entre outros).

c) Custo de oportunidade $\rightarrow$ reflete o valor da água para alocação em sua melhor alternativa de uso. Este é o custo incorrido pela sociedade, em situações de escassez, pela alocação do recurso hídrico a um usuário, em detrimento de outro, que apresente uma rentabilidade maior para a água em seu processo produtivo. $\mathrm{O}$

\footnotetext{
2 ROGERS, P; et al. Water as a social and economic good: how to put the principle into practice. Global water partnership, Estocolmo, Suécia, 1998.
} 
melhor uso pode ser apresentado por outro usuário do mesmo setor ou de setores diferentes, ou até para um uso ambiental. O custo de oportunidade é zero quando não existe uso alternativo ou quando não existe escassez.

d) Externalidade econômica $\rightarrow$ é o custo gerado para outras atividades econômicas em decorrência do uso do recurso hídrico na irrigação (por exemplo, aumento de custos de tratamento de água para abastecimento público pela presença de poluentes na água bruta oriundos da irrigação).

e) Externalidade ambiental $\rightarrow$ é o custo gerado para a sociedade em geral em decorrência do uso do recurso hídrico na irrigação (por exemplo, aumento de custos de tratamento de doenças ou redução da biodiversidade decorrentes da presença de poluentes na água bruta oriundos da irrigação).

Segundo Zocoler (1998, p. 4) "a análise econômica de sistemas de irrigação possui grande importância, uma vez que o capital neles empregado é freqüentemente expressivo e seus custos, podem viabilizar ou não as atividades produtivas de quem as utiliza”.

Kelman e Ramos (2005, p. 41) citam que "a análise de viabilidade de um empreendimento agrícola, quando feito por um investidor privado, considera pelo menos os custos de capital e O \& M" (operação e manutenção). Justamente esses itens são tratados neste trabalho de pesquisa.

Observa-se que os fatores relacionados com custo de oportunidade, externalidade econômica e ambiental, na maioria dos países, não são pagos pelo irrigante, que em sua maioria obtém pouco retorno econômico na produção de alimentos. Toda a diferença entre o custo total de alocação e o preço pago pelo irrigante recai sobre a sociedade local (KELMAN; RAMOS, 2005). 


\subsection{Pesquisa operacional}

Segundo Gavira (2003, p. 29) "não existe um consenso entre os autores quanto à definição mais apropriada a ser atribuída à pesquisa operacional, ou mesmo se esta pode ser definida".

A pesquisa operacional é uma aplicação do método cientifico, por equipes interdisciplinares, a problemas que dizem respeito ao controle de sistemas organizados, tendo a finalidade de obter as soluções que melhor satisfaçam aos objetivos da organização como um todo (ACKOFF; SASIENI, 1977).

Heillier e Lieberman (1988), em seu trabalho sobre pesquisa operacional, contribuem com diferentes abordagens. Segundo os autores a pesquisa operacional seria uma estruturação da situação de vida real num modelo matemático, abstraindo os elementos essenciais para que possa ser buscada uma solução relevante para os objetivos do tomador de decisões. Outra abordagem interessante estabelece que, a pesquisa operacional seria o desenvolvimento de uma solução, incluindo, se necessário, a teorias matemáticas, que permitam a obtenção de um valor ótimo para determinada medida desejada, ou possivelmente que compare cursos de ações alternativos através da avaliação de suas medidas.

Gavira (2003, p. 38) cita que “os métodos de otimização são também conhecidos como métodos de programação matemática, e os tópicos de probabilidade aplicada são usados na predição de resultados de uma seqüência de eventos incertos”.

Tucci (1998) cita que a otimização é a busca do valor de uma variável ou de $n$ variáveis, que proporcionem o melhor resultado para uma função dependente destas variáveis, dentro de um objetivo e obedecidas às restrições.

A pesquisa operacional é também conhecida como ciência do gerenciamento, por que tem em seu alicerce a utilização de métodos analíticos quantitativos formais para auxiliar na 
solução de problemas complexos e tomada de decisões, como é o caso do presente trabalho. Levando-se em consideração um cenário de melhoria de resultados, a abrangência de processos e a busca pela eficiência nos fatores envolvidos deixaram de ser uma simples minúcia. Em ambientes de produção, seja agrícola ou industrial, o trabalho de gerenciamento dos fatores das variáveis envolvidas às vezes se revela complexo demais para ser resolvido sem o auxilio da informática e de técnicas mais rigorosas de gerenciamento quanto à melhor alocação dos recursos envolvidos; caso em que pode-se recorrer às técnicas de pesquisa operacional, o que requer a modelagem matemática das variáveis referidas.

Diversos tipos de problemas complexos podem ser reinterpretados pela pesquisa operacional com o intuito de auxiliar seu gerenciamento. As variáveis dos problemas são matematicamente reformuladas, otimizadas, e as soluções explicadas para o mundo concreto, sempre em busca da melhor solução possível.

A matemática vem desenvolvendo várias ferramentas e métodos para auxiliar a pesquisa operacional, dentre as quais se destacam: programação linear e não-linear, modelagem estocástica, simulação e análise de decisões, algoritmos genéticos, etc.

As simulações que a pesquisa operacional modela, vêm auxiliar na tomada de decisão, como por exemplo, da otimização de sistemas de irrigação, devido à grande importância na produção de alimentos e no consumo de água (PORTO et al., 1997).

Segundo Gavira (2003, p. 12), "aquele que constrói e experimenta um modelo de simulação adquire conhecimento a respeito da metodologia de simulação e também do sistema modelado".

Na pesquisa operacional, o problema da seleção do melhor conjunto de diâmetros de uma rede de irrigação tem sido discutido há muito tempo por engenheiros que trabalham com dimensionamento de sistemas. As técnicas de otimização clássicas na pesquisa operacional, que têm sido propostas até agora, são as seguintes: programação linear, não-linear e dinâmica. 
Pesquisas matemáticas, usando os métodos citados, são complexas e por esta razão a solução numérica resulta em inúmeros cálculos, especialmente no caso de redes de distribuição de água com muitas derivações (THEOCHARIS et al., 2006).

Georgiou, Papamichail e Vougioukas (2006), trabalhando com pesquisa operacional no gerenciamento de reservatórios para irrigação na Grécia, concluíram que os resultados obtidos sugerem que a aproximação proposta da otimização pode ser usada eficazmente como uma ferramenta para a irrigação e o planejamento global ótimo da área da colheita. Os autores também concluíram que tal informação será muito útil às agências ou às autoridades regionais de irrigação que tratam do desenvolvimento regional da irrigação.

Wardlaw e Bhaktikul (2001), em um trabalho de alocação de água para irrigação usando pesquisa operacional na Escócia, escrevem que a irrigação, por ser o maior consumidor de água doce do mundo, deve ter sua gerência melhorada, com o uso da pesquisa operacional. Os recursos hídricos devem ser usados a seu benefício máximo e de maneira equilibrada. A gerência da alocação de água em grandes sistemas de irrigação é importante, já que mesmo com uma melhoria pequena na operação pode-se conduzir a benefícios significativos.

Verifica-se, com o exposto, que a pesquisa operacional é uma ferramenta útil para ser usada na solução de problemas simples e complexos, permitindo a localização do melhor resultado matemático frente a inúmeras possibilidades. O dimensionamento de um sistema de irrigação pode ser abordado pela pesquisa operacional, por exemplo, com o objetivo de se buscar uma melhor locação de cultura, em uma área onde há conflitos de interesse sobre os recursos hídricos. 
3.8. Otimização matemática em sistemas de irrigação

Ghahraman e Sepaskhah (2004, p. 52 e 53), em um trabalho sobre otimização linear e não-linear para alocação de água em regiões secas no Irã, mostraram que não havia nenhuma diferença entre as saídas dos modelos, além de que o tempo para rodar o programa com o modelo linear fosse muitas vezes menor do que o não-linear. Segundo os mesmos autores, há um outro ponto importante: um modelo linear garante uma solução global melhor, enquanto o não-linear mantém somente uma solução local melhor.

Lançando-se mão da otimização, restará apenas uma alternativa de máxima eficiência e/ou mínimo custo, que corresponderá ao ótimo hidráulico e/ou econômico (GOMES, 2004).

Saad e Mariño (2002, p. 123) relatam que o modelo de otimização linear que utilizaram para dimensionar uma rede de irrigação localizada provou ser eficiente para todas as inclinações do terreno avaliadas, assegurando altos níveis de uniformidade de emissão ao minimizar o custo anual do sistema de irrigação.

Silva e Gomes (1996, p. 536), em seu trabalho de dimensionamento econômico de instalações de recalque, discorrem que o dimensionamento de instalações de recalque é um problema hidraulicamente indeterminado, já que existem mais variáveis a serem calculadas do que equações hidráulicas disponíveis. Segundo os mesmos autores, essa indeterminação pode ser superada mediante o estabelecimento de uma velocidade máxima de escoamento, de uma perda de carga admissível, ou adotando-se um diâmetro normalizado entre os comerciais disponíveis. No entanto, a metodologia mais recomendada é aquela, através da qual se impõe uma restrição econômica ao problema, de modo que o custo total de investimento e operação das instalações seja mínimo. 
Rocha, Andrade e Merkley (1996, p. 547) no trabalho de seleção econômica de tubulação em sistema de irrigação pressurizada, citam que

[...] as metodologias existentes para dimensionamento econômico de tubulações são, freqüentemente, complexas, limitadas e difíceis de utilizar. Devido a esse fato, os projetistas, em geral, utilizam critérios como a velocidade e perda de carga unitária máxima para a seleção das tubulações. Entretanto, com o uso cada vez maior de microcomputadores pelos projetistas, surge a oportunidade do emprego de técnicas de seleção econômica de tubulação disponíveis na literatura há algum tempo.

Lucena (2002), em seu trabalho de otimização do dimensionamento de sistemas de irrigação localizada, cita que

A maioria dos trabalhos desenvolvidos para otimização de sistemas de irrigação tem como objetivo, a minimização dos custos fixos e variáveis ou a maximização do beneficio liquido, considerando, no entanto, apenas uma tarifa de energia elétrica e o sistema como um todo.

Zocoler (1998) estudou o efeito do diâmetro da tubulação nos custos dos sistemas de recalque de água com bombeamento utilizando motor a combustão e a eletricidade. Neste estudo foram consideradas as modalidades de tarifação da energia elétrica e os descontos especiais concedidos aos consumidores rurais com sistemas exclusivos para irrigação, a fim de obter a minimização do custo anual total através de um modelo matemático.

A escolha de tubulação com diâmetros maiores resulta em menor perda de carga e, conseqüentemente, requer menos energia para o bombeamento. Por outro lado, tubos de maior diâmetro custam mais caro, o que aumenta os custos fixos (MERKLEY, 1994). O ponto 
central é encontrar o custo total mínimo, seguindo as restrições dos problemas hidráulico e econômico.

Prasad, Umamahesh e Viswanath (2006), em um estudo de alocação ótima de água no sul da Índia, determinaram que os resultados que obtiveram de otimização linear pode significativamente melhorar o benefício líquido anual do irrigante, com uma estratégia da irrigação sob escassez de água.

O uso de programas de dimensionamento econômico de instalações de recalque podem resultar em valores de custo entre 5 e $20 \%$ inferiores aos de instalações dimensionadas sem levar em conta os critérios de otimização econômica (SILVA; GOMES, 1996).

Oron e Karmeli (1981, p. 569-570), em seu trabalho usando programação linear para o dimensionamento de redes de irrigação fixa, concluíram que os fatores de decisão no dimensionamento de um sistema de irrigação podem ser transformados em problemas de programação linear para um intensivo estudo de diferentes alternativas de dimensionamento.

Silva e Gomes (1996, p.534) em seu trabalho de dimensionamento econômico de instalações de recalque, citam que

[...] os projetos de instalações de recalque, quando analisados de maneira tradicional, apresentam diversas soluções para o dimensionamento, todas igualmente corretas, cabendo ao projetista, através da sua experiência, optar por uma solução que proporcione o menor custo de implantação e manutenção. Quando a análise é feita por métodos computacionais, pode-se considerar diversos fatores para a otimização do sistema de recalque, ou seja, menor gasto com a operação (energia elétrica, manutenção do sistema), entre outros. A utilização de programas computacionais que considerem tais métodos econômicos para a otimização, proporciona o aperfeiçoamento dos métodos tradicionais, visto que, é realizado uma série de possibilidades de 
implantação para o sistema, sendo selecionada a que acarrete o menor custo de manutenção e operação.

Contudo, a utilização de equipamentos não convencionais não deve aumentar os custos de produção do irrigante, havendo a necessidade de um estudo de viabilidade econômica que compare o custo de aquisição dos mesmos, anualizado sob determinada taxa de juros e período de pagamento, com o benefício proporcionado pelo seu uso, que é a economia de energia elétrica durante o ano (TIAGO FILHO, 1996).

Zocoler (1998), em um trabalho de otimização econômica de tubulação, cita que [...] "o diâmetro de adutora é o parâmetro mais importante no dimensionamento de um sistema, uma vez que os demais parâmetros são definidos pelas condições locais, ou seja, a vazão requerida, o comprimento da tubulação, o desnível topográfico, a pressão no final da adutora, etc., estão atrelados aos atributos físicos do local e às exigências dos equipamentos utilizados no final da adutora e, portanto, são constantes. Sendo assim, a variação deste parâmetro acarreta alteração nos que dele dependem diretamente, como por exemplo, a potência de bomba hidráulica e do motor que a aciona, com conseqüências nos custos do sistema”.

Hoffmann et al. (1983) citam que para fins de análise econômica, o termo custo significa a compensação que os donos dos fatores de produção, utilizados por uma firma para produzir determinado bem, devem receber para que eles continuem fornecendo esses fatores. 
Singh e Mahar (2003), trabalhando com otimização linear de diâmetros de linhas laterais de irrigação na Índia, determinaram custos mais baixos de implantação e operação do sistema em comparação a média de custo para projetos do mesmo tipo para aquele país.

Tsutiya (1989) diz que diante dos elevados custos da energia elétrica no Brasil, as adutoras que operam continuamente devem ser dimensionadas para uma velocidade média de escoamento de 1,0 m.s $\mathrm{s}^{-1}$ que é a mesma nos Estados Unidos da América e em Portugal.

Lucena (2002), em seu trabalho de otimização de redes de irrigação localizada, cita que "as tarifas de energia elétrica interferem tanto no dimensionamento quanto na operação do sistema e devem ser consideradas no planejamento da irrigação". As distribuidoras de energia disponibilizam diversos tipos de tarifação segundo as características dos consumidores e a localização. Tais alternativas de tarifação devem ser metodicamente estudadas no planejamento e otimização de redes para irrigação fixa, já que as mesmas são projetadas para terem uma vida útil de vários anos, ou seja, os custos operacionais de energia devem ser considerados nas tomadas de decisões por parte do projetista.

Valiantzas (2002), em um estudo de otimização de diâmetros de tubulação para irrigação na Grécia, discorreu que o comprimento total especificado de um encanamento de dois diâmetros possui uma equação algébrica simples que é derivada para calcular diretamente os comprimentos apropriados dos alcances de diâmetros diferentes, de tal maneira que o custo total do encanamento é minimizado.

Gomes (2004, p. 71), afirma que "os custos de implantação e de operação da instalação incidem em tempos distintos, já que o custo de implantação é fixo e atua no inicio do empreendimento, enquanto o energético incide ao longo do alcance do projeto". Gomes (2004, p. 91) também cita que "deve-se efetuar uma análise econômica calculando-se custo operacional (energético) ano a ano, considerando-se o aumento da vazão durante a vida útil do projeto". Saad e Frizzone (1996) e Lucena e Matos (2001) desenvolveram trabalhos de 
otimização em dimensionamento e análise de redes para irrigação, tomando como base de tomada de decisão as diferentes opções de operação do sistema. Tais trabalhos mostraram excelentes resultados, quanto aos objetivos propostos de otimização, mostrando ser, a programação matemática, uma boa ferramenta para a tomada de decisão no conflito entre o melhor manejo do sistema e o dimensionamento da rede de distribuição.

Lanzer (1988) discorre que o dimensionamento econômico de redes podem ser feitos utilizando-se ferramentas da pesquisa operacional, dentre as quais se destaca a programação matemática. Para o autor esta ferramenta é o instrumento mais usual nos problemas de otimização, devido à sua versatilidade e do fato de se poder utilizar fundamentos matemáticos simples, principalmente na análise e resolução de sistemas de equações lineares.

Com o exposto, verifica-se que as técnicas de otimização matemática do dimensionamento de redes de irrigação é uma excelente ferramenta na busca da melhor solução econômica, atendendo também às restrições hidráulicas. Pela revisão de literatura, observa-se que a otimização linear mostra-se eficiente na solução de problemas não só de dimensionamento de sistema, mas também na solução de problemas operacionais e no conflito entre custos fixos operacionais, onde o custo da energia elétrica para o bombeamento e o da tubulação são fatores decisórios e contraditórios.

3.9. Redes de distribuição, condutos mistos ou em série e sua otimização

Cheung (2004), em seu trabalho com reabilitação de redes de distribuição de água, cita que "com base no reconhecimento de que a água constitui um recurso natural limitado, a garantia de atendimento as necessidades das futuras gerações obriga a operação eficiente e eficaz dos sistemas de aproveitamento e de distribuição de águas em geral". Pesquisas que 
vêm ao encontro às necessidades de eficiência na alocação da água, em redes de distribuição, são pertinentes em uma visão da sociedade de que os recursos hídricos são importantes e limitados.

Gomes (2004, p. 68), em seu livro sobre sistemas de abastecimento de água, afirma que os custos de implantação e de operação de redes são antagônicos, ou seja, quando um aumenta o outro diminui e vice-versa. Para o autor, ao se escolher um diâmetro menor para uma tubulação, haverá uma diminuição no seu custo de implantação, mas em contrapartida, o custo da operação (energia para o bombeamento) será maior, sendo o inverso verdadeiro.

Tubulações fixas possibilitam o uso de combinações envolvendo diâmetros distintos e diferentes comprimentos, nos diversos trechos da rede hidráulica destes sistemas de irrigação. A otimização das possíveis configurações hidráulicas, das redes de condutos de diferentes diâmetros, vem ao auxilio de uma minimização de diâmetros e, por conseguinte, de custos de instalação do sistema (SAAD et al., 1994).

Carrijo e Reis (2006, p. 163) citam que "técnicas de otimização vêm sendo tradicionalmente usadas no dimensionamento de unidades de um sistema de distribuição de água, objetivando menores custos”. Os mesmos autores também discorrem sobre a interface entre o modelo de simulação hidráulica e o modelo de otimização. Tal interface deve ser cuidadosamente elaborada, no sentido de dar melhor transparência ao modelo, de forma a facilitar o seu uso além de permitir a análise de problemas de maior complexidade, quando envolve múltiplos objetivos.

Marcuzzo e Wendland (2006a), em seu trabalho de otimização linear de linhas laterais com dois diâmetros, com a utilização de seis diferentes tipos de equações de perda de carga, apontam a necessidade de uma boa heurística por parte do projetista de redes quando se opta por uma ou outra equação. Os mesmos autores, trabalhando com programação linear em tubulações de derivação (MARCUZZO; WENDLAND, 2006b), com a opção de três 
diâmetros diferentes, consideraram como restrições os diâmetros comerciais disponíveis e a uma máxima perda de carga admissível na tubulação. Os valores comerciais de cada diâmetro foram as variáveis de decisão de custo fixo da rede, ou seja, como resultado obteve-se o maior comprimento possível da tubulação com o menor diâmetro disponível comercialmente.

Bhave (1979) desenvolveu um método iterativo que seleciona o conjunto de diâmetros dos trechos centrando os diâmetros disponíveis consecutivos na solução da iteração anterior. Guimarães Junior (1998) desenvolveu uma metodologia geral de otimização do projeto hidráulico de sistemas de irrigação localizada, visando a formulação de um programa genérico que atenda as condições de projeto mais diversificadas possíveis.

A otimização matemática vem no auxilio do controle de perdas de água em redes de distribuição, seja ela rural ou urbana, sob as mais diversas condições operacionais. Enfatiza-se a fundamental importância, não só do ponto de vista financeiro, no que diz respeito ao desperdício da água bombeada e quimicamente tratada, mas principalmente na preservação deste recurso natural (SOARES; REIS, 2004).

Em seu trabalho sobre dimensionamento econômico de sistemas de distribuição de água, Gomes e Silva (2006, p.99) discorre que

O dimensionamento das redes de distribuição de água é feito, na grande maioria das vezes, por meio de técnicas de tentativa e erro, que buscam encontrar os diâmetros dos trechos e a altura manométrica da origem do sistema, de maneira que sejam cumpridos os requerimentos de pressões e vazões nos nós e que o sistema seja hidraulicamente equilibrado, para as condições mais desfavoráveis de escoamento permanente e uniforme. O processo de cálculo é hidraulicamente indeterminado, admitindo, inúmeras soluções. Estes métodos, considerados tradicionais, não levam em conta a 
busca de uma alternativa de projeto que minimize os custos de investimento e operação do sistema de abastecimento.

Os efeitos das variações dos parâmetros e das condições de operação, do projeto de rede de distribuição de água, devem ser considerados nos métodos de dimensionamento econômico de tubulações de sistemas de abastecimento (GOMES; SILVA, 2006). Tais efeitos também serão verificados neste trabalho, pois a heurística ${ }^{3}$ do projetista é peça fundamental na alocação dos dados de entrada para o dimensionamento econômico de tubulações, segundo o modelo proposto.

Carrijo e Reis (2006, p. 161), em seu trabalho sobre estratégias operacionais ótimas de sistemas de distribuição de água, discorrem sobre a necessidade da eficiência na operação de sistemas. Para os autores, é de fundamental importância o conhecimento do sistema, pois com a utilização de ferramentas como modelos de simulação hidráulica, otimização e definição de regras operacionais, é possível fornecer ao operador condições ideais para o manejo das unidades do sistema. Assim sendo, consegue-se a vantagem de abrir mão da exclusiva experiência do operador, mantendo a confiabilidade do sistema.

Neves (1960, p.267), em seu livro curso de hidráulica, diz que

[...] uma canalização é mista ou em série quando constituída por diversos trechos de diâmetro diferente, porém constante em cada trecho. Evidentemente, a vazão que percorre todos os condutos é a mesma, e a perda de carga total é igual à soma de todas as perdas que neles ocorrem. Usualmente se despreza a influência da taquicarga e das perdas acidentais, considerando a linha de energia confundida com a linha piezométrica, que

\footnotetext{
${ }^{3}$ Pode ser definida como uma capacidade de uma pessoa fazer, de forma analitica ou dedutiva, alterações positivas para uma determinado ação. Característica inerente ao ser humano, e pode ser descrita como a arte de achar, criar ou solucionar problemas mediante a criação, idéias paralelas ou contrárias.
} 
será constituída por uma série de retas tendo em cada trecho uma inclinação correspondente à respectiva perda de carga unitária. A perda total independe da ordem de sequiência dos diâmetros dos diversos condutos.

Segundo Cruz et al. (2001), em um estudo de fluxo de custo fixos e comparação estatística, "os problemas de otimização em redes representam uma grande classe dentre os problemas de otimização".

Saad e Marcuzzo (2006), em seu trabalho sobre distribuição de carga hidráulica em linhas de derivação otimizadas por programação linear, identificam ser a programação linear uma boa ferramenta para o dimensionamento de redes de distribuição para irrigação quando a mesma está submetida a diferentes declividades do terreno e uniformidades de emissão a serem alcançadas.

Guimarães Junior (1998, p.67), em sua tese sobre nova concepção de projeto otimizado de sistemas de irrigação localizada, cita que

[...] a minimização do custo das tubulações de uma parcela depende da pressão no terminal da rede que interfere diretamente no procedimento de otimização da rede. Uma redução da pressão no ponto de conexão aumenta o custo da parcela e diminui o custo da rede principal. Desta forma, as cargas de pressão nos pontos de alimentação das parcelas tornam-se as variáveis de decisão de um processo de otimização conjunto rede-parcela. Um procedimento interativo para a otimização do dimensionamento conjunto das parcelas e da rede principal pode partir das pressões máximas nos terminais e em seguida proceder a redução gradativa destas pressões até que o custo global seja mínimo. Neste caso, pode-se empregar métodos mais apropriados para cada procedimento de otimização, tais como: a programação linear para 
a otimização da rede principal e a metodologia estudada para a otimização do dimensionamento da parcela.

Mesmo tendo os diâmetros otimizados sob os critérios hidráulicos usuais, a escolha da equação de perda de carga no dimensionamento pode interferir significativamente nos custos de tubulações (MARCUZZO; WENDLAND, 2007).

Saad e Mariño (2002, p. 123) relatam que o uso de dois diâmetros na linha de derivação melhorou a uniformidade de emissão da linha em um estudo de otimização de rede sob diferentes declividades.

Verifica-se com o exposto que a utilização de condutos mistos, em redes de distribuição de água de irrigação, possibilita dimensionamentos indeterminados. Com isso, a implicação de restrições hidráulicas (como por exemplo, a velocidade máxima na tubulação) e das condições de manejo da rede (como por exemplo, a quantidade de horas por dia disponíveis para o bombeamento), devem ser considerados na metodologia de dimensionamento econômico quando se utiliza diferentes diâmetros de tubulação para uma mesma linha.

\subsection{Algoritmos genéticos}

Segundo Cheung (2004, p. 72), a pesquisa operacional tem mudado nos últimos anos pela introdução de algoritmos de otimização não convencionais denominados algoritmos evolucionários (AEs).

Algoritmos evolucionários vem de uma classe de métodos de otimização estocásticos que compartilham a mesma base conceitual, com o intuito de simular o processo de evolução de qualquer sistema. Pode-se classificar AEs em: algoritmos genéticos, estratégias de evolução, programação evolucionária, programação genética e sistemas classificatórios. Neste 
tópico trata-se apenas de algoritmos genéticos que foi a ferramenta de otimização utilizada no presente estudo.

Mognon (2004, p. 4 e 5), em sua dissertação com algoritmos genéticos (AGs), cita que Os GAs são métodos computacionais de otimização fundamentados nos princípios e conceitos da seleção natural e evolução. Os AGs são caracterizados como otimizadores estocásticos, pois utilizam operadores probabilísticos concebidos a partir de metáforas biológicas. A sistemática dos AGs consiste primeiramente na geração aleatória de uma população de possiveis soluções através de um processo interativo de acordo com operadores genéticos. Desta forma, há uma tendência de que, na média, os indivíduos representem soluções cada vez melhores a medida que o processo evolutivo continua, até que um determinado critério de convergência seja atingido. São particularmente efetivos quando o objetivo é obter um máximo global aproximado para funções multimodais e que apresentam domínios multidimensionais.

Na Figura 1 observa-se o funcionamento básico de um AG. Cada iteração do AG corresponde à aplicação de um conjunto de quatro operações básicas: avaliação da população inicial, seleção, cruzamento e mutação. 


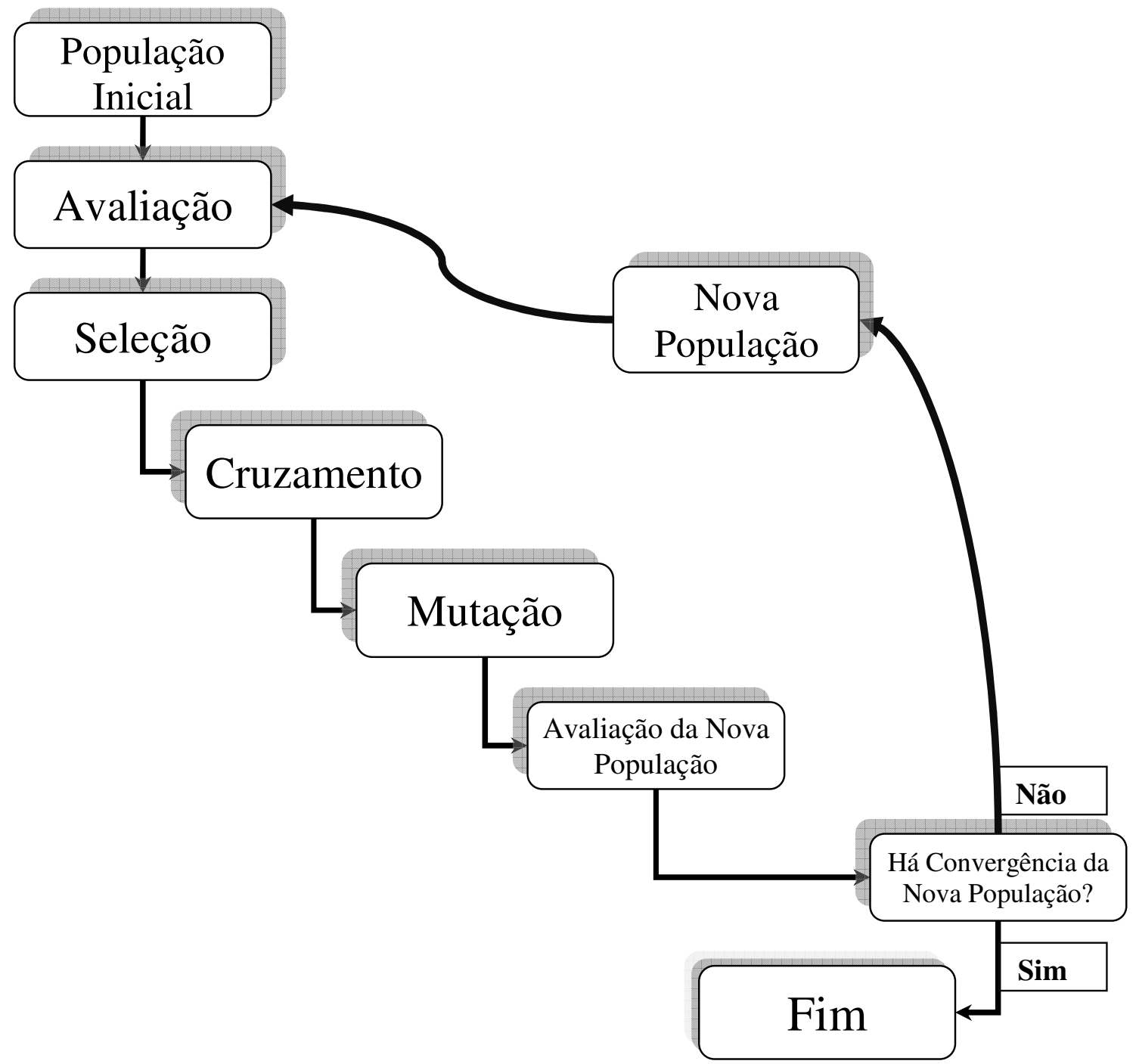

Figura 1. Fluxograma básico do funcionamento de um algoritmo genético

Ao fim das operações de avaliação, seleção, cruzamento e mutação (Figura 1), cria-se uma nova população, chamada de geração que, espera-se, represente uma melhor aproximação da solução do problema de otimização que a população anterior. A população inicial é gerada atribuindo-se aleatoriamente valores aos genes para cada cromossomo. A avaliação é normalizada (aptidão normalizada), permitindo um melhor controle no processo de seleção. Pode-se utilizar critérios de parada do algoritmo que, em geral, são a avaliação do melhor indivíduo em conjunto com a limitação do número de gerações (MICHALEWICZ, 1996). 
Soares (1997, p. 7), em seu trabalho sobre novas técnicas e aplicações dos AGs, cita que ... métodos estocásticos têm ganhado popularidade nos últimos anos, devido a sua robustez caracterizada principalmente pela eficácia. Eles buscam a solução a partir de regras de probabilidade. Dessa forma, a busca não é feita somente na vizinhança e, com isso, a chance de se encontrar um ótimo global aumenta. Neste grupo não há necessidade de calcular derivadas, pois os algoritmos usam apenas as informações contidas na função de otimização. Neles, a procura do ótimo é feita a partir da melhoria do melhor selecionado. Enquanto outros métodos trabalham com apenas um ponto e, consequentemente, encontram apenas uma solução, os AGs trabalham com uma população de pontos simultaneamente, selecionando entre eles os melhores, podendo, assim, formar subpopulações que se distribuem não só em torno da solução global, como também em outros picos, ...

Segundo Goldberg (1989), existem várias diferenças entre AGs e os outros métodos clássicos de otimização. Entre as diferenças, as que mais destacam são: Manipulação do código - Os AGs exploram a semelhança entre as boas soluções através de sua codificação, enquanto os outros métodos controlam as variáveis diretamente; Varredura pelo ótimo - Os AGs executam a procura a partir de uma população de resultados e não com um único resultado, ou seja, com mais pontos para basear a pesquisa, a probabilidade de cair numa solução local é reduzida de maneira acentuada; Varredura é feita por amostragem sem ser tendenciosa - A função de otimização é a única informação necessária, não requerendo o uso de derivadas de qualquer ordem, ou seja, a busca é guiada por soluções parciais, com a pesquisa sendo feita por amostragem e não por todo o espectro possível; AGs utilizam-se de operadores estocásticos e não regras determinísticas - Operadores genéticos utilizam-se de 
probabilidade e não regras pré-definidas determinísticas. Este ponto diferem os AGs de mecanismos de busca aleatória.

Machado (2005, p.2), cita que entre os métodos de otimização disponíveis, o algoritmo genético se destaca pela sua natureza robusta, que permite associar as características de eficácia e eficiência, e tem sido utilizado com freqüência na otimização de sistemas de abastecimento de água. Entre as suas principais vantagens, a mesma autora destaca: não ter requisitos de linearização e cálculo de derivadas parciais; maior probabilidade de encontrar o ótimo global por realizar buscas simultâneas em várias regiões do espaço de soluções; 3 facilidade de hibridização, flexibilidade e simplicidade na implementação.

Alencar Neto (2003, p. 85), cita que os métodos que utilizam os algoritimos genéticos introduzem uma alternativa aos processos clássivos de otimização. Para os mesmos autores as rotinas, em algoritmos genéticos, focalizam a função de adaptação usando a modelagem física do problema somente como validação das etapas subsequentes.

Mognon (2004, p. 2) enfatiza que, diferentemente dos métodos determinísticos, os AGs não dependem de cálculo de derivadas, o que é um atrativo para aplicações em problemas em que a função objetivo é não diferenciável ou descontínua.

Reis e Akutsu (2002) citam que a literatura oferece diversas possibilidades de implementação para AGs e seus operadores, bem como a definição de seus parâmetros de controle, tais como tamanho da população, probabilidades de recombinação e mutação, condição de finalização e tipo de substituição dos indivíduos pais pelos indivíduos filhos produzidos. Uma das dificuldades no uso dos Ags, além do fato de não se ter garantia de determinação do ótimo global, é a falta de padronização na sua utilização. Cada usuário explota os conceitos envolvidos de maneira diferente e a melhor implementação para uma aplicação particular não é tão óbvia, requerendo investigações ou certa experiência por parte 
do usário. É prudente que diferentes alternativas e valores para os parâmetros sejam investigados para assegurar que um bom desempenho seja atingido (Ribeiro, 2005).

Resume-se com esse tópico que AGs são mecanismos de otimização estocástica, que buscam sempre as melhores soluções parciais (gerações) através da simulação matemática de processos de genética e seleção natural. Verifica-se que os possíveis resultados são denominados indivíduos, e a otimização em si simula um ambiente hostil de sobrevivência. Os processos matemáticos probabilisticos de seleção escolhem quem sobrevive para "cruzar" com os opeardores genéticos a fim de se encontrar novas soluções parciais cada vez mais melhoradas. Ou seja, os AGs apresentam-se como uma excelente alternativa para os métodos clássicos de otimização matemática.

\subsection{Algoritmos genéticos no dimensionamento de redes}

Ribeiro (2005, p. 219), estudando algoritmos genéticos em adução de água em uma grande cidade, cita que grandes sistemas fazem parte da vida cotidiana de engenheiros e gestores de redes de água, e a complexidade é inerente a estes sistemas. A mesma autora enfatiza que os modelos de simulação e de otimização devem ser mais simplistas, na interface com os operadores, que são céticos quanto a eficiência destes modelos e sua confiabilidade, e sendo mais uma ferramenta que um problema, para os engenheiros e gestores destes sistemas.

Alencar Neto e Holanda (2004, p. 9), estudando algoritmos genéticos em redes de distribuição de água, citam que seus valores obtidos não apresentaram melhora em relação a otimização que fora tomada como referência, contudo a convergência rápida do método é notória, indicando a validade da aplicação. Os mesmos autores enfatizam a necessidade de maior refino da solução final. 
Montesinos, Camacho e Alvarez (2001), em seu artigo sobre manejo de redes de irrigação por sulco usando algoritmos genéticos, relata que a utilização de AGs resultam em melhores resultados do que técnicas de otimizações clássicas. O mesmo autor denomina os seus resultados como um ótimo quase global, pois o mesmo relata que os valores obtidos foram muito próximos de um ótimo global.

Soares (2003), trabalhando com calibração de redes para abastecimento urbano, relatou que uma dificuldade encontrada foi a faixa de variação dos valores das variáveis de decisão, principalmente quando diferentes tipos de parâmetros são considerados na caligração, como o coeficiente e expoente de vazamento, rugosidade absoluta, diâmetro e cota topográfica. Para o autor, a combinação dos valores dos parâmetros resulta em uma não convergência do modelo hidráulico, especialmente quando os valores dos parâmetros do modelo de vazamento são elevados.

Reca e Martínez (2006), trabalhando com otimização de redes de irrigação malhada com algoritmos genéticos, mesmo obtendo resultados satisfatórios com o uso de AGs, alguns ajustes são aconselhaveis para melhorar a performance dos algoritmos genéticos quando é grande a complexidade das redes de distribuição de água para irrigação.

A otimização matemática usual de redes trabalham na busca de uma única solução ótima, ou seja, um mínimo ou máximo global ou local. Entretanto, em projetos de redes de irrigação, quando se trabalha com apenas uma perspectiva de projeto pode-se acarretar uma maximização dos critérios de restrição hidráulica do sistema. A utilização de algoritmos genéticos em dimensionamento de sistemas de irrigação favorece o aparecimento de valores ótimos possíveis e não apenas de um valor ótimo local ou global. Isto pode acarretar uma rede com um custo um pouco maior, mas que apresenta uma maior capacidade de atendimento as restrições hidráulicas; sendo assim, se aceita um custo um pouco maior, obtendo resultados mais benéficos do funcionamento da rede. Concluí-se com o tópico que a otimização de redes 
de irrigação por algoritmos genéticos favorece o dimensionamento otimizado de forma mais sustentável do ponto de vista hidráulico, pois sempre acha um valor de rede ótima de um conjunto de soluções ótimas.

3.12. Parâmetros e operadores de algoritmos genéticos

O algoritmo genético é usado para resolver problemas de otimização imitando os princípios de evolução biológica, modificando repetidamente uma população de indivíduos singulares usando as regras baseadas em combinações dos genes na reprodução biológica. Devido a sua natureza de perscrutar boa parte das probabilidades, o algoritmo genético aumenta as possibilidades de encontrar uma solução global.

O ambiente de programação cientifica MatLab possui rotinas de algoritmos genéticos em sua caixa de ferramenta (ToolBox), simples ou multiobjetivos, pré-programadas para otimizar funções objetivo com ou sem restrições matemáticas. A caixa de ferramentas de otimização por algoritmos genéticos possui diversas rotinas de operadores consagrados pela literatura e apropriados para diferentes casos de estudos (THE MATHWORKS, 2008).

Descrevem-se a seguir os parâmetros e os operadores de algoritmos genéticos testados e os utilizados neste trabalho de otimização de rede de irrigação localizada. Todos os parâmetros e operadores genéticos discutidos neste tópico podem ser observados no arquivo da função fchamativadef.m no APÊNDICE E. A fundamentação dos parâmetros e operadores genéticos aqui explicados são baseados nas opções do programa computacional MatLab (THE MATHWORKS, 2008) e na literatura e em tutoriais específicos (WHITLEY, 1994; MICHALEWICZ 1996; MITCHEL, 1999). No 


\subsubsection{Opções para a população}

As opções de população permitem especificar os parâmetros da população (redes) que o algoritmo genético usa na otimização. Através destes parâmetros, que serão detalhados abaixo, pode-se melhorar o processo de otimização com o refinamento das condições de busca do algoritmo genético.

\subsubsection{Tamanho da população}

O tamanho da população especifica quantos indivíduos são criados em cada geração. Com um grande tamanho de população, o algoritmo genético varrerá o espaço de solução de maneira mais completa. Deste modo é reduzida a possibilidade do algoritmo retornar um mínimo local como resposta. Entretanto, um tamanho de população grande faz com que o algoritmo conclua mais lentamente, pois requer um número mais elevado de avaliações do problema. Ajustando o tamanho da população a um vetor, como é o caso deste estudo de rede de irrigação, o algoritmo genético cria múltiplas sub-populações, ou seja, os números que compõem o comprimento do vetor. Este tipo de procedimento provoca um amplo contingente de iterações necessárias para uma convergência em direção da solução ótima.

Neste estudo opta-se por uma população de 50 indivíduos (redes), pois nos testes realizados foi o número de indivíduos que melhor se adequou aos parâmetros estudados. 


\subsubsection{Função de criação}

Função de criação determina a maneira como é criada a população inicial de soluções para o AG. Na caixa de ferramentas do MatLab escolhe-se a função gacreationuniform.m, que cria uma população inicial aleatória com uma distribuição uniforme.

Neste estudo, como a população inicial de 50 indivíduos não foi fornecida por completo (fornece-se 40 indivíduos), o algoritmo utiliza-se desta função de criação de população para criar os indivíduos restantes, de tal modo que se complete os 50 indivíduos da população inicial de soluções. A população inicial não foi fornecida por completo de modo a se obter pela função de criação uma maior diversidade, como será mais bem discutido a seguir.

\subsubsection{População inicial}

Pode-se especificar uma população inicial para o algoritmo genético que, no decorrer do processamento dos operadores genéticos, vá evoluindo para populações que convergem para soluções próximas do ótimo ou à própria solução ótima. Caso não se especifique nenhuma população inicial, o algoritmo genético do MatLab lança mão da função de criação préestabelecida para criar uma população inicial inteira ou parcial.

Neste estudo, a população inicial é formada pelas redes. Na matriz formada para a população inicial (APÊNDICE E), cada linha é uma rede (indivíduo vetorizado) e cada coluna é um trecho de tubulação (comprimento de determinado diâmetro comercial, que pode variar de zero até o comprimento total da linha). Caso a opção fosse estabelecer uma população inicial completa para o número de indivíduos estabelecidos, o algoritmo genético não chamaria a função de criação. A opção de fornecer $80 \%$ dos indivíduos da população inicial 
(40 redes de um total de 50) neste estudo foi feita após exaustivos testes com a população inicial fornecida aleatoriamente pelo programa e com inúmeras combinações entre número de indivíduos fornecidos pelo usuário e pelo programa. Em todas as tentativas feitas a partir de redes geradas aleatóriamente pelo programa, os resultados obtidos não satisfazerão às restrições hidráulicas, retornando uma falha inicial do programa.

\subsubsection{Pontuação e escala inicial}

A pontuação inicial especifica pontos iniciais para a população inicial. Os pontos iniciais podem igualmente ser parciais, assim como a população inicial.

A escala inicial especifica a variação dos vetores na população inicial que é gerada pela função de criação.

Também é possível ajustar a escala inicial para uma matriz com duas fileiras e números de colunas das variáveis. Neste processo limita-se as fronteiras máximas e mínimas dos valores das variáveis que vão ser otimizadas. Neste estudo especificam-se os limites inferior como sendo zero e superior como sendo o comprimento total da tubulação na linha a ser otimizada (96,25 metros para linha lateral, 135 metros para linha de derivação e 700 metros para linha secundária).

\subsubsection{Escalonamento para a função de aptidão}

O escalonamento da aptidão converte os valores de aptidão, que são retornados pela função da aptidão a valores de uma escala mais apropriada para a função de seleção. 
A função de escalonamento especifica a função que executa o escalonamento da pontuação obtida através da função de aptidão, ou seja, consegue-se uma escala de valores ordenados para a seleção.

Existem diversos tipos de escalonamento. Descreve-se os mais utilizados, dentre os quais o tipo usado neste estudo:

- Escalonamento linear: gradua as contagens simples, de modo que a expectativa do indivíduo mais apto seja igual a uma constante multiplicada pela contagem média. Especifica-se a constante em um campo máximo da taxa de sobrevivência, que é indicado quando se seleciona o deslocamento linear.

- Escalonamento proporcional: faz o valor de escala de um indivíduo ser proporcional a sua pontuação simples de aptidão.

- Escalonamento superior: gradua os indivíduos superiores igualmente, ou seja, um conjunto de indivíduos superiores recebem a mesma escala. A quantidade destes indivíduos pode ser um número inteiro entre 1 e o tamanho da população ou uma fração entre 0 e 1, que especifica uma percentagem do tamanho da população a receber a mesma escala. A cada indivíduo que produz a descendência será atribuído um valor escalonado igual.

- Ranque: faz a escala dos pontos simples baseadas no ranque de cada indivíduo em vez de sua pontuação. O ranque de um indivíduo é sua posição nas pontuações classificatórias. Por exemplo, o ranque do indivíduo mais apto é um, o seguinte mais apto é dois, e assim por diante. O melhor indivíduo será o número um. O escalonamento da aptidão remove o efeito da propagação das pontuações simples. 
3.12.7. Operadores genéticos de seleção

O operador genético de seleção especifica como o algoritmo genético escolhe os genitores para a geração seguinte. Trata-se a seguir do funcionamento dos operadores genéticos de seleção mais conhecidos, dentre os quais o utilizado neste estudo.

- Operador de seleção uniforme estocástico. A seleção uniforme estocástica apresenta uma linha, em que cada genitor corresponde a uma trecho da linha de comprimento proporcional a seu valor escalonado. O algoritmo move-se ao longo da linha nas etapas de tamanho igual. Em cada etapa, o algoritmo aloca um genitor. A primeira etapa é um número aleatório uniforme menor que o tamanho da etapa em si.

- Operador de seleção de resto. A seleção de resto atribui genitores deterministicamente de uma parte do número inteiro de cada indivíduo e usa a seleção por roleta para a parte fracionada restante. Por exemplo, se o valor escalonado de um indivíduo é 2,3, o indivíduo será listado duas vezes como um genitor porque o número inteiro é 2. Depois que os genitores foram atribuídos de acordo com os inteiros dos valores escalonados, o restante dos genitores será escolhido estocasticamente. A probabilidade de um genitor ser escolhido nesta etapa é proporcional à parte fracionária de seu valor escalonado.

- Operador de seleção uniforme. A seleção uniforme escolhe os genitores usando as expectativas e o número de genitores. A seleção uniforme é útil para testes e eliminação de erros, mas não é uma estratégia de busca muito eficaz no que tange à convergência dos resultados.

- Operador de seleção por torneio. A seleção por torneio não atribui explicitamente probabilidades aos indivíduos. Por meio deste tipo de seleção, pode-se especificar o tamanho do torneio, no qual os indivíduos são escolhidos aleatoriamente a partir da população atual e suas funções de aptidão comparadas. $\mathrm{O}$ indivíduo com melhor valor da 
função de aptidão é selecionado para reprodução. O número de torneios é pré-definido. Quanto maior o número de torneios, maior a pressão seletiva, ou seja, maior a velocidade com que os indivíduos mais fortes dominam a população, causando a extinção dos menos aptos.

- Neste estudo optou-se pelo operador de seleção por roleta. A seleção por roleta escolhe genitores simulando uma roda de roleta, em que a área da roda que corresponde a um indivíduo é proporcional à aptidão deste indivíduo. O algoritmo usa um número aleatório para selecionar uma das seções com uma probabilidade igual a sua área.

\subsubsection{Parâmetros de reprodução}

Os parâmetros de reprodução especificam como o algoritmo genético gera a prole para a geração seguinte.

Um dos parâmetros mais utilizados é o da seleção da elite. A seleção da elite especifica o número de indivíduos que obtiveram melhores resultados, que são garantidos para sobreviver à geração seguinte. Deve-se escolher um número inteiro positivo inferior ou igual ao tamanho da população de cada geração para ser garantida na próxima geração. Neste estudo, escolhe-se o valor de 5 indivíduos, o que corresponde a $10 \%$ da população de cada geração.

Outro parâmetro de reprodução utilizado foi o de fração do cruzamento. A fração do cruzamento especifica a fração da geração seguinte, à exceção da prole de elite, que é produzida pelo cruzamento. Deve-se ajustar a fração do cruzamento para ser um valor entre 0 e 1. Neste estudo, optou-se por uma fração de cruzamento de 0,8 . 


\subsubsection{Operadores de mutação}

Os operadores genéticos de mutação especificam como o algoritmo genético faz pequenas mudanças aleatórias nos indivíduos da população, objetivando criar parte da prole mutante. A mutação fornece uma diversidade genética mais abrangente em cada geração e permite que o algoritmo genético tenha um espaço de busca maior. Trata-se, a seguir, de algumas funções de mutação testadas neste estudo, bem como a escolhida para o programa.

- Operador de mutação Gaussiano: adiciona um número aleatório tomado de uma distribuição Gaussiana ${ }^{4}$. O desvio padrão desta distribuição está determinado pelos parâmetros de escalonamento interno da curva de distribuição e de sua redução. O parâmetro da escala determina o desvio padrão na primeira geração. O controle de parâmetro de redução, como o desvio padrão, encolhem enquanto as gerações vão avançando.

- Operador de mutação uniforme: é um processo composto de dois passos. Primeiramente, o algoritmo seleciona uma fração das entradas do vetor de um indivíduo para a mutação, em que cada entrada tem uma mesma taxa da probabilidade a ser transformada. $\mathrm{O}$ valor normalmente utilizado é de 0,01 . Na segunda etapa, o algoritmo substitui cada entrada selecionada por um número aleatório selecionado uniformemente da escala para essa entrada.

- Operador de mutação adaptável e praticável: gera, de forma aleatória, as direções que são adaptáveis, no que diz respeito à última geração bem sucedida ou mal sucedida. A região praticável é limitada pelas restrições (no caso desta tese, pela função frestricoes.m do APÊNDICE D) e pelas restrições de desigualdade (quando for o caso). Um comprimento desta parte é escolhido ao longo de cada sentido de modo que as restrições e os limites

\footnotetext{
${ }^{4}$ A distribuição Gaussiana é derivada da estatística clássica, e tem muitas aplicações nas ciências que se utilizam de estatística. Os desvios a partir da distribuição Gaussiana são "não naturais". Sua forma de distribuição é uma curva familiar conhecida como "curva de sino".
} 
lineares da tubulação sejam satisfeitos. Para este estudo optou-se pelo operador de mutação denominado adaptável e praticável.

\subsubsection{Operadores de cruzamento}

Os operadores de cruzamento especificam como o algoritmo genético combina dois indivíduos de uma população, ou seja, os genitores, para dar forma a uma progênie do cruzamento para a geração seguinte.

- Operador de cruzamento de dispersão: cria um vetor binário aleatório, sendo que se o valor binário é um, o que é selecionado do primeiro pai e se o valor é zero, o que é selecionado do segundo pai, para dar forma à progênie. Por exemplo, se: g1 = [a b c d e f g h] e g2 = [1 $\left.\begin{array}{lllllll}2 & 4 & 5 & 6 & 7 & 8\end{array}\right]$ são os genitores e o vetor é o binário [ $\left[\begin{array}{llllllll}1 & 1 & 0 & 0 & 1 & 0 & 0 & 0\end{array}\right]$, o vetor da progênie será: $\mathrm{p} 1=$ [a b 34 e 67 8].

- Operador de cruzamento de um único ponto: escolhe um número inteiro aleatório que esteja entre 1 e o número de variáveis. As entradas do vetor progênie com número inferior ou igual ao número de cruzamento (inteiro aleatório) são selecionadas do primeiro genitor. As entradas do vetor com número maior são selecionadas do segundo pai. Por exemplo, se:

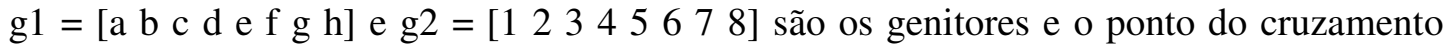
escolhido é 3, o vetor da progênie será: $\mathrm{p} 1$ = [a b c 4567 8 5 .

- Operador genético de dois pontos: seleciona dois números inteiros aleatórios A1 e A2 entre 1 e número de variáveis do problema a ser otimizado. O operador seleciona as entradas do primeiro genitor com número inferior ou igual a $\mathrm{A} 1$; as entradas de $\mathrm{A} 1+1$ a $\mathrm{A} 2$ do segundo genitor e as entradas maiores que $\mathrm{A} 2$ do primeiro genitor novamente. $\mathrm{O}$ algoritmo concatena então estes genes para dar forma a um único gene. Por exemplo, se: g1 = [a b c d 
e f g h] e g2 = [ [ $\left.\begin{array}{llllllll}1 & 2 & 3 & 4 & 5 & 6 & 7 & 8\end{array}\right]$ são os genitores, e os pontos do cruzamento escolhidos para o operador genético de dois pontos são 3 e 6 , a função retorna a seguinte progênie: p1 = [a b c $456 \mathrm{~g} \mathrm{~h}]$.

- Operador genético intermediário: gera progênies lançando mão de uma média ponderada a partir dos genitores. Pode-se especificar os pesos por um único parâmetro, a relação, que pode ser um valor escalonado ou um vetor do número do comprimento das variáveis. $\mathrm{O}$ operador genético intermediário gera a progênie, a partir dos genitores g1 e g2, usando o seguinte postulado. Progênie $=\mathrm{g} 1+$ margem*relação* $(\mathrm{g} 2-\mathrm{g} 1)$. Se todas as entradas da relação encontram-se na escala entre zero e um, as progênies produzidas estão dentro do espaço determinado. Se a relação não está dentro da escala de zero a um, as progênies podem encontrar-se fora do espaço amostral. Se a relação é um escalar, todas as progênies encontram-se entre os genitores.

- Operador genético heurístico: retorna uma progênie que se encontra na linha que contêm os dois genitores, com uma distância pequena do genitor com o valor de melhor aptidão no sentido longe do genitor com o valor de pior aptidão. Pode-se especificar o quão distante a progênie ficará do genitor de melhor aptidão pela relação do parâmetro matemático do operador genético heurístico apresentado abaixo. A relação mais utilizada é de um para dois. Se g1 e g2 são os genitores, e g1 tem o melhor valor de aptidão, o operador genético retorna uma progênie pela seguinte expressão: Progênie = g2+Relação*(g1-g2).

- Operador genético aritmético: gera as progênies que possuem um peso médio de genes dos dois genitores. As progênies são sempre praticáveis no que diz respeito as restrições hidráulicas e aos limites de menor e maior comprimento para cada tubulação (variáveis de decisão). No presente estudo optou-se pelo uso do operador genético aritmético. 


\subsubsection{Opções de migração}

As opções da migração especificam como os indivíduos se movem entre as subpopulações. A migração ocorre quando se ajusta o tamanho da população para ser um vetor de comprimento maior de 1. Quando a migração ocorre, os melhores indivíduos de uma subpopulação substituem os indivíduos piores de uma outra sub-população. Os indivíduos que migram de uma sub-população a outra são copiados, ou seja, não são removidos da subpopulação fonte. As formas mais comuns de se controlar a migração serão mostradas a seguir.

Controle do sentido da migração. A migração pode ocorrer em um ou ambos os sentidos. Se o ajuste da migração for feito para um sentido apenas, a migração ocorre em direção a última sub-população. Isto é, a sub-população $n$ migra na direção da sub-população $n+1$. Entretanto, se o sentido da migração for para ambos os lados, sub-população $n$ migra na direção $n$ - 1 e na direção $n+1$. Neste estudo opta-se pela migração nos dois sentidos.

Intervalo de migração. $O$ intervalo de migração especifica quantas gerações são necessárias para ocorrer uma migração entre sub-populações. Por exemplo, neste trabalho, optou-se por um ajuste do intervalo de 100, ou seja, a migração ocorrerá a cada 100 gerações.

Fração de migração. A fração de migração especifica quantos indivíduos se movem entre sub-populações, isto é, consegue-se determinar a menor fração das duas sub-populações que se move. Por exemplo, neste estudo, os indivíduos migram de uma sub-população de 100 indivíduos para uma sub-população de 100 indivíduos, e o ajuste de fração estabelecido é de 0,2 , ocorre que o número de indivíduos que migram é de $20(0,2 * 100)$. 


\subsubsection{Ajustes do algoritmo por penalidades}

Os ajustes do algoritmo por meio de penalidades definem parâmetros específicos do algoritmo. Como o algoritmo genético fundamenta-se na recombinação e mutação aleatórias, são obtidos, invariavelmente, soluções que não atendem às restrições do problema. Portanto, para induzir com que o algoritmo convirja para soluções viáveis, atribuiu-se uma penalidade que é somada ao custo total de uma solução cuja restrição não é atendida. A penalidade, basicamente, funciona diminuindo a utilidade das soluções que não atendem a todas as restrições do problema, enfraquecendo, assim, sua probabilidade de promover progênie. Contudo, os indivíduos da população que respeitarem um maior número de restrições matemáticas do problema serão beneficiados e designarão um maior número de progênies, garantindo uma melhor convergência para soluções próximas da ótima.

Os parâmetros de penalidade, que podem ser específicos para um algoritmo com restrições não-lineares, como é o caso deste trabalho, incluem a penalidade inicial e o fator de penalidade, que serão discutidos a seguir.

A penalidade inicial especifica um valor inicial do parâmetro da penalidade que é usado pelo algoritmo. A penalidade inicial deve ser superior ou igual a 1. Neste trabalho optou-se pela penalidade inicial de valor 10 .

O fator da penalidade do algoritmo aumenta o parâmetro da penalidade quando o problema não é resolvido e as restrições do problema não são satisfeitas. O fator da penalidade deve ser maior que 1 . Neste estudo optou-se por um fator de penalidade de 100.

O mecanismo de penalidade neste trabalho permite que soluções densamente inviáveis evoluam ligeiramente para soluções viáveis, dado o elevado valor adjunto à penalidade inicial e ao fator de penalidade. Este procedimento contribui para que o espaço total de busca da 
função de aptidão seja reduzido, já que há uma forte tendência para que indivíduos (redes) mais aptos sobrevivam às gerações seguintes.

\subsubsection{Critérios de parada do algoritmo}

Os critérios de parada do algoritmo determinam o que provoca o término do processamento do problema pelo algoritmo. A seguir discute-se os critérios mais utilizados de parada do algoritmo.

- Número de gerações. Especifica o número máximo de gerações para que o algoritmo genético execute o processamento. Neste estudo optou-se por 100 gerações.

- Limite de tempo de processamento do algoritmo. Especifica o tempo máximo em que o algoritmo genético funciona antes de parar. Neste estudo optou-se por não restringir o tempo de funcionamento do algoritmo.

- O limite de melhor resultado buscado pela função de aptidão. O algoritmo pára se o melhor valor da função de aptidão encontrado é inferior ou igual a o valor do limite da função de aptidão estabelecido. Neste estudo optou-se por não limitar o valor ótimo que pode ser encontrado.

- Limite de gerações consecutivas não melhoradas. O algoritmo pára se não ocorrer mudança significativa do valor da função de aptidão sobre o número limite de gerações sendo o mesmo menor do que a tolerância da função.

- Tolerância da função. $\mathrm{O}$ algoritmo funciona até que a mudança cumulativa no valor da função de aptidão sobre o limite de gerações consecutivas não melhoradas esteja inferior ou igual a tolerância da função. 
- Limite de tempo para o limite de gerações consecutivas não melhoradas. O algoritmo pára se não há nenhuma melhoria no melhor valor da aptidão, para um intervalo do tempo especificado, para o limite de gerações consecutivas não melhoradas.

- Tolerância não-linear da restrição. A tolerância não-linear da restrição não é usada como um critério de parada do algoritmo propriamente dita. A tolerância não-linear da restrição é usada para determinar a viabilidade da solução no que diz respeito a restrições nãolineares, ou seja, se essa tolerância for ultrapassada o programa pára.

\subsection{Custos fixos e variáveis em projetos de redes de irrigação}

Os sistemas de irrigação superficiais e sub-superficiais são os que demandam, na maioria dos casos, um menor investimento inicial, seguido dos sistemas de aspersão e os mais caros, os sistemas de irrigação localizada.

Zocoler (1998) diz que os custos são classificados em fixos, que não se alteram com a quantidade produzida, e variáveis, que variam de acordo com o nível de produção. Para um sistema de recalque, são considerados como custos fixos principalmente a depreciação dos componentes do sistema e a remuneração de capital investido, e como variáveis os dispêndios com a energia e com os reparos dos equipamentos e infra-estrutura utilizados na operação do sistema.

O custo fixo pode ser representado pelo custo anual uniforme empregando o investimento inicial, a vida útil prometida e o valor residual do componente calculado (MAROUELLI; SILVA, 1998).

Pode-se utilizar o Fator de Recuperação de Capital (FRC), o qual pressupõe a reserva de uma quantidade suficiente de dinheiro em cada ano para possibilitar a reposição do bem no 
tempo estudado, mais os juros sobre o capital empregado, para análise econômica a longo prazo (FRIZZONE; SILVEIRA, 2000; MARQUES; MARQUES; COELHO, 2002).

Pode-se destacar o custo com energia elétrica para o funcionamento da motobomba como um dos principais componentes dos custos variáveis (Andrade Júnior et al., 2001).

Em uma análise do consumo de energia elétrica na irrigação, Portugual (2001) citou que o consumo de energia elétrica do setor agrícola é de $4 \%$ do consumo total do país, e que a irrigação inadequada pode levar ao consumo excessivo de água e energia para o bombeamento.

Com este tópico, se conclui que, os custos com a aquisição de tubulações, conectores, válvulas, motobomba, emissores, e demais componentes de montagem da rede de distribuição de água do sistema, que pode ser fixa ou móvel, são componentes para o cálculo do custo fixo. Já os custos variáveis em irrigação, são os diretamente envolvidos na operação da rede, ou seja, manutenção do sistema, insumos como a água, mão-de-obra e, principalmente, a energia elétrica.

\subsection{Cobrança pelo uso da água na irrigação}

Blanco et al. (2004) pesquisando sobre a viabilidade econômica da irrigação da manga para o Estado de São Paulo, observaram que o custo da compra de equipamentos coligado à sua vida útil foi o fator de maior sensibilidade na análise de viabilidade do empreendimento e que a cobrança pela água não inviabilizou a implantação do sistema de irrigação.

Marques e Coelho (2003) que analisaram a viabilidade da irrigação da pupunheira no oeste do Estado de São Paulo, variando o custo da água, a vida útil e o tipo de motobomba; concluíram que para todas as simulações a irrigação foi viável. 
Ressalta-se que a cobrança da água, prevista pela lei federal número 9433/97 (artigo 19), estabelece a água como um bem econômico sujeito à cobrança, e que os recursos financeiros arrecadados devem ser utilizados em financiamento de programas e intervenções para a recuperação ambiental da bacia hidrográfica onde foram gerados (BALSALOBRE et al,. 2003). Marques (2005) cita que a cobrança incidirá sobre a utilização da água por qualquer setor e para qualquer uso, inclusive sobre os irrigantes, sendo este mais um item que deve ser computado no custo variável da irrigação.

Conclui-se que a cobrança pelo uso da água deve ser um moderno e eficiente instrumento de gestão dos recursos hídricos, em âmbito nacional, e colocado à disposição dos Comitês de Bacia Hidrográfica para que, espontaneamente, o utilizem, definindo os critérios de sua aplicação. Atualmente a literatura científica brasileira trás pouca informação sobre esse fato novo que está diretamente ligado aos projetos e pesquisas que envolvem a irrigação.

\subsection{Simulações para análise de sensibilidade}

Brunelli (1990), cita que a simulação de dados permite o cálculo de diferentes combinações que probabilisticamente podem ocorrer, obtendo-se como resultado não um valor determinístico, mas uma distribuição de frequiências, sendo o risco traduzido em números pela variância.

Iglesias, Garrido e Gomez-Ramos (2003) analisaram as conseqüências econômicas das secas no setor da irrigação, por meio de modelagem e simulação. Os resultados mostraram que a seca impôs altos custos aos agricultores, mas observaram também que os agricultores apresentaram custos exagerados devido a alocação excessiva de água para irrigação. 
Fazer uma análise de sensibilidade é medir em que magnitude uma alteração prefixada em um ou mais fatores do projeto altera o resultado final, ou seja, faz-se o teste do modelo de projeção para se determinar quais são os elementos mais relevantes para a decisão de investimento analisada. Procedendo-se desse modo com os diversos parâmetros do projeto será possível selecionar aqueles mais sensíveis em termos de influência na análise (NORONHA; LATAPIA, 1988; FRIZZONE, 2005). A análise de sensibilidade é uma técnica muito utilizada para análise de projetos de investimento, pois permite medir o efeito produzido na rentabilidade do investimento pela variação dos dados de entrada. A sensibilidade pode ser examinada para inúmeras variáveis como: taxa de juros, preço de venda, vida útil do projeto, custos, receitas e outros (FRIZZONE; SILVEIRA, 2000).

Verifica-se com este tópico que, uma análise de sensibilidade criteriosa sempre se faz necessária para validar códigos de programação e otimização, além de analisar a variação de resultados para estudos mais específicos do que foi modelado e/ou otimizado. 


\section{MATERIAL E MÉTODOS}

\subsection{Considerações sobre o material e métodos}

Por se tratar de um trabalho de pesquisa operacional (PO) visando a otimização de rede de irrigação com o uso de algoritmos genéticos, onde a modelagem matemática e a simulação são imprescindíveis, faz-se necessária a utilização de microcomputador pessoal e programa de simulação com elevada capacidade de iterações.

O código do programa foi desenvolvido em MatLab (7.5.0 - R2007b), que possui linguagem própria de alto nível (compatível com C++ e Java) e uma caixa de ferramentas ${ }^{5}$ de algoritmos genéticos com ampla quantidade de opções de operadores genéticos e vastamente utilizada no meio acadêmico. Ressalta-se que o código da função de aptidão (objetivo) produzido é compatível também para rodar no programa Octave ${ }^{6}$. Enfatiza-se que o MatLab é desenvolvido tanto para o Sistema Operacional Linux quanto para o Windows, e que o código produzido funciona de maneira igual nos dois Sistemas Operacionais.

Tendo como parâmetro inicial que não há uma normatização clara e definida para dimensionar uma rede de distribuição de água em irrigação localizada, optou-se por desenvolver um método próprio que fosse o mais fidedigno possível às necessidades reais. $\mathrm{O}$ método de dimensionamento da rede hidráulica, de sistema de irrigação localizada proposto, vem ao encontro das legítimas necessidades do engenheiro projetista de campo, pois se baseia em elementos reais. Tais elementos, como características fisiológicas de distribuição de sistema radicular de cultura ou diâmetros comerciais de tubulação disponíveis no mercado, não são usuais em livros didáticos de dimensionamento destes tipos de rede. A metodologia

\footnotetext{
${ }^{5}$ Popularmente conhecida como toolbox do MatLab.

${ }^{6}$ Programa de código aberto, que possui uma linguagem interativa para computação numérica, compatível com o MatLab em grande parte de sua estrutura.
} 
proposta pode ser empregada em qualquer tipo de dimensionamento de rede hidráulica de irrigação localizada, desde que respeitadas as restrições aqui estabelecidas.

Ressalta-se que esta metodologia foi desenvolvida não só através de estudos em livros didáticos, imprescindíveis, mas principalmente através da observação, discussão com irrigantes e projetistas e experiência no trabalho em campo com o manejo de sistemas de redes de irrigação localizada.

Todo o material de apoio utilizado e produzido para o dimensionamento da rede de irrigação e do código (Códigos, Tabelas, Quadros e Gráficos), e posterior otimização, encontram-se nos APÊNDICES e ANEXOS.

A ampla variedade de equações para determinação de perda de carga, disponíveis em livros de hidráulica e de dimensionamento de sistemas de irrigação, faz normalmente surgir dúvidas quanto à equação que se deve utilizar, segundo as recomendações (dependendo do diâmetro e comprimento do conduto) e a afinidade com as equações por parte dos projetistas. A equação proposta por Hazen-Williams (PORTO, 1999) é, até os dias atuais, a mais utilizada devido à facilidade de operação de cálculo. Contudo, equações mais precisas como a de Swamee-Jain e Darcy-Weisbach, vêm sendo mais utilizadas, devido à maior acessibilidade a computadores e calculadoras de maior capacidade de processamento.

O método de otimização da rede hidráulica por algoritmos genéticos visa à minimização do custo total do sistema, tanto de custos fixos (implantação do sistema) como variáveis (operação do sistema - energia elétrica e água), segundo os critérios pré-estabelecidos pelo projetista. Visando não só uma melhor discussão do método de otimização, mas também um melhor esclarecimento de critérios e restrições iniciais reais de operação do sistema hidráulico, optou-se por validar a metodologia sob vários cenários diferentes por meio de uma análise de sensibilidade. Os resultados da análise de sensibilidade constarão mais adiante no tópico de Resultados e Discussão. 
A metodologia deste trabalho será descrita em partes para um melhor entendimento. A primeira parte versará sobre o problema a ser otimizado, destacando os custos variáveis envolvidos, as variáveis de decisão e as restrições hidráulicas. A seção seguinte mostrará o leiaute da rede de irrigação a ser otimizada. A próxima parte versará sobre o prédimensionamento hidráulico, necessário a projetos de irrigação, onde se trata, dentre outros assuntos, de turno de rega. Em seguida, a parte que tratará da análise hidráulica efetuada nas redes concebidas na análise de sensibilidade. Outra parte versará sobre a otimização por algoritmos genéticos da rede, descrevendo os processos e os operadores envolvidos neste estudo de dimensionamento otimizado de rede e sua implementação. A última parte abordará os dados iniciais de entrada do programa e os parâmetros da análise de sensibilidade. 


\subsection{Problema a ser otimizado - Função de Aptidão}

O problema de otimização consiste na minimização do custo total anualizado, por hectare, da rede de irrigação localizada, ou seja, a soma dos custos fixos anuais (sistema de irrigação) e dos custos variáveis anuais (custos operacionais).

$f a=\frac{(C E Q \cdot F R C)+C T E+C A G T}{A U I}$

em que: $f a$ - função de aptidão - custo total com a rede de irrigação $\left(\mathrm{R} \$ \cdot \mathrm{ano}^{-1} \cdot \mathrm{ha}^{-1}\right) ; C E Q-$ custo total com os equipamentos de irrigação (R\$); CTE - custo total com energia elétrica $\left(\mathrm{R} \$ . \mathrm{ano}^{-1}\right) ; C A T G$ - custo total com água $\left(\mathrm{R} \$ . \mathrm{ano}^{-1}\right) ; A U I$ - área útil irrigada (ha).

São considerados custos fixos aqueles que ocorrem independentemente do número de horas anuais de operação do sistema de irrigação. Estes custos fixos foram calculados em $\mathrm{R} \$ \cdot \mathrm{ano}^{-1} \cdot \mathrm{ha}^{-1}$.

Utilizando-se os juros anuais, o fator de recuperação de capital $(F R C)$ fornece um coeficiente que permite, a partir do valor do investimento, calcular o custo fixo anual referente a este investimento. Este cálculo leva em conta a vida útil do equipamento e a taxa de juros ao ano.

$F R C=\frac{J(J+1)^{V}}{(J+1)^{V}-1}$

em que: $F R C$ - fator de recuperação de capital (decimal); $J$ - taxa anual de juros (decimal); $V$ vida útil dos equipamentos (anos).

Segundo a resolução da ANEEL DOU n ${ }^{0} 313$ de 07/04/2006, que é seguida pela Companhia Paulista de Força e Luz (CPFL), este projeto de irrigação enquadra-se no Grupo B - categoria do setor Rural, sendo paga somente a tarifa de consumo de $0,1768 \mathrm{R} \$ . \mathrm{kW}^{-1}$. 
Segundo a CPFL, entre os horários de 21h30min e 06h00min ("janela” de aproveitamento de 8,5 horas) há um desconto de $60 \%$ sobre a tarifa do setor rural, o que resulta em uma tarifa de $0,0707 \mathrm{R} \$ . \mathrm{kW}^{-1}$ para esta faixa de horário.

Por heurística, pode-se ajustar o sistema para funcionar 4,25 horas, trabalhando em dois turnos por dia, o que reduzirá a vazão de projeto, gerando economia em tubulação e potência requerida. Outra forma seria trabalhar com um turno de 8,5 horas. $\mathrm{O}$ ajuste pode ser feito aumentando a vazão dos emissores de acordo com a curva de vazão pela pressão fornecida pelo fabricante, ou simplesmente escolhendo outro emissor.

O custo total da água, é calculado a partir da demanda de água da cultura devido à evapotranspiração, dias irrigados por mês, número de meses de operação do sistema por ano e o preço da água $\left(\mathrm{R} \$ .\left(\mathrm{m}^{3}\right)^{-1}\right)$.

O pagamento pela água de irrigação é algo iminente no Estado de São Paulo e no Brasil (AGÊNCIA NACIONAL DE ÁGUAS, 2007a). Para tornar o modelo mais abrangente e real, foi adotado o custo da água como parâmetro de entrada para o custo operacional total do sistema.

Adotou-se como tarifa base, o valor de $0,01 \mathrm{R} \$ .\left(\mathrm{m}^{3}\right)^{-1}$. 


\subsubsection{Variáveis de decisão}

O processo de otimização é baseado na variação de elementos da função de aptidão, de forma a obter o menor custo de instalação e operação do sistema de irrigação. As variáveis de decisão para a escolha do melhor sistema são os comprimentos das tubulações em cada trecho, com os respectivos diâmetros disponíveis:

- linha lateral: comprimento dos trechos LLL1 e LLL2, com dois diâmetros;

- linha de derivação: comprimento dos trechos LLD1, LLD2, LLD3 e LLD4, com quatro diâmetros;

- linha secundária comprimento dos trechos LLS1, LLS2, LLS3 e LLS4, com quatro diâmetros. 


\subsubsection{Restrições hidráulicas}

As restrições hidráulicas para o dimensionamento da rede de irrigação deste trabalho serão descritas a seguir:

- velocidades máximas nos trechos da tubulação:

$$
\begin{array}{ll}
\text { linha lateral: } & \text { VILLT }<1,5 \mathrm{~m} . \mathrm{s}^{-1} ; \\
\text { linha de derivação: } & \text { VILDT }<2,5 \mathrm{~m} . \mathrm{s}^{-1} ; \\
\text { linha secundária: } & \text { VILST }<4,0 \mathrm{~m} . \mathrm{s}^{-1} ;
\end{array}
$$

- uniformidade estatística de distribuição de vazão dos microaspersores

$$
\mathrm{UEST} \geq 90 \%
$$

- faixa de pressão no microaspersor (segundo o fabricante):

$$
10 \text { mca } \leq \mathrm{h}_{\mathrm{e}} \leq 20 \mathrm{mca}
$$

- variação máxima de perda de carga permitida:

$$
\begin{array}{ll}
\text { linha lateral: } & \text { PCTLL }=0,55 . \text { DHV; } \\
\text { linha de derivação: } & \text { PCTLL }=0,45 . \text { DHV; }
\end{array}
$$

A variação de pressão na unidade operacional (DHV) é definida como sendo o somatório da variação de pressão na linha lateral e na linha de derivação. Saad e Frizzone (1996) adotaram faixas de tolerância para a variação de pressão de 60 e $40 \%$ para cada linha, respectivamente. Karmeli e Peri (1972) propuseram que a distribuição mais econômica seria de $55 \%$ da perda admissível para as linhas laterais e $45 \%$ para a linha de derivação.Esses valores foram adotados neste trabalho. 
A implementação destas restrições pode ser verificada no APÊNDICE D, que consiste no arquivo frestricoes.m, utilizado concomitantemente com os demais arquivos do código. 
4.3. Descrição da área e dos principais equipamentos utilizados

\subsection{1. Área de implantação do sistema de irrigação}

A área modelo a ser irrigada consiste em 78,72 ha $\left(787.200 \mathrm{~m}^{2}\right)$, tendo 1600 metros de comprimento e 492 metros de largura. Considerando uma faixa mínima de mata ciliar de 57 metros das margens do rio mais uma faixa de 7,5 metros destinada à movimentação de implementos e máquinas, optou-se por definir a área irrigável a partir de 64,5 metros distante do curso de água onde se fará a captação direta para o bombeamento. A área útil para irrigação será de 68,40 ha $\left(684.000 \mathrm{~m}^{2}\right)$. A Figura 2 mostra o arranjo da área modelo, no qual será implantada a de irrigação localizada.

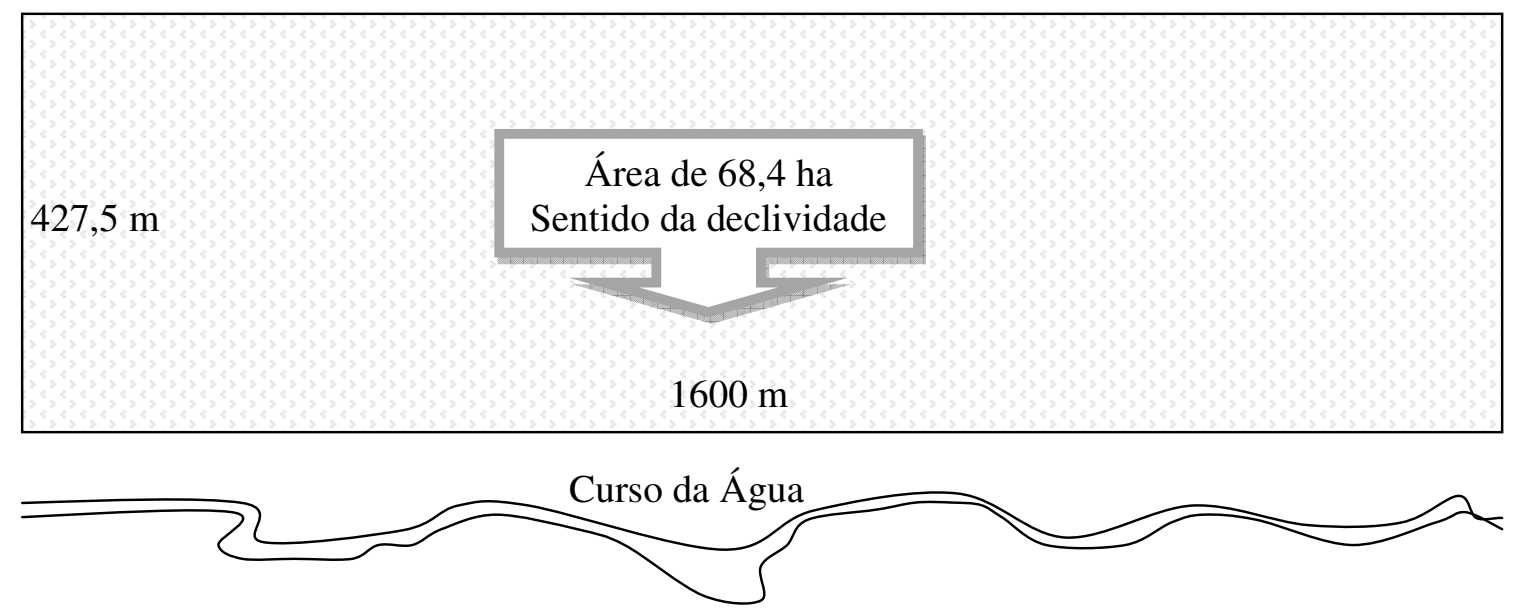

Figura 2. Arranjo da área modelo para implantação da rede hidráulica de irrigação

4.3.2. Leiaute da distribuição da rede hidráulica de irrigação em campo

A Figura 3 apresenta o arranjo da distribuição da rede hidráulica na área. As Figuras 4, 5 e 6 ilustram o detalhamento dos quadrantes 1, 2 e 3 da Figura 3. 


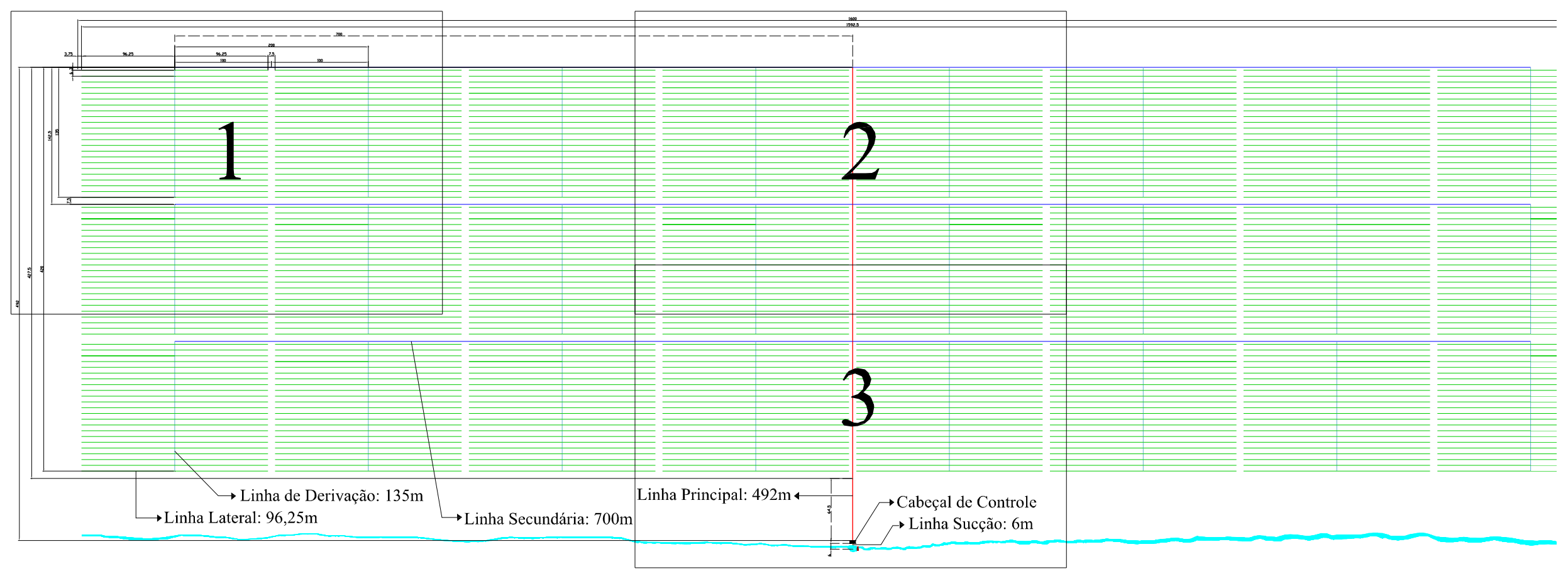

Figura 3. Leiaute da rede hidráulica do sistema de irrigação localizada, para uma área de 78,72 ha, em escala 1:6000 


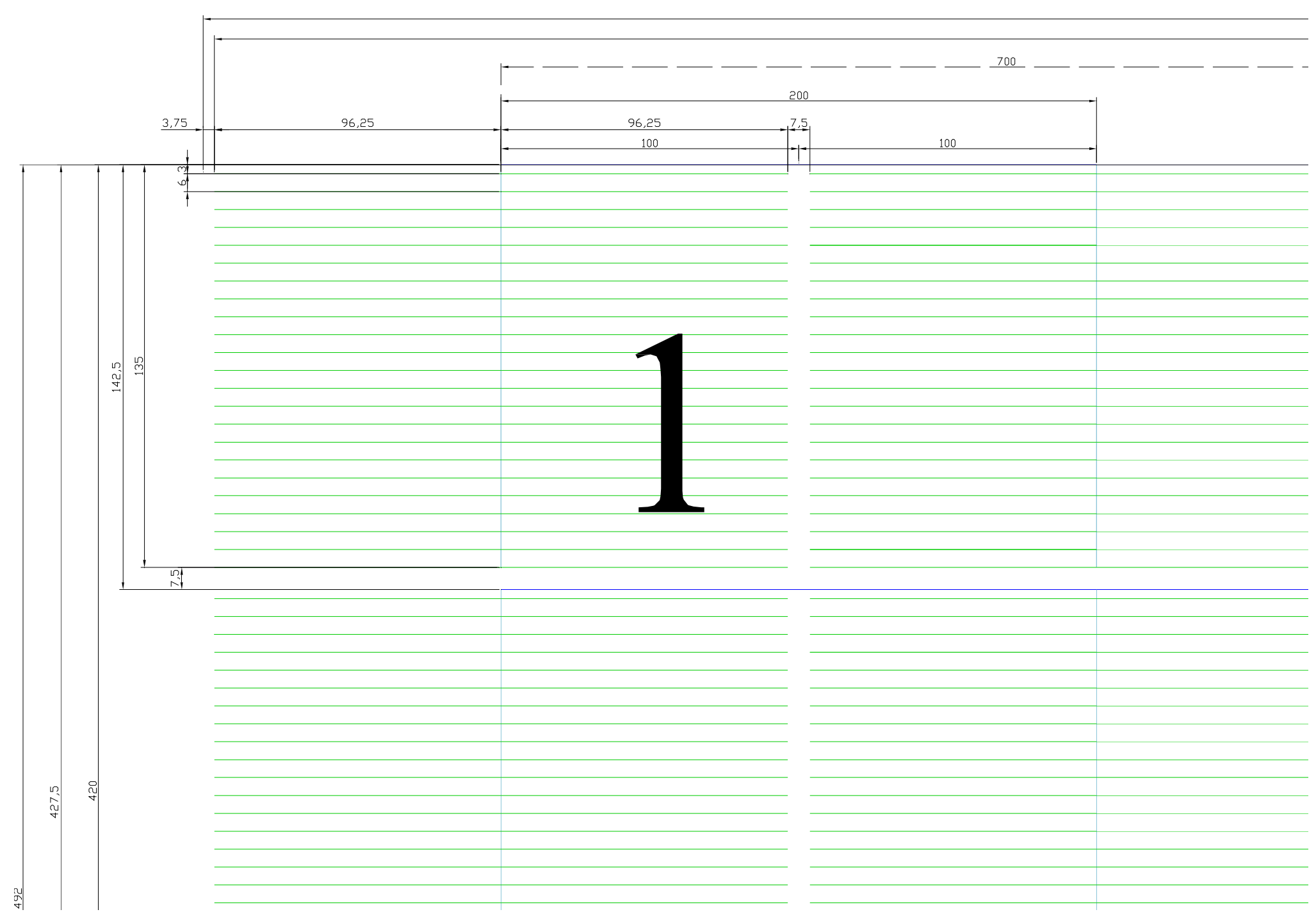

Figura 4. Detalhamento do quadrante 1 da Figura 3, em escala 1:2000 


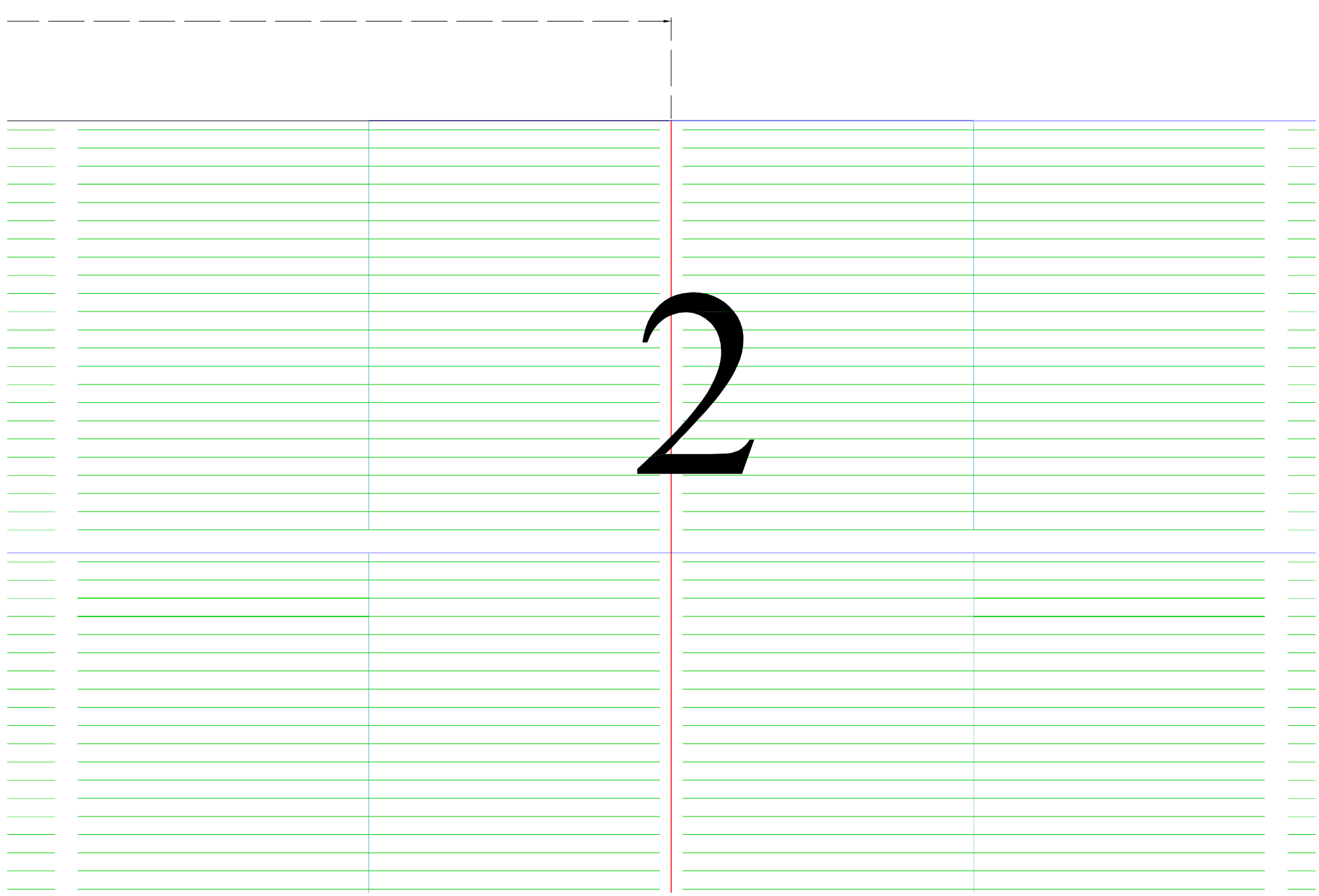

Figura 5. Detalhamento do quadrante 2 da Figura 3, em escala 1:2000 
Linha Principal: 492m ^

Figura 6. Detalhamento do quadrante 3 da Figura 3, em escala 1:2000
- Cabeçal de Controle - Linha Sucção: 6m 
A rede hidráulica do sistema de irrigação localizada estudado neste trabalho consiste de: emissores (microaspersores ou gotejadores), linhas laterais (nas quais os emissores ficam acoplados), linhas de derivação (nas quais as linhas laterais ficam acopladas), linhas secundárias (nas quais as linhas de derivação ficam acopladas), linha principal ou adutora (nas quais as linhas secundárias ficam acopladas), tubulação de sucção (a montante do conjunto moto-bomba), válvulas, registros, filtros (de areia e disco) e painel de controle.

O Quadro 1 detalha os diferentes trechos das tubulações usadas neste trabalho, quanto ao comprimento, se está em nível ou em declive ou aclive (segundo a direção do fluxo de água), material usado em sua fabricação e número de diâmetros a serem usados no trecho.

Quadro 1. Detalhamento dos diferentes trechos da rede hidráulica de irrigação

\begin{tabular}{|c|c|c|c|c|}
\hline Trecho da Rede & Declividade & Material & Comprimento & $\begin{array}{c}\text { Número de } \\
\text { Diâmetros Disponiveis } \\
\end{array}$ \\
\hline Linha Lateral & Nível & Polietileno & 96,25 & 2 \\
\hline Linha de Derivação & Declive & PVC & 135 & 4 \\
\hline Linha Secundária & Nível & PVC & 700 & 4 \\
\hline Linha Principal & Aclive & PVC & 492 & 1 \\
\hline Linha de Sucção & Aclive e Nível & PVC & 6 & 1 \\
\hline
\end{tabular}

O preço (em real e em dólar) pesquisado, junto as empresas, para simulação dos custos das tubulações e equipamentos pode ser verificado no ANEXO B.

\subsubsection{Descrição dos emissores}

Foram considerados microaspersores fixos, pois podem ser facilmente convertidos em microaspersores rotativos, apenas com a substituição do anel de impacto, caso seja necessário. Isto é feito segundo a necessidade de adaptação do emissor ao estágio de desenvolvimento em 
que se encontra a cultura a ser irrigada. Optou-se por emissores com pressão de serviço variando de 1 a 2 kgf. $\left(\mathrm{cm}^{2}\right)^{-1}$ (10 a $\left.20 \mathrm{mca}\right)$, que são os mais usuais. As opções de vazões pesquisadas variam de 31 a 103 L.h ${ }^{-1}$, permitindo uma grande gama de opções de cálculo de turno de rega. O diâmetro molhado varia de acordo com a pressão de serviço, dando possibilidade de sobreposição de área molhada (como no presente estudo, em que a cultura possui um espaçamento entre plantas de 3,5 m). O Quadro 2 mostra o detalhamento dos microaspersores pesquisados.

Quadro 2. Detalhamento das opções de microaspersores pesquisados

\begin{tabular}{|c|c|c|c|c|}
\hline Microaspersor & & PS $^{2}$ & $\mathrm{DM}^{3}$ & $\mathrm{Q}^{4}$ \\
\hline Cor do Bocal & Código $^{1}$ & ${\text { kgf. }\left(\mathrm{cm}^{2}\right)^{-1}}^{-1}$ & $----\mathrm{m}-----$ & $---1^{-1}----$ \\
\hline Grafite & 93352 & 1,5 & 2,6 & 31 \\
\hline Preto & 93353 & 1,5 & 2,9 & 35 \\
\hline Branco & 93049 & 1,5 & 3,3 & 55 \\
\hline Marrom & 93051 & 2 & 5,5 & 82 \\
\hline Verde & 93355 & 2 & 4,2 & 103 \\
\hline
\end{tabular}

Código do Fabricante.

${ }^{2}$ PS - Pressão de Serviço $\left(1 \mathrm{kgf} .\left(\mathrm{cm}^{2}\right)^{-1}=10 \mathrm{mca}\right)$.

${ }^{3} \mathrm{DM}$ - Diâmetro Molhado.

${ }^{4}$ Q - Vazão do Emissor com a Pressão de Serviço.

A determinação do diâmetro molhado do emissor é feita em laboratório, seguindo normas rígidas de testes hidráulicos para fabricantes. Contudo, em caso de projeto baseado em lâmina uniforme, não se deve considerar como valor do espaçamento entre emissores o espaçamento entre plantas, pois o projeto de irrigação localizada, normalmente, considera o emissor como aplicação pontual.

Neste estudo, optou-se por considerar a variação do diâmetro molhado pelo microaspersor segundo a variação de pressão de serviço média calculada. Para tanto, executou-se uma análise de regressão por lei de potência com os dados obtidos junto ao fabricante (Gráfico 1). 


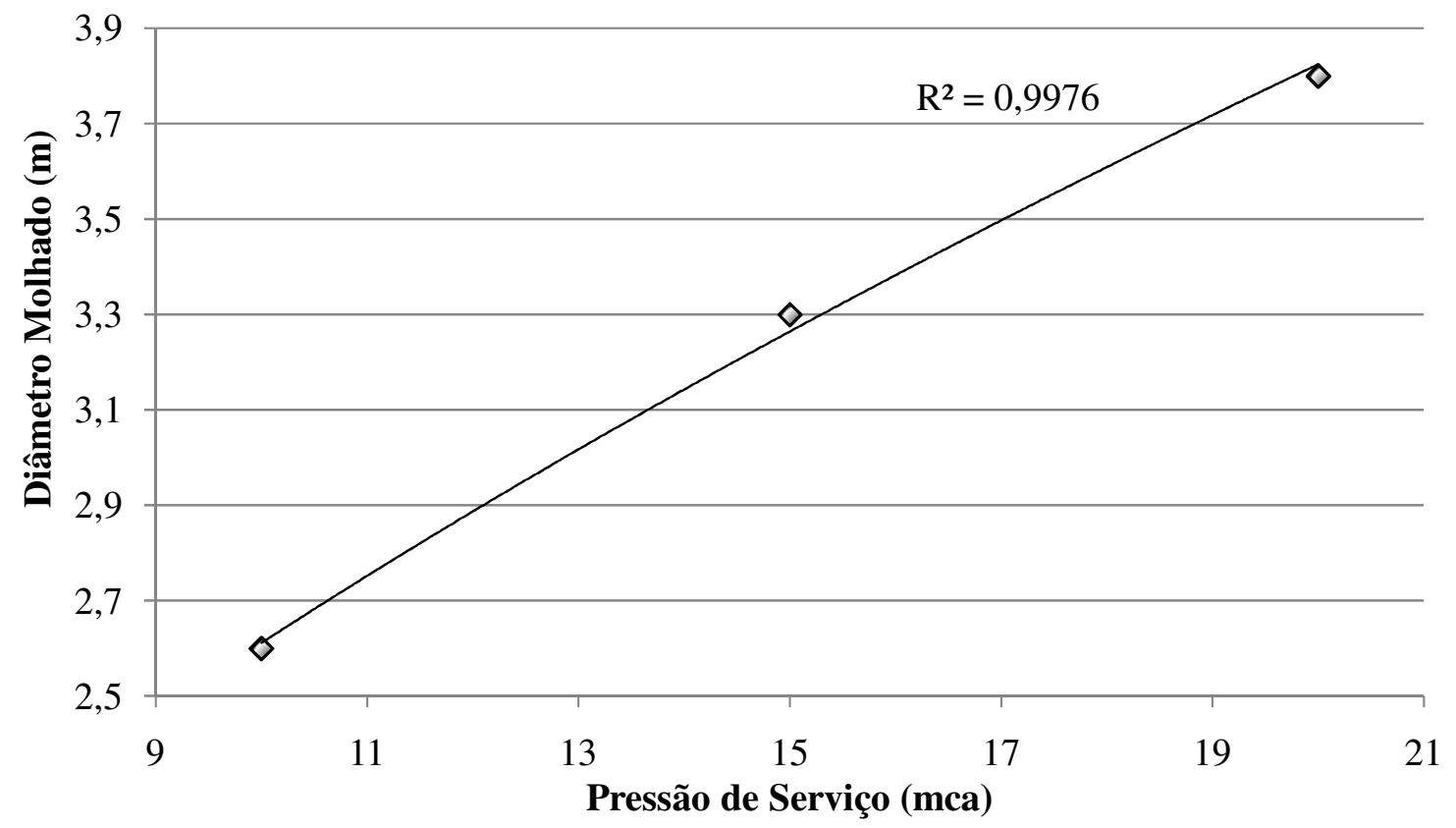

Gráfico 1. Análise de regressão para determinação da lei de potencial cálculo do diâmetro molhado pelo microaspersor segundo a sua pressão de serviço

Com a análise de regressão potencial (Gráfico 1) obteve-se uma equação que fornece o diâmetro molhado, em metros, segundo a pressão de serviço do emissor. Apresenta-se a equação abaixo:

$D M=0,7358 . P S^{0,5501}$

em que: $D M$ - diâmetro de solo molhado pelo emissor (m); $P S$ - pressão de serviço do emissor (mca).

4.3.4. Descrição das tubulações de polietileno para linha lateral

As tubulações feitas de polietileno (material flexível e resistente), em sua maioria, são produzidas a partir de resina virgem de polietileno linear de baixa densidade (PELBD), pelo processo de co-extrusão. Esta característica garante uma superfície interna extremamente lisa, abrandando muito a perda de carga por atrito, ao longo da tubulação. A maioria dos 
fabricantes adiciona aditivos à matéria-prima, garantindo uma excelente resistência aos raios ultravioleta (essenciais ao crescimento de microorganismos que entopem a tubulação). Denículi et al. (2004, p. 7), dissertando sobre linhas laterais de polietileno, descreveu como sendo "tubulações perfuradas, ou condutos perfurados, que permitem o escoamento e a distribuição de fluidos ao longo do seu comprimento".

O Quadro 3 mostra as características físicas das opções de tubo de polietileno linear de baixa densidade pesquisadas para utilização neste trabalho.

Quadro 3. Características físicas das opções de tubo de polietileno linear de baixa densidade

\begin{tabular}{|c|c|c|c|c|c|c|c|c|c|}
\hline Tubo & Descrição & $\mathrm{DN}^{3}$ & Dem $^{4}$ & $\mathrm{e}^{5}$ & $\mathrm{DI}^{6}$ & $\mathrm{DI}^{6}$ & $\mathrm{PS}^{7}$ & $\mathrm{CB}^{8}$ & $\mathrm{~PB}^{9}$ \\
\hline Código & Tubo PE & \multicolumn{2}{|c|}{$-----------\mathrm{mm}---------$} & $---\mathrm{m}---$ & $\mathrm{kgf}^{8}\left(\mathrm{~cm}^{2}\right)^{-1}$ & $---\mathrm{m}---$ & $---\mathrm{kg}---$ \\
\hline \hline 15017 & 437 & 4 & 4,30 & 0,94 & 2,4 & 0,00242 & 11,0 & 500 & 8,10 \\
\hline 15015 & 551 & 5 & 5,30 & 1,30 & 2,7 & 0,00270 & 11,0 & 500 & 13,70 \\
\hline 15018 & 1035 & 10 & 10,00 & 0,89 & 8,2 & 0,00822 & 4,0 & 600 & 17,00 \\
\hline 15011 & 1335 & 13 & 13,00 & 0,89 & 11,2 & 0,01122 & 3,0 & 500 & 18,00 \\
\hline 15012 & 1635 & 16 & 16,10 & 0,89 & 14,3 & 0,01432 & 3,0 & 400 & 17,50 \\
\hline 15014 & 2043 & 20 & 20,60 & 1,10 & 17,8 & 0,01780 & 3,0 & 200 & 14,00 \\
\hline 15016 & 2043 & 22 & 23,00 & 1,15 & 21,7 & 0,02170 & 4,0 & 200 & 14,60 \\
\hline
\end{tabular}

Código do Fabricante.

${ }^{2}$ Descrição do Tubo: PE 437, onde: 4 é a espessura da parede em 1/1000 de polegada e 37 é o Diâmetro Nominal Interno em mm.

${ }^{3}$ DN - Diâmetro Nominal.

${ }^{4}$ Dem - Diâmetro Externo Médio.

5 e - Espessura de Parede.

${ }^{6}$ DI - Diâmetro Interno.

${ }^{7}$ PS - Pressão de Serviço.

${ }^{8} \mathrm{CB}$ - Comprimento da Bobina.

${ }^{9} \mathrm{~PB}$ - Peso da Bobina.

Devido às características da rede hidráulica e do volume de água requerido por turno de rega para irrigação da cultura escolhida, optou-se pelos maiores diâmetros disponíveis de polietileno (DI de 0,0178 e 0,0217 m). Se opção fosse por diminuir o turno de rega, aumentando a freqüência de cada irrigação, poder-se-ia escolher tubulações com menores diâmetros. 


\subsubsection{Descrição das tubulações de PVC}

Parte da rede hidráulica fixa (linhas de derivação, secundárias, principal e sucção) será composta por tubos de PVC (Poli Cloreto de Vinila) com comprimento de 6 metros (comercialmente apresentados na cor azul) e diversas conexões. As espessuras de parede dos tubos comerciais normalmente usados estão dimensionadas para suportar uma pressão de serviço PN40 (4,0 kgf. $\left.\left(\mathrm{cm}^{2}\right)^{-1}\right)$ ou PN80 $\left(8,0 \mathrm{kgf} .\left(\mathrm{cm}^{2}\right)^{-1}\right)$, sob temperatura de $20^{\circ} \mathrm{C}$.

As linhas fixas de PVC para irrigação, em sua maioria, são fabricadas com dois sistemas de juntas: elástica com anel de borracha ou ponta/bolsa soldável. Os fabricantes recomendam para linhas enterradas com grandes extensões, a utilização de sistema de junta elástica. Para trechos instalados em superfície, ou para pequenas extensões, recomenda-se a utilização do sistema ponta/bolsa soldável. O Quadro 4 mostra as características físicas das opções de tubo de PVC pesquisadas para este trabalho.

Quadro 4. Características físicas das opções de tubo de PVC

\begin{tabular}{|c|c|c|c|c|c|c|}
\hline Tubo & $\mathrm{DN}^{2}$ & $\mathrm{Dem}^{3}$ & $\mathrm{e}^{4}$ & $\mathrm{DI}^{5}$ & $\mathrm{DI}^{5}$ & $\mathrm{Q}_{\text {máx }}{ }^{6}$ \\
\hline Código & ------------------------ & $----\mathrm{m}----$ & -- L.s $^{-1}--$ \\
\hline \hline 10838 & 35 & 38,1 & 1,2 & 35,7 & 0,03570 & 2,00 \\
\hline 10839 & 50 & 50,5 & 1,2 & 48,1 & 0,04810 & 3,63 \\
\hline 10840 & 75 & 75,5 & 1,5 & 72,5 & 0,07250 & 8,26 \\
\hline 10841 & 100 & 101,6 & 2,0 & 97,6 & 0,09760 & 14,96 \\
\hline 10842 & 125 & 125 & 2,5 & 120,0 & 0,12000 & 22,62 \\
\hline 11922 & 150 & 150 & 3,0 & 144,0 & 0,14400 & 32,57 \\
\hline 13212 & 200 & 222 & 8,9 & 204,2 & 0,2042 & 65,50 \\
\hline 13033 & 250 & 282 & 10,0 & 262,0 & 0,2620 & 99,75 \\
\hline
\end{tabular}

Código do Fabricante.

${ }^{2}$ DN - Diâmetro Nominal.

${ }^{3}$ Dem - Diâmetro Externo Médio.

${ }_{5}^{4}$ e - Espessura de Parede.

${ }^{5}$ DI - Diâmetro Interno.

${ }^{6} \mathrm{Q}_{\text {máx }}$ - Vazão Máxima na Tubulação. 
Lançando mão de cálculos anteriores e de conhecimento prático a opção foi por distribuir as opções de tubulação de PVC para a rede de irrigação, da seguinte forma: linhas de derivação com as opções de diâmetro interno comercial, em metros, de 0,1200, 0,0976, 0,0725, 0,0481; linhas secundárias com as opções de diâmetro interno comercial, em metros, de 0,2042, 0,1440, 0,1200, 0,0976; linha principal (adutora) com a opção de diâmetro interno comercial, em metros, de 0,2042; linha de sucção com a opção de diâmetro interno comercial, em metros, de 0,2620 .

4.3.6. Demais equipamentos e acessórios da rede hidráulica de irrigação

No Quadro 5 estão descritos os acessórios e equipamentos necessários para montagem e o adequado funcionamento da rede hidráulica do sistema de irrigação localizada. No ANEXO B, encontram-se mais detalhes dos equipamentos e acessórios bem como o preço (em R \$) dos mesmos. 
Quadro 5. Equipamentos e acessórios da rede hidráulica de irrigação localizada

\begin{tabular}{|c|c|}
\hline Trecho & Componentes \\
\hline Linha Lateral & $\begin{array}{l}\text { Redutor de diâmetro DI1 para DI2 } \\
\text { Anel fim de linha }\end{array}$ \\
\hline Linha de Derivação & $\begin{array}{l}\text { Conector de saída para linha lateral } \\
\text { Redutor de diâmetro DI1 para DI2 } \\
\text { Redutor de diâmetro DI2 para DI3 } \\
\text { Tampão fim de linha solda PVC macho }\end{array}$ \\
\hline Linha Secundária & $\begin{array}{l}\text { Válvula reguladora de pressão } \\
\text { Registro de solda PVC } \\
\text { Curva de } 90^{\circ} \text { PVC } \\
\text { Conexão "T" solda PVC } \\
\text { Redutor de diâmetro DI1 para DI2 } \\
\text { Redutor de diâmetro DI2 para DI3 } \\
\text { Redutor de diâmetro DI3 para DI4 }\end{array}$ \\
\hline Linha Principal & $\begin{array}{l}\text { Registro de esfera PVC } \\
\text { Conexão "T" solda PVC final de linha } \\
\text { Conexão "T" solda PVC derivação } \\
\end{array}$ \\
\hline Cabeçal de Controle & $\begin{array}{l}\text { Filtro de disco vazão } 501 \mathrm{~s}^{-1} \\
\text { Filtro de areia completo } 200 \text { mesh } \\
\text { Registro de gaveta } \\
\text { Injetor venturi } \\
\text { Painel de controle } 220 \mathrm{v} \\
\text { Hidrômetro } \\
\text { Manômetro }\end{array}$ \\
\hline Conjunto Motobomba & $\begin{array}{l}\text { Ampliação excêntrica } \\
\text { Bomba } \\
\text { Motor } \\
\text { Redução excêntrica } \\
\end{array}$ \\
\hline Demais Componentes & $\begin{array}{l}\text { Curva } 90^{\circ} \text { solda PVC } \\
\text { Válvula de pé com crivo } \\
\text { Lixa da água } \\
\text { Cola para PVC } \\
\text { Fita veda rosca }\end{array}$ \\
\hline
\end{tabular}




\subsection{Fluxograma do dimensionamento da rede de irrigação localizada}

Fluxograma apresentando um resumo do dimensionamento da rede de irrigação localizada estudada neste trabalho (Figuras 7 e 8 ).

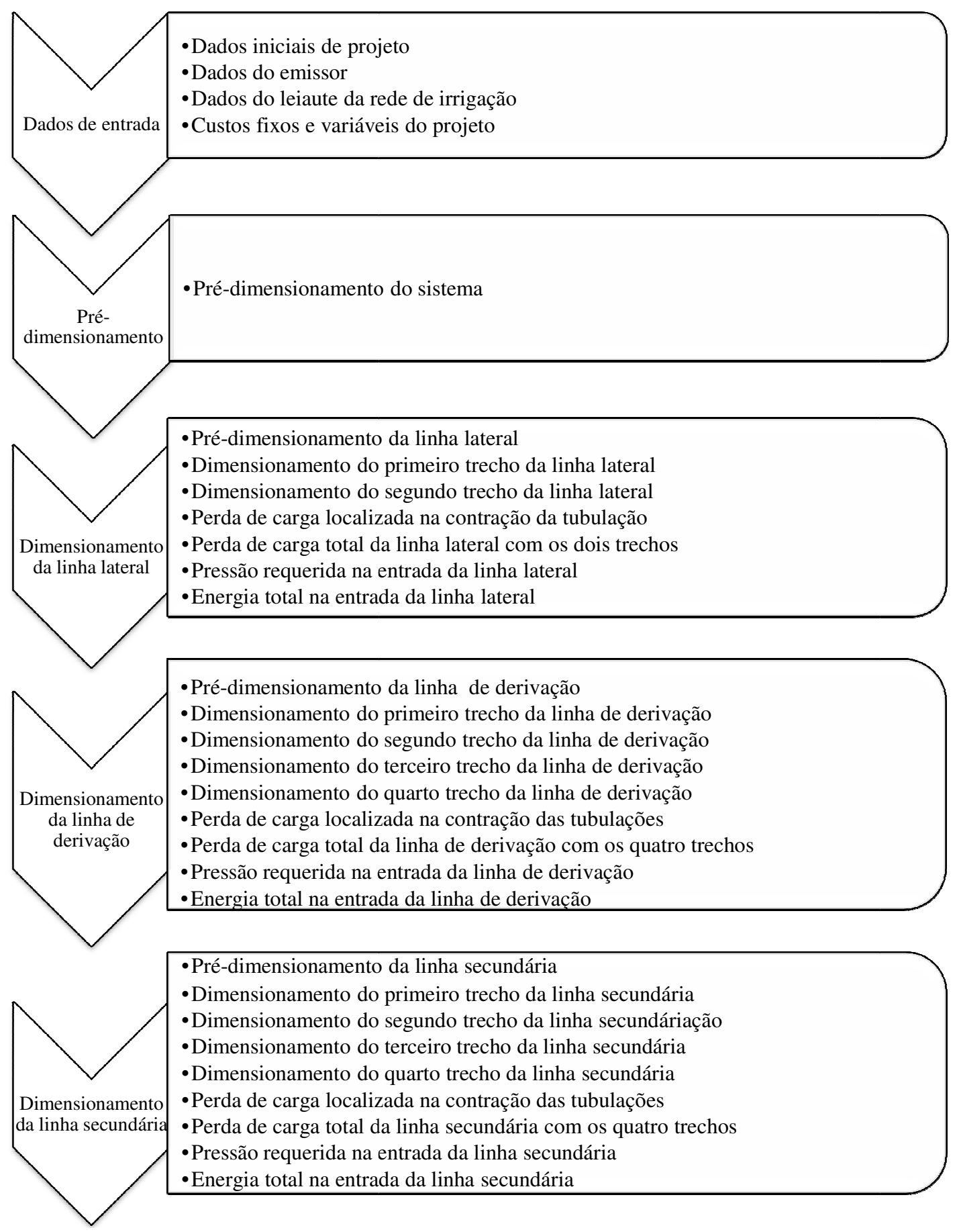

Figura 7. Primeira parte do fluxograma de dimensionamento da rede de irrigação 


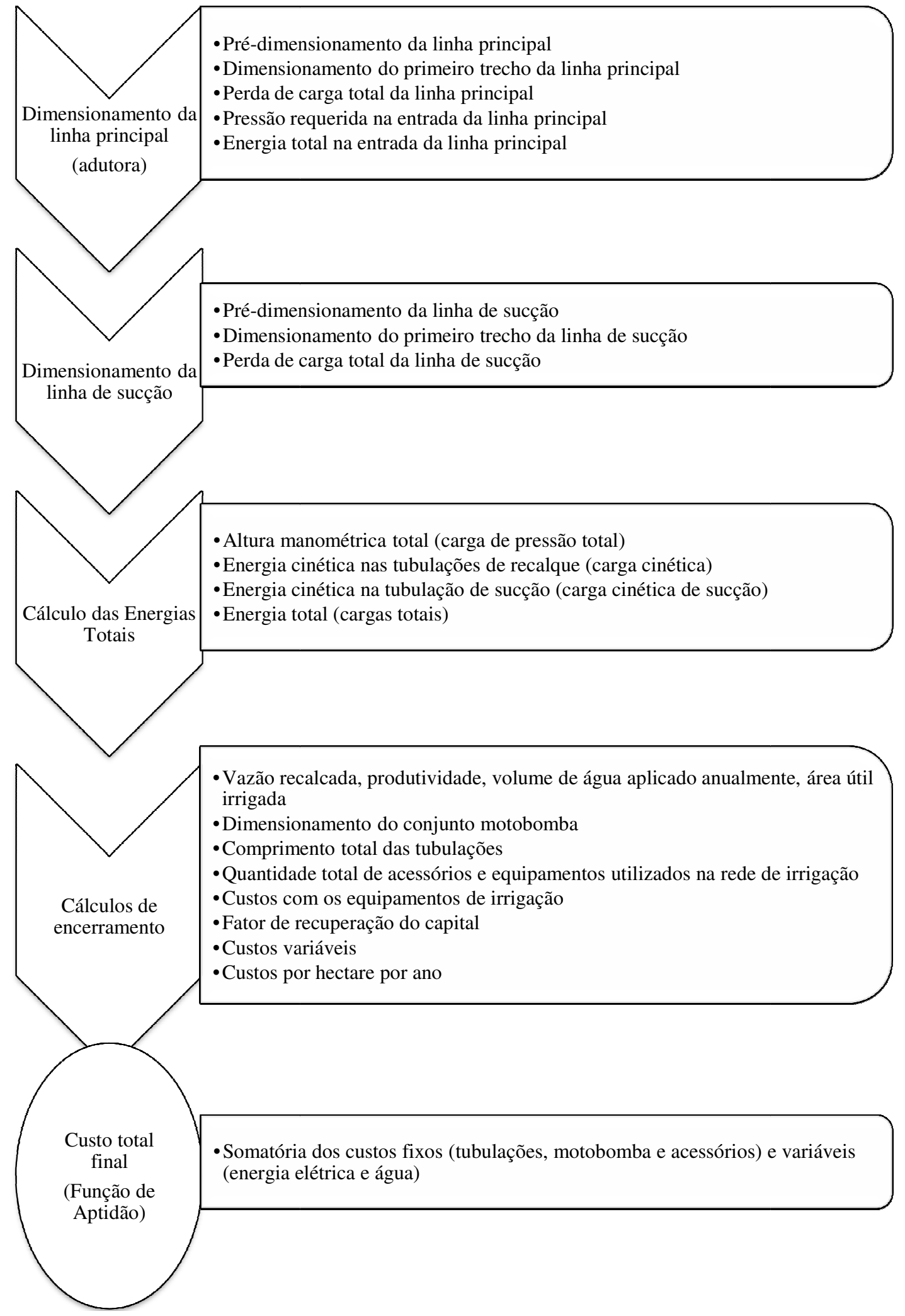

Figura 8. Segunda parte do fluxograma de dimensionamento da rede de irrigação 
4.5. Pré-dimensionamento e dimensionamento do sistema de irrigação localizada

A metodologia será descrita de forma seqüencial, para um melhor entendimento, considerando desde o sistema solo-planta (receptor da água a ser aplicada) até o sistema motobomba e a tubulação de sucção. Os fatores envolvidos no dimensionamento serão apresentados e, se for o caso, discutidos, conforme os termos das equações utilizadas forem necessários, obedecendo a seguinte seqüência de componentes do sistema: (a) emissores e cálculos preliminares de operação do sistema, (b) linha lateral, (c) linha de derivação, (d) linha secundária, (e) linha principal (adutora), (f) cabeçal de controle, (g) filtros, (h) válvulas e demais acessórios, (i) moto-bomba e (j) tubulação de sucção.

As equações descritas a seguir podem ser encontradas em Porto (1999) e Bernardo, Soares e Mantovani (2005).

4.5.1. Cálculos preliminares ao dimensionamento da rede de distribuição de água do sistema de irrigação localizada

\subsubsection{1. Área total irrigável disponível}

$A=\frac{L x \cdot L y}{10000}$

em que: $A$ - área total irrigável disponível (hectares); $L x$ - comprimento da área (m); $L y$ largura da área $(\mathrm{m})$.

4.5.1.2. Área total para cada unidade operacional

$A U O=\frac{A}{N T U O}$ 
em que: $A U O$ - área total de cada unidade operacional disponível (hectares); $N T U O$ - número total de unidades operacionais.

4.5.1.3. Espaçamento entre emissores para um volume de solo molhado continuo

See $=0,8 \cdot w$

em que: See - espaçamento entre emissores para se ter um volume de solo molhado continuo (m); $w$ - diâmetro molhado pelo emissor (m).

\subsubsection{Número de emissores por planta}

$N P=\frac{S p}{S e e}$

em que: $N P$ - número de emissores por planta; $S p$ - espaçamento entre plantas (m).

4.5.1.5. Número de emissores por planta ajustado

$N P A=\operatorname{round}(N P)$

em que: $N P A$ - número de emissores por planta ajustado para um número inteiro.

\subsubsection{Perímetro molhado pelo emissor}

$P m a=\pi \cdot w$

em que: Pma - perímetro molhado pelo emissor (m); $\pi$ - número PI.

4.5.1.7. Área molhada pelo emissor

$A m a=\frac{\pi \cdot\left(w^{2}\right)}{4}$

em que: Ama - área molhada pelo emissor $\left(\mathrm{m}^{2}\right)$. 
4.5.1.8. Percentagem da área molhado pelo emissor

$P W=N P A \cdot\left(\frac{A m a+\left(\frac{\text { See.Pma }}{2}\right)}{(S p \cdot S f)} .100\right)$

em que: $P w$ - percentagem da área molhada pelo emissor segundo a área ocupada pela planta (\%); $S f$ - espaçamento entre linhas $(\mathrm{m})$.

4.5.1.9. Disponibilidade total de água no solo

$D T A S=\left(\frac{C C-P M}{10}\right) \cdot D A$

em que: DTAS - disponibilidade máxima de água no solo $\left(\mathrm{mm} . \mathrm{cm}^{-1}\right) ; C C$ - capacidade de campo (\%); PM - ponto de murcha permanente (\%); DA - densidade aparente do solo (g. $\left.\left(\mathrm{cm}^{3}\right)^{-1}\right)$.

4.5.1.10. Irrigação real necessária

$I R N=\left(\frac{D T A S}{10}\right) \cdot\left(\frac{f}{100}\right) \cdot(z \cdot 100) \cdot\left(\frac{P w}{100}\right)$

em que: IRN - irrigação real necessária $(\mathrm{mm}) ; f$ - fator de disponibilidade total de água no solo $(\%) ; z$ - profundidade do sistema radicular (m).

4.5.1.11. Evapotranspiração da cultura por dia

$E T p c=E T_{O} \cdot K C$

em que: ETpc - evapotranspiração da cultura em um dia $\left(\mathrm{mm} \cdot \operatorname{dia}^{-1}\right) ; E T_{O}$ - média diária da evapotranspiração de referência anual $(\mathrm{mm}) ; K C$ - coeficiente de cultura para cálculo da evapotranspiração da cultura a ser instalada.

4.5.1.12. Evapotranspiração da cultura por ano

$E T C A=E T p c .365$ 
em que: ETCA - evapotranspiração da cultura no ano $\left(\mathrm{mm} \cdot \mathrm{ano}^{-1}\right)$.

4.5.1.13. Fator de ajuste para aplicação localizada de água

O fator de ajuste devido à aplicação localizada da água é calculado segundo a percentagem de área molhada $(P w)$ pelo emissor, para cada tipo de sistema de plantio e a cultura cultivada, e é utilizado para o cálculo da evapotranspiração média da área a ser irrigada.

As equações a seguir foram propostas por Fereres (1981) para culturas com grande espaçamento (árvores frutíferas).

Se $P w>65 \% \therefore K L=1,0$

Se $20 \%<P w<65 \% \therefore K L=1,09 .\left(\frac{P w}{100}\right)+0,30$

Se $P w<20 \% \therefore K L=1,94 .\left(\frac{P w}{100}\right)+0,1$

em que: $K L$ - fator de ajuste devido a aplicação localizada da água;

As equações a seguir foram propostas por Keller (1978) e Bernardo, Soares e Mantovani (2005), respectivamente equações 17 e 18, para culturas com plantios mais adensados, como olerícolas e café em sistema de colheita manual.

$$
\begin{aligned}
& K L=\left(\frac{P w}{100}\right)+0,15 \cdot\left(1-\frac{P w}{100}\right) \\
& K L=\left(\frac{P w}{100}\right)
\end{aligned}
$$

\subsubsection{Evapotranspiração média da cultura irrigada}

$E T g=E T p c . K L$

em que: ETg - evapotranspiração média da cultura irrigada em um dia (mm.dia $\left.{ }^{-1}\right)$. 
4.5.1.15. Turno de rega

$T R=\frac{I R N}{E T g}$

em que: $T R$ - turno de rega calculado (dias).

4.5.1.16. Turno de rega ajustado

$T R I=\operatorname{round}(T R)$

em que: TRI - turno de rega ajustado para número inteiro (dias); round - arredonda para o número inteiro mais próximo.

\subsubsection{Irrigação real necessária ajustada}

Em irrigação localizada existe a facilidade de se trabalhar com um turno de rega menor, ou seja, com uma maior freqüência pode-se aplicar uma menor quantidade de água por turno de rega. Este processo facilita na economia da locação da motobomba, pois proporciona uma menor potência instalada para recalque.

$I R N A I L=E T g . T R E$

em que: IRNAIL - irrigação real necessária ajustada para o turno de rega escolhido; TRE turno de rega escolhido (dias).

\subsubsection{Razão de lixiviação}

$R L=\frac{\text { CEemin }}{2 \cdot \text { CEemax }}$

em que: $R L$ - razão de lixiviação do solo; CEemin - condutividade elétrica mínima do solo para cultura instalada, valor tabelado $\left(\operatorname{mmhos} . \mathrm{cm}^{-1}\right)$. CEemax - condutividade elétrica máxima do solo para cultura instalada, valor tabelado $\left(\mathrm{mmhos} . \mathrm{cm}^{-1}\right)$. Valores na Tabela 2. 
Tabela 2. Mínimo e máximo valores de $\mathrm{CEe}\left(\mathrm{ds} \cdot \mathrm{m}^{-1}\right)$ para várias culturas

\begin{tabular}{|c|c|c|c|c|c|}
\hline \multirow[b]{2}{*}{ Cultura } & \multicolumn{2}{|c|}{$\mathrm{CEe}$} & \multirow[b]{2}{*}{ Cultura } & \multicolumn{2}{|c|}{ CEe } \\
\hline & Mínimo* & Máximo** & & Mínimo* & Máximo** \\
\hline Algodão & 7 & 27,0 & Milho & 101,7 & 10,0 \\
\hline Beterraba & 7,0 & 24,0 & Feijão & 1,0 & 6,5 \\
\hline Trigo & 6,0 & 20,0 & Sorgo & 4,0 & 18,0 \\
\hline Coco & 4,0 & 32,0 & Uva & 1,5 & 12,0 \\
\hline Figo & 2,7 & 14,0 & Oliveira & 2,7 & 14,0 \\
\hline Laranja & 1,7 & 8,0 & Ameixa & 1,5 & 7,0 \\
\hline Limão & 1,7 & 8,0 & Abacate & 1,3 & 6,0 \\
\hline Maçã e Pêra & 1,7 & 8,0 & Morango & 1,0 & 4,0 \\
\hline Castanha & 1,7 & 8,0 & Pêssego & 1,7 & 6,5 \\
\hline Milho-doce & 1,7 & 10,0 & Brócolis & 2,8 & 13,5 \\
\hline Tomate & 2,5 & 12,5 & Batata-doce & 1,5 & 10,5 \\
\hline Pimenta & 1,5 & 8,5 & Alface & 1,3 & 9,0 \\
\hline Pepino & 2,5 & 10,0 & Melão & 1,2 & 16,0 \\
\hline Rabanete & 1,2 & 9,0 & Espinafre & 2,0 & 15,0 \\
\hline Cebola & 1,2 & 7,2 & Repolho & 1,8 & 12,0 \\
\hline Cenoura & 1,0 & 8,0 & Batata & 1,7 & 10,0 \\
\hline
\end{tabular}

* Mínima CEe não reduz a produtividade

** Máxima CEe elimina a produtividade.

Fonte: Adaptado de Bernardo, Soares e Mantovani (2005).

\subsubsection{Irrigação total necessária}

$I T N=\frac{I R N A I L}{\left(\frac{U E}{100}\right) \cdot(1-R L)}$

em que: ITN - irrigação total necessária $(\mathrm{mm}) ; U E$ - uniformidade de emissão (\%); $R L$ - razão de lixiviação do solo.

4.5.1.20. Volume de água aplicado

$V p=I T N . S f . S p$

em que: $V p$ - volume de água aplicado em cada planta por irrigação (L.pl $\left.{ }^{-1}\right)$.

4.5.1.21. Determinação da vazão e da pressão mínima do emissor

$q \min =\frac{V p}{N P A \cdot T a C U O I S}$ 
$h \min =\left(\frac{q \min }{k}\right)^{\frac{1}{x e}}$

em que: qmin - vazão mínima do emissor $\left(\right.$ L.h $\left.^{-1}\right)$; TaCUOIS - tempo de irrigação por conjunto de unidades operacionais irrigadas simultaneamente (h); hmin - pressão mínima do emissor (mca); $k$ - coeficiente para cálculo de vazão unitária do emissor; $x e$ - coeficiente para cálculo de vazão unitária do emissor.

No Gráfico 2 observa-se a curva potencial para a vazão do emissor utilizado neste estudo.

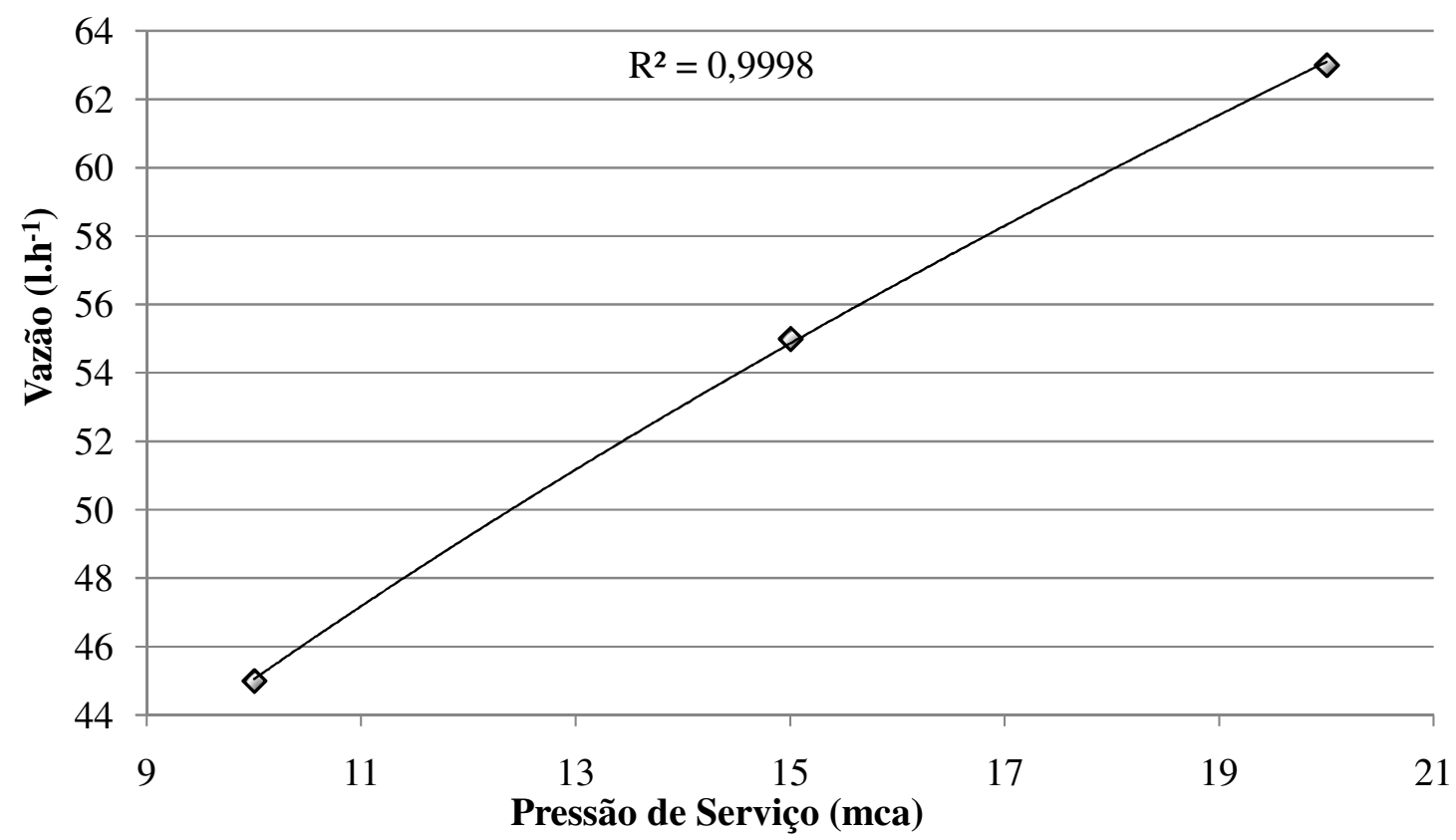

Gráfico 2. Função potencial de vazão do emissor

A função potencial do emissor é determinada pelos dados fornecidos pelo fabricante (ANEXO B), de vazão e pressão de serviço, conforme a curva de tendência potencial apresentada no Gráfico 2. A seguir apresenta-se a função de potencia do emissor:

$q=14,71 \cdot P S^{0,486}$

em que: $q$ - vazão unitária do emissor (L.h $\left.{ }^{-1}\right) ; P S$ - pressão de serviço (mca). 
Com a função potencial do emissor obtêm-se os coeficientes $k(14,71)$ e $x e(0,486)$ utilizados como dado de entrada da função de aptidão.

4.5.1.22. Determinação da vazão e da pressão média do emissor

O cálculo de uma vazão média, para o dimensionamento da tubulação com vazão em marcha, pode ser obtido pela equação de uniformidade de emissão proposta pela American Society of Agricultural Engineers (1995), segundo a norma EP405.1.

$q a=\frac{q m i n \cdot\left(1-1 \cdot 27 \cdot\left(\frac{C V F}{N S E^{-0.5}}\right)\right) \cdot 100}{U E}$

$h e=\left(\frac{q a}{k}\right)^{\frac{1}{x e}}$

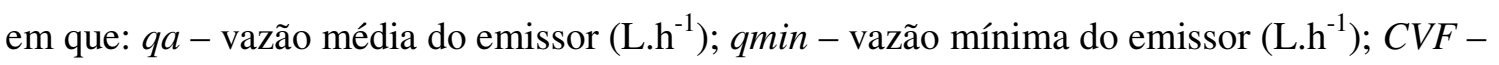
coeficiente de variação de fabricação do emissor; $N S E$ - número de saídas do emissor; $U E$ uniformidade de emissão (\%); he - pressão média do emissor (mca); $k$ - coeficiente para cálculo de vazão unitária do emissor; xe - coeficiente para cálculo de vazão unitária do emissor.

4.5.2. Equações de base para o dimensionamento da rede de distribuição de água do sistema de irrigação localizada

A seguir serão descritas todas as equações de base utilizadas no dimensionamento das linhas laterais, de derivação, secundárias, principal (adutora) e sucção, presentes no sistema de irrigação. Trata-se das equações particulares de cada trecho da rede, concomitantemente com a modelagem matemática da função objetivo a ser otimizada. 
4.5.2.1. Fator de diminuição de perda de pressão por atrito

Neste tópico trata-se das equações de fator de diminuição de perda de pressão por atrito, para vazão em marcha, visando à escolha da melhor equação para utilizar no programa de otimização desenvolvido.

GOMES (1999) cita que a perda de carga nas saídas laterais varia de forma não-linear em virtude da diminuição da vazão ao longo da tubulação. Sabe-se que a vazão em uma tubulação com múltiplas saídas decresce desde o valor $Q$, igual à soma das descargas das saídas da tubulação, até o valor $q$, correspondente à vazão da última derivação. Por esta razão, a perda de pressão por atrito ao longo da tubulação também decresce. O coeficiente $F$ corrige a perda de pressão por atrito conforme a vazão decai devido às derivações.

Christiansen (1942) considera as seguintes aproximações em seu coeficiente de perda de pressão por atrito:

- Diâmetro da tubulação constante em todo o seu comprimento;

- Saídas de água com espaçamento regular em toda a tubulação;

- A primeira saída de água encontra-se a uma distância do início da tubulação igual ao espaçamento entre as demais saídas.

Jensen e Fratini (1957) derivaram um coeficiente ajustado $\left(F^{\prime}\right)$ para a condição da primeira saída de água, localizada a uma distância do início da tubulação correspondente à metade do espaçamento regular adotado entre aspersores.

Scaloppi (1988) desenvolveu um coeficiente ajustado $(F a)$ para qualquer distância entre o início da tubulação e a primeira saída.

No Quadro 6, verifica-se por meio de uma análise comparativa, que o fator de diminuição de perda de pressão por atrito " $F a$ " de Scaloppi é o mais indicado para uma diversidade de situações que o projetista encontra no dimensionamento de redes. Isso se deve 
ao fato que os expoentes de velocidade ou vazão das equações mais utilizadas variam de 1 a 2 e essa é a equação que se ajusta a qualquer distância de tomada de água à primeira derivação $(0 \leq x \leq 1)$, em relação às demais saídas de água eqüidistantes entre si.

Quadro 6. Equações de perda de pressão por atrito em função de $\mathrm{N}$ (número de derivações na tubulação) e os respectivos valores de "m" (expoente de vazão ou velocidade da equação de perda de pressão) e " $x$ " (relação entre a primeira derivação e a tomada de água em função das demais saídas eqüidistantes)

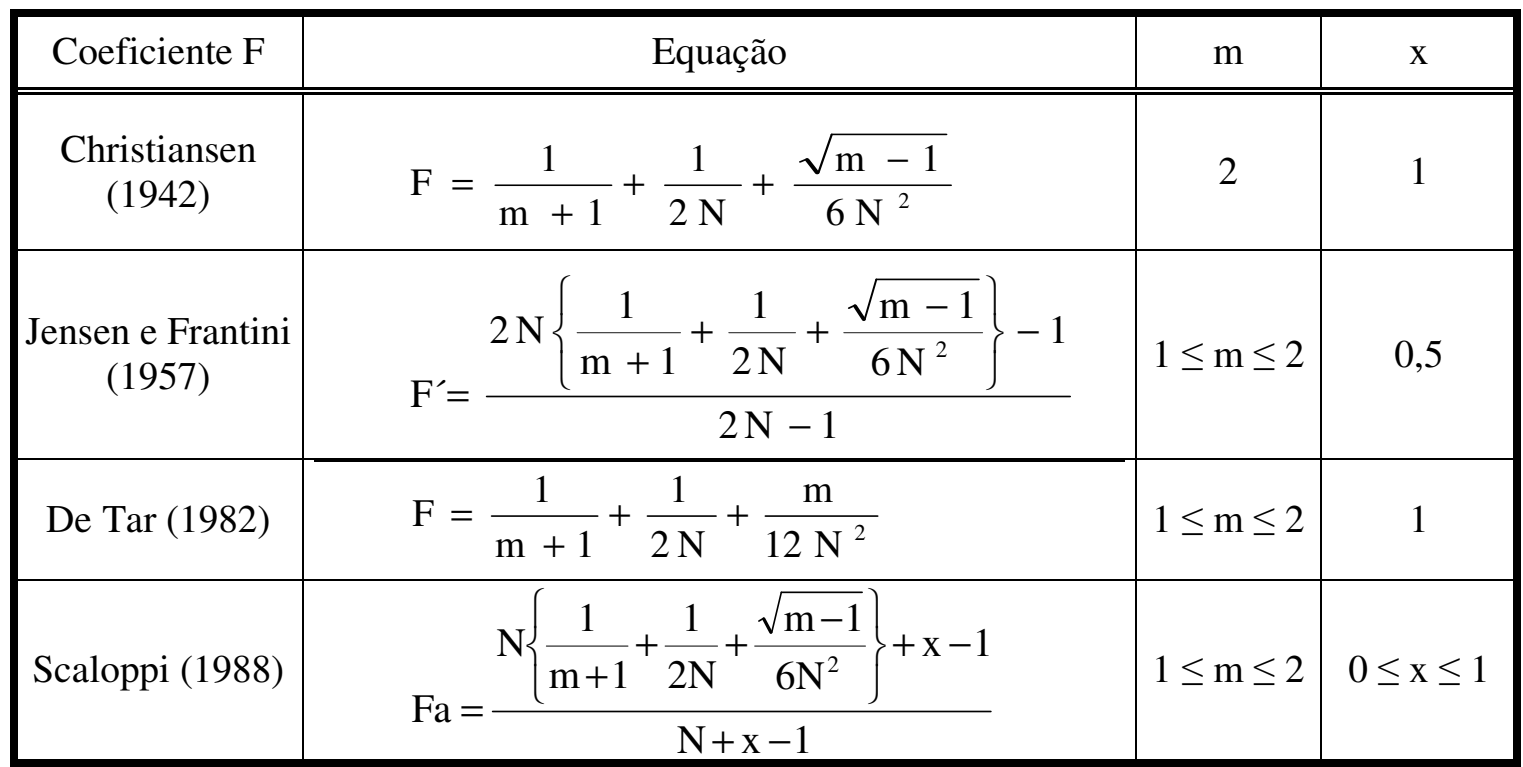

Observa-se que Jensen e Frantini (1957) e Scaloppi (1988) usam a equação de Christiansen (1942) no desenvolvimento de suas equações para determinar o coeficiente de diminuição de perda de pressão por atrito em tubulações com múltiplas saídas de água. Jensen e Frantini (1957) também fixam a relação entre a primeira derivação e a tomada de água (x), em função das demais saídas eqüidistantes, em 0,5 enquanto Scaloppi (1988) permite em sua equação qualquer valor fracionado para a mesma distância $(0 \leq \mathrm{x} \leq 1)$.

Aumentando-se o número de derivações de uma tubulação, os valores do coeficiente $F_{a}$ de Scaloppi convergem para uma mesma constante, independente da distância da primeira saída de água da tomada de água na tubulação (APÊNDICE A). Marcuzzo e Wendland (2007), 
em um trabalho com diferentes equações de perda de carga unitária frente a diferentes equações de perda de pressão em função de derivações na tubulação, observam que quanto menor é a distância da tomada de água à primeira derivação, em relação às demais derivações eqüidistantes, menor é o coeficiente $F_{a}$ de Scaloppi.

Devido aos resultados obtidos com as diferentes equações de perda de pressão por atrito, optou-se pela utilização neste trabalho da equação de ajuste proposta por Scaloppi (1988).

$F L i=\frac{N T D i *\left(\left(\frac{1}{m+1}\right)+\left(\frac{1}{2 . N T D i n}\right)+\left(\frac{(m-1)^{0.5}}{6 . N T D i n^{2}}\right)\right)+x L i-1}{N T D i+x L i-1}$

em que: $F L i$ - fator de ajuste para diminuição da perda de pressão por atrito para tubulação $i$; NTDin - número total de derivações na tubulação $i ; \mathrm{m}$ - expoente da equação de perda de carga unitária; $x L i$ - razão da distância do começo da linha $i$ à primeira derivação, em relação à distância eqüidistantes das outras derivações entre si.

\subsubsection{Equação usada para determinação do coeficiente de atrito}

A equação geral proposta por Swamee (1993), para o cálculo do coeficiente de atrito $(f)$, é usada para o regime de escoamento laminar, turbulento liso, de transição e turbulento rugoso. Convalida-se esta equação geral, para cálculo de coeficiente de atrito, utilizando-a para reprodução do diagrama de Moody (APÊNDICE A). Com isto obtém-se maior confiança em relação aos dados calculados no dimensionamento da rede, independente do tipo de escoamento, do número de Reynolds ou da rugosidade da tubulação da rede.

fin $=\left\{\left(\frac{64}{\text { Rein }}\right)^{8}+9,5\left[\ln \left(\frac{\varepsilon}{3,7 \text { Din }}+\frac{5,74}{\text { Rein }^{0,9}}\right)-\left(\frac{2500}{\text { Rein }}\right)^{6}\right]^{-16}\right\}^{0,125}$

em que: fin - coeficiente de atrito para cálculo de perda de carga na tubulação na linha $i$ no trecho $n$; Rein - número de Reynolds na linha $i$ no trecho $n$; $\varepsilon$ - rugosidade absoluta da tubulação usada na linha $i(\mathrm{~mm})$; Din - diâmetro da tubulação na linha $i$ no trecho $n(\mathrm{~m})$. 


\subsubsection{Darcy-Weisbach}

A fórmula de perda de carga unitária de Darcy-Weisbach é também conhecida como fórmula universal da perda de carga. É comumente utilizada para avaliação de outras fórmulas de perda de carga unitária em tubulações.

$\operatorname{Jin}=\frac{\operatorname{fin}}{\operatorname{Din}} \frac{\operatorname{Vin}^{2}}{2 g}$

em que: Jin - perda de carga unitária na linha $i$ no trecho $n\left(\mathrm{~m}^{\left.-\mathrm{m}^{-1}\right)}\right.$; Din - diâmetro da tubulação na linha $i$ no trecho $n(\mathrm{~m}) ; \operatorname{Vin}^{2}$ - velocidade do fluido na linha $i$ no trecho $n\left(\mathrm{~m} . \mathrm{s}^{-1}\right)$; fin - coeficiente de atrito para cálculo de perda de carga da tubulação na linha $i$ no trecho $n ; \mathrm{g}$ - aceleração da gravidade $\left(m \cdot\left(\mathrm{s}^{2}\right)^{-1}\right)$.

4.5.2.4. Metodologia de dimensionamento trecho a trecho utilizada e o prédimensionamento das tubulações da rede

Neste trabalho executa-se o dimensionamento trecho a trecho pelo começo da tubulação (tomada de água) e não pelo final da tubulação, como é usualmente encontrado na literatura especializada (WU; GITLIN, 1977; BHAVE, 1979; BENAMI; OFEN, 1984; SAAD et al., 1994; ROCHA; ANDRADE; MERLEY, 1996; VALIANTZAS, 2002; SAAD; MARIÑO, 2002; SINGH; MAHAR, 2003; DENÍCULE; SILVA; OLIVEIRA, 2004; SAAD; MARCUZZO, 2006; THEOCHARIS et al., 2006).

O dimensionamento começa pela linha lateral, na qual são acoplados os emissores. Determina-se primeiro a vazão que deve ter cada emissor (tópico 4.2.1.21) e faz-se o somatório da vazão de todos os emissores para determinar a vazão que deve estar disponível no inicio da linha lateral. Com isso se executa o dimensionamento trecho a trecho do começo da linha até o final, subtraindo a vazão do trecho anterior para o trecho seguinte, como será mais bem discutido adiante. Este principio é adotado para as linhas laterais, de derivação e secundária. Essa metodologia foi adotada visando solucionar o problema do cálculo da perda 
de carga localizada com a contração da tubulação, pois o cálculo é diferente dependendo do sentido do fluxo do escoamento. Para a linha principal (adutora) e para a linha de sucção, o dimensionamento não é executado trecho a trecho por não existirem derivações acopladas que recebam água simultaneamente.

Por se tratar de rede com vazão em marcha e o dimensionamento ser executado trecho a trecho, faz-se necessário um pré-dimensionamento das tubulações da rede. Este prédimensionamento consiste de cálculos necessários para o posterior dimensionamento hidráulico com a vazão em marcha. Essas informações consistem em, por exemplo, espaçamentos das derivações de cada tubulação acoplada a outra tubulação (ou o espaçamento de cada emissor acoplado na linha lateral). É a partir destas informações que se executa a determinação da quantidade de água que deve ser disponibilizada no começo da tubulação a partir do somatório das vazões “distribuídas” em cada derivação de tubulação (ou emissor).

A área de cada trecho de cada tubulação é determinada por:

$\operatorname{ADin}=\pi \cdot\left(\frac{\operatorname{Din}^{2}}{4}\right)$

em que: ADin - área da tubulação da linha $i$ no trecho $n\left(\mathrm{~m}^{2}\right)$; Din - diâmetro da tubulação $i$ no trecho $n(\mathrm{~m}) ; \pi$ - número PI.

As equações utilizadas no pré-dimensionamento da linha lateral são:

$$
\begin{aligned}
& E E E=\frac{S p}{N P A} \\
& E 1 E=\frac{E E E}{2} \\
& N T E=\left(\frac{(L L L-E 1 E)}{E E E}\right)+1 \\
& N E L L 1=\frac{L L L 1}{E E E} \\
& N E L L 2=N T E-N E L L 1 \\
& x L L=\frac{E 1 E}{E E E}
\end{aligned}
$$


em que: $E E E$ - espaçamento entre emissores da linha lateral (m); $S p$ - espaçamento entre plantas (m); NPA - número de emissores por planta ajustado para um número inteiro; $E 1 E$ espaçamento do primeiro emissor da linha lateral (m); NTE - número total de emissores na linha lateral; $L L L$ - comprimento total da linha lateral (m); NELL1 - número de emissores no primeiro trecho da linha lateral; $L L L 1$ - comprimento do primeiro trecho da linha lateral (m); NELL2 - número de emissores no segundo trecho da linha lateral; $x L L$ - razão da distância do começo da linha lateral ao primeiro emissor em relação à eqüidistância entre os outros emissores.

As equações utilizadas no pré-dimensionamento da linha de derivação são:

$E E L=S f$

$E 1 L=\frac{E E L}{2}$

$N T L=\left(\left(\frac{L L D-E 1 L}{E E L}\right)+1\right) \cdot 2$

$N L L D n=\frac{L L D n}{E E L}$

$x L D=\frac{E 1 L}{E E L}$

em que: $E E L$ - espaçamento entre as linhas laterais (m); $S f$ - espaçamento entre linhas de plantio (m); E1L - espaçamento da primeira linha lateral até a tomada de água na linha secundária $(\mathrm{m}) ; N T L$ - número total de linhas laterais acopladas na linha de derivação; $L L D$ comprimento total da linha de derivação $(\mathrm{m}) ; N L L D n$ - número de linhas laterais acopladas no trecho $n$ da linha de derivação; $L L D n$ - comprimento do trecho $n$ da linha de derivação (m); $x L D$ - razão da distância do começo da linha de derivação à primeira saída, em relação à eqüidistância entre as outras linhas laterais.

As equações utilizadas no pré-dimensionamento da linha secundária são:

$$
\begin{aligned}
& E E D=(L L L .2)+(E E U O) \\
& E 1 D=\frac{E E D}{2}
\end{aligned}
$$


$E 2 D=E 1 D+E E D$

$E 3 D=E 2 D+E E D$

$E 4 D=E 3 D+E E D$

$N T D=\left(\left(\frac{L L S-E 1 D}{E E D}\right)+1\right)$

$x L S=\frac{E 1 D}{E E D}$

em que: $E E D$ - espaçamento entre as linhas de derivação (m); $L L L$ - comprimento total da linha lateral (m); EEUO - espaçamento entre as unidades operacionais (m); ElD espaçamento da primeira linha de derivação até a tomada de água na linha principal (m); $E 2 D$ - espaçamento da segunda linha de derivação até a tomada de água na linha principal (m); $E 3 D$ - espaçamento da terceira linha de derivação até a tomada de água na linha principal (m); $E 4 D$ - espaçamento da quarta linha de derivação até a tomada de água na linha principal (m); NTD - número total de linhas de derivação acopladas em cada linha secundária; $L L S$ comprimento total da linha secundária $(\mathrm{m}) ; x L S$ - razão da distância do começo da linha secundária à primeira saída em relação à eqüidistância entre as outras saídas.

A determinação do número de linhas de derivação acopladas na linha secundária $(N L D D 1, N L D D 2, N L D D 3$ e $N L D D 4)$ é complexa devido à ampla quantidade de condicionantes envolvidas para cada comprimento possível, de cada trecho da linha secundária, e a quantidade de linhas de derivação que podem ser acopladas em cada trecho. Devido a ampla quantidade de condicionais, estes cálculos são apresentados no código principal da função de aptidão (APÊNDICE B).

As equações utilizadas no pré-dimensionamento da linha principal são:

$$
\begin{aligned}
& E E S=L L D+E E U O \\
& E 1 P=E E S \\
& S e(L L P>E 1 P) \therefore \mathrm{E} 2 \mathrm{P}=(2 . \mathrm{EES}) ; \text { Se também }(\mathrm{LLP}==\mathrm{E} 1 \mathrm{P}) \therefore \mathrm{E} 2 \mathrm{P}=0 ; \mathrm{fim} \\
& \mathrm{Se}(\mathrm{LLP}>E 2 P) \therefore \mathrm{E} 2 \mathrm{P}=(3 . \mathrm{EES}) ; \text { Se também }(\mathrm{LLP}==\mathrm{E} 2 \mathrm{P}) \therefore \mathrm{E} 3 \mathrm{P}=0 ; \mathrm{fim}
\end{aligned}
$$


$N T S=\left(\frac{L L P-L L A}{E E S}\right) \cdot 2$

em que: $E E S$ - espaçamento entre as linhas secundárias $(\mathrm{m}) ; E 1 P$ - espaçamento da tomada de água até a primeira linha secundária $(\mathrm{m}) ; E 2 P$ - espaçamento da tomada de água até a segunda linha secundária $(\mathrm{m}) ; E 3 P$ - espaçamento da tomada de água até a terceira linha secundária (m); NTS - número total de linhas secundárias acopladas na linha principal; $x L P$ razão da distância do começo da linha principal à primeira saída em relação à eqüidistância entre as outras saídas.

\subsubsection{Determinação das vazões nas tubulações da rede}

A determinação das vazões nas tubulações da rede, seja inteira no começo da tubulação ou fracionada, para cada derivação (emissores ou tubulações acopladas) é de fundamental importância na concepção do código da função de aptidão (APÊNDICE B). Por exemplo, o comprimento total da linha lateral é de 96,25 metros, sendo que para esta linha há dois diâmetros de tubulação disponíveis. O primeiro e o segundo trecho podem variar de zero a 96,25 metros sendo que o somatório dos dois trechos não pode passar de 96,25 metros (restrição de comprimento da tubulação). Com isso pode-se ter um trecho com 40 metros, por exemplo, e outro com 56,25 metros. Tanto a função de aptidão como a de análise de sensibilidade, possibilitam a verificação dos parâmetros hidráulicos da rede de irrigação tanto por derivação quanto por metro, como pode ser verificado de maneira mais detalhada no APÊNDICE B e C. Apresenta-se, abaixo, as principais equações de vazão utilizadas no dimensionamento das linhas laterais e da linha de derivação da rede de irrigação. Os cálculos das demais vazões, por apresentarem grande quantidade de condicionantes, não foram exemplificadas neste tópico, contudo, são detalhadas no próprio código, apresentado no APÊNDICE B.

QILLT1 $=N T E \cdot\left(\frac{q a}{1000}\right)$ 
$Q I L L 1 T=(N T E:-1:(\operatorname{round}(N E L L 2)+1)) \cdot\left(\frac{q a}{1000}\right)$

QILL2T $=((\operatorname{round}(N E L L 2)):-1: 1) \cdot\left(\frac{q a}{1000}\right)$

QILDT1 = NTL.QILLT1

$Q I L D 1 T=\left(\left(\frac{N T L}{2}\right):-1:(\operatorname{round}(N L L D 2)+\operatorname{round}(N L L D 3)+\operatorname{round}(N L L D 4)+\right.$

1)).(2 . QILLT1)

$Q I L D 2 T=((\operatorname{round}(N L L D 2)+\operatorname{round}(N L L D 3)+\operatorname{round}(N L L D 4)):-1:$

$(\operatorname{round}(N L L D 3)+\operatorname{round}(N L L D 4)+1)) \cdot(2 \cdot Q I L L T 1)$

QILD3T $=((\operatorname{round}(N L L D 3)+\operatorname{round}(N L L D 4)):-1:(\operatorname{round}(N L L D 4)+$

1)).(2 . QILLT1)

$Q I L D 4 T=((\operatorname{round}(N L L D 4)):-1: 1) \cdot(2 \cdot Q I L L T 1)$

em que: QILLT1 - vazão no início da linha lateral $\left(\mathrm{m}^{3} \cdot \mathrm{h}^{-1}\right) ;$ QILLIT - vazão distribuída por emissor no primeiro trecho da linha lateral $\left(\mathrm{m}^{3} \cdot \mathrm{h}^{-1}\right)$; QILL2T - vazão distribuída por emissor no segundo trecho da linha lateral $\left(\mathrm{m}^{3} \cdot \mathrm{h}^{-1}\right) ; N T E$ - número total de emissores na linha lateral; round - arredonda para o número inteiro mais próximo; NELL2 - número de emissores no

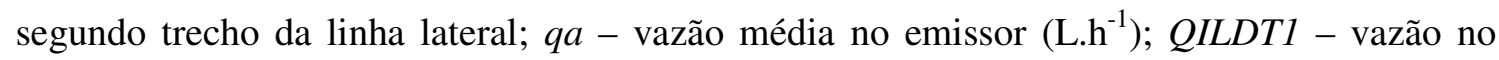
inicio da linha de derivação (m); QILDIT - vazão distribuída por saída no primeiro trecho da linha de derivação $\left(\mathrm{m}^{3} \cdot \mathrm{h}^{-1}\right) ; N T L$ - número total de laterais acopladas na linha de derivação; $N L L D n$ - número de linhas laterais acopladas no trecho $n$ da linha de derivação; QILD2T vazão distribuída por saída no segundo trecho da linha de derivação $\left(\mathrm{m}^{3} \cdot \mathrm{h}^{-1}\right) ; Q I L D 3 T$ - vazão distribuída por saída no terceiro trecho da linha de derivação $\left(\mathrm{m}^{3} \cdot \mathrm{h}^{-1}\right)$; QILD4T - vazão distribuída por saída no quarto trecho da linha de derivação $\left(\mathrm{m}^{3} \cdot \mathrm{h}^{-1}\right)$; 
4.5.2.6. Equações para o dimensionamento de todas as linhas da rede

Neste tópico apresenta-se todas as equações utilizadas no dimensionamento, que não foram apresentadas em tópicos anteriores e, em seguida, a descrição de todos os elementos de cada equação. Todo o dimensionamento é executado trecho a trecho por emissor ou derivações nas linhas, contudo os resultados podem também ser obtidos metro a metro, como pode ser observado no código da função objetivo no APÊNDICE B.

$$
\begin{aligned}
& \text { Vin }=\frac{\frac{Q i n}{A D L i n}}{3600} \\
& \text { ECINETLin }=\frac{\operatorname{Vin}^{2}}{2 \cdot g} \\
& \text { RELin }=\frac{\text { Vin.DLin }}{v} \\
& \text { PCLin }=\text { KLL. }\left(\frac{\text { Vin }^{2}}{2 \cdot g}\right) \\
& \text { DZLin }=\frac{\text { DZLi.LLin }}{100} \\
& \text { DZLinU }=\left(\frac{\text { DZLin }}{\text { numel }(Q I L i n T)}\right) \\
& \text { DZLLin }=\text { DZLinU } .((\text { numel }(Q I L i n T)):-1: 1) \\
& \text { hfin }=(\text { Jin.FLi.LLin })+P C L i n+D Z L L i n
\end{aligned}
$$

em que: Vin - velocidade na tubulação da linha $i$ no trecho $n\left(\mathrm{~m} \cdot \mathrm{s}^{-1}\right)$; Qin - vazão na tubulação da linha $i$ no trecho $n\left(\mathrm{~m}^{3} \cdot \mathrm{h}^{-1}\right)$; ADLin - área da tubulação da linha $i$ no trecho $n\left(\mathrm{~m}^{2}\right)$; ECINETLin - energia cinética da tubulação da linha $i$ no trecho $n$ (mca);. RELin - número de Reynolds da linha $i$ no trecho $n$; DLin - diâmetro da tubulação da linha $i$ no trecho $n(\mathrm{~m}) ; v$ viscosidade cinemática da água; PCLin - perda de carga localizada com os emissores da tubulação na linha $i$ no trecho $n$ (mca); $K L L$ - coeficiente de perda de carga localizada para os emissores acoplados na linha $i$ no trecho $n$; DZLin - aclive ou declive na linha $i$ no trecho $n$ (m); DZLi - aclive ou declive na linha $i(\%)$; LLin - comprimento da linha $i$ no trecho $n(\mathrm{~m})$; DZLin $U$ - aclive ou declive entre as saídas de água da linha $i$ no trecho $n(\mathrm{~m}) ;$ QILinT - vazão 
distribuída por saída de água da linha $i$ no trecho $n\left(\mathrm{~m}^{3} \cdot \mathrm{h}^{-1}\right) ;$ DZLLin - aclive ou declive distribuído por saída de água da linha $i$ no trecho $n(\mathrm{~m})$;. numel - retorna o número de dados de um conjunto qualquer de números qualquer; hfin - perda de carga total na linha $i$ no trecho $n$ mais o desnível geométrico (mca); Jin - perda de carga unitária na linha $i$ no trecho $n$ ( $\mathrm{m} \mathrm{m}^{-}$ $\left.{ }^{1}\right) ; F L i$ - fator de ajuste para diminuição da perda de pressão por atrito para tubulação $i$.

\subsubsection{Perda de carga localizada da redução brusca da seção da tubulação}

Para determinação da perda de carga localizada com a contração da tubulação utilizouse os dados fornecidos por Porto (1999, p. 73). Executou-se uma análise de regressão polinomial de sexta ordem (Gráfico 3) para os valores da relação da área da tubulação de menor diâmetro sobre a de maior diâmetro (A2/A1) para os respectivos coeficientes de perda de carga localizada $(\mathrm{K})$. Com este procedimento obteve-se uma equação que automatiza a busca do coeficiente $\mathrm{K}$ no código de otimização, independente da relação das áreas das tubulações escolhidas para o dimensionamento da rede. A implementação no código pode ser verificada no APÊNDICE B. 


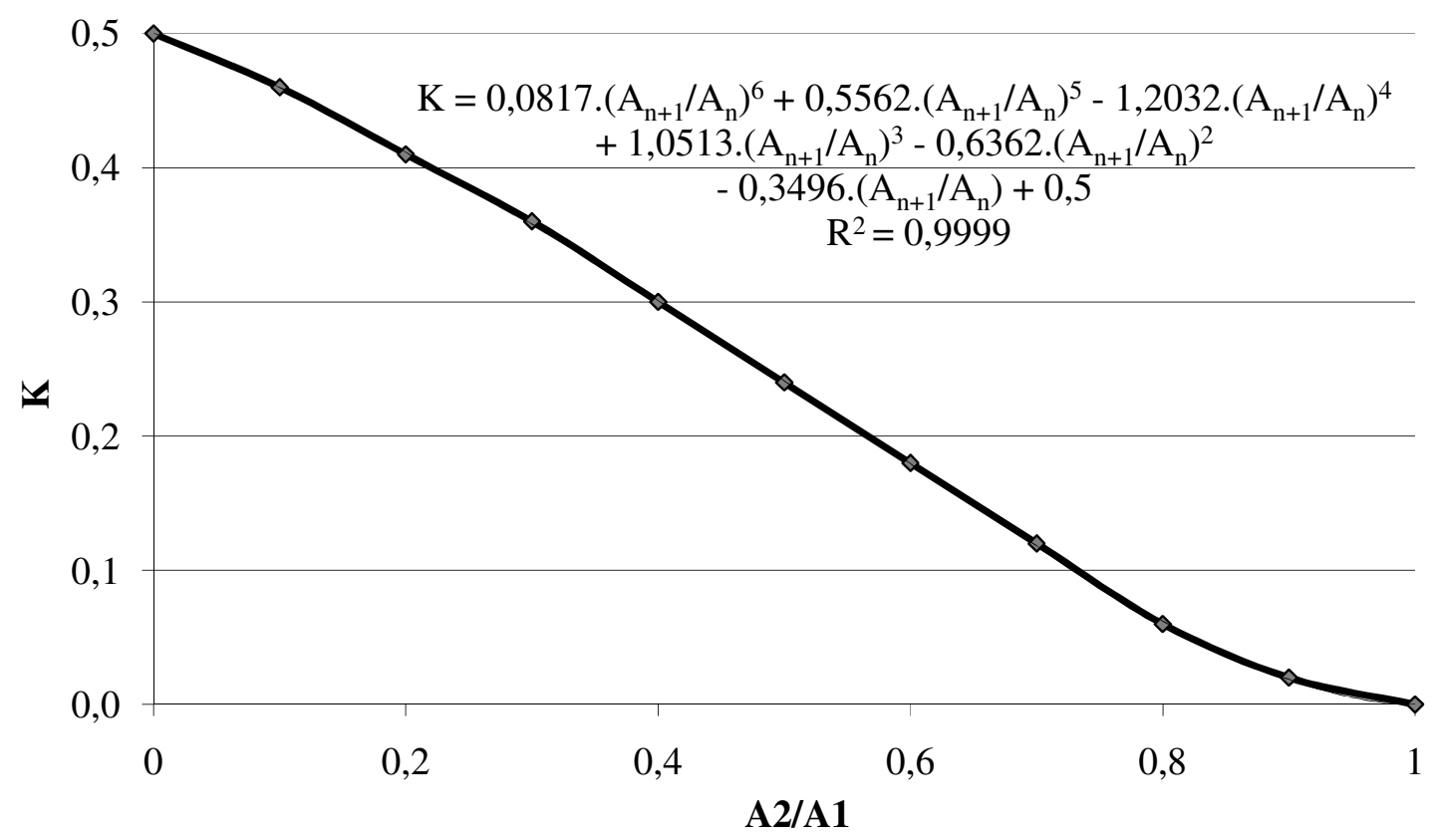

Gráfico 3. Análise de regressão para os coeficientes de perda de carga localizada (K) em uma contração brusca de diâmetros $\left(\mathrm{A}_{\mathrm{n}+1} / \mathrm{A}_{\mathrm{n}}\right)$, em relação à velocidade no trecho de menor diâmetro

As equações para o cálculo da perda de carga localizada com a contração da tubulação são descritas a seguir:

$$
\begin{aligned}
& R A_{n+1} A_{n} L i=\frac{A D L D i_{n+1}}{A D L D_{n}} \\
& K A_{n+1} A_{n} L i=0,0817 \cdot\left(R A_{n+1} A_{n} L i^{6}\right)+0,5562 \cdot\left(R A_{n+1} A_{n} L i^{5}\right) \\
& -1,2032 \cdot\left(R A_{n+1} A_{n} L i^{4}\right)+1,0513 \cdot\left(R A_{n+1} A_{n} L i^{3}\right)-0,6362 \cdot\left(R A_{n+1} A_{n} L i^{2}\right) \\
& -0,3496 \cdot\left(R A_{n+1} A_{n} L i\right)+0,5 \\
& P C L A_{n+1} A_{n} L i=K A_{n+1} A_{n} L i \cdot\left(\frac{V i n^{2}}{2 \cdot g}\right)
\end{aligned}
$$

em que: $R A_{n+1} A_{n} L i$ - relação entre a área da segunda e da primeira tubulação; $A D L i_{n+1}$ - área da tubulação da linha $i$ no trecho $n+1\left(\mathrm{~m}^{2}\right) ; A D L i_{n}$ - área da tubulação da linha $i$ no trecho $n$ $\left(\mathrm{m}^{2}\right) ; K A_{n+1} A_{n} L i$ - Coeficiente para reduções bruscas de diâmetro de tubulação da linha $i$ no trecho $n ; P C L A_{n+1} A_{n} L i$ - Perda de carga localizada para a contração da tubulação de diâmetro $n+1$ para o diâmetro $n$ (mca); Vin - velocidade na tubulação da linha $i$ no trecho $n\left(\mathrm{~m} . \mathrm{s}^{-1}\right)$. 
4.6. Uniformidade de emissão e uniformidade estatística

Visando à validação do funcionamento da rede de irrigação, executou-se a verificação da emissão do sistema na unidade operacional após o dimensionamento utilizando métodos consagrados pela literatura especializada (BENAMI; OFEN, 1984; BRALTS; EDWARD; WU, 1987; FAVETTA; BOTREL, 2001; BERNARDO; SOARES; MANTOVANI, 2005). A uniformidade de emissão (UE) foi originalmente conceituada por Keller e Karmeli (1974). Sua definição é baseada na razão entre as vazões mínima e média dos emissores:

$U E=100 \cdot \frac{q n}{\bar{q}}$

em que: $U E$ - uniformidade de emissão; qn - média das $25 \%$ menores vazões observadas; $\bar{q}$ média das vazões observadas.

Bralts (1986) relata que para efeito de dimensionamento de rede de irrigação, a equação 80 foi posteriormente modificada e redefinida, de forma a incluir o coeficiente de variação de fabricação do emissor e o número de emissores em cada planta, resultando na equação:

$U E_{b}=100 \cdot\left(1-1,27 \cdot e^{-0,5} \cdot C V F\right) \cdot \frac{q n}{\bar{q}}$

em que: $U E_{b}$ - uniformidade de emissão; $e$ - número de emissores por planta; $C V F$ coeficiente de variação de fabricação.

Bralts (1986) apresentou os critérios para classificação dos valores de $U E$ e $U E_{b}$ relacionados no Quadro 7.

Quadro 7. Critérios para classificação em função de $U E$ e $U E_{b}$, de acordo com Bralts (1986)

\begin{tabular}{|c|c|}
\hline UE ou $\mathrm{UE}_{\mathrm{b}}$ & Classificação \\
\hline \hline$\geq 90 \%$ & Excelente \\
\hline $80 \%$ a $90 \%$ & Bom \\
\hline $70 \%$ a $80 \%$ & Regular \\
\hline$<70 \%$ & Ruim \\
\hline
\end{tabular}


A uniformidade estatística (Us) foi proposta por Wilcox e Swailes (1947) na avaliação de equipamentos de irrigação pressurizados de aspersão, sendo baseada no coeficiente de variação da lâmina de água aplicada na área. Bralts, Edward e Wu (1987) ressaltam que uma abordagem estatística semelhante pode ser feita para os sistemas de irrigação localizada, como a microaspersão, apenas substituindo as lâminas de água pela vazão dos emissores. Essa metodologia baseada na $U s$ permite um outro tipo de avaliação da $U E$, tanto de sistemas implantados como também para efeito de dimensionamento, sendo expressa pela seguinte equação:

$U S=100 \cdot(1-C V E)=100 \cdot\left(1-\frac{S q}{\bar{q}}\right)$

em que: $U s$ - uniformidade estatística; $C V E$ - coeficiente de variação da vazão do emissor; $S q$ - desvio padrão da vazão do emissor.

O critério para classificação da Us é apresentado no Quadro 8 (WILCOX e SWAILES, 1947).

Quadro 8. Critérios para classificação de $U s$, de acordo com Wilcox e Swailes (1947)

\begin{tabular}{|c|c|}
\hline Us & Classificação \\
\hline \hline$\geq 90 \%$ & Excelente \\
\hline $80 \%$ a $90 \%$ & Muito bom \\
\hline $70 \%$ a $80 \%$ & Regular \\
\hline $60 \%$ a $70 \%$ & Péssimo \\
\hline$<60 \%$ & Inaceitável \\
\hline
\end{tabular}

Favetta e Botrel (2001), em seu trabalho para validação de equações para dimensionamento, utilizaram as equações de $U E, U E_{b}$ e $U s$ obtendo excelentes resultados na validação dos resultados. 
4.7. Resumo dos principais parâmetros e operadores genéticos

Os principais parâmetros de entrada e os operadores genéticos utilizados neste trabalho estão resumidos no Quadro 9. Todos os parâmetros e operadores genéticos descritos no Quadro 9 foram detalhados e discutidos na Revisão Bibliográfica.

Quadro 9. Principais parâmetros de entrada e operadores genéticos que foram utilizados no funcionamento do algoritmo genético

\begin{tabular}{|c|c|}
\hline Parâmetro & Especificação \\
\hline Gerações & 2000 \\
\hline Tamanho da população & 50 indivíduos \\
\hline $\begin{array}{l}\text { Indivíduos da geração atual que são garantidos para sobreviver na } \\
\text { geração seguinte }\end{array}$ & 5 indivíduos \\
\hline População inicial, que neste caso é formada por uma matriz de 50 & {$[48,12548,12533,75$} \\
\hline linhas e 10 colunas, com todos os valores iguais (apresenta-se o & $33,7533,7533,75$ \\
\hline primeiro vetor da matriz) & 175175175 175] \\
\hline $\begin{array}{l}\text { Fração da população na geração seguinte que é criada pela função } \\
\text { de cruzamento (não incluindo crianças da elite) }\end{array}$ & 0,80 \\
\hline Sentido da migração & Duplo \\
\hline $\begin{array}{l}\text { Número de gerações necessárias para ocorrer migrações dos } \\
\text { indivíduos entre sub-populações }\end{array}$ & 100 \\
\hline $\begin{array}{l}\text { Fração dos indivíduos em cada sub-população que migra a uma } \\
\text { outra sub-população diferente }\end{array}$ & 0,20 \\
\hline $\begin{array}{l}\text { Tempo estabelecido para o funcionamento do programa (em } \\
\text { segundos) }\end{array}$ & Infinito \\
\hline Valor limite da função de aptidão para parada do algoritmo & -Infinito \\
\hline $\begin{array}{l}\text { Limite de gerações para o algoritmo parar se não houver nenhuma } \\
\text { melhoria na função de aptidão }\end{array}$ & 100 \\
\hline $\begin{array}{l}\text { Tempo estabelecido para parada se não houver nenhuma melhoria } \\
\text { na função de aptidão }\end{array}$ & $10^{100000}$ \\
\hline Penalidade inicial & 10 \\
\hline Fator de penalidade & 100 \\
\hline Operador que cria a população inicial total ou parcial & Criação uniforme \\
\hline Operador de escala dos valores da função de aptidão & Escala por ranque \\
\hline Operador que escolhe os genitores para a geração seguinte & Roleta \\
\hline Operador de cruzamento & Aritmético \\
\hline Operador de mutação & Adaptável e praticável \\
\hline
\end{tabular}


Enfatiza-se que, tanto os parâmetros de cálculo como os operadores para o funcionamento do algoritmo genético foram escolhidos após numerosos testes de performance com diferentes combinações de parâmetros e operadores.

Ressalta-se que os operadores genéticos utilizados foram selecionados a partir de exaustivos testes com as diferentes opções fornecidas pelo programa MatLab, sendo escolhidos os que resultaram em uma melhor solução para o problema estudado. Os testes executados (para escolha dos operadores genéticos), devido ao tempo gasto no processamento, apresentaram um número limitado de 100 gerações e uma população de 20 indivíduos (redes).

4.8. Representação resumida do código de otimização por algoritmos genéticos

Neste tópico apresenta-se, na Figura 9, um resumo do funcionamento do programa de otimização por algoritmos genéticos da rede de irrigação localizada. Os códigos, bem como o seu detalhamento, são apresentados nos APÊNDICES B, C, D, E e F. 


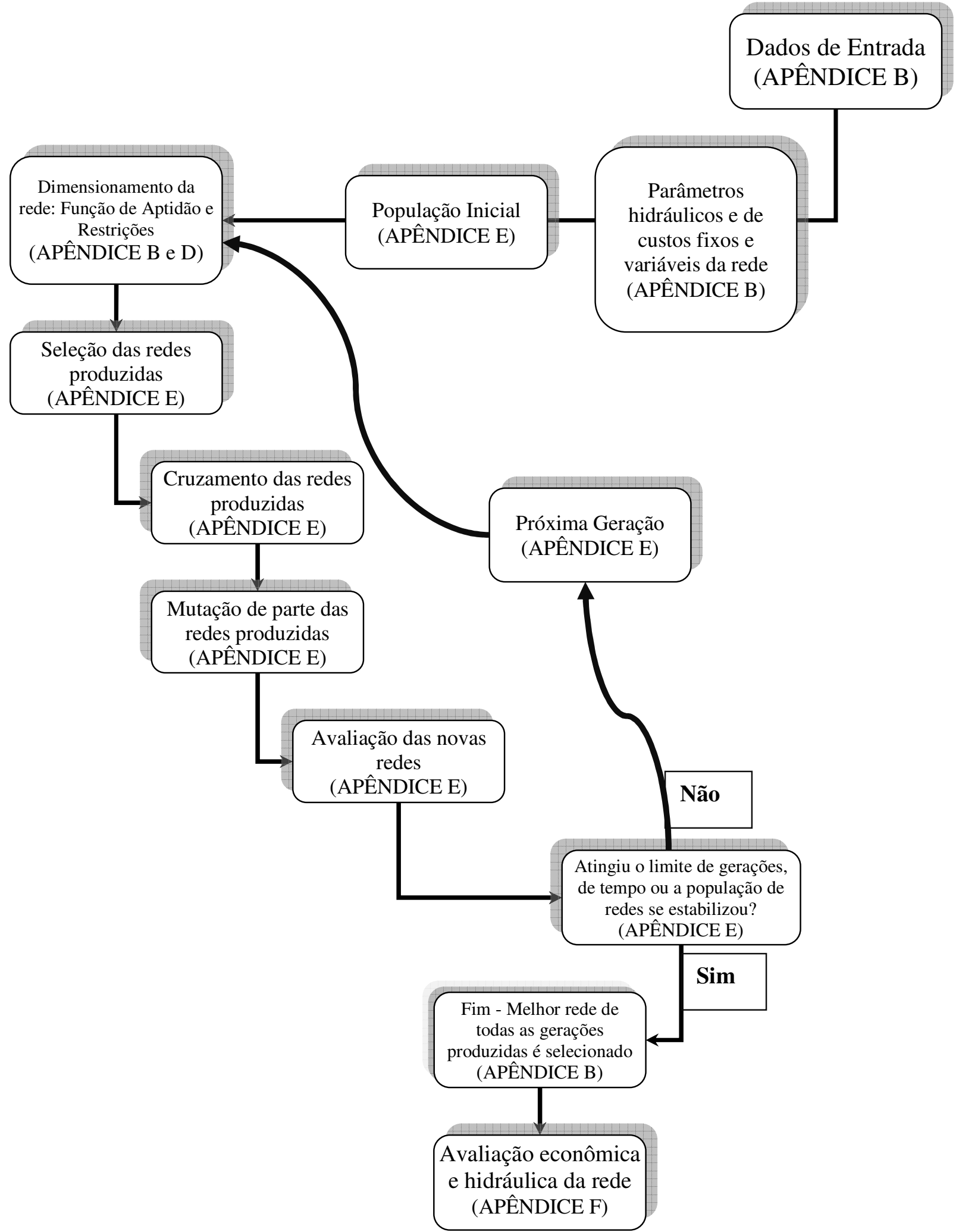

Figura 9. Representação esquemática do funcionamento do programa de otimização por algoritmo genético 
4.9. Volume de água a ser aplicado e análise de produtividade

Executou-se uma análise de regressão potencial (FRIZZONE, 1993) para os dados publicados por Bertonha (1997) que estudou a produtividade da cultura da laranja submetida a diferentes lâminas da água (Gráfico 4).

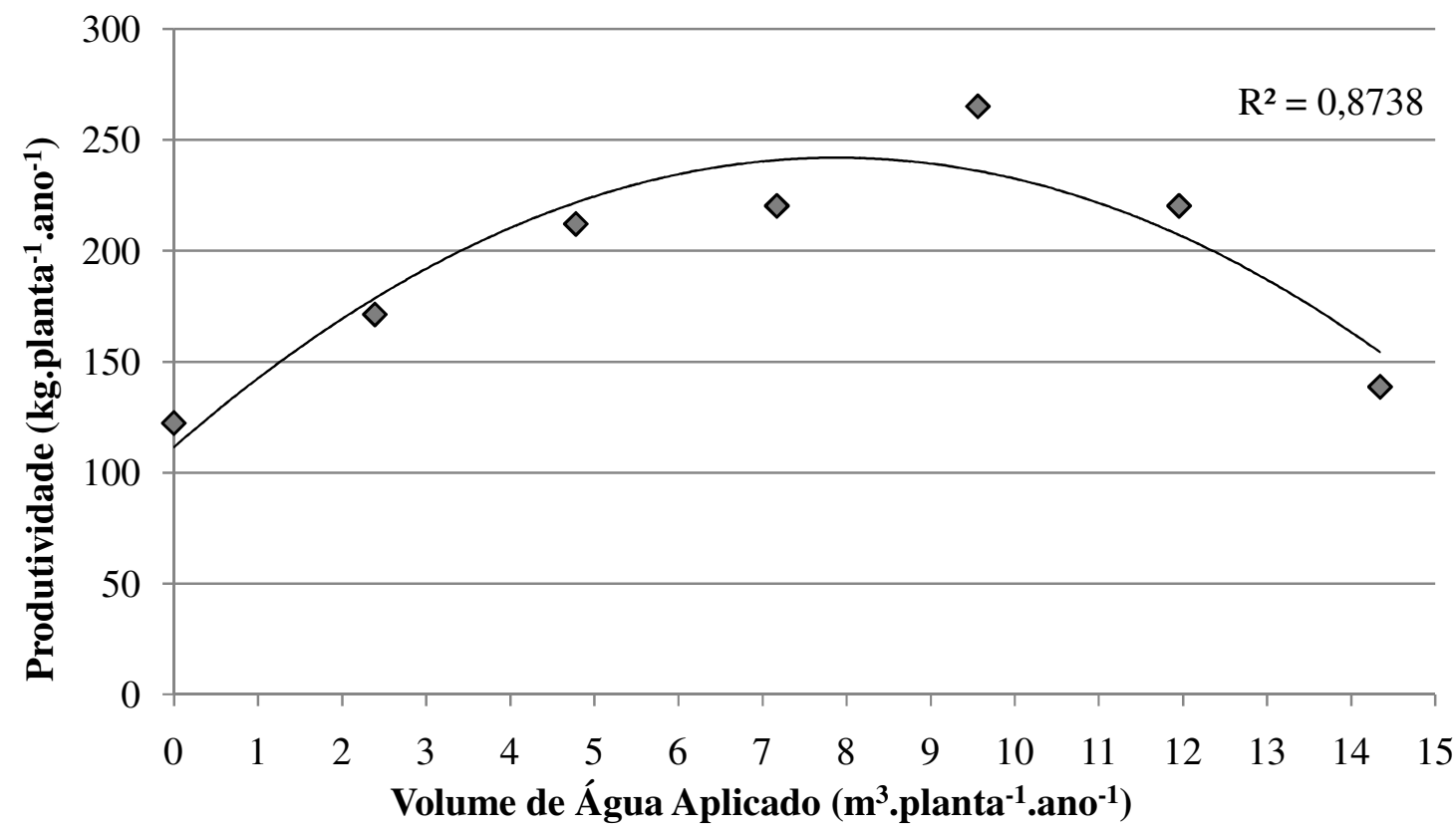

Gráfico 4. Curva e equação potencial de resposta a produtividade da planta segundo o volume de água aplicado

Com a análise de regressão, para os dados previamente tratados para o presente estudo, obteve-se uma equação potencial de resposta de produtividade, em quilogramas, segundo o volume de água aplicado, em metros cúbicos, por planta por ano.

$F P P L=-0,000002 \cdot(V A P)^{2}+0,0331 \cdot V A P+111,52$

em que: $F P P L$ - produtividade por planta de laranja (kg.planta ${ }^{-1} \cdot$ ano $\left.^{-1}\right) ; V A P$ - volume de água aplicado $\left(\mathrm{m}^{3} \cdot\right.$ planta $^{-1} \cdot$ ano $\left.^{-1}\right)$. 
Executando uma maximização não-linear da equação 83, obteve-se o volume de água aplicado máximo de $8.275 \mathrm{~m}^{3}$.planta ${ }^{-1} \cdot$ ano $^{-1}$ que retorna a maior produtividade possível, que é de $248,47 \mathrm{~kg} \cdot$ planta $^{-1} \cdot$ ano $^{-1}$.

$\mathrm{Na}$ verificação dos resultados obtidos, após a determinação do volume de água aplicado por ano por planta, analisou-se a distribuição de produtividade, segundo a distribuição de vazão dos emissores, obtida na unidade operacional.

\subsection{Ferramenta computacional utilizada na otimização}

Neste tópico apresenta-se o emprego da ferramenta computacional utilizada para a solução do problema de otimização por algoritmos genéticos da rede de irrigação localizada.

A ferramenta computacional utilizada foi o programa MatLab (MATrix LABoratory). Muito utilizado na área técnica e acadêmica, é um software interativo de alta performance direcionado para cálculos numéricos. O MatLab junta a análise numérica, cálculo com matrizes, processamento de sinais e construção de gráficos em um ambiente amigável ao usuário, onde problemas e soluções são expressos de uma maneira muito próxima de como eles são elaborados matematicamente (THE MATHWORKS, 2008).

O MatLab funciona como um sistema interativo, cujo elemento básico de informação é uma matriz ou vetor que não requer dimensionamento. Esse sistema permite a resolução de muitos problemas numéricos complexos em um tempo menor do que se levaria para escrever um programa idêntico em outras linguagens computacionais. Ressalta-se que o MatLab apesar de possuir uma linguagem própria, possui interatividade com outras linguagens, como Fortran e C, permitindo também para programadores destas linguagens uma fácil e rápida adaptação à linguagem do MatLab. 
O algoritmo genético empregado para minimizar a função escalar de várias variáveis com restrições foi a função "ga", encontrada na caixa de ferramentas do MatLab. Para iniciar a procura do resultado ótimo, esta função precisou ter uma estimativa inicial (população de redes iniciais), pois a busca completa na área de domínio da função objetivo implicaria em resultados iniciais não factíveis devido às restrições hidráulicas do problema. A função objetivo adotada foi atrelada a muitas variáveis, representadas por vetores ou não, mas que no caso dos vetores geraram um escalar como resposta. As restrições implementadas foram lineares e não-lineares. O problema deste mínimo custo de rede de irrigação é tipicamente não-linear, tanto no que diz respeito a função objetivo quanto a parte das restrições hidráulicas.

Relata-se que foram feitas várias tentativas de resolver este problema de otimização com a utilização de solver para programação não-linear, contudo, por se tratar de uma função objetivo não-linear e não-convexa, eram encontradas soluções com mínimos locais. A primeira tentativa para resolver o problema dos mínimos locais foi a de utilizar uma grande variedade de soluções iniciais para as variáveis estudadas, de tal forma que fosse executada uma varredura em todo o espectro de soluções factíveis dentro do domínio da função objetivo. Com este procedimento obteve-se resultados satisfatórios. Entretanto, além de ser um procedimento demorado (visto o tempo de processamento das iterações para otimização do problema), não resultava em uma garantia $100 \%$ segura de que o valor obtido era o mínimo global ótimo para o custo da rede de irrigação. Com isso, optou-se pela utilização do algoritmo genético, que apesar de não assegurar um mínimo global ótimo, não fica limitado em mínimos locais. Desta forma, o algoritmo genético encontra uma solução muito próxima do ótimo global (ou até mesmo a própria solução ótima global). 
4.11. Implementação e funcionamento da ferramenta computacional

Na utilização da função "ga", da caixa de ferramentas do MatLab, empregou-se as funções criadas especificamente para este estudo: foirriga.m (APÊNDICE B e C); frestricoes.m (APÊNDICE D); fchamativadef.m (APÊNDICE E); e a função fnonlin.m (função idêntica a foirriga.m que funciona como um "espelho" não-linear para a função frestrições.m).

A seguir explica-se a seqüência de procedimentos executadas pelo programa (a implementação está no APÊNDICE E).

A função base, que liga as funções elaboradas para a otimização da rede por algoritmos genéticos, bem como as restrições, é dada por: [x,fval,exitflag,output,population,scores $]=$ ga(fitnessfcn, nvars, A, b, Aeq, beq, LB, UB, nonlcon, options).

Os parâmetros em colchetes, após o fim do processo de otimização, mostram: o vetor com os valores de todas as variáveis otimizadas $(x)$; o valor da função objetivo $(f v a l)$; um número inteiro, que determina se a otimização obteve sucesso (exitflag $>0$ ) ou não (exitflag $\leq$ 0); uma estrutura que contém os valores de saída de cada geração e outras informações sobre o desempenho do algoritmo (output); uma matriz cujas linhas são a população final das redes otimizadas (population); e, por fim, a pontuação da população final das redes obtidas (scores).

Com as restrições hidráulicas aplicadas ao problema, o programa pode obter os valores ótimos das variáveis obedecendo a requisitos hidráulicos e, fornecendo como resposta, o valor minimizado da função objetivo $(f v a l)$ e os valores de todas as variáveis de otimização em um vetor $(x)$, obtendo-se então, respectivamente:

fval $=f=\frac{(C E Q \cdot F R C)+C T E+C A G T}{A U I}$

$x=[x(1), x(2), x(3), x(4), x(5), x(6), x(7), x(8), x(9), x(10)]=$

[LLL1, LLL2, LLD1, LLD2, LLD3, LLD4, LLS1, LLS2, LLS3, LLS4] 
O "ga" após o sinal de igualdade determina o processo de algoritmo genético simples. Os parâmetros em parênteses são: fitnessfcn é onde se coloca a função objetivo, ou seja, no nosso caso a função de dimensionamento e minimização dos custos da rede de irrigação; nvars é usado para colocar o número de variáveis a serem otimizadas, que no nosso caso são de 10 (número de trechos de tubulação com diferentes diâmetros); A e b são restrições de desigualdades (para este estudo não determina-se nenhuma restrição de desigualdade); Aeq e beq são restrições de igualdade (para este estudo determinou-se como sendo o comprimento total de cada linha das tubulações); $L B$ e $U B$ são os mínimos e máximos valores, respectivamente, que cada variável poderá atingir (neste estudo determina-se valores mínimos de zero e máximo como sendo o comprimento máximo da tubulação para a linha em questão); nonlcon é a função de restrição (para este estudo de dimensionamento de rede de irrigação, determinou-se a implementação de restrições hidráulicas); options substitui os operadores genéticos e os parâmetros de otimização pré-estabelecidos da caixa de ferramentas do MatLab por operadores e parâmetros determinados nas opções de estrutura, que podem ser criadas usando a função do gaoptimset, conforme pode ser observado no APÊNDICE E.

Os valores iniciais $(x 0)$ que o programa necessita para executar as iterações iniciais, sem transgredir as restrições hidráulicas, encontram-se na função fchamativadef.m (APÊNDICE E). Reitera-se que a função fchamativadef.m é executada em conjunto com a função frestricoes.m.

Os resultados obtidos na análise de sensibilidade do programa, pelo procedimento exposto, bem como a análise hidráulica das redes otimizadas, são apresentados no tópico de Resultados e Discussão. Os dados para a análise hidráulica da rede são obtidos com a utilização da função fanalisedesensibilidade.m, que é uma função semelhante a foirriga.m, tendo como diferença entre a entrada das variáveis otimizadas (comprimentos com diferentes 
diâmetros das tubulações) e as variáveis de análise de sensibilidade (declividade do terreno, custo da água e da energia elétrica).

4.12. Dados iniciais de entrada do código da função de aptidão

A seguir apresenta-se o Quadro 10 referente a um resumo dos principais dados de entrada da função de aptidão. Um melhor detalhamento de todos os dados de entrada utilizados neste trabalho, inclusive as cotações de tubulações e equipamentos, podem ser verificadas nos APÊNDICES E ANEXOS. 
Quadro 10. Resumo dos principais parâmetros de entrada do código da função de aptidão

\begin{tabular}{|c|c|c|c|}
\hline Parâmetro & Descrição do Parâmetro & Valor & Unidade \\
\hline Cultura & Laranja Pêra & - & - \\
\hline Solo irrigado & Cambissolo & - & - \\
\hline UE & Uniformidade de emissão & 92 & $\%$ \\
\hline CEemin & Condutividade elétrica mínima do solo & 1,7 & mmhos.cm ${ }^{-1}$ \\
\hline CEemax & Condutividade elétrica máxima do solo & 8,0 & mmhos.cm ${ }^{-1}$ \\
\hline Sf & Espaçamento entre linhas & 6,0 & $\mathrm{~m}$ \\
\hline $\mathrm{Sp}$ & Espaçamento entre plantas & 3,5 & $\mathrm{~m}$ \\
\hline PEP & Precipitação efetiva & 0 & $\mathrm{~mm}$ \\
\hline $\mathrm{CC}$ & Capacidade de campo & 24 & $\%$ \\
\hline PM & Ponto de murcha permanente & 10 & $\%$ \\
\hline DA & Densidade aparente do solo & 1,4 & $\mathrm{~cm}^{3}$ \\
\hline $\mathrm{Du}$ & Variação da umidade do solo & 0 & $\%$ \\
\hline $\mathrm{f}$ & Fator de disponibilidade de água no solo & 50 & $\%$ \\
\hline $\mathrm{V}$ & Viscosidade cinemática da água a $20^{\circ} \mathrm{C}$ & $1,004 \cdot 10^{-6}$ & $\mathrm{~m}^{2} \cdot \mathrm{s}^{-1}$ \\
\hline $\mathrm{Z}$ & Profundidade efetiva do sistema radicular & 1,0 & $\mathrm{~m}$ \\
\hline ETo & Evapotranspiração de referência & 3,0 & $\mathrm{~mm}$ \\
\hline $\mathrm{KC}$ & $\begin{array}{l}\text { Coeficiente de cultura para calculo da } \\
\text { evapotranspiração da cultura }\end{array}$ & 0,96 & - \\
\hline NTUO & Numero de subunidades do sistema & 24 & - \\
\hline TFMBD & $\begin{array}{l}\text { Tempo máximo de funcionamento da } \\
\text { motobomba por dia }\end{array}$ & 8,5 & $\mathrm{~h}$ \\
\hline NUOIS & $\begin{array}{l}\text { Número de subunidades operacionais irrigadas } \\
\text { simultaneamente }\end{array}$ & 4 & - \\
\hline TaCUOIS & Tempo de irrigação por conjunto de unidades & 4,25 & $\mathrm{~h}$ \\
\hline TRE & Turno de rega escolhido & 3 & - \\
\hline VAP & Volume de água aplicado por planta & 8275 & L. $\mathrm{pl}^{-1} \cdot$ ano $^{-1}$ \\
\hline a & $\begin{array}{l}\text { Coeficiente "a" da função de produção da } \\
\text { planta por lamina de água aplicada }\end{array}$ & $-0,000002$ & - \\
\hline $\mathrm{b}$ & $\begin{array}{l}\text { Coeficiente "b" da função de produção da } \\
\text { planta por lamina de água aplicada }\end{array}$ & 0,0331 & - \\
\hline $\mathrm{c}$ & $\begin{array}{l}\text { Coeficiente "c" da função de produção da } \\
\text { planta por lamina de água aplicada }\end{array}$ & 111,52 & - \\
\hline $\mathrm{g}$ & Aceleração da gravidade & 9,81 & $\mathrm{~m} \cdot\left(\mathrm{s}^{2}\right)^{-1}$ \\
\hline Lx & $\begin{array}{l}\text { Lado de maior comprimento na área a ser } \\
\text { irrigada }\end{array}$ & 1600 & $\mathrm{~m}$ \\
\hline Ly & $\begin{array}{l}\text { Lado de menor comprimento na área a ser } \\
\text { irrigada }\end{array}$ & 420 & $\mathrm{~m}$ \\
\hline $\mathrm{m}$ & $\begin{array}{l}\text { Expoente da vazão ou velocidade da equação } \\
\text { de perda de carga utilizada }\end{array}$ & 2 & - \\
\hline EEUO & Espaçamento entre unidades operacionais & 7,5 & $\mathrm{~m}$ \\
\hline
\end{tabular}


4.13. Análise de sensibilidade

Visando estudar a importância de diferentes insumos no custo total do projeto de irrigação, optou-se por estudar variações hidráulicas e econômicas importantes em qualquer dimensionamento de redes de irrigação. A análise de sensibilidade do presente trabalho avalia os efeitos nos custos e na hidráulica do sistema a partir da variação da declividade do terreno e da tarifa de água e energia elétrica no dimensionamento da rede.

As variações estudadas na declividade do terreno foram de: $0,2,5$ e $5 \%$, conforme o sentido já mostrado na Figura 2. As variações estudadas nas tarifas de água e energia elétrica são apresentadas na Tabela 3.

Tabela 3. Tarifas de água e energia elétrica utilizadas na análise de sensibilidade

\begin{tabular}{|c|c|c|c|c|c|}
\hline \multirow[b]{2}{*}{ Insumo } & \multicolumn{5}{|c|}{ Percentagem da Tarifa de Base } \\
\hline & $50 \%$ & $75 \%$ & $100 \%$ & $125 \%$ & $150 \%$ \\
\hline & \multicolumn{5}{|c|}{ - R $\$\left(m^{3}\right)^{-1}-$} \\
\hline \multirow[t]{2}{*}{ Água } & 0,0050 & 0,0075 & 0,0100 & 0,0125 & 0,0150 \\
\hline & \multicolumn{5}{|c|}{--- } \\
\hline Energia Elétrica & 0,0884 & 0,1326 & 0,1768 & 0,2210 & 0,2652 \\
\hline Energia Elétrica com $60 \%$ de Desconto & 0,0530 & 0,0796 & 0,1061 & 0,1326 & 0,1591 \\
\hline
\end{tabular}




\section{RESULTADOS E DISCUSSÃO}

Os resultados do trabalho são apresentados em 7 partes, visando uma melhor discussão analítica e entendimento.

Na primeira parte, executa-se uma análise do espaço de busca de redes objetivando-se verificar a eficiência do sistema de otimização da rede de irrigação por algoritmos genéticos. Na segunda parte, faz-se uma discussão das variáveis otimizadas obtidas, segundo a análise de sensibilidade proposta (alternando a declividade do terreno, custo da água e energia elétrica). Na terceira parte, é feita uma análise econômica dos custos obtidos, verificando as situações de dimensionamento da rede que retornaram o menor e o maior custo fixo e variável. $\mathrm{Na}$ quarta parte, executa-se uma análise hidráulica dos principais pontos da rede de irrigação como um todo, depois executa-se uma análise mais detalhada na linha lateral, linha de derivação e na unidade operacional (linhas laterais acopladas na linha de derivação). Objetivase com essa análise hidráulica validar os resultados obtidos, verificando o funcionamento hidráulico das redes obtidas. Na quinta parte, executa-se uma análise de distribuição da produtividade na área, segundo os dados obtidos de distribuição de vazão no item anterior. Com esta análise pretende-se verificar o efeito das diferentes opções da análise de sensibilidade e o funcionamento hidráulico da rede, no produto final em si, que é a distribuição da produtividade de frutos das plantas na unidade operacional. Na sexta parte, discute-se a uniformidade de emissão de água obtida na unidade operacional comparando com os dados padrões fornecidos pela literatura especializada. Na sétima e última parte faz-se um estudo do efeito de uma grande variação na tarifação da água nos custos da rede de irrigação. 
5.1. Espaço de busca e eficiência do sistema de otimização por algoritmos genéticos

O espaço de busca foi de 9625 possibilidades para a linha lateral, considerando que a mesma possui a possibilidade de dois diâmetros comerciais disponíveis. Para a linha de derivação e para a linha secundária, considerando 4 opções de diâmetros comerciais disponíveis para cada, obteve-se, respectivamente, um espaço de busca de 1350 (com 10 arranjos de tubulações possíveis na linha de derivação) e de 7000 (com 10 arranjos de tubulações possíveis na linha secundária). Totalizando as três linhas da rede de irrigação com mais de uma opção de diâmetro, obtêm-se um espaço de busca de 8.446 .250 diferentes combinações possíveis, sem considerar as restrições hidráulicas da rede. Neste estudo não é apresentado o espaço de busca considerando as restrições hidráulicas devido à variação que ocorre nos parâmetros de dimensionamento conforme o processo de otimização é executado. Por exemplo, a variação máxima de pressão permitida na linha lateral é dependente da velocidade calculada para os trechos da linha lateral e da linha de derivação, ou seja, a modificação no dimensionamento de um parâmetro, afeta as restrições de outros parâmetros hidráulicos da rede.

Considerando que foram utilizados 50 indivíduos (redes) por geração (conjunto de redes) e 2000 gerações, obtém-se um espaço de busca utilizado de $10^{4}$, o que corresponde a 0,12\% de todo o espaço de busca possível (8.446.250). Reca e Martínez (2006, p. 5), trabalhando com algoritmos genéticos em redes de irrigação malhada (sem restrições), utilizaram uma população de 500 indivíduos e 300 gerações, resultando em um espaço de busca utilizado de $0,67 \%$ do total possível $\left(1,48 \cdot 10^{9}\right)$. Os autores discorrem que, para a rede proposta por Alperovits e Shamir (1989), foram necessárias menos de 50 gerações para que seus valores convergissem para o ótimo, permanecendo as gerações seguintes sem alterações. 
Ressalta-se que neste trabalho optou-se pelo número de 50 indivíduos e de 2000 gerações após exaustivos testes com uma amplitude de indivíduos variando de 10 a 100 (de 10 em 10), e de gerações variando de 1000 a 5000 (de 1000 em 1000).

No Gráfico 5, verifica-se a eficiência da função de aptidão da otimização usando algoritmos genéticos, para as declividades estudadas, considerando $100 \%$ das tarifas de água $\left(0,01 \mathrm{R} \$ .\left(\mathrm{m}^{3}\right)^{-1}\right)$ e energia elétrica $\left(0,1768 \mathrm{R} \$ \cdot \mathrm{kW}^{-1}\right)$.

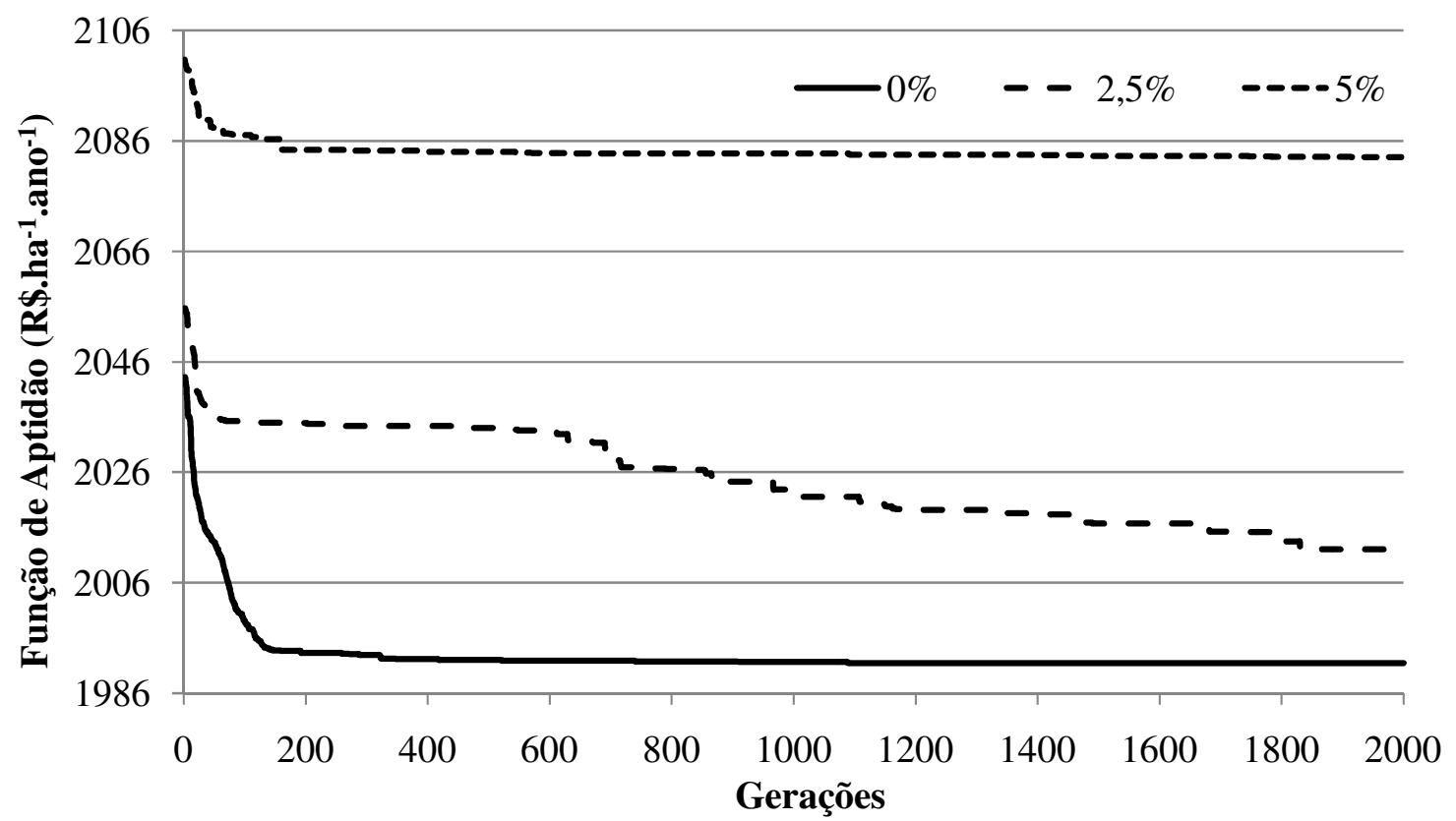

Gráfico 5. Eficiência da função de aptidão para as declividades de 0,2,5 e 5\%, com tarifa de água de $0,01 \mathrm{R} \$ .\left(\mathrm{m}^{3}\right)^{-1}$ e energia elétrica de $0,1768 \mathrm{R} \$ . \mathrm{kW}^{-1}$

As declividades de 0 e 5\% obtêm uma convergência mais rápida, resultando em um valor próximo do ótimo antes da geração número 200 (Tabela 4). Para a declividade de 2,5\% a convergência é lenta, estabilizando a busca pelo valor ótimo próximo à geração de número 1850 (Gráfico 5). Diferentemente das declividades de 0 e 5\%, em que houve uma convergência de mais de $92 \%$ até a geração número 200 (Tabela 4), a função de aptidão para a declividade de 2,5\% mostrou uma convergência de 47,6\% até a geração de número 200, ficando os 52,4\% restantes distribuídos da geração 201 até a 2000. 
Enfatiza-se que, independente das variações para as tarifas de água e energia elétrica, o comportamento das demais curvas de eficiência da função de aptidão da análise de sensibilidade têm um comportamento semelhante ao apresentado no Gráfico 5.

Tabela 4. Diferenças na convergência dos valores da função de aptidão entre conjuntos de gerações para as declividades de $0,2,5$ e $5 \%$, com tarifa de água de $0,01 \mathrm{R} \$ .\left(\mathrm{m}^{3}\right)^{-1}$ e energia elétrica de $0,1768 \mathrm{R} \$ . \mathrm{kW}^{-1}$

\begin{tabular}{cccc}
\hline \multirow{2}{*}{ Declividade } & Gerações & \multicolumn{2}{c}{ Diferença } \\
\cline { 3 - 4 } & $0-200$ & $\mathrm{R} \$ \cdot$ ha $^{-1} \cdot$ ano $^{-1}$ & $\%$ \\
\hline \multirow{3}{*}{$0 \%$} & $201-1000$ & 49,92 & 96,5 \\
& $1001-2000$ & 1,58 & 3,1 \\
& Total & 0,22 & 0,4 \\
\hline \hline \multirow{2}{*}{$2,5 \%$} & $0-200$ & 51,72 & 100,0 \\
\hline \hline & $201-1000$ & 20,74 & 47,6 \\
& $1001-2000$ & 12,95 & 29,7 \\
& Total & 9,84 & 22,6 \\
\hline \hline \multirow{2}{*}{$5 \%$} & $0-200$ & 43,53 & 100,0 \\
& $201-1000$ & 16,31 & 92,6 \\
& $1001-2000$ & 0,66 & 3,7 \\
& Total & 0,65 & 3,7 \\
\hline & & 17,62 & 100,0 \\
\hline
\end{tabular}

O tempo médio gasto de processamento foi 32,2 horas, para cada otimização da análise de sensibilidade. Optou-se pela utilização simultânea de 18 microcomputadores disponíveis no Laboratório de Hidráulica Computacional e da Sala de Ensino de Informática ${ }^{7}$. A otimização foi executada pelo MatLab instalado nos Sistemas Operacionais Windows e Linux. Os computadores utilizados variavam desde um Pentium 4 de $3 \mathrm{GHz}$ com 1 GB de memória RAM até um Dual Core de 2,2 GHz com 2 GB de memória RAM.

\footnotetext{
${ }^{7}$ Laboratório de Hidráulica Computacional (LHC) e Sala de Ensino de Informática (SEI) do Departamento de Hidráulica e Saneamento (SHS), da Escola de Engenharia de São Carlos (EESC) da Universidade de São Paulo (USP).
} 


\subsection{Análise das variáveis otimizadas}

A Tabela 5 apresenta os resultados obtidos com a variação da tarifa de água na otimização da rede de irrigação usando algoritmos genéticos. A variação na tarifa de água não afetou o dimensionamento otimizado por algoritmos genéticos. Mesmo com o custo da água sendo parte integrante do custo final na função de aptidão, juntamente com o custo de equipamentos e o custo de energia elétrica, ele não é ligado diretamente a uma variável de otimização. O custo final da água é diretamente dependente do volume de água aplicado por ano (determinado pela equação 80). O volume de água aplicado por ano é uma variável de entrada do programa, e por ser um número fixo que determina o volume de água a ser aplicado por irrigação, não atua diretamente como variável de otimização. Se o volume de água aplicado por ano fosse uma das variáveis a serem otimizadas haveria interferência da variação da tarifa da água na otimização. A interferência, neste estudo, ocorre com a declividade e a tarifa de energia elétrica, que afetam diretamente o dimensionamento hidráulico conforme sofrem variações.

Verifica-se na Tabela 5 que os comprimentos das duas tubulações com diferentes diâmetros para a linha lateral e os comprimentos das 4 tubulações com diferentes diâmetros para a linha secundária não sofreram alteração frente às diferentes declividades, por estarem posicionadas em nível na área (Figuras 2 e 3). Verifica-se, também que ocorre variação nos comprimentos disponíveis para a linha de derivação, já que está submetida às diferentes declividades. Para a linha de derivação há uma tendência de que quanto maior a declividade menor é o comprimento do primeiro trecho que possui maior diâmetro disponível, ocorrendo um ajuste para as tubulações intermediárias e final. Isto ocorre devido ao ganho de energia com a declividade do terreno, ou seja, o custo da energia elétrica para o bombeamento neste trecho vai diminuindo com o acréscimo da declividade. 
Tabela 5. Variáveis otimizadas segundo a variação da declividade e da tarifa de água na otimização da rede por algoritmos genéticos

\begin{tabular}{|c|c|c|c|c|c|c|c|c|c|c|c|c|}
\hline \multicolumn{3}{|c|}{$\begin{array}{c}\text { Variáveis da Análise de } \\
\text { Sensibilidade } \\
\end{array}$} & \multicolumn{10}{|c|}{ Variáveis Otimizadas } \\
\hline Declividade & Água & $\begin{array}{l}\text { Energia } \\
\text { Elétrica }\end{array}$ & LLL1 & LLL2 & LLD1 & LLD2 & LLD3 & LLD4 & LLS1 & LLS2 & LLS3 & LLS4 \\
\hline$\%$ & $\mathrm{R} \$ .\left(\mathrm{m}^{3}\right)^{-1}$ & $\mathrm{R} \$ . \mathrm{kW}^{-1}$ & \multicolumn{10}{|c|}{ 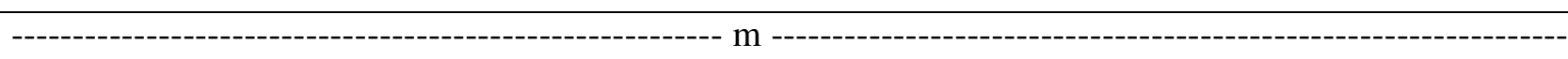 } \\
\hline 0 & 0,0050 & 0,1061 & 47,25 & 49,00 & 38 & 39 & 33 & 25 & 108 & 192 & 200 & 200 \\
\hline 2,5 & 0,0050 & 0,1061 & 47,25 & 49,00 & 14 & 51 & 47 & 23 & 108 & 192 & 200 & 200 \\
\hline 2,5 & 0,0075 & 0,1061 & 47,25 & 49,00 & 14 & 51 & 47 & 23 & 108 & 192 & 200 & 200 \\
\hline 5 & 0,0075 & 0,1061 & 47,25 & 49,00 & 6 & 61 & 39 & 29 & 108 & 192 & 200 & 200 \\
\hline 0 & 0,0100 & 0,1061 & 47,25 & 49,00 & 38 & 39 & 33 & 25 & 108 & 192 & 200 & 200 \\
\hline 2,5 & 0,0100 & 0,1061 & 47,25 & 49,00 & 14 & 51 & 47 & 23 & 108 & 192 & 200 & 200 \\
\hline 5 & 0,0100 & 0,1061 & 47,25 & 49,00 & 6 & 61 & 39 & 29 & 108 & 192 & 200 & 200 \\
\hline 2,5 & 0,0150 & 0,1061 & 47,25 & 49,00 & 14 & 51 & 47 & 23 & 108 & 192 & 200 & 200 \\
\hline 5 & 0,0150 & 0,1061 & 47,25 & 49,00 & 6 & 61 & 39 & 29 & 108 & 192 & 200 & 200 \\
\hline
\end{tabular}


A Tabela 6 mostra os resultados obtidos com a variação da tarifa de energia elétrica. Nota-se na Tabela 6 que a variação na tarifa de energia elétrica é mais sensível ao dimensionamento otimizado por algoritmos genéticos. O custo de energia elétrica é parte integrante do custo final na função de aptidão, juntamente com o custo de equipamentos e o custo da água, e sua interferência nas variáveis de otimização é direta pois é ligado indiretamente às variáveis de otimização que afetam diretamente o dimensionamento hidráulico conforme sofrem variações. Aumentando-se a tarifa de energia elétrica, aumenta-se o peso relativo da mesma na função de aptidão provocando alterações na busca pela rede economicamente ótima. Analisando a Tabela 5 verifica-se que o programa de otimização busca o menor custo total diminuindo o comprimento das tubulações de menor diâmetro, quando se aumenta a tarifa de energia elétrica. Isso ocorre por que, quanto maior o comprimento da tubulação de menor diâmetro, maior será o gasto para bombeamento, afetando o custo total final.

Verifica-se na Tabela 6 que os comprimentos das duas tubulações com diferentes diâmetros para a linha lateral não sofreram interferência, ou seja, independente das variações nas tarifas de água (Tabela 5) e energia elétrica, os comprimentos ótimos para cada tubulação permanecem os mesmos. Os comprimentos das 4 tubulações com diferentes diâmetros para a linha secundária, sofreram pouca alteração frente às diferentes declividades impostas para a linha principal e para a linha de derivação (Figuras 2 e 3), mesmo estando posicionadas em nível na área. Isto ocorre por que há uma interdependência entre os parâmetros de dimensionamento e de restrição hidráulica da linha principal e da linha de derivação quando há alteração da tarifa de energia elétrica, afetando diretamente o dimensionamento da linha secundária. Ressalta-se que houve modificação apenas nas duas primeiras tubulações da linha de derivação, não havendo alteração nos dois últimos trechos. 
Verifica-se, também que ocorre grande variação nos comprimentos de tubulação para a linha de derivação, já que esta é diretamente submetida às diferentes declividades.

Para a linha de derivação há uma tendência de que, quanto maior a declividade, menor é o comprimento do primeiro trecho que possui maior diâmetro disponível, sendo ajustados as tubulações intermediárias e final. Isto ocorre devido ao ganho de energia com a declividade do terreno, ou seja, o custo da energia elétrica para o bombeamento neste trecho aumenta com o acréscimo da declividade. 
Tabela 6. Variáveis otimizadas segundo a variação da declividade e da tarifa de energia elétrica na otimização da rede por algoritmos genéticos

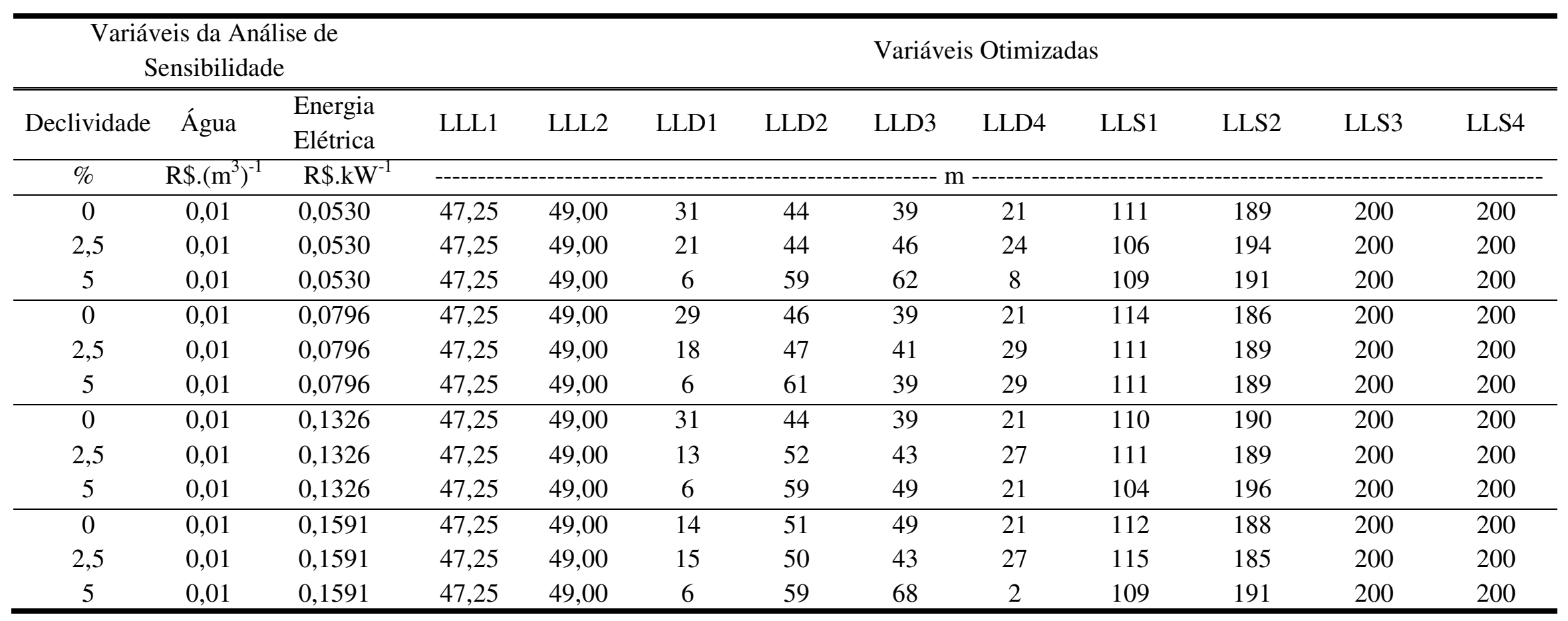


5.3. Análise econômica das redes de irrigação obtidas com a otimização

Com a análise econômica das redes de irrigação, utilizando-se os resultados da função de aptidão, verifica-se o peso de cada componente do custo (equipamentos, energia elétrica e água) no custo total de cada rede. Observa-se também a influência da variação da declividade e das tarifas de água e energia elétrica nos custos da rede de irrigação.

5.3.1. Análise econômica variando a declividade e a tarifa de água

A Tabela 7 apresenta os custos obtidos com a variação da declividade e da tarifa de água.

Tabela 7. Custos obtidos segundo a variação da declividade e da tarifa de água na otimização da rede por algoritmos genéticos

\begin{tabular}{|c|c|c|c|c|c|c|}
\hline \multicolumn{3}{|c|}{ Variáveis da Análise de Sensibilidade } & \multicolumn{4}{|c|}{ Custos Anualizados por Hectare da Rede de Irrigação } \\
\hline \multirow{2}{*}{ Declividade } & \multirow{2}{*}{ Água } & Energia & \multirow{2}{*}{ Equipamentos } & Energia & \multirow{2}{*}{ Água } & \multirow{2}{*}{ Total } \\
\hline & & Elétrica & & Elétrica & & \\
\hline$\%$ & $\mathrm{R} \$ .\left(\mathrm{m}^{3}\right)^{-1}$ & $\mathrm{R} \$ . \mathrm{kW}^{-1}$ & -------------- & --- R\$.h & $\mathrm{no}^{-1}-$ & . \\
\hline 0 & 0,0050 & 0,1061 & 1611,20 & 344,57 & 20,14 & 1975,91 \\
\hline 2,5 & 0,0050 & 0,1061 & 1576,48 & 396,64 & 20,14 & 1993,26 \\
\hline 5 & 0,0050 & 0,1061 & 1573,55 & 467,55 & 20,14 & 2061,24 \\
\hline 0 & 0,0075 & 0,1061 & 1611,20 & 344,57 & 30,21 & 1985,98 \\
\hline 2,5 & 0,0075 & 0,1061 & 1576,48 & 396,64 & 30,21 & 2003,33 \\
\hline 5 & 0,0075 & 0,1061 & 1573,55 & 467,55 & 30,21 & 2071,31 \\
\hline 0 & 0,0100 & 0,1061 & 1611,20 & 344,57 & 40,28 & 1996,05 \\
\hline 2,5 & 0,0100 & 0,1061 & 1576,48 & 396,64 & 40,28 & 2013,40 \\
\hline 5 & 0,0100 & 0,1061 & 1573,55 & 467,55 & 40,28 & 2081,38 \\
\hline 0 & 0,0125 & 0,1061 & 1611,20 & 344,57 & 50,35 & 2006,12 \\
\hline 2,5 & 0,0125 & 0,1061 & 1576,48 & 396,64 & 50,35 & 2023,47 \\
\hline 5 & 0,0125 & 0,1061 & 1573,55 & 467,55 & 50,35 & 2091,45 \\
\hline 0 & 0,0150 & 0,1061 & 1611,20 & 344,57 & 60,42 & 2016,19 \\
\hline 2,5 & 0,0150 & 0,1061 & 1576,48 & 396,64 & 60,42 & 2033,54 \\
\hline 5 & 0,0150 & 0,1061 & 1573,55 & 467,55 & 60,42 & 2101,52 \\
\hline
\end{tabular}


Verifica-se na Tabela 7 que a variação na tarifa de água influenciou o custo relativo da água em toda a rede de irrigação e, em consequiência, o custo total final da rede. Na Tabela 8, que apresenta o custo percentual de cada componente, verifica-se que o custo de água varia de 0,98\% (declividade de $5 \%$ e tarifa de $0,005 \mathrm{R} \$ . \mathrm{m}^{3}$ ) a $3 \%$ (declividade de $0 \%$ e tarifa de água de $0,015 \mathrm{R} \$ \cdot \mathrm{m}^{3}$ ). Essa variação, mesmo que pequena, pode representar um impacto considerável nos custos de produção do agricultor irrigante, que não está preparado para este novo encargo em seus gastos com insumos de produção. Ressalta-se que um aumento significativo na tarifa de água pode influenciar decisivamente na utilização ou não do insumo água, comprometendo diretamente a produção.

Tabela 8. Resultados percentuais dos custos obtidos segundo a variação da declividade e da tarifa de água na otimização da rede por algoritmos genéticos

\begin{tabular}{|c|c|c|c|c|c|c|}
\hline \multicolumn{3}{|c|}{ Variáveis da Análise de Sensibilidade } & \multicolumn{4}{|c|}{$\begin{array}{c}\text { Percentagem dos Custos Anualizados por } \\
\text { Hectare da Rede de Irrigação }\end{array}$} \\
\hline Declividade & Água & $\begin{array}{l}\text { Energia } \\
\text { Elétrica }\end{array}$ & Equipamentos & $\begin{array}{l}\text { Energia } \\
\text { Elétrica }\end{array}$ & Água & Total \\
\hline$\%$ & $\mathrm{R} \$ .\left(\mathrm{m}^{3}\right)^{-1}$ & $\mathrm{R} \$ . \mathrm{kW}^{-1}$ & ---------------- & $-\cdots$ & ------- & $\begin{array}{c}------- \\
---1\end{array}$ \\
\hline 0 & 0,0050 & 0,1061 & 81,54 & 17,44 & 1,02 & 100 \\
\hline 2,5 & 0,0050 & 0,1061 & 79,09 & 19,90 & 1,01 & 100 \\
\hline 5 & 0,0050 & 0,1061 & 76,34 & 22,68 & 0,98 & 100 \\
\hline 0 & 0,0075 & 0,1061 & 81,13 & 17,35 & 1,52 & 100 \\
\hline 2,5 & 0,0075 & 0,1061 & 78,69 & 19,80 & 1,51 & 100 \\
\hline 5 & 0,0075 & 0,1061 & 75,97 & 22,57 & 1,46 & 100 \\
\hline 0 & 0,0100 & 0,1061 & 80,72 & 17,26 & 2,02 & 100 \\
\hline 2,5 & 0,0100 & 0,1061 & 78,30 & 19,70 & 2,00 & 100 \\
\hline 5 & 0,0100 & 0,1061 & 75,60 & 22,46 & 1,94 & 100 \\
\hline 0 & 0,0125 & 0,1061 & 80,31 & 17,18 & 2,51 & 100 \\
\hline 2,5 & 0,0125 & 0,1061 & 77,91 & 19,60 & 2,49 & 100 \\
\hline 5 & 0,0125 & 0,1061 & 75,24 & 22,36 & 2,41 & 100 \\
\hline 0 & 0,0150 & 0,1061 & 79,91 & 17,09 & 3,00 & 100 \\
\hline 2,5 & 0,0150 & 0,1061 & 77,52 & 19,51 & 2,97 & 100 \\
\hline 5 & 0,0150 & 0,1061 & 74,88 & 22,25 & 2,88 & 100 \\
\hline
\end{tabular}


Analisando o efeito da declividade no dimensionamento (Tabelas 7 e 8), detecta-se 3 tendências no custo com o aumento da declividade do terreno: $1^{\mathrm{a}}$ - o custo total anualizado da rede de irrigação aumenta; $2^{\mathrm{a}}$ - o custo anualizado de equipamentos (custo fixo) diminui; $3^{\mathrm{a}}$ o custo com energia elétrica (custo variável) aumenta. O fato do custo anualizado com equipamentos diminuir, deve-se ao aumento do custo com energia elétrica para o bombeamento.

Com o aumento da declividade há um contrabalanceamento pela procura da rede de irrigação com menor custo, favorecida principalmente o ganho de carga do terreno para a linha de derivação, escolhendo um menor comprimento para tubulações com maiores diâmetros (respeitando as restrições hidráulicas).

Os resultados obtidos apresentam concordância com Saad e Mariño (2002, p. 123) que, estudando dimensionamento otimizado de irrigação localizada sob diferentes declividades, concluíram que o custo anual do sistema de irrigação aumenta com a inclinação da área.

5.3.2. Análise econômica variando a declividade e a tarifa de energia elétrica

A Tabela 9 apresenta os custos obtidos com a variação da declividade e da tarifa de energia elétrica. Ressalta-se que neste estudo o funcionamento da motobomba dá-se no intervalo das $21 \mathrm{~h} 30$ às $06 \mathrm{~h} 00$, em que há um desconto de $60 \%$ da tarifa normal para o setor rural.

A variação na tarifa de energia elétrica influenciou os custos anualizados de equipamentos, da própria energia elétrica e o custo total. A Tabela 10 apresenta as percentagens dos custos com a variação da declividade e da tarifa de energia elétrica. Verifica-se que a menor percentagem do custo de energia elétrica foi de 9,50\%, em relação ao 
custo total, para declividade de $0 \%$ e tarifa cheia de $0,0884 \mathrm{R} \$ . \mathrm{kW}$ (com $60 \%$ de desconto reduz para $0,0530 \mathrm{R} \$ \mathrm{~kW}$ ). Verifica-se na Tabela 10 , que o maior custo percentual com energia elétrica foi de $29,43 \%$, em relação ao custo total anualizado, para declividade de $5 \%$ e tarifa cheia de 0,2210 R\$.kW (com 60\% de desconto reduz para 0,1326 R\$.kW). Conclui-se que a tarifa de energia elétrica, associada à declividade da área, possui grande influência nos custos finais de uma rede de irrigação. Para uma mesma tarifação de energia elétrica, verificase pelas Tabelas $7,8,9$ e 10, que a declividade do terreno possui grande influência no custo total de uma rede de irrigação.

Tabela 9. Custos obtidos segundo a variação da declividade e da tarifa de energia elétrica na otimização da rede por algoritmos genéticos

\begin{tabular}{|c|c|c|c|c|c|c|}
\hline \multicolumn{3}{|c|}{ Variáveis da Análise de Sensibilidade } & \multicolumn{4}{|c|}{ Custos Anualizados por Hectare da Rede de Irrigação } \\
\hline Declividade & Água & $\begin{array}{l}\text { Energia } \\
\text { Elétrica }\end{array}$ & Equipamentos & $\begin{array}{l}\text { Energia } \\
\text { Elétrica }\end{array}$ & Água & Total \\
\hline$\%$ & $\mathrm{R} \$ .\left(\mathrm{m}^{3}\right)^{-1}$ & $\mathrm{R} \$ . \mathrm{kW}^{-1}$ & \multicolumn{4}{|c|}{ - } \\
\hline 0 & 0,01 & 0,0530 & 1603,65 & 172,49 & 40,28 & 1816,42 \\
\hline 2,5 & 0,01 & 0,0530 & 1585,92 & 200,80 & 40,28 & 1827,01 \\
\hline 5 & 0,01 & 0,0530 & 1586,58 & 226,62 & 40,28 & 1853,48 \\
\hline 0 & 0,01 & 0,0796 & 1601,75 & 258,72 & 40,28 & 1900,74 \\
\hline 2,5 & 0,01 & 0,0796 & 1579,29 & 301,39 & 40,28 & 1920,95 \\
\hline 5 & 0,01 & 0,0796 & 1574,47 & 350,38 & 40,28 & 1965,14 \\
\hline 0 & 0,01 & 0,1326 & 1603,34 & 431,39 & 40,28 & 2075,01 \\
\hline 2,5 & 0,01 & 0,1326 & 1573,44 & 500,44 & 40,28 & 2114,17 \\
\hline 5 & 0,01 & 0,1326 & 1574,57 & 566,71 & 40,28 & 2181,56 \\
\hline 0 & 0,01 & 0,1591 & 1571,37 & 521,84 & 40,28 & 2133,48 \\
\hline 2,5 & 0,01 & 0,1591 & 1577,71 & 601,27 & 40,28 & 2219,26 \\
\hline 5 & 0,01 & 0,1591 & 1591,43 & 680,42 & 40,28 & 2312,13 \\
\hline
\end{tabular}

Avaliando a implicação da variação da declividade do terreno e da tarifa de energia elétrica no dimensionamento (Tabelas 9 e 10), observam-se 3 tendências quando aumentamse a declividade do terreno e a tarifa de energia elétrica: $1^{\mathrm{a}}$ - o custo total anualizado da rede de irrigação aumenta; $2^{\mathrm{a}}$ - o custo anualizado de equipamentos (custo fixo) diminui; $3^{\mathrm{a}}-\mathrm{o}$ custo com energia elétrica (custo variável) aumenta. O custo pelo uso da água permanece 
constante uma vez que o volume de água aplicado por ano é fixo (8274 L.planta ${ }^{-1}$.ano ${ }^{-1}$ ) e pela tarifa, neste caso, não sofrer variação $\left(0,01 \mathrm{R} \$ .\left(\mathrm{m}^{3}\right)^{-1}\right)$.

Tabela 10. Resultados percentuais dos custos obtidos segundo a variação da declividade e da tarifa de energia elétrica na otimização da rede por algoritmos genéticos

\begin{tabular}{|c|c|c|c|c|c|c|}
\hline \multicolumn{3}{|c|}{ Variáveis da Análise de Sensibilidade } & \multicolumn{4}{|c|}{$\begin{array}{c}\text { Percentagem dos Custos Anualizados por } \\
\text { Hectare da Rede de Irrigação } \\
\end{array}$} \\
\hline Declividade & Água & $\begin{array}{l}\text { Energia } \\
\text { Elétrica }\end{array}$ & Equipamentos & $\begin{array}{l}\text { Energia } \\
\text { Elétrica }\end{array}$ & Água & Total \\
\hline$\%$ & $\mathrm{R} \$ .\left(\mathrm{m}^{3}\right)^{-1}$ & $\mathrm{R} \$ . \mathrm{kW}^{-1}$ & -----------------. & $----\%$ & -------- & $\begin{array}{l}------ \\
--1\end{array}$ \\
\hline 0 & 0,01 & 0,0530 & 88,29 & 9,50 & 2,22 & 100 \\
\hline 2,5 & 0,01 & 0,0530 & 86,80 & 10,99 & 2,20 & 100 \\
\hline 5 & 0,01 & 0,0530 & 85,60 & 12,23 & 2,17 & 100 \\
\hline 0 & 0,01 & 0,0796 & 84,27 & 13,61 & 2,12 & 100 \\
\hline 2,5 & 0,01 & 0,0796 & 82,21 & 15,69 & 2,10 & 100 \\
\hline 5 & 0,01 & 0,0796 & 80,12 & 17,83 & 2,05 & 100 \\
\hline 0 & 0,01 & 0,1326 & 77,27 & 20,79 & 1,94 & 100 \\
\hline 2,5 & 0,01 & 0,1326 & 74,42 & 23,67 & 1,91 & 100 \\
\hline 5 & 0,01 & 0,1326 & 72,18 & 25,98 & 1,85 & 100 \\
\hline 0 & 0,01 & 0,1591 & 73,65 & 24,46 & 1,89 & 100 \\
\hline 2,5 & 0,01 & 0,1591 & 71,09 & 27,09 & 1,82 & 100 \\
\hline 5 & 0,01 & 0,1591 & 68,83 & 29,43 & 1,74 & 100 \\
\hline
\end{tabular}

A variação da declividade e da tarifação da energia elétrica produz também uma pequena variação no custo final da água, mesmo com a tarifação da energia elétrica inalterada (Tabela 10). Verifica-se portanto que, quanto menor a tarifa de energia elétrica maior será o peso percentual do custo final da água. 


\subsection{Análise hidráulica}

Este tópico é dividido em 4 partes. Na primeira parte, apresenta-se uma análise hidráulica resumida dos principais pontos da rede de irrigação. Na segunda e terceira parte, apresenta-se uma análise hidráulica mais detalhada da linha lateral e da linha de derivação. Na quarta e última parte, apresenta-se uma análise hidráulica geral da unidade operacional (linhas laterais acopladas na linha de derivação).

Com a análise hidráulica dos resultados obtidos pode-se verificar um confiável funcionamento das redes de irrigação. Devido à grande quantidade de informação hidráulica produzida para cada análise de sensibilidade proposta neste estudo, optou-se por apresentar a análise hidráulica apenas para as tarifas de $100 \%$ de custo de água e energia elétrica, com 0 , 2,5 e 5\% de declividade do terreno. Ressalta-se que no tópico 5.6, sobre a uniformidade de emissão (vazão) na unidade operacional, considera-se a análise hidráulica de todas as variações propostas na análise de sensibilidade deste estudo.

\subsubsection{Análise hidráulica geral da rede de irrigação}

A Tabela 11 apresenta o diâmetro, vazão, velocidade, energia cinética, fator de atrito e perda de carga unitária para a linha de sucção, linha principal e para as quatro tubulações que compõem a linha secundária. Os valores obtidos são os mesmos, independente da análise de sensibilidade executada, devido ao volume de água aplicado ser sempre o mesmo (discutido no item 4.13). A discussão dos resultados será mais bem compreendida analisando concomitantemente a Figura 3 e a Tabela 6. 
Tabela 11. Diâmetro, vazão, velocidade, energia cinética, fator de atrito e perda de carga unitária para a linha de sucção, linha principal e para as quatro tubulações que compõem a linha secundária

\begin{tabular}{|c|c|c|c|c|c|}
\hline \multicolumn{6}{|c|}{ Trecho de Dimensionamento } \\
\hline DLSU & DLP & DLS1 & DLS2 & DLS3 & DLS4 \\
\hline \multicolumn{6}{|c|}{ 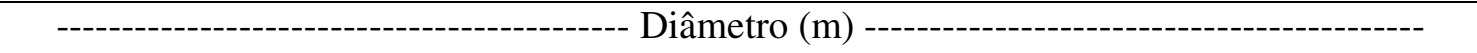 } \\
\hline 0,2320 & 0,2042 & 0,2042 & 0,1440 & 0,1200 & 0,0976 \\
\hline QILSUT & QILPT & QILS1T & QILS2T & QILS3T & QILS4T \\
\hline \multicolumn{6}{|c|}{ - Vazão $\left(\mathrm{m}^{3} \cdot \mathrm{h}^{-1}\right)$} \\
\hline 280,46 & 280,46 & 280,46 & 210,35 & 140,23 & 70,12 \\
\hline VILSUT & VILPT & VILS1T & VILS2T & VILS3T & VILS4T \\
\hline \multicolumn{6}{|c|}{ 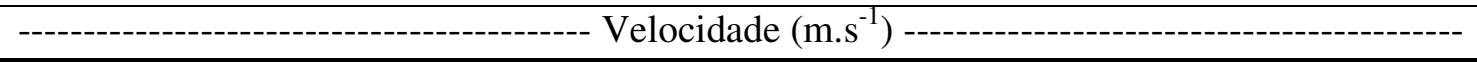 } \\
\hline 1,45 & 2,38 & 2,38 & 3,59 & 3,44 & 2,60 \\
\hline ECINETLSUT & ECINETLPT & ECINETLS1T & ECINETLS2T & ECINETLS3T & ECINETLS4T \\
\hline \multicolumn{6}{|c|}{------------------------------------------ Energia Cinética (mca) --------------------------------------- } \\
\hline 0,11 & 0,29 & 0,29 & 0,66 & 0,60 & 0,35 \\
\hline fSJTLSU & fSJTLPT & fSJTLS1 & fSJTLS2 & fSJTLS3 & fSJTLS4 \\
\hline \multicolumn{6}{|c|}{ 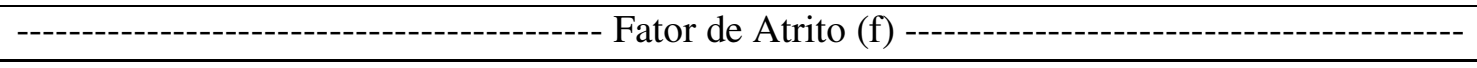 } \\
\hline 0,026 & 0,024 & 0,024 & 0,022 & 0,021 & 0,021 \\
\hline jLSUT & jLPT & jLST1 & jLST2 & jLST3 & jLST4 \\
\hline \multicolumn{6}{|c|}{ 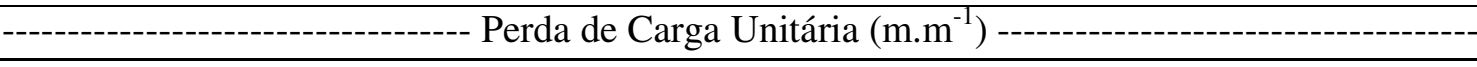 } \\
\hline 0,0104 & 0,0339 & 0,0339 & 0,1005 & 0,1073 & 0,0737 \\
\hline
\end{tabular}

Os valores de vazão para o início das linhas de sucção, principal e para a primeira tubulação da linha secundária são os mesmos por que não há derivações acopladas que retiram água em cada turno de rega. A velocidade, energia cinética, fator de atrito e perda de carga unitária para o início da linha principal e para a primeira tubulação da linha secundária são iguais devido ao diâmetro da tubulação serem o mesmo (Quadro 5 e APÊNDICE B).

Nota-se, na Tabela 11, que a maior velocidade foi obtida para a segunda tubulação da linha secundária, o que acarretou o maior ganho com energia cinética entre as tubulações analisadas. A linha de sucção, por possuir o maior diâmetro impetrou a menor velocidade e, conseqüentemente, a menor energia cinética. Verifica-se que a velocidade no segundo (VILS2T) e no terceiro (VILS3T) trecho da linha secundária foram relativamente elevadas devido aos diâmetros comerciais disponíveis pelos fabricantes. Em testes feitos utilizando 
diâmetros comerciais maiores, objetivando-se diminuir a velocidade do escoamento verificouse velocidades muito baixas e elevados custos de implantação da rede (custo fixo).O fator de atrito da linha de sucção é maior devido à maior rugosidade da tubulação $(\varepsilon=0,01)$. A maior perda de carga unitária ocorre na terceira tubulação da linha secundária, seguida pela segunda tubulação, devido à conjunção do fator de atrito com a alta velocidade do escoamento.

Na Tabela 12 apresenta-se a carga total $\left(\mathrm{p} / \gamma+\mathrm{v}^{2} / 2 . \mathrm{g}+\mathrm{z}\right)$ exigida na entrada das linhas lateral, de derivação, secundária, principal e na motobomba, segundo a variação da declividade do terreno e para diferentes tarifas de energia elétrica.

Tabela 12. Energia requerida na entrada das linhas lateral, de derivação, secundária, principal e na motobomba, segundo a variação da declividade do terreno e da tarifa de energia elétrica

\begin{tabular}{|c|c|c|c|c|c|}
\hline \multirow{2}{*}{ Declividade } & \multicolumn{5}{|c|}{ Percentagem da Tarifa Básica de Energia Elétrica } \\
\hline & $50 \%$ & $75 \%$ & $100 \%$ & $125 \%$ & $150 \%$ \\
\hline \multicolumn{6}{|l|}{----- \% ----- } \\
\hline & \multicolumn{5}{|c|}{ Energia no Início da Linha Lateral } \\
\hline 0 & 16,74 & 16,74 & 16,74 & 16,74 & 16,74 \\
\hline 2,5 & 16,74 & 16,74 & 16,74 & 16,74 & 16,74 \\
\hline \multirow[t]{2}{*}{5} & 16,74 & 16,74 & 16,74 & 16,74 & 16,74 \\
\hline & \multicolumn{5}{|c|}{ Energia no Início da Linha de Derivação } \\
\hline 0 & 19,07 & 19,15 & 18,86 & 19,07 & 19,78 \\
\hline 2,5 & 16,17 & 16,68 & 16,42 & 16,72 & 16,67 \\
\hline \multirow[t]{2}{*}{5} & 10,25 & 13,66 & 13,66 & 13,26 & 10,24 \\
\hline & \multicolumn{5}{|c|}{ Energia no Início da Linha Secundária } \\
\hline 0 & 45,82 & 45,81 & 45,73 & 45,84 & 46,43 \\
\hline 2,5 & 43,00 & 43,29 & 43,17 & 43,31 & 43,17 \\
\hline \multirow[t]{2}{*}{5} & 37,43 & 40,24 & 40,32 & 40,10 & 37,43 \\
\hline & \multicolumn{5}{|c|}{ Energia no Início da Linha Principal } \\
\hline 0 & 63,82 & 63,81 & 63,73 & 63,85 & 64,43 \\
\hline 2,5 & 75,75 & 75,80 & 74,71 & 75,49 & 75,59 \\
\hline \multirow[t]{2}{*}{5} & 86,63 & 89,57 & 89,65 & 86,66 & 86,71 \\
\hline & \multicolumn{5}{|c|}{ Energia Total na Motobomba } \\
\hline 0 & 72,69 & 72,69 & 72,60 & 72,72 & 73,30 \\
\hline 2,5 & 84,62 & 84,67 & 83,58 & 84,36 & 84,46 \\
\hline 5 & 95,51 & 98,44 & 98,52 & 95,53 & 95,58 \\
\hline
\end{tabular}


Nota-se na Tabela 12, que a linha de derivação, por encontrar-se em nível (Figuras 2 e 3) e não possuir nenhuma modificação no comprimento das duas tubulações com diferentes diâmetros que a compõem (Tabelas 5 e 6), não apresenta nenhuma modificação na energia requerida em seu início, independente da variação na declividade e na tarifa de energia elétrica. A linha de derivação, ganhando carga hidráulica por estar em declive, apresenta energia decrescente na entrada da linha, conforme aumenta-se a declividade do terreno. Nos tópicos 5.4.2. e 5.4.3., há uma análise mais detalhada da energia na linha lateral e de derivação, respectivamente.

A energia requerida na entrada da linha secundária é decrescente com o aumento declividade do terreno, mesmo com as tubulações em nível (Figuras 2 e 3), pois é diretamente ligada à energia requerida na entrada da linha de derivação, que está sujeita ao declive do terreno. Portanto, quanto maior a declividade no terreno e menor a energia na entrada da linha de derivação, menor será a energia requerida na entrada da linha secundária. Quanto à linha principal (adutora), observa-se um acréscimo da energia necessária conforme aumenta-se a declividade do terreno, pois encontra-se em aclive (Figuras 2 e 3).

A energia obtida na motobomba é a somatória cumulativa das energias obtidas em todas as linhas da rede, sofrendo um aumento concomitantemente com a declividade no terreno, ou seja, há mais perda de carga hidráulica nas tubulações com o aclive do terreno do que ganho com o declive.

A energia exigida na motobomba (Tabela 12), reflete diretamente a potência requerida (Tabela 13). Quanto maior a declividade do terreno, independente da variação da tarifa de energia elétrica, maior será a potência requerida na motobomba. Esta tendência de aumento da potência requerida na motobomba com o aumento da declividade resulta em maiores custos com energia elétrica, como foi observado na Tabela 10. 
Tabela 13. Potência requerida na motobomba, segundo a variação da declividade do terreno e da tarifa de energia elétrica

\begin{tabular}{|c|c|c|c|c|c|}
\hline \multirow{2}{*}{ Declividade } & \multicolumn{5}{|c|}{ Percentagem da Tarifa Básica de Energia Elétrica } \\
\hline & $50 \%$ & $75 \%$ & $100 \%$ & $125 \%$ & $150 \%$ \\
\hline ----- \% ---- & - & ----. & $--\mathrm{CV}-$ & l---'- & ------- \\
\hline 0 & 151 & 151 & 151 & 151 & 152 \\
\hline 2,5 & 176 & 176 & 174 & 175 & 176 \\
\hline 5 & 199 & 205 & 205 & 199 & 199 \\
\hline
\end{tabular}

5.4.2. Análise hidráulica da linha lateral

O Gráfico 6 apresenta a variação da velocidade e da vazão em marcha na linha lateral, além do diâmetro interno da tubulação (fornecido pelo fabricante - ANEXO B). A vazão em marcha foi calculada pelas equações $61,62,63,64,65,66,67$ e 68 . A velocidade foi calculada pela equação 69.

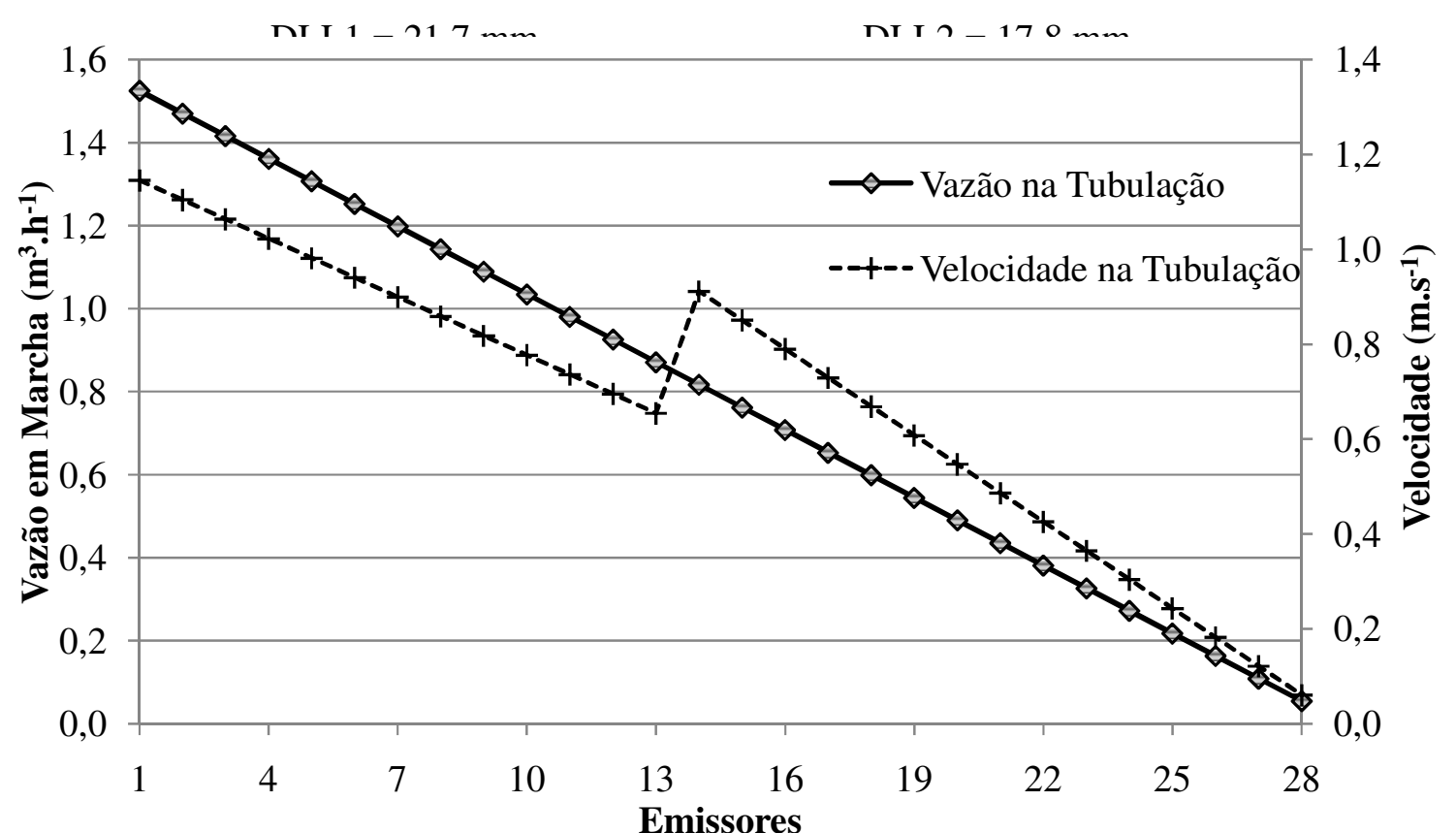

Gráfico 6. Vazão em marcha e velocidade calculadas no dimensionamento da linha lateral, sob dois diâmetros internos diferentes da tubulação 
No Gráfico 6 nota-se a influência direta do diâmetro da tubulação, sob a vazão em marcha e no aumento da velocidade do escoamento quando o diâmetro do primeiro trecho da tubulação sofre a contração para o diâmetro do segundo trecho da tubulação. O aumento da velocidade do escoamento ocorre por que há uma diminuição brusca na área interna da tubulação, não sendo suficiente a vazão nos emissores próximos para diminuir a velocidade ao redor do ponto de contração. A partir do $13^{\circ}$ emissor, são necessários 5 emissores (a partir do $19^{\circ}$ emissor) para que a velocidade do escoamento volte a ficar abaixo da velocidade de escoamento do $13^{\circ}$ emissor na linha lateral.

O Gráfico 7 apresenta o número de Reynolds nos emissores e as regiões que representam o escoamento turbulento, transicional e laminar, determinados pela Harpa de Nikuradse (Porto, 1999, p. 36 e 37).

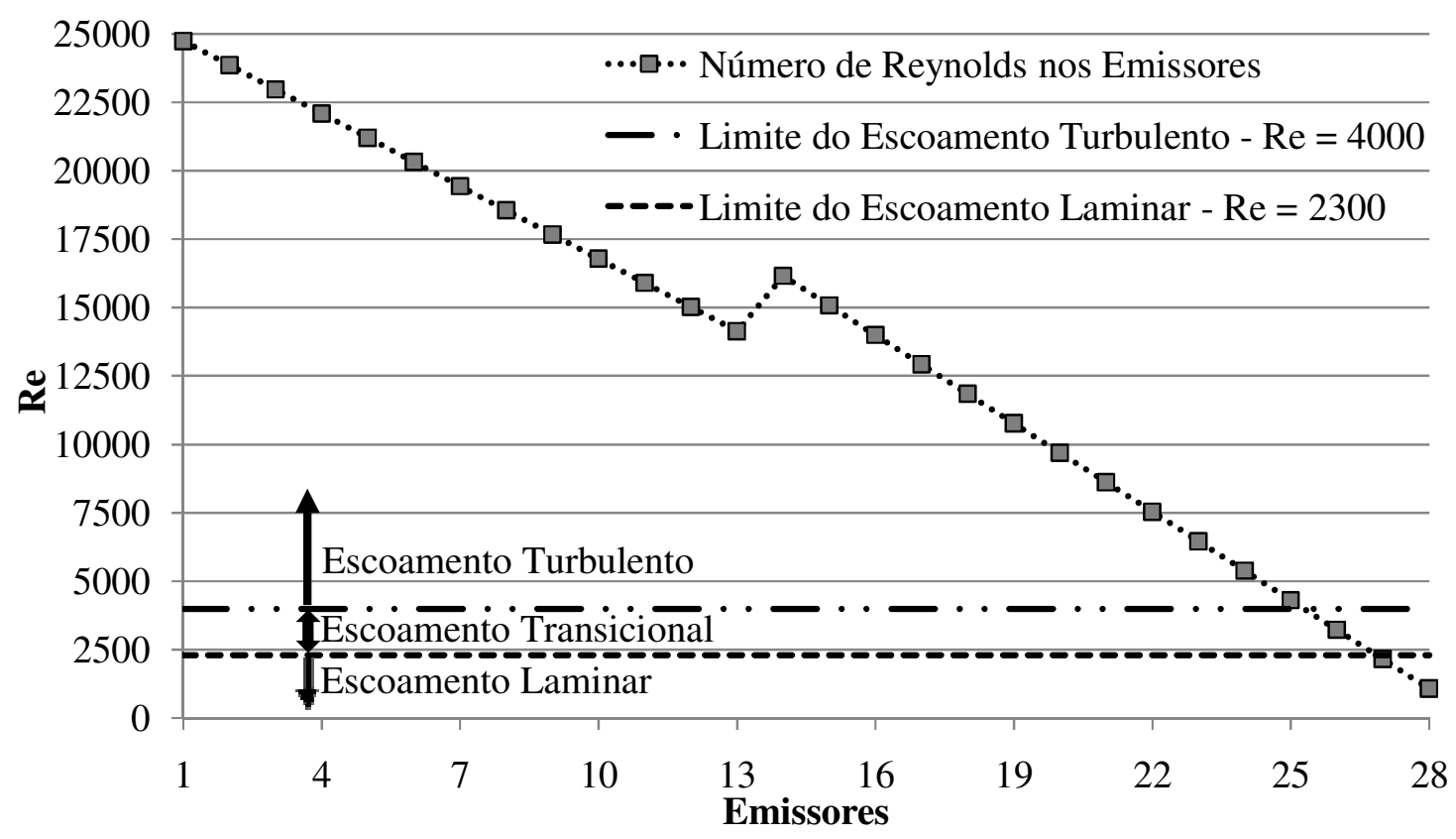

Gráfico 7. Número de Reynolds nos emissores e as regiões que representam o escoamento rugoso, transicional e laminar

A análise descritiva do Gráfico 7 mostra que o escoamento da linha lateral começa e permanece turbulento na tubulação, contemplando 25 emissores nesta faixa de escoamento, 
passando por um pequeno trecho de escoamento de transição e terminando na faixa de escoamento laminar. Neste escoamento sob vazão em marcha, a velocidade e o diâmetro da tubulação, calculados no Gráfico 6, tiveram efeito direto na variação do número de Reynolds e no tipo de escoamento da linha lateral. Verifica-se com isso que, a escolha da equação para o cálculo do fator de atrito (equação 35) é de suma importância para tubos lisos, como os feitos de polietileno e PVC (muito utilizados no dimensionamento de redes de irrigação), pois o tipo de escoamento pode mudar, como no caso do Gráfico 7 em que a tubulação de polietileno está sob vazão em marcha.

O Gráfico 8 apresenta a perda de carga localizada na contração da tubulação e a variação da perda de carga localizada ao longo dos emissores, perda de carga unitária entre os emissores, fator de atrito e a energia cinética resultantes do dimensionamento da linha lateral com vazão em marcha. A variação destes parâmetros de dimensionamento correspondem a tendência determinada pelo diâmetro interno da tubulação e da velocidade do escoamento, com a vazão em marcha (Gráfico 6).

A perda de carga localizada com a contração da tubulação foi pequena $(0,0045$ mca) em relação à perda de carga unitária $(0,0650$ mca $)$ e à perda de carga entre os emissores acoplados a linha lateral $(0,0212$ mca) no ponto de contração da tubulação.

A variação no fator de atrito (0,0246 no primeiro emissor até 0,0594 no último emissor) ao longo da linha lateral tende a ser inversamente proporcional a variação do número de Reynolds apresentada no Gráfico 7. No entanto verifica-se no ponto de emissão 26 uma leve tendência de queda no valor do fator de atrito e no ponto de emissão 27 uma queda exacerbada, seguida de uma elevação brusca e acentuada no último ponto de emissão. Este fenômeno ocorre devido as características intrínsecas do cálculo do fator de atrito (equação 35) e a sua variação. Este fenômeno pode ser observado analisando os respectivos números de 
Reynolds (dos três últimos pontos de emissão), frente a rugosidade da tubulação de polietileno (0,0015), no diagrama de Moody (APÊNDICE A).

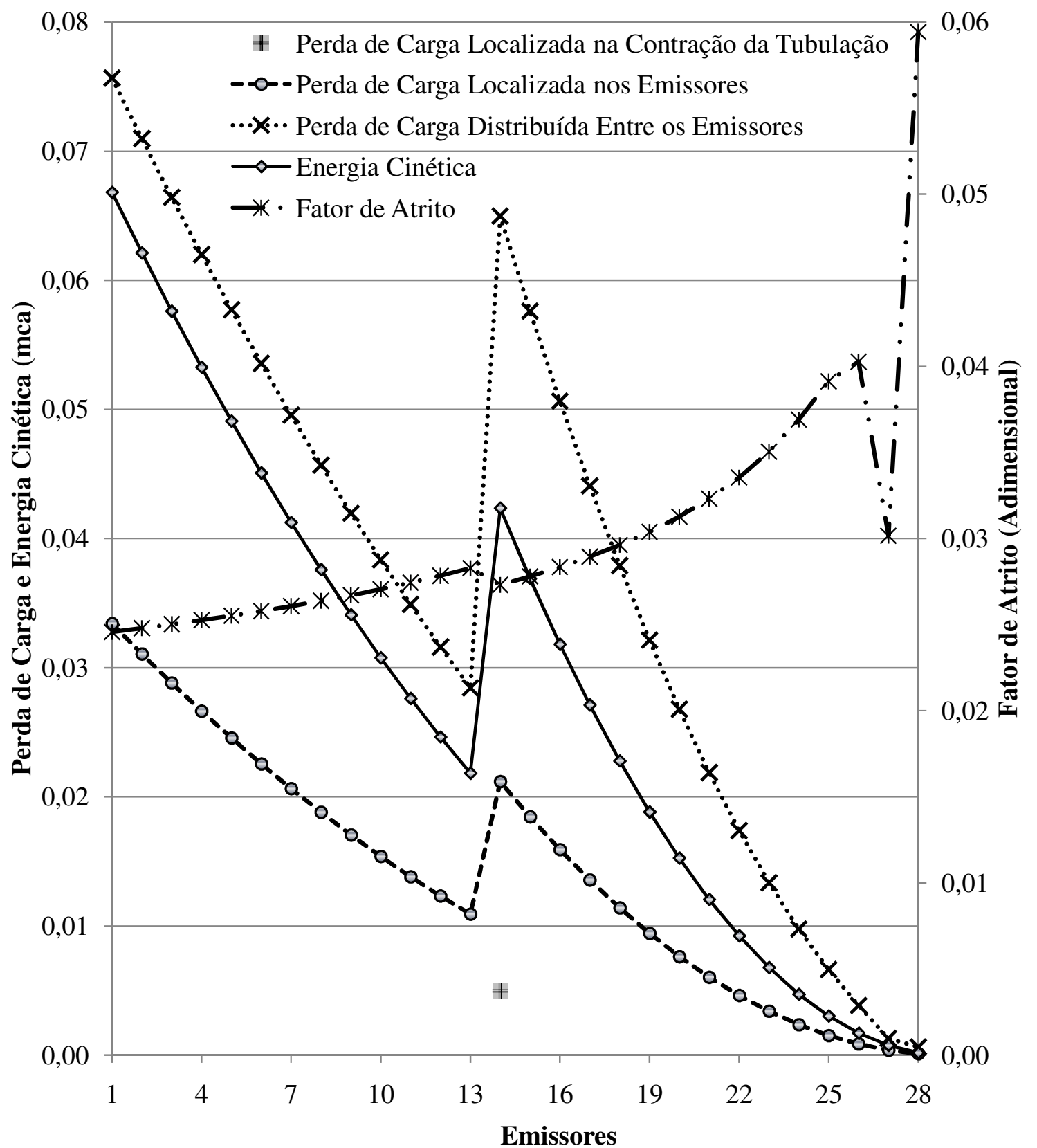

Gráfico 8. Perda de carga localizada na contração da tubulação e a variação da perda de carga localizada ao longo dos emissores, perda de carga unitária entre os emissores, fator de atrito e a energia cinética, na linha lateral com vazão em marcha. Dados obtidos no dimensionamento da rede 
O Gráfico 9 apresenta a relação das linhas de energia e piezométrica obtidos no dimensionamento da rede e a vazão nos emissores alcançados com a carga piezométrica em cada emissor (equação 31).

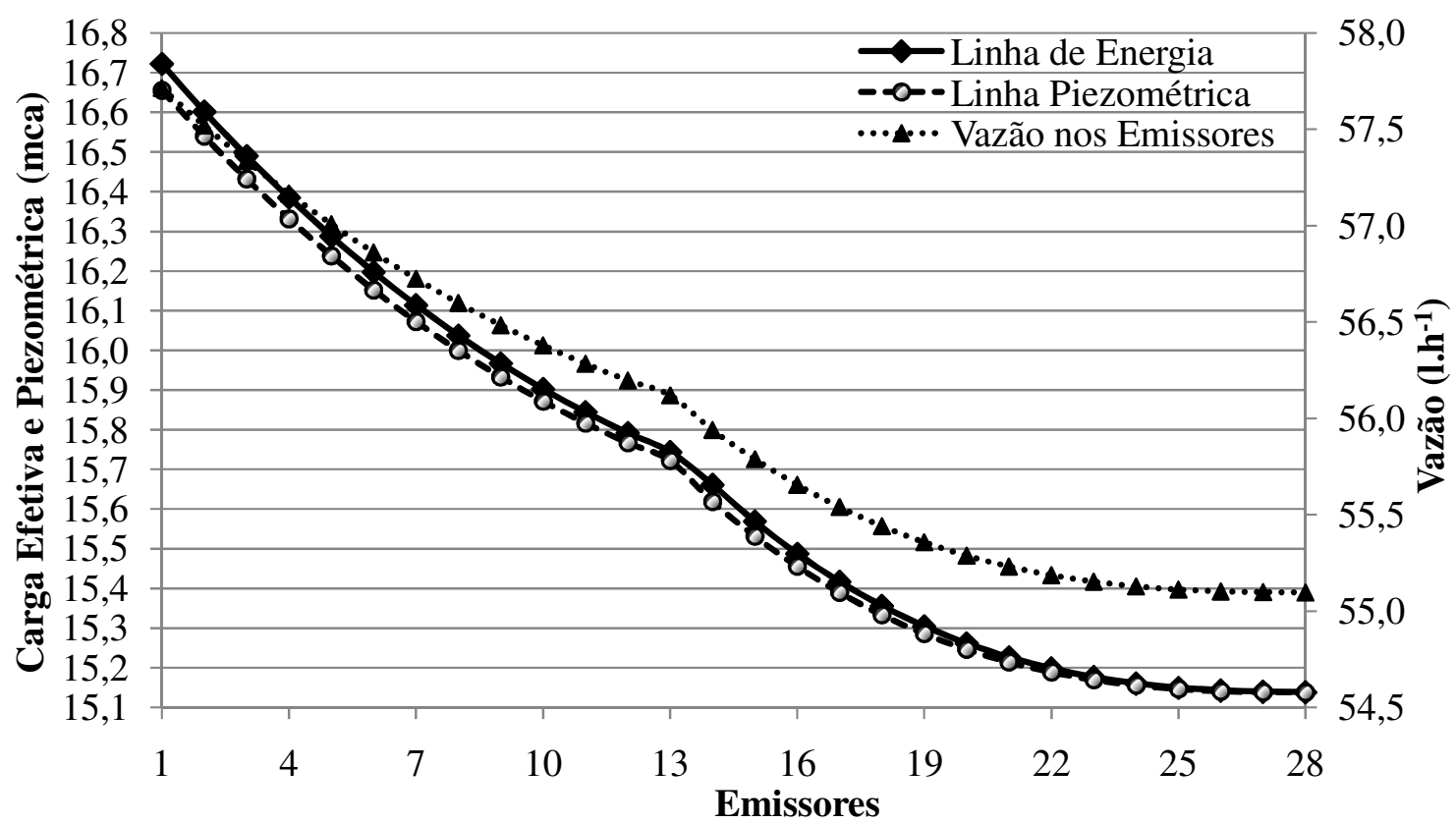

Gráfico 9. Variação das linhas de energia, piezométrica obtidos no dimensionamento da rede e a vazão nos emissores calculada posteriormente com a carga piezométrica em cada emissor

Observa-se que a influência do comportamento da energia cinética (Gráfico 8) na tubulação contribui para um distanciamento entre as linhas de energia e piezométrica no começo do primeiro e do segundo trecho da tubulação. Sendo que no final da tubulação, já a partir do emissor 26, os valores ficam muito próximos e praticamente se igualando no último emissor (28), quando o valor da energia cinética é muito próxima de zero.

Destaca-se a pouca variação $(9,1 \%)$ entre o maior $(16,66 \mathrm{mca})$ e o menor valor de carga piezométrica $(15,14$ mca) nos pontos de emissão da linha lateral, o que acarretará uma maior uniformidade de emissão na unidade operacional (item 5.5.). 
A variação da vazão ao longo da linha lateral tende a se estabilizar concomitantemente a estabilização da linha piezométrica, já que a vazão em cada emissor é determinada (equação 31) em função da carga de pressão no ponto de emissão. Um maior detalhamento da influência da variação da linha piezométrica na vazão dos emissores será feita no tópico 5.4.4., que tratará sobre a análise hidráulica em toda a unidade operacional (linhas laterais acopladas na linha de derivação) sob as diferentes declividades do terreno estudadas neste trabalho.

\subsubsection{Análise hidráulica da linha de derivação}

Os Gráficos 10, 11 e 12 apresentam variação da velocidade do escoamento na linha de derivação frente a vazão e o diâmetro interno da tubulação, respectivamente para as declividades de 0, 2,5 e 5\%, calculados no dimensionamento da rede de irrigação.

A velocidade aumenta no escoamento, mesmo a tubulação estando sob vazão em marcha (e por consequiência tendo a tendência de diminuir a velocidade do escoamento), por que há uma diminuição acentuada na área interna da tubulação.

Analisando os Gráficos 10, 11 e 12 nota-se uma velocidade média menor (1,49 m.s $\left.{ }^{-1}\right)$ na tubulação para $0 \%$ de declividade no terreno em relação às tubulações sob $2,5 \%\left(1,71 \mathrm{~m} . \mathrm{s}^{-1}\right) \mathrm{e}$ $5 \%\left(1,80 \mathrm{~m} . \mathrm{s}^{-1}\right)$ de declividade. Portanto, há uma tendência de aumento na velocidade média da tubulação da linha de derivação quando há um acréscimo da declividade sob mesma vazão em marcha. Nota-se também uma menor amplitude $\left(1,59 \mathrm{~m} \cdot \mathrm{s}^{-1}\right)$ entre a velocidade mínima $\left(0,47 \mathrm{~m} . \mathrm{s}^{-1}\right)$ e máxima $\left(2,05 \mathrm{~m} \cdot \mathrm{s}^{-1}\right)$ para a declividade de $0 \%$, em relação à amplitude alcançada para a declividade de 2,5\% (2,00 m.s $\mathrm{s}^{-1}$, com máxima de 2,46 m.s ${ }^{-1}$ e mínima de 0,47 m.s $\left.{ }^{-1}\right)$ e $5 \%\left(2,02 \mathrm{~m} \cdot \mathrm{s}^{-1}\right.$, com máxima de 2,49 $\mathrm{m} . \mathrm{s}^{-1}$ e mínima de $\left.0,47 \mathrm{~m} . \mathrm{s}^{-1}\right)$ 


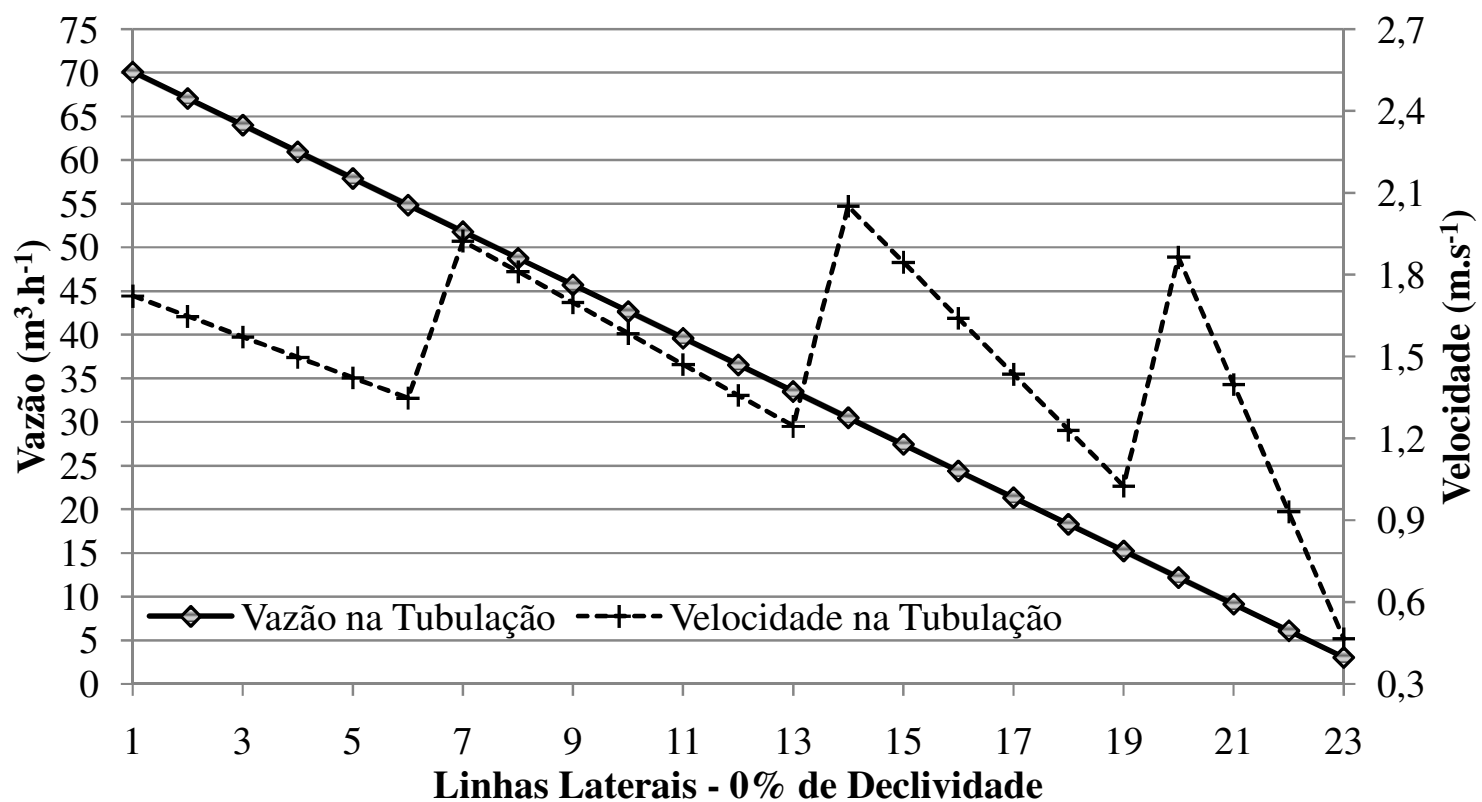

Gráfico 10. Variação da velocidade calculada no dimensionamento da linha de derivação, segundo a vazão em marcha na tubulação e os diferentes diâmetros de cada trecho da tubulação $(\mathrm{DLD} 1=204,2 \mathrm{~mm}$, DLD2 $=144,0 \mathrm{~mm}$, DLD3 $=120,0 \mathrm{~mm}$ e DLD4 $=97,6 \mathrm{~mm})$, para a declividade de $0 \%$

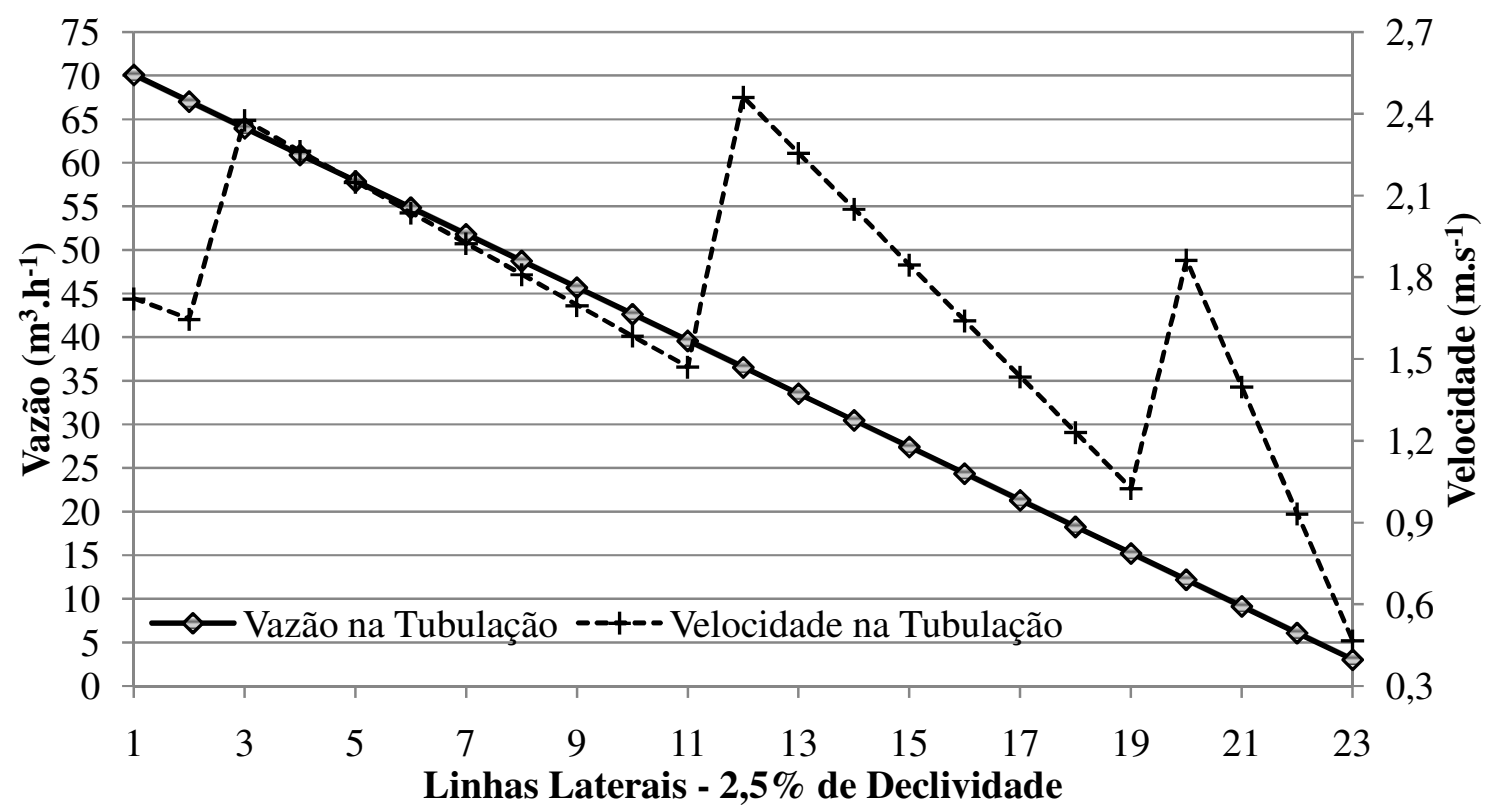

Gráfico 11. Variação da velocidade calculada no dimensionamento da linha de derivação, segundo a vazão em marcha na tubulação e os diferentes diâmetros de cada trecho da tubulação $($ DLD1 $=204,2 \mathrm{~mm}$, DLD2 $=144,0 \mathrm{~mm}$, DLD3 $=120,0 \mathrm{~mm} \mathrm{e}$ DLD4 $=97,6 \mathrm{~mm}$ ), para a declividade de $2,5 \%$ 


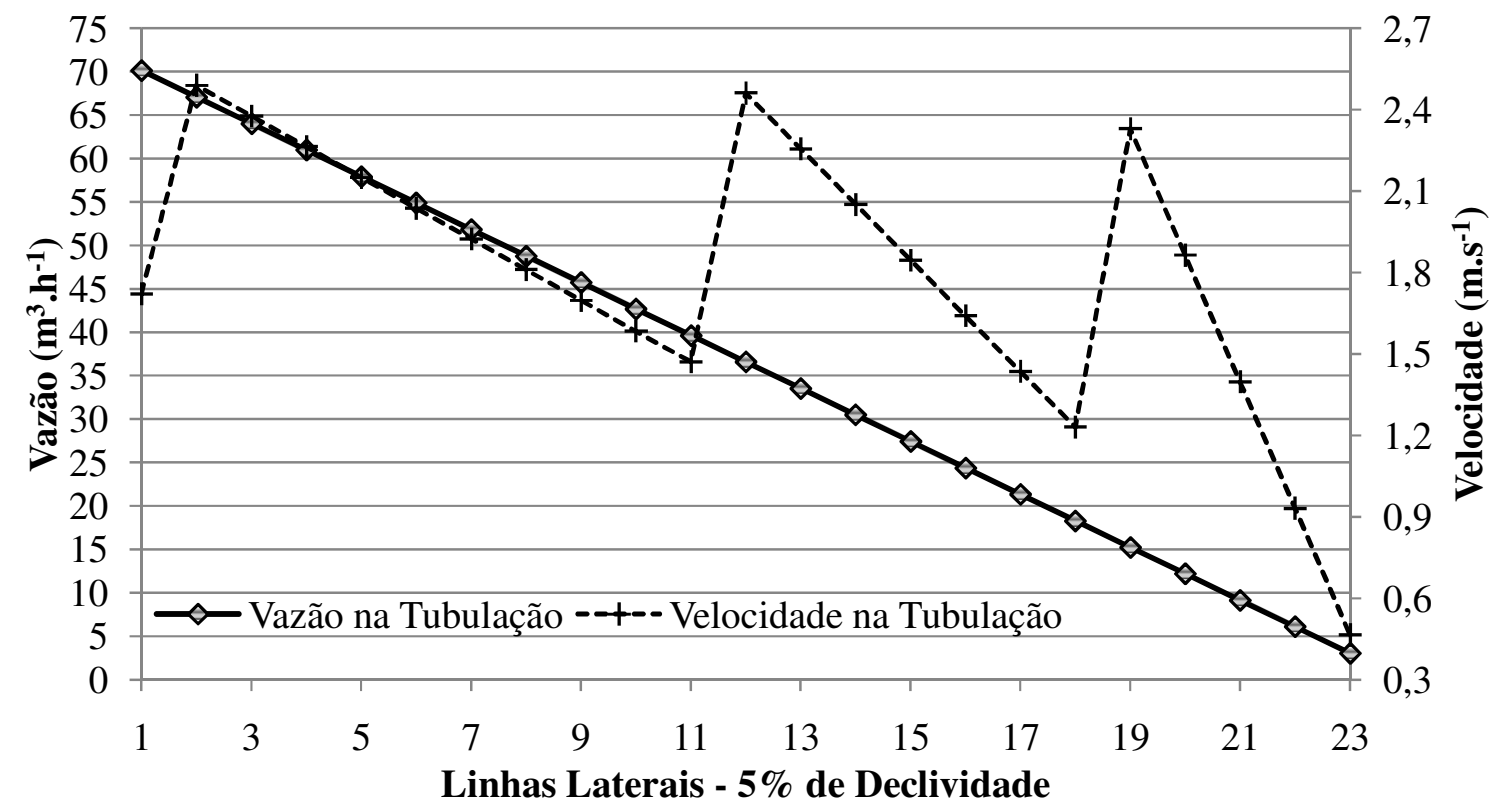

Gráfico 12. Variação da velocidade calculada no dimensionamento da linha de derivação, segundo a vazão em marcha na tubulação e os diferentes diâmetros de cada trecho da tubulação $(\mathrm{DLD} 1=204,2 \mathrm{~mm}$, DLD2 $=144,0 \mathrm{~mm}$, DLD3 $=120,0 \mathrm{~mm} \mathrm{e}$ DLD4 $=97,6 \mathrm{~mm}$ ), para a declividade de $5 \%$

Os Gráficos 13, 14 e 15 apresentam a variação do número de Reynolds ao longo da linha de derivação, respectivamente para as declividade de $0,2,5$, e $5 \%$. A variação do número de Reynolds ao longo da linha de derivação segue uma tendência observada nos Gráficos 10, 11 e 12. Na contração dos diâmetros há uma elevação do valor da velocidade do escoamento, ocasionando um aumento localizado no número de Reynolds, refletindo diretamente nos outros parâmetros de dimensionamento hidráulico (que serão discutidos em seguida).

A menor variação do número de Reynolds foi obtida com $0 \%$ de declividade do terreno, com o valor de $89,2 \%$, seguida pela declividade de $2,5 \%$, com $90,3 \%$ de variação, e por último a declividade de 5\%, com uma variação de $90,7 \%$. 


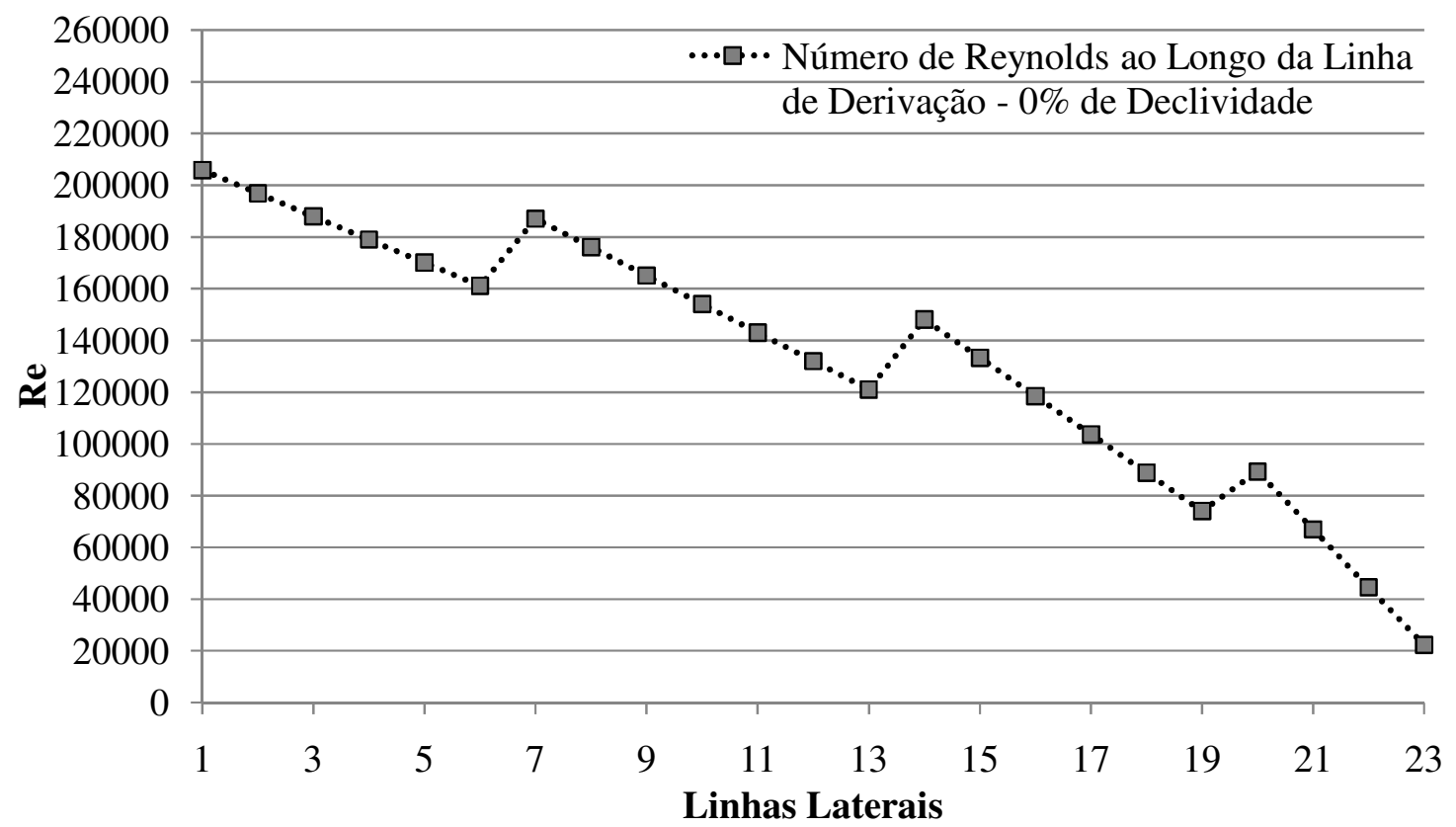

Gráfico 13. Variação do número de Reynolds ao longo da linha de derivação, sob vazão em marcha, para a declividade de $0 \%$

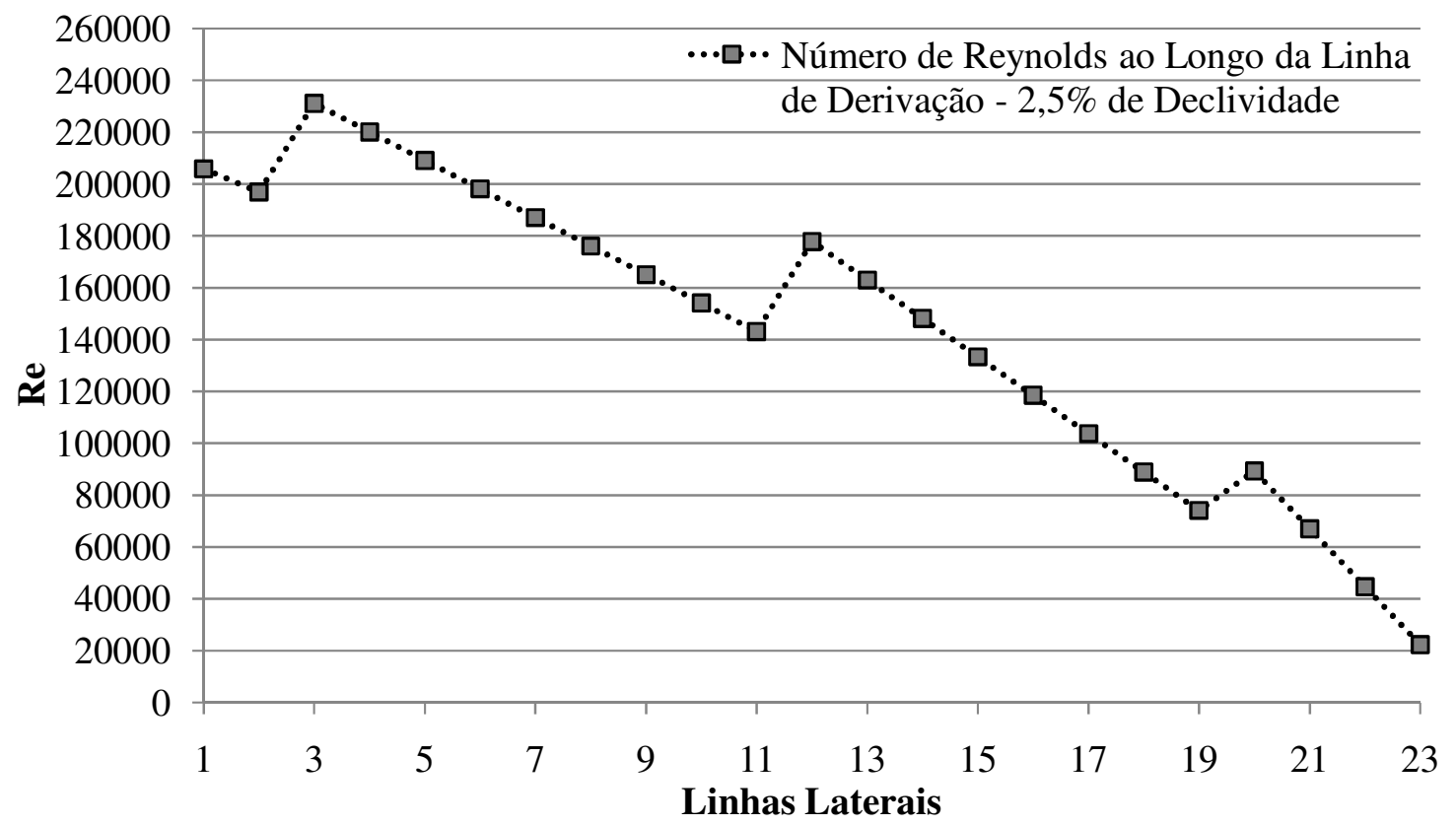

Gráfico 14. Variação do número de Reynolds ao longo da linha de derivação, sob vazão em marcha, para a declividade de $2,5 \%$ 


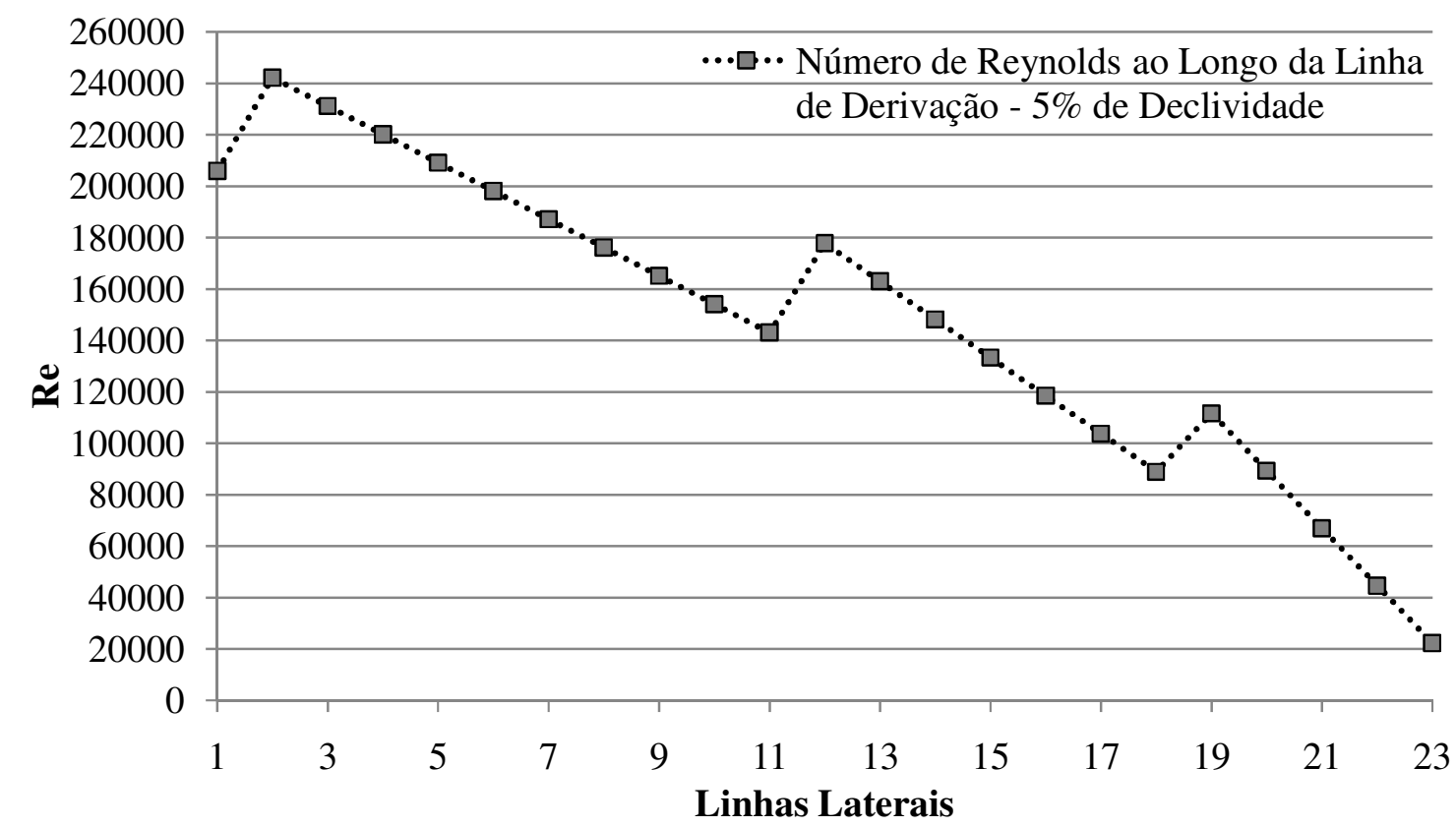

Gráfico 15. Variação do número de Reynolds ao longo da linha de derivação, sob vazão em marcha, para a declividade de $5 \%$

Os Gráficos 16, 17 e 18 apresentam os dados obtidos com o dimensionamento da rede de irrigação com a perda de carga localizada com 3 contrações da tubulação e o comportamento da perda de carga localizada com o acoplamento das linhas laterais, perda de carga unitária entre as linhas laterais, fator de atrito e a energia cinética, na linha de derivação com vazão em marcha. O comportamento destes parâmetros de dimensionamento obedecem a uma tendência determinada pela área interna da tubulação e da velocidade do escoamento, com a vazão em marcha (Gráficos 10, 11 e 12).

Verifica-se que a perda de carga localizada na contração da tubulação foi menor na primeira contração $(0,0247,0,0395,0,0447 \mathrm{mca}$, respectivamente para $0,2,5$ e $5 \%$ de declividade), em relação ao restante das contrações. Já a segunda contração obteve menores valores $(0,0464,0,0664,0,0628$ mca, respectivamente para $0,2,5$ e $5 \%$ de declividade $)$, em geral, que os valores obtidos na terceira contração $(0,0668,0,0576,0,0873$ mca, respectivamente para $0,2,5$ e $5 \%$ de declividade). A exceção foi a terceira contração da tubulação para a declividade de $2,5 \%$, que apresentou menor valor que a declividade de $5 \%$. 


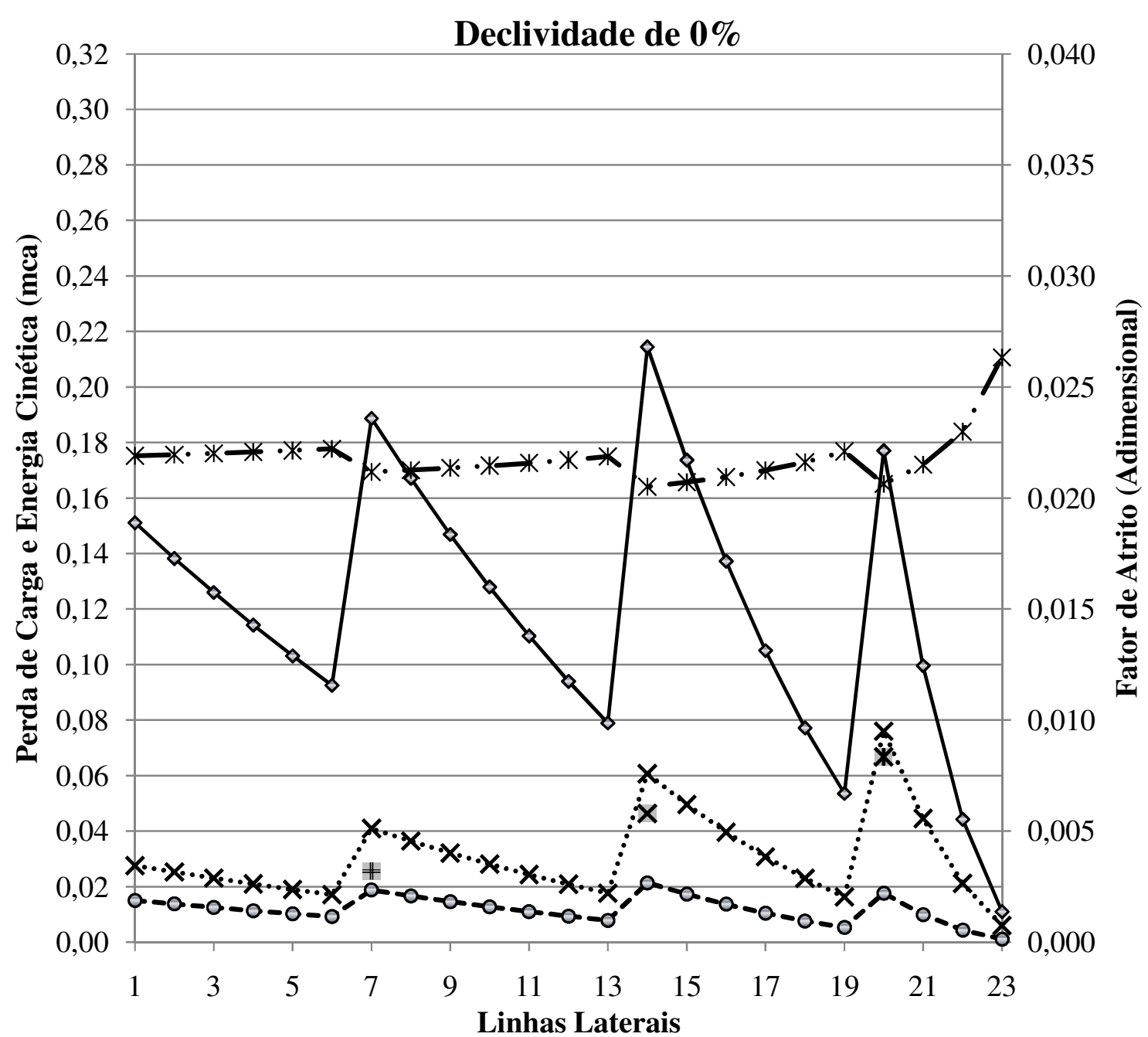

* Perda de Carga Localizada na Primeira Contração da Tubulação

X Perda de Carga Localizada na Segunda Contração da Tubulação

* Perda de Carga Localizada na Terceira Contração da Tubulação

- - - Perda de Carga Localizada com as Linhas Laterais

*.×• Perda de Carga Distribuída na Linha de Derivação

$\multimap$ Energia Cinética na Linha de Derivação

* . Fator de Atrito

Gráfico 16. Perda de carga localizada na primeira, a segunda e a terceira contração da tubulação e o comportamento da perda de carga localizada com as linhas laterais, perda de carga unitária entre as linhas laterais, fator de atrito e a energia cinética, na linha de derivação com vazão em marcha. Dados obtidos no dimensionamento da rede para $0 \%$ de declividade 


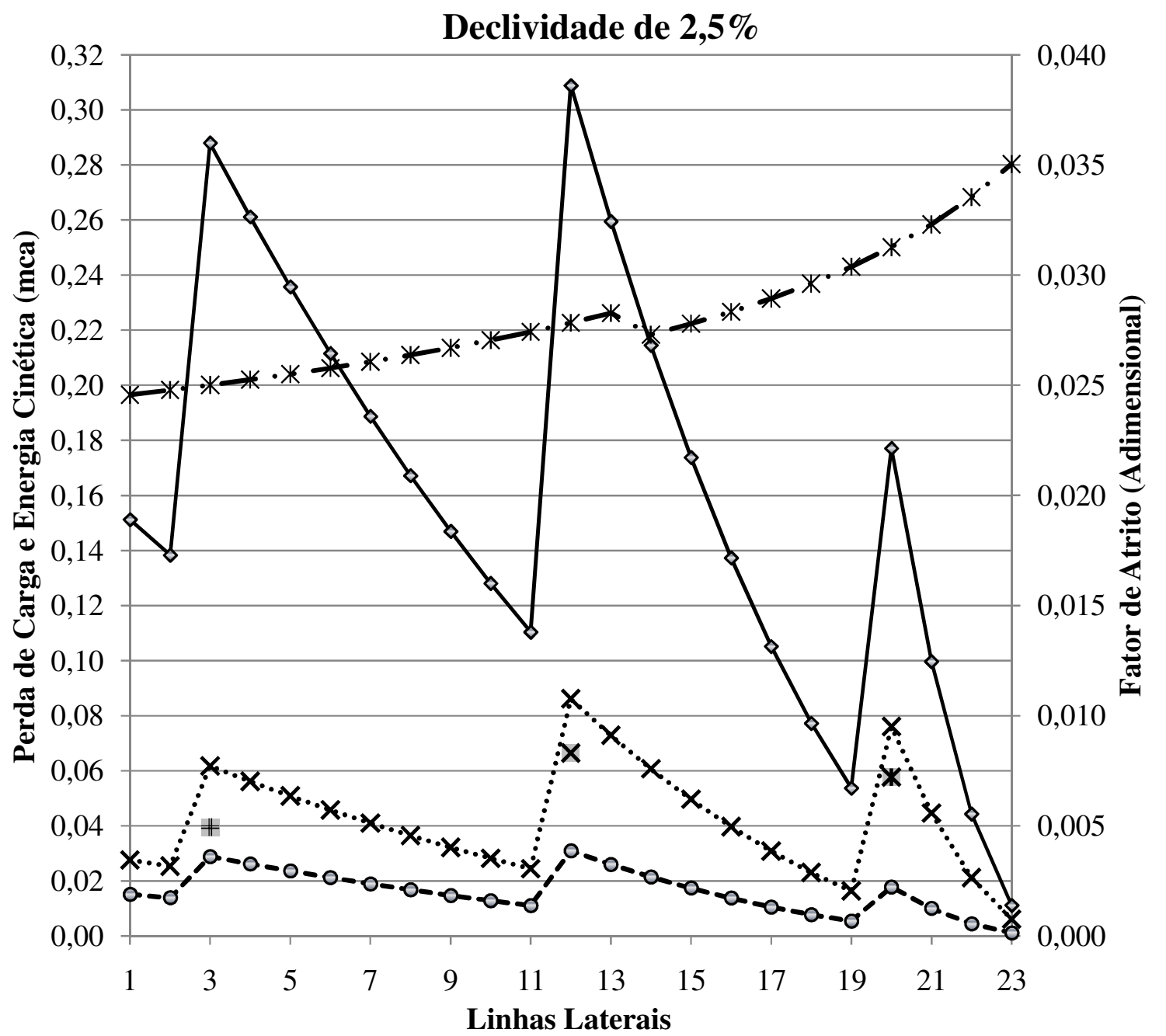

* Perda de Carga Localizada na Primeira Contração da Tubulação

X Perda de Carga Localizada na Segunda Contração da Tubulação

* Perda de Carga Localizada na Terceira Contração da Tubulação

- - - Perda de Carga Localizada com as Linhas Laterais

*.×• Perda de Carga Distribuída na Linha de Derivação

$\multimap$ Energia Cinética na Linha de Derivação

$\rightarrow$ * Fator de Atrito

Gráfico 17. Perda de carga localizada na primeira, a segunda e a terceira contração da tubulação e o comportamento da perda de carga localizada com as linhas laterais, perda de carga unitária entre as linhas laterais, fator de atrito e a energia cinética, na linha de derivação com vazão em marcha. Dados obtidos no dimensionamento da rede para $2,5 \%$ de declividade 


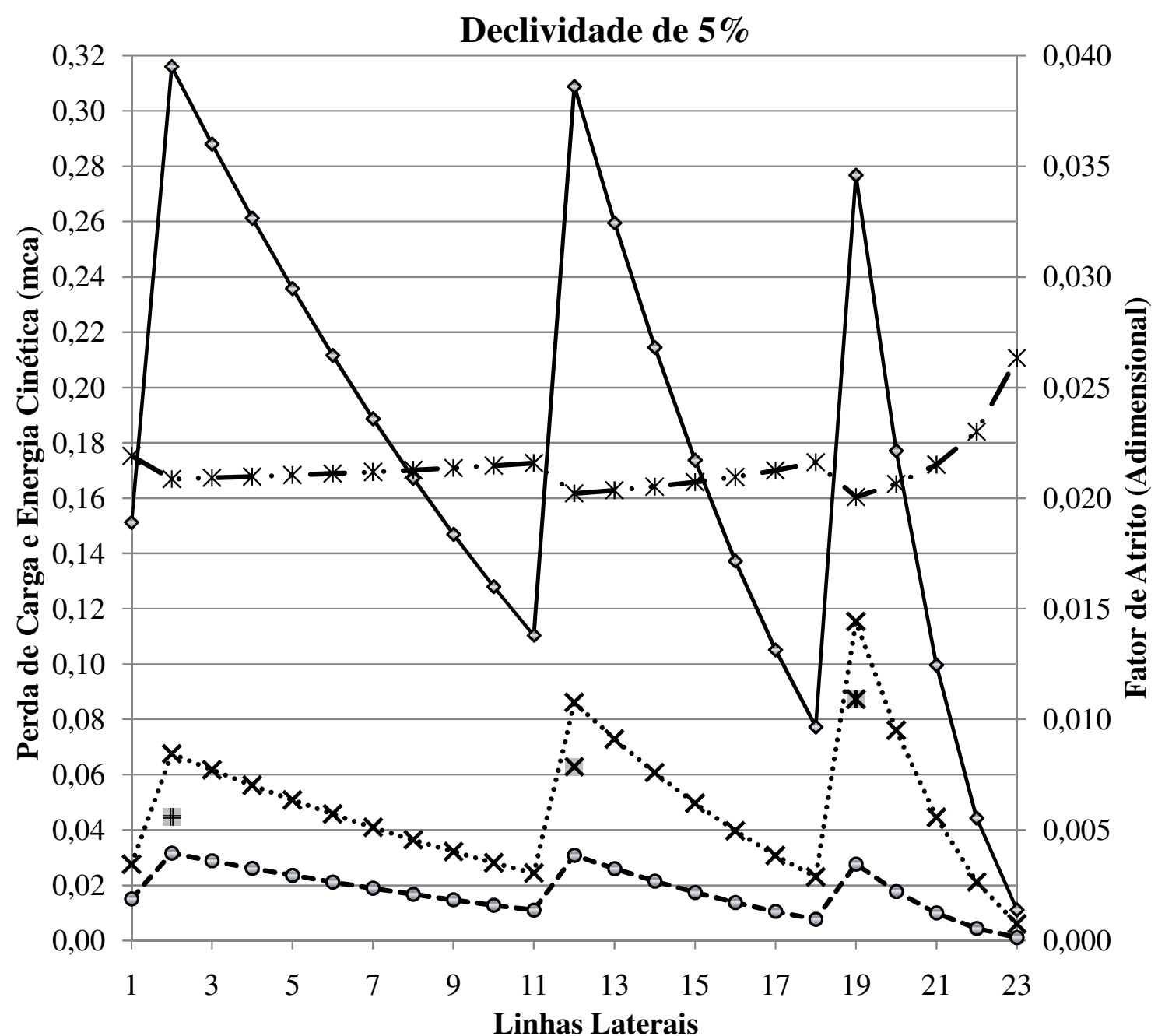

* Perda de Carga Localizada na Primeira Contração da Tubulação

X Perda de Carga Localizada na Segunda Contração da Tubulação

* Perda de Carga Localizada na Terceira Contração da Tubulação

- - - Perda de Carga Localizada com as Linhas Laterais

*.×• Perda de Carga Distribuída na Linha de Derivação

$\multimap$ Energia Cinética na Linha de Derivação

* . Fator de Atrito

Gráfico 18. Perda de carga localizada na primeira, a segunda e a terceira contração da tubulação e o comportamento da perda de carga localizada com as linhas laterais, perda de carga unitária entre as linhas laterais, fator de atrito e a energia cinética, na linha de derivação com vazão em marcha. Dados obtidos no dimensionamento da rede para $5 \%$ de declividade

Verifica-se que a perda de carga localizada no acoplamento das linhas laterais $(0,0247$, 0,0395, 0,0447 mca, respectivamente para 0, 2,5 e 5\% de declividade), em relação ao restante das contrações. Já a segunda contração obteve menores valores (0,0464, 0,0664, 0,0628 mca, 
respectivamente para $0,2,5$ e $5 \%$ de declividade), em geral, que os valores obtidos na terceira contração $(0,0668,0,0576,0,0873$ mca, respectivamente para $0,2,5$ e $5 \%$ de declividade). A exceção foi a terceira contração da tubulação para a declividade de $2,5 \%$, que ficou com menor valor que a declividade de $5 \%$.

Analisando os Gráficos 16, 17 e 18 nota-se que há uma menor variação para todos os parâmetros estudados para a declividade de $0 \%$, havendo um considerável aumento da variação dos valores com declividade de 2,5 e $5 \%$. Com isso verifica-se que quanto maior a declividade do terreno maiores serão os valores alcançados e a amplitude da perda de carga localizada com a contração da tubulação e com o acoplamento das linhas laterais, perda de carga unitária entre as linhas laterais, fator de atrito e a energia cinética, na linha de derivação com vazão em marcha.

Os Gráficos 19, 20 e 21 apresentam as linhas de energia, piezométrica, de carga de pressão e da cota do terreno da linha de derivação, sob vazão em marcha.

Observa-se que o comportamento da energia cinética (Gráficos 19, 20 e 21) na tubulação contribuí para um distanciamento entre as linhas de energia e piezométrica no começo dos 4 trechos da linha de derivação (Tabelas 5 e 6), tanto para a declividade de 0, 2,5 ou 5\%. No final dos 4 trechos da tubulação, os valores da linha de energia e da linha piezométrica ficam muito próximos, devido a contração da tubulação, e praticamente se igualando no final do quarto trecho, quando o valor da energia cinética é fica próximo de zero. Identifica-se também, na análise comparativa dos Gráficos 13, 14 e 15, que, devido ao ganho de energia mais contrabalanceado com a perda de carga total na tubulação, a declividade de 2,5\% favoreceu uma melhor distribuição das linhas de energia e piezométrica na tubulação. 


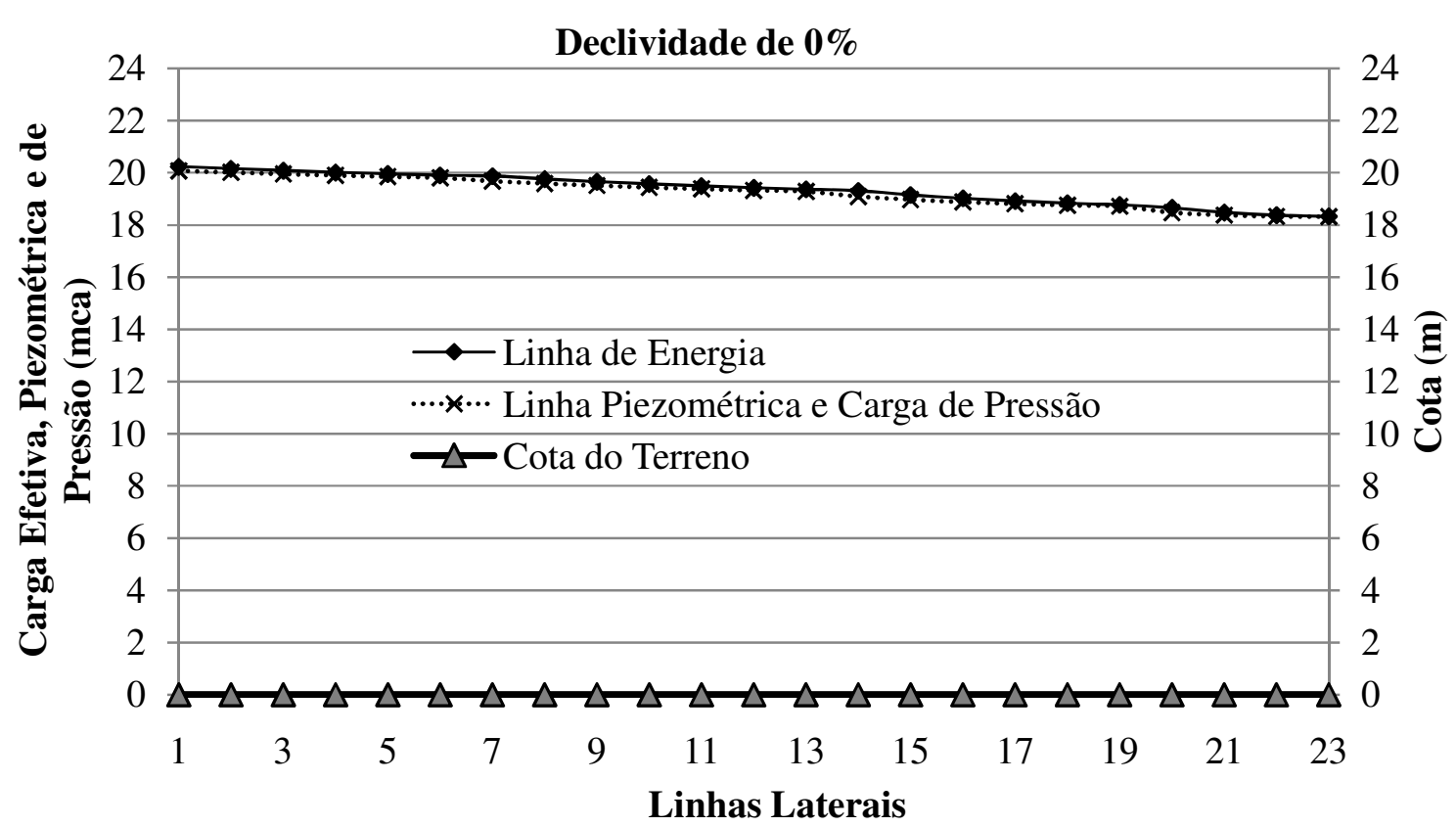

Gráfico 19. Variação das linhas de energia, piezométrica, de carga de pressão e da cota do terreno da linha de derivação, sob vazão em marcha, para $0 \%$ de declividade

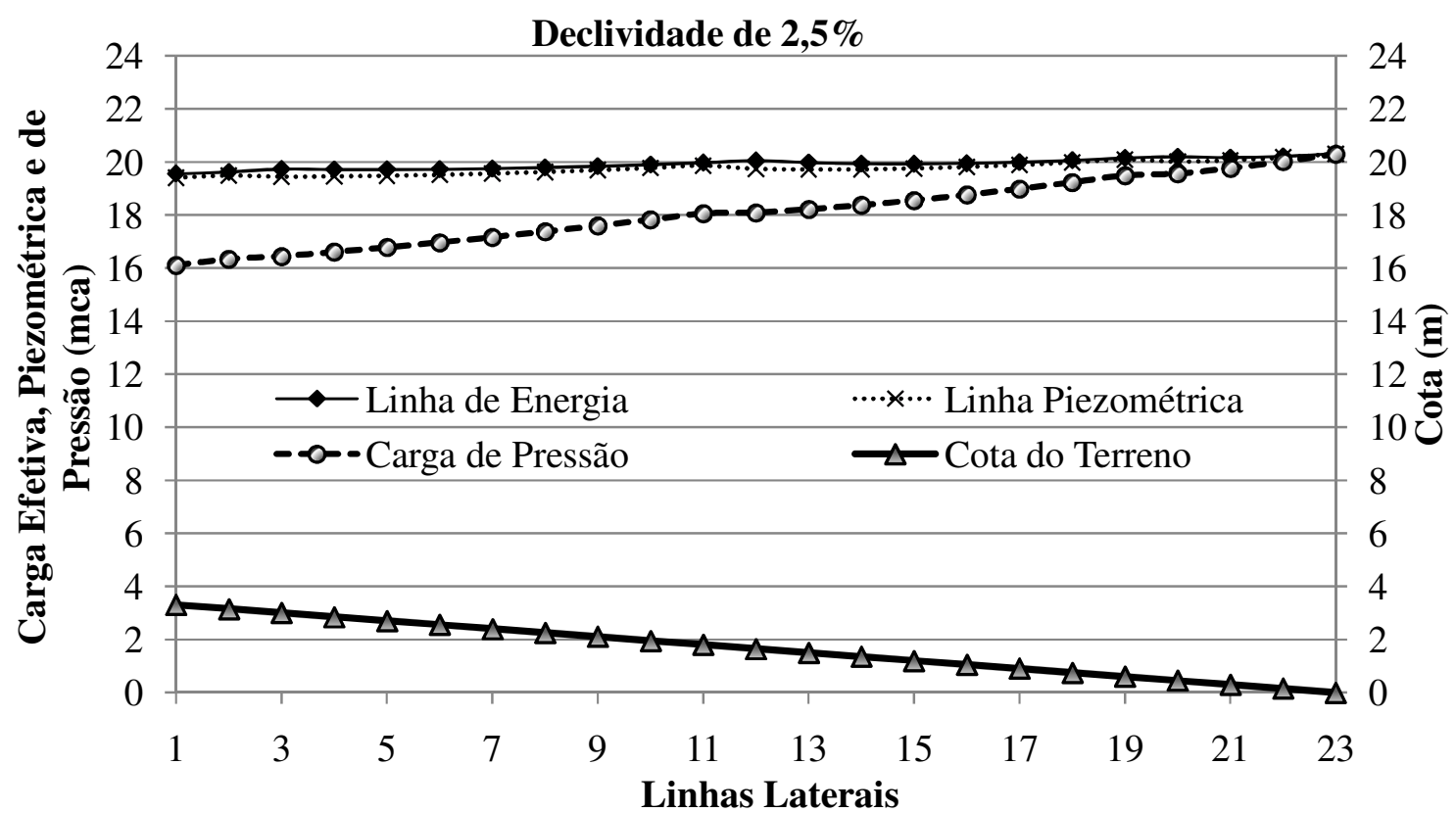

Gráfico 20. Variação das linhas de energia, piezométrica, de carga de pressão e da cota do terreno da linha de derivação, sob vazão em marcha, para a declividade de $2,5 \%$ 


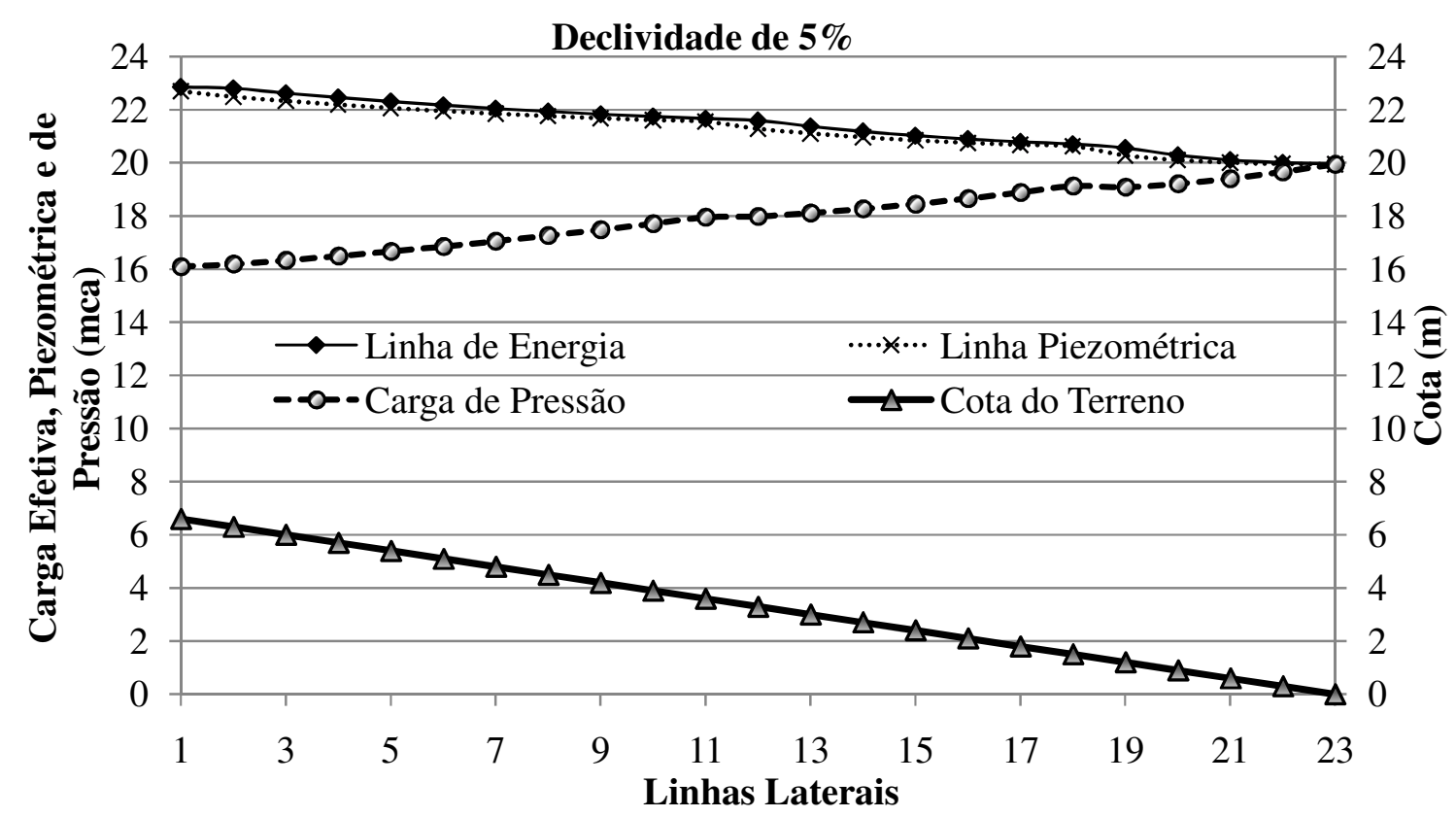

Gráfico 21. Variação das linhas de energia, piezométrica, de carga de pressão e da cota do terreno da linha de derivação, sob vazão em marcha, para a declividade de 5\%

Os Gráficos 20 e 21 mostram a influência que a cota do terreno, e seu respectivo ganho de energia (com a tubulação em declive), tem sobre as linhas de energia, piezométrica e da carga de pressão. Esta influência determinará as suas distribuições em toda unidade operacional e, conseqüentemente, na distribuição de vazão e de produção em toda a área (temas que serão discutidos nos próximos tópicos).

\subsubsection{Análise hidráulica da unidade operacional}

Os Gráficos 22, 23 e 24 mostram, respectivamente, o plano de carga efetiva (energia) para as declividades de $0,2,5$, e $5 \%$ em toda a unidade operacional, que consiste em 23 linhas laterais (com 28 emissores em cada linha lateral) acopladas em cada lado da linha de derivação, totalizando 46 linhas laterais e 1288 emissores na unidade operacional (Figuras 3, $4,5$ e 6$)$ 


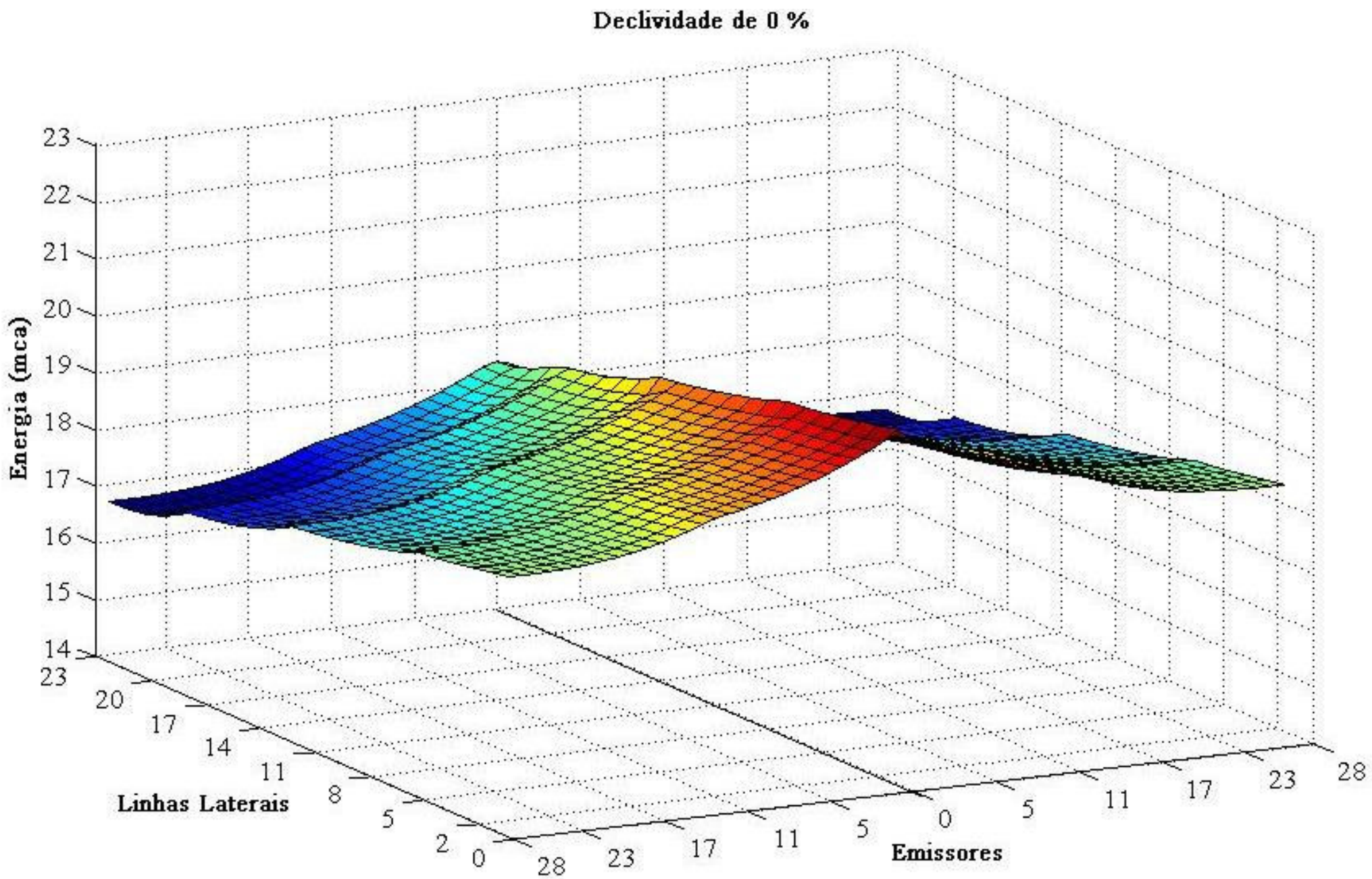

Gráfico 22. Plano de carga efetiva (energia) na unidade operacional para declividade de $0 \%$ 


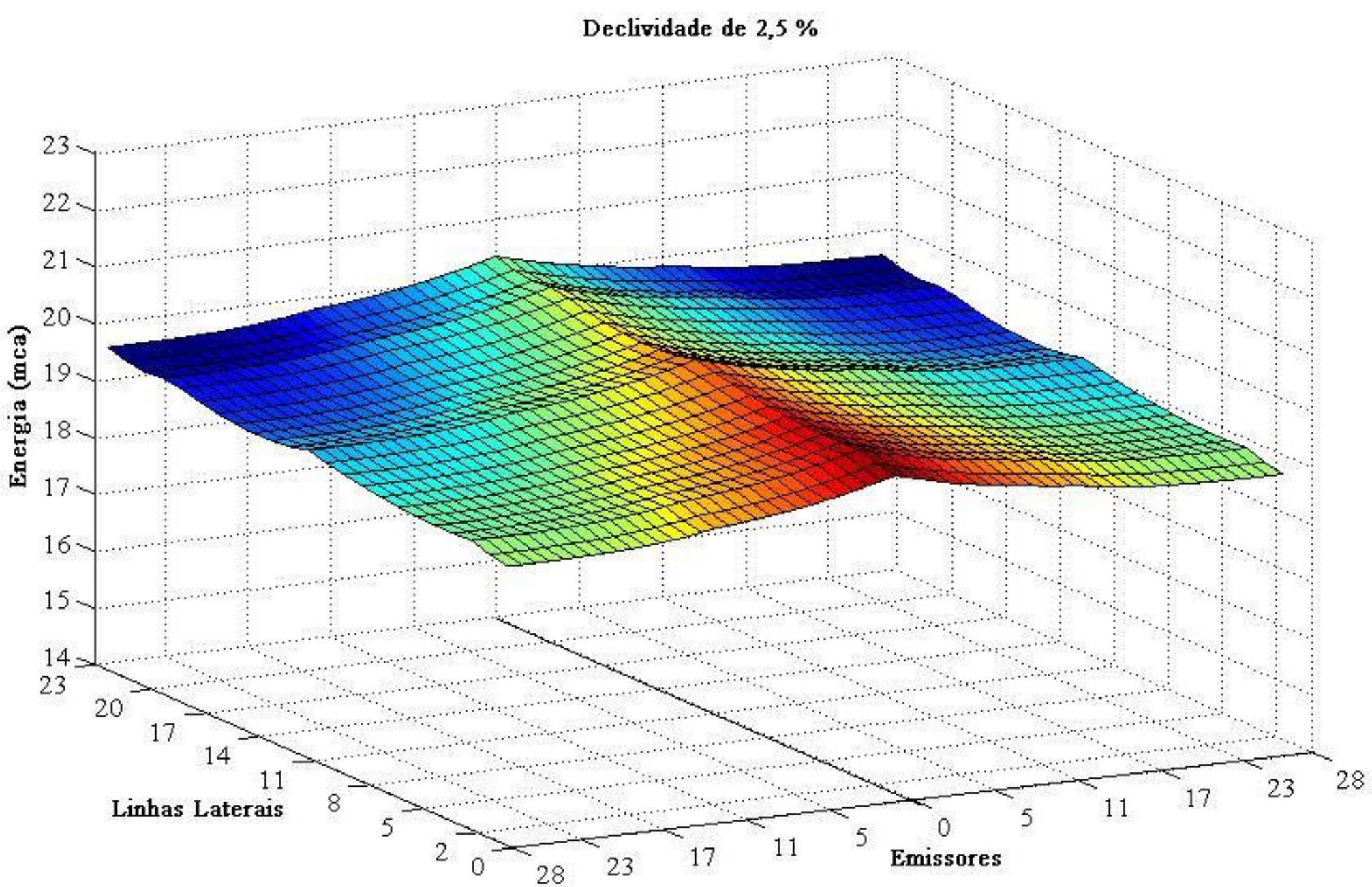

Gráfico 23. Plano de carga efetiva (energia) na unidade operacional para declividade de $2,5 \%$ 


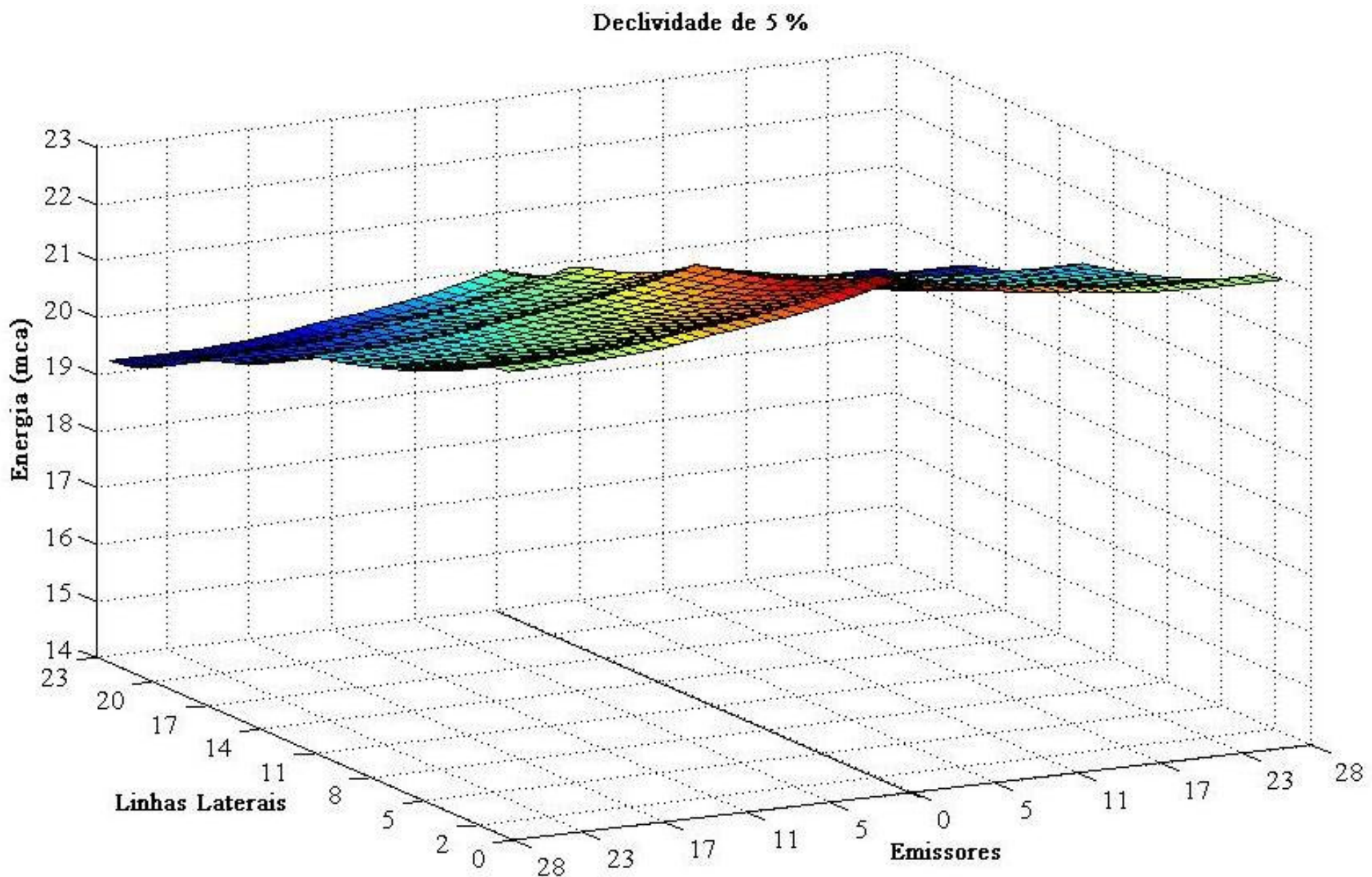

Gráfico 24. Plano de carga efetiva (energia) na unidade operacional para declividade de 5\% 
A variação de energia, considerando os pontos de emissão (emissores) acoplados nas linhas laterais e a declividade do terreno de 2,5\%, apresentaram uma menor amplitude, em relação as declividades de 0 e 5\% (Tabela 14). Analisando os Gráficos 22, 23 e 24 verifica-se que as maiores cargas totais encontram-se no começo da unidade operacional (em vermelho), ocorrendo uma queda gradual da energia conforme a declividade do terreno e a evolução da perda de carga segundo o diâmetro da tubulação (Tabela 6). Para toda análise de sensibilidade proposta, verifica-se que a amplitude entre a máxima e a mínima carga efetiva na unidade operacional foi mais que o dobro para a $0 \%$ de declividade em relação a $2,5 \%$ de declividade.

Devido ao ganho de energia com a declividade do terreno, verifica-se que os maiores valores de carga efetiva máxima, mínima e média foram observados com 5\% de declividade.

Tabela 14. Carga efetiva (energia) máxima, mínima, média, amplitude absoluta e percentual observada nos emissores da unidade operacional segundo a variação da declividade do terreno e da tarifa de energia elétrica

\begin{tabular}{|c|c|c|c|c|c|c|}
\hline \multirow{3}{*}{$\begin{array}{c}\text { Declividade } \\
---\% \text {---- }\end{array}$} & \multirow{3}{*}{$\begin{array}{c}\text { Tarifa } \\
\text { Água / } \\
\text { Energia Elétrica }\end{array}$} & \multicolumn{5}{|c|}{ Carga Efetiva (Energia) nos Emissores } \\
\hline & & Máxima & Mínima & Média & \multicolumn{2}{|c|}{ Amplitude } \\
\hline & & ----------- & ------- L.h'- & ------ & ---- & $---\%---$ \\
\hline 0 & & 20,35 & 16,82 & 18,37 & 3,53 & 17,3 \\
\hline 2,5 & $100 \% / 50 \%$ & 20,22 & 18,55 & 19,31 & 1,66 & 8,2 \\
\hline 5 & & 22,57 & 19,78 & 20,91 & 2,79 & 12,3 \\
\hline 0 & & 20,50 & 16,89 & 18,37 & 3,61 & 17,6 \\
\hline 2,5 & $100 \% / 75 \%$ & 20,30 & 18,97 & 18,97 & 1,33 & 6,5 \\
\hline 5 & & 22,99 & 19,38 & 21,08 & 3,61 & 15,7 \\
\hline 0 & & 20,02 & 16,68 & 18,16 & 3,34 & 16,7 \\
\hline 2,5 & $100 \% / 100 \%$ & 20,25 & 18,77 & 19,37 & 1,48 & 7,3 \\
\hline 5 & & 22,79 & 19,18 & 20,88 & 3,61 & 15,8 \\
\hline 0 & & 20,35 & 16,82 & 18,37 & 3,53 & 17,3 \\
\hline 2,5 & $100 \% / 125 \%$ & 20,24 & 18,99 & 19,55 & 1,24 & 6,1 \\
\hline 5 & & 23,01 & 19,66 & 21,15 & 3,35 & 14,6 \\
\hline 0 & & 21,63 & 17,66 & 19,32 & 3,96 & 18,3 \\
\hline 2,5 & $100 \% / 150 \%$ & 20,30 & 18,96 & 19,60 & 1,34 & 6,6 \\
\hline 5 & & 22,98 & 20,20 & 21,32 & 2,78 & 12,1 \\
\hline
\end{tabular}


A amplitude da variação da carga hidráulica (Tabela 15) apresentou a menor amplitude para a declividade de $0 \%$ e tarifa cheia de água e energia elétrica. A maior amplitude foi observada para $5 \%$ de declividade do terreno e tarifa cheia de água e 50\% da tarifa de energia elétrica. Verifica-se também que as maiores amplitudes e os menores valores de pressão mínima foram observadas para as declividades de 2,5 e $5 \%$. Com isto verifica-se que o terreno em nível contribuiu para uma menor queda nos valores de pressão ao longo das tubulações da unidade operacional, resultando em valores de pressão médios acima dos com declividade.

Tabela 15. Pressão máxima, mínima, média, amplitude absoluta e percentual observada nos emissores da unidade operacional segundo a variação da declividade do terreno e da tarifa de energia elétrica

\begin{tabular}{|c|c|c|c|c|c|c|}
\hline & Tarifa & \multicolumn{5}{|c|}{ Pressão nos Emissores } \\
\hline Declividade & Água / & Máxima & Mínima & Média & \multicolumn{2}{|c|}{ Amplitude } \\
\hline$---\%$ & Energia Elétrica & |---------- & ------- L & ------ n & 管---- & --- \% --- \\
\hline 0 & & 20,29 & 16,82 & 18,34 & 3,46 & 17,1 \\
\hline 2,5 & $100 \% / 50 \%$ & 20,15 & 14,25 & 16,96 & 5,90 & 29,3 \\
\hline 5 & & 20,44 & 14,25 & 16,92 & 6,18 & 30,3 \\
\hline 0 & & 20,43 & 16,89 & 18,42 & 3,54 & 17,3 \\
\hline 2,5 & $100 \% / 75 \%$ & 20,23 & 14,67 & 17,24 & 5,56 & 27,5 \\
\hline 5 & & 20,03 & 14,67 & 17,05 & 5,36 & 26,8 \\
\hline 0 & & 19,95 & 16,68 & 18,13 & 3,27 & 16,4 \\
\hline 2,5 & $100 \% / 100 \%$ & 20,19 & 14,47 & 17,01 & 5,72 & 28,3 \\
\hline 5 & & 19,83 & 14,47 & 16,85 & 5,36 & 27,0 \\
\hline 0 & & 20,29 & 16,82 & 18,34 & 3,46 & 17,1 \\
\hline 2,5 & $100 \% / 125 \%$ & 20,17 & 14,69 & 17,18 & 5,47 & 27,1 \\
\hline 5 & & 20,31 & 14,69 & 17,13 & 5,62 & 27,7 \\
\hline 0 & & 21,56 & 17,66 & 19,29 & 3,90 & 18,1 \\
\hline 2,5 & $100 \% / 150 \%$ & 20,23 & 14,66 & 17,23 & 5,57 & 27,5 \\
\hline 5 & & 20,86 & 14,66 & 17,33 & 6,20 & 29,7 \\
\hline
\end{tabular}

Ressalta-se que, as variações entre as distribuições de pressão e energia(Gráficos 25, 26, 27 e Tabela 15), para as diferentes declividades estudadas, são provocadas pelo ganho ou perda de carga de posição devido à declividade a que está submetida a linha de derivação, que distribui a água para as linhas laterais (Figuras 2 e 3). 


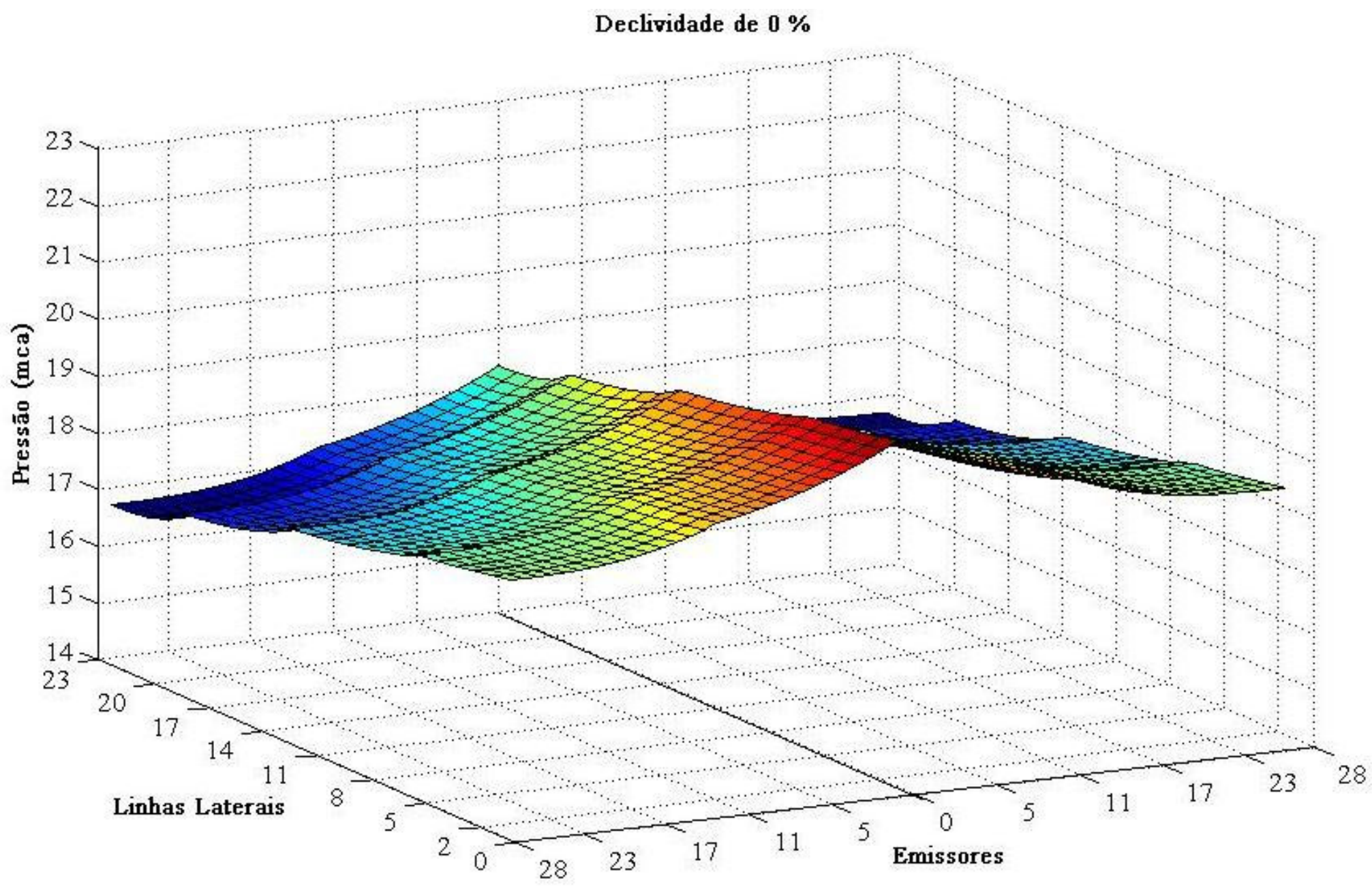

Gráfico 25. Plano de carga hidráulica (pressão) na unidade operacional para declividade de $0 \%$ 


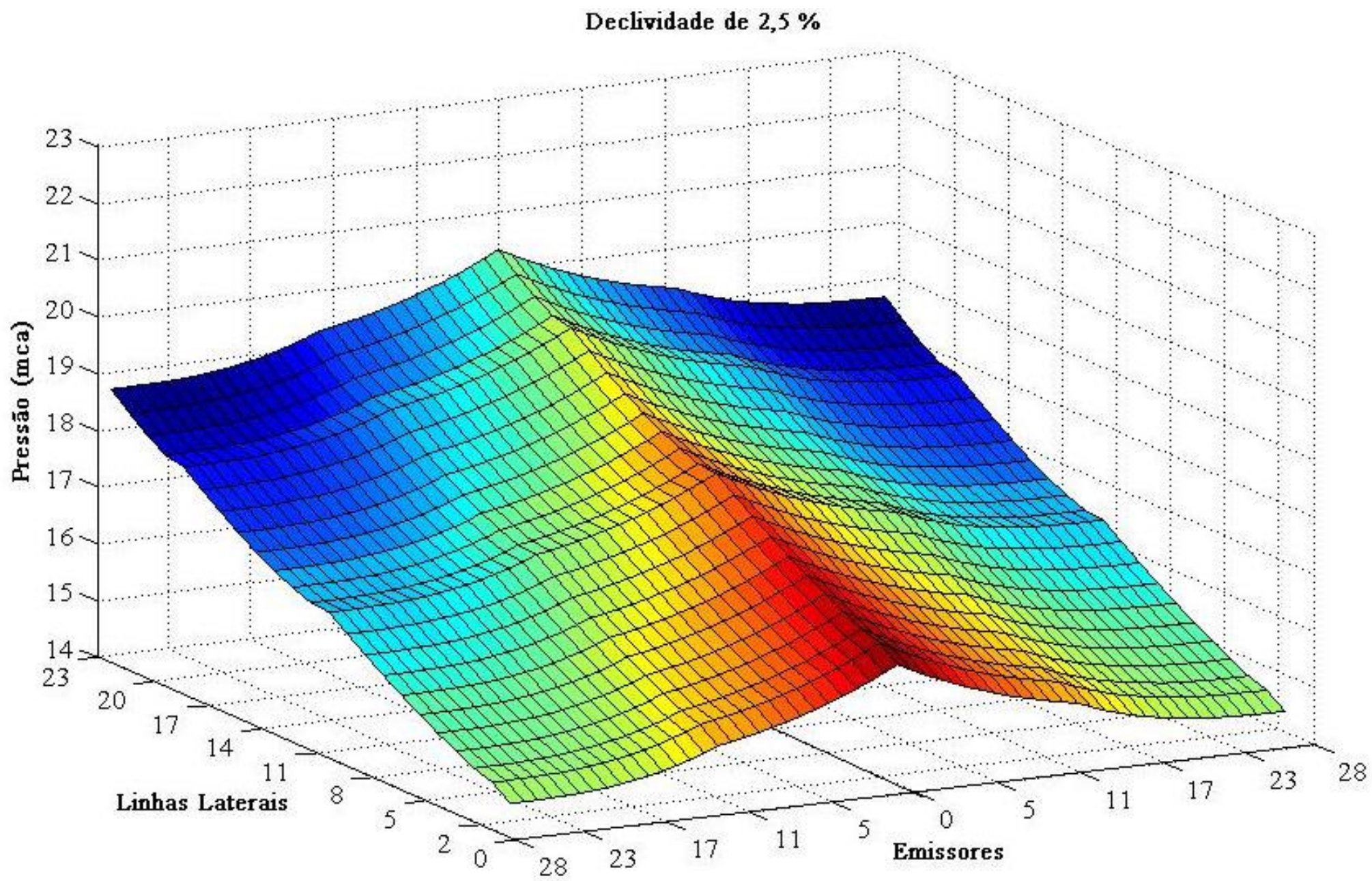

Gráfico 26. Plano de carga hidráulica (pressão) na unidade operacional para declividade de 2,5\% 


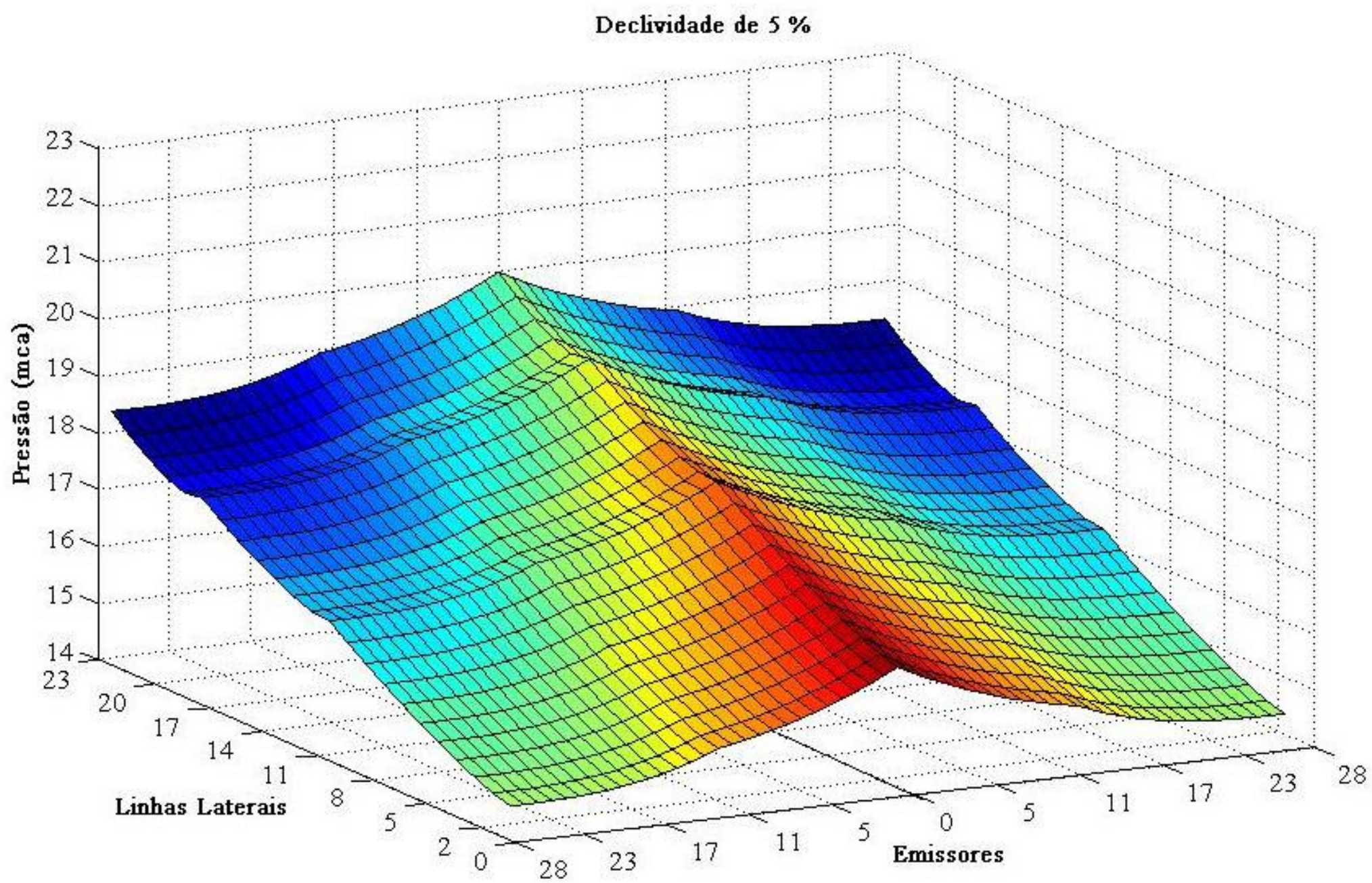

Gráfico 27. Plano de carga hidráulica (pressão) na unidade operacional para declividade de 5\% 
Os Gráficos 28, 29, 30 e a Tabela 16 apresentam a variação de vazão nos emissores na unidade operacional. A vazão em cada ponto de emissão foi calculada utilizando a equação (31) do emissor empregando os valores de pressão discutidos anteriormente.

Tabela 16. Vazão nos emissores máxima, mínima, média, amplitude absoluta e percentual observada na unidade operacional segundo a variação da declividade do terreno e da tarifa de energia elétrica

\begin{tabular}{|c|c|c|c|c|c|c|}
\hline & Tarifa & \multicolumn{5}{|c|}{ Vazão nos Emissores } \\
\hline \multirow{2}{*}{$\begin{array}{c}\text { Declividade } \\
\text {---- \% ---- }\end{array}$} & \multirow{2}{*}{$\begin{array}{c}\text { Água / } \\
\text { Energia Elétrica }\end{array}$} & Máxima & Mínima & Média & \multicolumn{2}{|c|}{ Amplitude } \\
\hline & & ---------. & - & 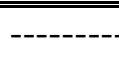 & ----- & $---\%$--- \\
\hline 0 & & 74,93 & 62,14 & 67,75 & 12,78 & 17,1 \\
\hline 2,5 & $100 \% / 50 \%$ & 74,42 & 52,64 & 62,64 & 21,78 & 29,3 \\
\hline 5 & & 75,48 & 52,64 & 62,49 & 22,84 & 30,3 \\
\hline 0 & & 75,46 & 62,39 & 68,04 & 13,07 & 17,3 \\
\hline 2,5 & $100 \% / 75 \%$ & 74,74 & 54,19 & 63,69 & 20,54 & 27,5 \\
\hline 5 & & 73,99 & 54,19 & 62,98 & 19,80 & 26,8 \\
\hline 0 & & 73,70 & 61,61 & 66,97 & 12,09 & 16,4 \\
\hline 2,5 & $100 \% / 100 \%$ & 74,56 & 53,44 & 62,82 & 21,12 & 28,3 \\
\hline 5 & & 73,24 & 53,44 & 62,23 & 19,80 & 27,0 \\
\hline 0 & & 74,93 & 62,14 & 67,75 & 12,78 & 17,1 \\
\hline 2,5 & $100 \% / 125 \%$ & 74,49 & 54,27 & 63,45 & 20,22 & 27,1 \\
\hline 5 & & 75,02 & 54,27 & 63,27 & 20,75 & 27,7 \\
\hline 0 & & 79,64 & 65,24 & 71,25 & 14,40 & 18,1 \\
\hline 2,5 & $100 \% / 150 \%$ & 74,72 & 54,15 & 63,65 & 20,57 & 27,5 \\
\hline 5 & & 77,06 & 54,15 & 64,00 & 22,91 & 29,7 \\
\hline
\end{tabular}

Verificando-se as tendências de distribuição de vazão para as 3 declividades avaliadas, observa-se que obedecem a mesma tendência de distribuição de pressão na unidade operacional, já que a vazão no emissor é diretamente dependente da pressão no ponto de emissão. Com isso verifica-se que as amplitudes calculadas com os valores de pressão (Tabela 15) e vazão (Tabela 16) são os mesmos.

Uma análise estatística mais consistente sobre a variação da vazão na unidade operacional, utilizando-se do conceito de uniformidade de emissão, será executada no item 5.5., utilizando-se de métodos freqüentemente aplicados pela literatura especializada. 


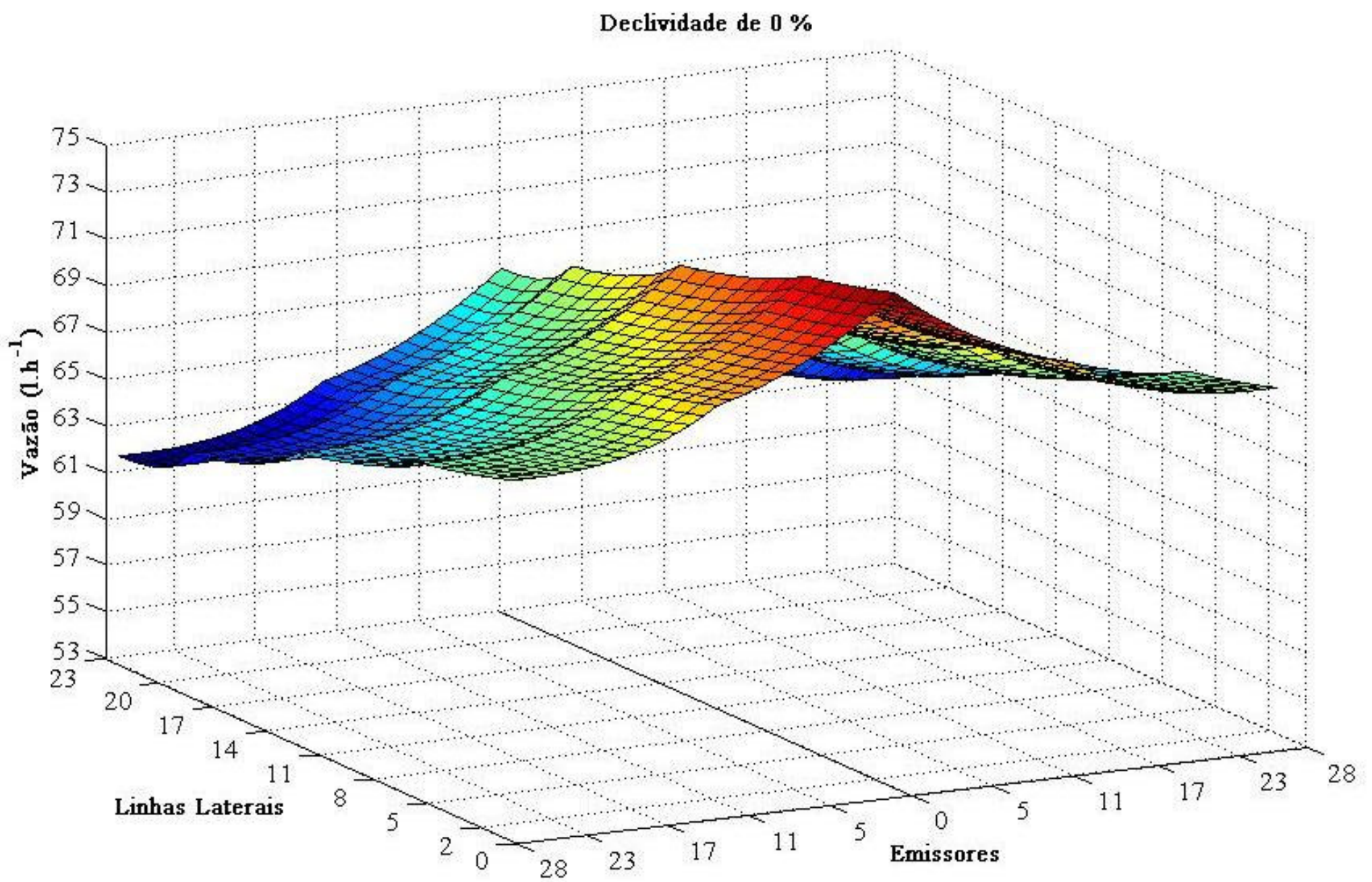

Gráfico 28. Distribuição da vazão na unidade operacional para declividade de $0 \%$ 


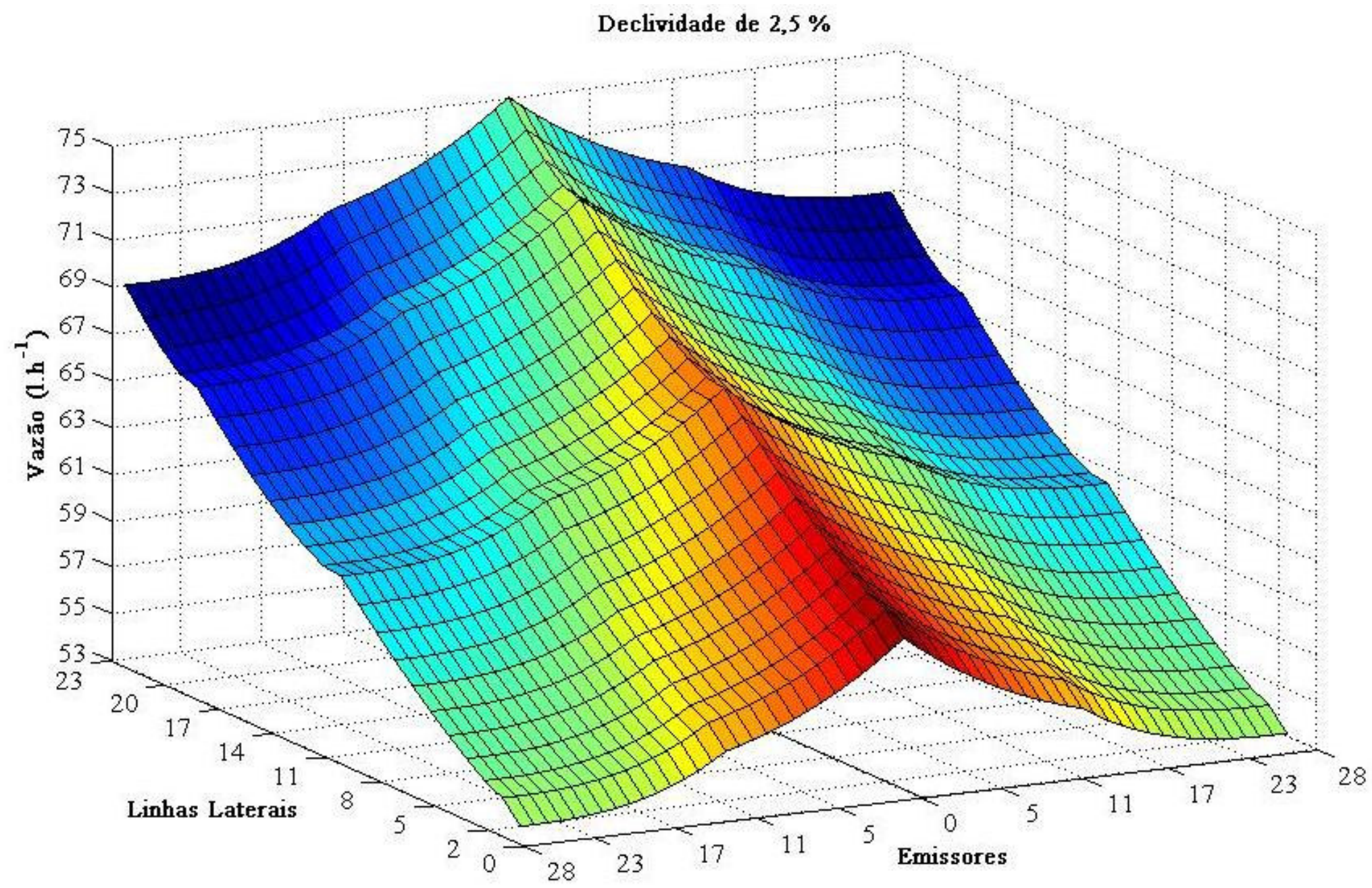

Gráfico 29. Distribuição da vazão na unidade operacional para declividade de 2,5\% 


\section{Declividade de $5 \%$}

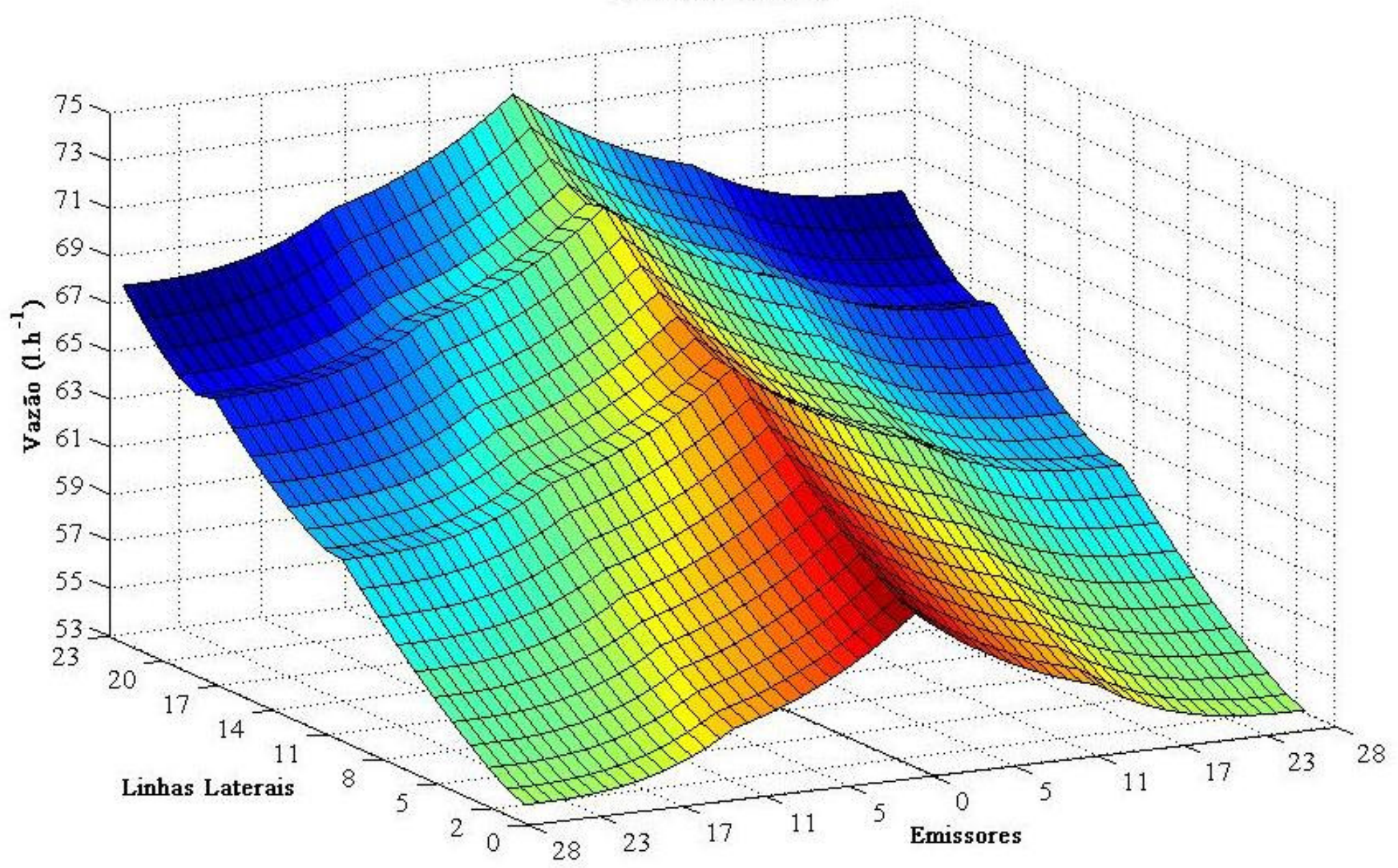

Gráfico 30. Distribuição da vazão na unidade operacional para declividade de 5\% 
5.5. Uniformidade de emissão, uniformidade estatística e diferença de vazão entre o primeiro e o último emissor na unidade operacional

A Tabela 17 mostra duas análises da uniformidade de emissão (Keller e Karmelli, 1974; Bralts, 1986), a uniformidade estatística (Wilcox e Swailes, 1947), além de apresentar a diferença total de vazão entre o primeiro e o último emissor na unidade operacional. No dimensionamento objetivou-se alcançar uma uniformidade de emissão (UE) de 92\% (APÊNDICE B), utilizando-se as equações 24 e 29. Ressalta-se também que uma das restrições impostas ao dimensionamento, otimizado por algoritmos genéticos, foi a uniformidade estatística (Us) mínima de $90 \%$ para os emissores acoplados na linha lateral (APÊNDICE D).

Tabela 17. Análise da uniformidade de emissão calculada por Keller e Karmelli (1974) $)^{1}$ e Bralts $(1986)^{2}$, uniformidade estatística calculado por Wilcox e Swailes $(1947)^{3} \mathrm{e}$ diferença total de vazão entre o primeiro e o último emissor $\left(\mathrm{DPU}^{4}\right)$ na unidade operacional

\begin{tabular}{|c|c|c|c|c|c|}
\hline \multirow{2}{*}{$\begin{array}{c}\text { Declividade } \\
---\% \text {---- }\end{array}$} & Tarifa & $\mathrm{UE}^{1}$ & $\mathrm{UE}_{\mathrm{b}}^{2}$ & $\mathrm{Us}^{3}$ & $\mathrm{DPU}^{4}$ \\
\hline & Água / Energia Elétrica & \multicolumn{4}{|c|}{ "------------------------- \% -------------------------- } \\
\hline 0 & \multirow{3}{*}{$100 \% / 50 \%$} & 94,35 & 91,01 & 95,66 & $-17,06$ \\
\hline 2,5 & & 89,70 & 86,52 & 92,05 & 18,22 \\
\hline 5 & & 89,18 & 86,02 & 91,39 & 20,05 \\
\hline 0 & \multirow{3}{*}{$100 \% / 75 \%$} & 94,31 & 90,97 & 95,60 & $-17,32$ \\
\hline 2,5 & & 90,36 & 87,16 & 92,67 & 15,68 \\
\hline 5 & & 90,34 & 87,14 & 92,67 & 14,44 \\
\hline 0 & \multirow{3}{*}{$100 \% / 100 \%$} & 94,72 & 91,37 & 95,93 & $-16,40$ \\
\hline 2,5 & & 90,00 & 86,82 & 92,21 & 16,85 \\
\hline 5 & & 90,29 & 87,09 & 92,58 & 14,62 \\
\hline 0 & \multirow{3}{*}{$100 \% / 125 \%$} & 94,36 & 91,02 & 95,66 & $-17,06$ \\
\hline 2,5 & & 90,42 & 87,22 & 92,69 & 15,12 \\
\hline 5 & & 90,12 & 86,93 & 92,28 & 16,00 \\
\hline 0 & \multirow{3}{*}{$100 \% / 150 \%$} & 94,06 & 90,73 & 95,36 & $-18,08$ \\
\hline 2,5 & & 90,34 & 87,14 & 92,65 & 15,75 \\
\hline 5 & & 89,43 & 86,26 & 91,58 & 19,66 \\
\hline
\end{tabular}


Os resultados de uniformidade de emissão calculados por Keller e Karmelli (1974) e Bralts (1986) apresentaram resultados classificados como muito bom ou excelente, segundo a classificação (Quadro 8) apresentada por Bralts (1986). Os resultados obtidos por Keller e Karmelli (1974) apresentaram valores relativamente mais elevados do que os resultados obtidos por Bralts (1986), independente da análise de sensibilidade aplicada.

Todos os resultados de uniformidade estatística são classificados como excelente (Quadro 9) segundo os critérios de classificação apresentados por Wilcox e Swailes (1947).

Para as 3 uniformidades analisadas, a rede de irrigação em terreno com $0 \%$ de declividade obteve os melhores resultados, seguida do terreno com 2,5\% de declividade e, por último, o que apresentou os piores resultados de uniformidade foi o terreno com $5 \%$ de declividade.

A análise da Tabela 13 também identifica que a uniformidade estatística calculada por Wilcox e Swailes (1947) obteve os melhores resultados médios, seguida da uniformidade de emissão calculada por Keller e Karmelli (1974) e por último a uniformidade de emissão calculada por Bralts (1986). Estas diferenças acontecem devido aos parâmetros de cálculo utilizados em todos os métodos (equações 80, 81 e 82), já discutidos no item 4.10.

Analisando-se os resultados da diferença total de vazão entre o primeiro e o último emissor, verifica-se que com $0 \%$ de declividade houve um decréscimo de vazão devido a diminuição de pressão pela perda de carga total na tubulação. Com as declividades de 2,5 e 5\% obteve-se mais ganho de carga do perda de carga na tubulação o que resultou em um aumento da vazão ao longo da unidade operacional. 
5.6. Análise da produtividade na área

Neste tópico é tratado a variação de produtividade (Gráficos 32, 33 e 34) em toda área da unidade operacional para as 3 declividades estudadas considerando $100 \%$ do valor das tarifas de água e energia elétrica. Discuti-se também a produtividade máxima, mínima, média, amplitude absoluta e percentual (Tabela 18) para as 3 declividades e as variações propostas na tarifa de energia elétrica.

Tabela 18. Produtividade máxima, mínima, média, amplitude absoluta e percentual observada na unidade operacional segundo a variação da declividade do terreno e da tarifa de energia elétrica

\begin{tabular}{|c|c|c|c|c|c|c|}
\hline & Tarifa & \multicolumn{5}{|c|}{ Produtividade } \\
\hline \multirow{2}{*}{$\begin{array}{l}\text { Declividade } \\
\text {---- \% ---- }\end{array}$} & \multirow{2}{*}{$\begin{array}{c}\text { Água / } \\
\text { Energia Elétrica }\end{array}$} & Máxima & Mínima & Média & \multicolumn{2}{|c|}{ Amplitude } \\
\hline & & "----------- & -- kg.plan & $\mathrm{ano}^{-1}-$. & ----- & $---\%---$ \\
\hline 0 & & 248,47 & 247,06 & 248,21 & 1,42 & 0,6 \\
\hline 2,5 & $100 \% / 50 \%$ & 248,47 & 241,48 & 246,88 & 7,00 & 2,8 \\
\hline 5 & & 248,47 & 241,48 & 246,71 & 7,00 & 2,8 \\
\hline 0 & & 248,47 & 246,83 & 248,21 & 1,64 & 0,7 \\
\hline 2,5 & $100 \% / 75 \%$ & 248,47 & 242,82 & 247,27 & 5,65 & 2,3 \\
\hline 5 & & 248,47 & 242,82 & 247,09 & 5,65 & 2,3 \\
\hline 0 & & 248,47 & 247,26 & 248,22 & 1,21 & 0,5 \\
\hline 2,5 & $100 \% / 100 \%$ & 248,47 & 242,18 & 246,96 & 6,29 & 2,5 \\
\hline 5 & & 248,47 & 242,18 & 246,85 & 6,29 & 2,5 \\
\hline 0 & & 248,47 & 247,06 & 248,21 & 1,42 & 0,6 \\
\hline 2,5 & $100 \% / 125 \%$ & 248,47 & 242,88 & 247,22 & 5,59 & 2,2 \\
\hline 5 & & 248,47 & 242,88 & 247,10 & 5,59 & 2,2 \\
\hline 0 & & 248,47 & 244,47 & 247,84 & 4,00 & 1,6 \\
\hline 2,5 & $100 \% / 150 \%$ & 248,47 & 242,78 & 247,26 & 5,69 & 2,3 \\
\hline 5 & & 248,47 & 242,78 & 247,14 & 5,69 & 2,3 \\
\hline
\end{tabular}

A distribuição de produtividade de cada planta foi calculada pela equação 83 segundo a distribuição de árvores irrigadas na área, sendo diretamente influenciada pela variação de vazão dos emissores já discutida no item anterior (volume de água aplicado anualizado). A 
equação 83 segue o comportamento de uma função potencial (Gráfico 4), ou seja, tanto a falta de água como o excesso, no ponto de emissão, provocam queda na produtividade localizada.

Os resultados da variação de produtividade na área mostram que o menor valor de produtividade, que foi de $241,48 \mathrm{~kg} \cdot \mathrm{planta}^{-1}$. ano ${ }^{-1}$, foi observada para 2,5 e $5 \%$ considerando $50 \%$ do valor da tarifa de energia elétrica. A maior produtividade média, que foi de 248,22 kg.planta ${ }^{-1} \cdot$ ano $^{-1}$, foi obtida para $0 \%$ de declividade considerando tarifa cheia de água e energia elétrica. Estas variações são elucidadas observando concomitantemente as Tabelas 16 e 18, pois a produtividade de cada planta, segundo a equação 83, é diretamente influenciada pelo volume de água aplicado por planta anualmente e, este por sua vez, é diretamente dependente da vazão do emissor.

A não alteração nos valores de produtividade máxima deve-se ao fato que a mesma é sempre alcançada com uma vazão no emissor de $68{\mathrm{~L} . \mathrm{h}^{-1} \text {, o equivalente a } 8275 \mathrm{~L}_{\text {.planta }}{ }^{-1} \text {.ano }}^{-}$ 1. Valores abaixo ou acima deste volume de água aplicado por ano, conforme pode ser constatado no Gráfico 4, retornam uma produtividade aquém da máxima possível. Atrelada a esta informação acrescenta-se que, todas as variações na analise de sensibilidade proposta fornecem valores de vazão que contemplam valores próximos de $681 . h^{-1}$ que retornam sempre a produtividade máxima para a planta. Esta discussão pode ser verificada analisando os Gráficos 28, 29, 30 e a Tabela 16.

Analisando os Gráficos 31, 32 e 33 e a Tabela 18, verifica-se que as melhores distribuições de produtividade na área e menores declividades, retornaram as maiores produções médias. 


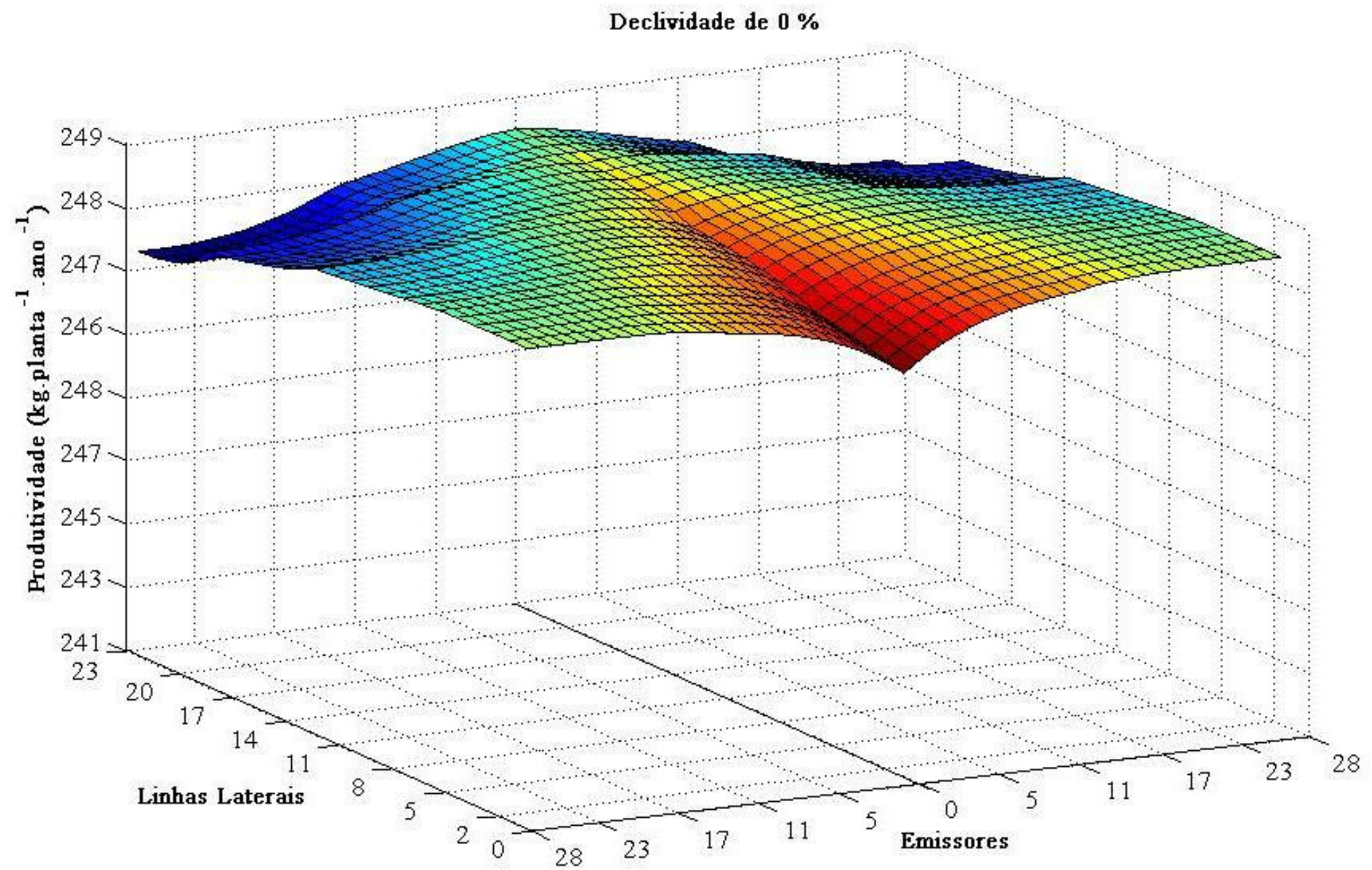

Gráfico 31. Distribuição de produção na unidade operacional para a declividade de $0 \%$ 


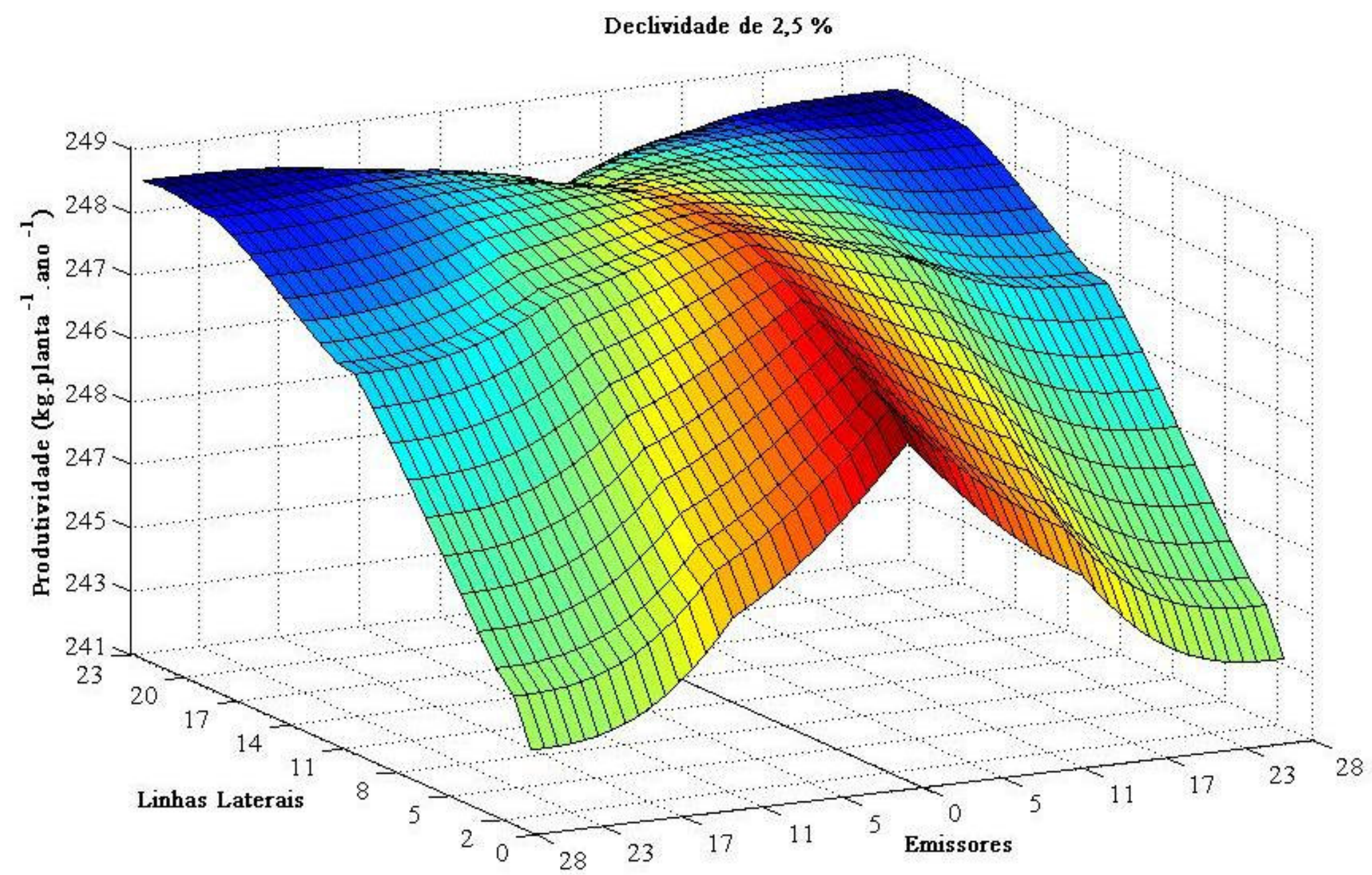

Gráfico 32. Distribuição de produção na unidade operacional para a declividade de 2,5\% 


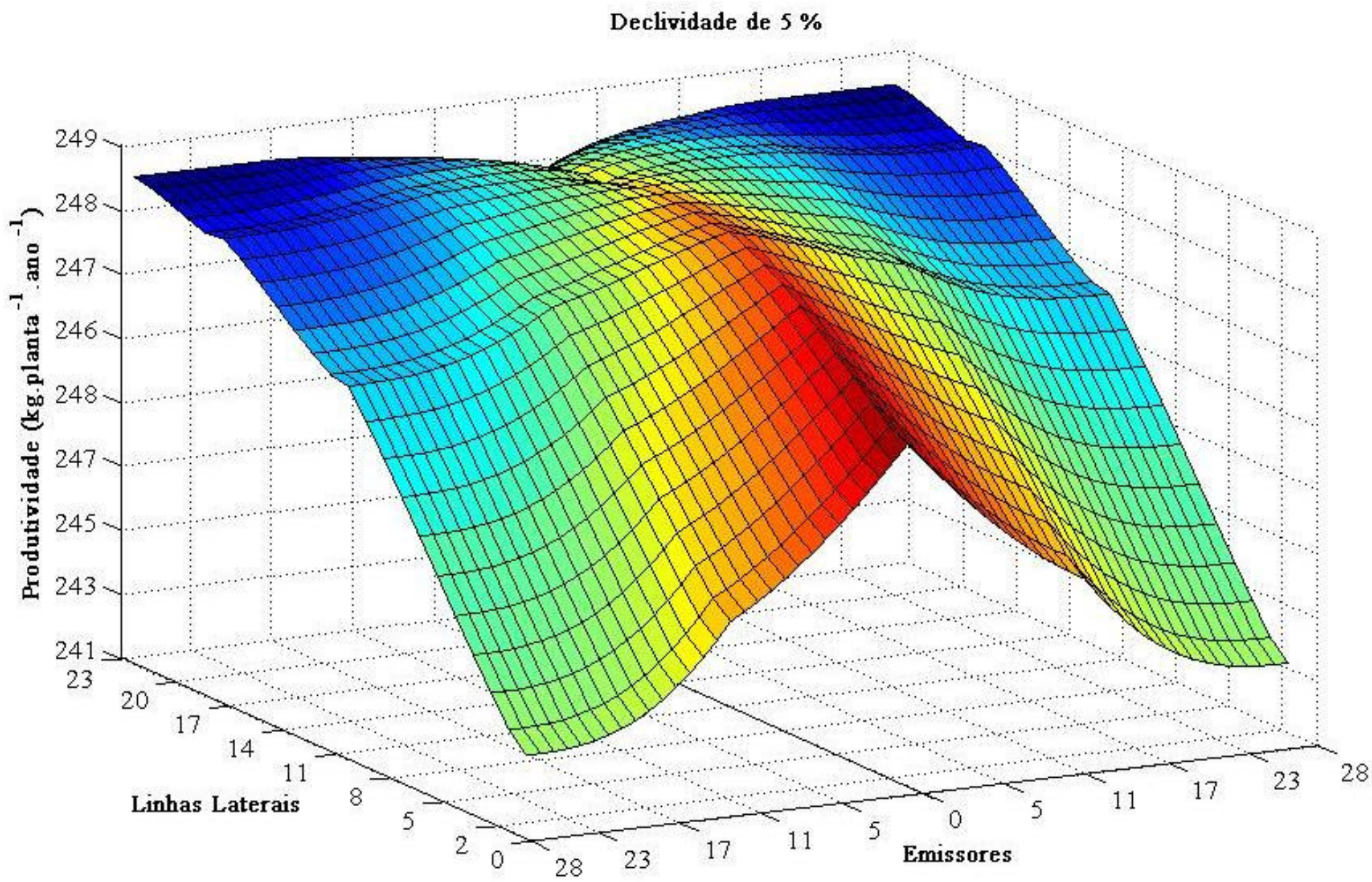

Gráfico 33. Distribuição de produção na unidade operacional para a declividade de $5 \%$ 
5.7. Grande variação na tarifação da água

Nesta seção é realizado um estudo do efeito de uma grande variação na tarifação da água (entre 0,01 e $\left.0,10 \mathrm{R} \$ .\left(\mathrm{m}^{3}\right)^{-1}\right)$ nos custos de equipamentos, energia elétrica e água do sistema de irrigação localizada. A declividade foi $0 \%$ e a tarifa de energia elétrica de 0,1768 $\mathrm{R} \$ \cdot \mathrm{kW}^{-1}$. Analisa-se a eficiência da convergência da função de aptidão e as variáveis otimizadas frente à otimização por algoritmos genéticos e, em seguida, executa-se uma análise das variáveis otimizadas e dos custos das redes de irrigação.

\subsubsection{Variação na convergência da função de aptidão}

A variação na convergência da função de aptidão, apresentada no Gráfico 34 e na Tabela 19, mostra que, para a maioria das tarifas estudadas, o processo de otimização converge para o valor ótimo nas primeiras 200 gerações. Para as tarifas de 0,03 e 0,09 $\mathrm{R}$ \$. $\left(\mathrm{m}^{3}\right)^{-1}$ obteve-se uma convergência lenta em direção ao valor ótimo. Este fenômeno pode ser explicado pelos valores totais de amplitude entre a primeira e a última geração na Tabela 19. Verifica-se que para as tarifas de 0,03 e $0,09 \mathrm{R} \$ .\left(\mathrm{m}^{3}\right)^{-1}$ houve um percurso maior a ser percorrido entre os primeiros valores obtidos e o valor ótimo final na geração 2000, ou seja, as primeiras populações de redes nestes dois casos produziram progênies que resultaram em valores da função de aptidão muito longe do valor ótimo global, o que desfavoreceu uma rápida convergência. Verifica-se que a tarifa de $0,09 \mathrm{R} \$ .\left(\mathrm{m}^{3}\right)^{-1}$, onde obteve-se a maior amplitude entre a primeira e a última geração, ocorreu a convergência mais lenta, quanto ao número de gerações, e a tarifa de $0,04 \mathrm{R} \$ .\left(\mathrm{m}^{3}\right)^{-1}$ resultou na convergência inicial mais rápida. Os valores de custo mais elevados, gerados pela função de aptidão (no caso das tarifas de 0,03 
e $\left.0,09 \mathrm{R} \$ .\left(\mathrm{m}^{3}\right)^{-1}\right)$, são resultados diretos da pouca aptidão das redes produzidas pelas primeiras gerações do algoritmo genético.

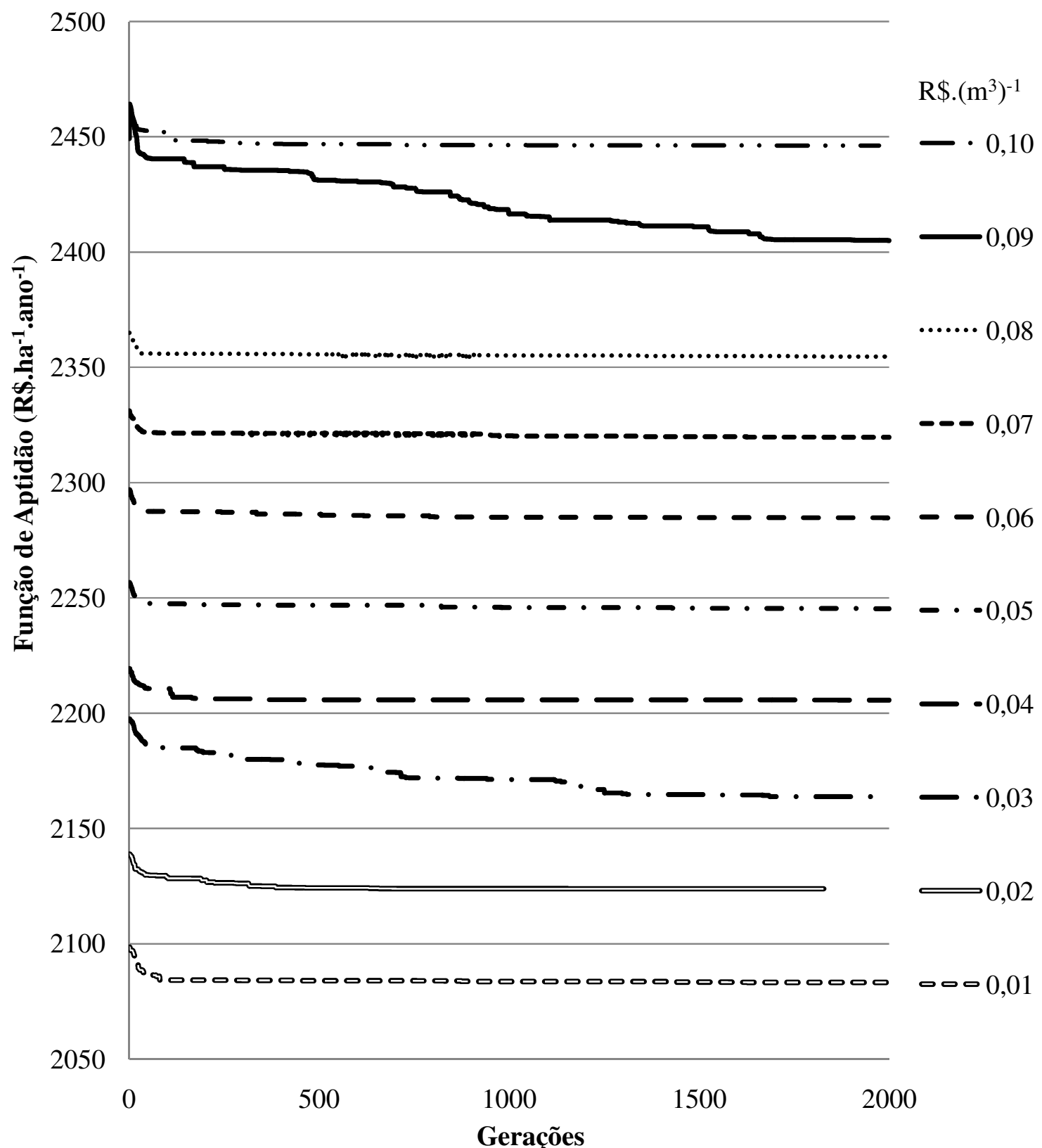

Gráfico 34. Variação na convergência da função de aptidão para uma variação na tarifação da água entre 0,01 e $0,10 \mathrm{R} \$ .\left(\mathrm{m}^{3}\right)^{-1}$

Verificando-se também que a convergência mais rápida, considerando todas as 2000 gerações, ocorreu com a tarifa do insumo água a $0,02 \mathrm{R} \$\left(\mathrm{~m}^{3}\right)^{-1}$. Neste caso $99,87 \%$ da 
convergência foi obtida até a geração de número 1000, restando uma evolução de apenas 0,13\% para os valores produzidos pela função de aptidão para as 1000 gerações seguintes.

Tabela 19. Partição da evolução na convergência dos valores da função de aptidão (em R $\$$.ha ${ }^{-}$ ${ }^{1}$. ano ${ }^{-1}$ e em \%) entre conjuntos de gerações para uma variação na tarifação da água entre 0,01 e $0,10 \mathrm{R} \$ .\left(\mathrm{m}^{3}\right)^{-1}$

\begin{tabular}{|c|c|c|c|c|c|c|c|c|c|c|}
\hline \multirow{2}{*}{ Geração } & \multicolumn{10}{|c|}{ Variação na Tarifação da água - $\mathrm{R} \$ .\left(\mathrm{m}^{3}\right)^{-1}$} \\
\hline & 0,01 & 0,02 & 0,03 & 0,04 & 0,05 & 0,06 & 0,07 & 0,08 & 0,09 & 0,10 \\
\hline & \multicolumn{10}{|c|}{ 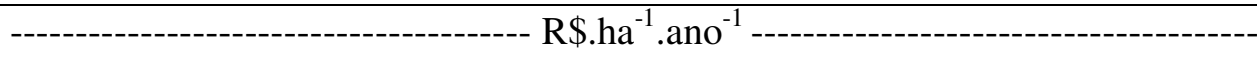 } \\
\hline $0-200$ & 14,31 & 11,25 & 14,54 & 13,13 & 9,51 & 9,58 & 9,73 & 9,05 & 12,21 & 12,66 \\
\hline $201-$ & 0,60 & 3,65 & 11,70 & 0,41 & 1,27 & 2,33 & 1,22 & 0,71 & 20,53 & 1,91 \\
\hline $1001-2000$ & 0,39 & 0,02 & 7,47 & 0,12 & 0,53 & 0,35 & 0,59 & 0,46 & 11,48 & 0,16 \\
\hline \multirow[t]{2}{*}{ Total } & 15,30 & 14,92 & 33,71 & 13,66 & 11,31 & 12,26 & 11,54 & 10,22 & 44,22 & 14,73 \\
\hline & \multicolumn{10}{|c|}{ 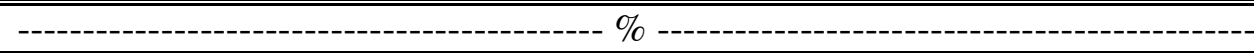 } \\
\hline & 93,53 & 75,40 & 43,13 & 96,12 & 84,08 & 78,14 & 84,32 & 88,55 & 27,61 & 85,95 \\
\hline $201-1000$ & 3,92 & 24,46 & 34,71 & 3,00 & 11,23 & 19,00 & 10,57 & 6,95 & 46,43 & 12,97 \\
\hline $1001-2000$ & 2,55 & 0,13 & 22,16 & 0,88 & 4,69 & 2,85 & 5,11 & 4,50 & 25,96 & 1,09 \\
\hline
\end{tabular}

5.7.2. Análise das variáveis otimizadas e dos custos das redes de irrigação

A Tabela 20 mostra as variáveis da rede otimizadas para variação da tarifação da água entre 0,01 e $0,10 \mathrm{R} \$ .\left(\mathrm{m}^{3}\right)^{-1}$.

Houve pequenas modificações nos diferentes trechos de tubulação em cada linha da rede frente à variação da tarifação da água. Contudo, para a tarifação de 0,07 e $0,08 \mathrm{R} \$ .\left(\mathrm{m}^{3}\right)^{-1}$ houve uma significativa modificação nos comprimentos do terceiro e quarto trecho da linha de derivação em comparação as demais tarifas de água testadas. Este fenômeno resultou em queda nos custos com equipamentos (Tabela 21) tendo em vista que houve um aumento do quarto trecho da tubulação (menor diâmetro) e redução do terceiro techo da tubulação (maior diâmetro). Este mesmo fenômeno provocou uma elevação no custo com a energia elétrica para a tarifa de $0,08 \mathrm{R} \$ .\left(\mathrm{m}^{3}\right)^{-1}$ devido ao aumento da perda de carga. 
Tabela 20. Variáveis otimizadas na variação da tarifação da água entre 0,01 e $0,10 \mathrm{R} \$ .\left(\mathrm{m}^{3}\right)^{-1}$

\begin{tabular}{|c|c|c|c|c|c|c|c|c|c|c|}
\hline \multirow{2}{*}{$\begin{array}{c}\text { Tarifa de } \\
\text { Água }\end{array}$} & \multicolumn{10}{|c|}{ Variáveis Otimizadas } \\
\hline & LLL1 & LLL2 & LLD1 & LLD2 & LLD3 & LLD4 & LLS1 & LLS2 & LLS3 & LLS4 \\
\hline $\mathrm{R} \$ .\left(\mathrm{m}^{3}\right)^{-1}$ & \multicolumn{10}{|c|}{ 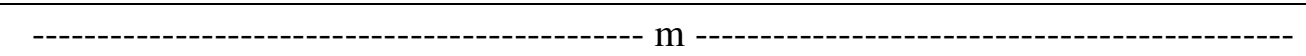 } \\
\hline 0,01 & 47,25 & 49,00 & 6 & 59 & 67 & 3 & 108 & 192 & 200 & 200 \\
\hline 0,02 & 47,25 & 49,00 & 6 & 59 & 67 & 3 & 110 & 190 & 200 & 200 \\
\hline 0,03 & 47,25 & 49,00 & 6 & 59 & 68 & 2 & 108 & 192 & 200 & 200 \\
\hline 0,04 & 47,25 & 49,00 & 6 & 59 & 69 & 1 & 110 & 190 & 200 & 200 \\
\hline 0,05 & 47,25 & 49,00 & 6 & 59 & 68 & 2 & 108 & 192 & 200 & 200 \\
\hline 0,06 & 47,25 & 49,00 & 6 & 59 & 67 & 3 & 109 & 191 & 200 & 200 \\
\hline 0,07 & 47,25 & 49,00 & 6 & 59 & 61 & 9 & 108 & 192 & 200 & 200 \\
\hline 0,08 & 47,25 & 49,00 & 6 & 59 & 55 & 15 & 106 & 194 & 200 & 200 \\
\hline 0,09 & 47,25 & 49,00 & 6 & 59 & 67 & 3 & 106 & 194 & 200 & 200 \\
\hline 0,10 & 47,25 & 49,00 & 6 & 59 & 67 & 3 & 112 & 188 & 200 & 200 \\
\hline
\end{tabular}

Tabela 21. Variação no custo total do sistema de irrigação, equipamentos, energia elétrica e água com variação na tarifação da água entre 0,01 e $0,10 \mathrm{R} \$ .\left(\mathrm{m}^{3}\right)^{-1}$

\begin{tabular}{|c|c|c|c|c|}
\hline \multirow[b]{2}{*}{ Tarifa de Água } & \multicolumn{4}{|c|}{ Custos por Hectare, Anualizados, do Sistema de Irrigação } \\
\hline & Equipamentos & Energia Elétrica & Água & Total \\
\hline $\mathrm{R} \$ .\left(\mathrm{m}^{3}\right)^{-1}$ & \multicolumn{4}{|c|}{ 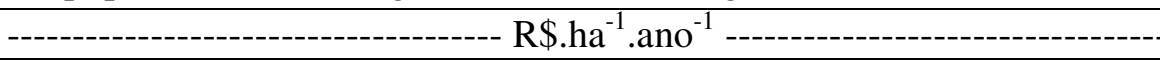 } \\
\hline 0,01 & 1571,20 & 337,33 & 40,28 & 1948,81 \\
\hline 0,02 & 1571,80 & 337,08 & 80,56 & 1989,44 \\
\hline 0,03 & 1572,00 & 337,33 & 120,84 & 2030,17 \\
\hline 0,04 & 1573,40 & 337,08 & 161,12 & 2071,60 \\
\hline 0,05 & 1572,00 & 337,33 & 201,42 & 2110,75 \\
\hline 0,06 & 1571,50 & 337,21 & 241,68 & 2150,39 \\
\hline 0,07 & 1566,40 & 337,38 & 281,96 & 2185,74 \\
\hline 0,08 & 1562,00 & 343,89 & 322,24 & 2228,13 \\
\hline 0,09 & 1570,60 & 337,58 & 362,52 & 2270,70 \\
\hline 0,10 & 1572,40 & 336,84 & 402,80 & 2312,04 \\
\hline
\end{tabular}

Na Tabela 22 verifica-se que quanto maior a tarifação da água, menor é a participação percentual dos custos com equipamentos e energia elétrica no custo total do sistema de irrigação. Concomitantemente a essa diminuição, há uma elevação substancial na participação percentual do custo com água.

O aumento da tarifação pelo insumo água de 0,01 para $0,10 \mathrm{R} \$ .\left(\mathrm{m}^{3}\right)^{-1}(1000 \%)$ resulta em um acréscimo de 8,4 vezes (de 2,07 para 17,42\%) na participação do custo da água no custo total do sistema de irrigação. 
Tabela 22. Variação percentual no custo total do sistema de irrigação, equipamentos, energia elétrica e água com a ampla variação na tarifação da água

\begin{tabular}{|c|c|c|c|c|}
\hline & \multicolumn{4}{|c|}{ Percentagem dos Custos por Hectare, Anualizados, do Sistema de Irrigação } \\
\hline Tarifa de Água & Equipamentos & Energia Elétrica & Água & Total \\
\hline $\mathrm{R} \$ .\left(\mathrm{m}^{3}\right)^{-1}$ & \multicolumn{4}{|c|}{ 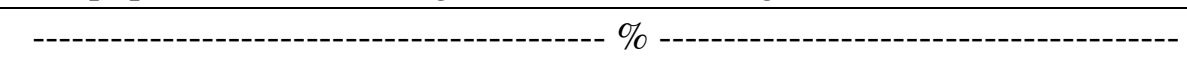 } \\
\hline 0,01 & 80,62 & 17,31 & 2,07 & 100 \\
\hline 0,02 & 79,01 & 16,94 & 4,05 & 100 \\
\hline 0,03 & 77,43 & 16,62 & 5,95 & 100 \\
\hline 0,04 & 75,95 & 16,27 & 7,78 & 100 \\
\hline 0,05 & 74,48 & 15,98 & 9,54 & 100 \\
\hline 0,06 & 73,08 & 15,68 & 11,24 & 100 \\
\hline 0,07 & 71,66 & 15,44 & 12,90 & 100 \\
\hline 0,08 & 70,10 & 15,43 & 14,46 & 100 \\
\hline 0,09 & 69,17 & 14,87 & 15,97 & 100 \\
\hline 0,10 & 68,01 & 14,57 & 17,42 & 100 \\
\hline
\end{tabular}

A variação na tarifação de água de 0,01 para $0,10 \mathrm{R} \$ .\left(\mathrm{m}^{3}\right)^{-1}$ provoca um aumento de $15,71 \%$ no custo total do sistema de irrigação (de 1948,81 para 2312,04 R $\$ \cdot$ ha $^{-1} \cdot$ ano $^{-1}$ ).

Observa-se que para as tarifas de água de 0,09 e $0,10 \mathrm{R} \$ .\left(\mathrm{m}^{3}\right)^{-1}$ e energia elétrica de 0,1768 R\$.kW ${ }^{-1}$, a participação do custo da água é maior que da energia elétrica no custo total da rede de irrigação localizada. 


\section{CONCLUSÕES}

O dimensionamento otimizado de redes de distribuição de água para irrigação é um problema de difícil resolução. Quanto maior é o número de variáveis de projeto utilizadas, maior será a quantidade de condicionais fomentando a complexidade da implementação do código. A implementação de cada perda localizada na rede, além de uma variação vetorial dos comprimentos de cada trecho, para cada diâmetro disponível, refinam os resultados obtidos por um lado, mas dificultam a implementação do código pelo outro.

O algoritmo genético utilizado nesta otimização resultou em uma resolução satisfatória do problema, sem tornar necessária a introdução de simplificações na formulação do código da função de aptidão.

O MatLab 7.5.0(R2007b) mesmo sendo um programa de linguagem de alto nível possui uma programação simples e intuitiva, o que contribuiu para implementação do código da função de aptidão. A "caixa de ferramentas do MatLab", com sua biblioteca de algoritmos genéticos, contribuiu decisivamente na fase de testes do programa e de refinamento das diferentes possibilidades que englobam a otimização por algoritmos genéticos. Portanto, foi possível encontrar o operador genético (dentre os vários possíveis) mais adequado para as principais fases da otimização executada pelo algoritmo genético (aptidão inicial, seleção, cruzamento e mutação).

Mesmo utilizando computadores pessoais com alto desempenho de processamento (Dual Core 2,2 GHz de processador com 2 GB de memória RAM) para a atualidade, gastouse um tempo elevado (em média 30 horas) para processar uma única otimização. Isto se deve à grande quantidade de iterações intrínsecas à otimização por algoritmos genéticos. O elevado tempo de processamento do código pode ser um fator limitante na escolha dos algoritmos genéticos para resolução de complexos dimensionamentos de redes de irrigação. 
Resume-se alguns pontos importantes do programa desenvolvido: Fácil implementação, para usuários que conheçam a linguagem $\mathrm{C}$ ou $\mathrm{C}++$ e que tenham algum conhecimento do MatLab; os arquivos das funções de dimensionamento não recorrem a cálculo de derivadas (comuns em otimização clássica) nem a inversão de matrizes; possibilita a modificação de grande quantidade de dados de entrada para pessoas que têm alguma afinidade com o dimensionamento de redes de irrigação localizada; é muito exigente em termos de memória para processamento; devido às características intrínsecas no algoritmo genético, a resolução não fica presa em mínimos locais, além de, em teoria, poder encontrar o ótimo global; as variáveis otimizadas, que são os comprimentos das tubulações e seus respectivos diâmetros, são expressas em diâmetros comerciais disponíveis na base de dados de entrada do programa, o que facilita a utilização do programa como ferramenta no auxílio decisório para dimensionamentos reais; as soluções apresentadas, além de garantirem uma variação máxima de pressão nas linhas laterais e de derivação, mostram também uma variação de vazão nas linhas dentro do buscado no pré-dimensionamento; a formulação usada na análise econômica inclui todo o tipo de acessórios, como válvulas reguladoras de pressão e filtros, o que favorece uma maior aproximação da rede dimensionada de um projeto real.

A simulação da cobrança da água no dimensionamento otimizado, resultou em um peso médio de $2 \%$ do custo anualizado do sistema. Os custos com equipamentos e energia elétrica representaram, respectivamente, 78,3 e 19,7\%. O custo com energia elétrica para o bombeamento da água faz parte do custo variável anual de uma rede de irrigação localizada, que continuará fomentando um maior esforço por parte do irrigante em busca de melhores tecnologias de manejo do sistema para economizar água.

A análise hidráulica mostrou um comportamento de pressão e vazão adequados a redes de distribuição de água por marcha. A análise criteriosa por meio da diferenciação dos componentes de linha de energia, linha piezométrica, linha de carga de pressão e de cota do 
terreno facilitou um melhor entendimento hidráulico da rede e a verificação do comportamento do sistema simulando o seu funcionamento.

O menor custo da rede de irrigação, 1816,45 R $\$ \cdot \mathrm{ha}^{-1}$.ano ${ }^{-1}$, foi encontrado para $0 \%$ de declividade, $100 \%$ de tarifa de água $\left(0,01 \mathrm{R} \$ .\left(\mathrm{m}^{3}\right)^{-1}\right)$ e $50 \%$ de tarifa de energia elétrica $\left(0,1768 \mathrm{R} \$ \cdot \mathrm{kW}^{-1}\right)$. Já o maior custo da rede de irrigação, 2312,13 R\$.ha ${ }^{-1}$.ano ${ }^{-1}$, foi encontrado para $5 \%$ de declividade, $100 \%$ de tarifa de água e $150 \%$ de tarifa de energia elétrica.

Com relação ao estudo da grande variação na tarifação do insumo água, observou-se um grande acréscimo na participação do custo da água no custo total da rede de irrigação, anualizado por hectare, quando se aumenta a tarifação da água de 0,01 para $0,10 \mathrm{R} \$ .\left(\mathrm{m}^{3}\right)^{-1}$. Observou-se também que esta grande variação na tarifação de água resulta num aumento de $15,71 \%$ no custo total do sistema de irrigação, anualizado por hectare, o que possivelmente pode influenciar negativamente na decisão da adoção ou não da tecnologia de irrigação por parte do empresário agrícola.

Por fim, conclui-se que o algoritmo genético utilizado para o dimensionamento otimizado da rede de irrigação proposta obteve resultados satisfatórios. A análise de sensibilidade econômica e, principalmente, a análise hidráulica das diferentes redes otimizadas pelo programa, concretizaram o resultado do dimensionamento e da otimização pelo algoritmo genético. 


\section{SUGESTÕES}

O importante papel desempenhado pela agricultura irrigada quanto à garantia no fornecimento de alimentos à população nos períodos de seca sazonal ou em regiões de baixa pluviosidade, faz com que a mesma seja sempre alvo de acaloradas discussões e da pesquisa das diferentes áreas do conhecimento acadêmico. Contudo, as pesquisas envolvendo o aprimoramento da irrigação, seja do ponto de vista de novas tecnologias em equipamentos ou do seu dimensionamento e gerenciamento, merecem especial atenção. Métodos de otimização matemática vêm ao encontro a tais necessidades, demonstrando ser uma excelente ferramenta para irrigantes, engenheiros projetistas e pesquisadores da ciência da irrigação. Entretanto, a grande maioria dos estudos e aplicações de algoritmos genéticos envolvendo irrigação trata da alocação de água em perímetros irrigados ou do manejo das redes.

Pela análise da bibliografia consultada e pelos resultados obtidos neste estudo, verificou-se a necessidade de um aprimoramento dos estudos de algoritmos genéticos em engenharia de irrigação, no que tange ao próprio dimensionamento hidráulico da rede do sistema e os fatores econômicos e edafoclimáticos que o envolve. Com base nos postulados anteriores, pode-se sugerir:

$\checkmark \quad$ Analise das diferentes opções de otimização por algoritmos genéticos, sob diferentes critérios de dimensionamento de redes hidráulicas de irrigação;

$\checkmark \quad$ Pesquisas com algoritmos genéticos, envolvendo fatores como precipitação e evapotranspiração, na tomada de decisão sobre o sistema de irrigação a adotar para uma determinada área;

$\checkmark \quad$ Refinamento dos resultados obtidos com o uso de algoritmos genéticos para redes de irrigação através da hibridização com algoritmos de otimização linear e não-linear. 


\section{REFERÊNCIAS}

ACKOFF, R.L.; SASIENI, M.W. Pesquisa operacional. Rio de Janeiro: Livros técnicos e científicos, 1977.

AGÊNCIA NACIONAL DE ÁGUAS. Brasília: ANA, 1997. Informativo eletrônico sobre outorga e fiscalização dos recursos hídricos no Brasil. Disponível em: < http://www.ana.gov.br/GestaoRecHidricos/OutorgaFiscalizacao/default.asp >. Acesso em: 8 jan. 2007.

AGÊNCIA NACIONAL DE ÁGUAS. Brasília: ANA, 2005. Informativo eletrônico sobre o uso múltiplos, conflitos de interesse e a utilização da água no Brasil. Disponível em: < http://www.ana.gov.br/GestaoRecHidricos/UsosMultiplos/default.asp>. Acesso em: 31 jan. 2007.

ÁGUA E AGRÍCULTURA. Associação guardiã da água, 2006. Informativo eletrônico sobre água e agricultura. Disponível em: < http://www.agua.bio.br/botao_d_N.htm>. Acesso em: 14 jan. 2007.

ALENCAR NETO, M.F. Otimização de Redes de distribuição de água por Algoritmos Genéticos. Fortaleza, 2003. 130p. Dissertação (Mestrado) Universidade Federal do Ceará, Fortaleza.

ALENCAR NETO, M.F.; HOLANDA, M.A.C. Projeto de redes de distribuição de água por algoritmo genético. In: Seminário Hispano-Brasileiro Sobre Sistemas de Abastecimento Urbano de Água. João Pessoa, Anais... Nov. 2004.

ALLEN, R. G.; PEREIRA, L. S.; RAES, D. Crop evapotranspiration: guidelines for computing crop water requirements. Rome: FAO, 1998 300p. (FAO. Irrigation and Drainage Paper, 56).

ALPEROVITS, E.; SHAMIR, U. Design of optimal water distribution systems. Water Resources Research, 1989. v. 13, n. 6, p. 885-900. 
AMERICAN SOCIETY OF AGRICULTURAL ENGINEERS. Standards' engineers practices data: EP405.1 Design and installation of microirrigation systems. St. Joseph, 1995. P. 720-3.

ANDRADE JÚNIOR, A.S.; FRIZZONE, J.A.; BASTOS, E.A.; CARDOSO, M.J.; RODRIGUES, B.H.N. Estratégias ótimas de irrigação para a cultura da melancia. Pesquisa Agropecuária Brasileira, v.36, n.2, p.301-305, fev. 2001.

ASSOCIAÇÃO BRASILEIRA DA INDUSTRIA DE MÁQUINAS E EQUIPAMENTOS. Campinas: ABIMAQ, 2002. Importância da irrigação no desenvolvimento do agronegócio. Disponível em: <http://www.agr.feis.unesp.br/csei.pdf> $>$. Acesso em: 16 mai. 2007.

BALSALOBRE, M.A.A.; SANTOS, P.M.; MAYA, F.L.A.; PENATI, M.A.; CORSI, M. Pastagens irrigadas. In: SIMPÓSIO SOBRE MANEJO DE PASTAGEM,20,, Piracicaba, 2003. Produção animal em pastagens: situação atual e perspectivas. Piracicaba: FEALQ, 2003. p.265-296.

BARBOSA, P.S.F. Modelos de programação linear em recursos hídricos. In: PORTO, R. L. L. (Org.). Técnicas quantitativas para o gerenciamento de recursos hídricos. Porto Alegre: Ed.Universitária/UFRGS/ABRH, 1997. v. 1.420 p.

BENAMI, A.; OFEN, A. Irrigation engineering. Haifa: Irrigation Engineering Scientific Publications, 1984. 257p.

BERNARDO, S.; SOARES, A. A.; MANTOVANI, E.C. Manual de irrigação. 7.ed. Viçosa, MG: Universidade Federal de Viçosa, 2005. 611p.

BERTONHA, A. Funções de resposta da laranja pêra a irrigação complementar e nitrogênio. 1997. 113 f. Tese (Doutorado em Irrigação e Drenagem) - Escola Superior de Agricultura Luiz de Queiroz, Universidade de São Paulo, 1997.

BHAVE, R. Selecting pipe sizes in network optimization by LP. Journal of Hydraulics Division, ASCE. August, 1979. 
BLANCO, F.F.; MACHADO, C.C; COELHO, R.D.; FOLEGATTI, M.V. Viabilidade econômica da irrigação da manga para o Estado de São Paulo. Revista Brasileira de Engenharia Agrícola e Ambiental, v.8, n.1, p.153-159, 2004.

BRAGA, A.L.; OLIVEIRA, J.C. Identificação e quantificação de áreas irrigadas por pivô central utilizando imagens CCD/CBERS. In: Anais do XII simpósio brasileiro de sensoriamento remoto, Goiânia, 16-21 abril 2005, INPE, p. 849-856.

BRALTS, V.F. Field performance and evaluation. In: NAKAYAMA, F.S.; BUCKS, D.A. (Ed.) Trickle irrigation for crop production. Amsterdam: Elsevier, 1986. p.216-240. (Development in Agricultural Engineering, 9).

BRALTS, V.F.; EDWARD, D.M.; WU, I.P. Drip irrigation design and evaluation based on statistical uniformity concept. In: HILLEL, D. (Ed). Advances in irrigation. Orlando: Academic Press, 1987. v.4, p.67-117.

BRUNELli, G.M. Simulação do custo de produção de laranja no Estado de São Paulo. Piracicaba, 1990. 99p. Dissertação (Mestrado) - Escola Superior de Agricultura "Luiz de Queiroz", Universidade de São Paulo.

CARRIJO, I.B.; REIS, L.F.R. Extração de estratégias operacionais ótimas de sistemas de distribuição de água utilizando algoritmos genéticos multiobjetivo e aprendizado de máquina - aplicação ao sistema de macro-distribuição de água de Goiânia. Revista Brasileira de Recursos Hídricos. Porto Alegre, v. 11, n. 2 abr/jun 2006, p. 161-172.

CARRUTHERS, I.A.; ROSEGRANT, M.W.; SECKLER, D. Irrigation and food security in the $21^{\text {st }}$ century. Irrigation and Drainage Systems. Netherlands, v.11, n.1. 1997, p. 83-101.

CHEUNG, P. B. Análise de reabilitação de redes de distribuição de água para abastecimento via algoritmos genéticos multiobjetivo. 2004. 268 f. Tese (Doutorado em Hidráulica e Saneamento) - Escola de Engenharia de São Carlos, Universidade de São Paulo, São Carlos, 2004.

CRISTIANSEN, J.E. Irrigation by sprinkling. Berkeley: University of California. Bulletin 670, 1942. $65 \mathrm{p}$. 
DE TAR, W.R. Modified Graphical Determination of Submain Size. Transactions of the ASAE. v. 25, n. 3, p. 695-696, 1982.

DENÍCULI, W. Bombas hidráulicas. $3^{\mathrm{a}}$ ed. Viçosa: Editora UFV, Departamento de Engenharia Agrícola, 2005. 152 p.

DENÍCULI, W.; SILVA, D.D.; OLIVEIRA, R.A. Hidráulica de condutos perfurados. $1^{\mathrm{a}}$ ed. Viçosa: Editora UFV, Departamento de Engenharia Agrícola, 2004. 93 p.

DEPARTAMENTO DE ÁGUA E ENERGIA ELÉTRICA. São Paulo: DAEE, 1996. Informativo eletrônico sobre o regulamento da outorga dos direitos do uso dos recursos hídricos. Disponível em: < http://www.daee.sp.gov.br/legislacao/decreto_41258.htm>. Acesso em: 12 dez. 2006.

DOORENBOS, J.; PRUITT, W.O. Crop water requirements. Rome: FAO, 1977. 144p. (Irrigation and Drainage Paper, 24).

EHRLICH, P.J. Programação linear e decisão. Apostila. FGV - EAESP, 2004.

FACHIN, O. Fundamentos de metodologia. $3^{\text {a }}$ ed. São Paulo: Saraiva, 2001.

FAVETTA, G.M.; BOTREL, T.A. Uniformidade de sistemas de irrigação localizada: validação de equações. Scientia Agricola, v.58, n.2, p.427-430, abr./jun. 2001.

FERERES, E. Drip Irrigation Management. $1^{\text {a }}$ ed. Leaflet 21259. Division of Agriculture, University of California. 1981.

FOLEGATTI, M.V., PESSOA, P.C.S. y PAZ, V.P.S. Avaliação do desempenho de um pivô central de grande porte e baixa pressão. Scientia agrícola. 1998, v. 55, no . 1, pp. 119-127.

FRANÇA, F.M.C. A importância do agronegócio da irrigação para o desenvolvimento do Nordeste. Fortaleza: Banco do Nordeste, 2001. 113 p. Séries políticas e estratégias para um novo modelo de irrigação. 
FRIZZONE, J.A. Análise de decisão econômica em irrigação. Piracicaba: ESALQ, 2005. $371 \mathrm{p}$.

FRIZZONE, J.A. Funções de resposta das culturas à irrigação (Série Didática 006). Piracicaba: Departamento de Engenharia Rural - ESAL/USP, 1993 (Didática).

FRIZZONE, J.A.; SILVEIRA, S.F.R. Análise econômica de projetos hidroagrícolas. In: SILVA, D.D.; PRUSKI, F.F. (Ed.). Gestão de recursos hídricos: aspectos legais, econômicos, administrativos e sociais. Brasília: Secretaria de Recursos hídricos; Viçosa: Universidade Federal de Viçosa; Porto Alegre: Associação Brasileira de Recursos Hídricos, 2000. cap.5 p. $449-617$.

GAVIRA, M.O. Simulação computacional como uma ferramenta de aquisição de conhecimento. 2003. 150 f. Dissertação (Mestrado em Engenharia de Produção) - Escola de Engenharia de São Carlos, Universidade de São Paulo, São Carlos, 2003.

GEORGIOU, P.E.; PAPAMICHAIL, D.M.; VOUGIOUKAS, S.G. Optimal irrigation reservoir operation and simultaneous multi-crop cultivation area selection using simulated annealing. Irrigation and Drainage. v. 55, n. 2, 2006, p. 129-144.

GHAHRAMAN, B.; SEPASKHAH, A. Linear and non-linear optimization models for allocation of a limited water supply . Irrigation and Drainage. v. 53, n. 1, 2004, p. 39-54.

GIACOIA NETO, J. História e evolução da irrigação. Mar/abr 2003. São Paulo. Informativo verde, pg. 7.

GOLDBERG D.E. Genetic algorithms in search, optimization and machine learning. Reading MA: Addison Wesley, 1989.

GOMES, H. P. Engenharia de irrigação - hidráulica dos sistemas pressurizados: aspersão e gotejamento. $3^{\mathrm{a}}$. ed. Campina Grande. Editora Universitária da Universidade Federal da Paraíba, 1999. 412p. 
GOMES, H. P. Sistemas de abastecimento de água: dimensionamento econômico e operação de redes elevatórias. $2^{\text {a }}$. ed. João Pessoa: Editora Universitária da Universidade Federal da Paraíba. 2004, 242 p.

GOMES, H. P.; SILVA, J.G. Dimensionamento econômico de sistemas de distribuição de água, considerando variáveis as condições de contorno do projeto. Revista Brasileira de Recursos Hídricos. Porto Alegre, v. 11, n. 2 abr/jun 2006, p. 99-110.

GUIMARÃES JUNIOR, J.A. Projeto otimizado de sistemas de irrigação localizada: nova concepção. 1998. 177 f. Tese (Doutorado em Hidráulica e Saneamento) - Escola de Engenharia de São Carlos, Universidade de São Paulo, São Carlos, 1998.

HILLIER, F.S.; LIEBERMAN, G.J. Introdução a pesquisa operacional. $1^{\text {a }}$ ed. São Paulo: Editora da Universidade de São Paulo, 1988.

HOFFMANN, R. ENGLER, J.J.C; SERRANO, O.; THAME, A.C.M.; NEVES, E.M. Administração da empresa agrícola. 5 ed. São Paulo: Pioneira, 1987. 325p.

IGLESIAS, E.; GARRIDO, A.; GÓMEZ-RAMOS, A. Evaluation of drought management in irrigated areas. Agricultural Economics, v.29, n.2, p.211-229, Oct. 2003.

INFORMATIVO VERDE. São Paulo: Itograss, 2004. Informativo eletrônico sobre irrigação. Disponível em: http://www.itograss.com.br/informativoverde/edicao62/pagina07.pdf. Acesso em: 30 jan. 2007.

INSTITUTO DE ECONOMIA AGRÍCOLA. São Paulo: 2007. Informativo eletrônico sobre custo de produção de laranja para indústria paulista: http://www.iea.sp.gov.br/out/verTexto.php?codTexto=1385. Acesso em: 30 mar. 2007.

JENSEN, M.C.; FRANTINI, A.M. Adjusted "F" factors for sprinkler lateral design. Agriculture engineer. v. 38, n. 4, 1957. 247 p.

KARMELI, D. PERI, G. Trickle irrigation design principles. Haifa: The Technion Studentes Publishing House, 1972. 
KARMELI, D.; KELLER, J. Trickle irrigation design. Rain bird sprinkler manufacturing corporation. California: Glendora, 1975. 133p.

KELLER, J. Trickle Irrigation. Section 15-7. National Engineering Handbook. Soil conservation Service. USDA. USA. 1978.

KELLER, J.; BLIESNER, R. D. Sprinkle and trickle irrigation. New York: Van Nostrand Reinhold, 1990. 652p.

KELLER, J.; KARMELI, D. Trickle irrigation design parameters. Transactions of the ASAE, v.17, p.678-684, 1974.

KELMAN, J.; RAMOS, M. Custo, valor e preço da água utilizada na agricultura. REGA: Revista de Gestão de Água na América Latina. Editora Evangraf, Porto Alegre, v. 2, n. 2, p. 39-48, jul./dez. 2005.

KUWABARA, G.; MATSURA, E.E. Avaliação do comportamento hidráulico das linhas laterais de tubogotejadores. In: CONGRESSO NACIONAL DE IRRIGAÇÃO E DRENAGEM, 11., 1996, Campinas. Anais... Viçosa: Associação Brasileira de Irrigação e Drenagem, 1996. p. 275-287.

LACHTERMACHER, G. Pesquisa operacional na tomada de decisão: modelagem em Excel. Rio de Janeiro: Editora Campus. 2002.

LANZER, E.A. Programação linear: conceitos e aplicações. 2. ed. Rio de Janeiro: IPEA/INPES, 1988. 270 p. (Série PNPE, 4).

LINSLEY, R.K.; FRANZINI, J.B. Engenharia de recursos hídricos. São Paulo, McGrawHill do Brasil, Editora da Universidade de São Paulo, 1978. 800p.

LOIOL, M.L.; SOUZA, F. Statistics on irrigation in Brazil according to the 1995-1996 Agricultural Census. Revista Brasileira de Engenharia Agrícola e Ambiental. 2001, vol. 5, no. 12007-05-16], pp. 171-180. 
LUCENA, K.F.M. Dimensionamento e operação de sistemas de irrigação localizada considerando diferentes tarifas de energia elétrica e tempos de irrigação. In: SEMINÁRIO DE PLANEJAMENTO, PROJETO E OPERAÇÃO DE REDES DE ABASTECIMENTO DE ÁGUA, O ESTADO DA ARTE E QUESTÕES AVANÇADAS, 2002, João Pessoa. Anais..., João Pessoa, 2002.

LUCENA, K.F.M. MATOS, J.A. Análise econômica em sub-unidades de irrigação localizada. In: CONGRESSO BRASILEIRO DE ENGENHARIA AGRÍCOLA, 30, 2001. Foz do Iguaçu: Anais... Associação Brasileira de Engenharia Agrícola.

MACHADO, E.C.M.N. et al. Otimização da operação de redes de adução de água utilizando algoritmos genéticos. In: SIMPÓSIO BRASILEIRO DE RECURSOS HÍDRICOS, 16, 2005. João Pessoa, SP: Anais... Sociedade Brasileira de Recursos Hídricos.

MALVEZZI, R. 2004. Informativo eletrônico: Água: crise e negócio. Disponível em: http://ifas.org.br/download/candeia4/artigo_agua.doc. Acesso em: 31 jan. 2007.

MANTOVANI, E.C.; BERNARDO, S.; PALARETTI, L.F. Irrigação: princípios e métodos. Viçosa: Editora da Universidade Federal de Viçosa, 2006. 318 p.

MARCUZZO, F.F.N.; WENDLAND, E. Análise de coeficientes de perda de carga em tubulações com múltiplas derivações sob diferentes condições. In: CONGRESSO BRASILEIRO DE ENGENHARIA AGRÍCOLA, 36, 2007. Bonito, MS: Anais... Sociedade Brasileira de Engenharia Agrícola.

MARCUZZO, F.F.N.; WENDLAND, E. Otimização linear de linhas de derivação de sistema de irrigação localizada com três diâmetros. In: CONGRESSO NACIONAL DE MATEMÁTICA APLICADA E COMPUTAÇÃO, 29, 2006b. Campinas, SP: Anais... Sociedade Brasileira de Matemática Aplicada e Computacional.

MARCUZZO, F.F.N.; WENDLAND, E. Otimização linear de linhas laterais de sistemas de irrigação localizada com dois diâmetros. In: CONGRESSO NACIONAL DE IRRIGAÇÃO E DRENAGEM, 16, 2006a. Goiânia, GO: Anais... Associação Brasileira de Irrigação e Drenagem. 
MARCUZZO, F.F.N.; WENDLAND, E. Otimização matemática linear de adutora com quatro diâmetros sob diferentes condições de contorno. In: CONGRESSO BRASILEIRO DE ENGENHARIA AGRÍCOLA, 36, 2007. Bonito, MS: Anais... Sociedade Brasileira de Engenharia Agrícola.

MAROUELLI, W. A.; SILVA, W. L. C.; SILVA, H. R. Seleção de sistemas de irrigação para o cultivo de tomateiro industrial. In: CONGRESSO BRASILEIRO DE ENGENHARIA AGRÍCOLA, 27., 1998, Poços de Caldas. Anais.... Poços de Caldas: SBEA: UFLA, 1998. v. 2, p. 67-69.

MAROUELLI, W.A.; SILVA, W.L.C. Seleção de sistemas de irrigação para hortaliças. Brasília: EMBRAPA, 1998. 16p. (Circular Técnica da Embrapa Hortaliças, 11).

MARQUES, P.A.A. Modelo computacional para determinação do risco econômico em culturas irrigadas. Piracicaba, 2005. 142p. Tese (Doutorado) - Escola Superior de Agricultura "Luiz de Queiroz", Universidade de São Paulo.

MARQUES, P.A.A.; COELHO, R.D. Estudo da viabilidade econômica da pupunha (Bactris Gasipaes H.B.K) para Ilha Solteira - SP, Brasil. Ciência Rural, v.33, n.2, p.291-297, 2003.

MARQUES, P.A.A.; MARQUES, T.A.; COELHO, R.D. Programa pupunha: software para avaliação econômica da irrigação da pupunha. Revista Brasileira deEngenharia Agrícola, v.6, n.2, p.379-384, 2002.

MERKLEY, G.P. BIE 607 lecture 12. In: Sprinkle and tricke irrigation course, Logan Utah State University, 1995. 5 p.

MICHALEWICZ, Z. Genetic algorithms + data structures = evolution programs. Springer Verlag Berlin Heidelberg New York. 3ed. 1996.

MIRANDA, E. E. de. Água na natureza, na vida e no coração dos homens. Campinas, 2004. Disponível em: <http://www.aguas.cnpm.embrapa.br>. Acesso em: 16 maio de 2004. 
MITCHEL, M. An introduction to genetic algorithms. Massachusetts Institute of Technology. A Bradford Book The MIT Press, London. 5ed., 1999.

MOGNON, R.V. Algoritmos genéticos aplicados na otimização de antenas. 2004. 85 f. Dissertação (Mestrado em engenharia elétrica) - Universidade Federal do Paraná, Curitiba, 2004.

MONTESINOS, P.; CAMACHO, E. ALVAREZ, S. Seasonal furrow irrigation model with genetic algorithms (OPTIMEC). Agricultural Water Management. v. 52, n. 1 p. 1-16, 2001.

NEVES, E.T. Curso de hidráulica. 8ª edição. Rio de Janeiro: Editora Globo, 1960. 578 p.

NORONHA, J.F.; LATAPIA, M.X.I.C. Custos de produção sob condições de risco no estado de São Paulo. Revista de Economia e Sociologia Rural, v.26, n.3, p.275-287, jul./set. 1988.

ORON, G.; KARMELI, D. Solid set irrigation system design using linear programming. Water Resources Bulletin. American Water Association. v. 17, n. 4. August 1981.

PORTO, R. L. L. (Org.). Técnicas quantitativas para o gerenciamento de recursos hídricos. Porto Alegre: Editora Universitária/UFRGS/ABRH, 1997. v. 1. 420 p.

PORTO, R.M. Hidráulica básica. $2^{a}$ ed. São Carlos: Editora da Universidade de São Paulo. 1999. 540p.

PORTUGUAL, A.D. A relação entre o consumo de energia e a prática da agricultura irrigada. ITEM: Irrigação e Tecnologia Moderna, n.50, p.10-11, 2001.

PRASAD, A.S.; UMAMAHESH, N.V.; VISWANATH, G.K. Optimal irrigation planning under water scarcity. Journal of irrigation and drainage engineering. v. 132, n. 3, p. 228237. may-jun. 2006. 
PRUSKI, F.F.; SILVA, D.D. Comitês da Bacia Hidrográfica: A descentralização em busca da ciência. In: I ENCONTRO PARA CONSERVAÇÃO DA NATUREZA, Viçosa - MG, Brasil, 21-24 de setembro 1997, Anais... Viçosa - UFV, p.156-163.

RECA, J.; Martínez, J. Genetic algorithms for the design of looped irrigation water distribution networks. Water Resources Research. v.42, n.1, p. 1-9, 2006.

REIS, L.F.R.; AKUTSU, J. Estratégias operacionais para sistemas de reservatórios via algoritmos genéticos (AGs). Revista Brasileira de Recursos Hídricos. v.7, n.3, JulhoSetembro, p. 5-17, 2002.

RIBEIRO, G.P. Operação otimizada do sistema adutor metropolitano utilizando algoritmos genéticos. Estudo de caso: Sam leste da região metropolitana de São Paulo (R.M.S.P.). 2005. 239 p. Tese (Doutorado em engenharia hidráulica e sanitária) - Escola Politécnica. Universidade de São Paulo, 2005.

ROBERT, J.B. Water in a changing world. Ecological Aplications. v. 11, n. 4, 2001. p. $1027-1045$.

ROCHA, A.F.; ANDRADE, C.L.T.; MERKLEY, G.P. Programa de computador para seleção econômica de tubulação em sistema de irrigação pressurizada. In: CONGRESSO NACIONAL DE IRRIGAÇÃO E DRENAGEM, 11., 1996, Campinas. Anais... Viçosa: Associação Brasileira de Irrigação e Drenagem, 1996. p. 546-560.

SAAD, J.C.C.; et al. Otimização da rede hidráulica de um sistema de irrigação por gotejamento utilizando programação linear. Revista Pesquisa Agropecuária Brasileira, v. 29, n. 5, p. 797-805, maio 1994.

SAAD, J.C.C.; FRIZZONE, J.A. Design and management optimization of trickle irrigation system using non-linear programming. Journal of Agricultural Researches. v. 64, n.1, 1996. p. 109-118.

SAAD, J.C.C.; MARCUZZO, F.F.N. Distribuição da carga hidráulica em linhas de derivação otimizadas por programação linear. Revista Engenharia Agrícola, Jaboticabal, v. 26, n.2, p. 406-414, mai/ago. 2006. 
SAAD, J.C.C.; MARIÑO, M. A. Optimum design of microirrigation systems in sloping lands. Journal of Irrigation and Drainage Engineering, Reston, VA, v. 128, n. 2, p. 116-124, 2002.

SANTIAGO, F.S.; MONTENEGRO, A.A.A.; MONTENEGRO, S.M.G.L. Avaliação de parâmetros hidráulicos e manejo da irrigação por microaspersão em área de assentamento. Revista Engenharia Agrícola, Jaboticabal, v. 24, n. 3, p.632-643, set/dez. 2004.

SANTO, B.R.E. Palestra sobre o uso e conservação dos recursos hídricos e importância da irrigação. III Encontro das águas. Santiago, Chile. Outubro de 2001.

SCALOPPI, E.J. Adjusted F factor for multiple-outlet pipes. Journal of irrigation and drainage engineering. ASCE, v. 114, n. 1, 1988, New York. p. 169-174.

SCALOPPI, E.J.; ALLEN, R.G. Hydraulics of irrigation laterals: comparative analyses. Journal of irrigation and drainage engineering. ASCE, v. 119, n. 1. 1993, New York. p. 91-115.

SILVA, D.D.; PRUSKI, F.F. Recursos hídricos e desenvolvimento sustentável da agricultura. Brasília: Ministério do Meio Ambiente; Secretária de Recursos Hídricos; ABEAS; Universidade Federal de Viçosa, 1997. 252p.

SILVA, R.A.P.; GOMES, H.P. DEIR: Programa para dimensionamento econômico de instalações de recalque. In: CONGRESSO NACIONAL DE IRRIGAÇÃO E DRENAGEM, 11, 1996, Campinas. Anais... Viçosa: Associação Brasileira de Irrigação e Drenagem, 1996. p. 532-545.

SINGH, R.P.; MAHAR, P.S. Optimal design of multidiameter, multioutlet pipelines. Journal of Water Resources Planning and Management. v. 129, n. 3, p. 226-233, may-jun. 2003.

SOARES, A.K. Calibração de modelos de redes de distribuição de água para abastecimento considerando vazamentos e demandas dirigidas pela pressão. 2003. 153 p. Dissertação (Mestrado em hidráulica e saneamento) - Escola de Engenharia de São Carlos, Universidade de São Paulo, 2003. 
SOARES, G.L. Algoritmos genéticos: estudo, novas técnicas e aplicações. 1997. 137 p. Dissertação (Mestrado em engenharia elétrica) - Centro de Pesquisa e Desenvolvimento em Engenharia Elétrica, Universidade Federal de Minas Gerais, 1997.

SWAMEE, P.K. Design of a submarine pipeline. Journal of Transportation Engineering. New York, v. 119, n. 1, p. 159-170, Jan. 1993.

THE MATHWORKS. Produced by The MathWorks. Disponível em: http://www.mathworks.com/. Acesso em 08 jun. 2008.

THEOCHARIS, M.E. et al. Design of optimal irrigation networks. Irrigation and Drainage. v. 55, n. 1, 2006, p. 21-32.

TIAGO FILHO, G.L. Uso de bombas com rotação variável. Itajubá: Escola Federal de Engenharia de Itajubá, 1996. 19p. (Apostila).

TSUTIYA, E.J. Exigências de energia para irrigação. ITEM - Irrigação e tecnologia moderna. Brasília, n.21, p. 13-17, jun. 1985.

TUCCI, E.M. et al. Hidrologia: ciência e aplicação. $3^{\mathrm{a}}$ ed. Porto Alegre: Editora da UFRGS, 1993. p.27-28.

VALIANTZAS, J.D. Hydraulic analyses and optimum design of multidiameter irrigation laterals. Journal of Irrigation and Drainage Engineering. v. 128, n. 2, p. 78-86, mar.-apr. 2002.

VELOSO, M.E.C. et al. Níveis de irrigação na cultura da banana no município de Teresina. Informativo Embrapa. Disponível em:< http://www.ufpel.tche.br/sbfruti/anais_xvii_cbf/irrigacao/265.htm\#_ftnref1>. Acesso em: 16 mai. 2007.

WARDLAW, R.; BHAKTILUL, K. Application of a genetic algorithm for water allocation in an irrigation system. Irrigation and Drainage. v. 50, n. 2, 2001, p. 159-170. 
WHITLEY, D. A genetic algorithm tutorial. In: Statistics and Computing. V.4, p. 65-85, 1994.

WILCOX, J.C.; SWAILES, G.E. Uniformity of water distribution by some under tree orchard sprinklers. Scientific Agricultural, v.27, p.565-583, 1947.

WORLD WATER DELEVOPMENT REPORT. New York: UNESCO, 2006. Informativo eletrônico sobre a utilização da água no mundo e a tecnologia que a envolve. Disponível em:< http://www.unesco.org/water/wwap/wwdr/index.shtml>. Acesso em: 3 jan. 2007.

WU, I.P.; GITLIN, H.M. Design of drip irrigation lines with varying pipe sizes. Journal of irrigation and drainage division, New York, v.103, n.4, p.499-503, 1977.

ZOCOLER, J.L. Modelo para dimensionamento econômico de sistemas de recalque em projetos hidroagrícolas. 1998. 107 f. Tese (Doutorado em Irrigação e Drenagem) - Escola Superior de Agricultura Luiz de Queiroz, Universidade de São Paulo, Piracicaba, 1998. 


\section{APÊNDICE A}

Equações utilizadas na concepção do diagrama de Moody para validação da equação proposta por Swamee (1993) visando a sua utilização na implementação do código.

São apresentadas a seguir as equações de Swamee (85), Hagen-Poiseuille (86), Blasius (87) e perda de carga para tubos rugosos (88):

$$
\begin{aligned}
& f_{S}=\left\{\left(\frac{64}{\operatorname{Re}}\right)^{8}+9,5\left[\ln \left(\frac{\varepsilon}{3,7 D}+\frac{5,74}{\operatorname{Re}^{0,9}}\right)-\left(\frac{2500}{\operatorname{Re}}\right)^{6}\right]^{-16}\right\}^{0,125} \\
& f b=\frac{64}{\operatorname{Re}} \\
& f l=\frac{0,361}{\operatorname{Re}^{0,25}} \\
& f r=\frac{0,25}{\left[\log \left(\frac{198}{f r^{1 / 2} \operatorname{Re} 2,7}\right)+\left(\frac{5,74}{\operatorname{Re}^{0,9}}\right)\right]^{2}}
\end{aligned}
$$

em que: $f s$ - fator de atrito para cálculo de perda de carga em tubulação de Swamee; $f b$ - fator de atrito para linha de perda de carga em tubulação de escoamento laminar; $f l$ - Fator de atrito para linha de perda de carga em tubulação de tubos lisos; $f r$ - Fator de atrito para linha de perda de carga em tubulação de tubos rugosos; $R e$ - número de Reynolds; $\varepsilon$ - rugosidade absoluta da tubulação (mm); $D$ - diâmetro da tubulação (mm). 
Tabela 23. Coeficientes de atrito f para construção do diagrama de Moody segundo o número de Reynolds e a rugosidade relativa da tubulação ( $\varepsilon$ /D)

\begin{tabular}{|c|c|c|c|c|c|c|c|c|c|c|c|c|c|}
\hline \multirow{2}{*}{$\begin{array}{c}\text { Rugosidade } \\
\text { Relativa }(\varepsilon / D)\end{array}$} & \multicolumn{13}{|c|}{ Número de Reynolds } \\
\hline & 1 & 10 & 100 & 1000 & 2000 & 4000 & 10000 & 100000 & 1000000 & 10000000 & 100000000 & 1000000000 & 10000000000 \\
\hline 0,0000001 & 64 & 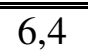 & 0,64 & 0,064 & 0,0320 & 0,0397 & $\begin{array}{c}0,0310 \\
\end{array}$ & 0,0179 & 0,0116 & 0,0082 & $\begin{array}{l}0,0061 \\
\end{array}$ & 0,0049 & 0,0045 \\
\hline 0,000001 & 64 & 6,4 & 0,64 & 0,064 & 0,0320 & 0,0397 & 0,0310 & 0,0179 & 0,0116 & 0,0083 & 0,0065 & 0,0059 & 0,0058 \\
\hline 0,000005 & 64 & 6,4 & 0,64 & 0,064 & 0,0320 & 0,0397 & 0,0310 & 0,0179 & 0,0117 & 0,0087 & 0,0075 & 0,0073 & 0,0073 \\
\hline 0,00001 & 64 & 6,4 & 0,64 & 0,064 & 0,0320 & 0,0397 & 0,0310 & 0,0179 & 0,0118 & 0,0091 & 0,0082 & 0,0081 & 0,0081 \\
\hline 0,00005 & 64 & 6,4 & 0,64 & 0,064 & 0,0320 & 0,0398 & 0,0310 & 0,0182 & 0,0127 & 0,0109 & 0,0106 & 0,0105 & 0,0105 \\
\hline 0,0001 & 64 & 6,4 & 0,64 & 0,064 & 0,0320 & 0,0398 & 0,0311 & 0,0184 & 0,0135 & 0,0122 & 0,0120 & 0,0120 & 0,0120 \\
\hline 0,0002 & 64 & 6,4 & 0,64 & 0,064 & 0,0320 & 0,0399 & 0,0313 & 0,0190 & 0,0148 & 0,0139 & 0,0137 & 0,0137 & 0,0137 \\
\hline 0,0004 & 64 & 6,4 & 0,64 & 0,064 & 0,0320 & 0,0402 & 0,0317 & 0,0200 & 0,0166 & 0,0160 & 0,0159 & 0,0159 & 0,0159 \\
\hline 0,0006 & 64 & 6,4 & 0,64 & 0,064 & 0,0320 & 0,0404 & 0,0320 & 0,0208 & 0,0179 & 0,0175 & 0,0174 & 0,0174 & 0,0174 \\
\hline 0,0008 & 64 & 6,4 & 0,64 & 0,064 & 0,0320 & 0,0406 & 0,0323 & 0,0216 & 0,0191 & 0,0187 & 0,0186 & 0,0186 & 0,0186 \\
\hline 0,001 & 64 & 6,4 & 0,64 & 0,064 & 0,0320 & 0,0408 & 0,0327 & 0,0223 & 0,0200 & 0,0197 & 0,0196 & 0,0196 & 0,0196 \\
\hline 0,002 & 64 & 6,4 & 0,64 & 0,064 & 0,0320 & 0,0419 & 0,0342 & 0,0253 & 0,0237 & 0,0234 & 0,0234 & 0,0234 & 0,0234 \\
\hline 0,004 & 64 & 6,4 & 0,64 & 0,064 & 0,0320 & 0,0439 & 0,0370 & 0,0297 & 0,0286 & 0,0284 & 0,0284 & 0,0284 & 0,0284 \\
\hline 0,006 & 64 & 6,4 & 0,64 & 0,064 & 0,0320 & 0,0458 & 0,0395 & 0,0332 & 0,0322 & 0,0321 & 0,0321 & 0,0321 & 0,0321 \\
\hline 0,008 & 64 & 6,4 & 0,64 & 0,064 & 0,0320 & 0,0477 & 0,0419 & 0,0361 & 0,0353 & 0,0352 & 0,0352 & 0,0352 & 0,0352 \\
\hline 0,01 & 64 & 6,4 & 0,64 & 0,064 & 0,0320 & 0,0494 & 0,0440 & 0,0387 & 0,0380 & 0,0379 & 0,0379 & 0,0379 & 0,0379 \\
\hline 0,015 & 64 & 6,4 & 0,64 & 0,064 & 0,0321 & 0,0536 & 0,0489 & 0,0444 & 0,0438 & 0,0437 & 0,0437 & 0,0437 & 0,0437 \\
\hline 0,02 & 64 & 6,4 & 0,64 & 0,064 & 0,0321 & 0,0574 & 0,0533 & 0,0492 & 0,0487 & 0,0486 & 0,0486 & 0,0486 & 0,0486 \\
\hline 0,03 & 64 & 6,4 & 0,64 & 0,064 & 0,0321 & 0,0645 & 0,0612 & 0,0577 & 0,0572 & 0,0572 & 0,0572 & 0,0572 & 0,0572 \\
\hline 0,04 & 64 & 6,4 & 0,64 & 0,064 & 0,0322 & 0,0710 & 0,0684 & 0,0651 & 0,0647 & 0,0647 & 0,0646 & 0,0646 & 0,0646 \\
\hline 0,05 & 64 & 6,4 & 0,64 & 0,064 & 0,0322 & 0,0771 & 0,0750 & 0,0720 & 0,0716 & 0,0715 & 0,0715 & 0,0715 & 0,0715 \\
\hline 0,06 & 64 & 6,4 & 0,64 & 0,064 & 0,0323 & 0,0830 & 0,0813 & 0,0784 & 0,0780 & 0,0780 & 0,0780 & 0,0780 & 0,0780 \\
\hline 0,07 & 64 & 6,4 & 0,64 & 0,064 & 0,0323 & 0,0886 & 0,0874 & 0,0846 & 0,0842 & 0,0842 & 0,0842 & 0,0842 & 0,0842 \\
\hline 0,08 & 64 & 6,4 & 0,64 & 0,064 & 0,0324 & 0,0941 & 0,0932 & 0,0905 & 0,0902 & 0,0901 & 0,0901 & 0,0901 & 0,0901 \\
\hline 0,09 & 64 & 6,4 & 0,64 & 0,064 & 0,0325 & 0,0995 & 0,0990 & 0,0963 & 0,0960 & 0,0959 & 0,0959 & 0,0959 & 0,0959 \\
\hline 0,1 & 64 & 6,4 & 0,64 & 0,064 & 0,0326 & 0,1048 & 0,1046 & 0,1020 & 0,1017 & 0,1016 & 0,1016 & 0,1016 & 0,1016 \\
\hline
\end{tabular}


Tabela 24. Coeficientes de atrito f para construção das retas de fronteira dos diferentes tipos de escoamento do diagrama de Moody segundo o número de Reynolds

\begin{tabular}{|c|c|c|c|c|c|c|c|c|c|c|c|c|c|}
\hline \multirow[b]{2}{*}{ Escoamento } & \multicolumn{13}{|c|}{ Número de Reynolds } \\
\hline & 1 & 10 & 100 & 1000 & 2000 & 4000 & 10000 & 100000 & 1000000 & 10000000 & 100000000 & 1000000000 & 10000000000 \\
\hline $\begin{array}{l}\text { Laminar } \\
\text { 64/Rey }\end{array}$ & 64 & 6,4 & 0,64 & 0,064 & 0,0320 & 0,0160 & 0,0064 & 0,0006 & 0,0001 & 0,0000 & 0,0000 & 0,0000 & 0,0000 \\
\hline $\begin{array}{c}\text { Liso / Blasius } \\
0,316 /(\operatorname{Rey} 0,25) \\
\end{array}$ & 0,3160 & 0,1777 & 0,0999 & 0,0562 & 0,0473 & 0,0397 & 0,0316 & 0,0178 & 0,0100 & 0,0056 & 0,0032 & 0,0018 & 0,0010 \\
\hline Turbulento & 0,0374 & 0,1491 & 2,9995 & 0,3373 & 0,2176 & 0,1492 & 0,0973 & 0,0424 & 0,0230 & 0,0142 & 0,0096 & 0,0069 & 0,0052 \\
\hline
\end{tabular}




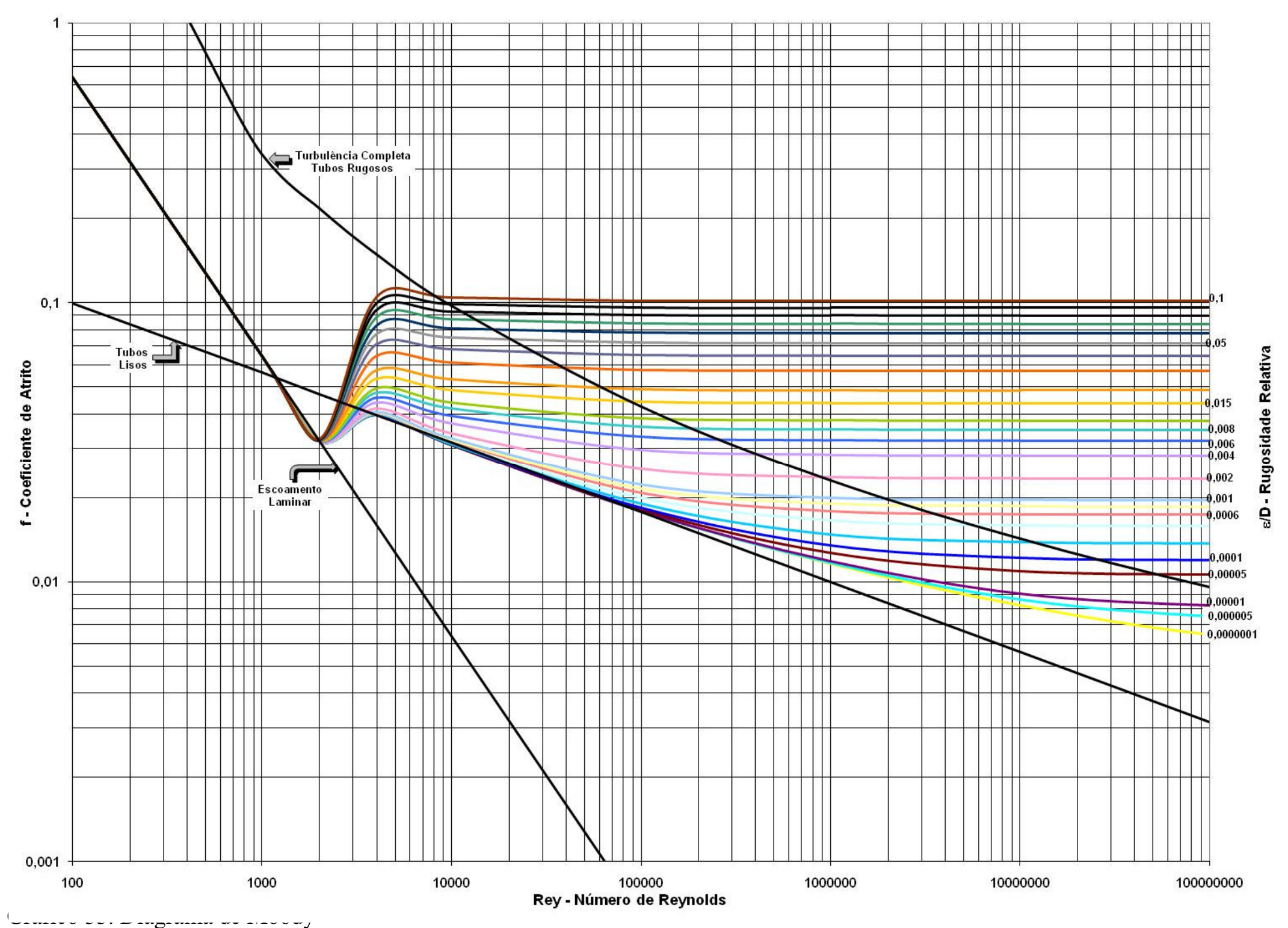


Tabela 25. Coeficiente de redução $\mathrm{F}$ (para cálculo da perda de carga) em função de $\mathrm{N}$ (número de saídas na tubulação), m (expoente da equação de perda de carga) e de x (distância do primeiro emissor à entrada da linha lateral)

Fc - Coeficiente de Christiansen (1942)

Fjf - Coeficiente de Jensen e Frantini (1957)

Fd - Coeficiente de De Tar (1982)

Fa - Coeficiente ajustado de Scaloppi (1986)

x Equações de perda de carga por atrito

\begin{tabular}{|c|c|c|c|c|c|c|c|c|c|c|c|c|c|c|c|c|c|c|c|c|}
\hline \multirow{2}{*}{$\begin{array}{c}0,5 \\
m \Rightarrow\end{array}$} & \multicolumn{4}{|c|}{ Expoente } & \multicolumn{4}{|c|}{ Flamant } & \multicolumn{4}{|c|}{ Hazen-Williams } & \multicolumn{4}{|c|}{ Scobey } & \multicolumn{4}{|c|}{ Manning e Swamee-Jain } \\
\hline & \multicolumn{4}{|c|}{1,0} & \multicolumn{4}{|c|}{1,75} & \multicolumn{4}{|c|}{1,852} & \multicolumn{4}{|c|}{1,9} & \multicolumn{4}{|c|}{2,0} \\
\hline $\mathrm{N}$ & Fc & Fjf & $\mathrm{Fd}$ & $\mathrm{Fa}$ & $\mathrm{Fc}$ & Fjf & $\mathrm{Fd}$ & $\mathrm{Fa}$ & $\mathrm{Fc}$ & Fjf & $\mathrm{Fd}$ & $\mathrm{Fa}$ & $\mathrm{Fc}$ & Fjf & $\mathrm{Fd}$ & $\mathrm{Fa}$ & $\mathrm{Fc}$ & Fjf & $\mathrm{Fd}$ & $\mathrm{Fa}$ \\
\hline 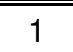 & 1,000 & 1,000 & 1,083 & 1,000 & 1,008 & 1,016 & 1,009 & 1,016 & 1,004 & 1,009 & 1,005 & 1,009 & 1,003 & 1,006 & 1,003 & 1,006 & 1,000 & 1,000 & 1,000 & 1,000 \\
\hline 2 & 0,750 & 0,667 & 0,771 & 0,667 & 0,650 & 0,533 & 0,650 & 0,533 & 0,639 & 0,519 & 0,639 & 0,519 & 0,634 & 0,512 & 0,634 & 0,512 & 0,625 & 0,500 & 0,625 & 0,500 \\
\hline 3 & 0,667 & 0,600 & 0,676 & 0,600 & 0,546 & 0,456 & 0,547 & 0,456 & 0,534 & 0,441 & 0,534 & 0,441 & 0,529 & 0,435 & 0,529 & 0,435 & 0,519 & 0,422 & 0,519 & 0,422 \\
\hline 4 & 0,625 & 0,571 & 0,630 & 0,571 & 0,498 & 0,426 & 0,498 & 0,426 & 0,485 & 0,412 & 0,485 & 0,412 & 0,480 & 0,405 & 0,480 & 0,405 & 0,469 & 0,393 &, 469 & 0,393 \\
\hline 5 & 0,600 & 0,556 & 0,603 & 0,556 & 0,469 & 0,410 & 0,469 & 0,410 & 0,457 & 0,396 & 0,457 & 0,396 & 0,451 & 0,390 & 0,451 & 0,390 & 0,440 & 0,378 & 0,440 & 0,378 \\
\hline 6 & 0,583 & 0,545 & 0,586 & 0,545 & 0,451 & 0,401 & 0,451 & 0,401 & 0,438 & 0,387 & 0,438 & 0,387 & 0,433 & 0,381 & 0,433 & 0,381 & 0,421 & 0,369 & 0,421 & 0,369 \\
\hline 7 & 0,571 & 0,538 & 0,573 & 0,538 & 0,438 & 0,395 & 0,438 & 0,395 & 0,425 & 0,381 & 0,425 & 0,381 & 0,419 & 0,375 & 0,419 & 0,375 & 0,408 & 0,363 & 0,408 & 0,363 \\
\hline 8 & 0,563 & 0,533 & 0,564 & 0,533 & 0,428 & 0,390 & 0,428 & 0,390 & 0,416 & 0,377 & 0,416 & 0,377 & 0,410 & 0,370 & 0,410 & 0,370 & 0,398 & 0,358 & 0,398 & 0,358 \\
\hline 9 & 0,556 & 0,529 & 0,557 & 0,529 & 0,421 & 0,387 & 0,421 & 0,387 & 0,408 & 0,373 & 0,408 & 0,373 & 0,402 & 0,367 & 0,402 & 0,367 & 0,391 & 0,355 & 0,391 & 0,355 \\
\hline 10 & 0,550 & 0,526 & 0,551 & 0,526 & 0,415 & 0,384 & 0,415 & 0,384 & 0,402 & 0,371 & 0,402 & & 0,396 & 0,365 & 0,396 & 0,365 & 0,385 & 0,353 & 0,385 & 0,353 \\
\hline 11 & 0,545 & 0,524 & 0,546 & & 0,4 & 0,382 & 0,410 & & & 0,369 & 0,397 & & & 0,363 & & & 0,380 & 0,351 & 0,380 & 0,351 \\
\hline 12 & 0,542 & 0,522 & 0,542 & 0,522 & 0,406 & 0,380 & 0,406 & 0,380 & 0,393 & 0,367 & 0,393 & 0,367 & 0,388 & 0,361 & 0,388 & 0,361 & 0,376 & 0,349 & 0,376 & 0,349 \\
\hline 13 & 0,538 & 0,520 & 0,539 & 0,520 & 0,403 & 0,379 & 0,403 & 0,379 & 0,390 & 0,366 & 0,390 & 0,366 & 0,384 & 0,360 & 0,384 & 0,360 & 0,373 & 0,348 & 0,373 & 0,348 \\
\hline 14 & 0,536 & 0,519 & 0,536 & 0,519 & 0,400 & 0,378 & 0,400 & 0,378 & 0,387 & 0,364 & 0,387 & 0,364 & 0,381 & 0,358 & 0,381 & 0,358 & 0,370 & 0,347 & 0,370 & 0,347 \\
\hline 15 & 0,533 & 0,517 & 0,534 & 0,517 & 0,398 & 0,377 & 0,398 & 0,377 & 0,385 & 0,363 & 0,385 & 0,363 & 0,379 & 0,357 & 0,379 & 0,357 & 0,367 & 0,346 & 0,367 & 0,346 \\
\hline 16 & 0,531 & 0,516 & 0,532 & 0,516 & 0,395 & 0,376 & 0,395 & 0,376 & 0,382 & 0,363 & 0,382 & 0,363 & 0,377 & 0,357 & 0,377 & 0,357 & 0,365 & 0,345 & 0,365 & 0,345 \\
\hline 17 & 0,529 & 0,515 & 0,530 & 0,515 & 0,394 & 0,375 & 0,394 & 0,375 & 0,381 & 0,362 & 0,381 & 0,362 & 0,375 & 0,356 & 0,375 & 0,356 & 0,363 & 0,344 & 0,363 & 0,344 \\
\hline 18 & 0,528 & 0,514 & 0,528 & 0,514 & 0,392 & 0,374 & 0,392 & 0,374 & 0,379 & 0,361 & 0,379 & 0,361 & 0,373 & 0,355 & 0,373 & 0,355 & 0,362 & 0,343 & 0,362 & 0,343 \\
\hline 19 & 0,526 & 0,514 & 0,527 & 0,514 & 0,390 & 0,374 & 0,390 & 0,374 & 0,377 & 0,361 & 0,377 & 0,361 & 0,372 & 0,355 & 0,372 & 0,355 & 0,360 & 0,343 & 0,360 & 0,343 \\
\hline 20 & 0,525 & 0,513 & 0,525 & 0,513 & 0,389 & 0,373 & 0,389 & 0,373 & 0,376 & 0,360 & 0,376 & 0,360 & 0,370 & 0,354 & 0,370 & 0,354 & 0,359 & 0,342 & 0,359 & 0,342 \\
\hline 21 & 0,524 & 0,512 & 0,524 & 0,512 & 0,388 & 0,373 & 0,388 & 0,373 & 0,375 & 0,360 & 0,375 & 0,360 & 0,369 & 0,354 & 0,369 & 0,354 & 0,358 & 0,342 & 0,358 & 0,342 \\
\hline 22 & 0,523 & 0,512 & 0,523 & 0,512 & 0,387 & 0,372 & 0,387 & & & 0,359 & 0,374 & & 0,368 & 0,353 & 0,368 & & 0,356 & 0,341 & 0,356 & 0,341 \\
\hline 23 & 0,522 & 0,511 & 0,522 & 0,511 & 0,386 & 0,372 & 0,386 & 0,372 & 0,373 & 0,359 & 0,373 & 0,359 & 0,367 & 0,353 & 0,367 & 0,353 & 0,355 & 0,341 & 0,355 & 0,341 \\
\hline
\end{tabular}




\begin{tabular}{|c|c|c|c|c|c|c|c|c|c|c|c|c|c|c|c|c|c|c|c|c|}
\hline & 521 & 0,511 & 0,521 & 0,511 & 0,385 & 0,372 & 0,385 & 0,372 & 0,372 & 0,358 & 0,372 & 0,358 & 0,366 & 0,352 & 0,366 & 0,352 & 0,354 & 0,341 & 0,354 & 0,341 \\
\hline & 520 & 510 & 0,520 & 510 & 0,384 & 0,371 & 0,384 & 0,371 & ,371 & 0,358 & 0,371 & 0,358 & 0,365 & ,352 & 0,365 & 0,352 & 0,354 & 0,340 & 0,354 & 0,340 \\
\hline & 519 & 510 & 519 & 510 & 383 & 371 & 383 & 0,371 & 370 & 358 & ,370 & 358 & 0,364 & 352 & 364 & 352 & 353 & & & \\
\hline & 519 & 509 & 519 & & 382 & 371 & 382 & ,371 & 369 & 357 & 369 & 357 & 364 & & 364 & 352 & & & & \\
\hline & 518 & 0,509 & 0,518 & 0,509 & 0,382 &, 370 & 0,382 & 0,370 & ,369 & 357, &, 369 & 357 & 0,363 & 351 & 363, & ,351 & 351 & ,340 & 351 & 340 \\
\hline & 517 & 0,509 & 0,517 & 0,509 & 0,381 & 0,370 & 0,381 & 0,370 & 0,368 & 0,357 & , 368 & 357 & 0,362 & 351 & , 362 & 351 & 351 & 0,339 & 351 & 339 \\
\hline & 517, & 0,508 & 0,517 & 0,508 & 0,380 & 0,370 & 0,380 & 0,370 & 0,367 & 0,357 & 0,367 & 357, & 0,362 &, 351 & 0,362 &, 351 & ,350 & ),339 & 350 &, 339 \\
\hline & 516 & 0,508 & 0,516 & 0,508 & 0,380 & ,370 & 0,380 & 0,370 & D,367 & 0,357 & 0,367 & ,357 & 0,361 & ,351 & 0,361 & 0,351 & ),350 & 0,339 & ,350 & 0,339 \\
\hline & ,516 & 0,508 & 0,516 & 0,508 & 0,379 & 0,370 & 0,379 & 0,370 & 0,366 & 0,356 & 0,366 &, 356 & 0,361 & 350 & & 350 & ,349 & ,339 & 349 &, 339 \\
\hline & ,515 & 0,508 & 515 & 0,508 & 0,379 & ,369 & 0,379 & 0,369 & 0,366 & 0,356 & 366 & 0,356 & 0,360 & & 0,360 & ),350 & 349, & ),339 & 349 & ,339 \\
\hline & 515 & 0,507 & 0,515 & , & 0,378 & 369 & 0,378 & 0,369 & ,365 & 0,356 & D,365 & 356, & 0,360 & 350 & 360 &, 350 & 348 & 0,338 & 348 & ,338 \\
\hline & 514 & 0,507 & 514 & 0,507 & 0,378 & 369 & 0,378 & 0,369 &, 365 & 0,356 & 365 & ,356 & 0,359 & 350 & 359 & 350 & 348 & ,338 & 348 & 338 \\
\hline & 514 & 507 & 0,514 & 0,507 & 0,378 & ,369 & 0,378 & 0,369 & 0,365 & 0,356 & 0,365 & 0,356 & 0,359 & 350 & 0,359 & 350 & , 347 & 0,338 & ,347 & 338 \\
\hline & 514 & 507 & 0,514 & 0,507 & 0,377 & ,369 & 0,377 & 0,369 & 0,364 & 0,356 & ,364 &, 356 & 0,358 & 350 & 358, & 350 &, 347 & 0,338 & ,347, & ,338 \\
\hline & ,513 & 0,507 & 0,513 & 0,507 & 0,377 &, 369 & 0,377 & 0,369 & 0,364 & 0,355 & 0,364 &, 355 & 0,358 & ,350 & & ,350 & & 0,338 & 347 & 338 \\
\hline & 513 & 0,506 & 0,513 & 0,506 & 0,377 & 0,368 & 0,377 & 0,368 & 0,364 & & 0,364 & & & & & 349 & & & & 0,338 \\
\hline & 513 & & 0,513 & 0,50 & 0,376 & & & & & & & & & & & 349 & & & & 338 \\
\hline & 0,512 & 0,5 & 0,512 & 0,506 & 0,376 & 368 & 0,376 & 0,368 & 63 & & & & & & & 349 & & 338 & & 338 \\
\hline & 512 & 0,506 & 512 & 0,506 & 0,376 & 368 & 376 & 0,368 & & & 363 & & & & & 349 & & 337 & & 337 \\
\hline & 512 & 0,506 & 0,512 & 0,506 & 0,375 & ,368 & 0,375 & 0,368 & 0,362 & 0,355 & 0,362 &, 355 & 0,357 & ),349 & 0,357 & 0,349 & 345 & 0,337 & 345 & ,337 \\
\hline & 511 & 0,506 & 0,511 & 0,506 & 0,375 & ),368 & 0,375 & 0,368 & 0,362 & 0,355 & 0,362 & 355 & 0,356 & ),349 & 0,356 & ),349 & ,345 & 0,337 & 345 & ,337 \\
\hline & 0,511 & 0,506 & 0,511 & 0,506 & 0,375 & 0,368 & 0,375 & 0,368 & 0,362 & 0,355 & 0,362 & 0,355 & 0,356 & ),349 & 356 & ,349 & ,345 & ,337 & 345 & ,337 \\
\hline & 511 & & 511 & 0 & 0,375 & 68 & & 0,3 & & & & & & & & 349 & & & & 0,337 \\
\hline 4 & 511 & & 11 & 0,5 & 0,3 & & & 368 & & & & & & & & 349 & & & & 337 \\
\hline & & & & & & & & & & & & & & & & & & & & 337 \\
\hline & & & & & & & & 0,3 & & & & & & & & & & & & 337 \\
\hline & 510 & 0,505 & 510 & 0,505 & 0,374 & ,367 & 0,374 & 0,367 & 361 & 0,354 & 0,361 & ),354 & 0,355 & 0,348 & 355 & 0,348 & 0,343 & 0,337 & 343 & 0,337 \\
\hline & 510 & 0,505 & 0,510 & 0,505 & 0,373 & 0,367 & 0,373 & 0,367 & 0,360 & 0,354 & 0,360 & 0,354 & 0,355 & 0,348 & 0,355 & 0,348 & 0,343 & 0,337 & 0,343 & 0,337 \\
\hline & 0,510 & 0,505 & 0,510 & 0,505 & 0,373 & , 367 & 0,373 & 0,367 & 0,360 & 0,354 & 0,360 & 0,354 & 0,355 & ),348 & 355 & 0,348 & 0,343 & 0,337 & , 343 & ,337 \\
\hline & 0,509 & 0,505 & 0,509 & 0,505 & 0,373 & 0,367 & 0,373 & 0,367 & 0,360 & 0,354 & 0,360 & 0,354 & 0,354 & 0,348 & 0,354 & 0,348 & 0,343 & 0,337 & , 343 & 0,337 \\
\hline & 0,509 & 0,505 & 509 & 0,50 & 0,373 & , 367 & 0,373 & 0,367 & 0,360 & ,354 &, 360 & 0,354 & 354 & 348 & & 348 & 343 & 337 & 343 & ,337 \\
\hline & 0,509 & 0,505 & 0,509 & 0,5 & 0,373 & 0,367 & 0,373 & 0,367 & 0,360 & 0,354 & 0,360 & & & 348 & & 0,348 & 342 & ,336 & , 342 & 0,336 \\
\hline 5 & 0,509 & & & & 0,373 & & & 0,367 & & & & & & 348 & & 348 & 342 & 336 & 342 & 0,336 \\
\hline & & & & & & & & & & & & & & & & & & & & 336 \\
\hline & & & & & & & & & & & & & & & & & & ,336 & 342 & 0,336 \\
\hline & & & & & 0,372 & & & & & & & & 53 & 348 & & 348 & ,342 & ,336 & ),342 & 0,336 \\
\hline & & & & & 0,372 & 367 & & 0,367 & & 0,354 & 0,359 & 0,354 & & 348 & 353 & 0,348 & ,342 & 0,336 & 0,342 & ),336 \\
\hline & & & & & 0,372 & ,367 & & 0,367 & & 0,354 & 0,359 & & & & & & 0,342 & 0,336 & ),342 & ),336 \\
\hline & 508 & 0,504 & ,508, & 0,504 & 0,372 & ,367, & 0,372 & 0,367 & 0,359 & 0,354 & ,359 & 0,354 & 0,353 & 0,348 & 0,353 & 0,348 & 0,341 & ,336 & ,341 & 0,336 \\
\hline
\end{tabular}




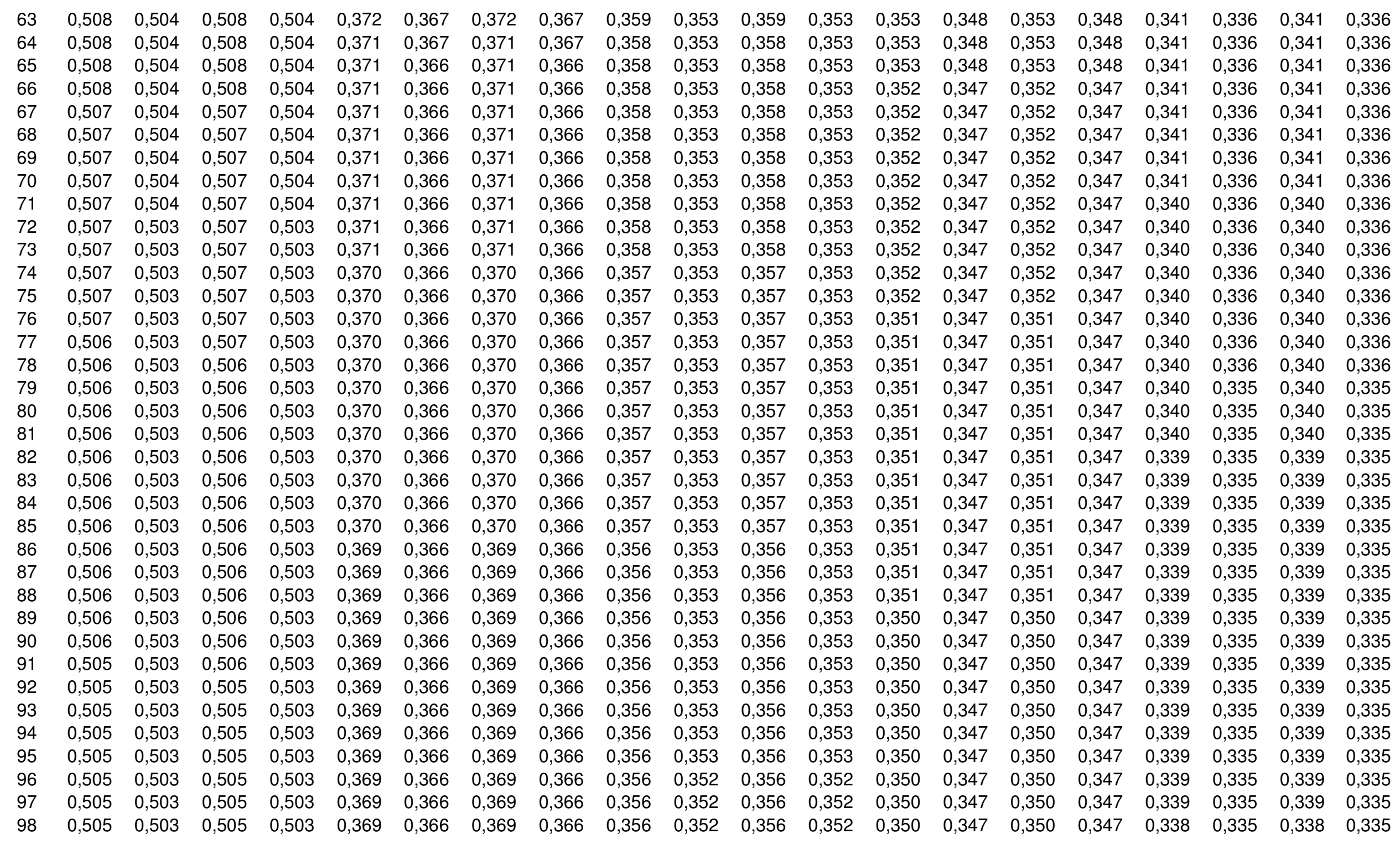




\begin{tabular}{|c|c|c|c|c|c|c|c|c|c|c|c|c|c|c|c|c|c|c|c|}
\hline 0,505 & 0,503 & 0,505 & 0,503 & 0,369 & 0,365 & 0,369 & 0,365 & 0,356 & 0,352 & 0,356 & 0,352 & 0,350 & 0,347 & 0,350 & 0,347 & 0,338 & 0,335 & 0,338 & 0,335 \\
\hline 0,505 & 0,503 & 0,505 & 0,503 & 0,369 & 0,365 & 0,369 & 0,365 & 0,356 & 0,352 & 0,356 & 0,352 & 0,350 & 0,347 & 0,350 & 0,347 & 0,338 & 0,335 & 0,338 & 0,335 \\
\hline 505 & 0,502 & 0,505 & ,502 & 0,369 & 0,365 & 0,369 & 0,365 & 0,356 & 0,352 & 0,356 & 352 & 0,350 & 0,347 & 0,350 & 347 & 338 & 335 & & 335 \\
\hline 0,505 & 0,502 & 0,505 & 502 & 0,369 & 365 & ,369 & ,365, & 356 & 352 & ,356 & 352 &, 350 & 347 & 350 & 347 & 338 & 335 & 338 & \\
\hline 0,505 & 0,502 & 0,505 & 502 & 0,369 & 365 & ,369 & 365 & 356 & 352 & 0,356 & 352 & ,350 & 347 & 350 & 347 & 338 & 0,335 & 338 & \\
\hline 0,505 & 0,502 & 0,505 & 0,502 & 0,368 & 0,365 & 0,368 & 0,365 & ,355 & 0,352 & 0,355 & 352, & 0,350 & 0,347 & 0,350 & 0,347 & 338 & 0,335 & 338 & ,335 \\
\hline 0,505 & 0,502 & 0,505 & 0,502 & 0,368 & 0,365 & 0,368 & 0,365 & 0,355 & 0,352 & 0,355 & 0,352 & 0,350 & 0,346 & 0,350 & 0,346 & 0,338 & 0,335 &, 338 &, 335 \\
\hline 0,505 & 0,502 & 0,505 & 0,502 & 0,368 & 0,365 & 0,368 & 0,365 & 0,355 & 0,352 & 0,355 & 0,352 & 0,350 & 0,346 & 0,350 & 0,346 & 0,338 & 0,335 & 338, & , 335 \\
\hline 0,505 & 0,502 & 0,505 & 0,502 & 0,368 & 0,365 & 0,368 & 0,365 & 0,355 & 0,352 & 0,355 & 0,352 & 0,350 & 0,346 & 0,350 & 0,346 & 0,338 & 0,335 & ,338 & ,335 \\
\hline 0,505 & 0,502 & 0,505 & 0,502 & 0,368 & 0,365 & 0,368 & 0,365 & 0,355 & 0,352 & 0,355 & 0,352 & 0,349 & 0,346 & 0,349 & 0,346 & 0,338 & 0,335 & 338 & ,335 \\
\hline 0,505 & 0,502 & 0,505 & 0,502 & 0,368 & 0,365 & 0,368 & 0,365 & 0,355 & 0,352 & 0,355 & 0,352 & 0,349 & 0,346 & 0,349 & 0,346 & 0,338 & 0,335 & 0,338 & ,335 \\
\hline 0,505 & 0,502 & 0,505 & 0,502 & 0,368 & 0,365 & 0,368 & 0,365 & 0,355 & 0,352 & 0,355 & 0,352 & 0,349 & 0,346 & 0,349 & 0,346 & 338 & 0,335 & ,338 & 335 \\
\hline 0,505 & 0,502 & 0,505 & 0,502 & 0,368 & 0,365 & 0,368 & 0,365 & 0,355 & 0,352 & 0,355 & 0,352 & 0,349 & 0,346 & 0,349 & 0,346 & 338 & 0,335 & 338 & 335 \\
\hline 0,504 & 0,502 & 0,504 & 0,502 & 0,368 & 0,365 & 0,368 & 0,365 & 0,355 & 0,352 & 0,355 & 0,352 & 0,349 & 0,346 & 0,349 & 0,346 & 338 & 0,335 & 338 & \\
\hline 0,504 & 0,502 & 0,504 & 0,502 & 0,368 & 0,365 & 0,368 & 0,365 & 0,355 & 0,352 & 0,355 & 0,352 & 49 & 346 & 0,349 & 0,346 & 338 & 335 & 338 & \\
\hline 0,504 & 0,502 & 0,504 & 0,502 & 0,368 & 0,365 & 0,368 & 0,365 & 0,355 & 0,352 & 0,355 & 0,352 & 0,349 & 0,346 & 0,349 & 0,346 & 0,338 & 0,335 & 0,338 & \\
\hline 0,504 & 0,502 & 0,504 & 0,502 & 0,368 & 0,365 & 0,368 & 0,365 & 0,355 & 0,352 & 0,355 & 0,352 & 0,349 & 0,346 & 0,349 & 0,346 & 0,338 & 0,335 & 0,338 & 0,335 \\
\hline 0,504 & 0,502 & 0,504 & 0,502 & 0,368 & 0,365 & 0,368 & 0,365 & 0,355 & 0,352 & 0,355 & & 0,349 & & & 0,346 & & 335 & 338 & \\
\hline 0,504 & 0,502 & 0,504 & 0,502 & 0,368 & 0,365 & 0,368 & 0,365 & 0,355 & 0,352 & 0,355 & 0,352 & 0,349 & 0,346 & 0,349 & 0,346 & 338 & 0,335 & 0,338 & 335 \\
\hline 0,504 & 0,502 & 0,504 & 0,502 & 0,368 & 0,365 & 0,368 & 0,365 & 0,355 & 0,352 & 0,355 & 0,352 & 0,349 & 0,346 & 0,349 & 0,346 & 0,338 & 0,335 & 0,338 & ,335 \\
\hline 0,504 & 0,502 & 0,504 & 0,502 & 0,368 & 0,365 & 0,368 & 0,365 & 0,355 & 0,352 & 0,355 & 0,352 & 0,349 & 0,346 & 0,349 & 0,346 & 0,338 & 0,335 & 0,338 & 335 \\
\hline 0,504 & 0,502 & 0,504 & 0,502 & 0,368 & 0,365 & 0,368 & 0,365 & 0,355 & 0,352 & 0,355 & 0,352 & 0,349 & 0,346 & 0,349 & 0,346 & 0,338 & 0,335 & 0,338 & ,335 \\
\hline 0,504 & 0,502 & 0,504 & 0,502 & 0,368 & 0,365 & 0,368 & 0,365 & 0,355 & 0,352 & 0,355 & 352 & 0,349 & 0,346 & 0,349 & 0,346 & 337 & 0,335 & 0,337 & 0,335 \\
\hline 0,504 & 0,502 & 0,504 & 0,502 & 0,368 & 0,365 & 0,368 & 0,365 & 0,355 & 0,352 & 0,355 & 0,352 & 0,349 & 0,346 & 0,349 & 0,346 & 0,337 & 0,335 & 0,337 & 0,335 \\
\hline 0,504 & 0,502 & 0,504 & 0,502 & 0,368 & 0,365 & 0,368 & 0,365 & 0,355 & 0,352 & 0,355 & & 0,349 & 346 & 49 & 0,346 & 0,337 & 335 & ,337 & 0,335 \\
\hline 504 & 0,502 & 0,504 & 0,502 & 0,368 & 0,365 & 0,3 & 0,365 & & & 0,355 & & 49 & 346 & & 0,346 & & 335 & 337 & 335 \\
\hline 504 & 0,502 & 0,504 & 0,502 & 0,368 & 0,365 & 0,368 & 0,365 & 0,355 & 0,352 & 0,355 & & 49 & & & 0,346 & 337 & 0,335 & 0,337 & 335 \\
\hline 0,504 & 0,502 & 0,504 & 0,502 & 0,368 & 0,365 & 0,368 & 0,365 & 0,355 & 0,352 & 0,355 & 352 & 0,349 & 0,346 & 0,349 & 0,346 & 0,337 & 0,335 & 0,337 & 335 \\
\hline 0,504 & 0,502 & 0,504 & 0,502 & 0,368 & 0,365 & 0,368 & 0,365 & 0,355 & 0,352 & 0,355 & 0,352 & 0,349 & 0,346 & 0,349 & 0,346 & 0,337 & 0,335 & 0,337 & 0,335 \\
\hline 0,504 & 0,502 & 0,504 & 0,502 & 0,368 & 0,365 & 0,368 & 0,365 & 0,355 & 0,352 & 0,355 & 0,352 & 0,349 & 0,346 & 0,349 & 0,346 & 0,337 & 0,335 & 0,337 & ,335 \\
\hline 0,504 & 0,502 & 0,504 & 0,502 & 0,368 & 0,365 & 0,368 & 0,365 & 0,355 & 0,352 & 0,355 & 352 & 0,349 & 0,346 & 0,349 & 0,346 & 337 & 0,335 & 0,337 & ,335 \\
\hline 0,504 & 0,502 & 0,504 & 0,502 & 0,367 & 0,365 & 0,367 & 0,365 & 0,354 & 0,352 & 0,354 & 0,352 & 0,349 & 0,346 & 0,349 & 0,346 & 337 & 0,335 & 0,337 & 0,335 \\
\hline 0,504 & 0,502 & 0,504 & 0,502 & 0,367 & 0,365 & 0,367 & 0,365 & 0,354 & 0,352 & 0,354 & 0,352 & 0,349 & 0,346 & 0,349 & 0,346 & 0,337 & 0,335 & 0,337 & 0,335 \\
\hline 0,504 & 0,502 & 0,504 & 0,502 & 0,367 & 0,365 & 0,367 & 0,365 & 0,354 & 0,352 & 0,354 & 0,352 & 0,349 & 0,346 & 0,349 & 0,346 & 337 & 0,335 & 0,337 & 0,335 \\
\hline 0,504 & 0,502 & 0,504 & ,502 & 0,367 & 0,365 & 0,367 & 0,365 & 0,354 & 0,352 & 0,354 & & 49 & 0,346 & 0,349 & 0,346 & 337 & 335 & 0,337 & 0,335 \\
\hline 0,504 & 0,502 & 0,504 & 0,502 & 0,367 & 0,365 & 0,367 & 0,3 & 54 & 52 & 0,3 & 52 & 49 & 346 & 49 & 346 & 337 & 335 & 0,337 & ,335 \\
\hline & & & & & & & & & & & & & & & & & 335 & 0,337 & \\
\hline & & & & & & & & & & & & & & & 0,346 & 337 & 335 & 0,337 & \\
\hline 0,504 & 0,502 & 0,504 & 0,502 & 0,367 & 0,365 & 0,367 & 0,365 & 0,354 & 0,352 & 0,354 & 0,352 & 0,348 & 0,346 & 0,348 & 0,346 & 0,337 & 0,335 & 0,337 & ,335 \\
\hline
\end{tabular}




\begin{tabular}{|c|c|c|c|c|c|c|c|c|c|c|c|c|c|c|c|c|c|c|c|c|}
\hline 138 & 0,504 & 0,502 & 0,504 & 0,502 & 0,367 & 0,365 & 0,367 & 0,365 & 0,354 & 0,352 & 0,354 & 0,352 & 0,348 & 0,346 & 0,348 & 0,346 & 0,337 & 0,335 & 0,337 & \\
\hline 139 & 0,504 & 0,502 & 0,504 & 0,502 & 0,367 & 0,365 & 0,367 & 0,365 & 0,354 & 0,352 & 0,354 & 0,352 & 0,348 & 0,346 & 0,348 & 0,346 & 0,337 & 0,335 & 0,337 & 0,335 \\
\hline 140 & 0,504 & 0,502 & 0,504 & 0,502 & 0,367 & 0,365 & 0,367 & 0,365 & 0,354 & 0,352 & 0,354 & 0,352 & 0,348 & 0,346 & 0,348 & 0,346 & 0,337 & 0,335 & 0,337 & 0,335 \\
\hline 141 & 0,504 & 0,502 & 0,504 & 0,502 & 0,367 & 0,365 & 0,367 & 0,365 & 0,354 & 0,352 & 0,354 & 0,352 & 0,348 & 0,346 & 0,348 & 0,346 & 0,337 & 0,335 & ,337 & ,335 \\
\hline 42 & 504 & 0,502 & 0,504 &, 502 & 0,367 & ,365 &, 367 & 0,365 & ,354 & 0,352 & ,354 &, 352 & ,348 & 0,346 & 0,348 & ,346 & 0,337 &, 335 &, 337 & ,335 \\
\hline 143 & 0,503 & 0,502 & 0,504 & 0,502 & 0,367 & 0,365 & 0,367 & 0,365 & 0,354 & 0,352 & ,354 & 0,352 & 0,348 & 0,346 & 0,348 & ,346 & 0,337 & ,335 & ,337 & ,335 \\
\hline 44 &, 503 & 0,502 & 0,503 & 0,502 & 0,367 & 0,365 & 0,367 & 0,365 & ,354 & 0,352 & ,354 & 352 & 0,348 & 0,346 & 0,348 & ),346 & 0,337 & ,335 & ,337 & ,335 \\
\hline 145 &, 503 & 0,502 & 0,503 & 0,502 & 0,367 & 0,365 & 0,367 & 0,365 &, 354 & 0,352 & ,354 & ,352 & 0,348 & 0,346 & 0,348 & 0,346 & 0,337 & ,334 & ,337 & ,334 \\
\hline 146 & ,503 & 0,502 & 0,503 & 0,502 & 0,367 & 0,365 & 0,367 & 0,365 & ,354 & 0,352 &, 354 & 0,352 & 0,348 & 0,346 & 0,348 & 0,346 & 0,337 &, 334 & ,337 & ),334 \\
\hline 147 & 503 & 0,502 & 0,503 & 0,502 & 0,367 & 0,365 & 0,367 & 0,365 & 0,354 & 0,352 & 0,354 & 0,352 & 0,348 & 0,346 & 0,348 & 0,346 & 0,337 & ,334 & 0,337 & ),334 \\
\hline 148 &, 503 & 0,502 & 0,503 & 0,502 & 0,367 & 0,365 & 0,367 & 0,365 & 0,354 & 0,352 & 0,354 & 0,352 & 0,348 & 0,346 & 0,348 & 0,346 & 0,337 & 0,334 & 0,337 & 0,334 \\
\hline 149 & 503 & 0,502 & 0,503 & 0,502 & 0,367 & 365 & 0,367 & 0,365 &, 354 & 0,352 & 0,354 & 352 & 0,348 & 0,346 & 0,348 & 0,346 & 0,337 & ,334 & 0,337 & 0,334 \\
\hline 150 & 0,503 & 0,502 & 0,503 & 0,502 & 0,367 & 0,365 & 0,367 & 0,365 & 0,354 & 0,352 & & 352 & 0,348 & 0,346 & 0,348 & 0,346 & 0,337 & ,334 & 0,337 & ,334 \\
\hline 151 & 0,503 & 0,502 & 0,503 & 0,502 & 0,367 & 0,365 & 0,367 & 0,365 & 0,354 & 0,352 & 0,354 & 0,352 & 0,348 & 0,346 & 0,348 & 0,346 & 0,337 & ,334 & ,337 & ),334 \\
\hline 152 & & 0,502 & 0,503 & 0,502 & 0,367 & & 0,367 & 0,365 & & 0,352 & & & & & & & & & 37 & \\
\hline 153 & 0,503 & 0,502 & 0,503 & 0,502 & 0,367 & 0,365 & 0,367 & 0,365 & 0,354 & 0,352 & 0,354 & 0,352 & 0,348 & 0,346 & 0,348 & 0,346 & 0,337 & 0,334 & 0,337 & 0,334 \\
\hline 154 &, 503 & 0,502 & 0,503 & 0,502 & 0,367 & 0,365 & 0,367 & 0,365 & 0,354 & 0,352 & 354 & 352 & 0,348 & 0,346 & 0,348 & 0,346 & 0,337 & 34 & 337 & 0,334 \\
\hline 156 & 0,503 & 0,502 & 0,503 & 0,502 & 0,367 & 0,365 & 0,367 & 0,365 & 0,354 & 0,352 & 0,354 & 0,352 & 0,348 & 0,346 & 0,348 & 0,346 & 0,337 & 0,334 & 0,337 & 0,334 \\
\hline 157 & & 0,502 & & & & 0,365 & 0,367 & 0,365 & & 0,352 & & 352 & 0,348 & 0,346 & 0,348 & 0,346 & 0,337 & 334 & 337 & \\
\hline 158 & 0,503 & 0,502 & 0,503 & 0,502 & 0,367 & 0,365 & 0,367 & 0,365 & 0,354 & 0,352 & 0,354 & 0,352 & 0,348 & 0,346 & 0,348 & 0,346 & 0,337 & 0,334 & 0,337 & 0,334 \\
\hline 159 &, 503 & 0,502 & 0,503 & 0,502 & 0,367 & 0,365 & 0,367 & 0,365 & 0,354 & 0,352 & 0,354 & 0,352 & 0,348 & 0,346 & 0,348 & 0,346 & 0,336 & & & \\
\hline 160 & 0,503 & 0,502 & 0,503 & 0,502 & 0,367 & 0,365 & 0,367 & 0,365 & 0,354 & 0,352 & 0,354 & 0,352 & 0,348 & 0,346 & 0,348 & 0,346 & 0,336 & 0,334 & 0,336 & 0,334 \\
\hline 161 & 0,503 & 0,502 & 0,503 & 0,502 & 0,367 & 0,365 & 0,367 & 0,365 & 0,354 & 0,352 & 0,354 & 0,352 & 0,348 & 0,346 & 0,348 & 0,346 & 0,336 & 0,334 & 0,336 & 0,334 \\
\hline 162 & ,503 & 0,502 & 0,503 & 0,502 & 0,367 & 0,365 & 0,367 & 0,365 & 0,354 & 0,352 & 54 & 0,352 & 0,348 & 0,346 & 0,348 & 0,346 & 0,336 & 334 & 0,336 & 0,334 \\
\hline 163 & 0,503 & 0,502 & 0,503 & 0,502 & 0,367 & 0,365 & 0,367 & 0,365 & 0,354 & 0,352 & 0,354 & 0,352 & 0,348 & 0,346 & 0,348 & 0,346 & 0,336 & 0,334 & 0,336 & 0,334 \\
\hline 164 & 0,503 & 0,502 & 0,503 & 0,502 & 0,367 & 0,365 & 0,367 & 0,365 & 0,354 & 0,352 & 0,354 & 0,352 & 0,348 & 0,346 & 0,348 & 0,346 & 0,336 & 0,334 & 0,336 & 0,334 \\
\hline 165 & 0,503 & 0,502 & 0,503 & 0,502 & 0,367 & 0,365 & 0,367 & 0,365 & 0,354 & 0,352 & 0,354 & 0,352 & 0,348 & 0,346 & 0,348 & 0,346 & 0,336 & 0,334 & 0,336 & 0,334 \\
\hline 166 & 0,503 & 0,502 & 0,503 & 0,502 & 0,367 & 0,365 & 0,367 & 0,365 & 0,354 & 0,352 & & & 0,348 & 0,346 & 0,348 & 0,346 & 0,336 & 0,334 & 0,336 & 0,334 \\
\hline 167 & 0,503 & 0,502 & 0,503 & 0,502 & 0,367 & 0,365 & 0,367 & 0,365 & 0,354 & 0,352 & 0,354 & 0,352 & 0,348 & 0,346 & 0,348 & 0,346 & 0,336 & 0,334 & 0,336 & 0,334 \\
\hline 168 & 0,503 & 0,501 & 0,503 & 0,501 & 0,367 & 0,365 & 0,367 & 0,365 & 0,354 & 0,352 & 0,354 & 0,352 & 0,348 & 0,346 & 0,348 & 0,346 & 0,336 & 0,334 & 0,336 & 0,334 \\
\hline 169 & 0,503 & 0,501 & 0,503 & 0,501 & 0,367 & 0,365 & 0,367 & 0,365 & 0,354 & 0,352 & 0,354 & 0,352 & 0,348 & 0,346 & 0,348 & 0,346 & 0,336 & 0,334 & 0,336 & 0,334 \\
\hline 170 & 0,503 & 0,501 & 0,503 & 0,501 & 0,367 & 0,365 & 0,367 & 0,365 & 0,354 & 0,352 & 0,354 & 0,352 & 0,348 & 0,346 & 0,348 & 0,346 & 0,336 & 0,334 & 0,336 & 0,334 \\
\hline 171 & 0,503 & 0,501 & 0,503 & 0,501 & 0,367 & 0,365 & 0,367 & 0,365 & 0,354 & 0,352 & 0,354 & 0,352 & 0,348 & 0,346 & 0,348 & 0,346 & 0,336 & 0,334 & 0,336 & 0,334 \\
\hline
\end{tabular}




\begin{tabular}{|c|c|c|c|c|c|c|c|c|c|c|c|c|c|c|c|c|c|c|c|c|}
\hline 174 & 0,503 & 0,501 & 0,503 & 0,501 & 0,367 & 0,365 & 0,367 & 0,365 & 0,354 & 0,352 & 0,354 & 0,352 & 0,348 & 0,346 & 0,348 & 0,346 & 0,336 & 0,334 & 0,336 & 0,334 \\
\hline 175 & 0,503 & 0,501 & 0,503 & 0,501 & 0,366 & 0,365 & 0,366 & 0,365 & 0,353 & 0,352 & 0,353 & 0,352 & 0,348 & 0,346 & 0,348 & 0,346 & 0,336 & 0,334 & 0,336 & 0,334 \\
\hline 176 & 0,503 & 0,501 & 0,503 & 0,501 & 0,366 & 0,365 & 0,366 & 0,365 & 0,353 & 0,352 & 0,353 & 0,352 & 0,348 & 0,346 & 0,348 & 0,346 & ,336 & 0,334 & 0,336 & ,334 \\
\hline 177 & 0,503 & 0,501 & 0,503 & 0,501 & 0,366 & 0,365 & 0,366 & 0,365 & 0,353 & 0,352 & 0,353 & ,352 & 0,348 & ,346 & 0,348 & 0,346 & ,336 & ,334 & 336 & ,334 \\
\hline 179 & 0,503 & 0,501 & 0,503 & 0,501 & 0,366 & 0,365 & 0,366 & 0,365 &, 353 & 0,352 & 0,353 & ,352 & 0,348 & ),346 & 0,348 & 0,346 & 0,336 & 0,334 & 0,336 & 0,334 \\
\hline 180 & 0,503 & 0,501 & 0,503 & 0,501 & 0,366 & 0,365 & 0,366 & 0,365 &, 353 & 0,352 & 0,353 & 0,352 & 0,348 & 0,346 & 0,348 & 0,346 & 0,336 & 0,334 & 0,336 & 0,334 \\
\hline 181 & 0,503 & 0,501 & 0,503 & 0,501 & 0,366 & 0,365 & 0,366 & 0,365 & 0,353 & 0,352 & 0,353 & 0,352 & 0,348 & 0,346 & 0,348 & 0,346 & 0,336 & 0,334 & 0,336 & 0,334 \\
\hline 182 & 0,503 & 0,501 & 0,503 & 0,501 & 0,366 & 0,365 & 0,366 & 0,365 & 0,353 & 0,352 & 0,353 & 0,352 & 0,348 & 0,346 & 0,348 & 0,346 & 0,336 & 0,334 & 0,336 & 0,334 \\
\hline 83 &, 503 & 0,501 & 0,503 & 0,501 & 0,366 & 0,365 & 0,366 & 0,365 & 0,353 & 0,352 & 0,353 & 0,352 & 0,348 & 0,346 & 0,348 & 0,346 & 0,336 & 0,334 & 0,336 & 0,334 \\
\hline 184 & 0,503 & 0,501 & 0,503 & 0,501 & 0,366 & 0,365 & 0,366 & 0,365 & & 0,352 & 0,353 & 0,352 & 0,348 & & & & 0,336 & 34 & 36 & 34 \\
\hline 185 & 0,503 & 0,501 & 0,503 & 0,501 & 0,366 & 0,365 & 0,366 & 0,365 & 0,353 & 0,352 & 0,353 & 0,352 & 0,348 & 0,346 & 0,348 & 0,346 & 0,336 & 0,334 & 0,336 & 0,334 \\
\hline 186 & 0,503 & 0,501 & 0,503 & 0,501 & 0,366 & 0,365 & 0,366 & 0,365 & 0,353 & 0,352 & & & & & & & & & & \\
\hline 187 & 0,503 & 0,501 & 0,503 & 0,501 & 0,366 & 0,365 & 0,366 & 0,365 & 0,353 & 0,352 & 0,353 & 0,352 & 0,348 & 0,346 & 0,348 & 0,346 & 0,336 & 0,334 & 0,336 & 0,334 \\
\hline 188 & 0,503 & 0,501 & 0,503 & 0,501 & 0,366 & 0,365 & 0,366 & 0,365 & 0,353 & 0,352 & 0,353 & 0,352 & 0,347 & 0,346 & 0,347 & 0,346 & 0,336 & 0,334 & 0,336 & 0,334 \\
\hline 189 & 0,503 & 0,501 & 0,503 & 0,501 & 0,366 & 0,365 & 0,366 & 0,365 & 0,353 & 0,352 & 0,353 & 0,352 & 0,347 & 0,346 & 0,347 & 0,346 & 0,336 & 0,334 & 0,336 & 0,334 \\
\hline 190 & 0,503 & 0,501 & 0,503 & 0,501 & 0,366 & 0,365 & 0,366 & 0,365 & 0,353 & 0,352 & 0,353 & 0,352 & 0,347 & 0,346 & 0,347 & 0,346 & 0,336 & 0,334 & 0,336 & 0,334 \\
\hline 192 & 0,503 & 0,501 & 0,503 & 0,501 & 0,366 & 0,365 & 0,366 & 0,365 & 0,353 & 0,352 & 0,353 & 0,352 & 0,347 & 0,346 & 0,347 & 0,346 & 0,336 & 0,334 & 0,336 & 0,334 \\
\hline 193 & 0,503 & 0,501 & 0,503 & 0,501 & 0,366 & 0,365 & 0,366 & 0,365 & 0,353 & & 0,353 & 0,352 & 0,347 & 0,346 & 0,347 & 0,346 & 0,336 & 34 & 0,336 & 0,334 \\
\hline 194 & 0,503 & 0,501 & 0,503 & 0,501 & 0,366 & 0,365 & 0,366 & 0,365 & 0,353 & 0,352 & 0,353 & 0,352 & 0,347 & 0,346 & 0,347 & 0,346 & 0,336 & 0,334 & 0,336 & 0,334 \\
\hline 195 & 0,503 & 0,501 & 0,503 & 0,501 & 0,366 & 0,365 & 0,366 & 0,365 & 0,353 & 0,352 & 0,353 & 0,352 & 0,347 & 0,346 & 0,347 & 0,346 & 0,336 & 0,334 & 0,336 & 0,334 \\
\hline 196 & 0,503 & 0,501 & 0,503 & 0,501 & 0,366 & 0,365 & 0,366 & 0,365 & 0,353 & 0,352 & 0,353 & 0,352 & 0,347 & 0,346 & 0,347 & 0,346 & 0,336 & 0,334 & 0,336 & 0,334 \\
\hline 197 & 0,503 & 0,501 & 0,503 & 0,501 & 0,366 & 0,365 & 0,366 & 0,365 & 0,353 & 0,352 & 0,353 & 0,352 & 0,347 & 0,346 & 0,347 & 0,346 & 0,336 & 0,334 & 0,336 & 0,334 \\
\hline 198 & 0,503 & 0,501 & 0,503 & 0,501 & 0,366 & 0,365 & 0,366 & 0,365 & 0,353 & 0,352 & 0,353 & 0,352 & 0,347 & 0,346 & 0,347 & 0,346 & 0,336 & 0,334 & 0,336 & 0,334 \\
\hline 199 & 0,503 & 0,501 & 0,503 & 0,501 & 0,366 & 0,365 & 0,366 & 0,365 & 0,353 & 0,352 & 0,353 & 0,352 & 0,347 & 0,346 & 0,347 & 0,346 & 0,336 & 0,334 & 0,336 & 0,334 \\
\hline 200 & 0,503 & 0,501 & 0,503 & 0,501 & 0,366 & 0,365 & 0,366 & 0,365 & 0,353 & 0,352 & 0,353 & 0,352 & 0,347 & 0,346 & 0,347 & 0,346 & 0,336 & 0,334 & 0,336 & 0,334 \\
\hline
\end{tabular}




\section{APÊNDICE B}

Arquivo foirriga.m, em que constam os dados de entrada (hidráulico e de custos),

o pré-dimensionamento, o dimensionamento hidráulico da rede e a função objetivo.

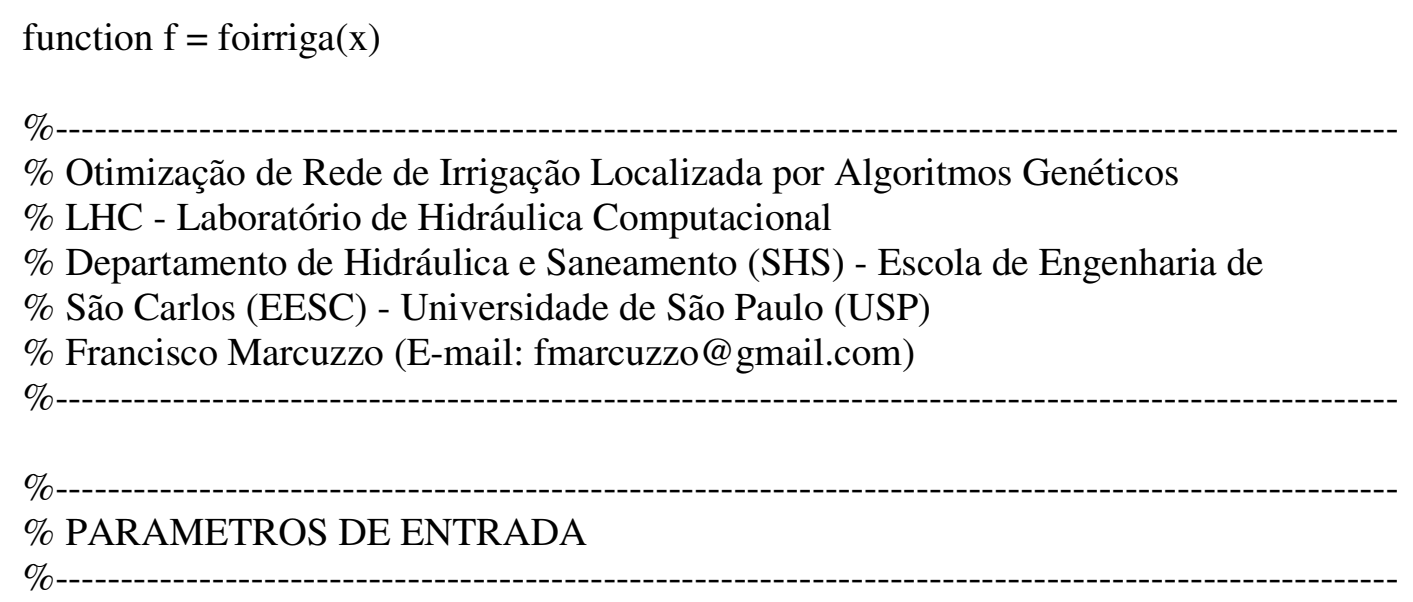

$\% \%$ Dados iniciais de entrada

$\mathrm{UE}=92$;

CEemin $=1.7$

CEemax $=8.0$

$\mathrm{Sf}=6.0$

$\mathrm{Sp}=3.5$

$\mathrm{PEP}=0$;

$\mathrm{CC}=24$;

$\mathrm{PM}=10$;

$\mathrm{DA}=1.4$;

$\mathrm{Du}=0$;

$\mathrm{f}=50$;

$\mathrm{v}=0.0000010040$;

$\mathrm{z}=1.0$;

$\mathrm{ETO}=3.00$;

$\mathrm{KC}=0.96$;

$\mathrm{NTUO}=24$;

TFMBD $=8.5$;

NUOIS $=4$;

TaCUOIS $=4.25$;

TRE $=3$;

$\mathrm{VAP}=8275$;

$\mathrm{a}=-0.000002$;

$\mathrm{b}=0.0331$;

$\mathrm{c}=111.52$;

$\mathrm{g}=9.81$; 
$\mathrm{Lx}=1600$

$\mathrm{Ly}=420$;

$\mathrm{m}=2$;

$\mathrm{EEUO}=7.5$;

$\% \%$ Escolha do microaspersor

$\mathrm{k}=14.71$;

$\mathrm{xe}=0.486$;

$\mathrm{PS}=1.5$;

$\mathrm{PSmin}=1.0$;

PSmax $=2.0$;

$\mathrm{KE}=0.5$;

$\mathrm{CVF}=0.02787$;

$\mathrm{h}=\mathrm{PS} * 10$;

$\mathrm{w}=0.7358 *\left(\mathrm{~h}^{\wedge} 0.5501\right)$;

$\mathrm{NSE}=1$;

$\%$

$\%$ DADOS DO LEIAUTE DA REDE DE DISTRIBUICAO

$\%$

$\% \%$ Linha lateral

$\%$ Material: Polietileno.

LLL $=96.25$;

DLL1 $=0.0217$;

DLL2 $=0.0178$;

$\mathrm{ELL}=0.0015$

$\mathrm{DZLL}=0$;

$\mathrm{KLL}=0.1$;

$\% \%$ Linha de derivação

$\%$ Material: PVC.

LLD = 135 ;

DLD1 $=0.1200$

DLD2 $=0.0976$;

DLD3 $=0.0725$;

DLD4 $=0.0481$;

$\mathrm{ELD}=0.01$

$\mathrm{DZLD}=-5$;

$\% \%$ Linha secundaria

$\%$ Material: PVC.

LLS $=700$;

DLS1 $=0.2042$;

DLS2 $=0.1440$;

DLS3 $=0.1200 ;$

DLS4 $=0.0976$;

$\mathrm{ELS}=0.01$;

DZLS $=0$;

$\mathrm{KLS}=0.1$; 


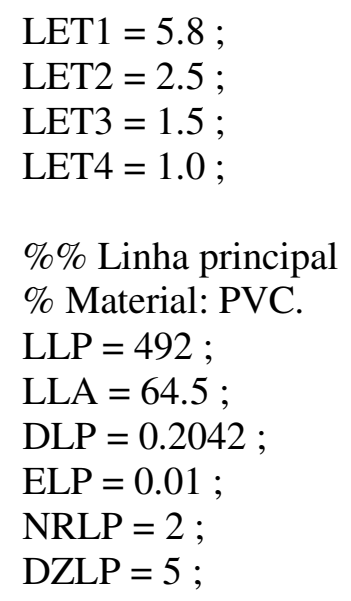

$\% \%$ Linha de succao

$\%$ Material: PVC.

LLSU $=6$;

DLSU $=0.262$;

$\mathrm{ELSU}=0.01$;

$\mathrm{AGSU}=2$;

$\mathrm{KLSU}=18$;

$\% \%$ Perda de carga no cabecal de controle $\mathrm{hfcc}=5.0$;

$\% \%$ Coeficientes de perda de carga localizada $(\mathrm{k})$

$\mathrm{KPCV}=0.2$;

$\mathrm{KPCR}=0.2$;

$\mathrm{KPCF}=2.0$;

$\mathrm{KPCTD}=0.9$;

$\mathrm{KPCTSL}=2.0$;

$\% \%$ Conjunto motobomba

Vrotor $=3450.0$;

Dcr $=128$;

nbomba $=64.1$;

nrotores $=1$;

nmotor $=85.7$;

FAPNB $=1.1$;

$\%$

$\%$ CUSTOS FIXOS E VARIAVEIS DO PROJETO

$\%$

$\% \%$ Preco dos equipamentos da rede de distribuição.

$\%$ Custo dos componentes da linha lateral.

$\mathrm{CTE}=0.57$;

CRDLL $=0.25$;

CANELFL $=0.24$;

CLLD1 $=0.93$; 
CLLD2 $=0.63$

$\%$ Custo dos componentes da linha de derivacao.

CCSLL $=0.44$;

CRDLD1 $=7.30$;

CRDLD2 $=3.99$;

CRDLD3 $=2.16$;

CTFL $=2.75$;

CLDD1 $=83.20$;

CLDD2 $=55.65$;

CLDD3 $=39.20$

CLDD4 $=23.92$;

$\%$ Custos dos componentes da linha secundaria.

$\mathrm{CFT}=148.77$

CVRPLS $=112.77$

CRLS $=13.07$

CCULS $=24.50$;

CCTDLS $=13.82$;

CRDLS1 $=26.50$;

CRDLS2 $=14.31$

CRDLS3 $=7.30$;

CLSD1 $=131.06$

CLSD2 $=105.93$

CLSD3 $=83.20$

CLSD4 $=55.65$;

$\%$ Custos dos componentes da linha principal.

CRLP $=13.07$

CCTFLP $=20.50$;

CCTDLP $=20.50$;

CLPDI $=105.93$;

$\%$ Custos dos componentes do cabecal de controle.

$\mathrm{CFD}=1338.86$

$\mathrm{CFA}=5430.17$;

$\mathrm{CRG}=13.07$;

$\mathrm{CIV}=266.41$

$\mathrm{CPC}=990.16$;

$\mathrm{CH}=1914.68$;

$\mathrm{CM}=60.00$;

$\%$ Custos dos componentes do conjunto motobomba.

$\mathrm{CAE}=0.44$

$\mathrm{CRE}=0.44$;

$\%$ Custos dos demais componentes da rede de distribuicao.

$\mathrm{CC} 90=24.50$

CVPC $=151.97$

CTS = 143.19; 
CCPVC $=10.09$

$\% \%$ Tarifa da agua no setor rural

$\mathrm{CA}=0.01$;

$\% \%$ Tarifa de energia eletrica

$\mathrm{TSR}=0.1768$;

DTNSR $=60$;

TDTEE $=8.5$;

$\% \%$ Fator de recuperacao do capital

$\mathrm{i}=0.06$;

$\mathrm{n}=10$;

$\%$

$\%$ Dimensionamento do Sistema

$\%$

$\% \%$ Dimensionamento inicial

$\mathrm{A}=(\mathrm{Lx} * \mathrm{Ly}) / 10000$;

$\mathrm{AUO}=\mathrm{A} / \mathrm{NTUO}$

See $=0.8 * w ;$

$\mathrm{NP}=\mathrm{Sp} / \mathrm{See}$

$\mathrm{NPA}=\operatorname{round}(\mathrm{NP})$;

$\mathrm{Pma}=\mathrm{pi} * \mathrm{w}$

$\mathrm{Ama}=\left(\mathrm{pi} *\left(\mathrm{w}^{\wedge} 2\right)\right) / 4$;

$\mathrm{Pw}=\mathrm{NPA} *((\mathrm{Ama}+((\mathrm{See} * \mathrm{Pma}) / 2)) /((\mathrm{Sp} * \mathrm{Sf})) * 100)$

DTAS $=((\mathrm{CC}-\mathrm{PM}) / 10) * \mathrm{DA} ;$

$\mathrm{IRN}=(\mathrm{DTAS} / 10) *(\mathrm{f} / 100) *(\mathrm{z} * 100) *(\mathrm{Pw} / 100) ;$

$\mathrm{ETpc}=\mathrm{ETO} * \mathrm{KC}$

$\mathrm{ETCA}=\mathrm{ETpc} * 365$

$\% \mathrm{KL}$ - Fator de ajuste devido a aplicacao localizada da agua.

if $(\mathrm{Pw}>65)$

$\mathrm{KL}=1$;

elseif $(21<\mathrm{Pw}<65)$

$\mathrm{KL}=(1.09 *(\mathrm{Pw} / 100)+0.3)$;

elseif $(\mathrm{Pw}<20)$ 
end

$$
\mathrm{KL}=(1.94 *(\mathrm{Pw} / 100)+0.1)
$$

$\mathrm{ETg}=\mathrm{ETpc} * \mathrm{KL}$;

$\mathrm{TR}=\mathrm{IRN} / \mathrm{ETg} ;$

$\mathrm{TRI}=\operatorname{round}(\mathrm{TR})$;

IRNAIL $=\mathrm{ETg} * \mathrm{TRE} ;$

$\mathrm{RL}=$ CEemin $/(2 *$ CEemax $) ;$

$\mathrm{ITN}=\mathrm{IRNAIL} /((\mathrm{UE} / 100) *(1-\mathrm{RL})) ;$

$\mathrm{Vp}=\mathrm{ITN} * \mathrm{Sf} * \mathrm{Sp}$

$\mathrm{qmin}=\mathrm{Vp} /(\mathrm{NPA} *$ TaCUOIS $) ;$

$\mathrm{hmin}=(\mathrm{qmin} / \mathrm{k})^{\wedge}(1 / \mathrm{xe})$

$\mathrm{qa}=\left(\mathrm{qmin} *\left(1-1.27 *\left(\mathrm{CVF} /\left(\mathrm{NSE}^{\wedge}-0.5\right)\right)\right) * 100\right) / \mathrm{UE}$;

he $=(\mathrm{qa} / \mathrm{k})^{\wedge}(1 / \mathrm{xe})$

$\% \%$ Dimensionamento da linha lateral

$\%$ Variaveis.

LLL1 $=\mathrm{x}(1)$;

LLL2 $=x(2) ;$

$\%$ Pre-dimensionamento da linha lateral.

ADLL1 $=\mathrm{pi}^{*}\left(\left(\mathrm{DLL1}^{\wedge} 2\right) / 4\right)$;

ADLL2 $=$ pi $*\left(\left(D_{L L 2}{ }^{\wedge} 2\right) / 4\right)$;

$\mathrm{EEE}=\mathrm{Sp} / \mathrm{NPA}$;

$\mathrm{E} 1 \mathrm{E}=\mathrm{EEE} / 2$;

$\mathrm{NTE}=((\mathrm{LLL}-\mathrm{E} 1 \mathrm{E}) / \mathrm{EEE})+1$;

NELL1 = LLL1 / EEE ;

round(NELL1);

NELL2 = NTE - NELL1 ;

round(NELL2);

$\mathrm{xLL}=\mathrm{E} 1 \mathrm{E} / \mathrm{EEE}$;

DZLLD $=(($ LLL $*$ DZLL $) / 100):-(((L L L * D Z L L) / 100) /$ NTE $):(((L L L *$ DZLL $) /$ 100) / NTE) ;

$\mathrm{FLL}=\left((\mathrm{NTE}) *\left((1 /(\mathrm{m}+1))+(1 /(2 *(\mathrm{NTE})))+\left(\left((\mathrm{m}-1)^{\wedge} 0.5\right) /\left(6 *\left(\left(\mathrm{NTE}^{\wedge} 2\right)\right)\right)\right)\right)+\right.$ $x L L-1) /((N T E)+x L L-1)$;

$\%$ Dimensionamento do trecho 1 da linha lateral.

QILLT1 $=$ NTE * $($ qa $/ 1000)$;

QILL1 $=($ NTE $:-1: 1) *($ qa $/ 1000)$; 


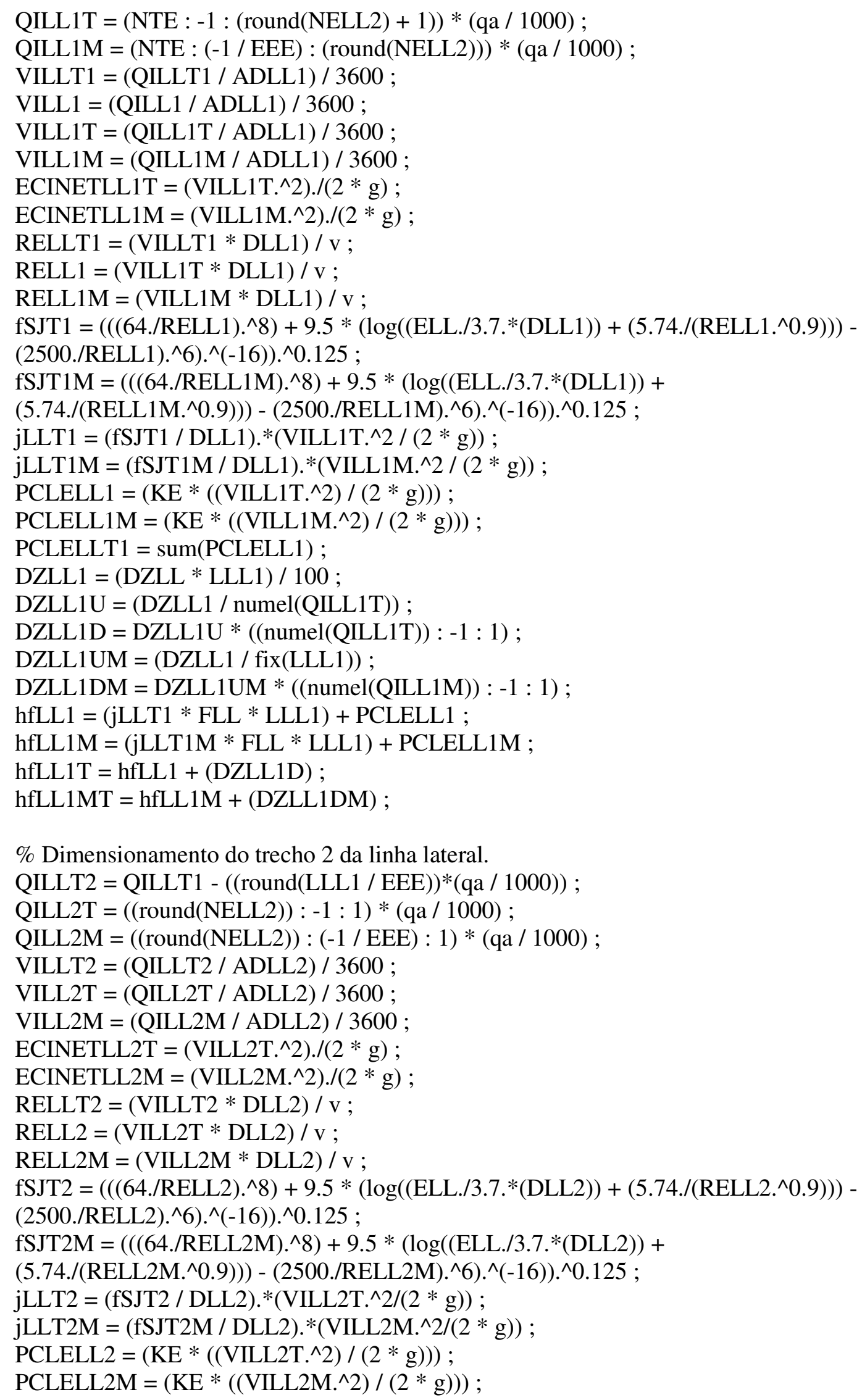


DZLL2 $=(\mathrm{DZLL} *$ LLL2) $/ 100$

DZLL2U $=($ DZLL2 $/$ numel $($ QILL2T $))$;

DZLL2D = DZLL2U * ((numel(QILL2T) $):-1: 1)$;

DZLL2UM $=($ DZLL2 $/$ fix $($ LLL2 $))$;

DZLL2DM = DZLL2UM * ((numel(QILL2M)) : -1 : 1);

hfLL2 $=(j L L T 2 *$ FLL $*$ LLL2 $)+$ PCLELL2 $;$

hfLL2M $=(j L L T 2 M *$ FLL $*$ LLL2 $)+$ PCLELL2M ;

hfLL2T $=$ hfLL2 $+($ DZLL2D $)$;

hfLL2MT $=$ hfLL2M + (DZLL2DM) ;

$\%$ Diferenca entre as perdas de carga em cada trecho de cada tubulacao da linha lateral.

DhfLL12 $=(-(\operatorname{diff}([$ hfLL1, hfLL2, 0] $)))$;

DhfLL12M $=(-(\operatorname{diff}([\mathrm{hfLL} 1 \mathrm{M}, \mathrm{hfLL2M}, 0])))$;

$\%$ Perda de carga localizada com a contracao da tubulacao.

RA2A1 = ADLL2 / ADLL1 ;

$\mathrm{KA} 2 \mathrm{~A} 1=\left(0.0817 *\left(\mathrm{RA} 2 \mathrm{~A} 1^{\wedge} 6\right)\right)+\left(0.5562 *\left(\mathrm{RA} 2 \mathrm{~A} 11^{\wedge} 5\right)\right)-(1.2032 *(\mathrm{RA} 2 \mathrm{~A} 1 \wedge 4))+$ $\left(1.0513^{*}\left(\mathrm{RA} 2 \mathrm{~A} 1{ }^{\wedge} 3\right)\right)-\left(0.6362^{*}(\mathrm{RA} 2 \mathrm{~A} 1 \wedge 2)\right)-\left(0.3496^{*}(\mathrm{RA} 2 \mathrm{~A} 1)\right)+0.5$;

PCLA2A $1=\mathrm{KA} 2 \mathrm{~A} 1 *\left(\left(\mathrm{VILLT} 2{ }^{\wedge} 2\right) /(2 * \mathrm{~g})\right)$;

$\%$ Perda de carga total na linha lateral com dois diametros, sem considerar o desvio geometrico do terreno.

if isempty(hfLL1)

hfLL1 $=0$;

end

if isempty(hfLL2)

hfLL2 $=0$;

end

if $((\max (\mathrm{hfLL} 2))>=(\min (\mathrm{hfLL} 1)))$

PCTLL $=(\max (h f L L 2))+((\max (h f L L 1))-(\min (h f L L 1)))+$ PCLA2A1; elseif $((\max ($ hfLL2 $))<(\min ($ hfLL1 $)))$

PCTLL $=\max ($ hfLL1 $)+$ PCLA2A1;

else

PCTLL $=(\max ($ hfLL2 $))+$ PCLA2A1 ;

end

$\%$ Perda de carga total na linha lateral com dois diametros, considerando o desvio geometrico do terreno.

if isempty(hfLL1T)

end

hfLL1T $=0$;

if isempty(hfLL2T)

hfLL2T $=0$;

end

if $((\max (\mathrm{hfLL} 2 \mathrm{~T}))>=(\min (\mathrm{hfLL} 1 \mathrm{~T})))$

PCTLLT $=(\max ($ hfLL2T $))+((\max ($ hfLL1T $))-(\min ($ hfLL1T $)))+$ PCLA2A1 ;

elseif $((\max ($ hfLL2T $))<(\min ($ hfLL1T $)))$

PCTLL $=\max ($ hfLL1T $)+$ PCLA2A 1

else

PCTLLT $=(\max ($ hfLL2T $))+$ PCLA2A $1 ;$ 
end

$\%$ Pressao requerida na entrada da linha lateral com dois diamentros, considerando o desvio geometrico do terreno no calculo final.

PRELL = he + PCTLL + ((DZLL * LLL) / 100) ;

$\%$ Pressao requerida na entrada da linha lateral com dois diamentros, considerando o desvio geometrico do terreno trecho a trecho.

PRELLT $=$ he + PCTLLT ;

$\%$ Energia total requerida na entrada da linha lateral com dois diametros, considerando o desvio geometrico do terreno no calculo final.

if $((\max ($ ECINETLL2T $))>=(\min ($ ECINETLL1T $)))$

ERELL $=(\max ($ ECINETLL2T $))+((\max ($ ECINETLL1T $))-(\min ($ ECINETLL1T $)))+$

PRELL;

elseif $((\max ($ ECINETLL2T $))<(\min ($ ECINETLL1T $)))$

$\mathrm{ERELL}=(\max (\mathrm{ECINETLL1T}))+$ PRELL $;$

else

ERELL $=(\max ($ ECINETLL2T $))+$ PRELL ;

end

$\%$ Energia total requerida na entrada da linha lateral com dois diametros, considerando

o desvio geometrico do terreno trecho a trecho.

if $((\max ($ ECINETLL2T $))>=(\min ($ ECINETLL1T $)))$

ERELLT $=(\max ($ ECINETLL2T $))+((\max ($ ECINETLL1T $))-(\min ($ ECINETLL1T $))$

+ PRELLT ;

elseif $((\max ($ ECINETLL2T $))<(\min ($ ECINETLL1T $)))$

$\mathrm{ERELLT}=(\max (\mathrm{ECINETLL1T}))+$ PRELLT $;$

else

ERELLT $=(\max ($ ECINETLL2T $))+$ PRELLT ;

end

$\%$ Analise da uniformidade de emissao obtida na linha lateral com dois diametros.

qce12 $=\mathrm{k} *($ he $+[$ hfLL1T, hfLL2T $]) .^{\wedge} \mathrm{xe}$;

$\mathrm{qce} 12 \mathrm{M}=\mathrm{k} *($ he $+[\mathrm{hfLL} 1 \mathrm{MT}, \mathrm{hfLL} 2 \mathrm{MT}]) .^{\wedge} \mathrm{xe}$;

qce $12 \mathrm{MAX}=(\max (\mathrm{qce} 12))$

qce12MMAX $=(\max (\mathrm{qce} 12 \mathrm{M}))$;

qce $12 \mathrm{MIN}=(\min (\mathrm{qce} 12))$;

qce $12 \mathrm{MMIN}=(\min ($ qce $12 \mathrm{M}))$;

qce12MEDIA $=($ median $($ qce 12$))$;

qce12MMEDIA $=(\operatorname{median}($ qce $12 \mathrm{M}))$;

hLL12 $=($ qce12 $/ \mathrm{k}) .^{\wedge}(1 / \mathrm{xe})$

$\mathrm{hLL12M}=(\mathrm{qce} 12 \mathrm{M} / \mathrm{k}) .^{\wedge}(1 / \mathrm{xe})$;

hLL12MAX $=(\max ($ hLL12 $))$;

hLL12MMAX $=(\max (\mathrm{hLL} 12 \mathrm{M}))$;

hLL12MIN $=(\min (\mathrm{hLL12}))$;

hLL12MMIN $=(\min (\mathrm{hLL} 12 \mathrm{M}))$; 
hLL12MEDIA $=($ median $($ hLL12 $))$;

hLL12MMEDIA $=(\operatorname{median}(\mathrm{hLL} 12 \mathrm{M}))$;

VAQRELL = var(qce12);

VAQRELLM = var(qce12M) ;

DPQELL $=\operatorname{std}($ qce 12$)$;

DPQELLM = std (qce12M);

VAHRELL $=\operatorname{var}($ hLL12) ;

VAHRELLM $=\operatorname{var}(\mathrm{hLL12M})$;

DPHELL $=\operatorname{std}($ hLL12) ;

DPHELLM $=\operatorname{std}(\mathrm{hLL12M})$;

$\mathrm{CVF}=(\mathrm{DPQELL} /($ median $($ qce 12$)))$

$\mathrm{UECLL}=\left(1-\left(1.27 * \mathrm{CVF}^{*}\left(\mathrm{NSE}^{\wedge} 0.5\right)\right)\right) *(\mathrm{qce} 12 \mathrm{MIN} / \mathrm{qce} 12 \mathrm{MEDIA}) * 100 ;$

$\mathrm{CUC}=100 *(1-(\operatorname{sum}($ qce $12-(\operatorname{median}(\mathrm{qce} 12)))) /(\mathrm{NSE} *(\operatorname{median}($ qce 12$)))) ;$

UEST $=100 *(1-($ DPQELL $/($ median $(q c e 12)))) ;$

$\mathrm{DHV}=2.5 *($ he $-\mathrm{hmin})$;

DHVLL $=0.55 *$ DHV;

DHVLD $=0.45 * \mathrm{DHV} ;$

$\% \%$ Dimensionamento da linha de derivacao

$\%$ Variaveis.

LLD1 $=\mathrm{x}(3)$;

LLD2 $=x(4) ;$

LLD3 $=\mathrm{x}(5) ;$

LLD4 $=\mathrm{x}(6) ;$

round(LLD1);

round(LLD2);

round(LLD3) ;

round(LLD4);

$\%$ Pre-dimensionamento da linha de derivacao.

PRFLD $=$ PRELL ;

ADLD1 $=$ pi $*((D L D 1 \wedge 2) / 4)$;

$\mathrm{ADLD} 2=\mathrm{pi} *\left(\left(\mathrm{DLD} 2^{\wedge} 2\right) / 4\right)$;

ADLD3 $=$ pi $*\left(\left(\mathrm{DLD}^{\wedge} 2\right) / 4\right)$;

ADLD4 $=$ pi $*((D L D 4 \wedge 2) / 4)$;

$\mathrm{EEL}=\mathrm{Sf}$;

$\mathrm{E} 1 \mathrm{~L}=\mathrm{EEL} / 2$;

$\mathrm{NTL}=(((\mathrm{LLD}-\mathrm{E} 1 \mathrm{~L}) / \mathrm{EEL})+1) * 2$;

NLLD1 = LLD1 / EEL ;

NLLD2 = LLD2 / EEL;

NLLD3 = LLD3 / EEL; 


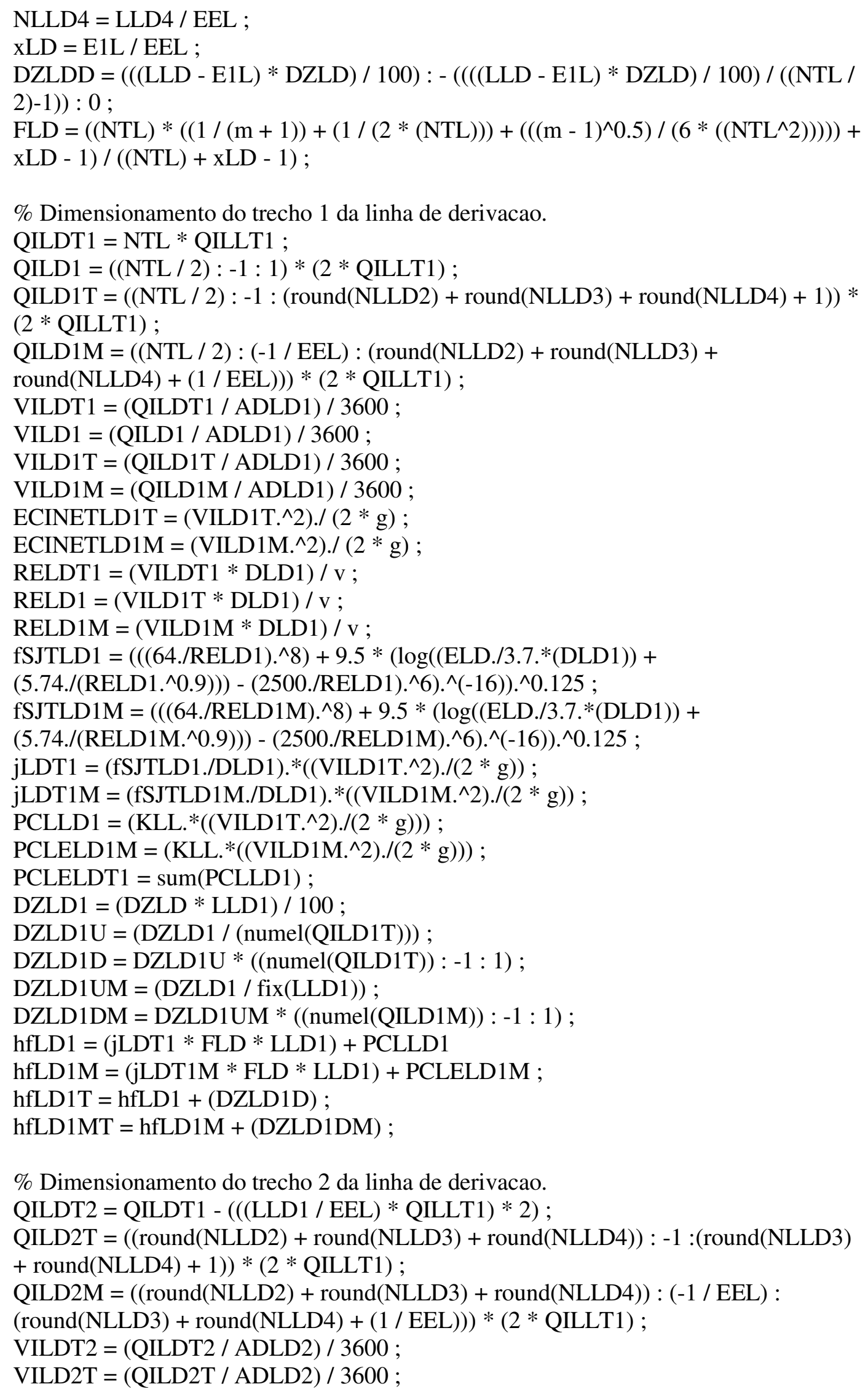


VILD2M = (QILD2M / ADLD2) / 3600 ;

ECINETLD2T $=\left(\right.$ VILD2T. $\left.^{\wedge} 2\right) . /(2 * \mathrm{~g})$;

ECINETLD2M = (VILD2M.^2)./(2* g);

RELDT2 $=($ VILDT2 $*$ DLD2 $) / v$;

RELD2 $=($ VILD2T $*$ DLD2 $) / v$;

RELD2M $=($ VILD2M $*$ DLD2 $) / \mathrm{v}$;

fSJTLD2 $=(((64 . /$ RELD2 $) . \wedge 8)+9.5 *(\log (($ ELD./3.7. $*(D L D 2))+$

(5.74./(RELD2.^0.9))) - (2500./RELD2).^.$\left.\left.^{\wedge}\right) .^{\wedge}(-16)\right) .^{\wedge} 0.125$;

fSJTLD2M $=(((64 . /$ RELD2M $) . \wedge 8)+9.5 *(\log (($ ELD./3.7.*(DLD2) $)+$

(5.74./(RELD2M.^0.9))) - (2500./RELD2M).^6).^(-16)).^0.125 ;

jLDT2 $=($ fSJTLD2./DLD2) $*(($ VILD2T.^2)./(2* g) $)$;

jLDT2M $=($ fSJTLD2M./DLD2).*((VILD2M.^2)./(2* g));

PCLLD2 $=($ KLL. $*(($ VILD2T.^2)./(2* g $)))$;

PCLELD2M $=($ KLL.*((VILD2M.^2)./(2* g) $))$;

PCLELDT2 $=\operatorname{sum}($ PCLLD2 $)$;

DZLD2 $=($ DZLD $*$ LLD2 $) / 100$;

DZLD2U $=($ DZLD2 / numel $($ QILD2T $))$;

DZLD2D $=$ DZLD2U * $(($ numel(QILD2T $)):-1: 1)$;

$\mathrm{DZLD} 2 \mathrm{UM}=(\mathrm{DZLD} 2 / \mathrm{fix}(\mathrm{LLD} 2))$;

$\mathrm{DZLD} 2 \mathrm{DM}=\mathrm{DZLD} 2 \mathrm{UM} *(($ numel$(\mathrm{QILD} 2 \mathrm{M})):-1: 1)$;

hfLD2 $=(\mathrm{jLDT} 2 * \mathrm{FLD} *$ LLD2 $)+$ PCLLD2 $;$

hfLD2M $=(\mathrm{jLDT} 2 \mathrm{M} * \mathrm{FLD} * \mathrm{LLD} 2)+\mathrm{PCLELD} 2 \mathrm{M}$;

hfLD2T $=$ hfLD2 $+($ DZLD2D $)$;

hfLD2MT $=$ hfLD2M + (DZLD2DM $)$;

$\%$ Dimensionamento do trecho 3 da linha de derivacao.

QILDT3 = QILDT1 - (((LLD1/EEL) * QILLT1) * 2) + (((LLD2 / EEL) * QILLT1) *

2)) ;

QILD3T $=((\operatorname{round}(\mathrm{NLLD} 3)+\operatorname{round}(\mathrm{NLLD} 4)):-1:(\operatorname{round}(\mathrm{NLLD} 4)+1)) *(2 *$

QILLT1) ;

QILD3M $=(($ round $(\mathrm{NLLD} 3)+\operatorname{round}(\mathrm{NLLD} 4)):(-1 /$ EEL $):(\operatorname{round}(\mathrm{NLLD} 4)+(1 /$

$\mathrm{EEL})) *(2 *$ QILLT1) ;

VILDT3 $=($ QILDT3 $/$ ADLD3 $) / 3600$;

VILD3T $=($ QILD3T $/$ ADLD3 $) / 3600 ;$

VILD3M = (QILD3M / ADLD3) / 3600 ;

ECINETLD3T $=\left(\right.$ VILD3T. $\left.^{\wedge} 2\right) . /(2 * \mathrm{~g})$;

ECINETLD3M = (VILD3M.^2)./(2* g);

RELDT3 $=($ VILDT3 $*$ DLD3 $) / v$;

RELD3 $=($ VILD3T $*$ DLD3 $) / v$;

RELD3M $=($ VILD3M $*$ DLD3 $) / \mathrm{v}$;

fSJTLD3 $=(((64 . /$ RELD3 $) . \wedge 8)+9.5 *(\log (($ ELD./3.7. $*($ DLD3 $))+$

(5.74./(RELD3.^0.9))) - (2500./RELD3).^6).^(-16)).^0.125;

fSJTLD3M $=\left(\left((64 . /\right.\right.$ RELD3M $\left.) \wedge^{\wedge} 8\right)+9.5 *(\log (($ ELD./3.7. $*(\mathrm{DLD} 3))+$

(5.74./(RELD3M.^0.9))) - (2500./RELD3M).^6).^(-16)).^0.125 ;

$\mathrm{jLDT} 3=(\mathrm{fSJTLD} 3 . / \mathrm{DLD} 3) \cdot *\left(\left(\mathrm{VILD} 3 \mathrm{~T} .{ }^{\wedge} 2\right) . /(2 * \mathrm{~g})\right) ;$

jLDT3M $=($ fSJTLD3M./DLD3).*((VILD3M.^2)./(2* g));

PCLLD3 $=($ KLL. $*(($ VILD3T.^2). $/(2 * \mathrm{~g})))$;

PCLELD3M $=($ KLL.*((VILD3M.^2)./(2* g) $))$;

PCLELDT3 $=$ sum(PCLLD3)

DZLD3 $=($ DZLD $*$ LLD3 $) / 100 ;$ 


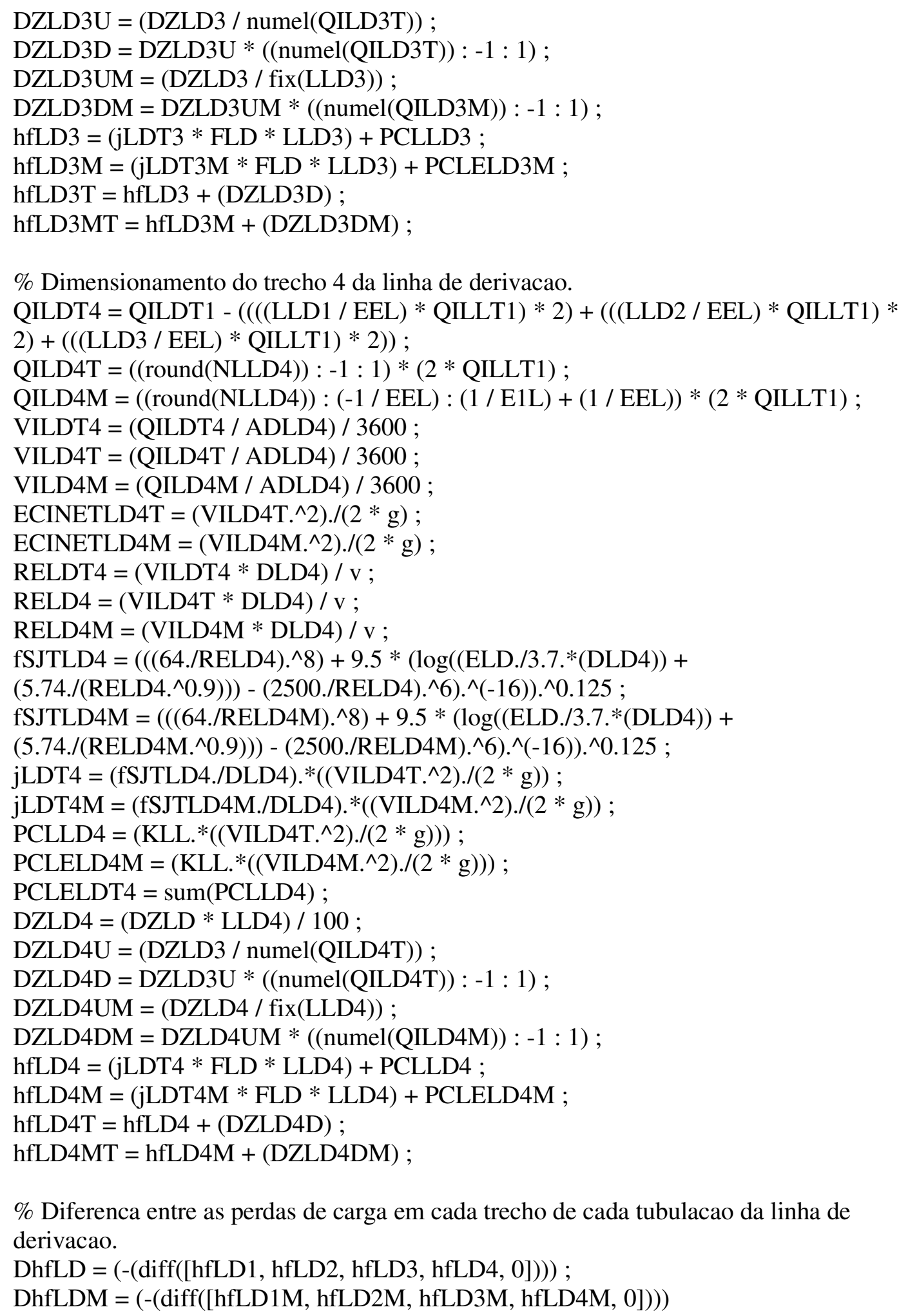

$\%$ Perda de carga localizada com a contracao da tubulacao.

RA2A1LD = ADLD2 / ADLD1 ;

RA3A2LD = ADLD3 /ADLD2 ;

RA4A3LD = ADLD4 / ADLD3 ; 


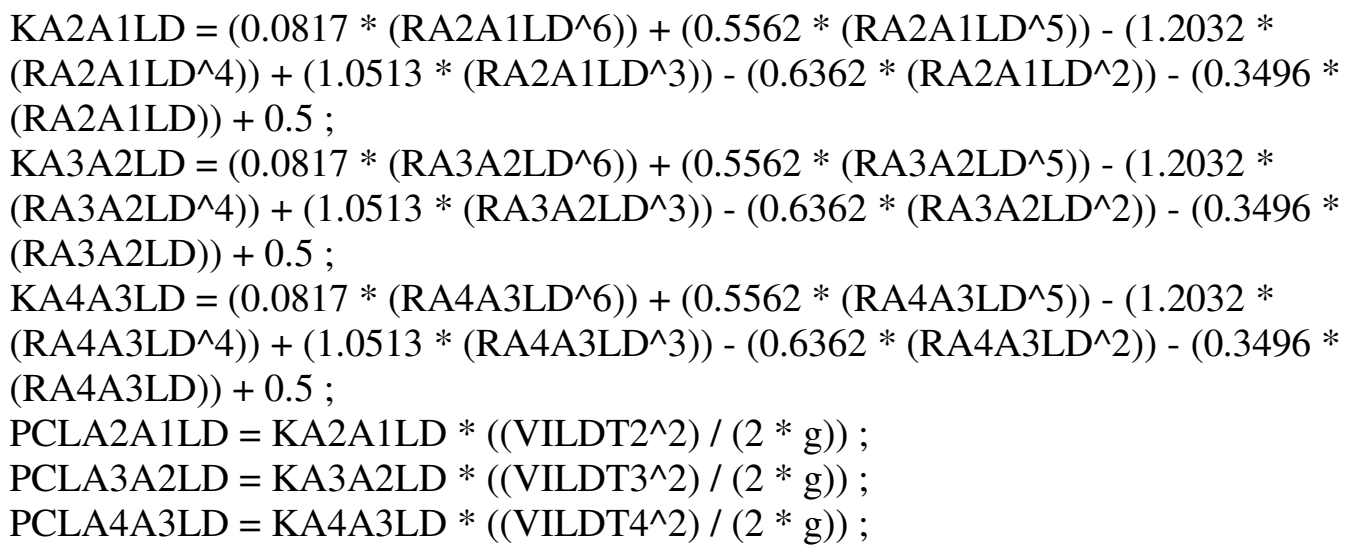

\% Perda de carga total na linha de derivacao com quatro diametros, sem considerando o desvio geometrico do terreno.

if isempty(hfLD1)

$$
\text { hfLD1 = } 0 \text {; }
$$

end

if isempty(hfLD2)

hfLD2 $=0$;

end

if isempty(hfLD3)

hfLD3 = 0 ;

end

if isempty(hfLD4)

hfLD4 = 0 ;

end

if $((\max (\mathrm{hfLD} 2))<(\min (\mathrm{hfLD} 1)) \& \&(\max (\mathrm{hfLD} 3))<(\min (\mathrm{hfLD} 2)) \& \&$

$(\max (\mathrm{hfLD} 4))<(\min (\mathrm{hfLD} 3)))$

PCTLD $=(\max ($ hfLD1 $))+$ PCLA2A1LD + PCLA3A2LD + PCLA4A3LD ;

elseif $((\max (\mathrm{hfLD} 2)) \& \&(\max (\mathrm{hfLD} 3)) \& \&(\max (\mathrm{hfLD} 4))<(\min (\mathrm{hfLD} 1)))$

PCTLD $=(\max (h f L D 1))+$ PCLA2A1LD + PCLA3A2LD + PCLA4A3LD ;

elseif $((\max (\mathrm{hfLD} 1)) \& \&(\max (\mathrm{hfLD} 3)) \& \&(\max (\mathrm{hfLD} 4))<(\min (\mathrm{hfLD} 2)))$

PCTLD $=(\max ($ hfLD2 $))+$ PCLA2A1LD + PCLA3A2LD + PCLA4A3LD ;

elseif $((\max (\mathrm{hfLD} 1)) \& \&(\max (\mathrm{hfLD} 2)) \& \&(\max (\mathrm{hfLD} 4))<(\min (\mathrm{hfLD} 3)))$

PCTLD $=(\max (\mathrm{hfLD} 3))+$ PCLA2A1LD + PCLA3A2LD + PCLA4A3LD ;

elseif $((\max (\mathrm{hfLD} 1)) \& \&(\max (\mathrm{hfLD} 2)) \& \&(\max (\mathrm{hfLD} 3))<(\min (\mathrm{hfLD} 4)))$

PCTLD $=(\max (h f L D 4))+$ PCLA2A1LD + PCLA3A2LD + PCLA4A3LD ; else

PCTLD $=((\max ($ hfLD1 $))-(\min ($ hfLD1 $)))+((\max ($ hfLD2 $))-(\min ($ hfLD2 $)))+$ $((\max (\mathrm{hfLD} 3))-(\min (\mathrm{hfLD} 3)))+((\max (\mathrm{hfLD} 4))-(\min (\mathrm{hfLD} 4)))+$ PCLA2A1LD + PCLA3A2LD + PCLA4A3LD ; \% Dado em mca.

end

$\%$ Perda de carga total na linha de derivacao com quatro diametros, considerando o desvio geometrico do terreno.

if isempty(hfLD1T)

hfLD1T $=0$;

end

if isempty(hfLD2T) 


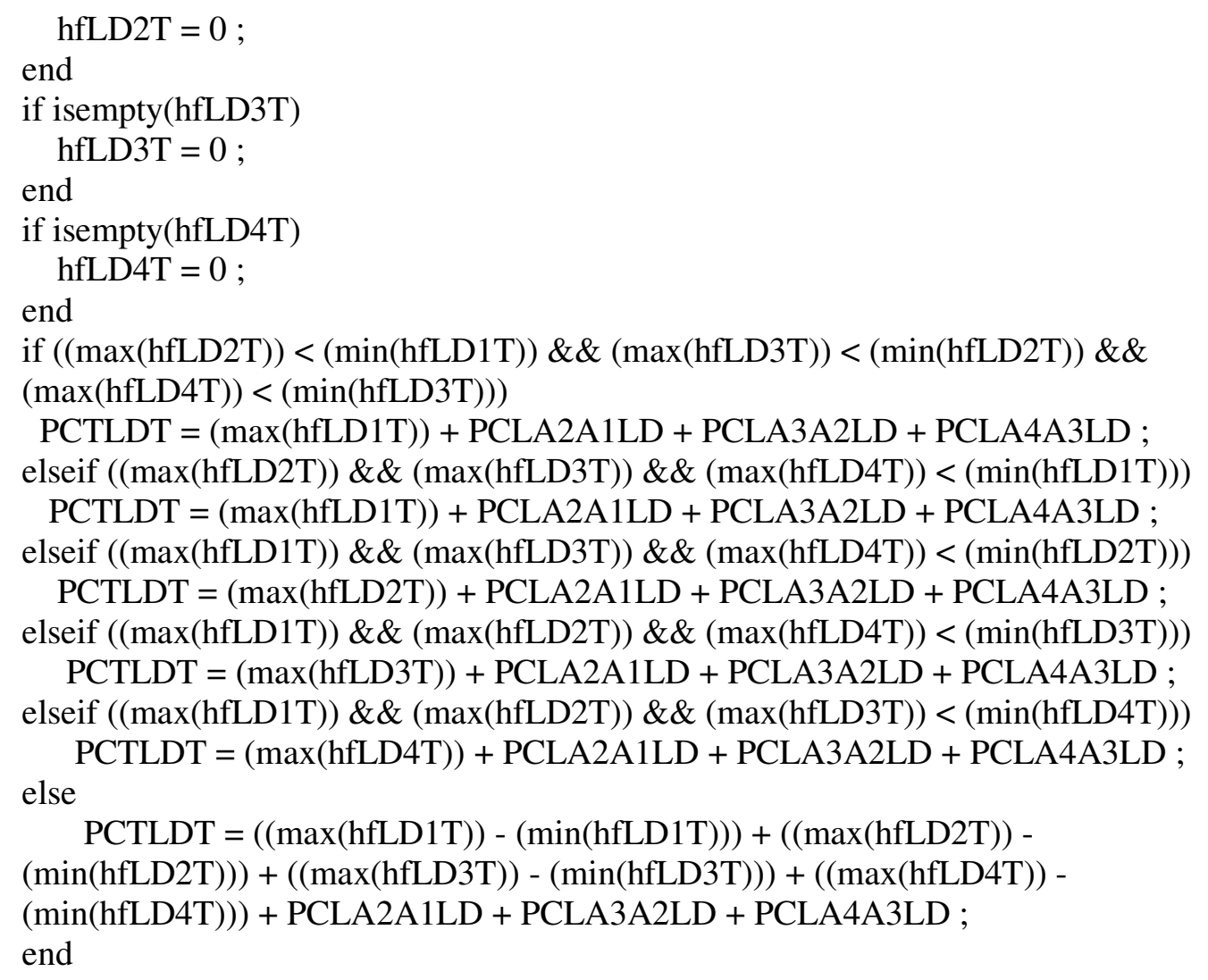

$\%$ Pressao requerida na entrada da linha de derivacao com quatro diamentros, considerando o desvio geometrico no calculo final.

PRELD = PRELL + PCTLD + ((DZLD * LLD $) / 100)$;

$\%$ Pressao requerida na entrada da linha de derivacao com quatro diamentros, considerando o desvio geometrico do terreno trecho a trecho.

PRELDT $=$ PRELLT + PCTLDT ;

$\%$ Energia total requerida na entrada da linha de derivacao com quatro, diametros, considerando o desvio geometrico no calculo final.

if isempty(ECINETLD1T)

ECINETLD1T $=0$;

end

if isempty(ECINETLD2T)

ECINETLD2T $=0$;

end

if isempty(ECINETLD3T)

ECINETLD3T $=0$;

end

if isempty(ECINETLD4T)

ECINETLD4T $=0$;

end

if $((\max ($ ECINETLD2T $))<(\min ($ ECINETLD1T $)) \& \&(\max ($ ECINETLD3T $))<$ $(\min ($ ECINETLD2T $)) \& \&(\max ($ ECINETLD4T $))<(\min ($ ECINETLD3T $))$

$\mathrm{ERELD}=(\max (\mathrm{ECINETLD} 1 \mathrm{~T}))+$ PRELD $;$ 
elseif $((\max (E C I N E T L D 2 T)) \& \&(\max (E C I N E T L D 3 T)) \& \&(\max (E C I N E T L D 4 T))<$ $(\min (\mathrm{ECINETLD1T})))$

ERELD $=(\max ($ ECINETLD1T $))+$ PRELD ;

elseif $((\max ($ ECINETLD1T $)) \& \&(\max ($ ECINETLD3T $)) \& \&(\max ($ ECINETLD4T $))<$ $(\min (\mathrm{ECINETLD} 2 \mathrm{~T})))$

$\mathrm{ERELD}=(\max (\mathrm{ECINETLD} 2 \mathrm{~T}))+$ PRELD $;$

elseif $((\max ($ ECINETLD1T $)) \& \&(\max ($ ECINETLD2T $)) \& \&(\max ($ ECINETLD4T $))<$ $(\min (\mathrm{ECINETLD} 3 \mathrm{~T})))$

$\mathrm{ERELD}=(\max (\mathrm{ECINETLD} 3 \mathrm{~T}))+$ PRELD $;$

elseif $((\max ($ ECINETLD1T $)) \& \&(\max ($ ECINETLD2T $)) \& \&(\max ($ ECINETLD3T $))<$ $(\min (\mathrm{ECINETLD} 4 \mathrm{~T})))$

$\mathrm{ERELD}=(\max (\mathrm{ECINETLD} 4 \mathrm{~T}))+$ PRELD $;$

else

$\operatorname{ERELD}=((\max ($ ECINETLD1T $))-(\min ($ ECINETLD1T $)))+$

$((\max ($ ECINETLD2T $))-(\min ($ ECINETLD2T $)))+((\max ($ ECINETLD3T $))-$

$(\min ($ ECINETLD3T $))+((\max ($ ECINETLD4T $))-(\min ($ ECINETLD4T $)))+$ PRELD $;$ end

$\%$ Energia total requerida na entrada da linha de derivacao com quatro diametros, considerando o desvio geometrico do terreno trecho a trecho.

if $((\max ($ ECINETLD2T $))<(\min ($ ECINETLD1T $)) \& \&(\max ($ ECINETLD3T $))<$

$(\min ($ ECINETLD2T $)) \& \&(\max ($ ECINETLD4T $))<(\min ($ ECINETLD3T $))$

ERELDT $=(\max ($ ECINETLD1T $))+$ PRELDT $;$

elseif $((\max ($ ECINETLD2T $)) \& \&(\max ($ ECINETLD3T $)) \& \&(\max ($ ECINETLD4T $))<$ $(\min ($ ECINETLD1T $)))$

ERELDT $=(\max ($ ECINETLD1T $))+$ PRELDT ;

elseif $((\max ($ ECINETLD1T $)) \& \&(\max ($ ECINETLD3T $)) \& \&(\max ($ ECINETLD4T $))<$ $(\min (\mathrm{ECINETLD} 2 \mathrm{~T})))$

ERELDT $=(\max ($ ECINETLD2T $))+$ PRELDT

elseif $((\max ($ ECINETLD1T $)) \& \&(\max ($ ECINETLD2T $)) \& \&(\max ($ ECINETLD4T $))<$ $(\min ($ ECINETLD3T $)))$

ERELDT $=(\max ($ ECINETLD3T $))+$ PRELDT ;

elseif $((\max ($ ECINETLD1T $)) \& \&(\max ($ ECINETLD2T $)) \& \&(\max ($ ECINETLD3T $))<$ $(\min (\mathrm{ECINETLD} 4 \mathrm{~T})))$

$\mathrm{ERELDT}=(\max (\mathrm{ECINETLD} 4 \mathrm{~T}))+$ PRELDT $;$

else

ERELDT $=((\max ($ ECINETLD1T $))-(\min ($ ECINETLD1T $)))+$

$((\max ($ ECINETLD2T $))-(\min ($ ECINETLD2T $)))+((\max ($ ECINETLD3T $))-$

$(\min ($ ECINETLD3T $))+((\max ($ ECINETLD4T $))-(\min ($ ECINETLD4T $)))+$ PRELDT ; end

$\% \%$ Dimensionamento da linha secundaria

$\%$ Variaveis.

LLS1 $=\mathrm{x}(7)$;

LLS2 $=\mathrm{x}(8) ;$

LLS3 $=x(9) ;$

LLS4 $=x(10)$;

round(LLS1);

round(LLS2); 


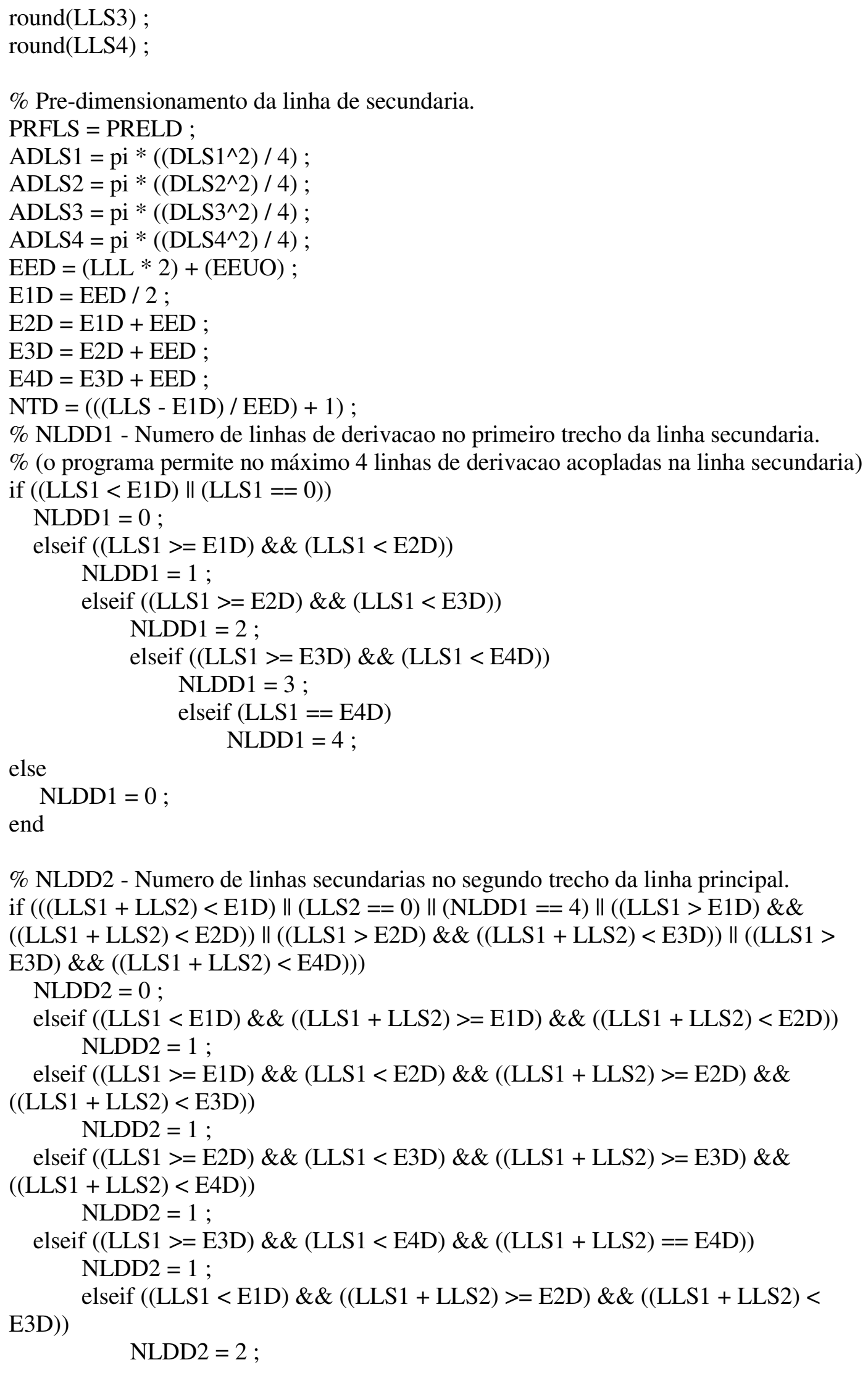


elseif $(($ LLS1 $>=$ E1D) $\& \&($ LLS1 < E2D) $\& \&(($ LLS1 + LLS2) $>=$ E3D $) \& \&$ $((\mathrm{LLS} 1+\mathrm{LLS} 2)<\mathrm{E} 4 \mathrm{D}))$

NLDD2 $=2$;

elseif $((\mathrm{LLS} 1>=\mathrm{E} 2 \mathrm{D}) \& \&(\mathrm{LLS} 1<\mathrm{E} 3 \mathrm{D}) \& \&((\mathrm{LLS} 1+\mathrm{LLS} 2)==\mathrm{E} 4 \mathrm{D}))$

NLDD2 $=2$;

elseif $((\mathrm{LLS} 1<\mathrm{E} 1 \mathrm{D}) \& \&((\mathrm{LLS} 1+\mathrm{LLS} 2)>=\mathrm{E} 3 \mathrm{D}) \& \&((\mathrm{LLS} 1+\mathrm{LLS} 2)$

$<$ E4D))

NLDD2 $=3$;

elseif $(($ LLS1 >= E1D) \& \& (LLS1 <E2D) \&\& ((LLS1 + LLS2) $==$ E4D $))$

NLDD2 $=3$;

elseif $(($ LLS2 $==$ E4D $) \|(($ LLS1 < E1D) \&\& $(($ LLS1 + LLS2 $)==$

E4D)))

$$
\mathrm{NLDD} 2=4
$$

else

NLDD2 $=0 ;$

end

$\%$ NLDD3 - Numero de linhas secundarias no terceiro trecho da linha principal.

if $(((\mathrm{LLS} 1+\mathrm{LLS} 2+\mathrm{LLS} 3)<\mathrm{E} 1 \mathrm{D})\|(\mathrm{LLS3}==0)\|(\mathrm{NLDD} 1==4)\|(\mathrm{NLDD} 2==4)\|$ $((\mathrm{NLDD} 1+\mathrm{NLDD} 2)==4) \|(((\mathrm{LLS} 1+\mathrm{LLS} 2)>\mathrm{E} 1 \mathrm{D}) \& \&((\mathrm{LLS} 1+\mathrm{LLS} 2+\mathrm{LLS} 3)<$ E2D $)) \|(((L L S 1+$ LLS2) $>$ E2D) $\& \&(($ LLS1 + LLS2 + LLS3) $)<$ E3D $) \|((($ LLS1 + LLS2) $>$ E3D) \&\& ((LLS1 + LLS2 + LLS3) $<$ E4D) ))

NLDD3 $=0$;

elseif $(((\mathrm{LLS} 1+\mathrm{LLS} 2)<\mathrm{E} 1 \mathrm{D}) \& \&((\mathrm{LLS} 1+\mathrm{LLS} 2+\mathrm{LLS} 3)>=\mathrm{E} 1 \mathrm{D}) \& \&((\mathrm{LLS} 1+$ LLS2 + LLS3) $<$ E2D))

NLDD3 = 1 ;

elseif $(((\mathrm{LLS} 1+\mathrm{LLS} 2)>=\mathrm{E} 1 \mathrm{D}) \& \&((\mathrm{LLS} 1+\mathrm{LLS} 2)<\mathrm{E} 2 \mathrm{D}) \& \&((\mathrm{LLS} 1+\mathrm{LLS} 2+$ LLS3 $)>=$ E2D) $\& \&((L L S 1+$ LLS2 + LLS3) $<$ E3D $))$

NLDD3 = 1 ;

elseif $(((\mathrm{LLS} 1+\mathrm{LLS} 2)>=\mathrm{E} 2 \mathrm{D}) \& \&((\mathrm{LLS} 1+\mathrm{LLS} 2)<\mathrm{E} 3 \mathrm{D}) \& \&((\mathrm{LLS} 1+\mathrm{LLS} 2+$ LLS3 $)>=$ E3D) $\& \&(($ LLS1 + LLS2 + LLS3 $)<$ E4D $))$

NLDD3 $=1$;

elseif $((($ LLS1 + LLS2) $>=$ E3D) $\& \&(($ LLS1 + LLS2) $<$ E4D) $\& \&(($ LLS1 + LLS2 + LLS3) $==\mathrm{E} 4 \mathrm{D})$ )

NLDD3 = 1 ;

elseif $(((\mathrm{LLS} 1+\mathrm{LLS} 2)<\mathrm{E} 1 \mathrm{D}) \& \&((\mathrm{LLS} 1+\mathrm{LLS} 2+\mathrm{LLS} 3)>=\mathrm{E} 2 \mathrm{D}) \& \&$

$((\mathrm{LLS} 1+\mathrm{LLS} 2+\mathrm{LLS} 3)<\mathrm{E} 3 \mathrm{D}))$

NLDD3 $=2$;

elseif $(((\mathrm{LLS} 1+\mathrm{LLS} 2)>=\mathrm{E} 1 \mathrm{D}) \& \&((\mathrm{LLS} 1+\mathrm{LLS} 2)<\mathrm{E} 2 \mathrm{D}) \& \&((\mathrm{LLS} 1+$

$\mathrm{LLS} 2+\mathrm{LLS} 3)>=\mathrm{E} 3 \mathrm{D}) \& \&((\mathrm{LLS} 1+\mathrm{LLS} 2+\mathrm{LLS} 3)<\mathrm{E} 4 \mathrm{D}))$

NLDD3 $=2$;

elseif $(((\mathrm{LLS} 1+\mathrm{LLS} 2)>=\mathrm{E} 2 \mathrm{D}) \& \&((\mathrm{LLS} 1+\mathrm{LLS} 2)<\mathrm{E} 3 \mathrm{D}) \& \&((\mathrm{LLS} 1+$

LLS2 + LLS3) == E4D))

NLDD3 = 2 ;

elseif $((($ LLS1 + LLS2) $<$ E1D) $\& \&(($ LLS1 + LLS2 + LLS3) $>=$ E3D) $\& \&$

$((\mathrm{LLS} 1+\mathrm{LLS} 2+\mathrm{LLS} 3)<\mathrm{E} 4 \mathrm{D}))$

NLDD3 $=3$;

elseif $(((\mathrm{LLS} 1+\mathrm{LLS} 2)>=\mathrm{E} 1 \mathrm{D}) \& \&((\mathrm{LLS} 1+\mathrm{LLS} 2)<\mathrm{E} 2 \mathrm{D}) \& \&((\mathrm{LLS} 1$

$+\mathrm{LLS} 2+\mathrm{LLS} 3)==\mathrm{E} 4 \mathrm{D}))$

NLDD3 $=3$; 


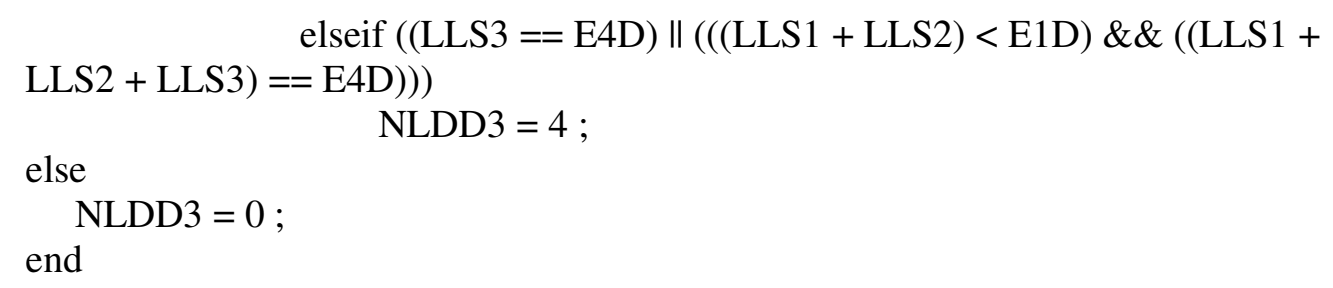

$\%$ NLDD4 - Numero de linhas secundarias no quarto trecho da linha principal.

if $(($ LLS4 = $=0) \|($ NLDD1 $==4) \|($ NLDD2 $==4) \|($ NLDD3 == 4) $\|(($ NLDD1 + NLDD2 + NLDD3 $)==4) \|((($ LLS1 + LLS2 + LLS3 $)>$ E1D) \&\& $(($ LLS1 + LLS2 + LLS3 + LLS4)) < E2D) $\|(((L L S 1+$ LLS2 + LLS3 $)>$ E2D) \&\& ((LLS1 + LLS2 + LLS3 + LLS4) <E3D)) $\|(((\mathrm{LLS} 1+\mathrm{LLS} 2+\mathrm{LLS} 3)>\mathrm{E} 3 \mathrm{D}) \& \&((\mathrm{LLS} 1+\mathrm{LLS} 2+$ LLS3 + LLS4) $<$ E4D)))

NLDD4 $=0$;

elseif $(((\mathrm{LLS} 1+\mathrm{LLS} 2+\mathrm{LLS} 3)>=\mathrm{E} 3 \mathrm{D}) \& \&((\mathrm{LLS} 1+\mathrm{LLS} 2+\mathrm{LLS} 3)<\mathrm{E} 4 \mathrm{D}) \& \&$ $((\mathrm{LLS} 1+\mathrm{LLS} 2+\mathrm{LLS} 3+\mathrm{LLS} 4)==\mathrm{E} 4 \mathrm{D}))$

NLDD4 = 1 ;

elseif $(($ LLS1 + LLS2 + LLS3) >= E2D) \&\& ((LLS1 + LLS2 + LLS3) $<$ E3D $)$

$\& \&((\mathrm{LLS} 1+\mathrm{LLS} 2+\mathrm{LLS} 3+\mathrm{LLS} 4)==\mathrm{E} 4 \mathrm{D}))$

NLDD4 = 2 ;

elseif $(((\mathrm{LLS} 1+\mathrm{LLS} 2+\mathrm{LLS} 3)>=\mathrm{E} 1 \mathrm{D}) \& \&((\mathrm{LLS} 1+\mathrm{LLS} 2+\mathrm{LLS} 3)<$

E2D) $\& \&(($ LLS1 + LLS2 + LLS3 + LLS4) $==$ E4D $))$

NLDD4 = 3 ;

elseif $((($ LLS1 + LLS2 + LLS3) < E1D) \& \& ((LLS1 + LLS2 + LLS3

+ LLS4 $)==\mathrm{E} 4 \mathrm{D})) \|(\mathrm{LLS} 4==\mathrm{E} 4 \mathrm{D}))$

else NLDD4 = 4 ;

NLDD4 $=0$;

end

$\mathrm{xLS}=\mathrm{E} 1 \mathrm{D} / \mathrm{EED}$;

DZLSD $=((($ LLS - E1D $) *$ DZLS $) / 100):-((((L L S-E 1 D) *$ DZLS $) / 100) /($ NTD 1)) : 0 ;

$\mathrm{FLS}=\left((\mathrm{NTD}) *\left((1 /(\mathrm{m}+1))+(1 /(2 *(\mathrm{NTD})))+\left(\left((\mathrm{m}-1)^{\wedge} 0.5\right) /\left(6 *\left(\left(\mathrm{NTD}^{\wedge} 2\right)\right)\right)\right)\right)+\right.$ $\mathrm{xLS}-1) /((\mathrm{NTD})+\mathrm{xLS}-1)$;

$\%$ Dimensionamento do trecho 1 da linha secundaria.

if (LLS1 $==0$ )

QILST1 =0 ;

elseif $($ LLS1 $>0)$

$$
\text { QILST1 = }(\mathrm{NTD} * \text { QILDT1) ; }
$$

else

QILST1 $=0$;

end

QILS1 = (NTD : $-1: 1) *$ QILDT1;

QILS1T = ((QILST1 / NTD) * NTD) : -(QILST1 / NTD) : ((round(NLDD2) + round(NLDD3) + round(NLDD4) + 1) * (QILST1 / NTD)) ;

QILS1M = ((NTD) : (-1 / EED) $:($ round(NLDD2) + round(NLDD3) + round(NLDD4) $+1)) *(\mathrm{QILDT} 1)$;

VILST1 $=($ QILST1 /ADLS1) $/ 3600$; 


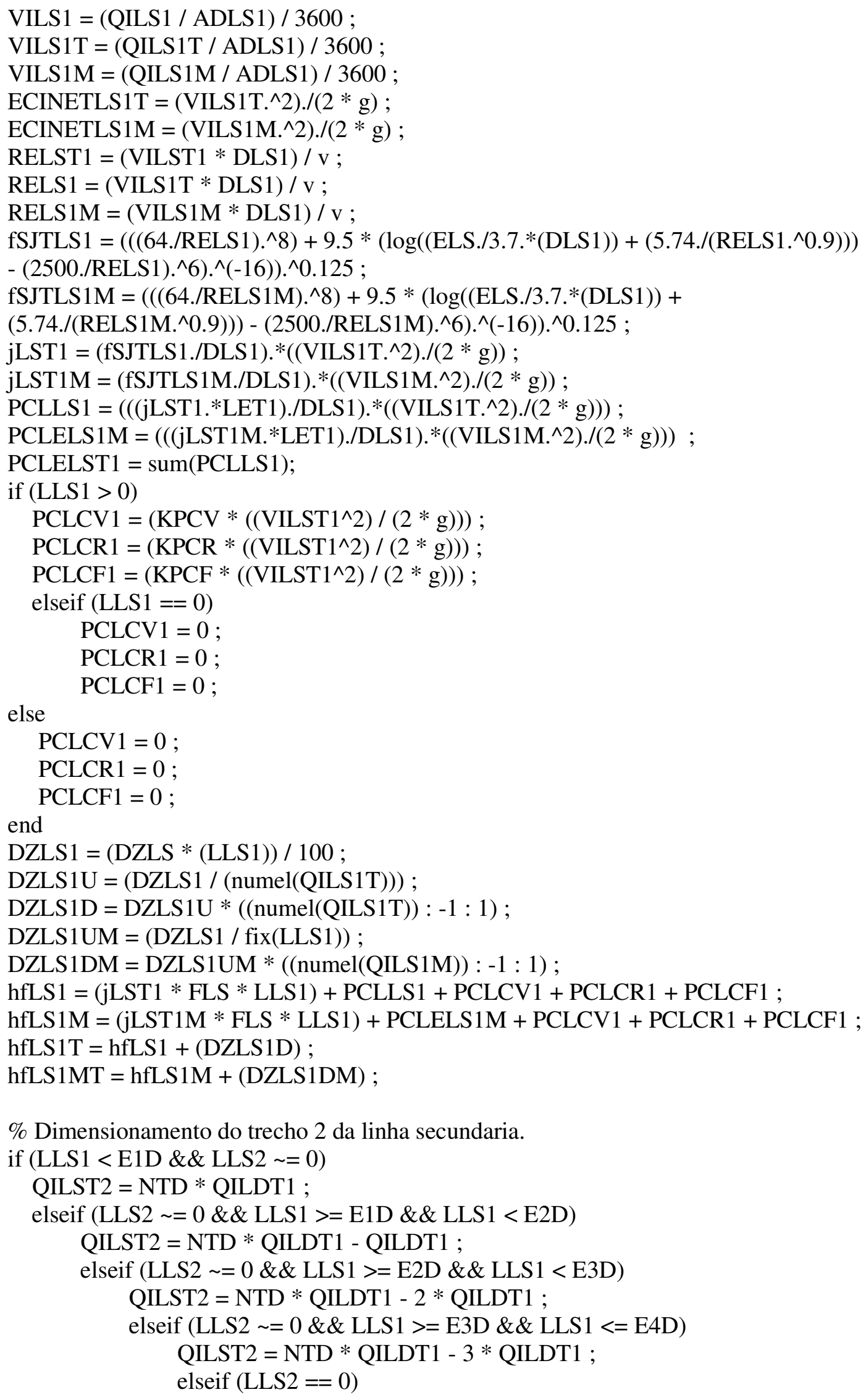


else

$$
\text { QILST2 = } 0 \text {; }
$$

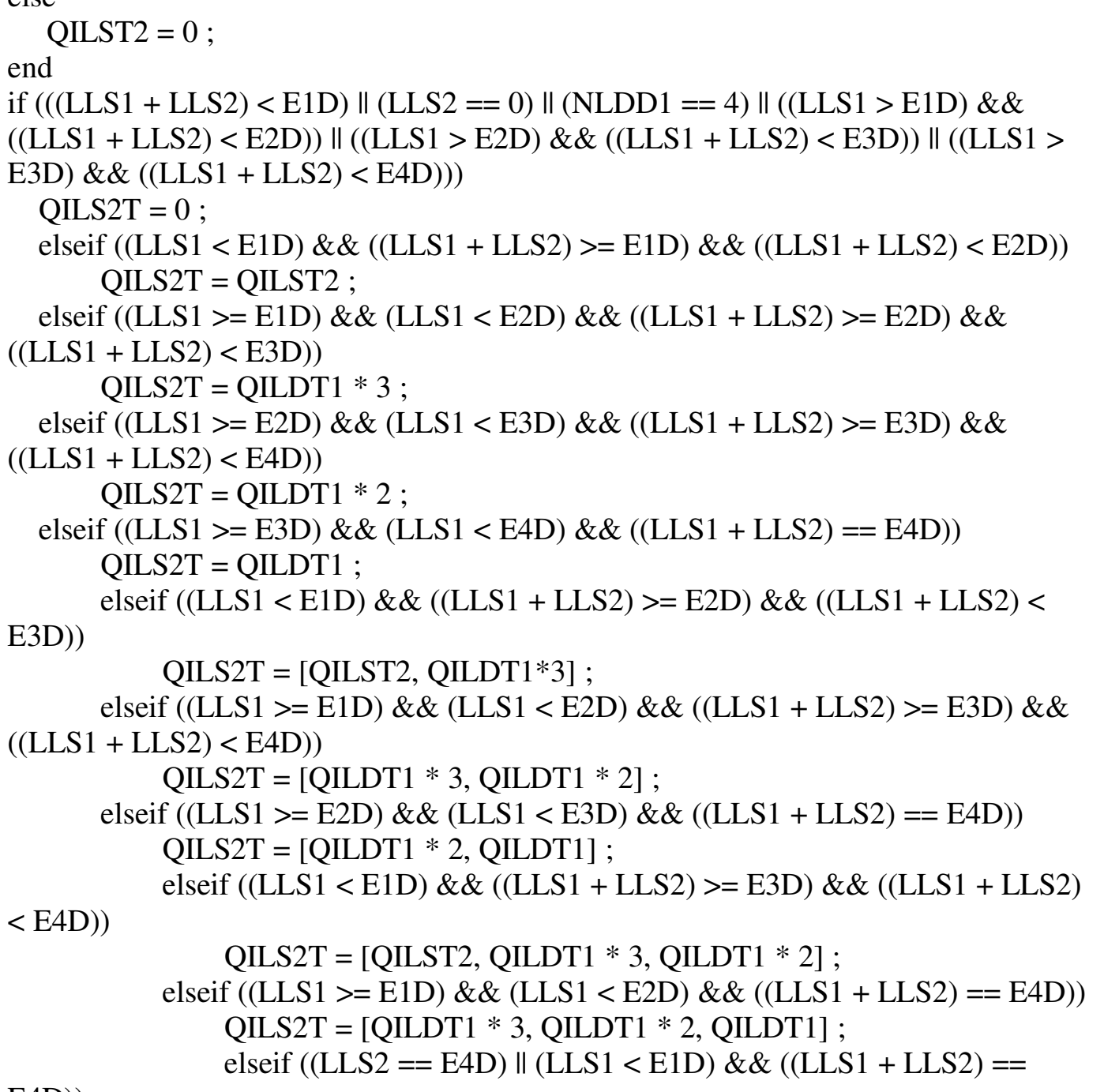

E4D))

else

$$
\mathrm{QILS} 2 \mathrm{~T}=[\mathrm{QILST} 2, \mathrm{QILDT} 1 * 3, \mathrm{QILDT} 1 * 2, \mathrm{QILDT} 1] \text {; }
$$

$$
\text { QILS2T }=0 \text {; }
$$

end

QILS2M = ((round(NLDD2) + round(NLDD3) + round(NLDD4) $):(-1 /$ EED) $:$

$($ round $(\mathrm{NLDD} 3)+$ round $(\mathrm{NLDD} 4)+(1 / \mathrm{EED}))) *(\mathrm{QILDT} 1)$;

VILST2 $=($ QILST2 / ADLS2) $/ 3600$;

VILS2T $=($ QILS2T $/$ ADLS2) $/ 3600$;

VILS2M = (QILS2M / ADLS2) / 3600 ;

ECINETLS2T $=\left(\right.$ VILS2T. $\left.^{\wedge} 2\right) . /(2 * \mathrm{~g})$;

ECINETLS2M = (VILS2M.^2)./(2* g);

RELST2 $=($ VILST2 $*$ DLS2 $) / v$;

RELS2 $=($ VILS2T $*$ DLS2 $) / v$;

RELS2M $=($ VILS2M $*$ DLS2 $) / \mathrm{v}$;

fSJTLS2 $=(((64 . /$ RELS2).^8) $+9.5 *(\log (($ ELS./3.7.* $($ DLS2 $))+(5.74 . /($ RELS2.^0.9) $))$

- (2500./RELS2).^6).^(-16)).^0.125 ; 


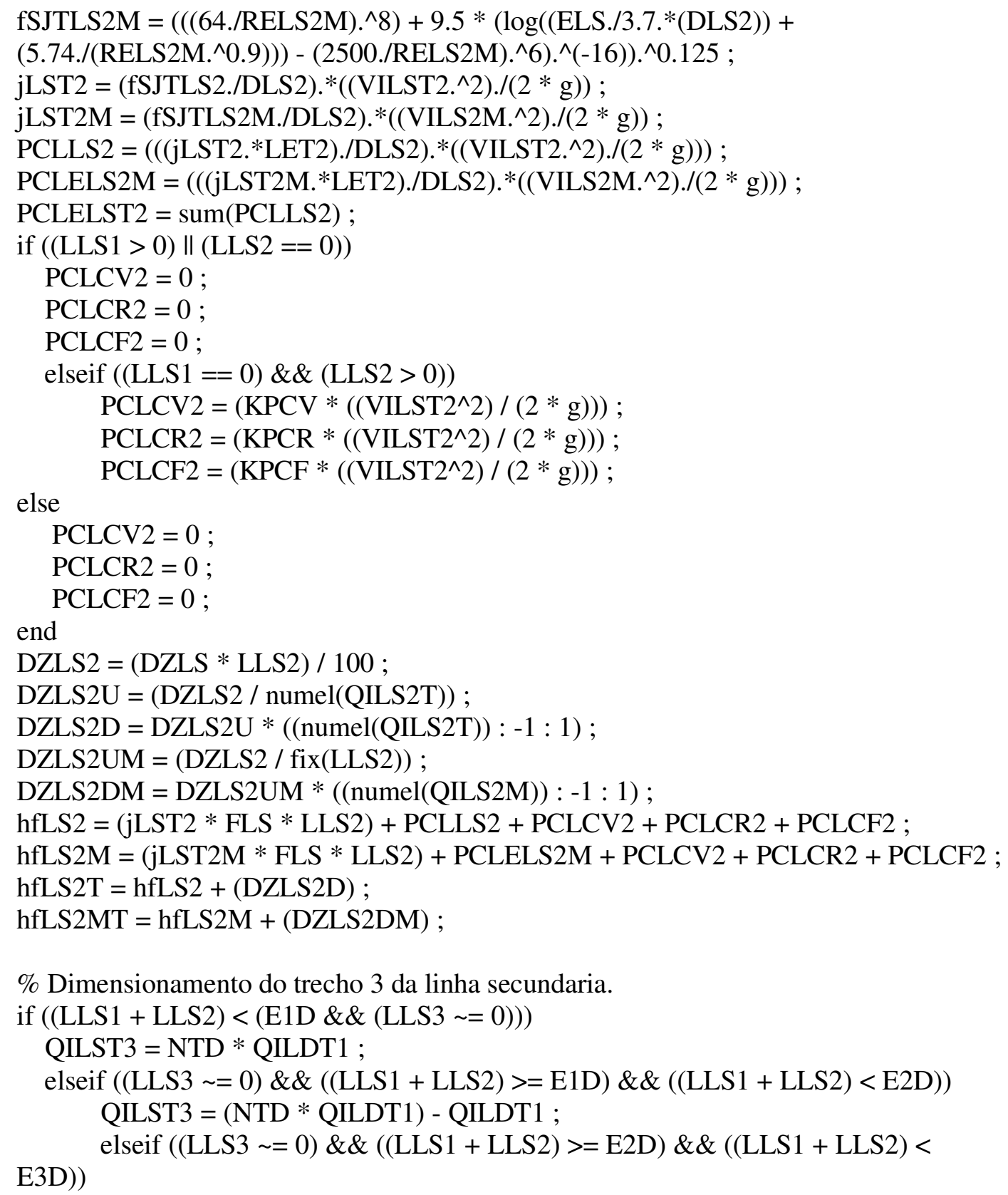$$
\text { QILST3 = (NTD * QILDT1) - (2* QILDT1) ; }
$$$$
\text { elseif }((\operatorname{LLS} 3 \sim=0) \& \&((\operatorname{LLS} 1+\mathrm{LLS} 2)>=\mathrm{E} 3 \mathrm{D}) \& \&((\mathrm{LLS} 1+\mathrm{LLS} 2)<=
$$

E4D))

else

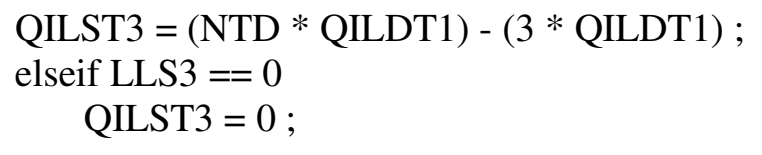

end

QILST3 = 0 ;

if $(((\mathrm{LLS} 1+\mathrm{LLS} 2+\mathrm{LLS} 3)<\mathrm{E} 1 \mathrm{D})\|(\mathrm{LLS} 3==0)\|(\mathrm{NLDD} 1==4)\|(\mathrm{NLDD} 2==4)\|$ $((\mathrm{NLDD} 1+\mathrm{NLDD} 2)==4) \|(((\mathrm{LLS} 1+\mathrm{LLS} 2)>\mathrm{E} 1 \mathrm{D}) \& \&((\mathrm{LLS} 1+\mathrm{LLS} 2+\mathrm{LLS} 3)<$ E2D $)) \|((($ LLS1 + LLS2) $>$ E2D) \&\& ((LLS1 + LLS2 + LLS3) < E3D) $) \|(((L L S 1+$ LLS2) $>$ E3D) \&\& ((LLS1 + LLS2 + LLS3) < E4D)) $)$ 


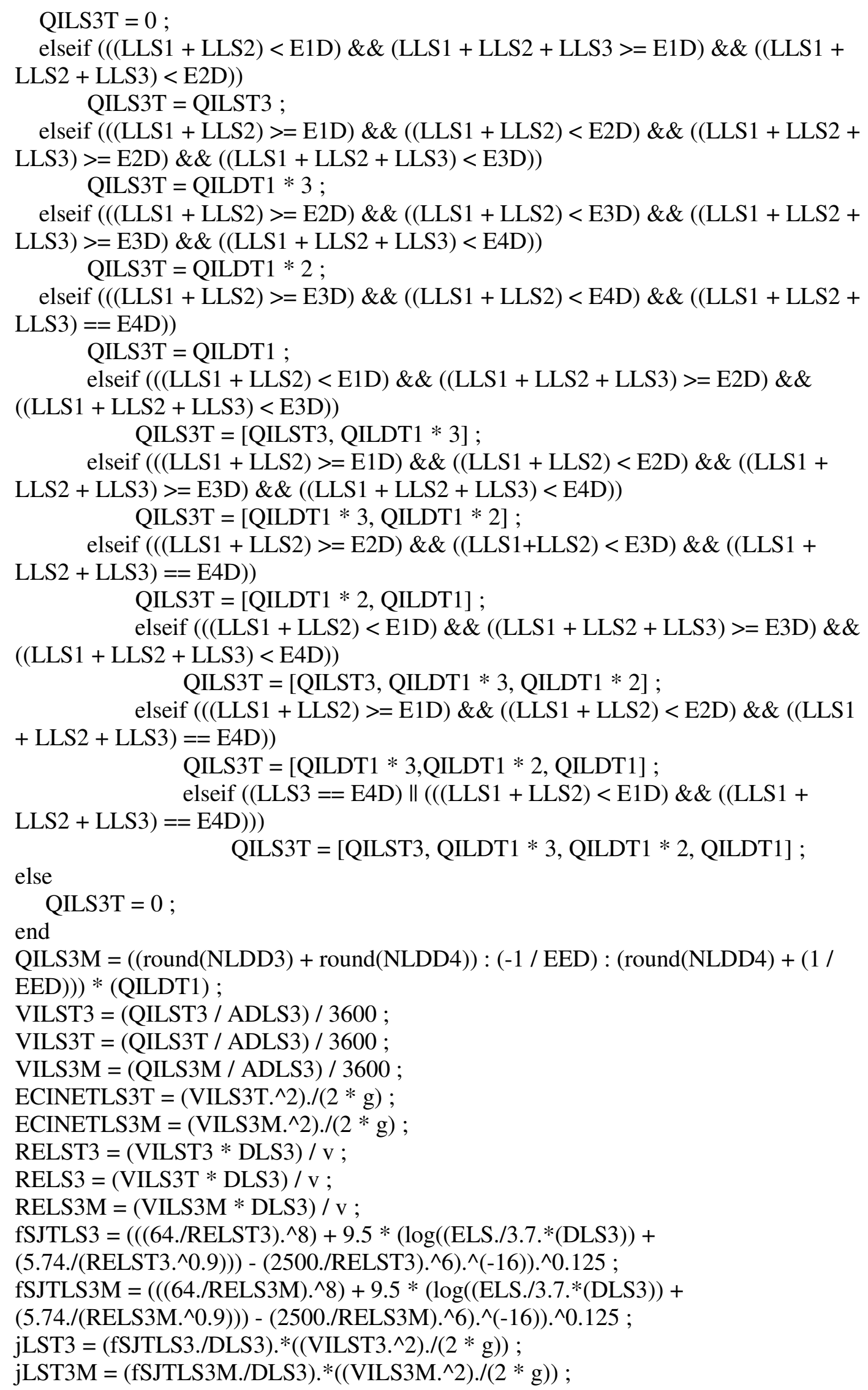




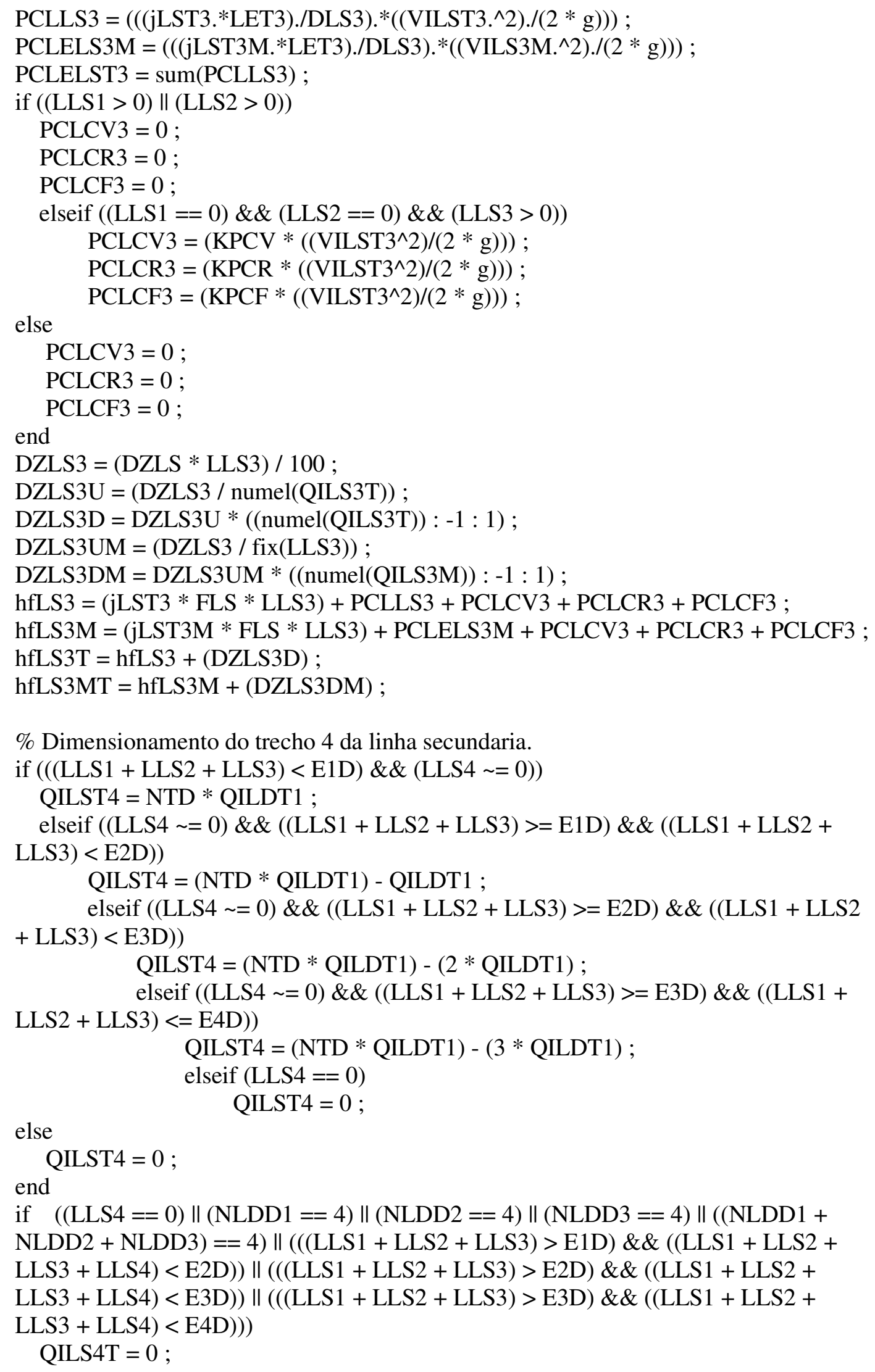




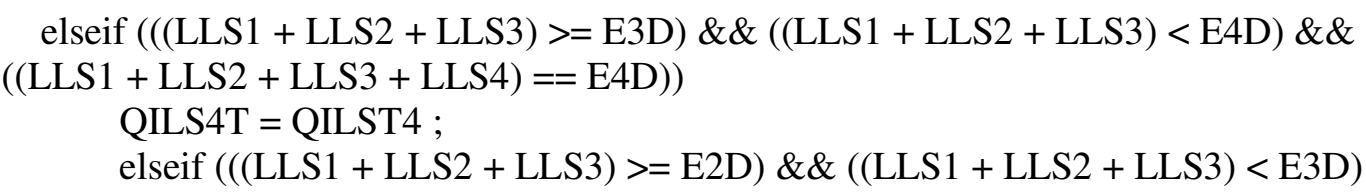


DZLS4DM = DZLS4UM * ((numel(QILS4M $)):-1: 1)$;

hfLS4 $=(\mathrm{jLST} 4 *$ FLS $*$ LLS4 $)+$ PCLELST4 + PCLCV4 + PCLCR4 + PCLCF4 ;

hfLS4M = (jLST4M * FLS * LLS4) + PCLELS4M + PCLCV4 + PCLCR4 + PCLCF4 ;

hfLS4T = hfLS4 + (DZLS4D);

hfLS4MT = hfLS4M + (DZLS4DM) ;

$\%$ Diferenca entre as perdas de carga em cada trecho de cada tubulacao da linha secundaria.

DhfLS $=(-(\operatorname{diff}([\mathrm{hfLS} 1, \mathrm{hfLS} 2, \mathrm{hfLS} 3, \mathrm{hfLS} 4,0])))$

DhfLSM $=(-(\operatorname{diff}([\mathrm{hfLS} 1 \mathrm{M}, \operatorname{hfLS} 2 \mathrm{M}, \operatorname{hfLS} 3 \mathrm{M}, \operatorname{hfLS} 4 \mathrm{M}, 0])))$;

$\%$ Perda de carga localizada com a contracao da tubulacao.

RA2A1LS = ADLS2 / ADLS1 ;

RA3A2LS = ADLS3 / ADLS2 ;

RA4A3LS $=$ ADLS4 / ADLS3 ;

$\mathrm{KA} 2 \mathrm{~A} 1 \mathrm{LS}=\left(0.0817 *\left(\mathrm{RA}_{2 \mathrm{~A} 1 \mathrm{LS}}^{\wedge} 6\right)\right)+\left(0.5562 *\left(\mathrm{RA}^{\wedge} \mathrm{A} 1 \mathrm{LS}^{\wedge} 5\right)\right)-(1.2032 *$

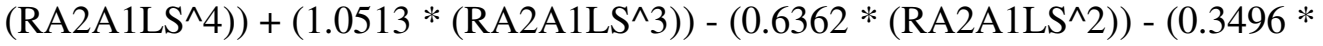

$($ RA2A1LS) $)+0.5$

KA3A2LS $=\left(0.0817 *\left(\operatorname{RA}^{2} A 2 L S^{\wedge} 6\right)\right)+\left(0.5562 *\left(\operatorname{RA}^{2} A 2 L S^{\wedge} 5\right)\right)-(1.2032 *$

$($ RA3A2LS^4) $)+\left(1.0513 *\left(\mathrm{RA}^{2} A 2 \mathrm{LS}^{\wedge} 3\right)\right)-\left(0.6362 *\left(\mathrm{RA}^{2} \mathrm{~A} 2 \mathrm{LS}^{\wedge} 2\right)\right)-(0.3496 *$

$($ RA3A2LS) $)+0.5$

$\mathrm{KA} 4 \mathrm{~A} 3 \mathrm{LS}=\left(0.0817 *\left(\mathrm{RA} 4 \mathrm{~A} 3 \mathrm{LS} \mathrm{S}^{\wedge} 6\right)\right)+\left(0.5562 *\left(\mathrm{RA} 4 \mathrm{~A} 3 \mathrm{LS} \mathrm{S}^{\wedge}\right)\right)-(1.2032 *$

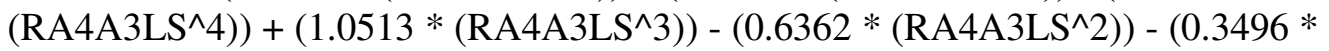

$($ RA4A3LS) $)+0.5$

PCLA2A1LS $=\mathrm{KA} 2 \mathrm{~A} 1 \mathrm{LS} *\left(\left(\mathrm{VILST}{ }^{\wedge} 2\right) /(2 * \mathrm{~g})\right)$;

PCLA3A2LS $=\mathrm{KA} 3 \mathrm{~A} 2 \mathrm{LS} *\left(\left(\mathrm{VILST} 3^{\wedge} 2\right) /(2 * \mathrm{~g})\right)$

PCLA4A3LS = KA4A3LS * ((VILST4^2) $/(2 * \mathrm{~g}))$;

if isempty(PCLA2A1LS)

PCLA2A1LS $=0$;

end

if isempty(PCLA3A2LS)

PCLA3A2LS $=0$;

end

if isempty(PCLA4A3LS)

PCLA4A3LS $=0$;

end

$\%$ Perda de carga total na linha secundaria com quatro diametros, nao considerando o desvio geometrico do terreno.

if isempty(hfLS1)

hfLS1 $=0$;

end

if isempty(hfLS2)

hfLS2 $=0$;

end

if isempty(hfLS3)

hfLS3 $=0$;

end

if isempty(hfLS4)

hfLS4 $=0$; 
end

PCTLS $=\max ($ hfLS1 $)+\max ($ hfLS2 $)+\max ($ hfLS3 $)+\max ($ hfLS4 $)+$ PCLA2A1LS +

PCLA3A2LS + PCLA4A3LS ;

if isempty(PCTLS)

PCTLS $=0$;

end

$\%$ Perda de carga total na linha secundaria com quatro diametros, considerando o desvio geometrico do terreno.

if isempty(hfLS1T)

hfLS1T = 0 ;

end

if isempty(hfLS2T)

end

$$
\text { hfLS2T }=0 \text {; }
$$

if isempty(hfLS3T)

$$
\text { hfLS3T }=0 \text {; }
$$

end

if isempty(hfLS4T)

hfLS4T $=0$;

end

PCTLST $=\max ($ hfLS1T $)+\max ($ hfLS2T $)+\max ($ hfLS3T $)+\max ($ hfLS4T $)+$ PCLA2A1LS + PCLA3A2LS + PCLA4A3LS ; \% Dado em mca.

if isempty(PCTLST)

PCTLST $=0$;

end

$\%$ Pressao requerida na entrada da linha secundaria com quatro diamentros, considerando o desvio geometrico no calculo final.

PRELS = PRELD + PCTLS + ((DZLS * LLS $) / 100)$;

$\%$ Pressao requerida na entrada da linha secundaria com quatro diamentros, considerando o desvio geometrico do terreno trecho a trecho.

PRELST $=$ PRELDT + PCTLST ;

$\%$ Energia total requerida na entrada da linha secundaria com quatro, considerando o desvio geometrico no calculo final.

if isempty(ECINETLS1T)

ECINETLS1T $=0$;

end

if isempty(ECINETLS2T)

ECINETLS2T $=0$;

end

if isempty(ECINETLS3T)

ECINETLS3T $=0$;

end

if isempty(ECINETLS4T)

ECINETLS4T $=0$;

end 
if $(((\max ($ ECINETLS2T $))<(\min ($ ECINETLS1T $))) \& \&(((\max ($ ECINETLS3T $))<$ $(\min ($ ECINETLS2T $))) \& \&((\max ($ ECINETLS4T $))<(\min ($ ECINETLS3T $))))$

ERELS $=(\max ($ ECINETLS1T $))+$ PRELS ;

elseif $((\max ($ ECINETLS2T $)) \& \&(\max ($ ECINETLS3T $)) \& \&((\max ($ ECINETLS4T $))<$ $(\min ($ ECINETLS1T $))))$

$\mathrm{ERELS}=(\max (\mathrm{ECINETLS} 1 \mathrm{~T}))+$ PRELS

elseif $((\max ($ ECINETLS1T $)) \& \&(\max ($ ECINETLS3T $)) \& \&((\max ($ ECINETLS4T $))<$ $(\min ($ ECINETLS2T $))))$

ERELS $=(\max ($ ECINETLS2T $))+$ PRELS ;

elseif $((\max ($ ECINETLS1T $)) \& \&(\max ($ ECINETLS2T $)) \& \&((\max ($ ECINETLS4T $))<$ $(\min ($ ECINETLS3T $)))$

ERELS $=(\max ($ ECINETLS3T $))+$ PRELS ;

elseif $((\max ($ ECINETLS1T $)) \& \&(\max ($ ECINETLS2T $)) \& \&(\max ($ ECINETLS3T $))<$ $(\min ($ ECINETLS4T $)))$

$\mathrm{ERELS}=(\max (\mathrm{ECINETLS} 4 \mathrm{~T}))+$ PRELS $;$

else

ERELS $=((\max ($ ECINETLS1T $))-(\min ($ ECINETLS1T $)))+$

$((\max ($ ECINETLS2T $))-(\min ($ ECINETLS2T $)))+((\max ($ ECINETLS3T $))-$

$(\min ($ ECINETLS3T $))+((\max ($ ECINETLS4T $))-(\min ($ ECINETLS4T $)))+$ PRELS ;

end

$\%$ Energia total requerida na entrada da linha secundaria com quatro, considerando o desvio geometrico do terreno trecho a trecho.

if $(((\max ($ ECINETLS2T $))<(\min ($ ECINETLS1T $))) \& \&(((\max ($ ECINETLS3T $))<$

$(\min ($ ECINETLS2T $))) \& \&((\max ($ ECINETLS4T $))<(\min ($ ECINETLS3T $)))$

$\mathrm{ERELST}=(\max (\mathrm{ECINETLS} 1 \mathrm{~T}))+$ PRELST $;$

elseif $((\max ($ ECINETLS2T $)) \& \&(\max ($ ECINETLS3T $)) \& \&((\max ($ ECINETLS4T $))<$ $(\min ($ ECINETLS1T $)))$

ERELST $=(\max ($ ECINETLS1T $))+$ PRELST ;

elseif $((\max ($ ECINETLS1T $)) \& \&(\max ($ ECINETLS3T $)) \& \&((\max ($ ECINETLS4T $))<$ $(\min ($ ECINETLS2T $))))$

$\mathrm{ERELST}=(\max ($ ECINETLS2T $))+$ PRELST $;$

elseif $((\max ($ ECINETLS1T $)) \& \&(\max ($ ECINETLS2T $)) \& \&((\max ($ ECINETLS4T $))<$ $(\min ($ ECINETLS3T $)))$

ERELST $=(\max ($ ECINETLS3T $))+$ PRELST ;

elseif $((\max ($ ECINETLS1T $)) \& \&(\max ($ ECINETLS2T $)) \& \&(\max ($ ECINETLS3T $))<$ $(\min (\mathrm{ECINETLS} 4 \mathrm{~T})))$

$\mathrm{ERELST}=(\max (\mathrm{ECINETLS} 4 \mathrm{~T}))+$ PRELST $;$

else

ERELST $=((\max ($ ECINETLS1T $))-(\min ($ ECINETLS1T $)))+$

$((\max ($ ECINETLS2T $))-(\min ($ ECINETLS2T $)))+((\max ($ ECINETLS3T $))-$

$(\min ($ ECINETLS3T $)))+((\max ($ ECINETLS4T $))-(\min ($ ECINETLS4T $)))+$ PRELST ; end

$\% \%$ Dimensionamento da linha principal (Adutora)

$\%$ Pre-dimensionamento da linha de principal.

PRFLP $=$ PRELS ;

$\mathrm{ADLP}=\mathrm{pi} *\left(\left(\mathrm{DLP}^{\wedge} 2\right) / 4\right)$;

$\mathrm{EES}=\mathrm{LLD}+\mathrm{EEUO}$; 


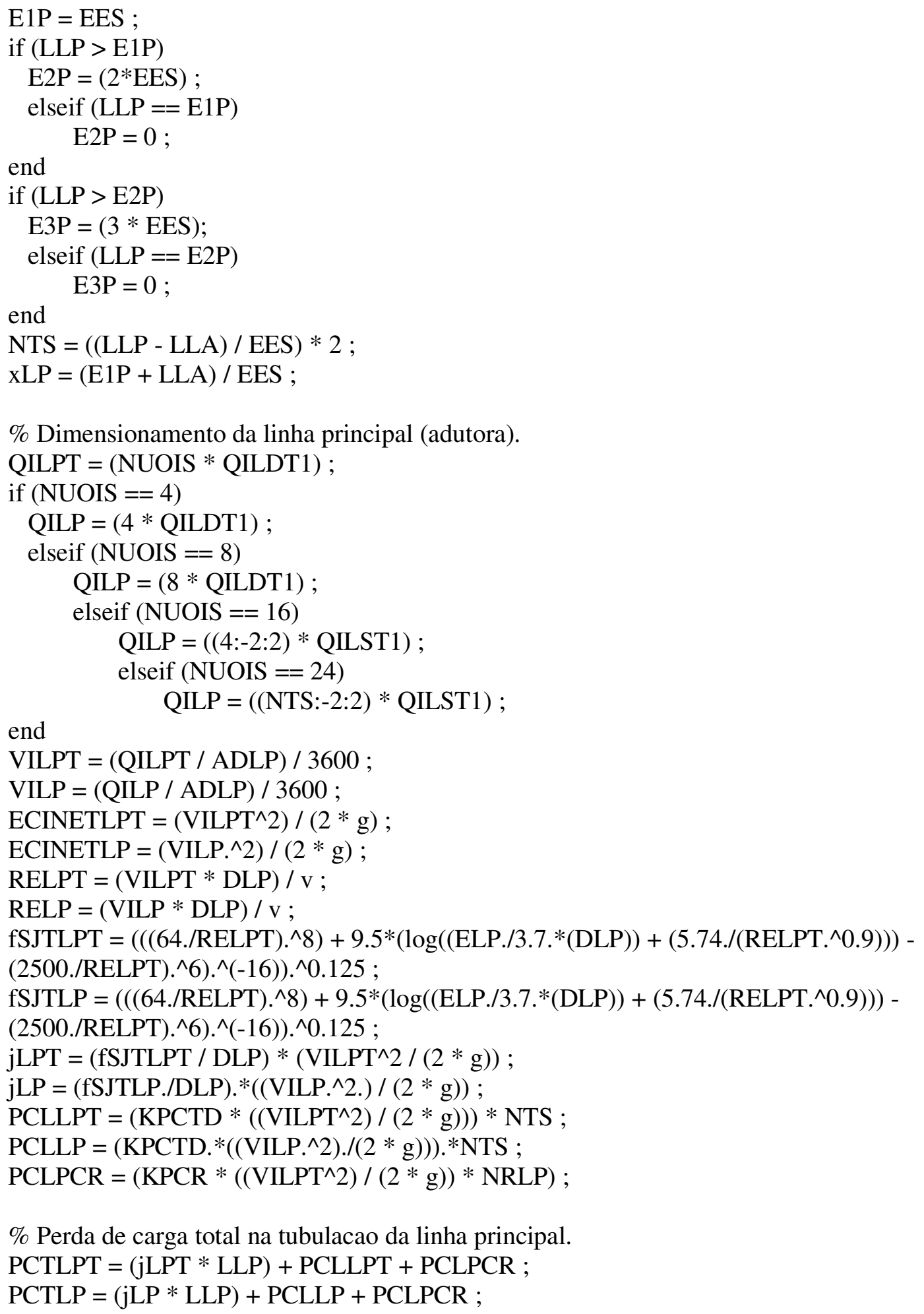

end

VILPT $=($ QILPT / ADLP $) / 3600$;

$\mathrm{VILP}=(\mathrm{QILP} / \mathrm{ADLP}) / 3600$;

ECINETLPT $=\left(\mathrm{VILPT}^{\wedge} 2\right) /(2 * \mathrm{~g})$;

ECINETLP $=($ VILP.^2) $/(2 * \mathrm{~g})$;

RELPT $=($ VILPT $*$ DLP $) / v$;

$\mathrm{RELP}=(\mathrm{VILP} * \mathrm{DLP}) / \mathrm{v}$;

fSJTLPT $=\left(\left((64 . /\right.\right.$ RELPT $\left.) .^{\wedge} 8\right)+9.5 *\left(\log ((\right.$ ELP./3.7.*(DLP $))+\left(5.74 . /\left(\right.\right.$ RELPT. $\left.\left.\left.{ }^{\wedge} 0.9\right)\right)\right)-$ (2500./RELPT).^6).^(-16)).^0.125;

fSJTLP $=\left(\left((64 . /\right.\right.$ RELPT $\left.) .^{\wedge} 8\right)+9.5^{*}\left(\log \left((\right.\right.$ ELP./3.7.* $($ DLP $))+\left(5.74 . /\left(\right.\right.$ RELPT. $\left.\left.\left.^{\wedge} 0.9\right)\right)\right)-$ $\left.\left.(2500 . / \mathrm{RELPT}) .^{\wedge} 6\right) .^{\wedge}(-16)\right) .^{\wedge} 0.125$;

$\mathrm{jLPT}=(\mathrm{fSJTLPT} / \mathrm{DLP}) *\left(\mathrm{VILPT}^{\wedge} 2 /(2 * \mathrm{~g})\right)$;

jLP $=($ fSJTLP./DLP).*((VILP.^2.) $/(2 * \mathrm{~g}))$;

PCLLPT $=\left(\mathrm{KPCTD}^{*}\left(\left(\mathrm{VILPT}^{\wedge} 2\right) /(2 * \mathrm{~g})\right)\right) * \mathrm{NTS}$;

PCLLP $=($ KPCTD. $*(($ VILP.^2). $/(2 * \mathrm{~g}))) . *$ NTS ;

$\mathrm{PCLPCR}=\left(\mathrm{KPCR} *\left(\left(\mathrm{VILPT}^{\wedge} 2\right) /(2 * \mathrm{~g})\right) * \mathrm{NRLP}\right)$;

$\%$ Perda de carga total na tubulacao da linha principal.

PCTLPT $=(\mathrm{jLPT} *$ LLP $)+$ PCLLPT + PCLPCR ;

$P C T L P=(j L P * L L P)+P C L L P+P C L P C R ;$

$\%$ Pressao requerida na entrada da linha principal com um diamentro.

PRELP = PRELST + PCTLP + ((DZLP * LLP $) / 100) ;$

$\%$ Energia total requerida na entrada da linha principal com quatro diametros.

$\mathrm{ERELP}=(\max ($ ECINETLP $))+$ PRELP ; 
$\% \%$ Dimensionamento da linha de succao

$\%$ Pre-dimensionamento da linha de succao.

$\mathrm{ADLSU}=\mathrm{pi} *\left(\left(\mathrm{DLSU}^{\wedge} 2\right) / 4\right)$;

$\%$ Dimensionamento da linha de succao.

QILSUT $=($ NUOIS * QILDT1) ;

VILSUT $=($ QILSUT $/$ ADLSU $) / 3600$;

ECINETLSUT $=\left(\right.$ VILSUT^$\left.^{\wedge}\right) /(2 * \mathrm{~g})$;

RELSUT $=($ VILSUT $*$ DLSU $) / \mathrm{v}$;

fSJTLSU $=(((64 . /$ RELSUT $) . \wedge 8)+(9.5 *(\log (($ ELSU./3.7. $*($ DLSU $))+$

(5.74./(RELSUT. $\left.\left.\left.{ }^{\wedge} 0.9\right)\right)\right)-\left(2500 . /\right.$ RELSUT).^$\left.\left.\left.{ }^{\wedge} 6\right) .^{\wedge}(-16)\right)\right) .^{\wedge} 0.125$;

$\mathrm{jLSUT}=(\mathrm{fSJTLSU} / \mathrm{DLSU}) *\left(\mathrm{VILSUT}^{\wedge} 2 /(2 * \mathrm{~g})\right) ;$

PCLLSU $=\left(\mathrm{KLSU}^{*}\left(\left(\mathrm{VILSUT}^{\wedge} 2\right) /(2 * \mathrm{~g})\right)\right)$;

$\%$ Perda de carga total na tubulacao da linha de succao.

PCTLSU $=(j L S U T *$ LLSU $)+$ PCLLSU + AGSU ;

$\% \%$ Altura manometrica total (carga de pressao total)

$\mathrm{HMT}=\mathrm{PRELP}+\mathrm{PCTLSU}+\mathrm{hfcc}$;

$\% \%$ Energia cinetica total na tubulacao de recalque (carga cinetica total)

$\mathrm{ECTR}=$ ECINETLPT ;

$\% \%$ Energia cinetica na tubulacao de succao (carga cinetica de succao)

ECTSU = ECINETLSUT ;

$\% \%$ Energia total (cargas totais)

HET $=$ HMT + (ECTR - ECTSU $)$;

$\% \%$ Vazao recalcada, produtividade, volume de agua aplicado e area util irrigada

QTRM3H $=($ NUOIS * QILDT1 $)$;

QTRM3S $=($ QTRM3H / 3600);

QTRLS $=(\mathrm{QTRM} 3 \mathrm{~S} * 1000)$;

$\mathrm{FPPL}=\left(\mathrm{a} *\left(\mathrm{VAP}^{\wedge} 2\right)\right)+(\mathrm{b} *(\mathrm{VAP}))+\mathrm{c} ;$

$\mathrm{M} 2 \mathrm{P}=\mathrm{Sf} * \mathrm{Sp}$;

NPLLL $=(L L L) / S p$;

NPUO $=$ NPLLL $*$ NTL ;

$\mathrm{NPAT}=\mathrm{NPUO} * \mathrm{NTUO}$;

$\mathrm{VAGUO}=(\mathrm{VAP} / 1000) * \mathrm{NPUO}$;

$\mathrm{VAGAT}=(\mathrm{VAP} / 1000) * \mathrm{NPAT}$;

$\mathrm{AUI}=(((\mathrm{LLL} * 2) * \mathrm{LLD}) * \mathrm{NTUO}) / 10000$;

$\% \%$ Conjunto motobomba

POTKW $=(\max ((0.735 *$ QTRLS $*$ HET $) /(75 *($ nbomba $/ 100) *($ nmotor $/ 100))) *$ FAPNB) ;

POTCV $=(\max ((\mathrm{QTRLS} * \mathrm{HET}) /(75 *($ nbomba/100 $) *($ nmotor $/ 100))) *$ FAPNB $)$;

$\mathrm{NS}=(\mathrm{ETCA} *(\mathrm{Lx} * \mathrm{Ly})) /((\mathrm{UE} / 100) * \mathrm{QTRLS} * 3600)$; 
$\mathrm{CTEKW}=\mathrm{POTKW} * \mathrm{NS}$;

$\mathrm{CTECV}=\mathrm{POTCV} * \mathrm{NS}$;

$\mathrm{TSRCD}=\mathrm{TSR}-((\mathrm{TSR} * \mathrm{DTNSR}) / 100)$;

$\% \%$ Comprimento total das tubulacoes

$\%$ Comprimentos das tubulacoes nas linhas laterais.

LLLD1UO $=$ LLL1 $*$ NTL;

LLLD2UO $=$ LLL2 $*$ NTL;

LLLTUO $=$ LLL $*$ NTL;

LLLD1 $=$ LLLD1UO $*$ NTUO ;

LLLD2 $=$ LLLD2UO $*$ NTUO;

LLLT $=$ LLLTUO $*$ NTUO ;

$\%$ Comprimentos das tubulacoes nas linhas de derivacao.

LLDD1UO = LLD1 $*$ NTD ;

$\mathrm{LLDD} 2 \mathrm{UO}=\mathrm{LLD} 2 * \mathrm{NTD} ;$

LLDD3UO $=$ LLD3 $*$ NTD ;

LLDD4UO $=$ LLD4 $*$ NTD;

LLDTUO $=$ LLD $*$ NTD ;

LLDD $1=$ LLDD1UO $*$ NTS ;

LLDD2 $=$ LLDD2UO $*$ NTS ;

LLDD3 $=$ LLDD3UO $*$ NTS ;

LLDD4 = LLDD4UO $*$ NTS ;

LLDT $=$ LLDTUO $*$ NTS ;

$\%$ Comprimentos das tubulacoes nas linhas secundarias.

LLSD1 $=$ LLS $1 *$ NTS ;

LLSD2 $=$ LLS2 $*$ NTS ;

LLSD3 $=$ LLS3 $*$ NTS ;

LLSD4 $=$ LLS4 $*$ NTS ;

LLST $=$ LLS $*$ NTS ;

$\%$ Comprimento da tubulacao na linha principal.

LLPT = LLP ;

\% Comprimento da tubulacao da linha de succao.

LLSUT = LLSU ;

\% Comprimento total de tubulacoes de PVC.

LLTPVC = LLDT + LLST + LLPT + LLSUT ;

$\%$ Comprimento total de todas as tubulacoes da rede de distribuicao de agua.

LLT = LLLT + LLDT + LLST + LLPT + LLSUT ;

$\% \%$ Quantidade total de acessorios e equipamentos utilizados na rede de irrigacao

$\%$ (Sao considerados como valor iqual a uma unidade todos os componentes da rede de irrigacao nao descritos nesta secao)

$\%$ Linha lateral. 


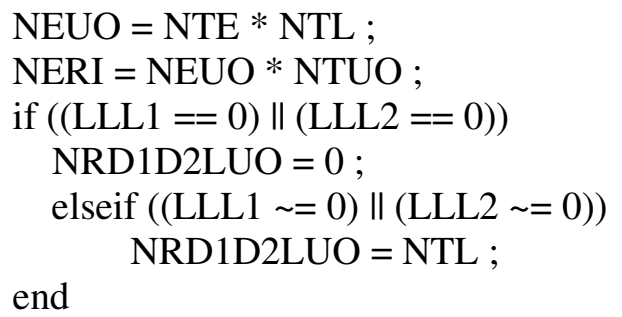




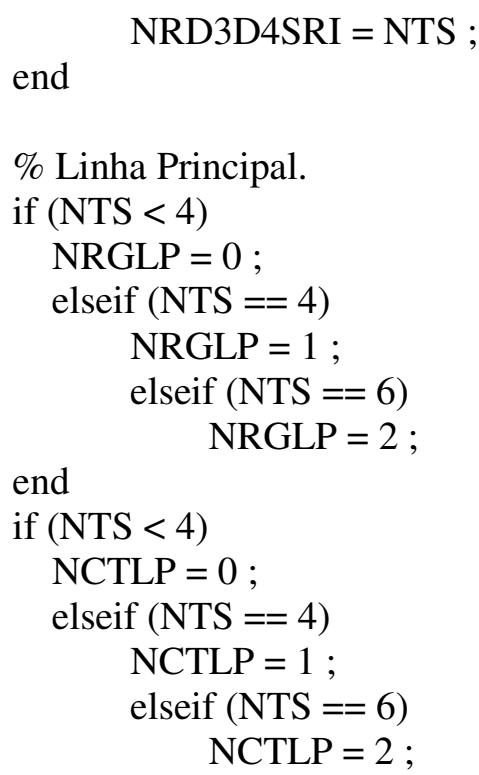

end

$\%$ Linha Principal.

if $(\mathrm{NTS}<4)$

NRGLP $=0$;

elseif $(\mathrm{NTS}==4)$

NRGLP $=1$;

elseif $(\mathrm{NTS}==6)$

$\mathrm{NRGLP}=2$;

end

if $(\mathrm{NTS}<4)$

NCTLP $=0$;

elseif $(\mathrm{NTS}==4)$

$\mathrm{NCTLP}=1$;

elseif $(\mathrm{NTS}==6$ )

$\mathrm{NCTLP}=2$;

end

$\%$ Demais componentes da rede de irrigacao.

$\mathrm{NCPVC}=12$;

$\% \%$ Custos com equipamentos de irrigacao

$\%$ Custos com equipamentos da linha lateral.

$\mathrm{CTTE}=\mathrm{CTE} * \mathrm{NERI}$;

CTRDLL $=$ CRDLL $*$ NRD1D2LRI ;

CTANELFL $=$ CANELFL $*$ NAFLLRI ;

CTLLD1 $=$ CLLD1 $*$ LLLD1;

CTLLD2 $=$ CLLD2 $*$ LLLD2 ;

CTLLD1D2 = CTLLD1 + CTLLD2 ;

CTLLL = CTTE + CTRDLL + CTANELFL + CTLLD1D2 ;

$\%$ Custo com equipamentos da linha de derivacao.

CTCSLL $=$ CCSLL $*$ NCSLLRI ;

CTRDLD1 $=$ CRDLD1 $*$ NRD1D2DRI ;

CTRDLD2 $=$ CRDLD2 $*$ NRD2D3DRI ;

CTRDLD3 $=$ CRDLD3 $*$ NRD3D4DRI ;

$\mathrm{CTTFL}=\mathrm{CTFL} * \mathrm{NTFLDRI}$;

CTLDD1 $=$ CLDD $1 *$ LLDD 1 ;

CTLDD2 $=$ CLDD2 $*$ LLDD2 ;

CTLDD3 $=$ CLDD3 $*$ LLDD3 ;

CTLDD4 $=$ CLDD4 $*$ LLDD4 ;

CTLDDN = CTLDD1 + CTLDD2 + CTLDD3 + CTLDD4;

CTLDD = CTCSLL + CTRDLD1 + CTRDLD2 + CTRDLD3 + CTLDDN + CTTFL ;

$\%$ Custos com equipamentos da linha secundaria.

$\mathrm{CTFT}=\mathrm{NFTLS} * \mathrm{CFT}$; 
CTVRPLS $=$ NVRPLS $*$ CVRPLS ;

$\mathrm{CTRLS}=\mathrm{NRGLS} * \mathrm{CRLS}$;

CTCULS $=$ NC90LS $*$ CCULS ;

CTCTDLS $=$ NCTLS $*$ CCTDLS ;

CTRDLS1 $=$ NRD1D2SRI $*$ CRDLS1;

CTRDLS2 $=$ NRD2D3SRI $*$ CRDLS2;

CTRDLS3 $=$ NRD3D4SRI $*$ CRDLS3 ;

CTLSD $1=$ CLSD $1 *$ LLSD 1 ;

CTLSD2 $=$ CLSD2 $*$ LLSD2;

CTLSD3 $=$ CLSD3 $*$ LLSD3 ;

CTLSD4 $=$ CLSD4 $*$ LLSD4 ;

CTLSDN = CTLSD1 + CTLSD2 + CTLSD3 + CTLSD4 ;

CTLSD = CTFT + CTVRPLS + CTRLS + CTCULS + CTCTDLS + CTRDLS $1+$ CTRDLS2 + CTRDLS3 + CTLSDN ;

$\%$ Custos com equipamentos da linha principal.

$\mathrm{CTRLP}=\mathrm{NRGLP} * \mathrm{CRLP}$;

CTCTFLP $=$ CCTFLP ;

CTCTDLP $=$ NCTLP $*$ CCTDLP ;

CTLPDI $=$ LLPT $*$ CLPDI ;

CTLPD $=$ CTRLP + CTCTFLP + CTCTDLP + CTLPDI ;

$\%$ Custos com equipamentos do cabecal de controle.

$\mathrm{CTFD}=\mathrm{CFD}$

$\mathrm{CTFA}=\mathrm{CFA}$

$\mathrm{CTRG}=\mathrm{CRG}$;

CTIV = CIV ;

$\mathrm{CTPC}=\mathrm{CPC}$

$\mathrm{CTH}=\mathrm{CH}$;

$\mathrm{CTM}=\mathrm{CM}$;

$\mathrm{CTCC}=\mathrm{CTFD}+\mathrm{CTFA}+\mathrm{CTRG}+\mathrm{CTIV}+\mathrm{CTPC}+\mathrm{CTH}+\mathrm{CTM}$;

$\%$ Custos com equipamentos do conjunto motobomba.

$\mathrm{CTAE}=\mathrm{CAE}$

$\mathrm{CTRE}=\mathrm{CRE}$;

$\mathrm{CTMB}=172.35 *(\max (\mathrm{POTCV}))+26.234 ;$

$\mathrm{CTCMB}=\mathrm{CTAE}+\mathrm{CTRE}+\mathrm{CTMB}$;

$\%$ Custos com demais componentes da rede de irrigacao.

CTC90 = CC90 ;

CTVPC $=$ CVPC ;

CTTS = CTS ;

$\mathrm{CTCPVC}=\mathrm{CCPVC} *(\mathrm{NTUO} / 2)$;

$\%$ Custo fixo total.

$\mathrm{CEQ}=\mathrm{CTLLL}+\mathrm{CTLDD}+\mathrm{CTLSD}+\mathrm{CTLPD}+\mathrm{CTCC}+\mathrm{CTCMB}+\mathrm{CTCPVC}+$ CTC90 + CTVPC + CTTS ; 
$\% \%$ Fator de recuperacao do capital

$\mathrm{FRC}=\left(\left((1+\mathrm{i})^{\wedge} \mathrm{n}\right) * \mathrm{i}\right) /\left(\left((1+\mathrm{i})^{\wedge} \mathrm{n}\right)-1\right)$;

$\% \%$ Custos variaveis

$\%$ Custo total de funcionamento do conjunto moto-bomba, dado em reais por ano.

if (TFMBD $<=$ TDTEE)

$\mathrm{CTE}=(\mathrm{TSRCD} * \mathrm{CTEKW})$;

elseif (TFMBD > TDTEE)

$\mathrm{CTE}=(\mathrm{TSR} * \mathrm{CTEKW})$;

end

$\mathrm{CAUO}=\mathrm{VAGUO} * \mathrm{CA}$

$\mathrm{CAGT}=\mathrm{VAGAT} * \mathrm{CA}$;

$\% \%$ Custos por hectare por ano

$\mathrm{CEQH}=(\mathrm{CEQ} * \mathrm{FRC}) / \mathrm{AUI}$;

$\mathrm{CTEH}=(\mathrm{CTE} / \mathrm{AUI})$;

$\mathrm{CAGTH}=(\mathrm{CAGT} / \mathrm{AUI})$;

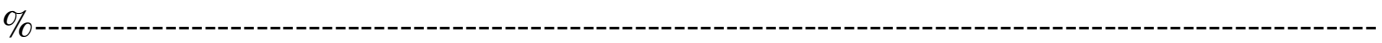

$\%$ Funcao Objetivo

$\%$

$\mathrm{f}=((\mathrm{CEQ} * \mathrm{FRC})+\mathrm{CTE}+\mathrm{CAGT}) / \mathrm{AUI}$; 


\section{APÊNDICE C}

Detalhamento do algoritmo do código de modelagem para otimização, da rede de irrigação localizada, apresentado no APÊNDICE B.

1. Parâmetros de entrada do programa (dados a serem digitados).

1.2. Dados iniciais do dimensionamento.

1.1.1. Digitar a uniformidade de emissão (UE) desejada, em percentagem.

1.1.2. Digitar a condutividade elétrica mínima do solo (CEemin), dado tabelado em mmhos.cm ${ }^{-1}$.

1.1.3. Digitar a condutividade elétrica máxima do solo (CEemax), dado tabelado em mmhos.cm ${ }^{-1}$.

1.1.4. Digitar o espaçamento entre linhas (Sf), em metros.

1.1.5. Digitar o espaçamento entre plantas $(\mathrm{Sp})$, em metros.

1.1.6. Digitar a precipitação efetiva (PEP), em milímetros.

1.1.7. Digitar a capacidade de campo do solo (CC), em percentagem.

1.1.8. Digitar o ponto de murcha permanente (PM), em percentagem.

1.1.9. Digitar a densidade aparente do solo (DA), em gramas por centímetro cúbico.

1.1.10. Digitar a variação da umidade do solo $(\mathrm{Du})$, em percentagem.

1.1.11. Digitar o fator de disponibilidade de água no solo (f), em percentagem.

1.1.12. Digitar a viscosidade cinemática da água (v), valor tabelado.

1.1.13. Digitar a profundidade efetiva do sistema radicular (z), em metros. 
1.1.14. Digitar a média diária da evapotranspiração anual (ETO), em milímetros.

1.1.15. Digitar o coeficiente de cultura (KC) para cálculo da evapotranspiração da cultura a ser instalada.

1.1.16. Digitar o número de subunidades do sistema (NTUO - unidades operacionais).

1.1.17. Digitar o tempo máximo de funcionamento da motobomba por dia (TFMBD), em horas.

1.1.18. Digitar o número de unidades operacionais irrigadas simultaneamente (NUOIS).

1.1.19. Digitar o tempo de irrigação por conjunto de unidades operacionais irrigadas simultaneamente (TaCUOIS), em horas. ${ }^{8}$

1.1.20. Digitar o turno de rega escolhido (TRE), em dias.

1.1.21. Digitar o volume de água aplicado (VAP), em litros por planta por ano. ${ }^{9}$

1.1.22. Digitar o coeficiente "a" da função (polinomial de segunda ordem) de produção da planta por lamina de água aplicada (a).

1.1.23. Digitar o coeficiente "b" da função (polinomial de segunda ordem) de produção da planta por lamina de água aplicada (b).

\footnotetext{
${ }^{8}$ Das 21 h30min às 06 h00min a economia com o custo de energia é de $70 \%$. Ao total 8,5 horas de funcionamento do sistema. Pela heurística pode-se ajustar o sistema para funcionar 4,25 horas, trabalhando em dois turnos por dia, o que reduzirá a vazão de projeto, gerando economia em tubulação e potência requerida. Outra forma seria trabalhar com um turno de 8,5 horas, dependendo do objetivo que se pretende atingir. $\mathrm{O}$ ajuste pode ser feito aumentando a vazão dos microaspersores de acordo com a curva de vazão pela pressão fornecida pelo fabricante, ou simplesmente escolhendo outro microaspersor. Isto dependerá de quantos dias será o turno de rega e quantos setores com as unidades operacionais que serão irrigadas por dia, conforme o sistema a ser implantado. Para fazer estes ajustes, retorne ao item de seleção do emissor.

9 Tempo para que o mesmo conjunto de unidades operacionais volte a ser irrigado. Escolher o TRE conforme o leiaute da rede, o TFMBD, NUOIS e o TaCUOIS.
} 
1.1.24. Digitar o coeficiente "c" da função (polinomial de segunda ordem) de produção da planta por lamina de água aplicada (c).

1.1.25. Digitar a aceleração da gravidade (g), em metros por segundo.

1.1.26. Digitar o lado de maior comprimento na área a ser irrigada (Lx), em metros.

1.1.27. Digitar o lado de menor comprimento na área a ser irrigada (Ly), em metros.

1.1.28. Digitar o expoente da vazão ou velocidade da equação de perda de carga de Darcy-Weisbach, Manning e Swamee-Jain (m).

1.1.29. Digitar o espaçamento entre unidades operacionais (EEUO), em metros.

1.2. Escolha do microaspersor.

1.2.1. Digitar o nome do fabricante do microaspersor.

1.2.2. Digitar a cor do microaspersor.

1.2.3. Digitar o coeficiente para cálculo da vazão unitária do emissor (k). ${ }^{10}$

1.2.4. Digitar o coeficiente para cálculo da vazão unitária do emissor (x).

1.2.5. Digitar a pressão de serviço ideal do emissor (PS), em kgf. $\mathrm{cm}^{2}$.

1.2.6. Digitar a pressão de serviço mínima do emissor (PSmin), em kgf.cm².

1.2.7. Digitar a pressão de serviço máxima do emissor (PSmax), em kgf. $\mathrm{cm}^{2}$.

1.2.8. Digitar o coeficiente de perda de carga localizada do emissor (KE).

\footnotetext{
${ }^{10} \mathrm{k}$ e x geralmente são dados pelo fabricante do emissor. Pode ser obtido fazendo-se uma analise de regressão do tipo exponencial para os dados de vazão versus pressão do emissor.
} 
1.2.9. Digitar o coeficiente de variação de fabricação do emissor (CVF).

1.2.10. Determinar a pressão nominal (h - pressão de serviço), em mca.

1.2.11. Digitar a equação do diâmetro molhado ou um valor de diâmetro molhado estabelecido (w), em metros. ${ }^{11}$

1.2.12. Digitar o número de saídas no emissor (NSE). ${ }^{12}$

1.3. Dados do leiaute da rede de distribuição de água.

1.3.1. Dados da linha lateral.

1.3.1.1. Digitar o material da tubulação da linha lateral.

1.3.1.2. Digitar o comprimento total da linha lateral (LLL - um lado), em metros.

1.3.1.3. Digitar o diâmetro da linha lateral 1 (DLL1), em metros.

1.3.1.4. Digitar o diâmetro da linha lateral 2 (DLL2), em metros.

1.3.1.5. Digitar a rugosidade absoluta da tubulação (ELL), em milímetros.

1.3.1.6. Digitar o desvio geométrico no conjunto de linhas laterais (DZLL), em metro por 100 metros. ${ }^{13}$

1.3.1.7. Digitar o coeficiente de perda de carga localizada da linha lateral (KLL).

1.3.2. Dados da linha de derivação.

1.3.2.1. Digitar o material da tubulação da linha de derivação.

${ }^{11}$ Cada emissor possui uma equação diferente para o diâmetro molhado, segundo a pressão de serviço.

${ }^{12}$ Sempre verificar se a vazão unitária do emissor calculada (qa) condiz com a vazão unitária do emissor escolhido segundo a margem de pressão de operacao.

${ }^{13}$ DZLL pode ser positivo ou negativo dependendo da direção da vazão em relação ao desvio de altitude do terreno. 
1.3.2.2. Digitar o comprimento total da linha de derivação (LLD), em metros.

1.3.2.3. Digitar o diâmetro da linha de derivação 1 (DLD1), em metros.

1.3.2.4. Digitar o diâmetro da linha de derivação 2 (DLD2), em metros.

1.3.2.5. Digitar o diâmetro da linha de derivação 3 (DLD3), em metros.

1.3.2.6. Digitar o diâmetro da linha de derivação 4 (DLD4), em metros.

1.3.2.7. Digitar a rugosidade absoluta da tubulação (ELD), dado em milímetros.

1.3.2.8. Digitar o desvio geométrico no conjunto de linhas de derivação (DZLD), em metro por 100 metros. $^{14}$

1.3.3. Dados da linha secundária.

1.3.3.1. Digitar o material da tubulação da linha secundária.

1.3.3.2. Digitar o comprimento total da linha secundária (LLS), em metros.

1.3.3.3. Digitar o diâmetro da linha secundária 1 (DLS1), em metros.

1.3.3.4. Digitar o diâmetro da linha secundária 2 (DLS2), em metros.

${ }^{14}$ DZLD pode ser positivo ou negativo dependendo da direção da vazão em relação ao desvio de altitude do terreno. 
1.3.3.5. Digitar o diâmetro da linha secundária 3 (DLS3), em metros.

1.3.3.6. Digitar o diâmetro da linha secundária 4 (DLS4), em metros.

1.3.3.7. Digitar a rugosidade absoluta da tubulação (ELS), em milímetros.

1.3.3.8. Digitar o desvio geométrico no conjunto de linhas secundárias (DZLS), em metro por 100 metros. $^{15}$

1.3.3.9. Digitar o coeficiente de perda de carga localizada da linha secundária (KLS).

1.3.3.10.Digitar o comprimento equivalente de te com passagem livre para o diâmetro DLS1 (LET1).

1.3.3.11.Digitar o comprimento equivalente de te com passagem livre para o diâmetro DLS2 (LET2).

1.3.3.12.Digitar o comprimento equivalente de te com passagem livre para o diâmetro DLS3 (LET3).

1.3.3.13.Digitar o comprimento equivalente de te com passagem livre para o diâmetro DLS4 (LET4).

\subsubsection{Dados da linha principal.}

1.3.4.1. Digitar o material da tubulação da linha principal.

1.3.4.2. Digitar o comprimento total da linha principal (LLP), em metros.

\footnotetext{
${ }^{15}$ DZLS pode ser positivo ou negativo dependendo da direção da vazão em relação ao desvio de altitude
} do terreno. 
1.3.4.3. Digitar o comprimento da linha adutora. Distancia da saída da bomba ate o inicio da área a ser irrigada (LLA), em metros.

1.3.4.4. Digitar o diâmetro da linha principal (DLP), em metros.

1.3.4.5. Digitar a rugosidade absoluta da tubulação (ELP), em milímetros.

1.3.4.6. Digitar o número de registros na linha principal (NRLP).

1.3.4.7. Digitar o desvio geométrico no conjunto da linha principal (DZLP), em metro por 100 metros. $^{16}$

1.3.5. Dados da linha de sucção.

1.3.5.1. Digitar o material da tubulação da linha de sucção.

1.3.5.2. Digitar o comprimento total da linha de sucção (LLSU), em metros.

1.3.5.3. Digitar o diâmetro da linha de sucção (DLSU), em metros.

1.3.5.4. Digitar a rugosidade absoluta da tubulação (ELSU), em milímetros.

1.3.5.5. Digitar a altura geométrica de sucção (AGSU), em metros.

1.3.5.6. Digitar o coeficiente de perda de carga localizada para a válvula de pé com crivo (KLSU).

1.4. Perda de carga no cabeçal de controle.

1.4.1. Digitar a perda de carga no cabeçal de controle que é dada pelo fabricante (hfcc), em mca.

${ }^{16}$ DZLP pode ser positivo ou negativo dependendo da direção da vazão em relação ao desvio de altitude do terreno. 
1.5. Coeficientes de perda de carga localizada $(\mathrm{k})$.

1.5.1. Digitar o coeficiente de perda de carga de válvula reguladora de pressão (KPCV).

1.5.2. Digitar o coeficiente de perda de carga de registro de gaveta (KPCR).

1.5.3. Digitar o coeficiente de perda de carga de filtro de tela (KPCF).

1.5.4. Digitar o coeficiente de perda de carga de te passagem livre (KPCTD).

1.5.5. Digitar o coeficiente de perda de carga de te saída lateral (KPCTSL).

1.6. Conjunto motobomba.

1.6.1. Digitar a marca do fabricante.

1.6.2. Digitar o modelo.

1.6.3. Digitar a velocidade do rotor (Vrotor), em rotações por minuto.

1.6.4. Digitar o diâmetro comercial do rotor (Dcr), em milímetro.

1.6.5. Digitar o rendimento da bomba (nbomba), em percentagem.

1.6.6. Digitar o número de rotores (nrotores).

1.6.7. Digitar o rendimento do motor (nmotor), em percentagem.

1.6.8. Digitar o fator de acréscimo a potência necessária no conjunto motobomba elétrico (FAPNB). Valor tabelado.

1.7. Custos fixos e variáveis da rede de distribuição.

1.7.1. Custos dos componentes da linha lateral. 
1.7.1.1. Digitar o custo do microaspersor (CTE), em reais por unidade.

1.7.1.2. Digitar o custo do redutor de diâmetro Di1 para Di2 (CRDLL), em reais por unidade.

1.7.1.3. Digitar o custo do anel do fim de linha (CANELFL), em reais por unidade.

1.7.1.4. Digitar o custo do tubo de polietileno Di1 (CLLD1), em reais por metro.

1.7.1.5. Digitar o custo do tubo de polietileno Di2 (CLLD2), em reais por metro.

1.7.2. Custos dos componentes da linha de derivação.

1.7.2.1. Digitar o custo do conector de saída para linha lateral (CCSLL), em reais por unidade.

1.7.2.2. Digitar o custo do redutor de diâmetro Di1 para Di2 (CRDLD1), em reais por unidade.

1.7.2.3. Digitar o custo do redutor de diâmetro Di2 para Di3 (CRDLD2), em reais por unidade.

1.7.2.4. Digitar o custo do redutor de diâmetro Di3 para Di4 (CRDLD3), em reais por unidade.

1.7.2.5. Digitar o custo do tampão de fim de linha (CTFL), em reais por unidade.

1.7.2.6. Digitar o custo do tubo de PVC Di1 (CLDD1), em reais por 6 metros. 
1.7.2.7. Digitar o custo do tubo de PVC Di2 (CLDD2), em reais por 6 metros.

1.7.2.8. Digitar o custo do tubo de PVC Di3 (CLDD3), em reais por 6 metros.

1.7.2.9. Digitar o custo do tubo de PVC Di4 (CLDD4), em reais por 6 metros.

1.7.3. Custos dos componentes da linha secundária.

1.7.3.1. Digitar o custo do filtro de tela (CFT), em reais por unidade.

1.7.3.2. Digitar o custo da válvula reguladora de pressão (CVRPLS), em reais por unidade.

1.7.3.3. Digitar o custo do registro da linha secundária (CRLS), em reais por unidade.

1.7.3.4. Digitar o custo da curva de 90 graus PVC (CCULS), em reais por unidade.

1.7.3.5. Digitar o custo da conexão "T" PVC (CCTDLS), em reais por unidade.

1.7.3.6. Digitar o custo do redutor de diâmetro Di1 para Di2 (CRDLS1), em reais por unidade.

1.7.3.7. Digitar o custo do redutor de diâmetro Di2 para Di3 (CRDLS2), em reais por unidade.

1.7.3.8. Digitar o custo do redutor de diâmetro Di3 para Di4 (CRDLS3), em reais por unidade. 
1.7.3.9. Digitar o custo do tubo de PVC Di1 (CLSD1), em reais por 6 metros.

1.7.3.10. Digitar o custo do tubo de PVC Di2 (CLSD2), em reais por 6 metros.

1.7.3.11. Digitar o custo do tubo de PVC Di3 (CLSD3), em reais por 6 metros.

1.7.3.12. Digitar o custo do tubo de PVC Di4 (CLSD4), em reais por 6 metros.

1.7.4. Custos dos componentes da linha principal.

1.7.4.1. Digitar o custo do registro da linha principal (CRLP), em reais por unidade.

1.7.4.2. Digitar o custo da conexão "T" PVC do final de linha (CCTFLP), em reais por unidade.

1.7.4.3. Digitar o custo da conexão "T" PVC na derivação (CCTDLP), em reais por unidade.

1.7.4.4. Digitar o custo do tubo de PVC Di (CLPDI), em reais por 6 metros.

1.7.5. Custos dos componentes do cabeçal de controle.

1.7.5.1. Digitar o custo do filtro de disco (CFD), em reais por unidade.

1.7.5.2. Digitar o custo do filtro de areia (CFA), em reais por unidade.

1.7.5.3. Digitar o custo do registro (CRG), em reais por unidade. 
1.7.5.4. Digitar o custo do injetor Venturi (CIV), em reais por unidade.

1.7.5.5. Digitar o custo do painel de controle (CPC), em reais por unidade.

1.7.5.6. Digitar o custo do hidrômetro $(\mathrm{CH})$, em reais por unidade.

1.7.5.7. Digitar o custo do manômetro (CM), em reais por unidade.

1.7.6. Custos dos componentes do conjunto motobomba. ${ }^{17}$

1.7.6.1. Digitar o custo da ampliação excêntrica (CAE), em reais por unidade.

1.7.6.2. Digitar o custo da redução excêntrica (CRE), em reais por unidade.

1.7.7. Custos dos demais componentes da rede de distribuição.

1.7.7.1. Digitar o custo da curva de 90 graus PVC (CC90), em reais por unidade.

1.7.7.2. Digitar o custo da válvula de pé com crivo (CVPC), em reais por unidade.

1.7.7.3. Digitar o custo do tubo de sucção de PVC Di (CTS), em reais por 6 metros.

1.7.7.4. Digitar o custo da cola de PVC (CCPVC), em reais por litro.

1.7.8. Tarifa da água no setor rural.

17 Custo do moto-bomba (CMB ) será determinado por equação segundo a potência gasta, em reais por unidade. 
1.7.8.1. Digitar o custo da água para irrigação $(\mathrm{CA})$, em reais por metro cúbico.

1.7.9. Tarifa de energia elétrica.

1.7.9.1. Digitar a tarifa de energia elétrica para o setor rural (TSR), em reais por kilowatt.

1.7.9.2. Digitar o desconto na tarifa de energia elétrica (DTNSR), em percentagem.

1.7.9.3. Digitar o tempo máximo para o desconto na tarifa de energia elétrica (TDTEE), em horas por dia.

1.7.10. Fator de recuperação do capital.

1.7.10.1.Digitar a taxa anual de juros (i), em decimal.

1.7.10.2. Digitar a vida útil do equipamento (n), dado em anos.

2. Dimensionamento inicial.

2.1. Determinar a área total irrigável disponível (A), em hectares.

2.2. Determinar a área total de cada unidade operacional (AUO), dado em hectares.

2.3. Determinar o espaçamento entre emissores para se ter um volume de solo molhado continuo (See), dado em metros.

2.4. Determinar o número de emissores por planta (NP).

2.5. Determinar o número de emissores por planta ajustado para um número inteiro (NPA).

2.6. Determinar o perímetro molhado pelo emissor (Pma), dado em metros. 
2.7. Determinar a área molhada pelo emissor (Ama), dado em metros quadrados.

2.8. Determinar a percentagem de área molhada pelo emissor $(\mathrm{Pw})$.

2.9. Determinar a disponibilidade total de água no solo (DTAS), dado em milímetros por centímetro.

2.10. Determinar a irrigação real necessária (IRN), dado em milímetros.

2.11. Determinar a evapotranspiração da cultura em um dia (ETpc), dado em milímetros por dia.

2.12. Determinar a evapotranspiração da cultura no ano (ETCA), dado em milímetros por ano.

2.13. Determinar o fator de ajuste (KL) devido à aplicação localizada da água. Equações propostas para culturas com grande espaçamento como fruteiras.

2.14. Determinar a evapotranspiração media da cultura irrigada em um dia (ETg), dado em milímetros por dia.

2.15. Determinar o turno de rega calculado (TR), dado em dias.

2.16. Determinar o turno de rega inteiro (TRI), dado em dias.

2.17. Determinar a irrigação real necessária ajustada para o turno de rega calculado (IRNAIL). Em irrigação localizada existe a facilidade de se trabalhar com um turno de rega menor, ou seja, com uma maior freqüência aplicar uma menor quantidade de água.

2.18. Determinar a razão de lixiviação (RL).

2.19. Determinar a irrigação total necessária (ITN), dado em milímetros.

2.20. Determinar o volume de água aplicado em cada planta por irrigação (Vp), dado em litros por planta. 
2.21. Determinar a vazão mínima unitária para o microaspersor (qmin), dado em litros por hora.

2.22. Determinar a pressão mínima requerida pelo microaspersor para aspergir a vazão unitária requerida (hmin), dado em mca.

2.23. Determinar a vazão media unitária requerida pelo microaspersor (qa), dado em litros por hora.

2.24. Determinar a pressão média requerida pelo microaspersor para aspergir a vazão unitária requerida (he), dado em mca.

3. Dimensionamento da linha lateral da rede de distribuição.

3.1. Variáveis a serem otimizadas na linha lateral.

3.1.1. Comprimento do tubo (x(1)) com diâmetro D1 (LLL1), dado em metros.

3.1.2. Comprimento do tubo (x(2)) com diâmetro Di2 (LLL2), dado em metros.

3.2. Pré-dimensionamento da linha lateral.

3.2.1. Determinar a área do tubo com diâmetro D1, dado em metros.

3.2.2. Determinar a área do tubo com diâmetro Di2, dado em metros.

3.2.3. Determinar o espaçamento entre emissores da linha lateral (EEE), dado em metros.

3.2.4. Determinar o espaçamento do primeiro emissor da linha lateral ate a linha de derivação (E1E), dado em metros.

3.2.5. Determinar o número total de emissores na linha lateral (NTE). 
3.2.6. Determinar o número de emissores no primeiro trecho da linha lateral (NELL1).

3.2.7. Arredondar o número de emissores no primeiro trecho da linha lateral (NELL1) para o inteiro mais próximo.

3.2.8. Determinar o número de emissores no segundo trecho da linha lateral (NELL2).

3.2.9. Arredondar o número de emissores no segundo trecho da linha lateral (NELL2) para o inteiro mais próximo.

3.2.10. Determinar a razão da distância do começo da linha lateral ao primeiro emissor em relação às eqüidistâncias dos outros emissores entre si (xLL).

3.2.11. Determinar o coeficiente de redução Scaloppi (FLL) na linha lateral para Darcy-Weisbach, Manning e Swamee-Jain.

3.3. Dimensionamento do trecho 1 da linha lateral.

3.3.1. Determinar a vazão no inicio da linha lateral (QILLT1), dado em metros cúbicos por hora.

3.3.2. Determinar a vazão distribuída na linha lateral (QILL1), dado em metros cúbicos por hora.

3.3.3. Determinar a vazão distribuída por emissor no primeiro trecho da linha lateral (QILL1T), dado em metros cúbicos por hora.

3.3.4. Determinar a vazão fictícia distribuída por metro no primeiro trecho da linha lateral (QILL1M), dado em metros cúbicos por hora. 
3.3.5. Determinar a velocidade no inicio da linha lateral (VILLT1), dado em metros por segundo.

3.3.6. Determinar a velocidade distribuída na linha lateral (VILL1), dado em metros por segundo.

3.3.7. Determinar a velocidade distribuída por emissor no primeiro trecho da linha lateral (VILL1T), dado em metros cúbicos por hora.

3.3.8. Determinar a velocidade fictícia distribuída por metro no primeiro trecho da linha lateral (VILL1M), dado em metros cúbicos por hora.

3.3.9. Determinar a energia cinética por emissor no primeiro trecho da linha lateral

\subsubsection{0. (ECINETLL1T).}

3.3.11. Determinar a energia cinética por metro no primeiro trecho da linha lateral (ECINETLL1M).

3.3.12. Determinar o número de Reynolds para o primeiro trecho da linha lateral (RELLT1).

3.3.13. Determinar o número de Reynolds distribuído por emissor para o primeiro trecho da linha lateral (RELL1).

3.3.14. Determinar o número de Reynolds distribuído por metro para o primeiro trecho da linha lateral (RELL1M).

3.3.15. Determinar o coeficiente de atrito de Swamee-Jain distribuído por emissor para o primeiro trecho da linha lateral (fSJT1).

3.3.16. Determinar o coeficiente de atrito de Swamee-Jain distribuído por metro para o primeiro trecho da linha lateral (fSJT1M). 
3.3.17. Determinar a perda de carga unitária distribuída por emissor para o primeiro trecho da linha lateral (jLLT1).

3.3.18. Determinar a perda de carga unitária distribuída por metro para o primeiro trecho da linha lateral (jLLT1M).

3.3.19. Determinar a perda de carga localizada com os emissores distribuída por emissor no primeiro trecho da tubulação (PCLELL1).

3.3.20. Determinar a perda de carga localizada com os emissores distribuída por metro no primeiro trecho da tubulação (PCLELL1M).

3.3.21. Determinar a somatória da perda de carga localizada com os emissores no primeiro trecho da tubulação (PCLELLT1).

3.3.22. Determinar a perda de carga total com o desnível do terreno considerando apenas o diâmetro D1 da tubulação (PCDTLL1).

3.3.23. Determinar a perda de carga com o desnível do terreno por saída distribuída ao longo do primeiro trecho da tubulação (PCDDLL1).

3.3.24. Determinar a perda de carga com o desnível a cada metro (PCD1M).

3.3.25. Determinar a perda de carga com o desnível do terreno por metro distribuída ao longo do primeiro trecho da tubulação (PCDDLL1M).

3.3.26. Determinar a perda de carga total distribuída por emissor no primeiro trecho da linha lateral (hfLL1), dado em mca.

3.3.27. Determinar a perda de carga total distribuída por metro no primeiro trecho da linha lateral (hfLL1M), dado em mca. 
3.4. Dimensionamento do trecho 2 da linha lateral.

3.4.1. Determinar a vazão no inicio do segundo trecho da linha lateral (QILLT2), dado em metros cúbicos por hora.

3.4.2. Determinar a vazão distribuída por emissor no segundo trecho da linha lateral (QILL2T), dado em metros cúbicos por hora.

3.4.3. Determinar a vazão fictícia distribuída por metro no segundo trecho da linha lateral (QILL2M), dado em metros cúbicos por hora.

3.4.4. Determinar a velocidade no inicio do segundo trecho da linha lateral (VILLT2), dado em metros por segundo.

3.4.5. Determinar a velocidade distribuída no segundo trecho da linha lateral (VILL2T), dado em metros cúbicos por hora.

3.4.6. Determinar a velocidade fictícia distribuída por metro no segundo trecho da linha lateral (VILL2M), dado em metros cúbicos por hora.

3.4.7. Determinar a energia cinética por emissor no segundo trecho da linha lateral (ECINETLL2T).

3.4.8. Determinar a energia cinética por metro no segundo trecho da linha lateral (ECINETLL2M).

3.4.9. Determinar o número de Reynolds para o segundo trecho da linha lateral (RELLT2).

3.4.10. Determinar o número de Reynolds distribuído para o primeiro trecho da linha lateral (RELL2).

3.4.11. Determinar o número de Reynolds distribuído por metro para o segundo trecho da linha lateral (RELL2M). 
3.4.12. Determinar o coeficiente de atrito de Swamee-Jain para o segundo trecho da linha lateral (fSJT2).

3.4.13. Determinar o coeficiente de atrito de Swamee-Jain distribuído por metro para o segundo trecho da linha lateral (fSJT2M).

3.4.14. Determinar a perda de carga unitária para o segundo trecho da linha lateral (jLLT2).

3.4.15. Determinar a perda de carga unitária distribuída por metro para o segundo trecho da linha lateral (jLLT2M).

3.4.16. Determinar a perda de carga localizada com os emissores no segundo trecho da tubulação (PCLELL).

3.4.17. Determinar a perda de carga localizada com os emissores distribuída por metro no segundo trecho da tubulação (PCLELL2M).

3.4.18. Determinar a somatória da perda de carga localizada com os emissores no segundo trecho da tubulação (PCLELLT2).

3.4.19. Determinar a perda de carga total com o desnível do terreno no segundo trecho da tubulação (PCDTLL2).

3.4.20. Determinar a perda de carga com o desnível do terreno por saída distribuída ao longo do segundo trecho da tubulação (PCDDLL2).

3.4.21. Determinar a perda de carga com o desnível do terreno por metro distribuída ao longo do segundo trecho da tubulação (PCDDLL2M).

3.4.22. Determinar a perda de carga total distribuída no segundo trecho da linha lateral (hfLL2), dado em mca. 
3.4.23. Determinar a perda de carga total distribuída por metro no segundo trecho da linha lateral (hfLL2M), dado em mca.

3.5. Diferença entre as perdas de carga em cada trecho de cada tubulação da linha lateral.

3.5.1. Determinar a diferença entre as perdas de carga distribuídas por emissor (DhfLL12).

3.5.2. Determinar a diferença entre as perdas de carga distribuídas por metro (DhfLL12M).

3.6. Perda de carga localizada com a contração da tubulação.

3.6.1. Relação entre a área da segunda com a primeira tubulação (RA2A1).

3.6.2. Coeficiente $\mathrm{K}$ para reduções bruscas de diâmetro de tubulação (KA2A1).

3.6.3. Perda de carga localizada para a contração da tubulação, dado em mca (PCLA2A1).

3.7. Perda de carga total na linha lateral com dois diâmetros.

3.7.1. Determinar a perda de carga total na linha lateral (PCTLL), dado em mca.

3.8. Pressão requerida na entrada da linha lateral com dois diâmetros.

3.8.1. Determinar a pressão requerida na entrada da linha lateral com dois diâmetros (PRELL), dado em mca. 
3.9. Energia total requerida na entrada da linha lateral com dois diâmetros.

3.9.1. Determinar a energia total requerida na entrada da linha lateral com dois diâmetros (ERELL), dado em mca.

3.10. Analise da uniformidade de emissão obtida na linha lateral com dois diâmetros.

3.10.1. Determinar a vazão obtida em cada emissor de toda linha lateral, considerando os dois trechos (qce12), dado em litros por hora.

3.10.2. Determinar a vazão fictícia obtida por metro de toda linha lateral, considerando os dois trechos (qce12M), dado em litros por hora.

3.10.3. Determinar a máxima vazão obtida dos emissores em toda linha lateral (qce12MAX).

3.10.4. Determinar a máxima vazão fictícia obtida por metro dos emissores em toda linha lateral (qce12MMAX).

3.10.5. Determinar a mínima vazão obtida dos emissores em toda linha lateral (qce12MIN).

3.10.6. Determinar a mínima vazão fictícia obtida por metro dos emissores em toda linha lateral (qce12MMIN).

3.10.7. Determinar a vazão media obtida dos emissores em toda linha lateral (qce12MEDIA).

3.10.8. Determinar a vazão media dos emissores obtida por metro em toda linha lateral (qce12MMEDIA).

3.10.9. Determinar a pressão obtida em cada emissor da linha lateral, considerando os dois trechos (hLL12), dado em mca. 
3.10.10. Determinar a pressão obtida por metro na linha lateral, considerando os dois trechos (hLL12M), dado em mca.

3.10.11. Determinar a máxima pressão observada por emissor em toda linha lateral (hLL12MAX).

3.10.12. Determinar a máxima pressão observada por metro em toda linha lateral (hLL12MMAX).

3.10.13. Determinar a mínima pressão observada por emissor em toda linha lateral (hLL12MIN).

3.10.14. Determinar a mínima pressão observada por metro em toda linha lateral (hLL12MMIN).

3.10.15. Determinar a pressão media observada por emissor em toda linha lateral (hLL12MEDIA).

3.10.16. Determinar a pressão media observada por metro em toda linha lateral (hLL12MMEDIA).

3.10.17. Determinar a variância da vazão obtida dos emissores na linha lateral (VAQRELL).

3.10.18. Determinar a variância da vazão obtida fictícia por metro na linha lateral (VAQRELLM).

3.10.19. Determinar o desvio padrão da vazão obtida dos emissores na linha lateral (DPQELL).

3.10.20. Determinar o desvio padrão da vazão fictícia obtida por metro na linha lateral (DPQELLM).

3.10.21. Determinar a variância da pressão obtida dos emissores na linha lateral (VAHRELL). 
3.10.22. Determinar a variância da pressão obtida por metro na linha lateral (VAHRELLM).

3.10.23. Determinar o desvio padrão da pressão obtida dos emissores na linha lateral (DPHELL).

3.10.24. Determinar o desvio padrão da pressão obtida por metro na linha lateral (DPHELLM).

3.10.25. Determinar o coeficiente de variação de fabricação dos emissores na linha lateral (CVF).

3.10.26. Determinar a uniformidade de emissão calculada na linha lateral, apos o dimensionamento (UECLL).

3.10.27. Determinar o coeficiente de uniformidade de Christiansen (CUC).

3.10.28. Determinar a variação de pressão permitida na unidade operacional (linhas laterais (55\%) e de derivação (45\%)) (DHV), dado em mca.

3.10.29. Determinar a variação de pressão permitida na linha lateral (DHVLL), dado em mca.

3.10.30. Determinar a variação de pressão permitida na linha de derivação (DHVLD), dado em mca.

4. Dimensionamento da linha de derivação.

4.1. Variáveis a serem otimizadas na linha de derivação.

4.1.1. Comprimento do primeiro trecho da linha de derivação x(3) com D1 (LLD1), dado em metros.

4.1.2. Comprimento do segundo trecho da linha de derivação x(4) com Di2 (LLD2), dado em metros. 
4.1.3. Comprimento do terceiro trecho da linha de derivação x(5) com Di3 (LLD3), dado em metros.

4.1.4. Comprimento do quarto trecho da linha de derivação $x(6)$ com Di4 (LLD4), dado em metros.

4.2. Pré-dimensionamento da linha de derivação.

4.2.1. Determinar a pressão requerida no final da linha de derivação (PRFLD), dado em mca.

4.2.2. Determinar a área do tubo com D1 (ADLD1), dado em metros quadrados.

4.2.3. Determinar a área do tubo com Di2 (ADLD2), dado em metros quadrados.

4.2.4. Determinar a área do tubo com Di3 (ADLD3), dado em metros quadrados.

4.2.5. Determinar a área do tubo com Di4 (ADLD4), dado em metros quadrados.

4.2.6. Determinar o espaçamento entre as linhas laterais (EEL), dado em metros.

4.2.7. Determinar o espaçamento da primeira linha lateral ate a tomada de água na linha secundária (E1L), dado em metros.

4.2.8. Determinar o número total de linhas laterais acopladas na linha de derivação (NTL).

4.2.9. Determinar o número de linhas laterais no primeiro trecho da linha de derivação (NLLD1). 
4.2.10. Determinar o número de linhas laterais no segundo trecho da linha de derivação (NLLD2).

4.2.11. Determinar o número de linhas laterais no terceiro trecho da linha de derivação (NLLD3).

4.2.12. Determinar o número de linhas laterais no quarto trecho da linha de derivação (NLLD4).

4.2.13. Determinar a razão da distância do começo da linha de derivação à primeira saída em relação das eqüidistâncias das outras saídas entre si (xLD).

4.2.14. Determinar o coeficiente de redução Scaloppi (FLD) na linha de derivação para Darcy-Weisbach, Manning e Swamee-Jain.

4.3. Dimensionamento do trecho 1 da linha de derivação.

4.3.1. Determinar a vazão no inicio da linha de derivação (QILDT1), dado em metros cúbicos por hora.

4.3.2. Determinar a vazão distribuída por duas saídas para laterais em toda linha de derivação (QILD1), dado em metros cúbicos por hora.

4.3.3. Determinar a vazão distribuída por saída no primeiro trecho da linha de derivação (QILD1T), dado em metros cúbicos por hora.

4.3.4. Determinar a vazão fictícia distribuída por metro no primeiro trecho da linha lateral (QILD1M), dado em metros cúbicos por hora.

4.3.5. Determinar a velocidade no inicio da linha de derivação (VILDT1), dado em metros por segundo. 
4.3.6. Determinar a velocidade distribuída na linha de derivação (VILD1), dado em metros por segundo.

4.3.7. Determinar a velocidade distribuída por lateral no primeiro trecho da linha de derivação (VILD1T), dado em metros cúbicos por hora.

4.3.8. Determinar a velocidade fictícia distribuída por metro no primeiro trecho da linha de derivação (VILD1M), dado em metros cúbicos por hora.

4.3.9. Determinar a energia cinética por emissor no primeiro trecho da linha de derivação (ECINETLD1T).

4.3.10. Determinar a energia cinética por metro no primeiro trecho da linha de derivação (ECINETLD1M).

4.3.11. Determinar o número de Reynolds para o primeiro trecho da linha de derivação (RELDT1).

4.3.12. Determinar o número de Reynolds distribuído para o primeiro trecho da linha de derivação (RELD1).

4.3.13. Determinar o número de Reynolds distribuído por metro para o primeiro trecho da linha de derivação (RELD1M).

4.3.14. Determinar o coeficiente de atrito de Swamee-Jain para o primeiro trecho da linha de derivação (fSJTLD1).

4.3.15. Determinar o coeficiente de atrito de Swamee-Jain distribuído por metro para o primeiro trecho da linha de derivação (fSJTLD1M).

4.3.16. Determinar a perda de carga unitária para o primeiro trecho da linha de derivação (jLDT1).

4.3.17. Determinar a perda de carga unitária distribuída por metro para o primeiro trecho da linha de derivação (jLDT1M). 
4.3.18. Determinar a perda de carga localizada com as saídas no primeiro trecho da tubulação (PCLLD1).

4.3.19. Determinar a perda de carga localizada com as linhas laterais distribuída por metro no primeiro trecho da tubulação (PCLELD1M).

4.3.20. Determinar a somatória da perda de carga localizada com as linhas laterais no primeiro trecho da tubulação (PCLELDT1).

4.3.21. Determinar a perda de carga total no primeiro trecho da linha de derivação (hfLD1), dado em mca.

4.3.22. Determinar a perda de carga total distribuída por metro no primeiro trecho da linha de derivação (hfLD1M), dado em mca.

4.4. Dimensionamento do trecho 2 da linha de derivação.

4.4.1. Determinar a vazão no inicio do segundo trecho da linha de derivação (QILDT2), dado em metros cúbicos por hora.

4.4.2. Determinar a vazão distribuída por linha lateral no segundo trecho da linha de derivação (QILD2T), dado em metros cúbicos por hora.

4.4.3. Determinar a vazão fictícia distribuída por metro no segundo trecho da linha de derivação (QILD2M), dado em metros cúbicos por hora.

4.4.4. Determinar a velocidade no inicio do segundo trecho da linha de derivação (VILDT2), dado em metros por segundo.

4.4.5. Determinar a velocidade distribuída no segundo trecho da linha de derivação (VILD2T), dado em metros cúbicos por hora. 
4.4.6. Determinar a velocidade fictícia distribuída por metro no segundo trecho da linha de derivação (VILD2M), dado em metros cúbicos por hora.

4.4.7. Determinar a Energia cinética por emissor no segundo trecho da linha de derivação (ECINETLD2T).

4.4.8. Determinar a Energia cinética por metro no segundo trecho da linha de derivação (ECINETLD2M).

4.4.9. Determinar o número de Reynolds para o segundo trecho da linha de derivação (RELDT2).

4.4.10. Determinar o número de Reynolds distribuído para o segundo trecho da linha de derivação (RELD2).

4.4.11. Determinar o número de Reynolds distribuído por metro para o segundo trecho da linha de derivação (RELD2M).

4.4.12. Determinar o coeficiente de atrito de Swamee-Jain para o segundo trecho da linha de derivação (fSJTLD2).

4.4.13. Determinar o coeficiente de atrito de Swamee-Jain distribuído por metro para o segundo trecho da linha de derivação (fSJTLD2M).

4.4.14. Determinar a perda de carga unitária para o segundo trecho da linha de derivação (jLDT2).

4.4.15. Determinar a perda de carga unitária distribuída por metro para o segundo trecho da linha de derivação (jLDT2M).

4.4.16. Determinar a perda de carga localizada com as saídas no segundo trecho da tubulação (PCLLD2). 
4.4.17. Determinar a perda de carga localizada com os emissores distribuída por metro no segundo trecho da tubulação (PCLELD2M).

4.4.18. Determinar a somatória da perda de carga localizada com os emissores no segundo trecho da tubulação (PCLELDT2).

4.4.19. Determinar a perda de carga total no segundo trecho da linha de derivação (hfLD2), dado em mca.

4.4.20. Determinar a perda de carga total distribuída por metro no segundo trecho da linha de derivação (hfLD2M), dado em mca.

4.5. Dimensionamento do trecho 3 da linha de derivação.

4.5.1. Determinar a vazão no inicio do terceiro trecho da linha de derivação (QILDT3), dado em metros cúbicos por hora.

4.5.2. Determinar a vazão distribuída por linha lateral no terceiro trecho da linha de derivação (QILD3T), dado em metros cúbicos por hora.

4.5.3. Determinar a vazão fictícia distribuída por metro no terceiro trecho da linha de derivação (QILD3M), dado em metros cúbicos por hora.

4.5.4. Determinar a velocidade no inicio do terceiro trecho da linha de derivação (VILDT3), dado em metros por segundo.

4.5.5. Determinar a velocidade distribuída no terceiro trecho da linha de derivação (VILD3T), dado em metros cúbicos por hora.

4.5.6. Determinar a velocidade fictícia distribuída por metro no terceiro trecho da linha de derivação (VILD3M), dado em metros cúbicos por hora. 
4.5.7. Determinar a energia cinética por emissor no terceiro trecho da linha de derivação (ECINETLD3T).

4.5.8. Determinar a energia cinética por metro no terceiro trecho da linha de derivação (ECINETLD3M).

4.5.9. Determinar o número de Reynolds para o terceiro trecho da linha de derivação (RELDT3).

4.5.10. Determinar o número de Reynolds distribuído para o terceiro trecho da linha de derivação (RELD3).

4.5.11. Determinar o número de Reynolds distribuído por metro para o terceiro trecho da linha de derivação (RELD3M).

4.5.12. Determinar o coeficiente de atrito de Swamee-Jain para o terceiro trecho da linha de derivação (fSJTLD3).

4.5.13. Determinar o coeficiente de atrito de Swamee-Jain distribuído por metro para o terceiro trecho da linha de derivação (fSJTLD3M).

4.5.14. Determinar a perda de carga unitária para o terceiro trecho da linha de derivação (jLDT3).

4.5.15. Determinar a perda de carga unitária distribuída por metro para o terceiro trecho da linha de derivação (jLDT3M).

4.5.16. Determinar a perda de carga localizada com as saídas no terceiro trecho da tubulação (PCLLD3).

4.5.17. Determinar a perda de carga localizada com os emissores distribuída por metro no terceiro trecho da tubulação (PCLELD3M).

4.5.18. Determinar a somatória da perda de carga localizada com os emissores no terceiro trecho da tubulação (PCLELDT3). 
4.5.19. Determinar a perda de carga total no terceiro trecho da linha de derivação (hfLD3), dado em mca.

4.5.20. Determinar a perda de carga total distribuída por metro no terceiro trecho da linha de derivação (hfLD3M), dado em mca.

4.6. Dimensionamento do trecho 4 da linha de derivação.

4.6.1. Determinar a vazão no inicio do quarto trecho da linha de derivação (QILDT4), dado em metros cúbicos por hora.

4.6.2. Determinar a vazão distribuída por linha lateral no quarto trecho da linha de derivação (QILD4T), dado em metros cúbicos por hora.

4.6.3. Determinar a vazão fictícia distribuída por metro no quarto trecho da linha de derivação (QILD4M), dado em metros cúbicos por hora.

4.6.4. Determinar a velocidade no inicio do quarto trecho da linha de derivação (VILDT4), dado em metros por segundo.

4.6.5. Determinar a velocidade distribuída no quarto trecho da linha de derivação (VILD4T), dado em metros cúbicos por hora.

4.6.6. Determinar a velocidade fictícia distribuída por metro no quarto trecho da linha de derivação (VILD4M), dado em metros cúbicos por hora.

4.6.7. Determinar a energia cinética por emissor no quarto trecho da linha de derivação (ECINETLD4T).

4.6.8. Determinar a energia cinética por metro no quarto trecho da linha de derivação (ECINETLD4M). 
4.6.9. Determinar o número de Reynolds para o quarto trecho da linha de derivação (RELDT4).

4.6.10. Determinar o número de Reynolds distribuído para o quarto trecho da linha de derivação (RELD4).

4.6.11. Determinar o número de Reynolds distribuído por metro para o quarto trecho da linha de derivação (RELD4M).

4.6.12. Determinar o coeficiente de atrito de Swamee-Jain para o quarto trecho da linha de derivação (fSJTLD4).

4.6.13. Determinar o coeficiente de atrito de Swamee-Jain distribuído por metro para o quarto trecho da linha de derivação (fSJTLD4M).

4.6.14. Determinar a perda de carga unitária para o quarto trecho da linha de derivação (jLDT4).

4.6.15. Determinar a perda de carga unitária distribuída por metro para o quarto trecho da linha de derivação (jLDT4M).

4.6.16. Determinar a perda de carga localizada com as saídas no quarto trecho da tubulação (PCLLD4).

4.6.17. Determinar a perda de carga localizada com os emissores distribuída por metro no quarto trecho da tubulação (PCLELD4M).

4.6.18. Determinar a somatória da perda de carga localizada com os emissores no quarto trecho da tubulação (PCLELDT4).

4.6.19. Determinar a perda de carga total no quarto trecho da linha de derivação (hfLD4), dado em mca.

4.6.20. Determinar a perda de carga total distribuída por metro no quarto trecho da linha de derivação (hfLD4M), dado em mca. 
5.7. Diferença entre as perdas de carga em cada trecho de cada tubulação da linha de derivação.

4.7.1. Determinar a diferença entre as perdas de carga distribuídas por saída para linha lateral (DhfLD).

4.7.2. Determinar a diferença entre as perdas de carga distribuídas por metro (DhfLDM).

4.8. Perda de carga localizada com a contração da tubulação.

4.8.1. Determinar a relação entre a área da segunda com a primeira tubulação (RA2A1LD).

4.8.2. Determinar a relação entre a área da terceira com a segunda tubulação (RA3A2LD).

4.8.3. Determinar a relação entre a área da quarta com a terceira tubulação (RA4A3LD).

4.8.4. Determinar o coeficiente k1 da segunda com a primeira tubulação para reduções bruscas de diâmetro (KA2A1LD).

4.8.5. Determinar o coeficiente $\mathrm{k} 2$ da terceira com a segunda tubulação para reduções bruscas de diâmetro (KA3A2LD).

4.8.6. Determinar o coeficiente $\mathrm{k} 3$ da quarta com a terceira tubulação para reduções bruscas de diâmetro (KA4A3LD).

4.8.7. Perda de carga localizada para a contração da tubulação D1 para Di2 (PCLA2A1LD), dado em mca.

4.8.8. Perda de carga localizada para a contração da tubulação Di2 para Di3 (PCLA3A2LD), dado em mca. 
4.8.9. Perda de carga localizada para a contração da tubulação Di3 para Di4 (PCLA4A3LD), dado em mca.

4.9. Perda de carga total na linha de derivação com quatro diâmetros.

4.9.1. Determinar a perda de carga total na linha de derivação com quatro diâmetros (PCTLD), dado em mca.

4.10. Pressão requerida na entrada da linha de derivação com quatro diâmetros.

4.10.1. Determinar a pressão requerida na entrada da linha de derivação com quatro diâmetros (PRELD), dado em mca.

4.11. Energia total requerida na entrada da linha de derivação com quatro diâmetros.

4.11.1. Determinar a energia total requerida na entrada da linha de derivação com quatro diâmetros (ERELD), dado em mca.

5. Dimensionamento da linha secundária

5.1. Variáveis a serem otimizadas na linha secundária.

5.1.1. Comprimento do primeiro trecho da linha secundária $x(7)$ com D1 (LLS1), dado em metros.

5.1.2. Comprimento do segundo trecho da linha secundária $\mathrm{x}(8)$ com Di2 (LLS2), dado em metros.

5.1.3. Comprimento do terceiro trecho da linha secundária $x(9)$ com Di3 (LLS3), dado em metros. 
5.1.4. Comprimento do quarto trecho da linha secundária $x(10)$ com Di4 (LLS4), dado em metros.

5.2. Pré-dimensionamento da linha de secundária.

5.2.1. Determinar a pressão requerida no final da linha secundária (PRFLS), dado em mca.

5.2.2. Determinar a área do tubo com D1 (ADLS1), dado em metros quadrados.

5.2.3. Determinar a área do tubo com Di2 (ADLS2), dado em metros quadrados.

5.2.4. Determinar a área do tubo com Di3 (ADLS3), dado em metros quadrados.

5.2.5. Determinar a área do tubo com Di4 (ADLS4), dado em metros quadrados.

5.2.6. Determinar o espaçamento entre as linhas de derivação (EED), dado em metros.

5.2.7. Determinar o espaçamento da primeira linha de derivação ate a tomada de água na linha principal (E1D), dado em metros.

5.2.8. Determinar o espaçamento da segunda linha de derivação ate a tomada de água na linha principal (E2D), dado em metros.

5.2.9. Determinar o espaçamento da terceira linha de derivação ate a tomada de água na linha principal (E3D), dado em metros.

5.2.10. Determinar o espaçamento da quarta linha de derivação ate a tomada de água na linha principal (E4D), dado em metros. 
5.2.11. Determinar o número total de linhas de derivação acopladas em cada linha secundária (NTD).

5.2.12. Determinar o número de linhas de derivação no primeiro trecho da linha secundária (NLDD1).

5.2.13. Determinar o número de linhas de derivação no segundo trecho da linha secundária (NLDD2).

5.2.14. Determinar o número de linhas de derivação no terceiro trecho da linha secundária (NLDD3).

5.2.15. Determinar o número de linhas de derivação no quarto trecho da linha secundária (NLDD4).

5.2.16. Determinar à razão da distância do começo da linha secundária a primeira saída em relação das eqüidistâncias das outras saídas entre si (xLS).

5.2.17. Determinar o coeficiente de redução Scaloppi (FLS) na linha secundária para Darcy-Weisbach, Manning e Swamee-Jain.

5.3. Dimensionamento do trecho 1 da linha secundária.

5.3.1. Determinar a vazão no inicio do primeiro trecho da linha secundária (QILST1), dado em metros cúbicos por hora.

5.3.2. Determinar a vazão distribuída na linha secundária (QILS1), dado em metros cúbicos por hora.

5.3.3. Determinar a vazão distribuída por saída no primeiro trecho da linha secundária (QILS1T), dado em metros cúbicos por hora. 
5.3.4. Determinar a vazão fictícia distribuída por metro (apenas entre os pontos de emissão) no primeiro trecho da linha secundária (QILS1M), dado em metros cúbicos por hora.

5.3.5. Determinar a velocidade no inicio da linha secundária (VILST1), dado em metros por segundo.

5.3.6. Determinar a velocidade distribuída na linha secundária (VILS1), dado em metros por segundo.

5.3.7. Determinar a velocidade distribuída por derivação no primeiro trecho da linha secundária (VILS1T), dado em metros cúbicos por hora.

5.3.8. Determinar a velocidade fictícia distribuída por metro no primeiro trecho da linha secundária (VILS1M), dado em metros cúbicos por hora.

5.3.9. Determinar a energia cinética por derivação no primeiro trecho da linha secundária (ECINETLS1T).

5.3.10. Determinar a energia cinética por metro no primeiro trecho da linha secundária (ECINETLS1M).

5.3.11. Determinar o número de Reynolds para o primeiro trecho da linha secundária (RELST1).

5.3.12. Determinar o número de Reynolds distribuído para o primeiro trecho da linha secundária (RELS1).

5.3.13. Determinar o número de Reynolds distribuído por metro para o primeiro trecho da linha secundária (RELS1M).

5.3.14. Determinar o coeficiente de atrito de Swamee-Jain para o primeiro trecho da linha secundária (fSJTLS1). 
5.3.15. Determinar o coeficiente de atrito de Swamee-Jain distribuído por metro para o primeiro trecho da linha secundária (fSJTLS1M).

5.3.16. Determinar a perda de carga unitária para o primeiro trecho da linha secundária (jLST1).

5.3.17. Determinar a perda de carga unitária distribuída por metro para o primeiro trecho da linha secundária (jLST1M).

5.3.18. Determinar a perda de carga localizada com as saídas no primeiro trecho da tubulação (PCLLS1).

5.3.19. Determinar a perda de carga localizada com as linhas de derivação distribuída por metro no primeiro trecho da tubulação (PCLELS1M).

5.3.20. Determinar a somatória da perda de carga localizada com as linhas de derivação no primeiro trecho da tubulação (PCLELST1).

5.3.21. Determinar a perda de carga localizada na válvula reguladora de pressão (PCLCV1), perda de carga localizada no registro de gaveta (PCLCR1) e a perda de carga localizada no filtro de tela (PCLCF1).

5.3.22. Perda de carga total no primeiro trecho da linha secundária (hfLS1), dado em mca.

5.3.23. Perda de carga total distribuída por metro no primeiro trecho da linha secundária (hfLS1M), dado em mca.

5.4. Dimensionamento do trecho 2 da linha secundária. 
5.4.1. Determinar a vazão no inicio do segundo trecho da linha secundária (QILST2), dado em metros cúbicos por hora.

5.4.2. Determinar a vazão distribuída por emissão no segundo trecho da linha secundária (QILS2T), dado em metros cúbicos por hora.

5.4.3. Determinar a vazão fictícia distribuída por metro no segundo trecho da linha secundária (QILS2M), dado em metros cúbicos por hora.

5.4.4. Determinar a velocidade no inicio do segundo trecho da linha secundária (VILST2), dado em metros por segundo.

5.4.5. Determinar a velocidade distribuída por derivação no segundo trecho da linha secundária (VILS2T), dado em metros cúbicos por hora.

5.4.6. Determinar a velocidade fictícia distribuída por metro no segundo trecho da linha secundária (VILS2M), dado em metros cúbicos por hora.

5.4.7. Determinar a energia cinética por emissor no segundo trecho da linha secundária (ECINETLS2T).

5.4.8. Determinar a energia cinética por metro no segundo trecho da linha secundária (ECINETLS2M).

5.4.9. Número de Reynolds para o segundo trecho da linha secundária (RELST2).

5.4.10. Número de Reynolds distribuído para o segundo trecho da linha secundária (RELS2).

5.4.11. Número de Reynolds distribuído por metro para o segundo trecho da linha secundária (RELS2M). 
5.4.12. Coeficiente de atrito de Swamee-Jain para o segundo trecho da linha secundária (fSJTLS2).

5.4.13. Coeficiente de atrito de Swamee-Jain distribuído por metro para o segundo trecho da linha secundária (fSJTLS2M).

5.4.14. Determinar a perda de carga unitária para o segundo trecho da linha secundária (jLST2).

5.4.15. Determinar a perda de carga unitária distribuída por metro para o segundo trecho da linha secundária (jLST2M).

5.4.16. Determinar a perda de carga localizada com as saídas no segundo trecho da tubulação (PCLLS2).

5.4.17. Determinar a perda de carga localizada com as linhas de derivação distribuída por metro no segundo trecho da tubulação (PCLELS2M).

5.4.18. Determinar a somatória da perda de carga localizada com as linhas de derivação no segundo trecho da tubulação (PCLELST2).

5.4.19. Determinar a Perda de carga localizada na válvula reguladora de pressão (PCLCV2), perda de carga localizada no registro de gaveta (PCLCR2) e a perda de carga localizada no filtro de tela (PCLCF2).

5.4.20. Determinar a perda de carga total no segundo trecho da linha secundária (hfLS2), dado em mca.

5.4.21. Determinar a perda de carga total distribuída por metro no segundo trecho da linha secundária (hfLS2M), dado em mca.

5.5. Dimensionamento do trecho 3 da linha secundária. 
5.5.1. Determinar a vazão no inicio do terceiro trecho da linha secundária (QILST3), dado em metros cúbicos por hora.

5.5.2. Determinar a vazão distribuída por emissão no terceiro trecho da linha secundária (QILS3T), dado em metros cúbicos por hora.

5.5.3. Determinar a vazão fictícia distribuída por metro no terceiro trecho da linha secundária (QILS3M), dado em metros cúbicos por hora.

5.5.4. Determinar a velocidade no inicio do terceiro trecho da linha secundária (VILST3), dado em metros por segundo.

5.5.5. Determinar a velocidade distribuída por derivação no terceiro trecho da linha secundária (VILS3T), dado em metros cúbicos por hora.

5.5.6. Determinar a velocidade fictícia distribuída por metro no terceiro trecho da linha secundária (VILS3M), dado em metros cúbicos por hora.

5.5.7. Determinar a energia cinética por emissor no terceiro trecho da linha secundária (ECINETLS3T).

5.5.8. Determinar a energia cinética por metro no terceiro trecho da linha secundária (ECINETLS3M).

5.5.9. Número de Reynolds para o terceiro trecho da linha secundária (RELST3).

5.5.10. Número de Reynolds distribuído para o terceiro trecho da linha secundária (RELS3).

5.5.11. Número de Reynolds distribuído por metro para o terceiro trecho da linha secundária (RELS3M). 
5.5.12. Coeficiente de atrito de Swamee-Jain para o terceiro trecho da linha secundária (fSJTLS3).

5.5.13. Coeficiente de atrito de Swamee-Jain distribuído por metro para o terceiro trecho da linha secundária (fSJTLS3M).

5.5.14. Determinar a perda de carga unitária para o terceiro trecho da linha secundária (jLST3).

5.5.15. Determinar a perda de carga unitária distribuída por metro para o segundo trecho da linha secundária (jLST3M).

5.5.16. Determinar a perda de carga localizada com as saídas no terceiro trecho da tubulação (PCLLS3).

5.5.17. Determinar a perda de carga localizada com as linhas de derivação distribuída por metro no terceiro trecho da tubulação (PCLELS3M).

5.5.18. Determinar a somatória da perda de carga localizada com as linhas de derivação no terceiro trecho da tubulação (PCLELST3).

5.5.19. Determinar a perda de carga localizada na válvula reguladora de pressão (PCLCV3), perda de carga localizada no registro de gaveta (PCLCR3) e a perda de carga localizada no filtro de tela (PCLCF3).

5.5.20. Determinar a perda de carga total no terceiro trecho da linha secundária (hfLS3), dado em mca.

5.5.21. Determinar a perda de carga total distribuída por metro no terceiro trecho da linha secundária (hfLS3M), dado em mca.

5.6. Dimensionamento do trecho 4 da linha secundária 
5.6.1. Determinar a vazão no inicio do quarto trecho da linha secundária (QILST4), dado em metros cúbicos por hora.

5.6.2. Determinar a vazão distribuída por emissão no quarto trecho da linha secundária (QILS4T), dado em metros cúbicos por hora.

5.6.3. Determinar a vazão fictícia distribuída por metro no quarto trecho da linha secundária (QILS4M), dado em metros cúbicos por hora.

5.6.4. Determinar a velocidade no inicio do quarto trecho da linha secundária (VILST4), dado em metros por segundo.

5.6.5. Determinar a velocidade distribuída por derivação no quarto trecho da linha secundária (VILS4T), dado em metros cúbicos por hora.

5.6.6. Determinar a velocidade fictícia distribuída por metro no quarto trecho da linha secundária (VILS4M), dado em metros cúbicos por hora.

5.6.7. Determinar a energia cinética por emissor no quarto trecho da linha secundária (ECINETLS4T).

5.6.8. Determinar a energia cinética por metro no quarto trecho da linha secundária (ECINETLS4M).

5.6.9. Número de Reynolds para o quarto trecho da linha secundária (RELST4).

5.6.10. Número de Reynolds distribuído para o quarto trecho da linha secundária (RELS4).

5.6.11. Número de Reynolds distribuído por metro para o quarto trecho da linha secundária (RELS4M).

5.6.12. Coeficiente de atrito de Swamee-Jain para o quarto trecho da linha secundária (fSJTLS4). 
5.6.13. Coeficiente de atrito de Swamee-Jain distribuído por metro para o quarto trecho da linha secundária (fSJTLS4M).

5.6.14. Determinar a perda de carga unitária para o quarto trecho da linha secundária (jLST4).

5.6.15. Determinar a perda de carga unitária distribuída por metro para o segundo trecho da linha secundária (jLST4M).

5.6.16. Determinar a perda de carga localizada com as saídas no quarto trecho da tubulação (PCLLS4).

5.6.17. Determinar a perda de carga localizada com as linhas de derivação distribuída por metro no quarto trecho da tubulação (PCLELS4M).

5.6.18. Determinar a somatória da perda de carga localizada com as linhas de derivação no quarto trecho da tubulação (PCLELST4).

5.6.19. Determinar da perda de carga localizada na válvula reguladora de pressão (PCLCV4), perda de carga localizada no registro de gaveta (PCLCR4) e da perda de carga localizada no filtro de tela (PCLCF4).

5.6.20. Determinar a perda de carga total no quarto trecho da linha secundária (hfLS4), dado em mca.

5.6.21. Determinar a perda de carga total distribuída por metro no quarto trecho da linha secundária (hfLS4M), dado em mca.

5.7. Diferença entre as perdas de carga em cada trecho de cada tubulação da linha secundária.

5.7.1. Determinar a diferença entre as perdas de carga distribuídas por saída para linha de derivação (DhfLS). 
5.7.2. Determinar a diferença entre as perdas de carga distribuídas por metro (DhfLSM).

5.8. Perda de carga localizada com a contração da tubulação.

5.8.1. Determinar a relação entre a área da segunda com a primeira tubulação da linha secundária (RA2A1LS).

5.8.2. Determinar a relação entre a área da terceira com a segunda tubulação da linha secundária (RA3A2LS).

5.8.3. Determinar a relação entre a área da quarta com a terceira tubulação da linha secundária (RA4A3LS).

5.8.4. Determinar o coeficiente k1 para reduções bruscas de diâmetro da tubulação da linha secundária (KA2A1LS).

5.8.5. Determinar o coeficiente $\mathrm{k} 2$ para reduções bruscas de diâmetro da tubulação da linha secundária (KA3A2LS).

5.8.6. Determinar o coeficiente $\mathrm{k} 3$ para reduções bruscas de diâmetro da tubulação da linha secundária (KA4A3LS).

5.8.7. Determinar a perda de carga localizada para a contração da tubulação D1 para Di2 da linha secundária (PCLA2A1LS), dado em mca.

5.8.8. Determinar a perda de carga localizada para a contração da tubulação Di2 para Di3 da linha secundária (PCLA3A2LS), dado em mca.

5.8.9. Determinar a perda de carga localizada para a contração da tubulação Di3 para Di4 da linha secundária (PCLA4A3LS), dado em mca. 
5.9. Perda de carga total na linha secundária com quatro diâmetros

5.9.1. Determinar a perda de carga total na linha secundária com quatro diâmetros (PCTLS), dado em mca.

5.10. Pressão requerida na entrada da linha secundária com quatro diâmetros.

5.10.1. Determinar a pressão requerida na entrada da linha secundária com quatro diâmetros (PRELS), dado em mca.

5.11. Energia total requerida na entrada da linha secundária com quatro diâmetros.

5.11.1. Determinar a energia total requerida na entrada da linha secundária com quatro diâmetros (ERELS), dado em mca.

6. Dimensionamento da linha principal (Adutora).

6.1. Pré-dimensionamento da linha de principal.

6.1.1. Determinar a pressão requerida no final da linha principal (PRFLP), dado em mca.

6.1.2. Determinar a área do tubo com D1 (ADLP), dado em metros quadrados.

6.1.3. Determinar o espaçamento entre as linhas secundárias (EES), dado em metros.

6.1.4. Determinar o espaçamento da tomada de água ate a primeira linha secundária (E1P), dado em metros.

6.1.5. Determinar o espaçamento da tomada de água ate a segunda linha 
6.1.6. Determinar o espaçamento da tomada de água ate a terceira linha secundária (E3P), dado em metros.

6.1.7. Determinar o número total de linhas secundárias acopladas na linha principal (NTS).

6.1.8. Determinar à razão da distância do começo da linha principal a primeira saída em relação das eqüidistâncias das outras saídas entre si (xLP).

6.2. Dimensionamento da linha principal (adutora).

6.2.1. Determinar a vazão no inicio da linha principal (QILPT), dado em metros cúbicos por hora.

6.2.2. Determinar a vazão distribuída na linha principal (QILP), dado em metros cúbicos por hora.

6.2.3. Determinar a velocidade no inicio da linha principal (VILPT), dado em metros por segundo.

6.2.4. Determinar a velocidade distribuída na linha principal (VILP), dado em metros por segundo.

6.2.5. Determinar a energia cinética por emissor na linha principal (ECINETLPT).

6.2.6. Determinar a energia cinética por metro na linha principal (ECINETLP).

6.2.7. Determinar o número de Reynolds para a linha principal (RELPT).

6.2.8. Determinar o número de Reynolds distribuído para a linha principal (RELP). 
6.2.9. Determinar o coeficiente de atrito de Swamee-Jain para a linha principal (fSJTLPT).

6.2.10. Determinar o coeficiente de atrito de Swamee-Jain para a linha principal (fSJTLP).

6.2.11. Determinar a perda de carga unitária para linha principal (jLPT).

6.2.12. Determinar a perda de carga unitária para linha principal (jLP).

6.2.13. Determinar a perda de carga localizada com as saídas das laterais na tubulação (PCLLPT).

6.2.14. Determinar a perda de carga localizada distribuída por emissão com as saídas das laterais na tubulação (PCLLP).

6.2.15. Determinar a perda de carga localizada no registro de gaveta (PCLPCR).

6.3. Perda de carga total na tubulação da linha principal.

6.3.1. Determinar a perda de carga total na tubulação da linha principal (PCTLPT), dado em mca.

6.3.2. Determinar a perda de carga distribuída por emissão na tubulação da linha principal (PCTLP), dado em mca.

6.4. Pressão requerida na entrada da linha principal com um diâmetro.

6.4.1. Determinar a pressão requerida na entrada da linha principal com um diâmetro (PRELP), dado em mca.

6.5. Energia total requerida na entrada da linha principal com quatro diâmetros. 
6.5.1. Determinar a energia total requerida na entrada da linha principal com quatro diâmetros (ERELP), dado em mca.

7. Dimensionamento da linha de sucção.

7.1. Pré-dimensionamento da linha de sucção.

7.1.1. Determinar a área do tubo com D1 (ADLSU), dado em metros quadrados.

7.2. Dimensionamento da linha de sucção

7.2.1. Determinar a vazão no inicio da linha de sucção (QILSUT), dado em metros cúbicos por hora.

7.2.2. Determinar a velocidade no inicio da linha de sucção (VILSUT), dado em metros por segundo.

7.2.3. Determinar a energia cinética por emissor na linha principal (ECINETLSUT).

7.2.4. Determinar o número de Reynolds para o primeiro trecho da linha de sucção (RELSUT).

7.2.5. Determinar o coeficiente de atrito de Swamee-Jain para a linha de sucção (fSJTLSU).

7.2.6. Determinar a perda de carga unitária para linha de sucção (jLSUT).

7.2.7. Determinar a perda de carga localizada com a válvula de pé com crivo (PCLLSU).

7.3. Perda de carga total na tubulação da linha de sucção. 
7.3.1. Determinar a Perda de carga total na tubulação da linha de sucção (PCTLSU), dado em mca.

8. Altura manométrica total da rede.

8.1. Determinar a carga hidráulica de pressão total (HMT), dado em mca.

9. Energia cinética total na tubulação de recalque (carga cinética total).

9.1. Determinar a carga cinética total na tubulação de recalque (ECTR), dado em mca.

10. Energia cinética na tubulação de sucção (carga cinética de sucção).

10.1. Determinar a carga cinética de sucção (ECTSU), dado em mca.

11. Energia total (cargas totais).

11.1. Determinar a energia para o bombeamento (resultante da somatória dos desníveis de cada tubulação (HET), mais as perdas de carga distribuídas e localizadas mais a diferença de (energia cinética do recalque e da sucção), dado em mca.

12. Vazão recalcada, produtividade, volume de água aplicado e área útil irrigada.

12.1. Determinar a vazão total recalcada (QTRM3H), dado em metros cúbicos por hora.

12.2. Determinar a vazão total recalcada (QTRM3S), dado em metros cúbicos por segundo. 
12.3. Determinar a vazão total recalcada (QTRLS), dado em litros por segundo.

12.4. Determinar a produção de planta por lamina de água aplicada (FPPL), dado em kg por planta por litro. Função de produção - relação entre a produtividade de cada árvore e o volume de água aplicado por árvore.

12.5. Determinar quantos metros quadrados tem por planta (M2P).

12.6. Determinar o número de plantas por linha lateral (NPLLL).

12.7. Determinar o número de plantas por unidade operacional (NPUO).

12.8. Determinar o número de plantas na área total a ser irrigada (NPAT).

12.9. Determinar o volume de água aplicado na unidade operacional (VAGUO), dado em metros cúbicos por ano por unidade operacional.

12.10. Determinar o volume de água aplicado na área total (VAGAT), dado em metros cúbicos por ano na área.

12.11. Determinar a área útil irrigada (AUI), dado em hectares.

13. Conjunto motobomba.

13.1. Determinar a potência necessária ao funcionamento da bomba (POTKW), dado em kilowatt.

13.2. Determinar a potência necessária ao funcionamento da bomba (POTCV), dado em cavalo-vapor.

13.3. Determinar a quantidade de tempo de funcionamento da bomba (NS), dado em horas por ano.

13.4. Determinar o consumo total de energia (CTEKW), dado em kilowatt por ano. 
13.5. Determinar o consumo total de energia (CTECV), dado em cavalo-vapor por ano.

13.6. Determinar a tarifa de energia elétrica no setor rural com desconto (TSRCD), para uso entre $21 \mathrm{~h} 30 \mathrm{~min}$ as $06 \mathrm{~h} 00 \mathrm{~min}$.

14. Comprimento total das tubulações.

14.1. Comprimentos das tubulações nas linhas laterais.

14.1.1. Determinar o comprimento total da tubulação de polietileno com diâmetro Di1 na unidade operacional (LLLD1UO), dado em metros.

14.1.2. Determinar o comprimento total da tubulação de polietileno com diâmetro Di2 na unidade operacional (LLLD2UO), dado em metros.

14.1.3. Determinar o comprimento total das tubulações de polietileno na unidade operacional (LLLTUO), dado em metros.

14.1.4. Determinar o comprimento total da tubulação de polietileno com diâmetro Di1 em toda a rede de distribuição (LLLD1), dado em metros.

14.1.5. Determinar o comprimento total da tubulação de polietileno com diâmetro Di2 em toda a rede de distribuição (LLLD2), dado em metros.

14.1.6. Determinar o comprimento total das tubulações de polietileno em toda a rede de distribuição (LLLT), dado em metros.

14.2. Comprimentos das tubulações nas linhas de derivação. 
14.2.1. Determinar o comprimento total da tubulação de PVC com diâmetro Di1 em cada linha secundária (LLDD1UO), dado em metros.

14.2.2. Determinar o comprimento total da tubulação de PVC com diâmetro Di2 em cada linha secundária (LLDD2UO), dado em metros.

14.2.3. Determinar o comprimento total da tubulação de PVC com diâmetro Di3 em cada linha secundária (LLDD3UO), dado em metros.

14.2.4. Determinar o comprimento total da tubulação de PVC com diâmetro Di4 em cada linha secundária (LLDD4UO), dado em metros.

14.2.5. Determinar o comprimento total das tubulações de PVC em cada linha secundária (LLDTUO), dado em metros.

14.2.6. Determinar o comprimento total da tubulação de PVC com diâmetro Di1 em toda a rede de distribuição (LLDD1), dado em metros.

14.2.7. Determinar o comprimento total da tubulação de PVC com diâmetro Di2 em toda a rede de distribuição (LLDD2), dado em metros.

14.2.8. Determinar o comprimento total da tubulação de PVC com diâmetro Di3 em toda a rede de distribuição (LLDD3), dado em metros. 
14.2.9. Determinar o comprimento total da tubulação de PVC com diâmetro Di4 em toda a rede de distribuição (LLDD4), dado em metros.

14.2.10. Determinar o comprimento total das tubulações de PVC em toda a rede de distribuição (LLDT), dado em metros.

14.3. Comprimentos das tubulações nas linhas secundárias.

14.3.1. Determinar o comprimento total da tubulação de PVC com diâmetro Di1 nas linhas secundárias (LLSD1), dado em metros.

14.3.2. Determinar o comprimento total da tubulação de PVC com diâmetro Di2 nas linhas secundárias (LLSD2), dado em metros.

14.3.3. Determinar o comprimento total da tubulação de PVC com diâmetro Di3 nas linhas secundárias (LLSD3), dado em metros.

14.3.4. Determinar o comprimento total da tubulação de PVC com diâmetro Di4 nas linhas secundárias (LLSD4), dado em metros.

14.3.5. Determinar o comprimento total das tubulações de PVC nas linhas secundárias (LLST), dado em metros.

14.4. Comprimento da tubulação na linha principal.

14.4.1. Determinar o comprimento total da tubulação de PVC na linha principal (LLPT), dado em metros.

14.5. Comprimento da tubulação da linha de sucção.

14.5.1. Determinar o comprimento total da tubulação de PVC na linha de sucção (LLSUT), dado em metros. 
14.6. Comprimento total de tubulações de PVC.

14.6.1. Determinar o comprimento total da tubulação de PVC em toda a rede (LLTPVC), dado em metros.

14.7. Comprimento total de todas as tubulações da rede de distribuição de água 14.7.1. Determinar o comprimento total de tubulações no sistema de irrigação (LLT), dado em metros

15. Quantidade total de acessórios e equipamentos utilizados na rede de irrigação. (Serão considerados como valor igual a uma unidade todos os componentes da rede de irrigação não descritos nesta seção)

15.1. Acessórios na linha lateral.

15.1.1. Determinar o número de emissores na unidade operacional (NEUO).

15.1.2. Determinar o número total de emissores em toda a rede de irrigação (NERI).

15.1.3. Determinar o número de redutores de diâmetros na linha lateral na unidade operacional (NRD1D2LUO).

15.1.4. Determinar o número de redutores de diâmetros nas linhas laterais de toda a rede de irrigação (NRD1D2LRI).

15.1.5. Determinar o número de anéis de fim de linha da linha lateral na unidade operacional (NAFLLUO).

15.1.6. Determinar o número de anéis de fim de linha da linha lateral em toda a rede de irrigação (NAFLLRI). 
15.2. Acessórios na linha de derivação.

15.2.1. Determinar o número de conectores de saída da linha de derivação para linha lateral na unidade operacional (NCSLLUO).

15.2.2. Determinar o número de conectores de saída para linha lateral na rede de irrigação (NCSLLRI).

15.2.3. Determinar o número de redutores de diâmetros D1D2 nas linhas de derivação de toda a rede de irrigação (NRD1D2DRI).

15.2.3. Determinar o número de redutores de diâmetros D2D3 nas linhas de derivação de toda a rede de irrigação (NRD2D3DRI).

15.2.4. Determinar o número de redutores de diâmetros D3D4 nas linhas de derivação de toda a rede de irrigação (NRD3D4DRI).

15.2.5. Determinar o número tampões de fim de linha das linhas de derivação em toda a rede de irrigação (NTFLDRI).

15.3. Acessórios na linha secundária.

15.3.1. Determinar o número de filtros de tela nas linhas secundárias de toda a rede de irrigação (NFTLS).

15.3.2. Determinar o número válvulas reguladoras de pressão nas linhas secundárias de toda a rede de irrigação (NVRPLS).

15.3.3. Determinar o número de registros de gaveta nas linhas secundárias de toda a rede de irrigação (NRGLS).

15.3.4. Determinar o número de conectores com curva de 90 graus nas linhas secundárias de toda a rede de irrigação (NC90LS). 
15.3.5. Determinar o número de conectores te nas linhas secundárias de toda a rede de irrigação (NCTLS).

15.3.6. Determinar o número de redutores de diâmetros D1D2 nas linhas secundárias de toda a rede de irrigação (NRD1D2SRI).

15.3.7. Determinar o número de redutores de diâmetros D2D3 nas linhas secundárias de toda a rede de irrigação (NRD2D3SRI).

15.3.8. Determinar o número de redutores de diâmetros D3D4 nas linhas secundárias de toda a rede de irrigação (NRD3D4SRI).

15.4. Acessórios na linda principal.

15.4.1. Determinar o número de registros de gaveta na linha principal (NRGLP).

15.4.2. Determinar o número de conectores te da linha principal para a linha secundária (NCTLP).

15.5. Demais componentes da rede de irrigação.

15.5.1. Determinar o número de bisnagas de cola de PVC para as conexões da rede (NCPVC).

16. Custos com equipamentos de irrigação.

16.1. Custos com equipamentos da linha lateral.

16.1.1. Determinar o custo total com emissores (CTTE), dado em reais.

16.1.2. Determinar o custo total com redutores de diâmetro nas linhas laterais (CTRDLL), dado em reais. 
16.1.3. Determinar o custo total com anéis fim de linha nas linhas laterais (CTANELFL), dado em reais.

16.1.4. Determinar o custo total das linhas laterais com Di1 (CTLLD1), dado em reais.

16.1.5. Determinar o custo total das linhas laterais com Di2 (CTLLD2), dado em reais.

16.1.6. Determinar o custo total da linha lateral com Di1 e Di2 (CTLLD1D2), dado em reais.

16.1.7. Determinar o custo total de toda linha lateral (CTLLL), dado em reais.

16.2. Custos com equipamentos da linha de derivação.

16.2.1. Determinar o custo total dos conectores das linhas de derivação nas linhas laterais (CTCSLL), dado em reais.

16.2.2. Determinar o custo total dos redutores de diâmetro Di1 para D2 das linhas de derivação (CTRDLD1), dado em reais.

16.2.3. Determinar o custo total dos redutores de diâmetro Di2 para D3 das linhas de derivação (CTRDLD2), dado em reais.

16.2.4. Determinar o custo total dos redutores de diâmetro Di3 para D4 das linhas de derivação (CTRDLD3), dado em reais.

16.2.5. Determinar o custo total dos tampões fim de linha das linhas de derivação (CTTFL), dado em reais.

16.2.6. Determinar o custo total das linhas de derivação de diâmetro Di1 (CTLDD1), dado em reais. 
16.2.7. Determinar o custo total das linhas de derivação de diâmetro Di2 (CTLDD2), dado em reais.

16.2.8. Determinar o custo total das linhas de derivação de diâmetro Di3 (CTLDD3), dado em reais.

16.2.9. Determinar o custo total das linhas de derivação de diâmetro Di4 (CTLDD4), dado em reais.

16.2.10. Determinar o custo total das linhas de derivação (Di1maisDi2maisDi3maisDi4) (CTLDDN), dado em reais.

16.2.11. Determinar o custo total de toda linha de derivação (CTLDD), dado em reais.

16.3. Custos com equipamentos da linha secundária.

16.3.1. Determinar o custo total dos filtros de tela nas linhas secundárias (CTFT), dado em reais.

16.3.2. Determinar o custo total das válvulas reguladoras de pressão nas linhas secundárias (CTVRPLS), dado em reais.

16.3.3. Determinar o custo total dos registros nas linhas secundárias (CTRLS), dado em reais.

16.3.4. Determinar o custo total das curvas de 90 graus nas linhas secundárias (CTCULS), dado em reais.

16.3.5. Determinar o custo total das conexões te nas linhas secundárias (CTCTDLS), dado em reais.

16.3.6. Determinar o custo total dos redutores de diâmetro Di1 para Di2 das linhas secundárias (CTRDLS1), dado em reais. 
16.3.7. Determinar o custo total dos redutores de diâmetro Di2 para Di3 das linhas secundárias (CTRDLS2), dado em reais.

16.3.8. Determinar o custo total dos redutores de diâmetro Di3 para Di4 das linhas secundárias (CTRDLS3), dado em reais.

16.3.9. Determinar o custo total das linhas secundárias de diâmetro Di1 (CTLSD1), dado em reais.

16.3.10. Determinar o custo total das linhas secundárias de diâmetro Di2 (CTLSD2), dado em reais.

16.3.11. Determinar o custo total das linhas secundárias de diâmetro Di3 (CTLSD3), dado em reais.

16.3.12. Determinar o custo total das linhas secundárias de diâmetro Di4 (CTLSD4), dado em reais.

16.3.13. Determinar o custo total das linhas secundárias (Di1maisDi2maisDi3maisDi4) (CTLSDN), dado em reais.

16.3.14. Determinar o custo total de toda linha secundárias (CTLSD), dado em reais.

16.4. Custos com equipamentos da linha principal.

16.4.1. Determinar o custo total dos registros da linha principal (CTRLP), dado em reais.

16.4.2. Determinar o custo total da conexão te de final de linha (CTCTFLP), dado em reais.

16.4.3. Determinar o custo total da conexão te de meio de linha (CTCTDLP), dado em reais. 
16.4.4. Determinar o custo total da linha principal de diâmetro Di1 (CTLPDI), dado em reais.

16.4.5. Determinar o custo total de toda linha principal (CTLPD), dado em reais.

16.5. Custos com equipamentos do cabeçal de controle.

16.5.1. Determinar o custo total do filtro de disco (CTFD), dado em reais.

16.5.2. Determinar o custo total do filtro de areia (CTFA), dado em reais.

16.5.3. Determinar o custo total do registro (CTRG), dado em reais.

16.5.4. Determinar o custo total injetor Venturi (CTIV), dado em reais.

16.5.5. Determinar o custo total do painel de controle (CTPC), dado em reais.

16.5.6. Determinar o custo total do hidrômetro (CTH), dado em reais.

16.5.7. Determinar o custo total do manômetro (CTM), dado em reais.

16.5.8. Determinar o custo total dos componentes do cabeçal de controle (CTCC), dado em reais.

16.6. Custos com equipamentos do conjunto motobomba.

16.6.1. Determinar o custo total da ampliação excêntrica (CTAE), dado em reais.

16.6.2. Determinar o custo total da redução excêntrica (CTRE), dado em reais.

16.6.3. Determinar o custo total do conjunto motobomba (CTMB), dado em reais. 
16.6.4. Determinar o custo total do motobomba e seus acessórios (CTCMB), dado em reais.

16.7. Custos com demais componentes da rede de irrigação.

16.7.1. Determinar o custo total do cotovelo de 90 graus da tubulação de sucção (CTC90), dado em reais.

16.7.2. Determinar o custo total da válvula de pé com crivo (CTVPC), dado em reais.

16.7.3. Determinar o custo total da tubulação de sucção de Di (CTTS), dado em reais.

16.7.4. Determinar o custo total das bisnagas de cola de PVC (CTCPVC), dado em reais.

16.8. Custo fixo total da rede de irrigação.

16.8.1. Determinar o custo total com equipamentos de irrigação (CEQ), dado em reais.

17. Fator de recuperação do capital.

17.1. Determinar o fator de recuperação do capital (FRC) para o cálculo do custo total da rede.

18. Custos variáveis.

18.1. Determinar o custo total de funcionamento do conjunto motobomba, dado em reais por ano. 
18.2. Determinar o custo total da água na unidade operacional (CAUO), dado em reais por ano por unidade operacional.

18.3. Determinar o custo total da água na área total (CAGT), dado em reais por ano para a área.

19. Custos por hectare por ano.

19.1. Determinar o custo fixo por hectare por ano.

19.2. Determinar o custo com energia elétrica por hectare por ano.

19.3. Determinar o custo com água por hectare por ano.

20. Custo total da rede (função objetivo).

20.1. Minimizar o custo total da rede de irrigação (f), dado em reais por hectare por ano. 


\title{
APÊNDICE D
}

Arquivo frestricoes.m, em que constam as restrições do dimensionamento hidráulico da rede.

$\%$

$\% \%$ Otimização de Rede de Irrigação Localizada por Algoritmo Genético

$\%$ LHC - Laboratório de Hidráulica Computacional

\% Departamento de Hidráulica e Saneamento (SHS) - Escola de Engenharia

\% de São Carlos (EESC) - Universidade de São Paulo (USP)

$\%$ Francisco Marcuzzo (E-mail: fmarcuzzo@gmail.com)

$\% \%$

function $[\mathrm{c}, \mathrm{ceq}]=$ frestricoes $(\mathrm{x})$

\% Valores "iniciais" de "x" para teste de solução factível. Se rodar apenas a função $\%$ "frestricoes" e retornar um vetor negativo na janela Command Window do MatLab a \% solução e factível, se o vetor conter um ou mais valores positivos a solução não e $\%$ factível para as restrições estabelecidas.

$\% \mathrm{x}=[47.25070524,48.99929476,50.62320014,27.73078628,31.00370121, \ldots$

$\%$ 25.64231237,105.0127933,195.6670515,205.2241827,194.0959724];

[VILLT1, VILLT2, VILDT1, VILDT2, VILDT3, VILDT4, VILST1, VILST2,... VILST3, VILST4, PCTLLT, PCTLDT, DHV, he, UEST] = fnonlin(x) ;

\author{
$\mathrm{c}=[-$ VILLT1; \\ -VILLT1+0; \\ VILLT1-1.5; \\ -VILLT2; \\ -VILLT2+0; \\ VILLT2-1.5; \\ -VILDT1; \\ -VILDT1+0; \\ VILDT1-2.5; \\ -VILDT2; \\ -VILDT2+0; \\ VILDT2-2.5; \\ -VILDT3; \\ -VILDT3+0; \\ VILDT3-2.5; \\ -VILDT4; \\ -VILDT4+0; \\ VILDT4-2.5; \\ -VILST1;
}




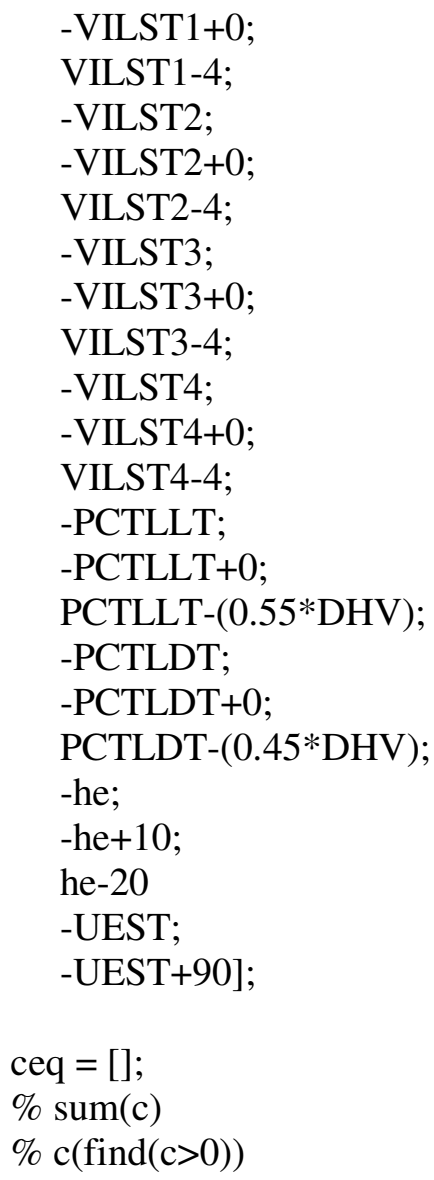




\section{APÊNDICE E}

Arquivo fchamativadef.m, responsável por ativar os outros arquivos, ou seja, pelo funcionamento de todo o código.

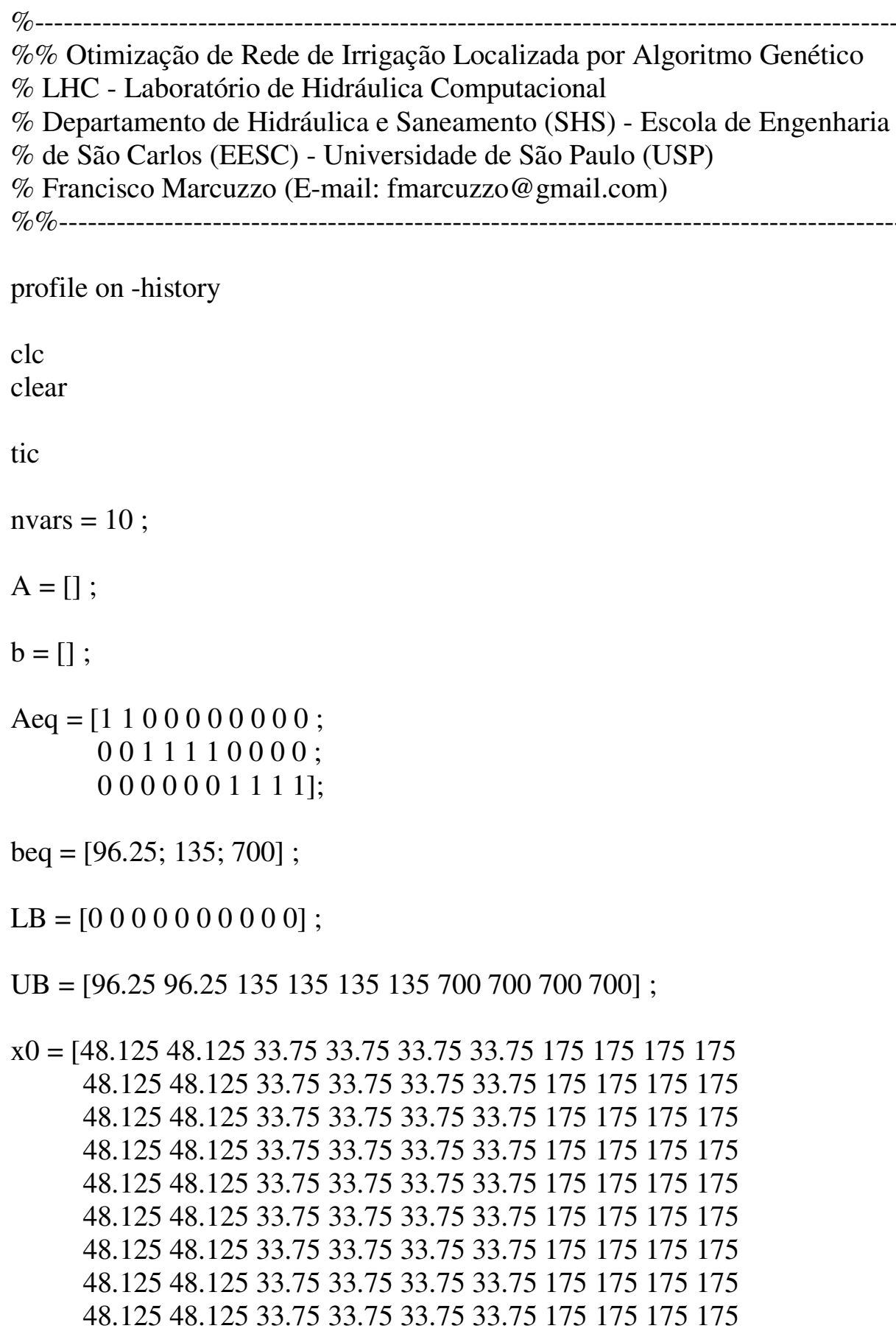


48.12548 .12533 .7533 .7533 .7533 .75175175175175 48.12548 .12533 .7533 .7533 .7533 .75175175175175 48.12548 .12533 .7533 .7533 .7533 .75175175175175 48.12548 .12533 .7533 .7533 .7533 .75175175175175 48.12548 .12533 .7533 .7533 .7533 .75175175175175 48.12548 .12533 .7533 .7533 .7533 .75175175175175 48.12548 .12533 .7533 .7533 .7533 .75175175175175 48.12548 .12533 .7533 .7533 .7533 .75175175175175 48.12548 .12533 .7533 .7533 .7533 .75175175175175 48.12548 .12533 .7533 .7533 .7533 .75175175175175 48.12548 .12533 .7533 .7533 .7533 .75175175175175 48.12548 .12533 .7533 .7533 .7533 .75175175175175 48.12548 .12533 .7533 .7533 .7533 .75175175175175 48.12548 .12533 .7533 .7533 .7533 .75175175175175 48.12548 .12533 .7533 .7533 .7533 .75175175175175 48.12548 .12533 .7533 .7533 .7533 .75175175175175 48.12548 .12533 .7533 .7533 .7533 .75175175175175 48.12548 .12533 .7533 .7533 .7533 .75175175175175 48.12548 .12533 .7533 .7533 .7533 .75175175175175 48.12548 .12533 .7533 .7533 .7533 .75175175175175 48.12548 .12533 .7533 .7533 .7533 .75175175175175 48.12548 .12533 .7533 .7533 .7533 .75175175175175 48.12548 .12533 .7533 .7533 .7533 .75175175175175 48.12548 .12533 .7533 .7533 .7533 .75175175175175 48.12548 .12533 .7533 .7533 .7533 .75175175175175 48.12548 .12533 .7533 .7533 .7533 .75175175175175 48.12548 .12533 .7533 .7533 .7533 .75175175175175 48.12548 .12533 .7533 .7533 .7533 .75175175175175 48.12548 .12533 .7533 .7533 .7533 .75175175175175 48.12548 .12533 .7533 .7533 .7533 .75175175175175 48.12548 .12533 .7533 .7533 .7533 .75175175175 175];

options.MaxFunEvals = Inf ;

options = gaoptimset $(\ldots$

'PopulationType','doubleVector',...

'PopulationSize',50,...

'EliteCount',2,...

'PopInitRange',[],...

'CrossoverFraction', $0.8, \ldots$

'MigrationDirection','both',...

'MigrationInterval',20,...

'MigrationFraction', $0.2, \ldots$

'Generations',2000,...

'TimeLimit', \{\}$, \ldots$.

'FitnessLimit',-Inf,...

'StallGenLimit',500,...

'StallTimeLimit',1e100000,...

'TolFun',1e-1000,...

'TolCon', \{\}$, \ldots$ 
'InitialPopulation',x0,...

'InitialScores',[],...

'InitialPenalty', \{\}$, \ldots$

'PenaltyFactor', \{\}$, \ldots$

'CreationFcn', @gacreationuniform,...

'FitnessScalingFcn', @ fitscalingrank,...

'SelectionFcn',@ selectionroulette,...

'CrossoverFcn',@ crossoverarithmetic,...

'MutationFcn',@ mutationadaptfeasible,...

'DistanceMeasureFcn', \{\}$, \ldots$

'HybridFen', \{\}$, \ldots$

'Display','diagnose',...

'OutputFens',@gaoutputgen,...

'PlotFcns',\{@gaplotbestf,@gaplotstopping,@gaplotdistance,@gaplotexpectation,

@ gaplotrange,@gaplotscorediversity,@gaplotbestindiv\},...

'PlotInterval', \{\}$, \ldots$

'Vectorized','off');

[x,fval,exitflag,output,population,scores]=ga(@foirriga,nvars,A,b,Aeq,beq,...

LB,UB,@frestricoes,options);

fprintf('O número de gerações foram de: \%d\n', output.generations);

fprintf('O número de funções avaliadas foram de: \%d\n', output.funccount);

fprintf('O menor custo da rede hidráulica de irrigação achado foi de: \%gln', fval);

\%barh(x); \% Imprime um histograma horizontal com os comprimentos de cada

$\%$ trecho otimizado da rede de irrigacao.

$\% \operatorname{grid}\left('{ }^{\prime}{ }^{\prime}\right)$;

\%colormap('summer');

\%title('Comprimento de Cada Trecho da Tubulacao');

$\%$ xlabel('m');

\%ylabel('Tubulacao');

toc

disp('O programa terminou de rodar. Confira os resultados!')

profile viewer

$\mathrm{p}=$ profile ('info');

profsave(p,'profile_results'); 


\section{APÊNDICE F}

Arquivo fanalisedesensibilidade.m, responsável pela análise de sensibilidade das redes otimizadas.

clc

clear

$\% \%$ Dados iniciais de entrada

LLL1 = input ('Digite o comprimento do trecho 1 da linha lateral: $\operatorname{LLL1}(\mathrm{m})=$ ');

LLL2 = input ('Digite o comprimento do trecho 2 da linha lateral: LLL2 $(m)=$ ');

LLD1 = input ('Digite o comprimento do trecho 1 da linha de derivação: LLD1 $(\mathrm{m})=$ ');

LLD2 = input ('Digite o comprimento do trecho 2 da linha de derivação: $\operatorname{LLD} 2(\mathrm{~m})=$ ');

LLD3 = input ('Digite o comprimento do trecho 3 da linha de derivação: LLD3(m)= ');

LLD4 = input ('Digite o comprimento do trecho 4 da linha de derivação: LLD4(m)= ');

LLS1 = input ('Digite o comprimento do trecho 1 da linha secundária: $\operatorname{LLS1}(\mathrm{m})=$ '); LLS2 = input ('Digite o comprimento do trecho 2 da linha secundária: $\operatorname{LLS} 2(\mathrm{~m})=$ '); LLS3 = input ('Digite o comprimento do trecho 3 da linha secundária: LLS3(m)= '); LLS4 = input ('Digite o comprimento do trecho 4 da linha secundária: LLS4(m)= ');

DZLD = input ('Digite o desnível da linha de derivação: DZLD(m/100m) = ');

DZLP = input ('Digite o desnível da linha principal: DZLP(m/100m)= ');

$\mathrm{CA}=$ input ('Digite o custo da água: $\mathrm{CA}(\mathrm{R} \$ / \mathrm{m} 3)=$ ');

$\mathrm{TSR}=$ input ('Digite a tarifa de energia elétrica: $\operatorname{TSR}(\mathrm{R} \$ / \mathrm{kW})=$ ');

Tic

\% Copiar aqui todo o arquivo foirriga.m sem as variáveis do "input" acima citadas.

toc 


\section{ANEXO A}

Neste ANEXO (A), são apresentadas Tabelas, Quadros e Gráficos, elaborados a partir de dados ou equações encontrados na literatura especializada, para serem utilizados na simulação de dimensionamentos e/ou otimização da rede hidráulica do sistema de irrigação localizada através do código desenvolvido.

Quadro 11. Viscosidade cinemática da água segundo a sua temperatura

\begin{tabular}{|c|c|}
\hline $\mathrm{T}\left({ }^{\circ} \mathrm{C}\right)$ & $v\left(\mathrm{~m}^{2} . \mathrm{s}^{-1} \times 10^{-6}\right)$ \\
\hline \hline 0 & 1,787 \\
\hline 5 & 1,519 \\
\hline 10 & 1,307 \\
\hline 15 & 1,140 \\
\hline 20 & 1,004 \\
\hline 25 & 0,893 \\
\hline 30 & 0,801 \\
\hline 35 & 0,742 \\
\hline 40 & 0,658 \\
\hline 45 & 0,602 \\
\hline
\end{tabular}

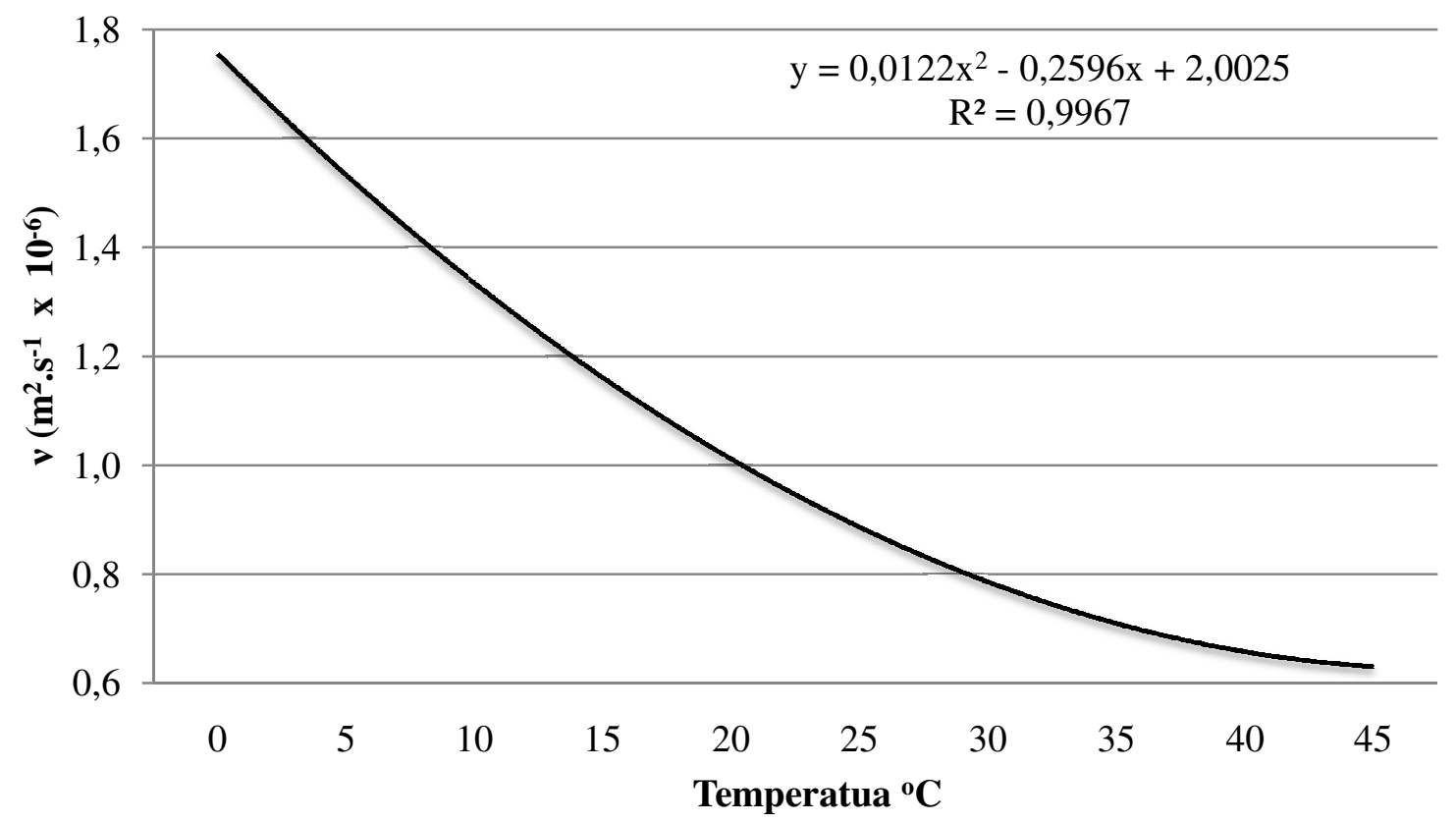

Gráfico 36. Equação da viscosidade cinemática da água segundo a temperatura 
Tabela 26. Propriedades físicas usuais dos solos

\begin{tabular}{lrccc}
\hline & \multicolumn{1}{c}{$\mathrm{VI}^{1}$} & Densidade & $\mathrm{CC}^{2}$ & $\mathrm{PM}^{3}$ \\
\multicolumn{1}{c}{ Tipo de Solo } & $\mathrm{mm} \mathrm{h}^{-1}$ & ${\mathrm{~g}\left(\mathrm{~cm}^{3}\right)^{-1}}$ & $\%$ & $\%$ \\
\hline \hline Arenoso & 5,000 & 1,65 & 9 & 4 \\
& 2,5 até 22,5 & 1,55 até1,80 & 6,0 até 12,0 & 2 até 6 \\
\hline Barro Arenoso & 2,500 & 1,50 & 14 & 6 \\
& 1,3 até 7,6 & 1,40 até 1,60 & 10 até 118 & 4 até 8 \\
\hline Barro & 1,300 & 1,40 & 22 & 10 \\
& 0,8 até 2,0 & 1,35 até 1,50 & 18 até 26 & 8 até 12 \\
\hline Barro Argiloso & 0,800 & 1,35 & 27 & 13 \\
& 0,25 até 1,5 & 1,30 até 1,40 & 23 até 31 & 1 até 11 \\
\hline Argiloso Arenoso & 0,250 & 1,30 & 31 & 15 \\
& 0,03 até 0,5 & 1,25 até 1,35 & 27 até35 & 13 até 17 \\
\hline Argiloso & 0,005 & 1,25 & 35 & 17 \\
& 0,01 até 0,1 & 1,20 até 1,30 & 31 até 39 & 15 até 19 \\
\hline
\end{tabular}

${ }^{1}$ Volume infiltrado no solo.

${ }^{2}$ Capacidade de campo do solo.

${ }^{3}$ Ponto de murcha permanente.

Quadro 12. Margem percentual de segurança recomendável para motores elétricos

\begin{tabular}{|c|c|}
\hline Potência exigida pela bomba & Acréscimo \\
\hline cv & $\%$ \\
\hline \hline Até 2 & 50 \\
\hline De 2 a 5 & 30 \\
\hline De 5 a 10 & 20 \\
\hline De 10 a 20 & 15 \\
\hline Acima de 20 & 10 \\
\hline
\end{tabular}

Quadro 13. Perda de carga localizada dos gotejadores expressa como porcentagem da perda contínua ao longo da linha lateral

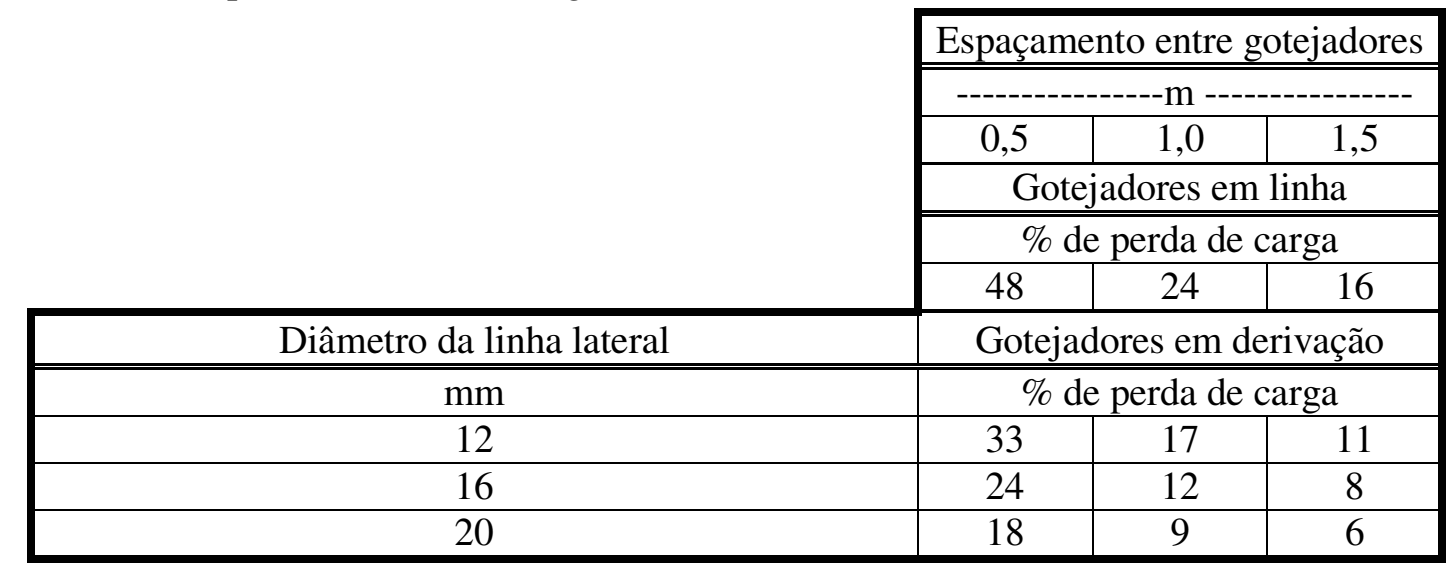


Quadro 14. Rugosidade absoluta de tubulação

\begin{tabular}{|l|c|}
\hline \multicolumn{1}{|c|}{ Material da tubulação } & $\varepsilon$ \\
\hline \hline Aço comercial novo & 0,045 \\
\hline Aço laminado novo & $0,04-0,10$ \\
\hline Aço soldado novo & $0,05-0,10$ \\
\hline Aço soldado limpo, usado & $0,15-0,20$ \\
\hline Aço soldado moderadamente oxidado & 0,40 \\
\hline Aço soldado revestido de cimento centrifugado & 0,10 \\
\hline Aço laminado revestido de asfalto & 0,05 \\
\hline Aço rebitado novo & $1,0-3,0$ \\
\hline Aço rebitado em uso & 6,0 \\
\hline Aço galvanizado, com costura & $0,15-0,20$ \\
\hline Aço galvanizado, sem costura & $0,06-0,15$ \\
\hline Ferro forjado & 0,05 \\
\hline Ferro fundido novo & $0,25-0,50$ \\
\hline Ferro fundido com leve oxidação & 0,30 \\
\hline Ferro fundido velho & $3,0-5,0$ \\
\hline Ferro fundido centrifugado & 0,05 \\
\hline Ferro fundido em uso com cimento centrifugado & 0,10 \\
\hline Ferro fundido com revestimento asfaltico & $0,12-0,20$ \\
\hline Ferro fundido oxidado & $1,0-1,5$ \\
\hline Cimento amianto novo & 0,03 \\
\hline Concreto centrifugado novo & 0,16 \\
\hline Concreto armado liso, vários anos de uso & $0,20-0,30$ \\
\hline Concreto com acabamento normal & $1,0-3,0$ \\
\hline Concreto protendido Freyssinet & 0,04 \\
\hline Cobre, latão, aço revestido de epoxi, PVC, & $0,0015-0,010$ \\
\hline plásticos em geral, tubos extrudados & $0,0015-0,010$ \\
\hline
\end{tabular}

Quadro 15. Valores do coeficiente K para reduções bruscas

\begin{tabular}{|c|ccccccccccc|}
\hline $\mathrm{A} 2 / \mathrm{A} 1$ & 0 & 0,1 & 0,2 & 0,3 & 0,4 & 0,5 & 0,6 & 0,7 & 0,8 & 0,9 & 1 \\
\hline \hline $\mathrm{K}$ & 0,50 & 0,46 & 0,41 & 0,36 & 0,30 & 0,24 & 0,18 & 0,12 & 0,06 & 0,02 & 0,00 \\
\hline
\end{tabular}




\section{ANEXO B}

Neste ANEXO (B), são apresentadas Tabelas com a cotação média em real e em dólar, dos materiais pesquisados para o dimensionamento da rede hidráulica do sistema de irrigação localizada.

Tabela 27. Cotação de emissores, em real (R\$) e em dólar (US\$), no mês de janeiro de 2007

\begin{tabular}{cccc}
$\begin{array}{c}\text { Item } \\
\text { (descrição) }\end{array}$ & Código do Fabricante & $\begin{array}{c}\text { Preço } \\
(\text { R } \$)\end{array}$ & $\begin{array}{c}\text { Preço } \\
\text { (US\$) }\end{array}$ \\
\hline
\end{tabular}

Tubo Gotejador Amanco Drip (0,7 mm)

\begin{tabular}{|c|c|c|c|}
\hline $\mathrm{Q}=4,5 \mathrm{lph}$ - Espaçamento $0,40 \mathrm{~m}$ & 13975 & 0,51 & 0,23 \\
\hline $\mathrm{Q}=4,5 \mathrm{lph}-$ Espaçamento $0,80 \mathrm{~m}$ & 13983 & 0,53 & 0,24 \\
\hline $\mathrm{Q}=4,5 \mathrm{lph}$ - Espaçamento $1,00 \mathrm{~m}$ & 13987 & 0,36 & 0,17 \\
\hline $\mathrm{Q}=4,5 \mathrm{lph}-$ Espaçamento $1,10 \mathrm{~m}$ & 13989 & 0,36 & 0,17 \\
\hline $\mathrm{Q}=4,5 \mathrm{lph}$ - Espaçamento $1,25 \mathrm{~m}$ & 13991 & 0,47 & 0,21 \\
\hline \multicolumn{4}{|l|}{ Gotejador de Fluxo Turbulento } \\
\hline $\mathrm{Q}=2,3$ lph - Branco & 93010 & 0,29 & 0,13 \\
\hline $\mathrm{Q}=4,0 \mathrm{lph}-\mathrm{Azul}$ & 93004 & 0,29 & 0,13 \\
\hline $\mathrm{Q}=8,0 \mathrm{lph}-$ Verde & 93005 & 0,26 & 0,12 \\
\hline \multicolumn{4}{|l|}{$\begin{array}{c}\text { Microaspersores } \\
\end{array}$} \\
\hline $\begin{array}{l}\text { Microaspersor Fixo } 360^{\circ} \text { x } 16 \text { jatos } \\
\text { d.m.=2,6 m e } Q=311 \mathrm{ph}-\text { Bocal grafite }\end{array}$ & 93352 & 0,57 & 0,26 \\
\hline $\begin{array}{l}\text { Microaspersor Fixo } 360^{\circ} \text { x } 16 \text { jatos } \\
\text { d.m. }=2,9 \mathrm{~m} \text { e } \mathrm{Q}=35 \mathrm{lph} \text { Bocal preto }\end{array}$ & 93353 & 0,57 & 0,26 \\
\hline $\begin{array}{l}\text { Microaspersor Fixo } 360^{\circ} \text { x } 16 \text { jatos } \\
\text { d.m.=3,3 m e } Q=55 \mathrm{lph}-\text { Bocal branco }\end{array}$ & 93049 & 0,57 & 0,26 \\
\hline $\begin{array}{l}\text { Microaspersor Fixo } 360^{\circ} \text { x } 16 \text { jatos } \\
\text { d.m. }=5,5 \mathrm{~m} \text { e } \mathrm{Q}=82 \mathrm{lph} \text { - Bocal marrom }\end{array}$ & 93051 & 0,57 & 0,26 \\
\hline $\begin{array}{l}\text { Microaspersor Fixo } 360^{\circ} \text { x } 16 \text { jatos } \\
\text { d.m.=4,2 m e } Q=1031 \mathrm{ph}-\text { Bocal verde }\end{array}$ & 93355 & 0,57 & 0,26 \\
\hline
\end{tabular}


Tabela 28. Cotação de tubos de polietileno e PVC, em real (R\$) e em dólar (US\$), no mês de janeiro de 2007

\begin{tabular}{lccc}
\hline \multicolumn{1}{c}{$\begin{array}{c}\text { Item } \\
\text { descrição) }\end{array}$} & Código do Fabricante & $\begin{array}{c}\text { Preço } \\
\text { (R\$) }\end{array}$ & $\begin{array}{c}\text { Preço } \\
\text { (US\$) }\end{array}$ \\
\hline Tubo de Polietileno PELBD & & & \\
\hline Tubo PE 0437 (DI 2,4 mm) & 15017 & 0,16 & 0,07 \\
\hline Tubo PE 0551 (DI 2,7 mm) & 15015 & 0,23 & 0,10 \\
\hline Tubo PE 1035 (DI 8,2 mm) & 15018 & 0,22 & 0,10 \\
\hline Tubo PE 1335 (DI 11,2 mm) & 15011 & 0,31 & 0,14 \\
\hline Tubo PE 1635 (DI 14,3 mm) & 15012 & 0,36 & 0,16 \\
\hline Tubo PE 2043 (DI 18,4 mm) & 15014 & 0,63 & 0,29 \\
\hline Tubos PVC PN 40/Bolsa Soldável & & 5,64 & \\
\hline \hline Bitola 35 (DI 35,7 mm) & 10838 & 4,80 & 2,59 \\
\hline Bitola 50 (DI 48,1 mm) & 10839 & 14,97 & 6,87 \\
\hline Bitola 75 (DI 72,5 mm) & 10840 & 23,92 & 10,97 \\
\hline Bitola 100 (DI 97,6 mm) & 10841 & 39,20 & 17,98 \\
\hline Bitola 125 (DI 120,0 mm) & 10842 & 55,65 & 25,53 \\
\hline Bitola 150 (DI 144,0 mm) & 11922 & $81,93^{*}$ & $37,58^{*}$ \\
\hline Bitola 200 (DI 212,0 mm) & - & $101,10^{*}$ & $46,38^{*}$ \\
\hline Bitola 250 (DI 261,6 mm) & - & &
\end{tabular}

*Valores estimados.

Tabela 29. Cotação de estacas de microaspersor, adaptador de fim e início de linha e união pra tubo gotejador, em real (R\$) e em dólar (US\$), no mês de janeiro de 2007

\begin{tabular}{lccc}
\hline $\begin{array}{c}\text { Item } \\
\text { descrição) }\end{array}$ & Código do Fabricante & $\begin{array}{c}\text { Preço } \\
\text { Estaca }\end{array}$ & $\begin{array}{c}\text { Preço } \\
\text { (US\$) }\end{array}$ \\
\hline Estaca MF Preta & 15004 & 0,21 & 0,10 \\
\hline Adaptador Fim de Linha & & & \\
\hline \hline Fim de linha & 15001 & 0,24 & 0,11 \\
\hline Adaptador Início de Linha & & 0,44 & 0,20 \\
\hline Inicio de linha União & 93006 & & \\
\hline \hline União Tb. Gotej. (16x20) & & 1,01 & 0,46 \\
\hline
\end{tabular}


Tabela 30. Cotação de redução soldável, tê de redução, adaptador de final de linha de PVC, curva $90^{\circ}$ e adesivo plástico para tubos de PVC, em real (R\$) e em dólar (US\$), no mês de janeiro de 2007

\begin{tabular}{|c|c|c|c|}
\hline $\begin{array}{c}\text { Item } \\
\text { (descrição) }\end{array}$ & Código do Fabricante & $\begin{array}{c}\text { Preço } \\
\text { (R\$) }\end{array}$ & $\begin{array}{l}\text { Preço } \\
\text { (US\$) }\end{array}$ \\
\hline \multicolumn{4}{|l|}{ Redução Soldável LF } \\
\hline Bitola 50x35 & 10761 & 2,37 & 1,09 \\
\hline Bitola 75x50 & 10762 & 2,05 & 0,94 \\
\hline Bitola $100 \times 50$ & 10763 & 3,97 & 1,82 \\
\hline Bitola 100x75 & 10764 & 3,99 & 1,83 \\
\hline Bitola $125 \times 100$ & 90557 & 7,30 & 3,35 \\
\hline Bitola 150x125 & 90558 & 14,31 & 6,56 \\
\hline Bitola 200x150 & - & $26,50 *$ & $12,16^{*}$ \\
\hline \multicolumn{4}{|l|}{ Tê de Redução LF } \\
\hline Bitola $75 \times 50$ & 10720 & 5,66 & 2,60 \\
\hline Bitola $100 \times 50$ & 10725 & 12,30 & 5,64 \\
\hline Bitola $100 \times 75$ & 10726 & 13,82 & 6,34 \\
\hline \multicolumn{4}{|l|}{ Cap (adaptador final de PVC) LF } \\
\hline Bitola 35 & 10714 & 0,54 & 0,25 \\
\hline Bitola 50 & 10712 & 1,04 & 0,48 \\
\hline Bitola 75 & 10713 & 2,75 & 1,26 \\
\hline Bitola 100 & 10715 & 5,13 & 2,35 \\
\hline Bitola 150 & - & $7,50 *$ & $3,44^{*}$ \\
\hline Bitola 200 & - & $10,15^{*}$ & $4,66^{*}$ \\
\hline \multicolumn{4}{|l|}{ Curva $90^{\circ}$ LF } \\
\hline Bitola 35 & 10807 & 2,45 & 1,12 \\
\hline Bitola 50 & 10808 & 5,58 & 2,56 \\
\hline Bitola 75 & 10809 & 11,28 & 5,18 \\
\hline Bitola 100 & 10810 & 18,42 & 8,45 \\
\hline Bitola 125 & 90542 & 24,50 & 11,24 \\
\hline \multicolumn{4}{|c|}{ Adesivo Plástico para Tubos de PVC } \\
\hline Frasco com pincel aplicador - CCB & 90126 & 10,09 & 4,63 \\
\hline
\end{tabular}

*Valores estimados. 
Tabela 31. Cotação de filtro de areia completo, filtro metálico de tela e válvulas de retrolavagem, hidráulica de plástico, de alívio, piloto e relês e solenóides, em real (R\$) e em dólar (US\$), no mês de janeiro de 2007

\begin{tabular}{|c|c|c|c|}
\hline $\begin{array}{c}\text { Item } \\
\text { (descrição) }\end{array}$ & Código do Fabricante & $\begin{array}{l}\text { Preço } \\
\text { (R\$) }\end{array}$ & $\begin{array}{l}\text { Preço } \\
\text { (US\$) }\end{array}$ \\
\hline \multicolumn{4}{|l|}{ Filtro de Areia Completo } \\
\hline Vazão $25 \mathrm{~m}^{3} / \mathrm{h} 200$ mesh & 15094 & 3544,45 & 1625,89 \\
\hline Vazão $35 \mathrm{~m}^{3} / \mathrm{h} 200 \mathrm{mesh}$ & 15086 & 4312,32 & 1978,13 \\
\hline Vazão $50 \mathrm{~m}^{3} / \mathrm{h} 200$ mesh & 15089 & 5430,17 & 2490,90 \\
\hline Vazão $100 \mathrm{~m}^{3} / \mathrm{h} 200$ mesh & 15074 & 13080,30 & 6000,14 \\
\hline \multicolumn{4}{|l|}{$\begin{array}{l}\text { Filtro Metálico de Tela } \\
\end{array}$} \\
\hline Filtro de Disco Y $50 \mathrm{~m}^{3} / 120$ mesh & 15143 & 1338,86 & 614,16 \\
\hline Filtro de Tela Y $50 \mathrm{~m}^{3} / 200$ mesh & 15049 & 931,62 & 427,35 \\
\hline \multicolumn{4}{|l|}{$\begin{array}{l}\text { Válvula de Retrolavagem } \\
\end{array}$} \\
\hline Bitola 3" x 2" vic & 15044 & 561,87 & 257,74 \\
\hline \multicolumn{4}{|l|}{ Válvula Hidráulica de Plástico } \\
\hline Válvula Hidráulica 1 1/2" & 93423 & 112,77 & 51,73 \\
\hline Válvula Hidráulica 2" & 93175 & 151,97 & 69,71 \\
\hline \multicolumn{4}{|l|}{ Válvula de Alívio } \\
\hline Válvula de alívio 2" BSP & 15071 & 441,42 & 202,48 \\
\hline \multicolumn{4}{|l|}{ Válvulas, Relês e Solenóides } \\
\hline Válvula Piloto 3 Vias Navaton & 93085 & 179,08 & 82,15 \\
\hline Relê Hidráulico Galit & 93245 & 75,37 & 34,57 \\
\hline Relê Hidráulico Ted & 93473 & 62,68 & 28,75 \\
\hline Solenóide Bermad S 200 NC com Base & 92090 & 76,68 & 35,18 \\
\hline Solenóide Bermad S 200 NO com Base & 93476 & 78,27 & 35,90 \\
\hline
\end{tabular}

Tabela 32. Cotação de painel de controle do sistema, em real (R\$) e em dólar (US\$), no mês de janeiro de 2007

\begin{tabular}{lccc}
\hline \multicolumn{1}{c}{$\begin{array}{c}\text { Item } \\
\text { (descrição) }\end{array}$} & Código do Fabricante & $\begin{array}{c}\text { Preço } \\
\text { (R\$) }\end{array}$ & $\begin{array}{c}\text { Preço } \\
\text { (US\$) }\end{array}$ \\
\hline \multicolumn{1}{c}{ Painel de Controle } & & & \\
\hline \hline Total Control 6 estações 220 v & 93082 & 748,42 & 343,31 \\
\hline Total Control 9 estações 220 v & 93376 & 885,96 & 406,40 \\
\hline Total Control 12 estações 220 v & 93080 & 990,16 & 454,20 \\
\hline Painel Controlador de Filtro MD 400 & 91890 & 1133,41 & 519,91 \\
\hline Painel Controlador de Bomba MD 514 & 92071 & 1221,63 & 560,38 \\
\hline
\end{tabular}


Tabela 33. Cotação de hidrômetro e registro de esfera em PVC soldável, em real (R\$) e em dólar (US\$), no mês de janeiro de 2007

\begin{tabular}{lccc}
\hline $\begin{array}{c}\text { Item } \\
\text { (descrição) }\end{array}$ & Código do Fabricante & $\begin{array}{c}\text { Preço } \\
\text { (R\$) }\end{array}$ & $\begin{array}{c}\text { Preço } \\
\text { (US\$) }\end{array}$ \\
\hline Hidrômetro & & & \\
\hline Hidrômetro Turbobar FL 4" & 9358 & 1456,86 & 668,29 \\
\hline Hidrômetro Turbobar FL 6" & 93241 & 1914,68 & 878,29 \\
\hline Registro de Esfera em PVC Soldável & & & \\
\hline \hline Bitola 20 & 10443 & 4,63 & 2,12 \\
\hline Bitola 25 & 10444 & 5,96 & 2,73 \\
\hline Bitola 32 & 10445 & 8,31 & 3,81 \\
\hline Bitola 40 & 10446 & 11,01 & 5,05 \\
\hline Bitola 50 & 10447 & 13,07 & 6,00 \\
\hline
\end{tabular}

Tabela 34. Cotação de injetor de fertilizantes tipo Venturi, em real (R\$) e em dólar (US\$), no mês de janeiro de 2007

\begin{tabular}{llcc}
\hline \multicolumn{1}{c}{$\begin{array}{c}\text { Item } \\
\text { (descrição) }\end{array}$} & Código do Fabricante & $\begin{array}{c}\text { Preço } \\
\text { Injetor Venturi }\end{array}$ & $\begin{array}{c}\text { Preço } \\
\text { (US\$) }\end{array}$ \\
\hline \hline Injetor Fertilizante 1 & & & \\
\hline Injetor Fertilizante 1.1/2 & sem código & 205,32 & 94,18 \\
\hline Injetor Fertilizante 2 & sem código & 266,41 & 122,21 \\
\hline Injetor Fertilizante 3/4 & sem código & 602,90 & 276,56 \\
\hline
\end{tabular}

Tabela 35. Cotação do conjunto motobomba segundo a potência da bomba em cv (cavalo vapor)

\begin{tabular}{ccccrc}
\hline cv & Preço $(\mathbf{R} \$)$ & Preço (US\$) & cv & Preço (R\$) & Preço (US\$) \\
\hline \hline $\mathbf{1}$ & 355,42 & 163,04 & $\mathbf{1 1}$ & 2282,42 & 1046,98 \\
$\mathbf{2}$ & 694,82 & 318,72 & $\mathbf{1 2}$ & 2381,62 & 1092,49 \\
$\mathbf{3}$ & 989,14 & 453,73 & $\mathbf{1 3}$ & 2482,54 & 1138,78 \\
$\mathbf{4}$ & 1243,06 & 570,21 & $\mathbf{1 4}$ & 2589,86 & 1188,01 \\
$\mathbf{5}$ & 1461,26 & 670,30 & $\mathbf{1 5}$ & 2708,26 & 1242,32 \\
$\mathbf{6}$ & 1648,42 & 756,16 & $\mathbf{1 6}$ & 2842,42 & 1303,86 \\
$\mathbf{7}$ & 1809,22 & 829,92 & $\mathbf{1 7}$ & 2997,02 & 1374,78 \\
$\mathbf{8}$ & 1948,34 & 893,73 & $\mathbf{1 8}$ & 3176,74 & 1457,22 \\
$\mathbf{9}$ & 2070,46 & 949,75 & $\mathbf{1 9}$ & 3386,26 & 1553,33 \\
$\mathbf{1 0}$ & 2180,26 & 1000,12 & $\mathbf{2 0}$ & 3630,26 & 1665,26 \\
\hline
\end{tabular}

